Practical Aspects of Steam Injection Processes

A Handbook for Independent Operators

By

Partha S. Sarathi

David K. Olsen

October 1992
NIPER--580

DE92 001070

Work Performed Under Cooperative Agreement No. DE-FC22-83FE60149

Prepared for

U.S. Department of Energy

Assistant Secretary for Fossil Energy

Thomas B. Reid, Project Manager

Bartlesville Project Office

P. O. Box 1398

Bartlesville, OK 74005

Prepared by

IIT Research Institute

National Institute for Petroleum and Energy Research

P. O. Box 2128

Bartlesville, OK 74005 
Abstract Page

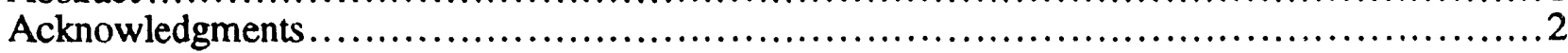

CHAPTER 1. Fundamentals of Steam Injection Processes ................................. 3

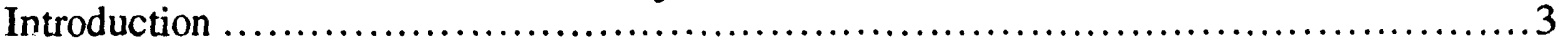

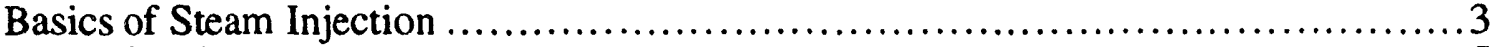

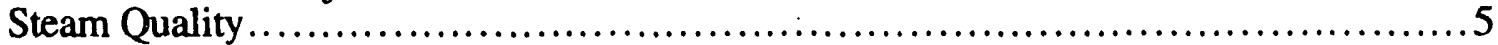

Steam Injection Process .....................................................

Steam Injection Process Mechanisms................................................... 10

Steam Distillation ............................................................ 10

Gas Stripping .......................................................... 10

In Situ Solvent Drive................................................................ 10

Viscosity Reduction.............................................................. 11

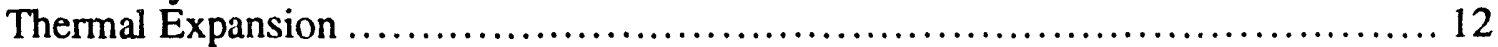

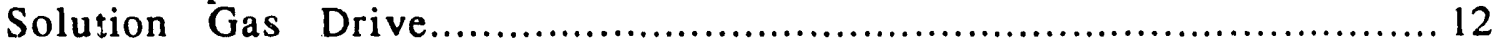

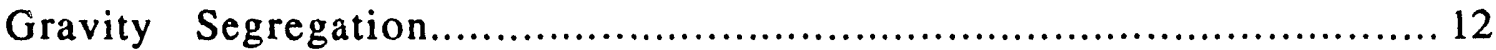

Emulsion Drive ........................................................... 13

Cyclic Steam Injection................................................................. 13

Process Description .................................................... 13

Mechanism of Cyclic Steam Process .................................................... 16

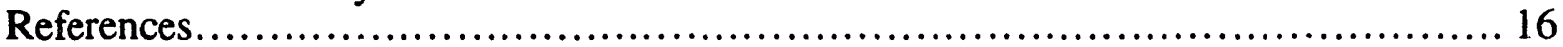

TABLES

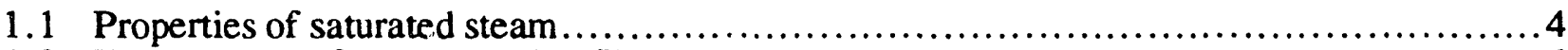

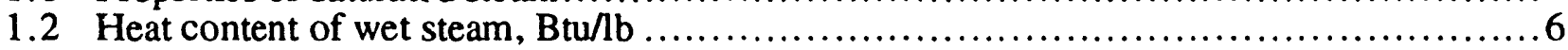

1.3 Approximate contribution of various steamflood mechanisms to overall recovery

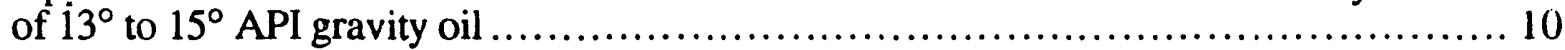

\section{ILLUSTRATIONS}

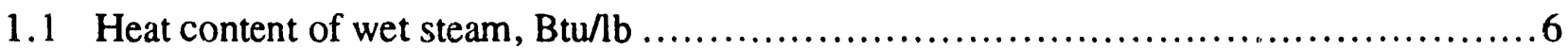

1.2 Schematic of steamflood process .................................................... 7

1.3 Schematic of steamflood temperature profile .............................................. 8

1.4 Schematic of steamflood saturation profile ........................................... 9

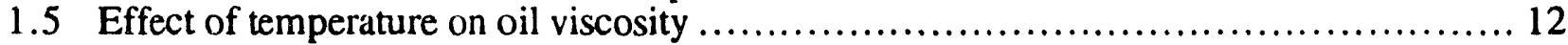

1.6 Schematic of cyclic steam process........................................................ 14

1.7 Schematic of push-pull cyclic steam process ...................................... 15

CHAPTER 2. Criteria for Evaluating Steam Injection Prospects ...................... 18 Introduction ........................................................................... 18

Rock and Fluid Properties .................................................... 18

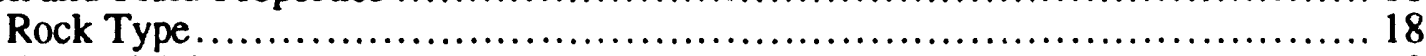

Pay Zone Thickness ............................................................ 18

Depth and Reservoir Pressure ................................................... 18 


\section{TABLE OF CONTENTS-Continued}

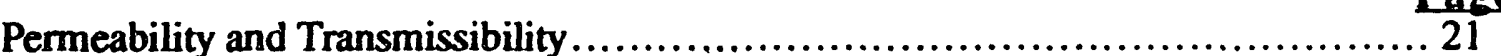

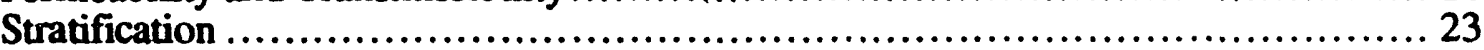

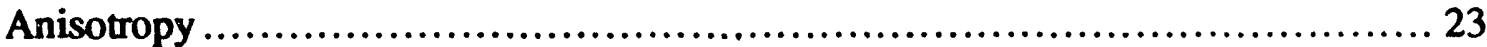

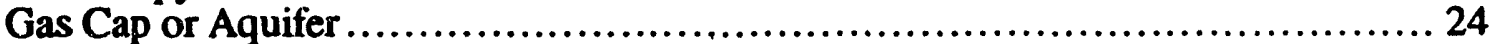

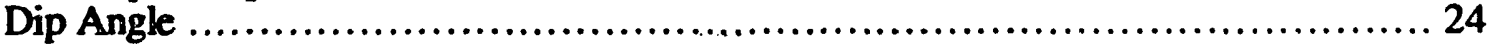

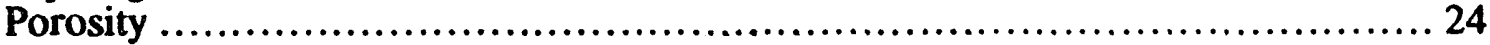

Oil Saturation ....................................................................... 24

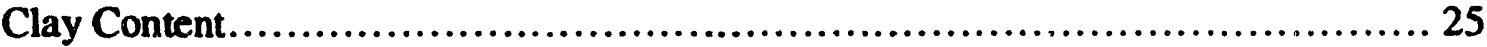

Crude Oil Characteristics............................................................ 25

Gravity..................................................................... 25

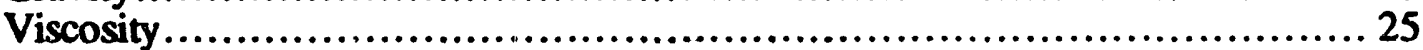

Field History and Status ............................................................... 26

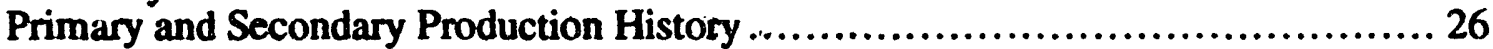

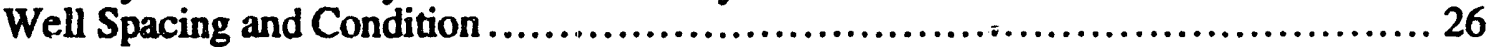

Pattem Configuration................................................................ 26

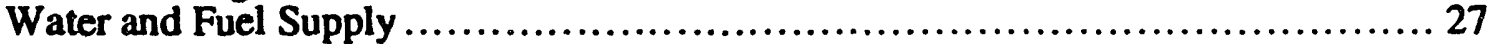

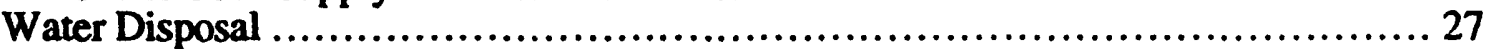

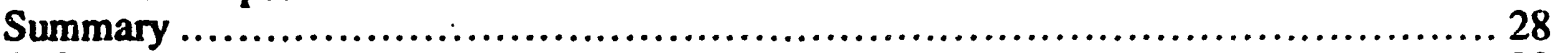

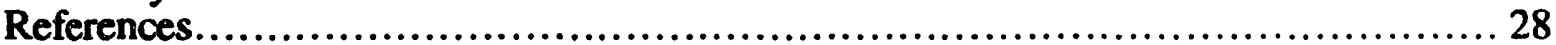

TABLES

2.1 Cyclic steam screening criteria ....................................................... 19

2.2 Steamflooding screening criteria ................................................... 20

\section{ILLUSTRATIONS}

2.1 Estimated heat loss as function of depth ......................................... 22

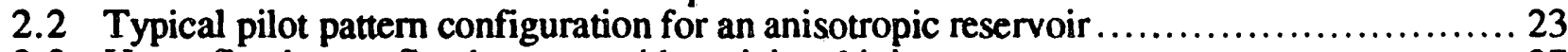

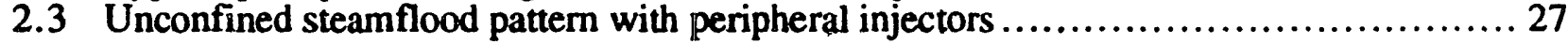

CHAPTER 3. Project Planning ....................................................... 29

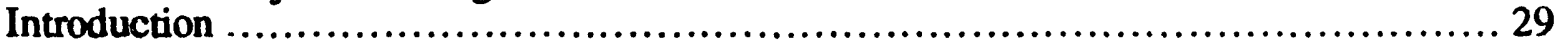

Reservoir Selection ......................................................... 29

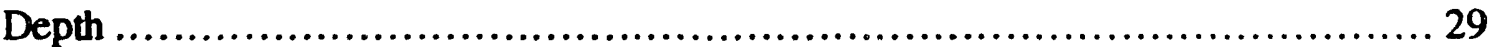

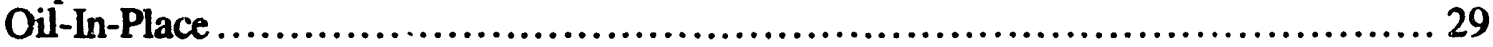

Reservoir Segregation and Inhomogeneities......................................... 30

Preliminary Evaluation ............................................................... 30

Laboratory Analysis ................................................................. 30

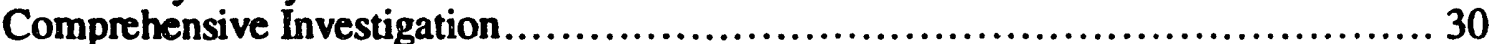

Comprehensive Performance Investigation ....................................... 31

Comparison with Conventional Practices ............................................ 31

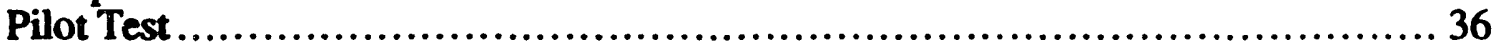

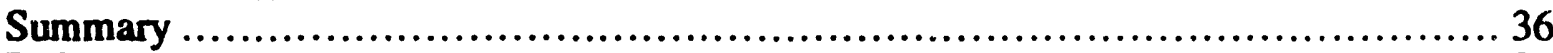

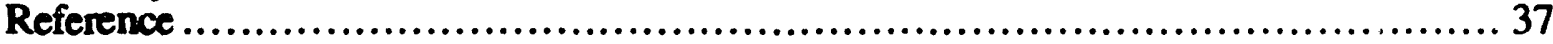




\section{TABLE OF CONTENTS-Continued}

\section{TABLES}

3.1 List of major initial expenses to be included in the steam injection project economic

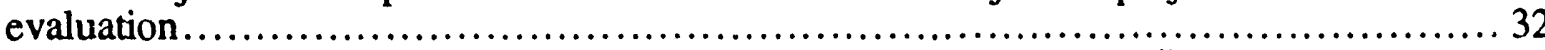

3.2 Steps for steam injection prospect evaluation process selection, and field

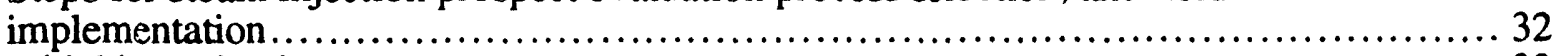

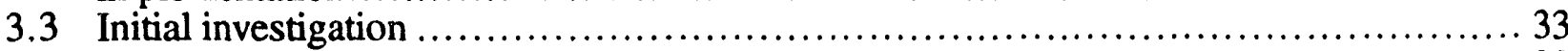

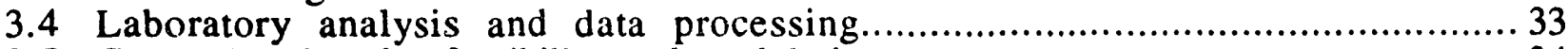

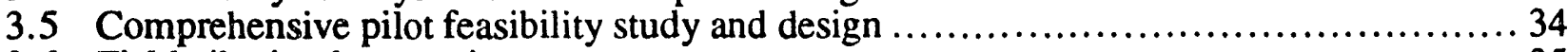

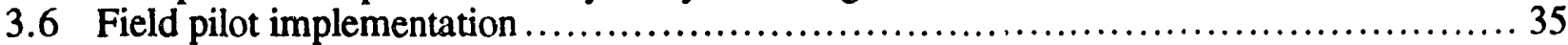

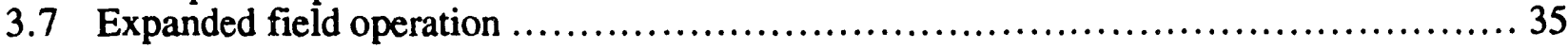

CHAPTER 4. Economics of Steam Injection ....................................... 38

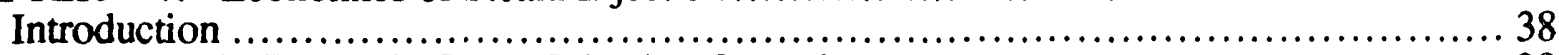

Economic Factors in Steam Injection Operation .............................. 38

Estimation of Economically Recoverable Oil ..............................................................43

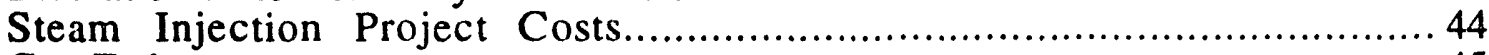

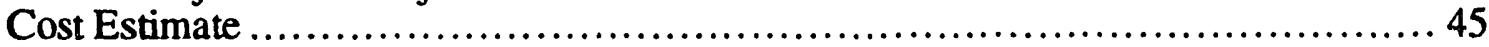

Development Costs ........................................................ 45

Well Costs.............................................................. 45

Water Treatment Facilities..................................................... 45

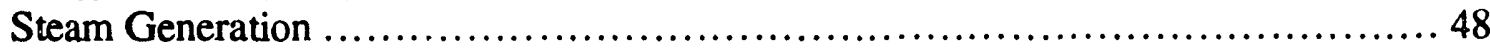

Steam Distribution System .................................................. 49

Other Surface Facilities..................................................... 50

Free Water Knockout Unit.................................................... 50

Heater Treater............................................................................. 50

Well-Testing Unit .................................................................. 50

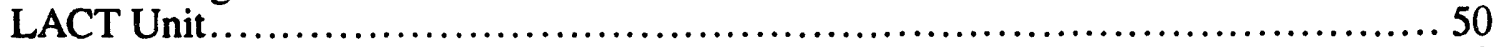

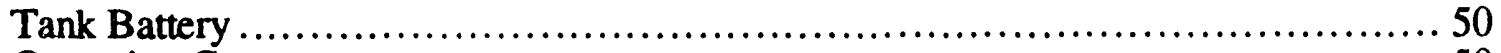

Operating Costs .......................................................... 50

Raw Water Production and Transportation Costs ............................ 50

Water Treatment............................................................. 50

Steam Generation Operation Costs..................................................... 51

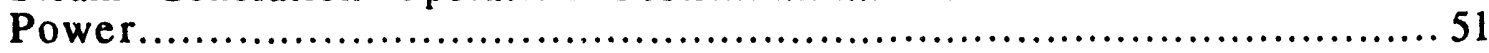

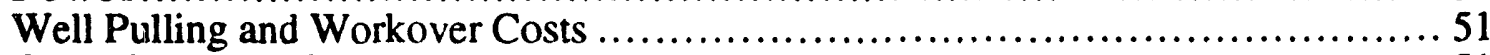

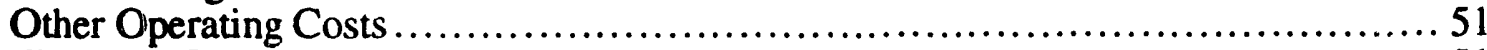

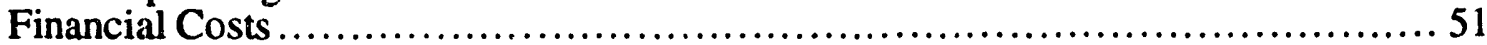

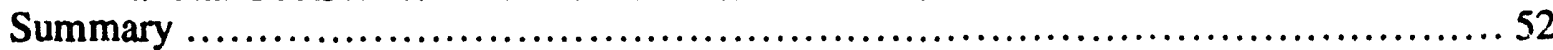

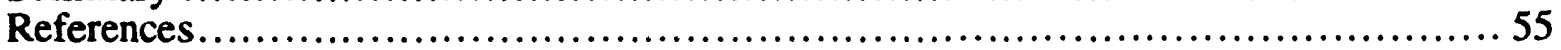

Appendix 4-A-Review of Department of Energy Steam Drive Predictive Models....... 57

Background ............................................................... 57

Review of Available Steamflood Models from BPO ................................ 57

Model Recommendation ........................................................... 58

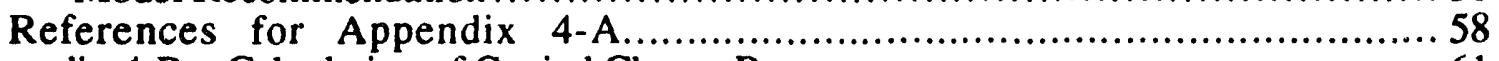

Appendix 4-B - Calculation of Capital Charge Rate .............................6 61 


\section{TABLE OF CONTENTS-Continued}

\section{TABLES}

4.1 Kern County, CA, new steam injection well costs, excluding well head injection equipment.

County, CA, new production well costs, excluding downhole pump.

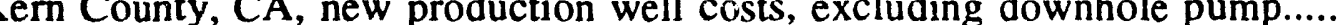

4.3 Cost to drill and equip a $1,000 \mathrm{ft}$ steam injection well ............................. 46

4.4 Cost to drill and equip a 1,000 foot production well ................................ 47

4.5 Index of drilling and equipping wells unadjusted for depth $\ldots \ldots \ldots \ldots \ldots \ldots \ldots \ldots \ldots \ldots \ldots, 48$

4.6 Characteristics of conventional lease crude fired steam generator ..................... 49

4.7 Conventional oil fired surface steam generator costs ................................. 49

4.8 Comparisons of economic factors affecting oil production from selected oil production states ................................................................. 53

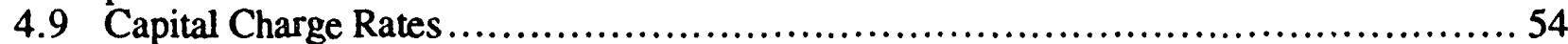

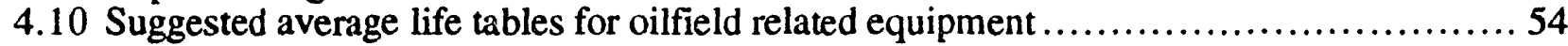

CHAPTER 5. Water Treatment for Steam Generation..................................6. 62

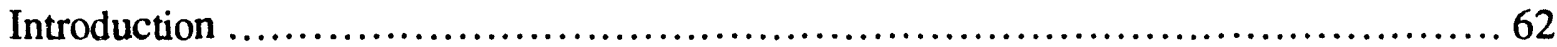

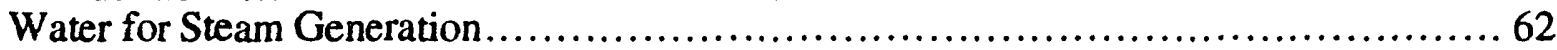

Sources of Water for Steam Generators .................................... 62

Water Treating Consideration........................................................6 63

Total Hardness .............................................................. 65

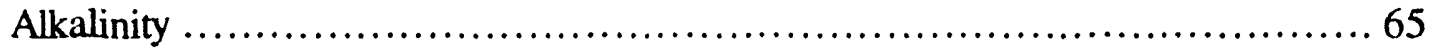

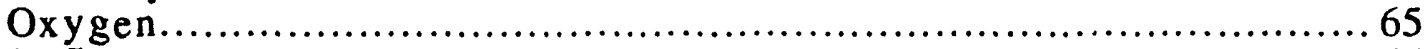

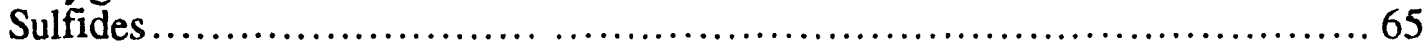

Dissolved Solids....................................................... 65

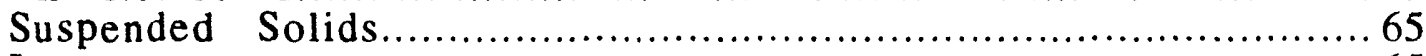

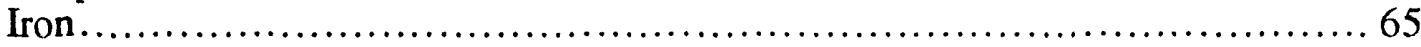

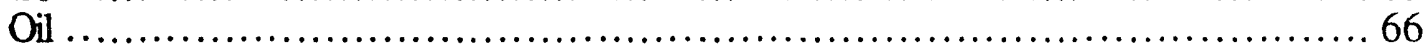

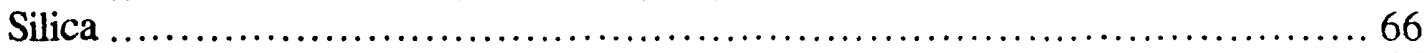

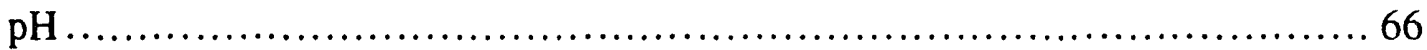

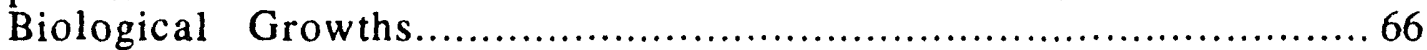

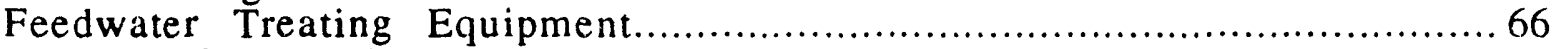

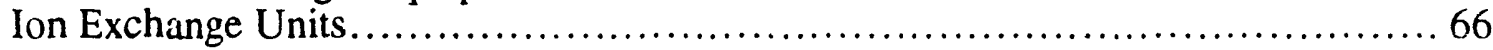

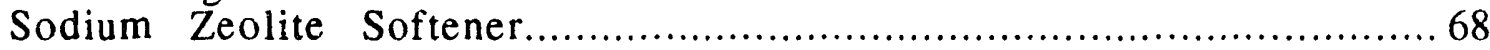

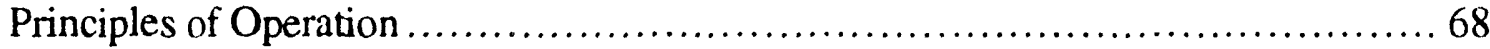

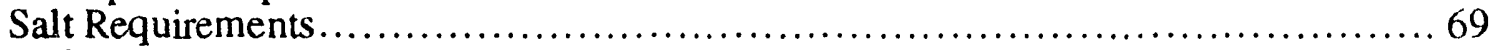

Softener Equipment and Operation.................................................. 71

Brining System ...................................................................... 74

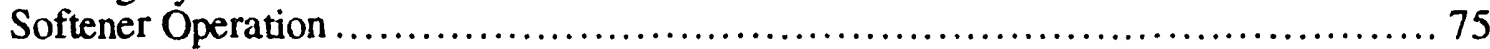

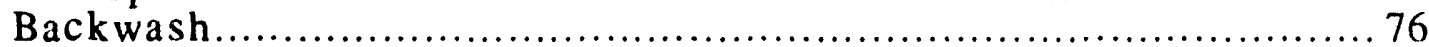

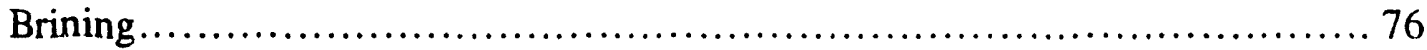

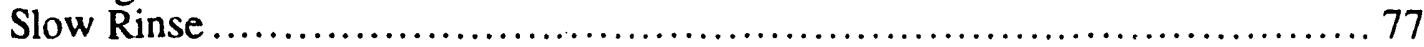

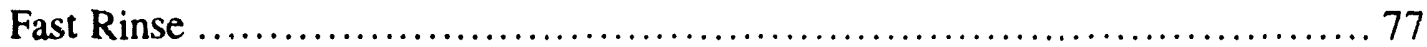

Limitations of Strong Acid Resins ......................................... 77

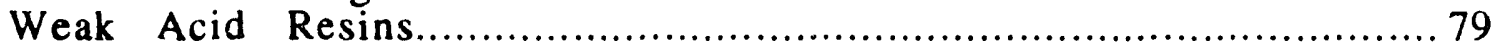

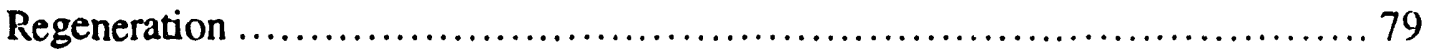

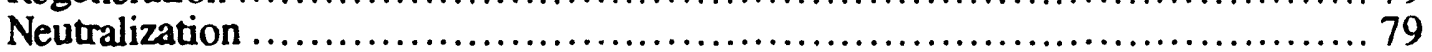

Weak Acid Cation Exchange Resin Equipment and Operation ...................... 80

Limitation of Weak Acid Cation Exchange Resins ................................ 80

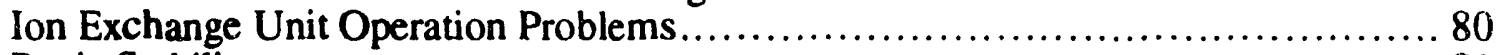

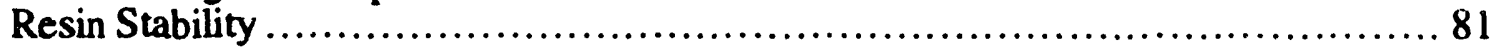




\section{TABLE OF CONTENTS-Continued}

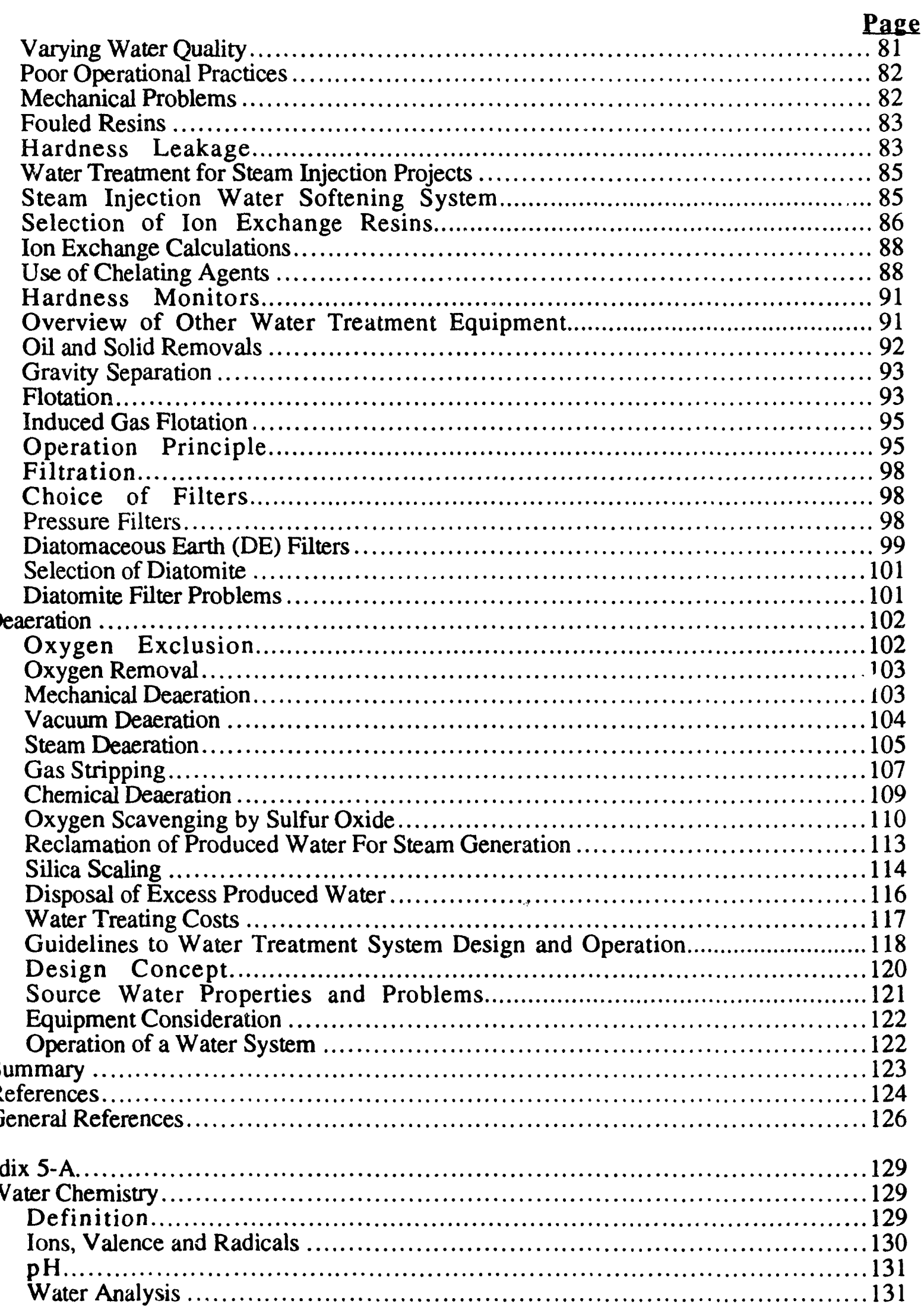




\section{TABLE OF CONTENTS-Continued}

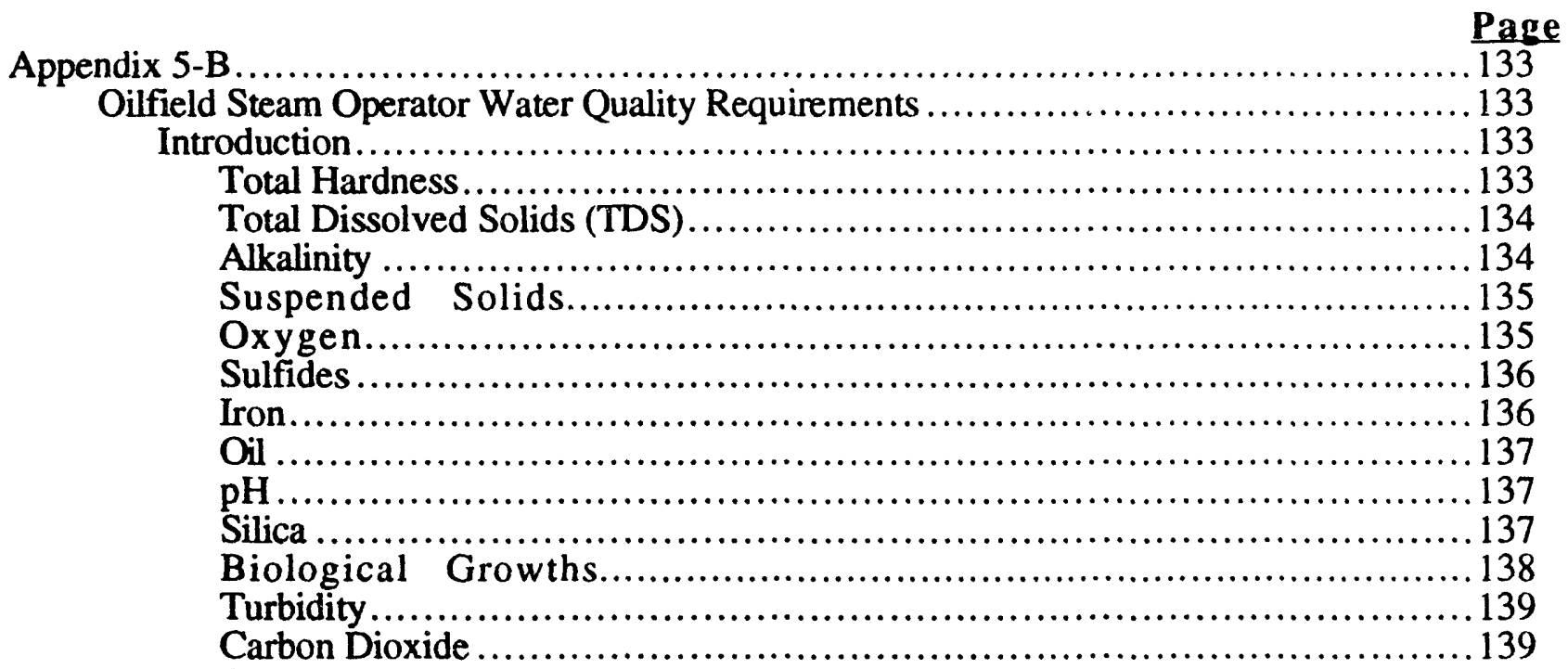

Appendix 5-C. Feedwater Treatment Equipment and Chemical Vendors......................... 141

\section{TABLES}

5.1 Typical analysis of raw waters used in the San Jaoquin Valley, California, steam

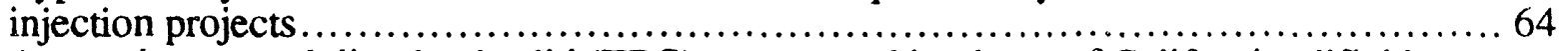

5.2 Approximate total dissolved solid (TDS) content and hardness of California oilfield

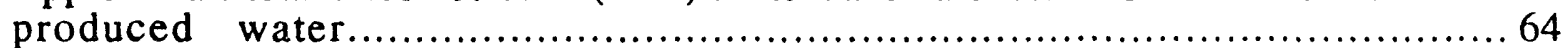

5.3 Steam generator feedwater requirements............................................. 65

5.4 Methods for removal of common raw water impurities............................. 67

5.5 Effects of salt level on the performance of a typical synthetic sodium zeolite exchanger .. 71

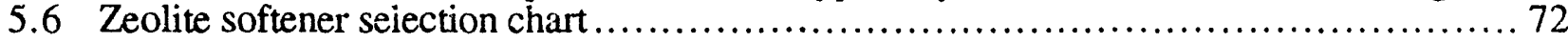

5.7 Rules-of-Thumb for selection of ion exchange resins for oilfield steam generator

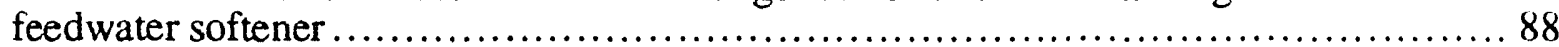

5.8 Ion exchange softening system calculations .......................................... 89

5.9 Concentration of EDTA and its sodium salts necessary to complex $1 \mathrm{ppm}$ of hardness ion ............................................................................ 90

5.10 Induced gas flotation cell selection chart............................................. 96

5.11 Feedwater oil reduction achievable using a depurator............................. 97

5.12 Summary of advantages and disadvantages of water deoxygenation systems .......... 104

5.13 Oxygen towers selection chart ................................................. 109

5.14 Typical $\mathrm{SO}_{2}$ scrubber waste analysis.............................................. 113

5.15 Typical water analysis for water treatment cost estimation .............................118

5.16 Fresh water treatment costs........................................................119

5.17 Produced water treatment costs ............................................... 19

\section{ILLUSTRATIONS}

5.1 Effect of feedwater hardness and salt dosage on resin capacity....................... 70

5.2 Effect of brine hardness and salt dosage on water softening costs $\ldots \ldots \ldots \ldots \ldots \ldots \ldots \ldots 72$

5.3 Schematic of a typical ion exchange water softener .................................. 73

5.4 Schematic of the internals of a typical zeolite softener unit $\ldots \ldots \ldots \ldots \ldots \ldots \ldots \ldots \ldots \ldots \ldots \ldots$ 


\section{ILLUSTRATIONS-Continued}

5.5 Schematic of a bulk salt storage facility ........................................ Page

5.6 Effect of water hardness and salt dosage on hardness leakage from primary beds ........ 78

5.7 Resin exchange capacity as a function of water hardness and salt dosage ................. 78

5.8 Schematic of steam injection water softener piping arrangement ..................... 86

5.9 Flow schematics of steamflood ion exchange softener regeneration cycle.................... 87

5.10 Schematic of an automatic hardness monitor ....................................... 92

5.11 Schematic of a typical dissolved gas flotation unit............................................ 94

5.12 Schematic of an induced gas flotation cell .......................................... 96

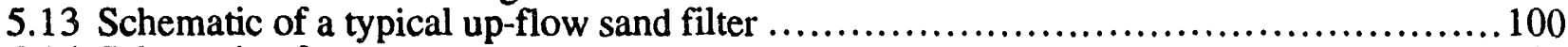

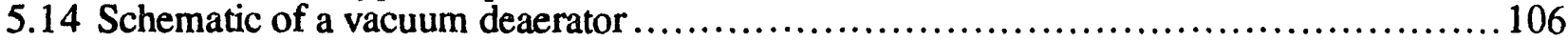

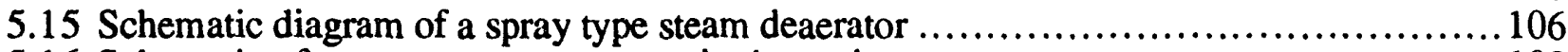

5.16 Schematic of a counter current gas stripping unit................................... 108

5.17 Schematic of sulfur burner process for oxygen deaeration ............................111

5.18 Flow diagram for Kern River, CA, steamflood produced water reclamation plant .......116

CHAPTER 6. Steam Generation .................................................... 145

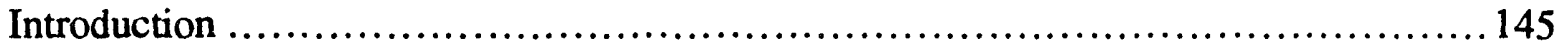

General Features of Oil Field Steam Generators .............................. 145

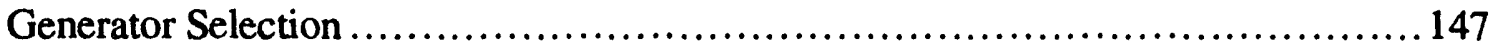

Design Requirements For Oilfield Steam Generators.......................... 152

Steam Generator Components ................................................ 152

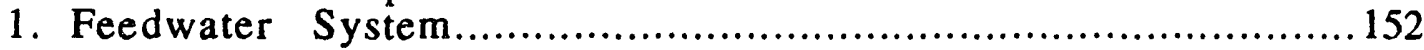

2. Feedwater Preheater .................................................... 152

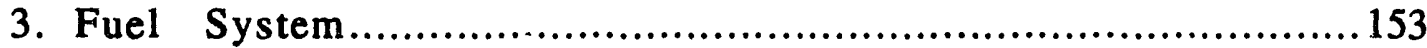

4. Combustion Air System ........................................... 153

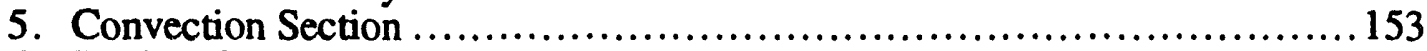

6. Radiant Section .................................................... 154

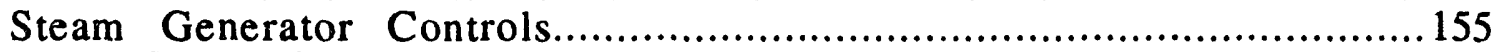

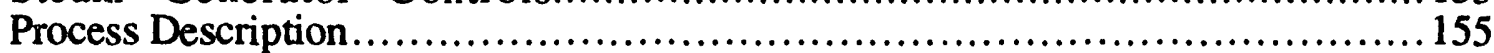

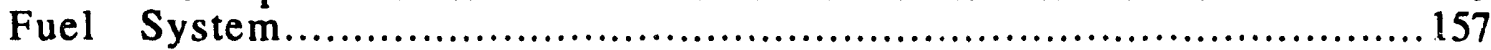

Combustion Air System ................................................. 158

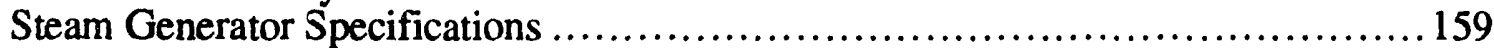

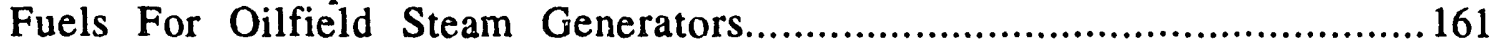

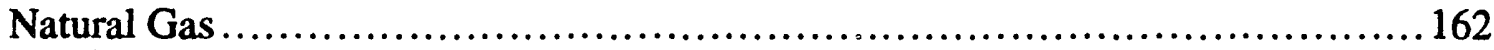

Liquified Petroleum Gas (LPG) ........................................... 162

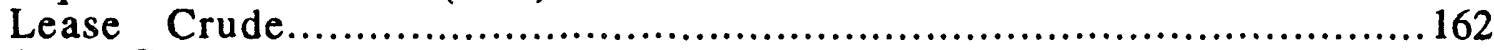

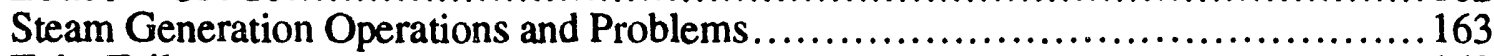

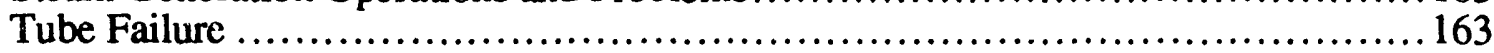

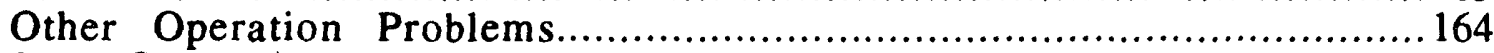

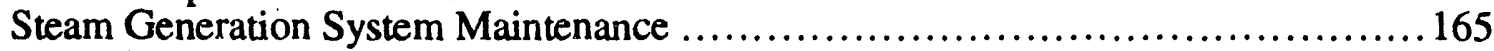

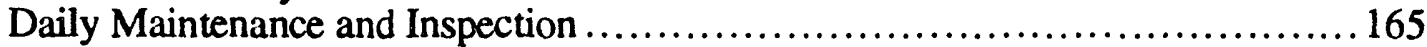

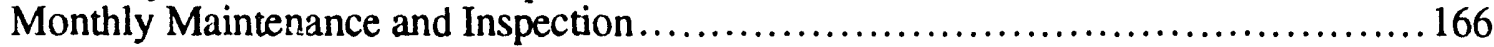

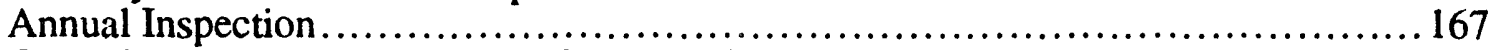

Operational Problems Because of Poor Maintenance .............................. 167

Steam Generator Efficiency ..................................................... 169

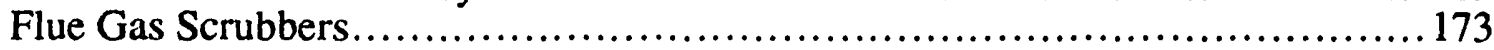

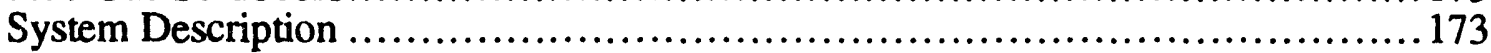

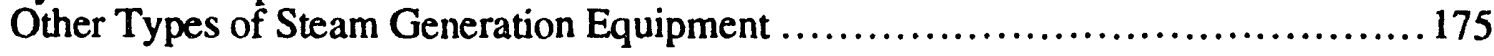




\section{TABLE OF CONTENTS-Continued}

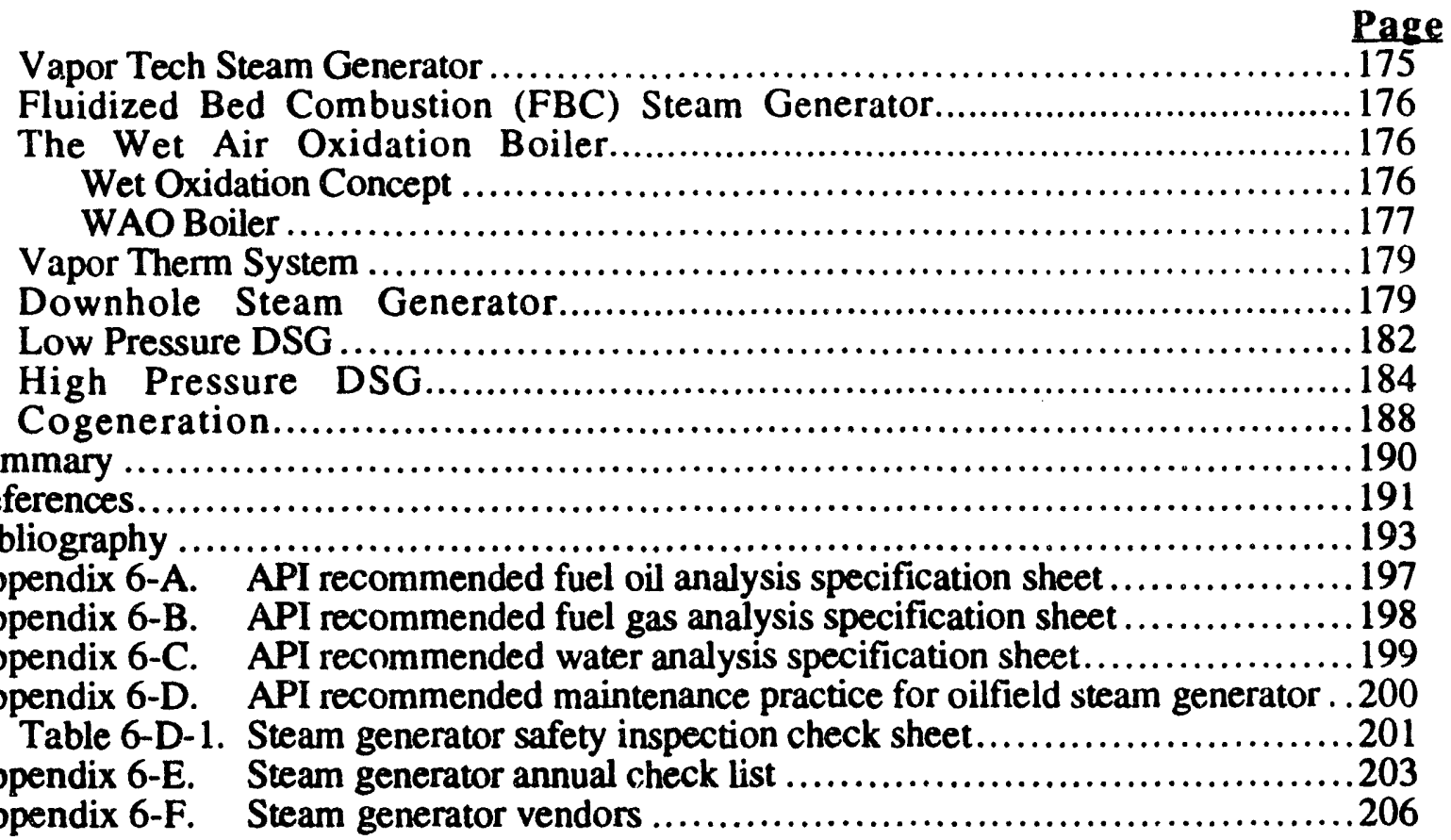

\section{TABLES}

6.1 Oilfield steam generator selection chart .......................................... 148

6.2 Oilfield steam generator fuel requirements.............................................. 148

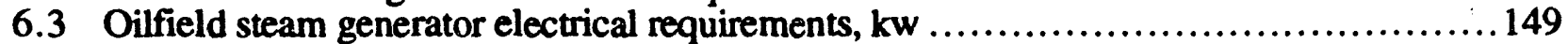

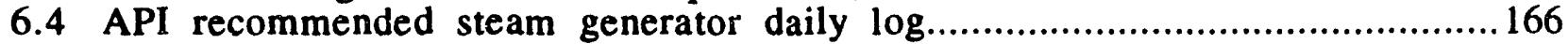

6.5 API recommended steam generator monthly maintenance and inspection check list ...... 168

6.6 Advantages and disadvantages of downhole steam generators.......................... 181

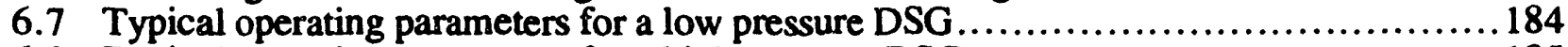

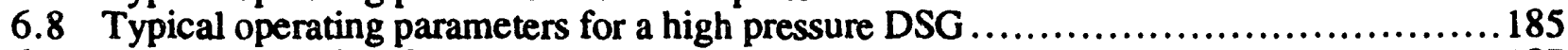

6.9 Comparison of surface and downhole steam generators cost .......................... 187

6.10 Capital cost itemization of a California cogeneration project (all costs are in 1989

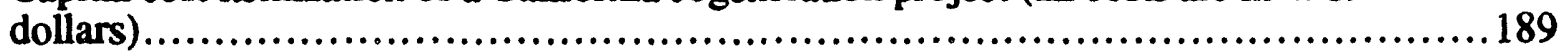

6.11 Economic summary for a skid-mounted cogeneration unit ........................ 191

\section{ILLUSTRATIONS}

6.1 Iosmetric view of a skid-mounted oilfield steam generator........................... 146

6.2 Schematic of oilfield steam generator ............................................... 147

6.3 Approximate steam generator output ( $\mathrm{lbs} / \mathrm{hr} / \mathrm{bhp}$ ) at various pressures, steam quality and feedwater temperature ....................................................... 149

6.4 Daily fuel (lease crude) costs for operating various capacity steam generators..............150

6.5 Daily fuel (natural gas) costs for operating various capacity steam generators ...........150

6.6 Tubing arrangements in the steam generator flue gas convection section ................ 154

6.7 Layout of a typical oilfield steam generator burning lease crude ......................156

6.8 Approximate flue gas dewpoints for heavy oils........................................ 171

6.9 Thermal efficiency versus flue gas temperature for $10^{\circ}$ API crude $\ldots \ldots \ldots \ldots \ldots \ldots \ldots \ldots 171$

6.10 Thermal efficiency versus flue gas temperature for $15^{\circ} \mathrm{API}$ crude $\ldots \ldots \ldots \ldots \ldots \ldots \ldots \ldots 172$

6.11 Thermal efficiency versus flue gas temperature for natural gas $(1,000 \mathrm{Btu} / \mathrm{SCF}) \ldots \ldots \ldots 172$ 


\section{TABLE OF CONTENTS-Continued}

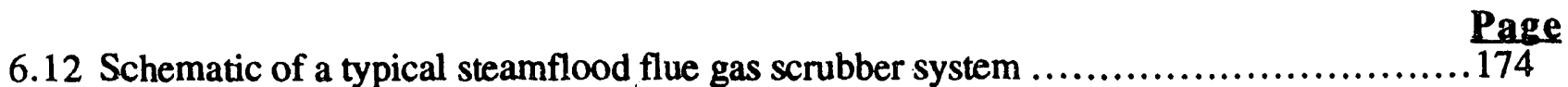

6.13 Schematic of a fluidized bed combustion steam generator............................... 177

6.14 Schematic of a wet air oxidation boiler arrangement for steamflood application...........178

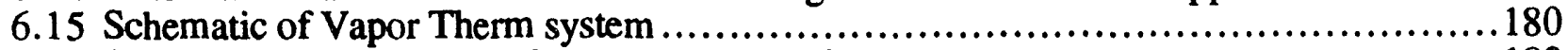

6.16 Schematic of a downhole steam generation system.........................................182

6.17 Low pressure downhole steam generator........................................... 183

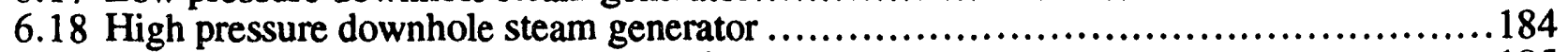

6.19 Downhole steam generator selection chart.........................................185

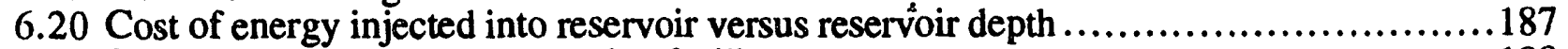

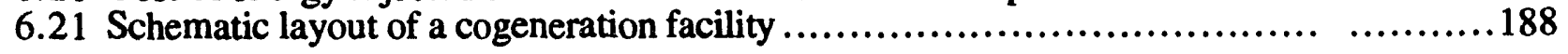

CHAPTER 7. Steam Distribution .......................................................207

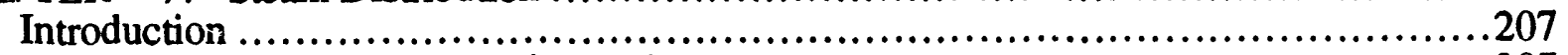

Components of a Steam Distribution Network .................................... 207

General System Pressure and Temperature Design Requirements .....................209

Main Steam Headers..................................................................212

Lateral Steam Lines ..........................................................213

Steam Flow Rates and Pressure Drop........................................213

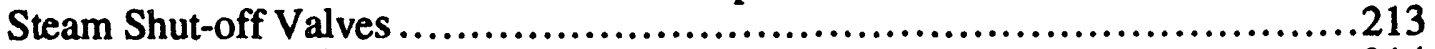

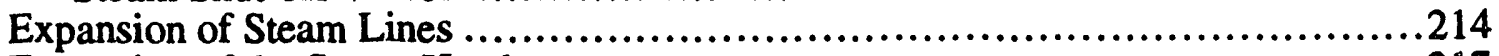

Expansion of the Steam Headers...................................................217

Wellhead Connection ..................................................................217

Support of Steam Lines .........................................................217

Insulation and Heat Loss.........................................................220

Effects of Branching on Steam Quality ..............................................2223

Wellhead Equipment...........................................................224

Wellhead Steam Rate Control Devices.................................................2229

Static Chokes in Critical Flow ..............................................229

Adjustable Chokes Operated in the Subcritical Flow Regime ...................2232

The Effect of Steam Quality on Injection Rate Control.............................234

Control of Individual Well Steam Quality ...........................................234

Steam Distribution System Maintenance and Monitoring $\ldots \ldots \ldots \ldots \ldots \ldots \ldots \ldots \ldots \ldots \ldots . .235$

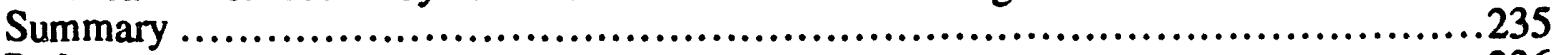

References.......................................................................236

Appendix 7-A. Steam distribution network components suppliers ...................237

\section{TABLES}

7.1 Design properties and allowable working pressures for piping ........................210

7.2 Pressure - temperature ratings for low carbon forged steel pipe flanges .................211

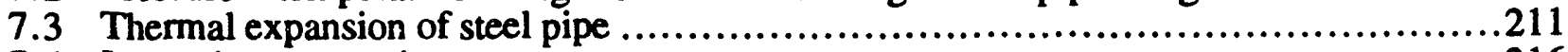

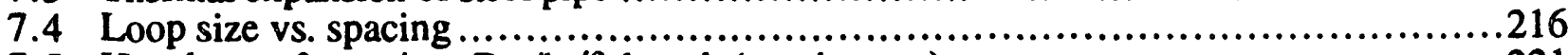

7.5 Heat losses from pipes Btu/hr/ft length (steady state) .............................221

\section{ILLUSTRATIONS}

7.1 Schematic of a typical steam distribution system layout ...........................208

7.2 Typical expansion loops used in steam injection operations to relieve steam flow line thermal stresses. 


\section{TABLE OF CONTENTS-Continued}

7.3 Schematic $\quad$ Page

7.3 Schematic of different expansion methods for steam injection lines.....................215

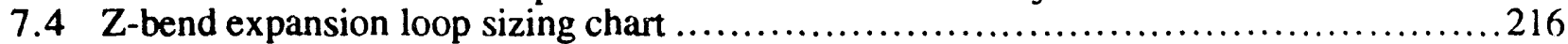

7.5 Schematic of a typical swivel joint used at the steam injection wellhead................218

7.6 Schematic of expansion manifold connection to steam injection well Christmas tree ....218

7.7 Steam injection line heat loss versus cash loss......................................221

7.8 Schematic of insulated pipe for heat loss transfer estimation.........................222

7.9 Schematic of pipe tee installations in steam injection lines................................224

7.10 Schematic of typical steam injection wellhead arrangement ..........................225

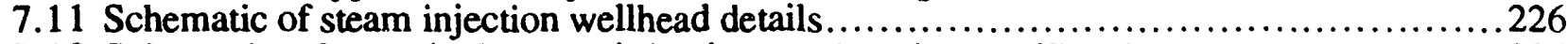

7.12 Schematic of a typical steam injection well casing stuffing box........................226

7.13 Schematic of a typical steam injection well tubing stuffing box.........................227

7.14 Schematic of steam injection wellhead assembly showing casing and tubing stuffing box arrangement ............................................................... 227

7.15 Schematic of steamflood production wellhead arrangement showing the facilities for pump hookup ............................................................. 228

7.16 Schematic of acceptable and nonacceptable choke inserts for steam injection rate control choke bean.........................................................230

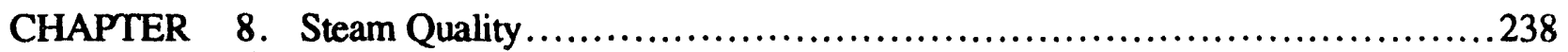

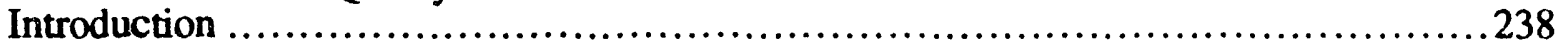

Surface Steam Quality Measurement ..............................................239

Separator Method .............................................................. 239

Orifice Metering Method ..........................................................240

Total Dissolved Solids Method .............................................. 242

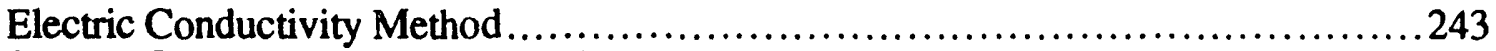

Stack Gas Analysis Method................................................. 244

Fixed Heat Rate Method.........................................................245

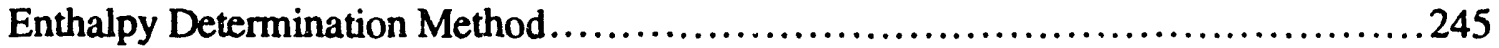

Wellhead Steam Quality ........................................................... 246

Vibrating Densitometer ..................................................... 247

Gamma Ray Absorption Technique...........................................249

Neutron Densitometer Steam Quality Measurement System ..................... 250

Downhole Steam Quality Measurement ...................................... 252

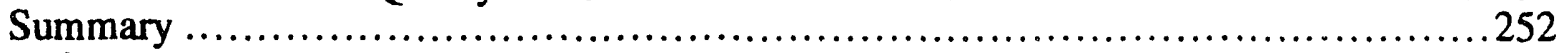

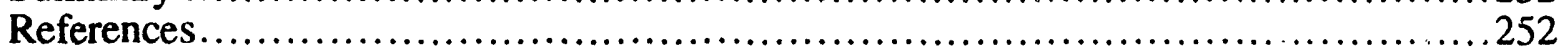

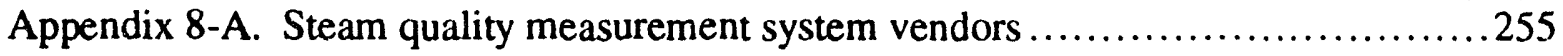

TABLES

8.1 Steam injection welihead steam quality ........................................247

\section{ILLUSTRATIONS}

8.1 Schematic of equipment arrangement for steam quality measurement by the vapor-liquid

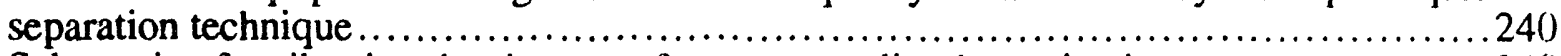

8.2 Schematic of a vibration densitometer for steam quality determination .................248

8.3 Schematic of gamma ray steam quality measurement technique ......................249 


\section{TABLE OF CONTENTS-Continued}

Page

8.4 Schematic of the principles of operation of a neutron densitometer $\ldots \ldots \ldots \ldots \ldots \ldots \ldots \ldots .251$

8.5 Arrangements for steam quality measurement using a neutron densitometer............251

CHAPTER 9. Thermal Well Completion Practices...........................................256

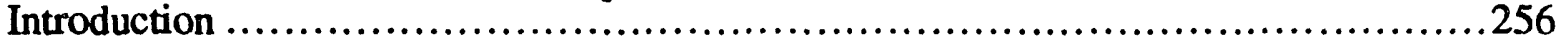

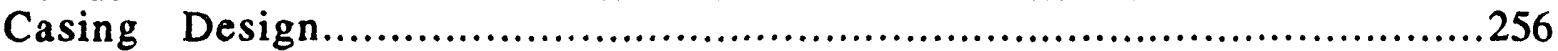

Temperature Effects on Casings and Tubings $\ldots \ldots \ldots \ldots \ldots \ldots \ldots \ldots \ldots \ldots \ldots \ldots \ldots \ldots . .256$

Thermal Well Casing Design ................................................... 261

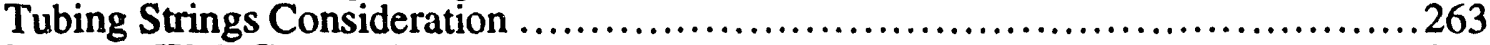

Thermal Well Completion...................................................263

Drilling Fluids............................................................. 264

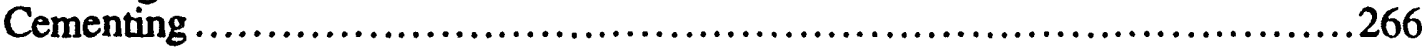

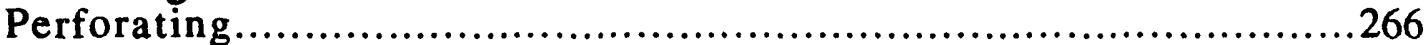

Well Completion and Workover Fluids.....................................267

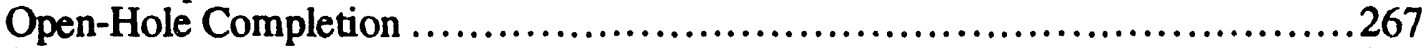

Screens.................................................................... 267

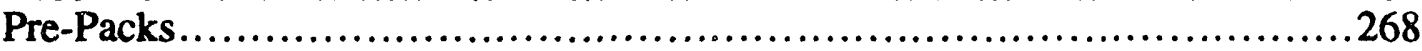

Open-Hole Gravel Packing......................................................268

Consolidated Pack................................................................2269

Case-Hole Completion......................................................269

Clay Stabilization ............................................................2270

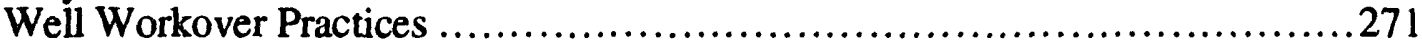

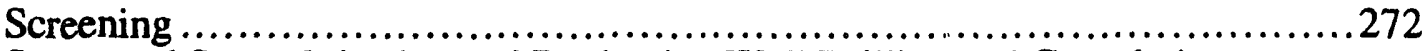

Suggested Steam Injection and Production Well Drilling and Completion

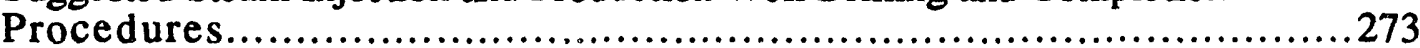

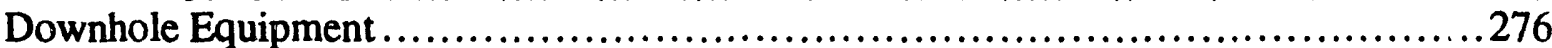

Thermal Packers.......................................................... 276

Packer Installation............................................................ 279

Seal Systems...............................................................2 279

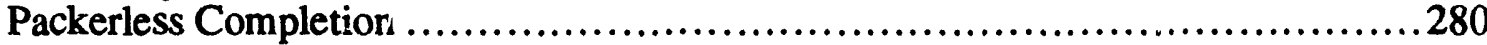

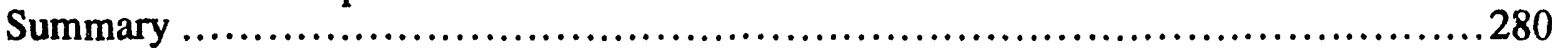

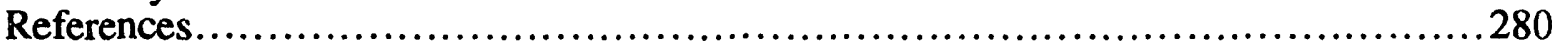

Appendix 9-A. Thermal well completion tools and accessories suppliers .............283

TABLES

9.1 Recommended operating temperature range for thermal well tubular goods ............258

9.2 Tensile Properties of various grades of seamless casing and tubing ....................259

9.3 Typical casing completions in California thermal wells..............................262

\section{ILLUSTRATIONS}

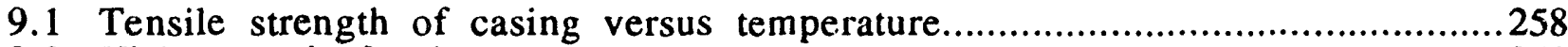

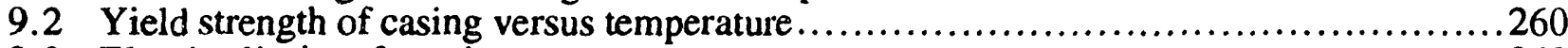

9.3 Elastic limit of casing versus temperature...........................................260

9.4 Schematic of a typical steam injection well completion ...............................264

9.5 Schematic of a typical steamflood production well completion .........................265

9.6 Schematic of a typical steamflood observation well completion $\ldots \ldots \ldots \ldots \ldots \ldots \ldots \ldots \ldots .265$ 


\section{TABLE OF CONTENTS-Continued}

9.7 Schematic showing retrievable and permanent packer position in steam injection well $\frac{\text { Page }}{277}$

9.8 Schematic detailing packer installation for multizone corppletion .

9.9 High-pressure steam injection well packer details .................................278

C.HAPTER 10. Thermal Well Cementing Practices.........................................284

Introduction ..................................................................284

Stean Injection Well Cementing Requirements ..................................284

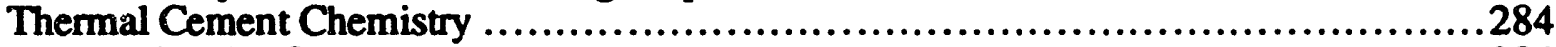

Portland Cement...................................................................284

High Alumina Cement............................................................... 288

Steamflood Cementing Practices......................................................288

Steam Well Problerns .............................................................. 288

Cementing Practices ..................................................................292

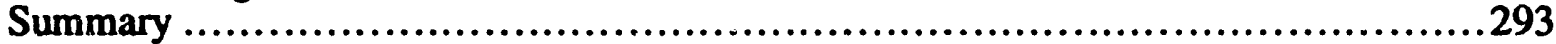

References...................................................................293

Appendix 10-A. Thermai well cementing service vendors................................295

\section{ILLUSTRATIONS}

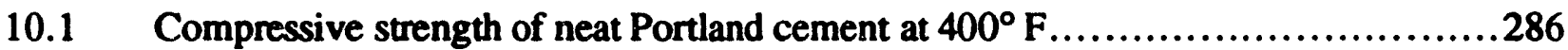

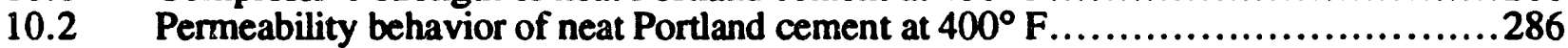

10.3 Compressive strength of Portland cement stabilized with $35 \%$ silica flour at various temperatures .................................................................... 287

10.4 Permeability behavior of Portland cument stabilized with $35 \%$ silica flour at various temperatures .............................................................287

10.5 Compressive strength of conventionally extended Portland cement at $400^{\circ} \mathrm{F} \ldots \ldots \ldots .290$

10.6 Permeability performance of conventionally extended Portland cement at $400^{\circ} \mathrm{F}$..... 290

10.7 Compressive strength of conventionally extended Portland cement at $600^{\circ} \mathrm{F} \ldots \ldots \ldots .291$

10.8 Permeability performance of conventionally extended Portland cement at $600^{\circ} \mathrm{F}$.....291

CHAPTER 11. Thermal Well Lifting Fouipment.........................................296

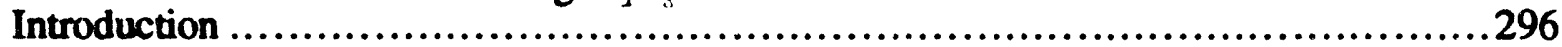

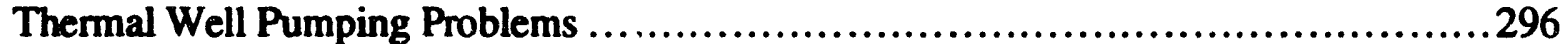

Rod Fall and Rod Drag........................................................296

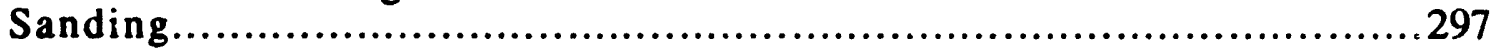

Steam Breakthrough ...........................................................298

Production Conditions Variations...............................................298

System Operations Problems ......................................................299

Solutions to Heavy Oil Thermal Well Pumping Problems......................................299

Novel Pump Jacks ................................................................ 30

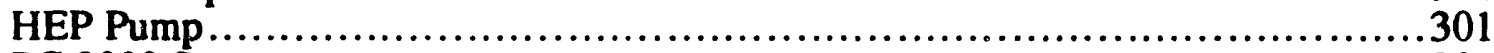

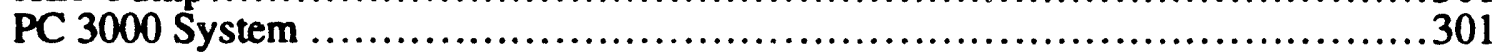

Variable Speed Beam Pump ........................................................ 302

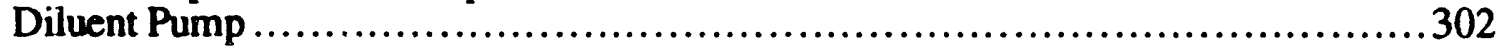

U.S. Thermal Well Pump Systems .............................................. 304

Use of Pump-Off Controls in Thermal Well....................................... 304

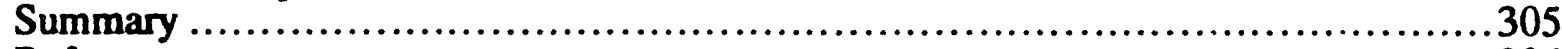

References................................................................ 306

Appendix 11-A. Thermal well lifting equipment suppliers .........................309 


\section{TABLE OF CONTENTS-Continued}

\section{ILLUSTRATIONS}

11.1 Schematic of a diluent pump used in the Cat Canyon field of California to produce the $6^{\circ}$ API oil

CHAPTER 12. Use of Insulated Tubulars in Thermal Projects............................310

Introduction ....................................................................... 310

Wellbore Heat Losses ...........................................................310

Benefits of Using Insulated Tubing...........................................................

Insulated Tubing Design Requirements ...........................................311

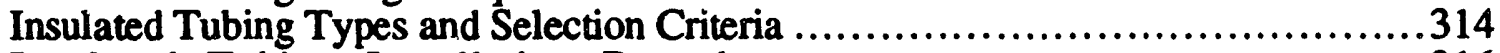

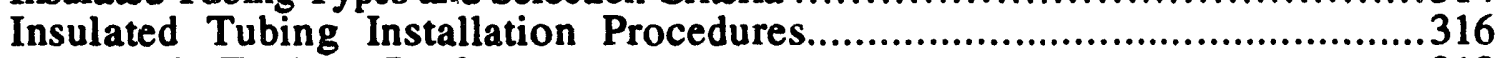

Insulated Tubing Performance...........................................................318

Insulated Tubing Cost Effectiveness.....................................................318

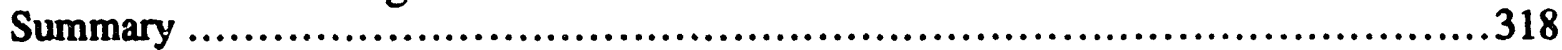

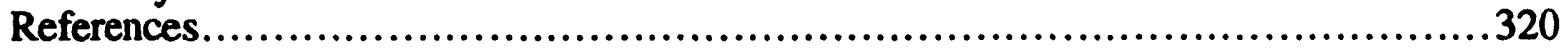

Appendix 12-A. Downhole insulated tubing suppliers...............................321

TABLES

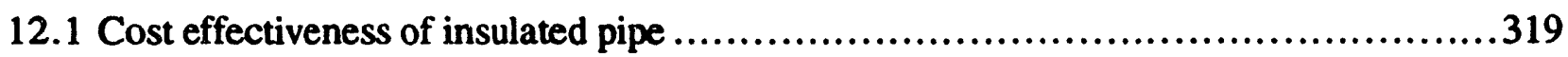

\section{ILLUSTRATIONS}

12.1 Heat loss in the wellbore and casing temperature during steam injection .................312

12.2 Variation of overall heat transfer coetficient (U) with tubing temperature for different tubing surfaces and annulus pressure .........................................313

12.3 Estimated heat loss as function of depth .................................................

12.4 Schematic of basic insulated tubular design ........................................................

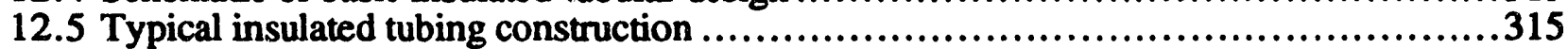

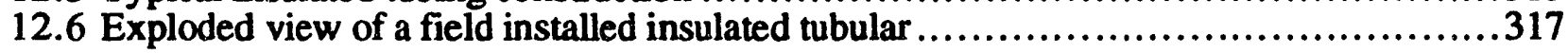

CHAPTER 13. Sand Control Problems..........................................................322

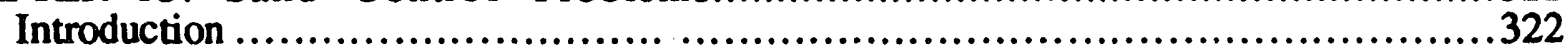

Occurrence and Identification of Problems-Causing Sands........................322

Prevention of Problems in Producing Wells.........................................323

Use of Open-Hole or Gravel Pack Completion.............................................324

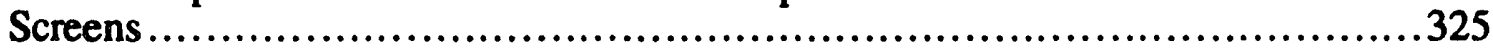

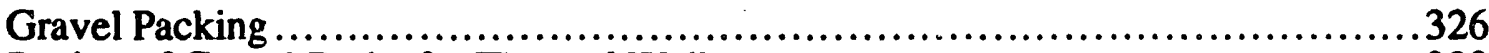

Design of Gravel Packs for Thermal Wells ...................................................329

Chemical Methods of Sand Control........................................................333

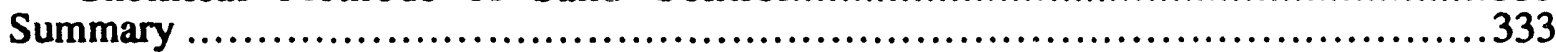

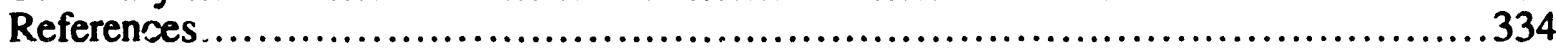

Appendix 13-A. Sand control and gravei pack system vendors.................................337

\section{TABLES}

13.1 Sanding problems encountered in U.S. steam stimulation projects .....................325

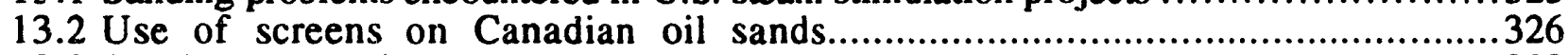

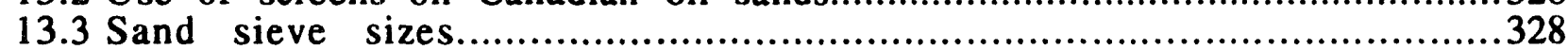

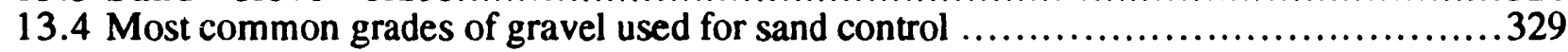




\section{TABLE OF CONTENTS-Continued}

\section{ILLUSTRATIONS}

Page

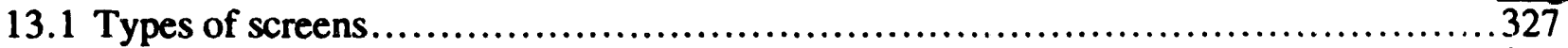

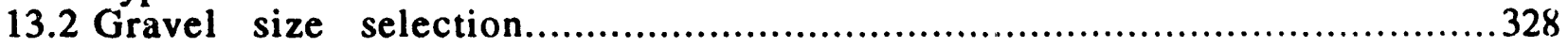

13.3 Schematic of a thermal well gravel pack completion ............................... 330

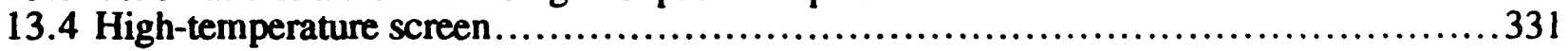

CHAPTER 14. Steam Injection Profile Control...............................................338

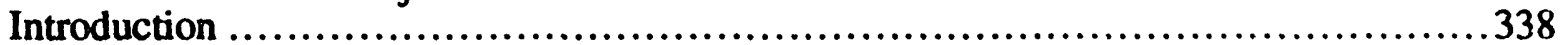

Distribution of Steam $/$ Water in Tubing ....................................... 338

Measurement of Steam Injection Profile..........................................339

Spinners ....................................................................340

Temperature Surveys....................................................... 341

Radioactive Tracer Surveys ................................................ 343

Methods of Altering Profiles......................................................... 347

Concentric Tube Method ................................................................. 348

Parallel Tubing Injection .......................................................... 348

Limited Entry Injection ........................................................ 350

Use of Monitoring Wells....................................................... 353

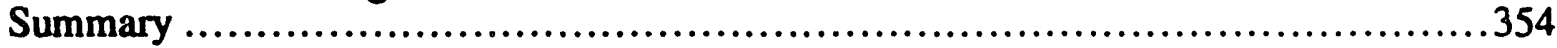

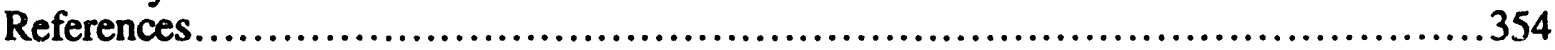

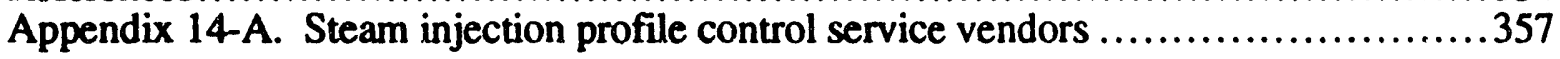

TABLES

14.1 Procedure for determining steam injection profile using a spinner ....................341

14.2 Properties of tracers ................................................................. 344

14.3 Procedure for running radioactive tracer survey with sodium iodide.......................344

14.4 Procedure for running radioactive tracer survey using inert gas tracers....................345

14.5 Calculation of the critical pressure ratio............................................ 351

\section{ILLUSTRATIONS}

14.1 Mist and annular flow regimes for two-phase flow .................................339

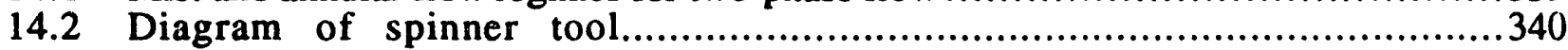

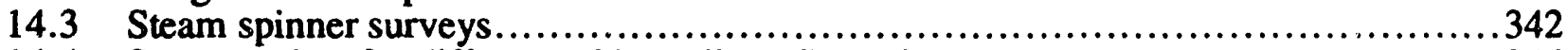

14.4 Survey points for different tubing tail configurations................................ 346

14.5 Survey results: well configuration, vapor phase profile by krypton, liquid phase profile by sodium iodide, and heat profile..............................................347

14.6 Schematic of concentric tubing completion............................................349

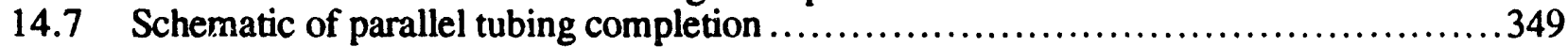

14.8 Three steam injection well completion designs .................................... 350

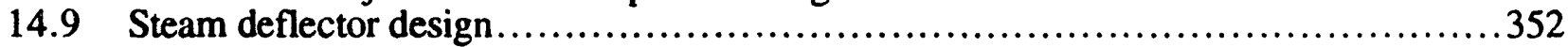

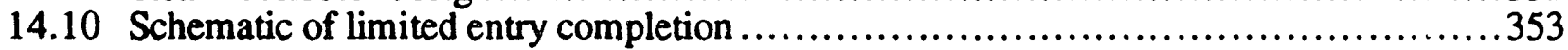


CHAPTER 15. Emulsion Problems in Steam Injection Projects............................358

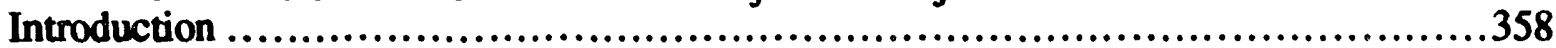

Definition of an Emulsion..................................................358

Emulsion Formation and Stability..........................................................359

Methods Used to Break Emulsions ............................................360

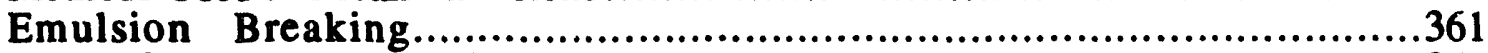

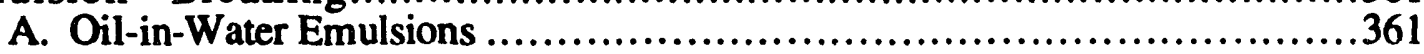

B. Water-in-Oil Emulsions ................................................363

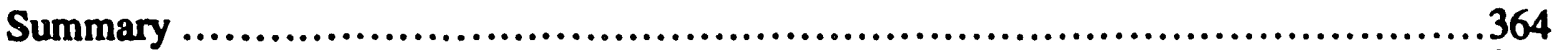

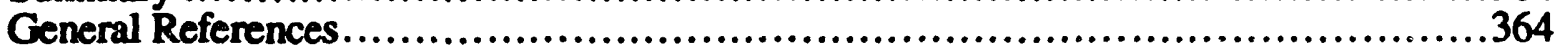

Appendix 15-A. Emulsion treatment chemical suppliers................................365

CHAPTER 16. Surface Production Facilities ..........................................366

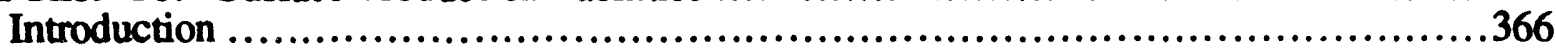

Production Gathering System ........................................................366

Automatic Well Test (AWT) Units ...............................................369

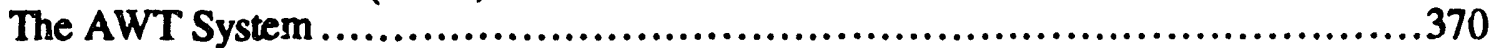

Treatment of Produced Fluids...................................................................371

Freewater Knockout (FWKO) Vessels........................................372

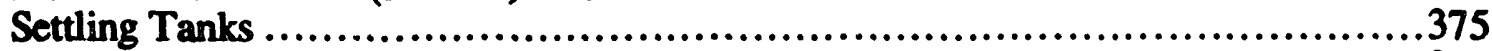

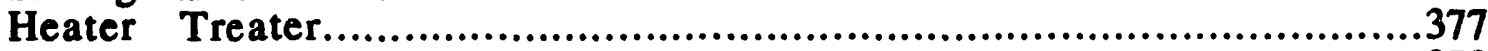

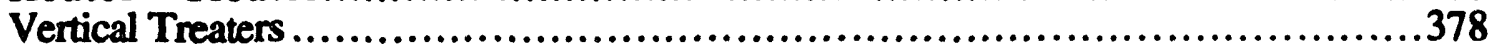

Horizontal Heater Treater ........................................................378

Electrostatic Treaters............................................................383

Emulsion Breaker Treatrnent...........................................................383

Lease Automatic Custody Transfer (LACT) Unit .................................384

Tank Bottoms Cleaning ......................................................385

Cyclone Desanders......................................................................386

Operation, Maintenance and Monitoring Considerations...........................386

Automation of Dehydration Plant .............................................386

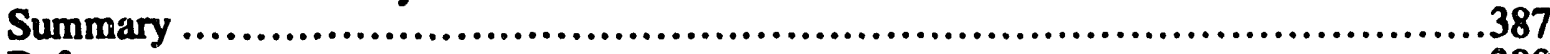

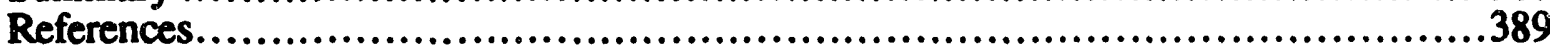

Appendix 16-A. Steam injection production facilities vendors............................391

TABLES

16.1 Specifications for horizontal freewater knockouts.................................375

16.2 Specifications for vertical freewater knockouts .....................................375

16.3 Computerized automation of oilfield productions-costs and benefits.......................388

\section{ILLUSTRATIONS}

16. Schematic of a steamflood surface production facility ............................367

16.2 Schematic of a typical steamflood production gathering network .......................368

16.3 Schematic of steamflood automatic well testing system ...............................371

16.4 Typical horizontal freewater knockout ............................................374

16.5 Typical vertical freewater knockout ............................................374

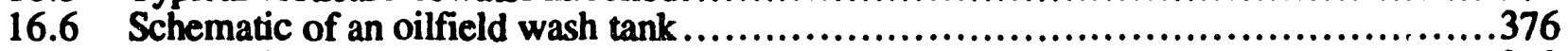

16.7 Schematic of a vertical heater treater ............................................379

16.8 Schematic of a second type of vertical heater treater ..............................380 


\section{TABLE OF CONTENTS-Continued}

16.9 Schem atic of a third type of vertical heater treater ....................................

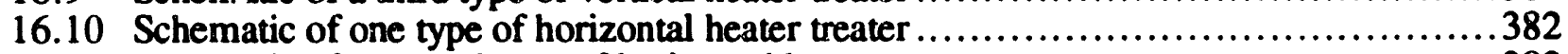

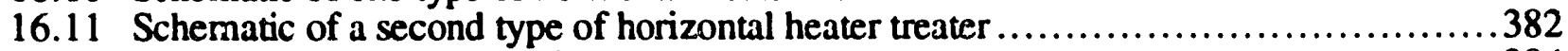

16.12 Schematic of an electrostatic treater .................................................. 384

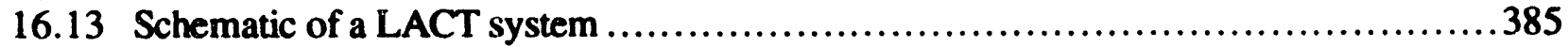

CHAPTER 17. Steam Injection Project Performance Monitoring Tools..................392

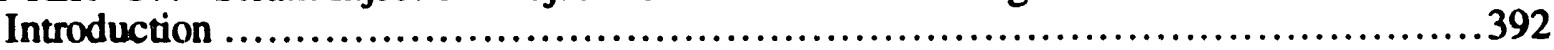

Physical Data Monitoring Tools ................................................ 393

Automated Well Testing ....................................................393

Steam Generator Fuel Usage Report ...........................................393

Steam Distribution-Steam Injection Rates ............................... 393

Water Treatment System ............................................... 393

Electrical Power Consumption Report...........................................394

Comments on Physical Data Monitoring Tools..................................394

Economic Data Monitoring Tools ............................................. 394

Monitoring Capital Expenses.................................................... 395

Monitoring Tools Improvement.............................................395

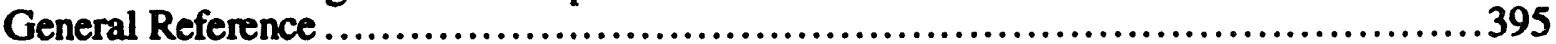

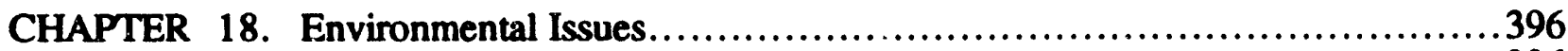

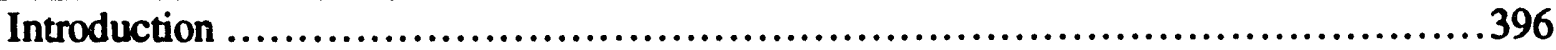

Obtaining an Environmental Permit ................................................. 396

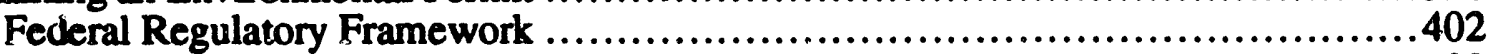

Enforcement Agencies..........................................................403

Air Resources Board (ARB) ..............................................403

Air Pollution Control and Air Quality Management Districts (APCD/AQMD) ....403

State Water Resoumees Control Board (SWRCB) ...........................403

Regional Water Quality Control Boards (RWQCB).........................403

Department of Health Services (DHS) ....................................403

Air Quality Regulations Impacting Steam Injection Operations ..................408

National Ambient Air Quality Standards.....................................408

State Implementation Plans (SIP) .........................................411

Emission Limitations ..........................................................411

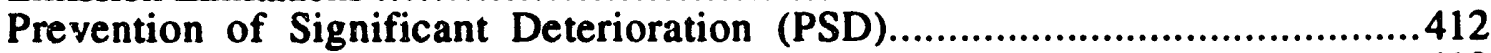

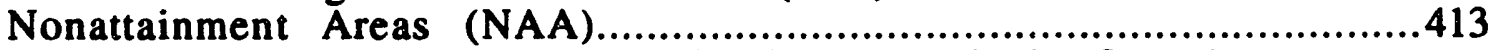

Best Available Control Technology (BACT) for Steam Injection Operation

Pollutants............................................................................4414

Lowest Achievable Emission Rate (LAER) .......................................414

The Clean Air Act (CAA) Amendments of $1990 \ldots \ldots \ldots \ldots \ldots \ldots \ldots \ldots \ldots \ldots \ldots \ldots . \ldots \ldots 15$

Water Quality Regulations Impacting Steam Injection Operations ..................415

Federal Clean Water Act (CWA) .................................................415

Safe Drinking Water Act (SDWA) .........................................416

Miscellaneous Regulations Governing Oil and Gas Wastewaters.................. 417

Spill Prevention Regulations...................................................417

Ciassification of Injection Wells in California ..................................417 


\section{TABLE OF CONTENTS-Continued}

Waste Management Regulations Impacting Steam Injection Operations.................418

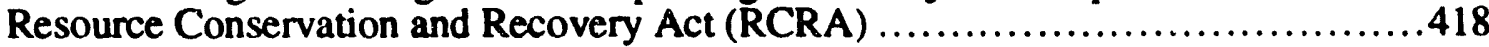

Noise Quality Regulations Impacting Steam Injection Operations ................418

Sources of Pollution in Steam Injection Field Activities..................................420

Air Quality ............................................................... 420

Water Quality ...............................................................420

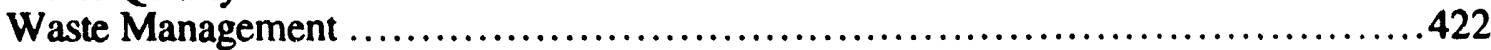

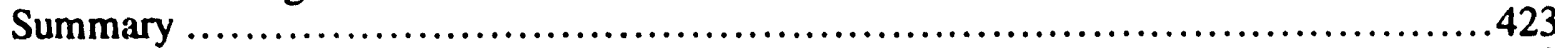

References.....................................................................423

Appendix 18-A. Thermal EOR environmental Consultants................................425

\section{TABLES}

18.1 State EOR Environmental Regulatory Agencies .................................404

18.2 Abbreviations used in the text............................................................409

18.3 Current national primary and secondary ambient air quality standards ..............4 410

18.4 Permitted air-quality increments for prevention of significant deterioration ............413

18.5 Typical emissions from an oil-fired steam generator ..............................413

18.6 EPA list of exempt and nonexempt oilfield wastes from RCRA hazardous management requirements................................................ 419

18.7 Estimated air emissions from a typical steam injection project during site preparation activities 


\title{
PRACTICAL ASPECTS OF STEAM INJECTION PROCESSES \\ A HANDBOOK FOR INDEPENDENT OPERATORS
}

\author{
By \\ Partha S. Sarathi and David K. Olsen
}

\begin{abstract}
More than $80 \%$ of the total steam injection process operating costs are for the production of steam and the operation of surface and subsurface equipment. The proper design and operation of the surface equipment is of critical importance to the success of any steam injection operation. However, the published monographs on thermal recovery have attached very little importance to this aspect of thermal oil recovery; hence, a definite need exists for a comprehensive manual that places emphasis on steam injection field practices and problems. This handbook is an attempt to fulfill this need.

This handbook explores the concept behind steam injection processes and discusses the information required to evaluate, design, and implement these processes in the field. The emphasis is on operational aspects and those factors that affect the technology and economics of oil recovery by steam. The intended purpose of this handbook is twofold: (a) to provide operators with a ready reference, a starting point when searching for information to engineer a steam injection project; and (b) to provide a bibliographic source on the subjects discussed in the handbook. It should, however, be emphasized that this handbook is not a detailed "trouble snooter" manual on field pioblems. Steam injection process problems and solutions are field specific, and only experienced field personnel or consultants can solve these specific problems.

The first four chapters describe the screening criteria, engineering, and economics of steam injection operation as well as discussion of the steam injection fundamentals. The next four chapters begin by considering the treatment of the water used to generate steam and discuss in considerable detail the design, operation and problems of steam generations, distribution and steam quality determination. Tne subsurface aspects of steamflood operations are addressed in chapters 9 through 12. These include thermal well completion and cementing practices, insulated tubulars, and lifting equipment. The next two chapters are devoted to subsurface operational problems encountered with the use of steam. Briefly described in chapters 15 and 16 are the steam injection process surface production facilities, problems and practices. Chapter 17 discusses the importance of monitoring in a steam injection project. The environmental laws and issues of importance to steam injection operation are outlined in chapter 18.
\end{abstract}


The handbook is organized in the above manner so that the reader will have a good understanding of the engineering and financial requirements of a steam injection project before he reads the steam injection field practices, problems and solutions.

\section{ACKNOWLEDGMENTS}

This work was sponsored by the U.S. Department of Energy (DOE) under Cooperative Agreement DE-FC22-83FE60149 and performed within project BE11B as outlined in the FY91 Annual Research Plan (DOE Report NIPER-465). The work of this nature could not have been completed without the help and cooperation of various personnel. Many people have made significant contributions to the preparation of this report. In particular, the authors wish to offer their thanks to John Ball, consultant, for his assistance in the preparation of chapters 12,13, and 14; Bruce Ramzel, and Summer DOE Interns, Heather Horstman, Yesh Tyagi, William Lucas, Johnathan Grigsby and Robert Pendergrass II, all of NIPER, for their help in preparing the figures; and Rex Thomas, Consultant, for his assistance in gathering materials for the report. We offer our thanks to Michael Madden for his assistance in preparing chapter 18 and Arden Strycker and Min Tham, all of NIPER, and Thomas B. Reid of the U.S. Department of Energy, Bartlesville Project Office, for their critical reviews of the manuscript. We also extend our appreciation to Bill Linville and Ron Kendall of NIPER for their editorial review. We also thank the American Petroleum Institute for permission to reproduce portions of RP11T report and various technical journals and equipment manufacturers for permission to use their illustrations, tables, and charts. 


\section{CHAPTER 1 \\ FUNDAMENTALS OF STEAM INJECTION PROCESSES}

\section{INTRODUCTION}

Steam injection is a thermal drive process that adds heat to the reservoir to expand the oil-inplace, reduce its viscosity, provide drive energy and thereby improve the displacement efficiency of injected fluid. For more than $\mathbf{1 0 0}$ years, steam has been used in attempts to solve the problems of low recovery from heavy oil reservoirs. Its full potential was not realized until the early 50s when field testing of the steam injection process began. In the United States in 1990, steamflooding recovered 520,000 barrels of oil per day (BOPD) or $73 \%$ of all enhanced oil recovery. ${ }^{1}$

This manual explores the concepts behind steam injection processes and discusses the information required to evaluate, design, and implement these processes in the field. The emphasis is on the practical aspects of steam injection. Details of equations and calculation methods for estimating steam injection performance are not discussed in this manual. Other publications ${ }^{2-4}$ cover these subjects in detail. There is a heavy emphasis on surface and subsurface facilities, field practices, and operational problems which are not discussed in sufficient detail in other publications. The material presented is directed toward engineers and independent operators who have become familiar with routine waterflood operations but have had no exposure to thermal operations.

This chapter reviews the stearn injection process and recovery mechanisms. In subsequent chapters, various aspects of steam injection are discussed in detail.

\section{Basics of Steam Injection}

Although in situ reservoir energy is responsible for the displacement of oil through porous rock into wellbores, it is not always sufficient for oil displacement, especially in shallow heavy oil reservoirs. Hence, energy needs to be imparted to the reservoir to allow the oil to flow toward a wellbore. This usually takes the form of mechanical displacement such as pushing the oil with water or gas. In steam injection, steam is used as the displacing fluid. Steam augments the reservoir energy by parting its heat content as well as mechanical energy because of pressure differential.

Steam is an ideal fluid for adding energy to a reservoir because of its high heat content per pound. For example, water at $400^{\circ} \mathrm{F}$ contains $375 \mathrm{Btu} / \mathrm{lb}$, but saturated steam at $400^{\circ} \mathrm{F}$ has 1,201 $\mathrm{Btu} / \mathrm{lb}$, or over three times the heat content of water.

To fully realize why steam is effective in producing oil, one needs to understand the properties of steam as well as what happens in a reservoir when steam is injected. Some properties of saturated steam for a few selected temperatures and pressures are listed in table 1.1. 
TABLE 1.1. - Properties of Saturated Steam

\begin{tabular}{|c|c|c|c|c|c|c|c|}
\hline $\begin{array}{l}\text { Absolute } \\
\text { pressure. } \\
\text { psia }\end{array}$ & $\begin{array}{l}\text { Saturation } \\
\text { temperature. } \\
{ }^{\circ} \mathrm{F}\end{array}$ & $\begin{array}{l}\text { Heat of } \\
\text { liquid. } \\
\text { Baulb }\end{array}$ & $\begin{array}{l}\text { Latent } \\
\text { heat of } \\
\text { vaporization, } \\
\text { Bunlb }\end{array}$ & $\begin{array}{l}\text { Heat } \\
\text { content } \\
\text { of steam. } \\
\text { Burbs }\end{array}$ & $\begin{array}{l}\text { Weight } \\
\text { of } 1 \mathrm{cu} \mathrm{ft} \\
\text { of steam. } \\
\mathrm{B}\end{array}$ & $\begin{array}{l}\text { Volume } \\
\text { of } 1 \mathrm{lb} \\
\text { of steam. } \\
\text { cu } \mathrm{ft}\end{array}$ & $\begin{array}{c}\text { Volume } \\
\text { of } 1 \mathrm{lb} \\
\text { of liquid. } \\
\text { cu } \mathrm{ft}\end{array}$ \\
\hline so & 281.0 & 250.2 & 923.9 & 1.174 .1 & 0.1175 & 8.514 & 0.01727 \\
\hline 100 & 327.8 & 298.5 & 888.6 & $1,187.2$ & 0.2257 & 4.431 & 0.01774 \\
\hline 150 & 358.4 & 330.6 & 863.4 & 1.194 .1 & 0.3318 & 3.014 & 0.01809 \\
\hline 200 & 381.8 & 355.5 & 842.8 & $1,198.3$ & 0.4372 & 2.287 & 0.01839 \\
\hline 250 & 401.0 & 376.1 & 825.0 & $1,201.1$ & 0.5425 & 1.843 & 0.01865 \\
\hline 300 & 417.4 & 394.0 & 808.9 & 1.202 .9 & 0.6482 & 1.543 & 0.01889 \\
\hline 400 & 444.6 & 424.2 & 780.4 & $1,204.6$ & 0.8614 & 1.161 & 0.01934 \\
\hline 300 & 467.0 & 449.5 & 755.1 & $1,204.7$ & 1.0781 & 0.9276 & 0.01975 \\
\hline 600 & 486.2 & 471.7 & 732.0 & $1,203.7$ & 1.2991 & 0.7698 & 0.02013 \\
\hline 700 & 503.0 & 491.6 & 710.2 & 1.201 .8 & 1.5254 & 0.6556 & 0.0205 \\
\hline 800 & 518.2 & 509.8 & 689.6 & $1,199.4$ & 1.7576 & 0.567 & 0.02087 \\
\hline 900 & 532.0 & 526.7 & 669.7 & $1,196.4$ & 1.9964 & 0.501 & 0.02123 \\
\hline 1.000 & 544.6 & 542.6 & 650.4 & 1.192 .9 & 2.2424 & 0.446 & 0.02159 \\
\hline 1.100 & 556.3 & 557.5 & 631.5 & 1.189 .1 & 2.4964 & 0.401 & 0.02195 \\
\hline 1.200 & 567.2 & 571.9 & 613.0 & $1,184.8$ & 2.759 & 0.3624 & 0.02232 \\
\hline 1,300 & 577.4 & 585.6 & 594.6 & 1.180 .2 & 3.0311 & 0.33 & 0.02269 \\
\hline 1,400 & 587.1 & $\$ 98.8$ & 576.5 & 1.175 .3 & 3.3137 & 0.3018 & 0.02307 \\
\hline 1,500 & 596.2 & 611.7 & 558.4 & $1,170.1$ & 3.6076 & 0.2771 & 0.02346 \\
\hline 2,000 & 635.8 & 672.1 & 466.2 & $1,138.3$ & 5.3104 & 0.1883 & 0.02565 \\
\hline 2,500 & 668.1 & 731.7 & 361.6 & 1.093 .3 & 7.6523 & 0.1307 & 0.02859 \\
\hline 3.000 & 695.3 & 801.8 & 218.4 & $1,020.3$ & 11.765 & 0.085 & 0.03428 \\
\hline
\end{tabular}

Note that the heat content of steam is considerably higher than the heat content of liquid water. This difference is the latent heat and represents the amount of additional energy required to convert boiling water at a given pressure into steam at the same pressure and temperature. Latent heat is large at lower pressure and decreases with increase in pressure and becomes zero at $705.47^{\circ} \mathrm{F}$ temperature and 3,208.2 psia pressure. This temperature and pressure is known as the critical point of water. Above this point, water exists only as a single phase. Also, note that steam saturation temperature increases with pressure and the rate of increase is greatest at lower pressures. This rate of change in temperature becomes smaller at higher pressure. For example, 
when the steam pressure increases from 100 to 200 psia, the saturation temperature changes from $328^{\circ}$ to $381^{\circ} \mathrm{F}$ or an increase of $53^{\circ} \mathrm{F}$. On the other hand, when the pressure of steam increases from 1,000 to 1,100 psia, the corresponding increase in saturation temperature is only about $12^{\circ} \mathrm{F}$.

The other important charactenstic of steam is the change in volume. The volume of $1 \mathrm{lb}$. of saturated steam at various pressures and temperatures is depicted in Table 1.1. At 400 psia and $444^{\circ} \mathrm{F}, 1 \mathrm{lb}$ of water occupies $0.0193 \mathrm{cu} \mathrm{ft}$, but $1 \mathrm{lb}$ of saturated steam at the same conditions has a volume of $1.161 \mathrm{cu} \mathrm{ft}$. Therefore, the saturated vapor occupies about 60 times the volume of water. Naturally, this ratio decreases with an increase in steam pressure but still is significant at the pressure range where most thermal projects operate. For example, at 1,500 psia, the upper limit for many steamflood projects, the ratio is 12 . This is one of the reasons why steam heating has had such success in the thermal process. A given amount of reservoir heating can be accomplished with a much smaller unit weight of steam than hot water.

\section{Steam Quality}

Another term frequently encountered in the steam injection processes is steam quality. This term refers to the degree of dryness of steam. For example, an $80 \%$ quality steam refers to a steam water mixture containing $80 \%$ steam and $20 \%$ water by weight. A $100 \%$ quality steam refers to steam containing no water and is known as dry saturated steam. The heat content of a wet steam (mixture of steam and water) is always lower than that of a dry saturated steam. For example, a $70 \%$ quality steam at 200 psia contains about $946 \mathrm{Btu} / \mathrm{lb}$, and dry steam at the same pressure contains 1,200 Btu/lb, or about 1.3 times as much heat as the wet stean. At higher pressures, this ratio becomes smaller since the effect of steam quality becomes less predominant. This is because the enthalpy of water increases with pressure and the latent heat of vaporizaticn decreases with pressure.

In table 1.2, the heat content of several qualities of steam is presented. The heat content of various quality steam is also shown graphically in figure 1.1. Most oilfield steam generators are designed to give $80 \%$ quality steam. Nevertheless, in the 100 to 1,500 psia pressure range, where most steam injection projects operate, wet steam carries more heat than hot water. For example, 1 $\mathrm{lb}$ of an $80 \%$ quality steam at 200 psia carries $674 \mathrm{Btu}$ more heat than $1 \mathrm{lb}$ of boiling water at the same temperature. This allows an operator to introduce more heat in a reservoir per pound of injected fluid.

\section{Steam Injection Process}

What happens in a reservoir when steam is injected? Obviously, steam moves through the reservoir and in the process it heats the oil and displaces it towards a producing well. Figure 1.2 depicts schematically a steamflood process. 
TABLE 1.2. - Heat Content of Wet Steam Btu/lb

\begin{tabular}{|c|c|c|c|c|c|c|c|c|c|c|}
\hline \multirow{2}{*}{$\begin{array}{c}\text { Absolute } \\
\text { pressure, } \\
\text { Psi }\end{array}$} & \multirow{2}{*}{$\begin{array}{l}\text { Temperature, } \\
\text { oF }\end{array}$} & \multicolumn{9}{|c|}{$\begin{array}{l}\text { Heat content, Btw/b } \\
\text { Steam quality, percent }\end{array}$} \\
\hline & & 100 & 90 & 80 & 70 & 60 & 50 & 40 & 20 & 0 \\
\hline $\begin{array}{r}50 \\
100 \\
150 \\
200 \\
250 \\
300 \\
400 \\
500 \\
600 \\
700 \\
800 \\
900 \\
1,000 \\
1,100 \\
1,200 \\
1,300 \\
1,400 \\
1,500 \\
2,000 \\
2,500 \\
3,000\end{array}$ & $\begin{array}{l}281.0 \\
327.8 \\
358.4 \\
381.8 \\
401.0 \\
417.4 \\
444.6 \\
467.0 \\
486.2 \\
503.0 \\
518.2 \\
532.0 \\
544.6 \\
556.3 \\
567.2 \\
577.4 \\
587.1 \\
596.2 \\
635.8 \\
668.1 \\
695.3\end{array}$ & $\begin{array}{l}1,174.1 \\
1,187.2 \\
1,194.1 \\
1,198.3 \\
1,201.1 \\
1,204.6 \\
1,204.6 \\
1,204.7 \\
1,203.7 \\
1,201.8 \\
1,199.4 \\
1,196.4 \\
1,192.9 \\
1,189.1 \\
1,184.8 \\
1.180 .2 \\
1,175.3 \\
1,170.1 \\
1,138.3 \\
1,093.3 \\
1,020.3\end{array}$ & $\begin{array}{r}1,081.7 \\
1,098.2 \\
1,107.7 \\
1,114.0 \\
1,118.6 \\
1,122.0 \\
1,126.6 \\
1,129.1 \\
1,130.5 \\
1,130.8 \\
1,130.4 \\
1,129.4 \\
1,128.0 \\
1,125.9 \\
1,123.6 \\
1,120.7 \\
1,117.7 \\
1,114.3 \\
1,091.7 \\
1,057.1 \\
998.4\end{array}$ & $\begin{array}{r}989.3 \\
1,009.4 \\
1,021.3 \\
1,029.7 \\
1,036.1 \\
1,041.1 \\
1,048.5 \\
1,053.6 \\
1,057.3 \\
1,159.8 \\
1,061.5 \\
1,062.5 \\
1,062.9 \\
1,062.7 \\
1,062.3 \\
1,061.3 \\
1,060.0 \\
1,058.4 \\
1,045.1 \\
1,002.1 \\
976.5\end{array}$ & $\begin{array}{r}896.9 \\
920.5 \\
935.0 \\
945.6 \\
953.6 \\
960.5 \\
970.5 \\
978.1 \\
984.1 \\
988.7 \\
992.5 \\
995.5 \\
997.9 \\
999.6 \\
1,001.0 \\
1,001.8 \\
1,002.4 \\
1,002.6 \\
998.4 \\
984.8 \\
954.7\end{array}$ & $\begin{array}{l}804.5 \\
831.7 \\
848.6 \\
861.2 \\
871.1 \\
879.3 \\
892.4 \\
902.6 \\
910.9 \\
917.7 \\
923.6 \\
928.5 \\
932.8 \\
936.4 \\
939.7 \\
942.4 \\
944.7 \\
946.7 \\
951.8 \\
948.7 \\
932.8\end{array}$ & $\begin{array}{l}712.2 \\
742.8 \\
762.3 \\
776.9 \\
788.6 \\
798.5 \\
814.4 \\
827.1 \\
837.7 \\
846.7 \\
854.6 \\
861.6 \\
867.8 \\
873.3 \\
878.4 \\
882.9 \\
887.1 \\
890.9 \\
905.2 \\
912.5 \\
911.0\end{array}$ & $\begin{array}{l}619.8 \\
653.9 \\
676.0 \\
692.6 \\
706.1 \\
717.6 \\
736.4 \\
751.5 \\
764.5 \\
775.7 \\
785.6 \\
794.6 \\
802.8 \\
810.1 \\
817.1 \\
809.7 \\
829.4 \\
835.1 \\
858.6 \\
876.3 \\
889.2\end{array}$ & $\begin{array}{l}435.0 \\
476.2 \\
503.3 \\
524.1 \\
541.1 \\
555.8 \\
580.3 \\
600.5 \\
618.1 \\
633.6 \\
647.7 \\
660.7 \\
672.7 \\
683.8 \\
694.5 \\
704.5 \\
714.1 \\
723.4 \\
765.3 \\
804.0 \\
845.4\end{array}$ & $\begin{array}{l}250.2 \\
298.5 \\
330.6 \\
355.5 \\
376.1 \\
394.0 \\
424.2 \\
449.5 \\
486.2 \\
491.6 \\
509.8 \\
526.7 \\
542.6 \\
557.5 \\
571.9 \\
585.6 \\
598.8 \\
611.7 \\
672.1 \\
731.7 \\
801.8\end{array}$ \\
\hline
\end{tabular}

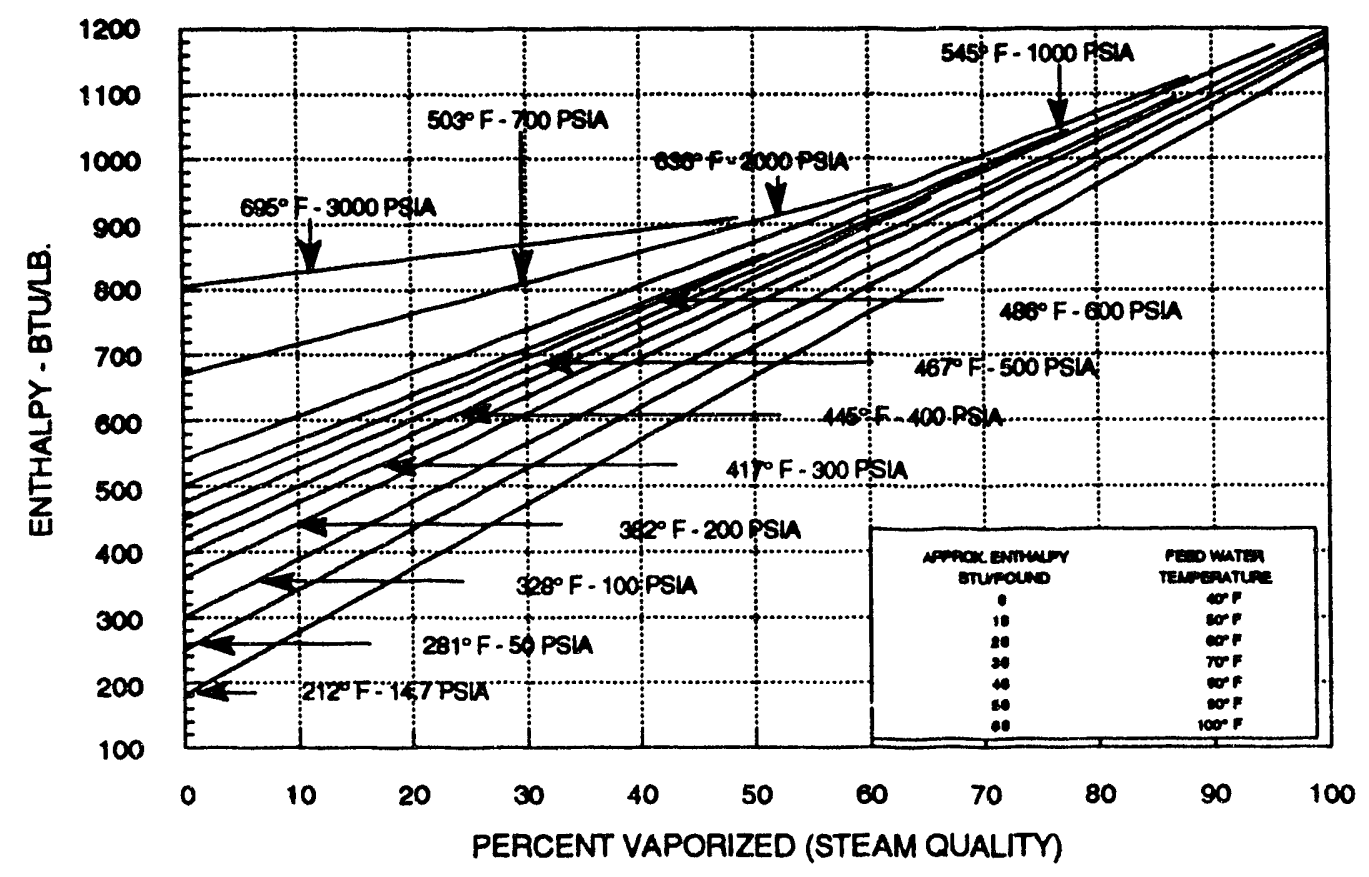

FIGURE 1.1. - Heat content of wet steam, Btu/lb. 


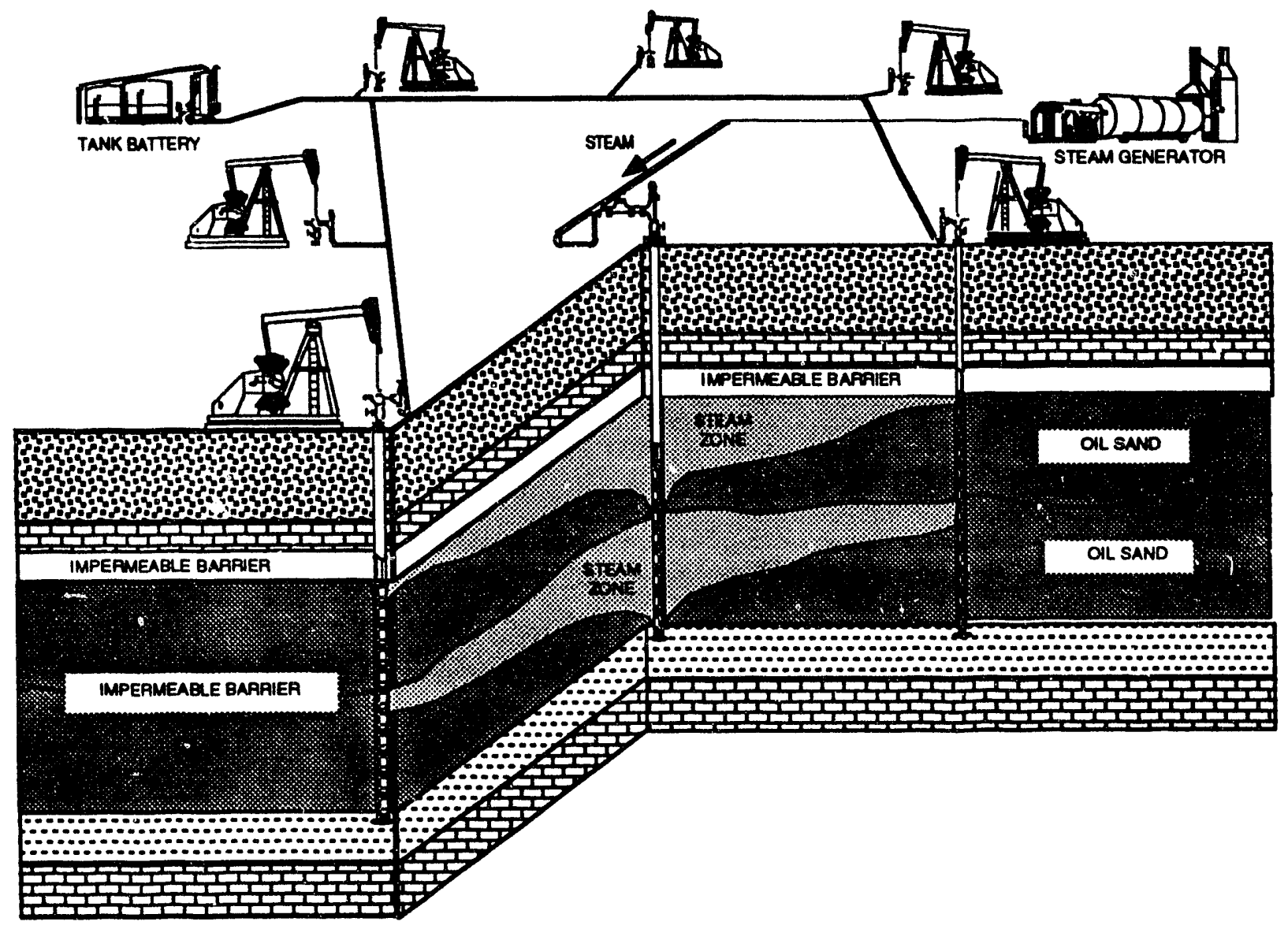

FIGURE 1.2. - Schematic of steamflood process. ${ }^{7}$

As steam moves through a reservoir between injector and producer, it creates several temperature fluid-flow regions. These regions are designated as the steam zone, hot condensate zone, oil bank, and initial zone (figure 1.3).

The hot condensate zone is further divided into a solvent bank and a hot-water bank. Even though there is no clear-cut boundary between these regions, they serve to describe the various processes occurring during a steamflood.

The temperature decreases from steam temperature at the injection well to the initial reservoir temperature at the producer. As steam enters the reservoir, it forms a steam zone around the injection well. As more steam is injected, this zone expands. As steam moves away from the injection well, it contacts the cooler portions of the formatiun causing the steam to condense into water. Thus, a hot condensate zone is formed ahead of the steam zone. As this condensate zone progresses through the formation, it gradually loses its heat to the rock and reservoir fluids and eventually reaches reservoir temperature. 


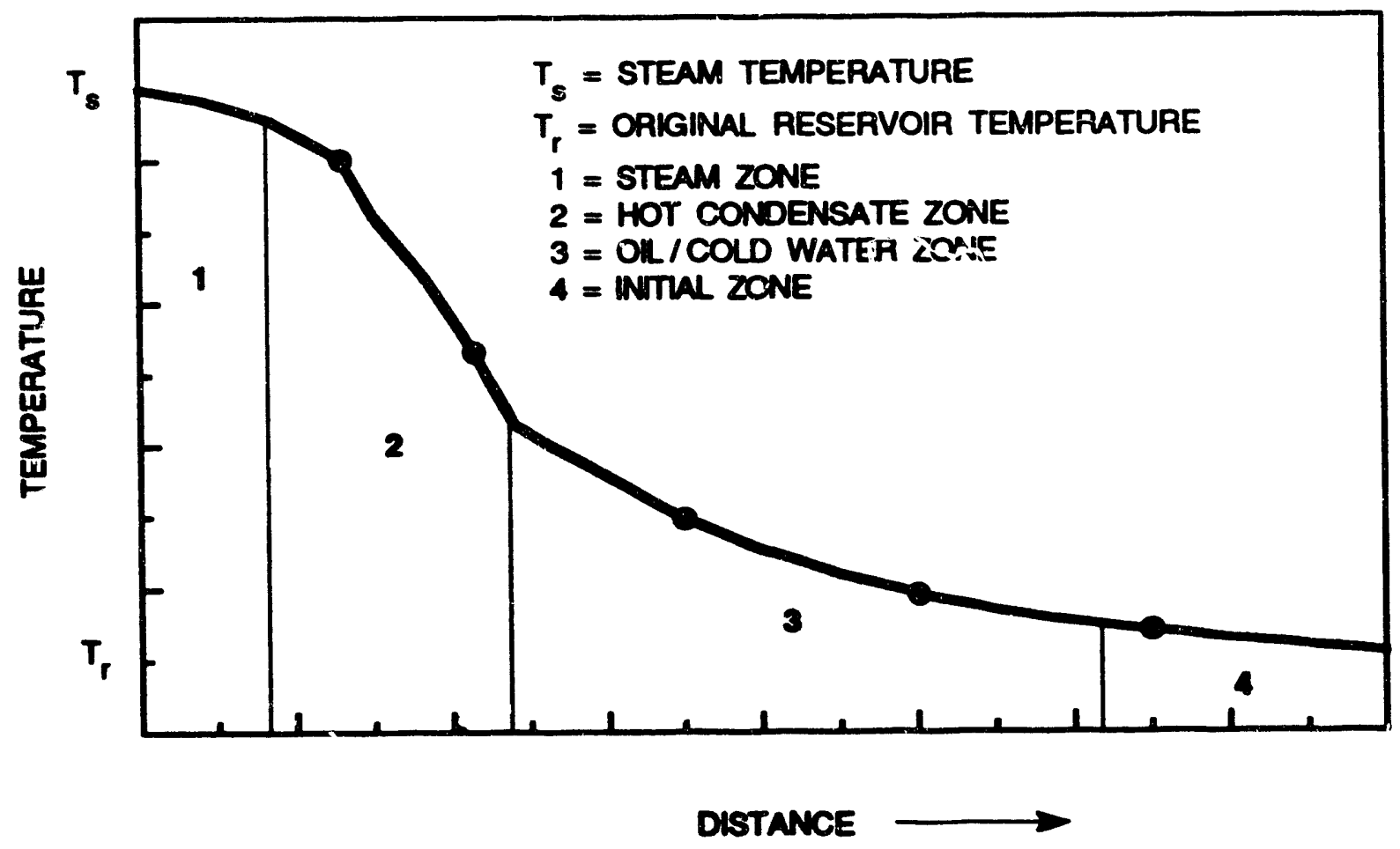

FIGURE 1.3. - Schematic of steamflood temperature profile. 5

Figure 1.4 is a typical oil-saturation profile for a lirear steamflood. Since the oildisplacement mechanisms in each region are different, oil saturation varies characteristically between injector and producer.

The rajor mechanisms - hence the oil saturation - in different regions depend upon the type of oil and formation properties. Steamflood mechanisms are closely associated with the heat and temperature effects on the reservoir rock and fluid.

$\mathrm{Wu}^{6}{ }^{6}$ identified the principal steamflood mechanisms as follows: (1) steam distillation (including gas stripping), (2) steam drive, (3) viscosity reduction, (4) thermal expansion, (5) gravity segregation, (6) relative permeability and capillary pressure variation, (7) solution gas drive, (8) oil phase miscible (in situ solvent) drive, and (9) emulsion drive.

Wu further suggested that an oil reservoir undergoing steam drive can be divided into the following temperature-fluid regions: (1) steam zone, (2) hot condensate zone (including solvent and hot water bank), (3) oil bank, and (4) initial zone.

In the steam zone, the major steamflood mechanisms are steam distillation and steam displacement. In the hot condensate zone, viscosity reduction, thermal expansion, thermal permeability variation, gravity segregation, and in situ solvent drive occur. In the initial zone, the main mechanisms are conventional water drive and gravity segregation. 


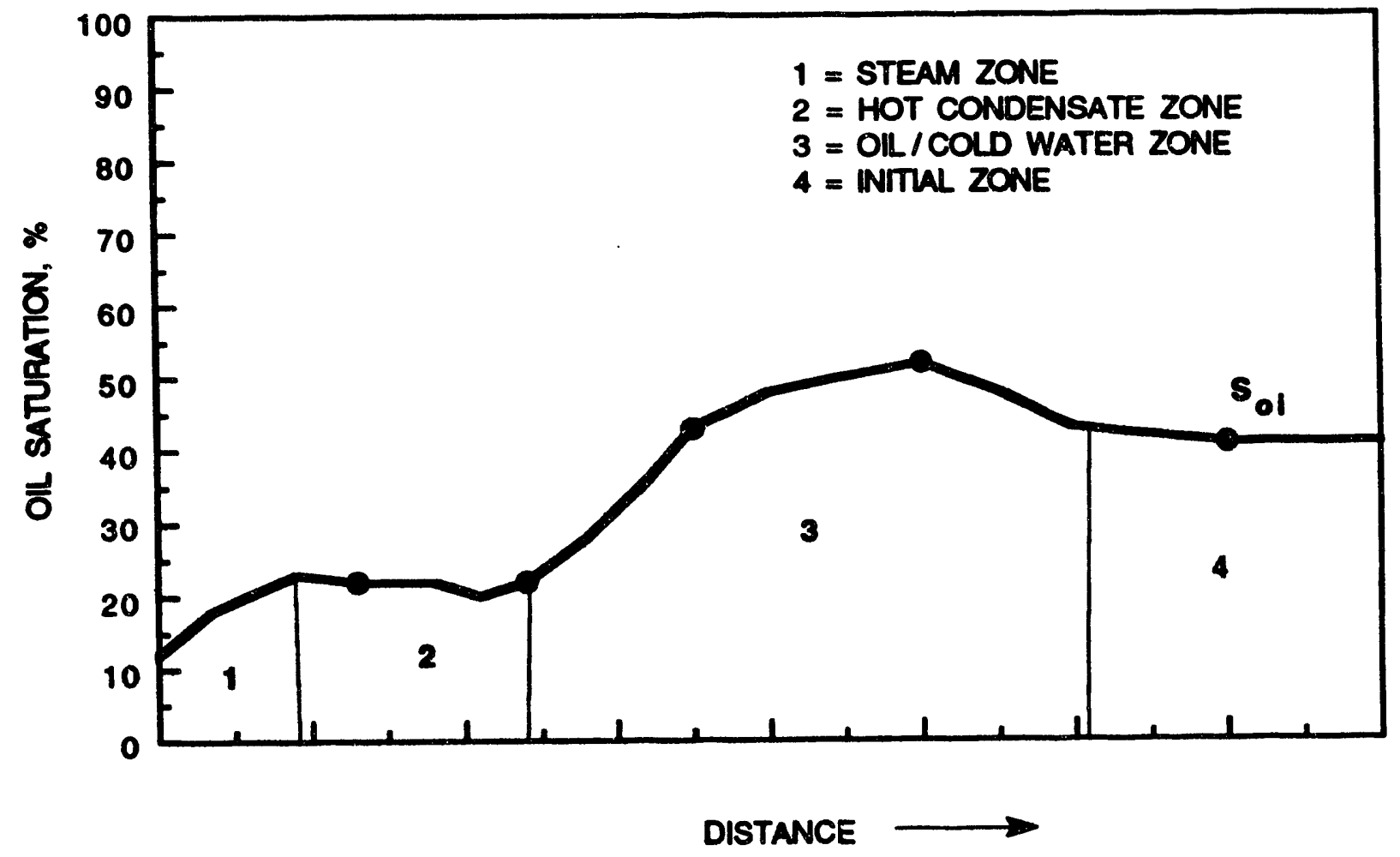

FIGURE 1.4. - Schematic of steamflood saturation profile. 5

Table 1.3 shows the approximate contribution of each mechanism to overall recovery by steamflooding a heavy oil reservoir.

The dominant mechanism in any steamflood depends on the type of oil. For example, in heavy oil reservoirs viscosity reduction and steam distiliation may be the most important recovery mechanisms; whereas in light oil reservoirs thermal expansion, steam distillation (with accompanying solvent bank formation), and gas stripping are the chief mechanisms that cause light oil to flow. However, the effectiveness of gas stripping and steam distillation are primarily controlled by oil composition, system pressure, and steam injection rate. ${ }^{7}$ Further, it should be pointed out that formation thickness, steam quality, and temperature greatly affect the dominance of a particular steamflood mechanism. In thick, permeable heavy oil reservoirs, gravity segregation is the most important producing mechanism. 8

The following section discusses major steamflood mechanisms in more detail. 
TABLE 1.3. - Approximate Contribution of Various Steamflood Mechanisms to Overall Recovery of $13^{\circ}$ to $15^{\circ} \mathrm{API}$ Gravity $\mathrm{Oil}^{5}$

\begin{tabular}{|c|c|c|c|}
\hline Mechanism & 200 & $\begin{array}{c}\text { Temperature, }{ }^{\circ} \mathrm{F} \\
300\end{array}$ & 400 \\
\hline $\begin{array}{l}\text { Viscosesty reduction, } \% \\
\text { Thermal expansion, } \% \\
\text { Stean distillation, } \% \\
\text { Solution gas drive, } \% \\
\text { Solvent de emulsion drive. } \%\end{array}$ & $\begin{array}{l}10-12 \\
1-2 \\
=\end{array}$ & $\begin{array}{c}20-24 \\
2-4 \\
10-14 \\
1-2 \\
1-2\end{array}$ & $\begin{array}{c}24-26 \\
2-4 \\
12-15 \\
1-2 \\
1-2\end{array}$ \\
\hline
\end{tabular}

\section{Steam Injection Process Mechanisms}

\section{Steam Distillation}

Steam distillation, the principal oil recovery mechanism in the steam zone, recovers reservoir fluids in the following manner. When steam contacts the crude, a portion of steam condenses and provides heat to the crude. The mixture of heated crude and hot condensate begins to boil when the vapor pressure of the mixture (equal to the sum of the partial pressure of water and crude) is equal to or exceeds the system pressure. The mixture will always boil at a temperature lower than either of the constituent's boiling point at the system pressure. The degree of boiling point lowering depends on vapor phase composition, since this composition influences total system pressure.

Steam distillation results in the rapid vaporization of oil and water. This rapid boiling disturbs and partially redistributes oil from a dead end pore to a connecting pore. This phenomena, known as the "chipping effect," 6 results in a more efficient displacement of the crude oil by the injected steam.

The chipping effect is more pronounced in a heavy oil reservoir than in a light oil reservoir because the low volatility of the heavy oil inhibits effective separation of the lighter components from the crude. As the volatility of a crude increases, the chipping effects diminishes and the importance of distillation increases. Depending upon the volatility of crudes, up to $70 \%$ of oil-inplace has been recovered in laboratory 2-D steamfloods. ${ }^{9}$ However, in the field the contribution of steam distillation to overall recovery is expected to be lower.

\section{Gas Stripping}

Along with steam distillation, gas stripping also occurs in the steam zone.6 Gas stripping occurs because in the steam zone, steam selectively desorbs light fractions from the crude. However, this process is less efficient than steam distillation.

\section{In Situ Solvent Drive}

A substantial portion of the light oil fraction and the carrier steam condenses in the cooler region ahead of the steam zone and forms the hot condensate zone. 
The condensed steam (hot water) being more viscous than steam, reduces steam fingering. The degree of reduction of steam fingering depends on the oil-water mobility ratio. The steam condensate flows along with the oil to form a hot water drive.

In the hot condensate zone, the lighter fractions of the oil mix with the in situ oil and dilute it. This dilution reduces the overall density and viscosity of the oil. As the steam front pushes further towards the producers, the light ends accumulate and extract additional light fractions from the oil with which it comes in contact. Thus, the volume of the light oil solvent bank grows as it moves through the reservoir. The result is a miscible displacement of the oil phase. The amount of additional oil recovery due to this miscible displacement has been estimated at 3 to $5 \%$ of the initial oil-in-place for some heavy oils. 10

The net effects of dilution and extraction of oil in the hot water flood region are (a) decrease in residual oil saturation and (b) reduction in the amount of heavy fractions at the trailing edge of the hot water flood region. Since the oil left behind in the hot water flood region is likely to be steam distilled by the advancing steamfront, only a small amount of the heavy oil fraction will be left behind by the steamflood.

\section{Viscosity Reduction}

The most obvious effect of heating a heavy oil reservoir is reduction of oil viscosity. Figure 1.5 shows this pronounced change in viscosity. This plot shows the effect of temperature on the viscosity of a $14^{\circ} \mathrm{API}$ gravity oil. It is evident that the viscosity improvement is greatest at lower temperatures and tends to be marginal after reaching a certain temperature. Greater viscosity reductions are experienced in the more viscous low API gravity crudes than in higher API gravity crudes. Note that the viscosity of a typical $14^{\circ}$ API crude at $80^{\circ} \mathrm{F}$ is reduced from 1,445 to about $47 \mathrm{cP}$ at $175^{\circ} \mathrm{F}$; more than thirty-fold. In the case of a low viscosity crude, viscosity reduction with temperature is not as dramatic as with the more viscous crude. The plot clearly indicates the advantage of temperature in making viscous crude more "flowable" in the reservoir rock. Thus, the net result of increasing temperature is to improve the mobility ratio. With the oil viscosity lowered, the displacement efficiency and sweep efficiency are improved.

The change in oil viscosity with temperature is reversible, i.e. the oil viscosity returns to its original value when the temperature decreases to the initial value. This reversibility of the change in oil viscosity with temperature explains the formation of an oil bank.

When a steamfront moves through a reservoir, the temperature immediately ahead of the front increases, thereby decreasing the oil viscosity. Oil is readily displaced from this high temperature region to a region where the temperature may be considerably lower. In this low temperature region, the oil regains its viscosity; thus, retarding the oil flow. Consequently, a large amount of 


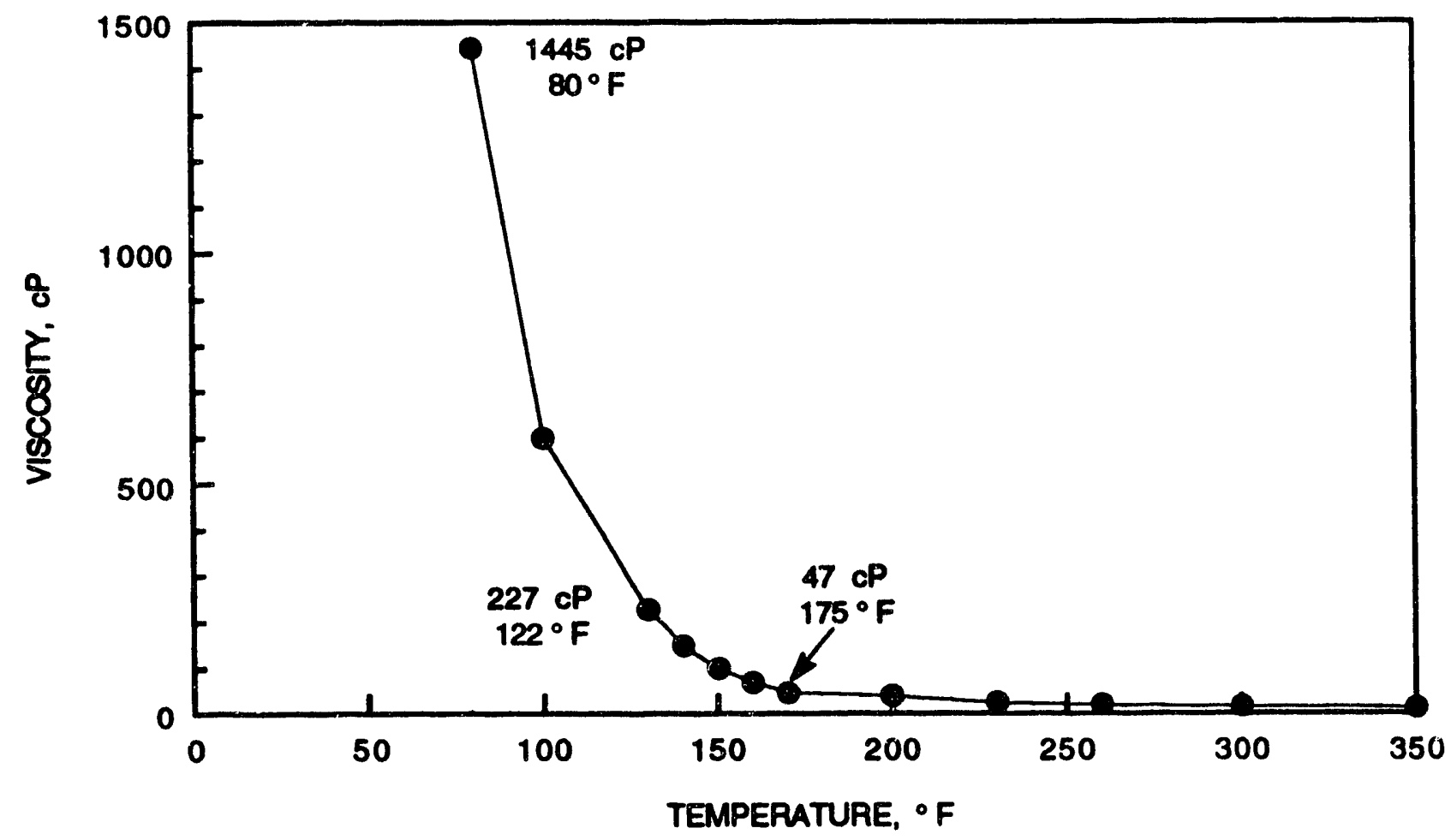

FIGURE 1.5. - Effect of temperature on oil viscosity.

oil accumulates as an oil bank. This bank, often observed in steamflooding heavy oils, is responsible for high oil production rates and low water-oil ratios.

\section{Thermal Expansion}

Crude oil, like most liquids, increases in volume when heated. This change in volume, increases its saturation and fluidity. The amount of swelling of an oil because of temperature rise depends on the composition of the oil. Light oils expand more than heavy oils; thus, thermal expansion is more effective in recovering light oils than heavy oils. Thermal swelling is an important oil recovery mechanism in a hot water drive. Depending upon the type of oil and initial saturation, as much as $10 \%$ of initial oil-in-place can be recovered by thermal expansion.

\section{Solution Gas Drive}

As the temperature ahead of a steamfront increases, the heated crude expels the dissolved gases. These liberated gases expand, push the oil, and aid in oil recovery.

\section{Gravity Segregation}

Gravity segregation occurs because steam is lighter than oil or water. This difference in density causes steam to rise to the top of a sand and spread out areally. The oil heated by steam 
expands and becomes lighter and less viscous, permitting the steam to move quickly in the upper part of a producing zone. Thus, the reservoir becomes divided into two layers, a steam-invaded override zone at the top and a noninvaded zone at the bottom (see figure 1.2).

At first, the overriding steam spreads areally, but as steam injection continues, the steam zone grows downward forcing the hot water in front of it. Thus, the oil at the interface between the steam and hot water can be stripped from the reservoir rock and transported towards producing wells along with the hot water condensing from the steam zone. With time, and at the expense of recycling steam, an entire reservoir could be heated this way. However, with very viscous oil, this process would not be economical because of inordinate amounts of time needed to achieve good areal coverage.

\section{Emulsion Drive}

Emulsions are an integral part of the produced fluid in heavy oil steamfloods. Both oil-inwater emulsions and water-in-oil emulsions are observed. The high specific volumes and velocities of steam in the steam zone, coupled with the energy released by the condensing steam, provide the agitation needed to form emulsions in situ.

Viscosity of an emulsion, of ten higher than either oil or water viscosity, depends upon the oil viscosity and the type of emulsion formed. In a high-permeability, unconsolidated formation, a viscous emulsion may plug the high-permeability streak, divert the steam to a lower permeability region and improve oil recovery by reducing steam fingering in the hot condensate region.

\section{Cyclic Steam Injection}

\section{Process Description}

Cyclic steam injection, also known as "huff-'n-puff," or steam soak, involves the injection of steam into a producing well for a short time. The well is then shut in for several days to permit the soaking of the reservoir by steam, and then placed on production (see figure 1.6).

The cyclic steam process is similar to hydraulic fracturing. However, instead of increasing the flow capacity of the reservoir, the viscosity of the oil is reduced. The result is the same. The producing capacity of the well is increased whether the permeability is increased or the viscosity reduced. Although the terms are sometimes used interchangeably, steamflooding has the same relationship to the cyclic steam process as waterflooding does to hydraulic fracturing with water. There is one difference, in that the heat injected is not produced except as sensible heat in the produced fluids. The injected heat is expended in heating and decreases the viscosity of the oil in the reservoir. After repeated cyclic steam treatments, it is possible to displace some of the oil between wells. 


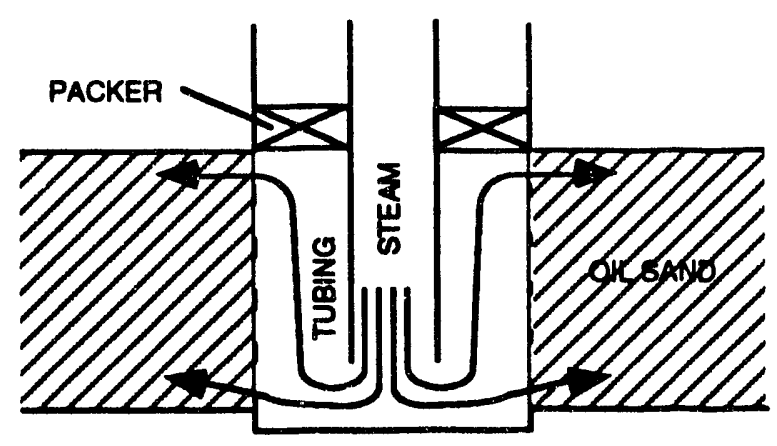

a. Steam Injection

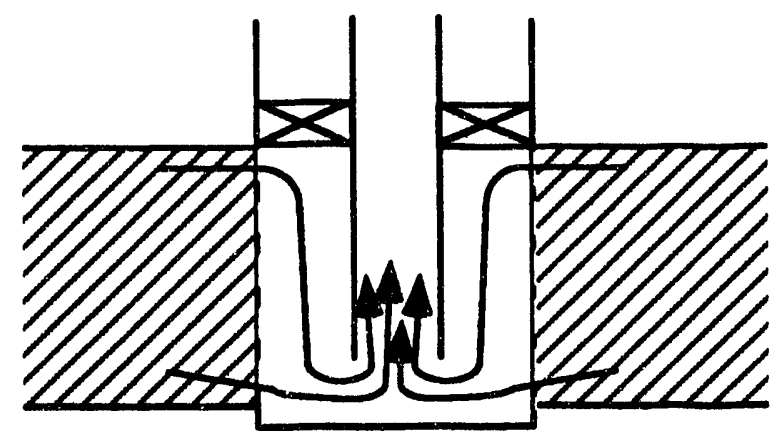

b. Fluid Production Cycle

FIGURE 1.6. - Schematic of cyclic steam process.

In an alternative process known as the "push-pull" method, steam is circulated around a packer. As shown in figure 1.7, steam is injected down the annulus and into the formation above the packer. The steam heats the oil and allows it to flow into the bottom of the hole where it is pumped to the surface. The advantage of this method is that the well is never shut down. A thick and homogeneous reservoir with good vertical permeability is required for this process.

Cyclic steam injection is often used to boost primary recovery from viscous heavy oil reservoirs. It boosts the primary recovery through viscosity reduction and wellbore clean-up effects. The process can increase recovery by an additional 3 to 5\% OIP. Since the steam soak process permits immediate oil production, it provides an opportunity to observe and evaluate inany of the variables early in the life of the project when using steam, among which is treating the problem of produced fluids. The steam soak process is used as a precursor to steam drive and is a process for which field application has been a predecessor to theory.

A first step in the cyclic steam process is the injection of a certain volume $(5,000-20,000$ bbl/cycle of cold water equivalent) of high-pressure steam over a period of 2 to 10 days. The amount of steam injected per cycle varies with the thickness of the pay zone. To prevent excessive heat loss, the steam is usually injected at the highest practical rate, approaching the formation fracture pressure. 


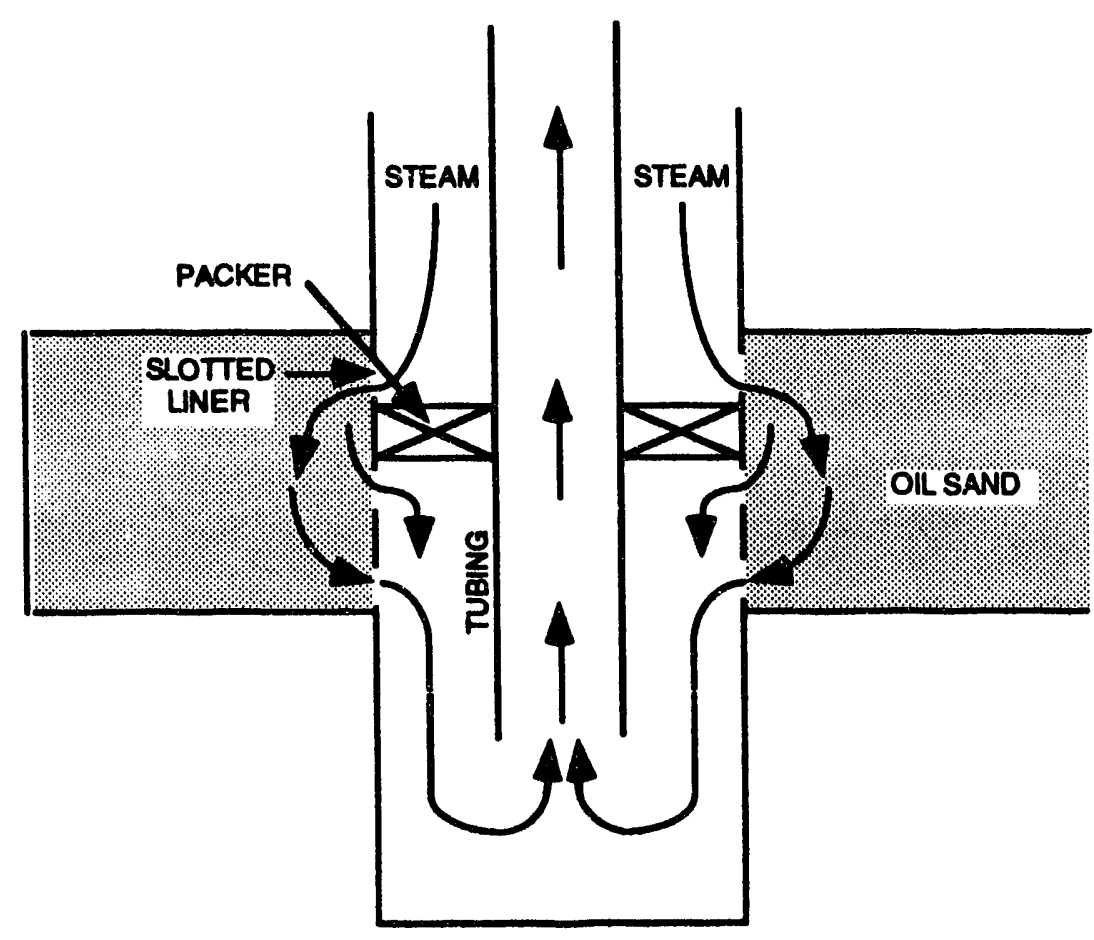

FIGURE. 1.7. - Schematic of push-pull cyclic steam process.

The well is then shut in for several days to permit the soaking of the reservoir by steam. During this soaking period, injected steam condenses as it distributes heat to a larger volume of the reservoir. After the steam is soaked for several days, the well is allowed to flow under primary production and is later pumped.

Cyclic steam process performance depends on existing reservoir pressure. Heat is needed to make the heavy crude mobile, but energy is required for it to flow into a wellbore. Where some reservoir pressure exists, injected steam can reinforce natural reservoir energy, increase the pressure differential, and allow oil to flow naturally at economic rates and volumes.

Both injection and soak times generally increase as the total volume of steam injected increases. During the production period, which may range from 1 to 7 months, the well pressure decreases and some of the steam condensate vaporizes, driving heated oil toward the producer. The well is produced until the decline in production warrants another treatment with steam.

When economical amounts of oil are no longer being produced, the whole cycle is repeated. Usually three complete cycles are used in a single well. Response to cyclic steam injection depends on formation thickness, oil-in-place, volume of steam injected, and the number of preceding cycles. Regardless of reservoir type, cyclic injection becomes less efficient as the 
number of cycles increases. With each succeeding cycle, oil production declines, water cut increases, and the cycle becomes longer.

After many cycles, large fractions of injected steam are produced as water, making water handling important. From an economic standpoint, a good indicator of performance is the produced oil to injected water ratio. When this ratio falls below 1 , the project becomes marginal and the cyclic steam process is frequently converted to steamflood.

\section{Mechanism of Cyclic Steam Process}

Mechanisms that increase oil production rates during cyclic steam injection are diverse. They include reduction in crude oil viscosity in the heated zone near the wellbore, thermal and solution gas expansion which produces the driving force, gravity drainage, and wellbore cleanup.

The injected steam loses its heat to the formation and causes the reservoir temperature to rise. This temperature increase, in turn, lowers the oil viscosity and allows it to flow much more readily into the wellbore.

The increase in temperature also causes the oil to expand and become less dense. The lighter oil then flows toward the wellbore by gravity drainage. Gravity drainage is the dominant recovery mechanism in California's thick, steeply dipping reservoirs containing low-gravity crudes. In these reservoirs, many cycles are possible because the heated, less viscous oil continues to flow downdip to the producers with each cycle. In low-dip reservoirs, where the displacing mechanism is solution gas drive rather than gravity drainage, only a few cycles are possible due to rapid reservoir energy depletion.

Finally, the cyclic steam process contributes to oil recovery by dissolving organic deposits near a wellbore. This wellbore cleanup effect significantly reduces the pressure drop between a reservoir and a wellbore and assists natural reservoir energy in expelling oil.

\section{REFERENCES}

1. Pautz, J. F. and R. Thomas. Applications of EOR Technology in Field Projects-1990 update. DOE Report, NIPER-513, November 1990. TX, 1982.

2. Prats, M. Thermal Recovery. SPE Monograph Series No. 7, SPE of AIME, Dallas,

3. Burger, J., P. Sourieau and M. Combarnous. Thermal Methods of Oil Recovery. Gulf Publishing Co., Houston, TX, 1985. 1988.

4. Boberg, T. C. Thermal Methods of Oil Recovery, John Wiley \& Sons, New York,

5. Goodlett, G. O., M. M. Honarpour, H. B. Carroll and P. S. Sarathi. Diverse Mechanisms Add to Increased Oil Production in Thermal and Gas Projects. Oil \& Gas J., v. 84, No. 26, July 28, 1986, pp. 98-102. 
6. Wu, C. H. and A. Brown. A Laboratory Study on Steam Distillation in Porous Media. Pres. at the SPE Annual Tech. Conf. and Exhib. of the Soc. of Pet. Eng., Dallas, TX, Sept. 28Oct. 1, 1975. SPE paper 5569.

7. Wu, C. H. A Critical Review of Steam Flood Mechanisms. Pres. at the Annual California Regional Meeting of the Soc. of Pet. Eng., Bakersfield, CA, Apr. 13-15, 1977. SPE paper 6550.

8. Chu, C. State-of-the-Art Review of Steamflood Field Projects. J. Pet. Tech., v. 37, No. 10 , October 1985, pp. 1887-1902.

9. Sarathi, P., D. Roark and A. Strycker. Light Oil Steamflooding: A Laboratory Study. Soc. of Pet. Eng. Reservoir Engineering, v. 5, No. 2, May 1990, pp. 177-184.

10. Willman, B. T., V. V. Valleroy, G. W. Runberg, A. J. Cornelius and L. W. Powers. Laboratory Studies of Oil Recovery by Steam Injection. J. Pet. Tech., v. 13, No. 7, July 1961, pp. 681-690. 


\section{CHAPTER 2 \\ CRITERIA FOR EVALUATING STEAM INJECTION PROSPECTS}

\section{INTRODUCTION}

Several factors must be taken into consideration when evaluating candidate reservoirs for steam injection operation. These include reservoir rock and fluid properties, crude oil characteristics, field history and current well status. Tables 2.1 and 2.2 summarize the criteria that must be considered in evaluating a prospect for cyclic steam and steamflood. Note that these recommendations are general guidelines with which to identify target reservoirs for further study, and the use of engineering judgment in the application of these criteria is advocated.

This chapter discusses each of these criteria and their relative importance to a reservoir engineer evaluating the properties for a particular steam injection project. Although the screening criteria for cyclic steam treatment and steamflooding are slightly different, the following discussion is applicable to both processes.

\section{Rock and Fluid Properties \\ Rock Type}

Any formation that permits the injection of steam at an acceptable rate should be considered for additional study. Since sandstone generally has high permeability and limestone and dolomite have low permeability, steamflooding has mainly been applied to unconsolidated sandstone reservoirs. However, steam has been injected successfully into a fractured consolidated sandstone reservoir in Wyoming ${ }^{1}$ and in a fractured dolomite reservoir in Southwest France. ${ }^{2}$

\section{Pay Zone Thickness}

Pay zone thickness criterion is important, since heat losses from thin reservoirs may be quite significant. This will lower the heating efficiency of the thermal process and may also adversely affect its economics.

Pay zones from 30 to $150 \mathrm{ft}$ thick are desirable for steamflooding. However, steamflood pilots have been carried out successfully in Edison Groves (CA) field, ${ }^{3}$ which has a pay thickness of only $12 \mathrm{ft}$. Larger areal patterns, combined with high initial steam injection rates, are offered as the means to recover oil economically from reservoirs with thin pay sections. If the pay zone is thicker than $150 \mathrm{ft}$, steam would have difficulty sweeping the formation uniformly.

\section{Depth and Reservoir Pressure}

Reservoir pressure and depth are interrelated screening criteria; their importance arises from the difficulty they present to the injection of steam into a reservoir. 
Qil

Viscosity $>40 \mathrm{cP}$ (centipoise) at reservoir conditions

Gravity is not critical by itself, but $12^{\circ}$ to $20^{\circ} \mathrm{API}$ oil is preferred

Water

Reservoir connate water properties are not critical. Water for steam generator should be chemically treated so it is, soft, slightly alkaline, and free of oxygen, solids, oil, $\mathrm{H}_{2} \mathrm{~S}$ (hydrogen sulfide), and dissolved iron.

\section{Lithology}

Low clay content

\section{Reservoir}

Thickness $>20 \mathrm{ft}$

Depth $<3,000 \mathrm{ft}$

Porosity $>25 \%$

Oil-in-place $>1,000 \mathrm{bbl} /$ acre-ft

Permeability $>250 \mathrm{mD}$ (millidarcy)

\section{Eavorable Factors}

\section{Factors Which Increase Risk}

1. Existing wells adaptable to steam injection

2. Available fuel supply for steam generation

1. Strong water drive

3. Available water which is cheap, slightly alkaline, and free of $\mathrm{H}_{2} \mathrm{~S}$, oil, dissolved iron, and turbidity

4. Adequate reservoir pressure in thinner sands

5. Homogeneous formation

2. Gas cap

3. Low net to gross pay fraction

4. Extensive fractures (not as serious as in other injection methods)

Laboratory Screening Tests

1. Oil analysis (gravity, viscosity at formation temperature)

2. Oil atmospheric-vacuum distillation

3. Water analysis

4. Mineral analysis of reservoir cores 
Qil

Viscosity $\left(\mu_{0}\right)$ is not critical, but less than $10,000 \mathrm{cP}$ (centipoise) oil is preferred.

Gravity is not critical by itself, but 10 to $20^{\circ}$ API oil is preferred.

\section{Water}

Formation water properties are not critical.

Water for steam should be chemically treated so that it is slightly alkaline and free from factors such as hardness, oxygen, solids, oil, $\mathrm{H}_{2} \mathrm{~S}$ (hydrogen sulfide), and dissolved iron.

\section{Lithology}

Low clay content

\section{Reservoir}

Thickness $(\mathrm{h})>15 \mathrm{ft}$

Depth $<4,500 \mathrm{ft}$

Porosity $(\phi)>25 \%$

Oil Saturation $\left(S_{0}\right)>0.4$

Oil-in-place $>600$ bbV/acre-ft $\left(\phi S_{o}>0.08\right)$

Permeability (k) is not critical by itself, but a value $>300 \mathrm{mD}$ (millidarcy) is preferred.

Transmissibility, $\frac{k h}{\mu_{0}}>50 \frac{\mathrm{mD}-\mathrm{ft}}{\mathrm{cP}}$

\section{Eavorable Factors}

1. High porosity

2. High net to gross pay

3. High well density

4. High quality water

5. Low fuel costs

6. Usable existing wells

5. Homogeneous formation

Laboratory Screening Tests

1. Oil analysis (gravity, viscosity)

2. Oil atmospheric-vacuum distillation

3. Water analysis

4. Mineral analysis of reservoir cores

5. Predicted SOR from gravity and distillation properties

6. Steamflooding tests for SOR determination

\section{Eactors Which Increase Risk}

1. Strong water drive

2. Large gas cap

3. Extensive fractures 
Steam is normally injected into shallow reservoirs. With increasing depth, heat losses in the wellbore as well as to the overburden and underburden of the formation increases. However, the incorporation of insulated downhole steam injection tubulars in planned project operations will reduce the thermal losses to the overburden soil and therefore improve the process efficiency.

Normally, depths less than $4,500 \mathrm{ft}$ are preferred for steamflooding. The deepest steam injection to date has been in an $8,500 \mathrm{ft}$ well in the Boscan reservoir in the Lake Maracaibo Basin of Venezuela. ${ }^{4}$ The use of insulated tubing at this field maintained heat losses at the design value of 5\% of the injected heat Figure 2.1 shows the wellbore heat loss accompanying steam injection through a $27 / 8$-in. uninsulated tubing and an insulated tubing in a 7-in. casing. The well depth was 3,000 ft, and the steam injection rate was $950 \mathrm{bbl} / \mathrm{d}$ of cold water equivalent. The steam injection pressure was chosen as 1,800 psig. The overall heat losses were estimated using Ramey's method ${ }^{5}$ for both insulated and uninsulated tubing. From this plot, it is clear that there is no technical justification to use depth as a criterion of ineligibility for steam injection. Rather, it may be that the injection of steam into a deeper formation will violate an economic constraint. Economic computations which consider the extra cost of insulated tubulars versus the savings in fuel will have to be carried out.

The high pressures associated with deep reservoirs will also prohibit the use of steam. With increasing depth, steam injection pressure generally increases with a corresponding increase in steam temperature. If the reservoir pressure is higher than $3,200 \mathrm{psig}$, the critical pressure of steam, steam injection is nearly impossible. Even at reservoir pressures close to 2,000 psig, the operating pressure would be close to 3,000 psig. Additionally, with increase in pressure the total heat of steam (sum of latent heat and sensible heat of steam) decreases.

Further, a high reservoir pressure may bring about a low steam injection rate. This will affect the economics of the process because of increased wellbore heat loss, lower production volumes, longer project life, and resulting increased heat losses to adjacent strata. Ideally, reservoir pressure should be less than 500 psig.

\section{Permeability and Transmissibility}

Although a permeability greater than $100 \mathrm{mD}$ is acceptable, an air permeability of greater than $300 \mathrm{mD}$ is desirable for steamfloods. Low permeabilities would result in lower injection rates and hence in a longer flood life. This slow injection would increase heat losses to the formation overburden and underburden as well as to the surrounding air during steam generation. Such heat losses would mean that more oil must be consumed in the steam generators to recover the same amount of oil as a shorter steamflood in a more permeable reservoir. 


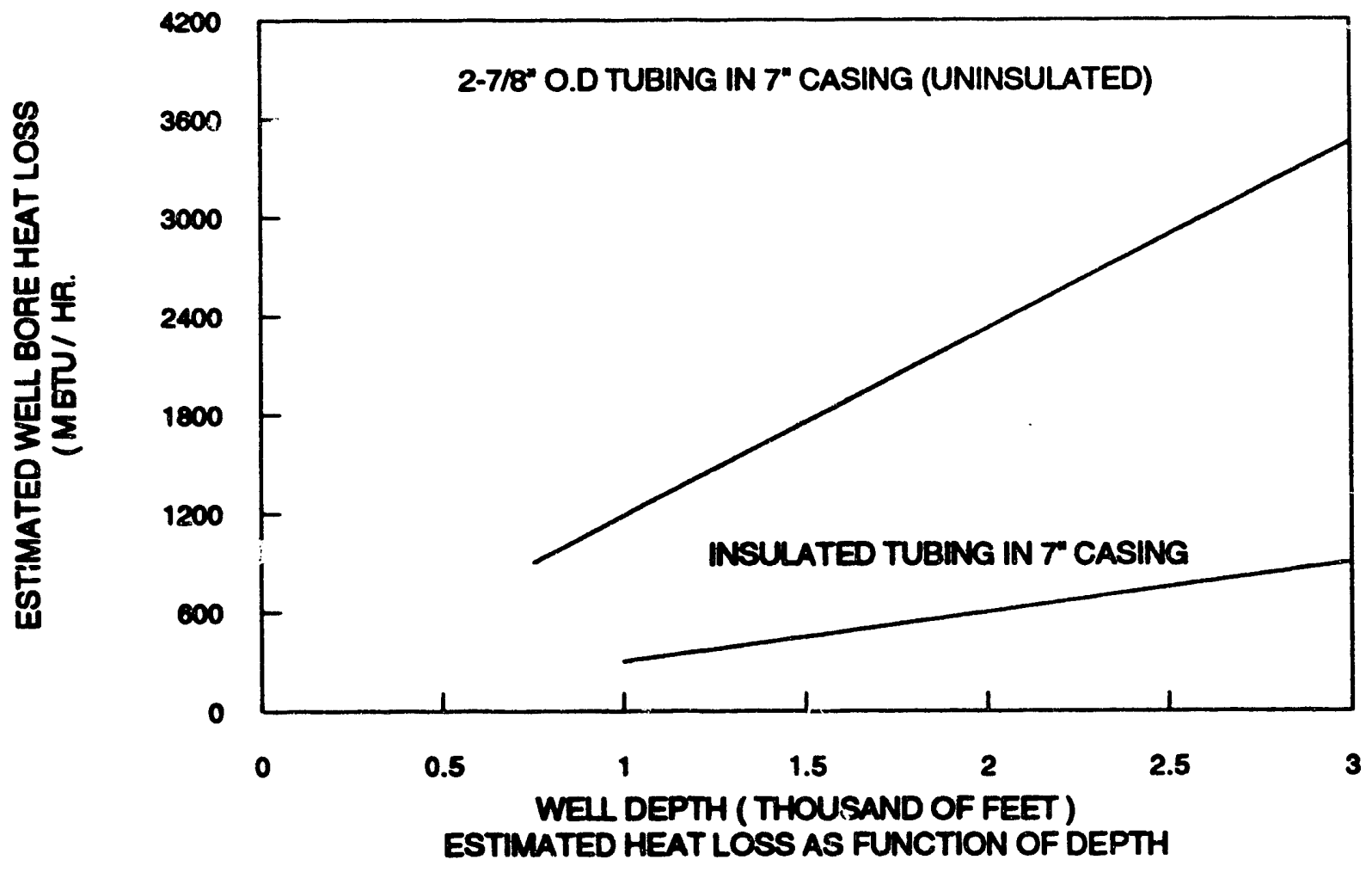

FIGURE 2.1. - Estimated heat loss as function of depth.

The effective transmissibility, $T_{i}$, of a reservoir to a fluid phase "in" is defined by the equation $T_{1}=\frac{k_{1} h_{1}}{\mu_{1}}$

where $k_{i}$ is the permeability to the fluid phase $i$ and $\mu_{i}$, is the fluid viscosity, and $h_{i}$ is the pay thickness. The ratio $k_{i} / \mu_{i}$ is calred the fluid mobility.

The fluid mobility is a function of the fluid, fluid saturation, and the displacement temperature. Adverse transmissibilities of the injected and reservoir fluid render the steamflood process inefficient. A low reservoir permeability and/or a very high oil viscosity results in low oil mobility. The effect of low permeability on the process efficiency was discussed in the previous paragraph. Scaled physical model studies of steamflooding for different oil viscosities indicate a strong negative influence of oil viscosity on the efficiency of the steam drive process.

The problem of low oil mobility and reservoir transmissibi 'ity has been addressed by some operators by injecting steam above the formation pressure and allowing the fractures to provide a path between injector and producer. An example of this is the Saner Ranch fractures assisted steamflood process. ${ }^{6}$ In summary, aúverse ñuid mobility and reservoir transmissibilities can be 
modified by tailoring the process to the reservoir. As long as these modifications are economically sound, there can be no restrictions on these parameters.

\section{Stratification}

Steamflooding generally works best in a massive sand with no stratification. However, reservoirs with shale stringers are frequently encountered.

If the shale stringers are very thin $(<2$ - $\mathrm{ft}$ thick) and continuity of the sand can be traced from injector to producer, the formation can still be used for steam injection. If the shale breaks are thick, the pay sands should be flooded separately. In such cases, a packer is used to separate the steam injection for the upper and lower sands, thus avoiding injection into the shale break. If the shale break is greater than $40-\mathrm{ft}$ thick, flood the two zones separately.

\section{Anisotropy}

An anisotropic reservoir is one in which the reservoir properties vary areally. The most common anisotropic effect is preferential permeability, which causes fluid to flow nonradially from the injection well. As long as the injection and producing well are in communication, anisotropy will not hinder steam injection.

If the preferential permeabilities have been found, the project can be designed to account for this effect. For example, an inverted seven-spot pattern can be rotated and stretched (see figure 2.2) along the major high permeability axis of an anisotropic reservoir to achieve uniform steam breakthrough at the producing wells.

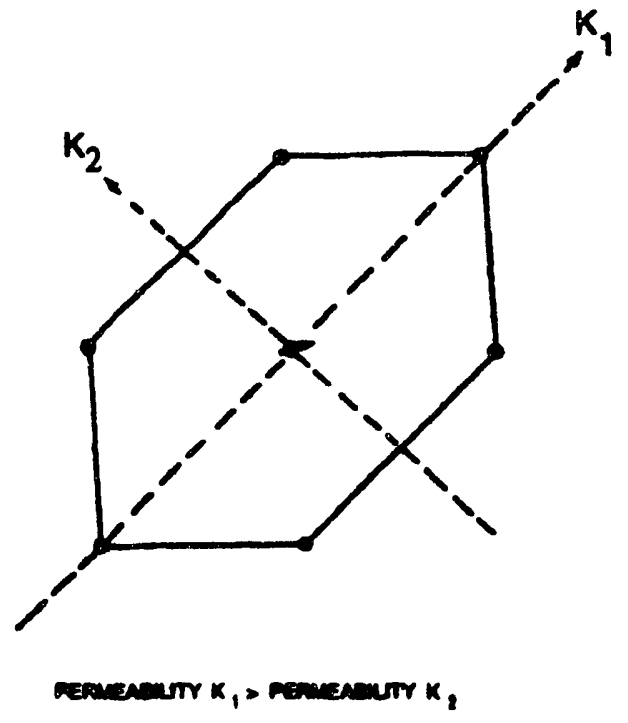

FIGURE 2.2. - Typical pilot pattern configuration for an anisotropic reservoir. 


\section{Gas Cap Or Aquifer}

Normally, formations with a gas cap should be avoided for steam injection. If steam is injected near a gas cap, the gas cap could act as a sink, i.e., steam might enter the gas cap rather than the reservoir. A small gas cap, which could be waterflooded to residual gas saturation prior to steam injection, may be tolerated.

Since oil reservoirs with an underlying aquifer (often called bottom water) are quite common, they cannot be ruled out for steam injection. However, if steam enters the aquifer, all the injected heat will be dissipated. Steam injection projects should be carefully designed to avoid this possibility, in most cases.

Steam may be injected into the aquifer if the aquifer is much thinner than the pay zone (for example, a 5 to 10-ft aquifer below a 30 to 50-ft pay zone, as in Slocum Field, Anderson County, Texas). ${ }^{7}$ The thin aquifer is heated by steam and conducts heat to the pay zone. Oil in the pay zone is mobilized and will drain to the aquifer to be produced.

\section{Dip Angle}

Although most steam injection projects to date have been in low dip reservoirs, dip angle is not a restriction in selecting steam injection candidates. The Brea Field $\mathbf{8}$ and the Mid-Way Sunset Fields of California are the best examples of dipping reservoirs where steam has been successfully injected.

\section{Porosity}

As porosity increases, the amount of heat energy needed to heat the reservoir rock decreases. Also, a greater porosity will hold more oil per unit volume of reservoir rock. Ideally, a reservoir being considered for steamflood should have a porosity of at least 0.2 from an energy usage standpoint; a lower porosity will not have a significant impact on overall process efficiency because part of the heat stored in the rock could be recovered through scavenging operations, such as conversion of a steamflood to waterflood. The main impact of porosity will be in its oil content. Porosity lower than 0.2 is acceptable only if oil saturation is greater than 0.65 .

\section{Oil Saturation}

A minimum oil content (the product of oil saturation and porosity) is necessary in order to offset the energy requirements of a steamflood process. A rule-of-thumb in the oil industry says that the product of oil saturation and porosity $\left(\phi \times S_{0_{i}}\right)$ must be at least 0.13 or $1,000 \mathrm{bbl} / \mathrm{ac}-\mathrm{ft}$, for steamflooding. Thus, if porosity is 0.2 , the oil saturation should be at least 0.65 . For light oils that can be flooded to a lower residual saturation, the oil content must be greater than 0.08 or 600 bbl/ac-ft. 
This combination of porosity and oil saturation implies that the reservoir should have enough recoverable oil to cover the energy requirements of the process, and to supply additional production to make the process economically attractive. Dugdale and Belgrave ${ }^{9}$ performed a detailed energy analysis and concluded that it is possible to perform steamflood at oil content values below 0.1 in heavy oil reservoirs. Thus, no general guidelines on the minimum oil content requirement for a feasible steamflood project can be given. Individual reservoirs must be analyzed independently. The only valid guide line for oil content is that it should be high enough to furnish the energy needs of the process and supply sufficient additional oil production to make the process economical.

\section{Clay Content}

Clay content of a reservoir is not a restriction in selecting a steam injection candidate. Reservoirs with or without nonswelling clays can be used for steam injection projects. Some reservoirs contain water sensitive clays, such as montmorillonite clays which swell when contacted with injected steam or water. The swollen clays greatly reduce the formation permeability. Nevertheless, this type of reservoir can also be used for steam injection if the clays are properly stabilized. For example, in a California reservoir containing swellable clays, swelling was prevented by injecting a saturated potassium chloride $(\mathrm{KCl})$ slug near the wellbore. In addition, a $0.5 \%$ (wt) $\mathrm{KCl}$ solution was continuously injected into the generator feedwater downstream of the water softener. This approach was effective in treating swellable clays so that steam injection rate could be maintained. If the reservoir contains swelling clays which cannot be controlled and the effective permeability would be reduced to less than $100 \mathrm{md}$, this reservoir should be excluded from steam injection.

\section{Crude Oil Characteristics}

Gravity - Crude oils with gravities from $6^{\circ}$ to $50^{\circ}$ API are amenable to steam injection. Steamflooding has usually been successful in heavy oils of $8^{\circ}$ to $25^{\circ}$ API gravity. In the range between $26^{\circ}$ to $50^{\circ} \mathrm{API}$, steam distillation is the major recovery mechanism. Most fields producing oil with gravity higher than $40^{\circ}$ API are deeper than 5,000 feet, a depth that was once impractical for injecting steam. However, with the development of insulated tubing, it is now possible to recover light oils from these very deep formations.

Viscosity - Since a minimum oil mobility is required at reservoir temperature for a displacement process to operate, an upper limit is usually imposed on oil viscosity for the steam injection process. These values are in the range of $15,000 \mathrm{cP}$ for steamflood. For steamflooding, Yan et al. ${ }^{10}$ reported a decrease in recovery from 32 to $29 \%$ when viscosity was increased from $500 \mathrm{cP}$ to $4,000 \mathrm{cP}$ for a $15-\mathrm{ft}$ thick reservoir. The corresponding steam oil ratios were 6.6 and 
8.8, respectively. Doscher, ${ }^{11}$ on the basis of scaled physical model studies, concluded that very viscous crudes could not be recovered economically. However, steam injection has been successfully carried out in Canadian reservoirs containing highly viscous crudes. These include Cold Lake, Primrose, Peace River, etc.

\section{FIELD HISTORY AND STATUS}

\section{Primary and Secondary Production History}

Steamflooding can be implemented at any stage in the life of the reservoir. However, it is usually used as a secondary process in heavy oil reservoirs. A field which produces during primary production is most likely to be a good steamflood prospect. The primary or secondary production history also provides a production decline curve which can be used as a baseline for assessing the effectiveness of steam injection. Any oil production above the extrapolated decline curve can be attributed to steamflooding. Only this steamflood oil should be used in calculating the economics of the flood.

\section{Well Spacing and Condition}

Usually, the primary recovery or waterflood oil wells are drilled at 40-acre well spacing. This spacing is not suitable for most reservoirs in steamflooding because excessive heat will be lost between the injectors and the producers. Although steamflood patterns can be as large as 20 acres (10-acre spacing), smaller spacing will improve areal and vertical sweep efficiency. Ideally, a 2.5-acre spacing or less is preferred.

During steamflooding, both the injection and producing wells will be subjected to high thermal stress from exposure to either live steam or hot produced fluid. Any old well or wells not equipped to handle this stress should be worked over. Wells with holes in the casing should be repaired prior to a steamflood. A later chapter will discuss equipping wells for use in a steamflood.

\section{Pattern Configuration}

While a producing well in a confined pattern can capture all movable fluid inside a pattern, such patterns have an unfavorable producing to injection well ratio. On the other hand, an unconfined pattern has a favorable producing to injection well ratio, but it loses a large portion of movable fluids outside the pattern. Therefore, if possible, multiple patterns with more than one injector and producer (such as the pattern shown in fig. 2.3) are preferred. 


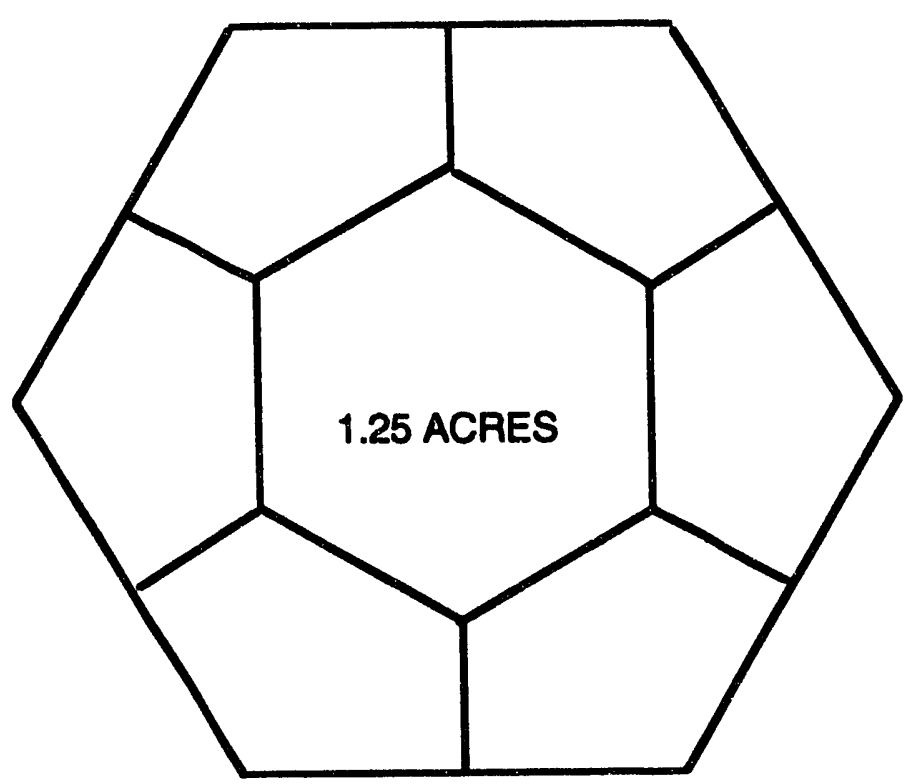

3.75 ACRES

FIGURE 2.3. - Unconfined steamflood pattern with peripheral injectors.

\section{Water and Fuel Supply}

The successful operation of a steamflood project depends upon the availability of good quality feed water in sufficient quantity. River water, lake water or produced water from different formations can be used. Produced water from the formation being flooded can also be used as generator feed water, if correctly treated. The quality of the raw water dictates the amount of treating required. The requirements for treating source water for steam generators and the equipment necessary for the treatment will be described in detail in a subsequent chapter.

Enough fuel must be available to fire the steam generator so that high quality steam can be generated continuously. Fuel such as natural gas or diesel oil can be used. After oil production reaches a steady level, part of the produced crude could be used as the generator fuel.

\section{Water Disposal}

As mentioned previously, produced water can sometimes be used as generator feedwater after treatment. The rest of the produced water, after the removal of the oil particles must be disposed of properly. The produced water after treatment, for example, can be disposed by injecting into a disposal well completed in a different formation. If water disposal is a problem in the area, the field should not be considered for steam injection. 


\section{SUMMARY}

Guidelines for selecting candidate reservoirs for steam injection are presented. These are general guidelines that reflect the current technology and economic climate. The criteria presented should not be regarded as sacred, i.e., that all criteria must be met before the process can be considered for a particular reservoir. Each reservoir should be examined closely on an individual basis and engineering judgment applied before a decision can be made to pilot testa reservoir.

\section{REFERENCES}

1. Chappelle, H. H., G. P. Emsurak and S. L. Obernyer. Screening and Evaluation of Enhanced Oil Recovery at Teapot Dome in the Shannon Sandstone: A Shallow, Heterogeneous Light Oil Reservoir. Pres. at the Soc. of Pet. Eng.JDOE Symposium on Enhanced Oil Recovery, Tulsa, OK. Apr. 20-23, 1986. SPE/DOE paper 14919.

2. Sahuquet, B. C. and J. J. Ferrier. Steam Drive Pilot in a Fractured Carbonate Reservoir - Lacq Superior Field. J. Pet. Tech., v. 34, No. 4, pp. 873-80, April 1982.

3. Doscher, T. M. and M. A. El-Arabi. Steamflooding Strategy for Thin Sands. Pres. at the 1983 California Regional Meeting, Ventura, CA. SPE paper 11679.

4. Chacin, E., I. Gomez, O. Erdaneta and P. Colonomos. Feasibility of Steam Injection at $8200 \mathrm{ft}$. Pres. at the 4th UNITAR/UNDP Conference on Heavy Crude and Tar Sands, Edmonton, Alberta, Canada, August 1988. Paper 192.

5. Ramey, H. J. Wellbore Heat Transmission. J. Pet. Tech., v. 14, No. 4, pp. 427-435, April 1962.

6. Stang, H. R. and Y. Soni. The Saner Ranch Pilot Test of Fractured-Assisted Steamflood Technology. Pres. at the Soc. of Pet. Eng. Annual Tech. Conf. and Exhib., Houston, TX, Sept. 16-19, 1984. SPE paper 13036.

7. Hall, A. L. and R. W. Bowman. Operation and Performance of the Slocum Thermal Recovery Project. J. Pet. Tech. v. 25, pp. 402-408, April 1973.

8. Volek, C. W. and J. A. Pryor. Steam Distillation Drive, Brea Field California. J. Pet. Tech., v. 24, No. 8, pp. 899-906, August 1972.

9. Dugdale, P. J. and J. D. M. Belgrave. Thermal Screening Criteria - Should They Exist? Paper pres. at the 6th Annual Heavy Oil and Oil Sands Tech. Symp., Calgary, Canada, March 8, 1989.

10. Yan, C., Z. Jianhua and Z. Mengyi. Effects of Oil Viscosity on the Steam Recovery Efficiency. Paper 20 pres. at the China-Canada Heavy Oil Tech. Symp., Zhuo Zhuo, China, October 1987.

11. Doscher, T. M. Limitations on the Oil-Steam Ratio for Truly Viscous Crudes. Pres. at the California Regional Meeting, Ventura, CA, March 1983. SPE paper 11681. 


\section{CHAPTER 3 \\ PROJECT PLANNING}

\section{INTRODUCTION}

Steam injection is typically a high cost, low profit operation-hence proper planning is important to achieve maximum economic benefits. The success depends on proper selection of reservoirs for injection, sound program planning, consideration of capital expenditures and high operating costs involved, and an awareness of the degree of success which can reasonably be expected.

The objective of this chapter is to appraise operators of the various steps which must be considered when planning a steam injection pilot.

\section{Reservoir Selection}

In selecting a reservoir for the steam injection process, all readily available information must be taken into consideration. These factors must then be carefully appraised and the prospect selected. Criteria for evaluating steam injection prospects are discussed in detail in Chapter 2. Some of the parameters involved include depth, oil-in-place, porosity, inhomogeneities, sand thickness, oil mobility, and special conditions that may influence steam injection mechanisms such as gas cap and bottom water.

\section{Depth}

While depth is a controlling factor costwise, there is no trend or concentration of projects in any particular depth range. Projects have been successfully implemented at depths from a few hundred to over 4,500 ft. A deeper depth requires a higher injection pressure, which means that high-pressure steam-injection equipment may be required. Also, since the temperature is determined by steam pressure, higher steam pressure translates to higher temperature. Disadvantages of high steam temperature include greater heat losses, lower recovery, casing or tubing failure in older wells, and accelerated corrosion of well equipment.

On the favorable side, increased depth means that a greater pressure drawdown can be applied to producing wells. This will yield higher producing rates for a given crude in a specific formation.

\section{Oil-In-Place}

Oil-in-place at the time of steam injection initiation is another important consideration. One of the most frequently asked questions is: How much oil must be in place to support a steam injection operation? There is no simple answer to this question. The only thing that san be said about oilin-place is that it should be high enough to sustain a cash flow sufficient to pay for high operating costs and provide an acceptable return on the capital invested. Chances for an economically successful steam injection operation increase as oil-in-place increases above $600 \mathrm{bbl} / \mathrm{acre}-\mathrm{ft}$. 


\section{Reservoir Segregation and Inhomogeneities}

Reservoir segregation and inhomogeneities must be considered when appraising a prospect for steam injection. Reservoirs initially produced by solution gas drive, and in which some gravity segregation of oil and gas (gas cap) has occurred, can present problems to steam injection operators. A gas cap can be a thief zone. Steam might channel across the top of the sand resulting in early breakthrough of the injected fluid.

Although situations of this type are not ideal, they can be tolerated. The presence of gas cap may enhance areal coverage and gravity segregation, so that a significant portion of the reservoir can be heated. An example of this situation is the Phillips Petroleum Co. successful Smackover, Arkansas steamflood project. 2

\section{Preliminary Evaluation}

Once a reservoir has been selected, all geological data pertaining to the reservoir should be gathered and carefully studied. An estimate of in-place resource should be made. Consideration should be given to the site and the amount and condition of surface and well equipment. Suitability of the existing wells for steam injection should be established. If the existing wells were found unsuitable for steam injection, the cost of drilling and completion of wells for steamflood use should be estimated. At this stage, maximum use of applicable correlations and rules-of-thumb should be made.

\section{Laboratory Analysis}

Assuming favorable results and no known significant deterrents, the next step is to undertake laboratory investigations. The extent and type of laboratory analysis needed will depend on the amount of data already available. Cores should be obtained and subjected to flooding at selected temperatures and pressures to determine the residual oil saturation and recovery. Using these data, a preliminary estimate of recovery on a barrels-per-acre-foot basis should be made. Reservoir fluids should be obtained, and the viscosity-temperature characteristics of the crude oil determined. Steam distillation characteristics of the crude must be established. These test data, together with data from logs, core analysis, and past production history, should be used to estimate recovery efficiencies and life expectancy of the project. Results from these studies will usually establish the viability of the process.

\section{Comprehensive Investigation}

If the steam injection process still appears attractive, a decision should be made to go further into a comprehensive investigation. This involves the undertaking of a complete economic study and a more thorough performance investigation for new projects. 
A complete economic study should consider both capital investment and operating costs, equipment and completion problems, and the cost of complying with regulatory requirements. Factors that must be considered in the planning stage include: type and quality of available fuel; water availability; required water treating and sizing of water handling equipment; necessary steam, injection and production facilities to handle anticipated volumes of injection and production fluicis; condition of existing wells and equipment; additional well equipment; drilling and remedial costs; safety precautions; availability of market outlets for the produced fluid; and waste disposal costs. These and other equally important points must be carefully evaluated to arrive at an economic justification for starting a project. Table 3.1 lists major capital and operating costs that must be considered in the preliminary economic evaluation. Economic analysis should also include the cost of regulatory compliance expenses.

Loss of revenue due to operational problems should be included in the projected annual cash flow. The likely operational problems include: mechanical failure of steam generation equipment, sand production and attendant pumping problems, emulsion problems, casing failure in old wells, surface equipment malfunction, etc. Finally, in making economic evaluation, the operator should consider special tax breaks given for enhanced oil recovery projects. If the economic analysis is improperly done, the profitability of the project is jeopardized and the possibility of obtaining adequate financing is materially reduced.

\section{Comprehensive Performance Investigation}

In addition to economic analysis, a more comprehensive performance investigation must be carried out during the evaluation stage. Additional reservoir data such as capillary pressure, relative permeability, and PVT fluid analysis data must be obtained. An estimate of the quantity and volume of heat required for a pilot project should be made. More displacement tests over a broader temperature and pressure range must be made. A detailed computer simulation study should be undertaken to predict steamflood performance. Many variations of spacing and injection patterns and rates should be investigated.

If results of a comprehensive engineering and economic analysis are favorable and meet the necessary profitability criteria, a pilot operation should be planned. The various steps for thermal prospect evaluation are summarized in table 3.2. These steps are amplified in tables 3.3 through 3.7.

\section{Comparison With Conventional Practices}

Conventional practices in an enhanced recovery sense are def..ed as waterflooding, pressure maintenance by gas injection, or liquids recovery by gas cycling. The major difference between 
TABLE 3.1. - Major Initial Expenses to be Included in a Steam Injection Project Economic Evaluation

Equioment

1. Steam generators

2. Steam lines to injection wells and production lines to tank battery

3. Fuel lines to steam generators

4. Flow lines to steam generators (include expansion loops and anchors)

5. Electrical systems

6. Water supply equipment (supply pump, chemical pump, chemical tank, and water storage tank)

7. Water treatment oquipment (ion exchange unit, filters, treated water storage tank, deoxygenator)

8. Satellite stations (lest headers and separators)

9. Pumping installations (electric motors, controllers, rod strings, and pumps)

10. Tank battery (treating tank, storage tank and transfer pump)

11. Water disposal equipment (collection tank, transfer pump, disposal pump, dispersed oil extractor, etc.)

12. Injection and production wellhead equipment and downbole facilities

\section{Drilline and Completion Costs and Intangible Drilline Costs}

1. Injection wells

2. Producing wells

3. Water disposal wells

4. Water supply wells

\section{Qperating Costs}

1. Water treatment costs (include production or purchase price of raw water, transportation cost, chemicals necessary for treatment to generator quality, and labor to accomplish all of this)

2. Steam production costs (include fuel cost, power for generators and fuel oil heating, and labor to operate equipment and system)

3. Well preparation cost (include cost of pulling or downhole workover)

4. Water disposal well (include waste water treatment cost)

5. Emulsion treatment cost

\section{TABLE 3.2. - Steps for Steam Injection Prospect Evaluation Process} Selection and Field Implementation

\footnotetext{
1. Application of screening criteria

2. Initial investigation and selection

3. Laboratory analysis and data processing

4. Comprehensive pilot feasibility study and design

5. Field pilot implementation

6. Expansion to full-scale field development
}

Economics must be considered in every step.

A decision point should be built-iv at each level, i.e., study can be dropped or continued based on the results 2 . that point. 


\section{TABLE 3.3. - Initial Investigation}

This step is essentially a preliminary evaluation based on existing information. It involves selection and appraisal of the better prospects based on the following considerations.

- Geographic Location

- Topography

- Fuel and water availability

- Market availability

- Availability of oilfield services, supplies, and equipment

- Federal, state, and local restrictions

- Geological Information

- Reservoir depth and thickness

- Structure

- Competence of overburden strata

- Pormation dip

- Pederal, state, and local restrictions

- Reservoir Data

- Rock and fluid properties

- Pressure, temperature, and saturations

- Fluid withdrawals

- Recovery mechanisms

- Peasibility Sudy (Idealized Conditions)

- Computer analysis based on existing or readily-available information

- Determine expected producing rates and fuel consumption versus time

- Surface and Well Equipment

- Size and location of present equipment

- Suitability of existing wells

- Storage and transportation facilities

- Disposal of unwanted produced fluids

- Economic Factors

- Preliminary evaluation based on expected producing rates, crude oil selling price, capital and operating costs, and taxes.

\section{TABLE 3.4. - Laboratory Analysis and Data Processing}

- Drill core boles to get samples of reservoir rock and fluids, and obtain logs.

- Laboratory measurement of rock and fluid properties

- Porosity, permeability, and compressibility

- Water-oil and gas-oil relative permeabilities at elevated temperatures

- Rock composition (swelling or dispersible clay material)

- Effect of salinity on permeability

- API gravity of crude oil

- Oil viscosity versus temperature

- Distillation characteristics (light oils)

- Chemical composition of oil (sulfur content)

- Analysis of produced water and other source waters

* Geological studies and log analysis

* Compile all available data and make estimate of target reserves 
TABLE 3.5. - Comprehensive Pilot Feasibility Study and Design

- Site selection(s)

- Initiate eavironmental studies

- Detailed reservoir performance study with thermal simulation model

- Study the main operator-controlled variables:

Pattern type

Pattern size - well spacing

Sieam injection rate and steam quality

Injection pressure (temperature)

Completion intervals

Steam stimulation of production welk

- Primary information obtained:

Production rate history - oil, water, steam

Estimation of project life

Steen requirements

- Sensitivity analysis with respect to uncertainty of fixed variables

Recervoir parameters

- Design facilities

- Steam generator

Fuel

Pollution control

- Steam distribution system

Surface lines

Insulation

- Oil gathering system

Flow lines

Production tanks

De-emulsification equipment

Upgrading if necessary

- Water treating system

Collection tanks

Flotation cells

Filtration equipment

Softening equipment

Pumps

- Monitoring system

Process Monitoring

Environmental Monitoring

- Economic analysis

- Drilling and completion costs:

(New vs existing wells)

- Initial investment:

Steam generators (lease or buy)

Facilities

Pumping equipment

Wellibead and downhole equipment

- Operating costs:

Fuel for generators

Water plant operation

Electrical power

Wages

- Repair and maintenance costs:

Sand production workovers

Equipment repair

System leak repair

- Taxes

- Estimated gross revenue 
* Obtain necessary permits

- Pilot installation

- Drilling and completion

- Injection system

- Production gathering and treating system

- Metering and monitoring system

- Waste disposal system

- Pollution control system

* Operation and monitoring

- Data gathering and processing

Rates, pressures, temperatures of injection and production fluids

- Identification of special problems

- Evaluation

- Economic appraisal of pilot

TABLE 3.7. - Expanded Field Operation

* History-match pilot reservoir performance

- Make recovery predictions for undeveloped parts of the field

- Select best prospects for pilot expansion or for new pilots

- Consider design changes based on pilot performance

- Process design

- Equipment

* Plan annual expansions based on available investment capital, manpower, required resources, and other constraints

- Consolidate scattered properties

these more or less conventional practices and the enhanced recovery processes being developed today are as follows:

1. More detailed and exacting laboratory screening tests to determine process applicability.

2. More specialized and costly equipment, some of which may have to be designed. New well completion procedures and materials may be required.

3. Proper project evaluation requires the taking of more detailed and complex data, necessitating the installation of specialized and more costly monitoring equipment.

4. All of the above requires more and better trained field personnel in order to evaluate and cope with operating problems and environmental considerations.

These differences, along with many others such as special chemicals and storage facilities, etc., dictate the need for a carefully controlled and monitored field pilot test.

One of the most difficult phases in developing any new oil recovery process is the design, implementation, and interpretation of field pilot tests. They are expensive, yet represent only one of many possible sets of operating conditions. One must take every possible precaution to choose 
an optimum set of conditions and to design a pilot that provides maximum opportunities for interpretation. 1 To summarize:

\section{Pilot Test}

\section{Apilot test is -}

a. An experiment where the field is the laboratory

b. A simulation of the larger field effort

c. A place for making mistakes before they become too costly

d. A place for working bugs out of equipment

e. A place for developing needed controls and data to ensure the success of a project

f. A place for putting available engineering talent to the test and for training engineers

g. A place for intensive planning

h. A place for open minds and compromise

i. A place for finding every problem imaginable and many not yet thought of with their attendant delays

\section{Apilot test is not -}

a. A money making proposition in the short run

b. A total field simulation

c. Usually a great place to demonstrate "theory in action"

d. A hallowed shrine

e. A place where deadlines set 6 months earlier are proved correct

Performance of a pilot test will give the first practical understanding of the reservoir performance under a steam injection. Upon completion of a pilot test, most of the questions pertaining to the feasibility of a steam injection project will have been answered. Again, an economic aporaisal must be made, and a decision on an enlarged operation should be made only when enough data from the pilot operation have been obtained to indicate favorable economic benefits. Size of the enlarged operation will be determined primarily by economic considerations. Management must indicate desired flood-out time, amount of capital available to invest, and expected rate of retum on investment.

\section{SUMMARY}

Steam injection is a practical, tried and proven method of increasing both rate of recovery and ultimate recovery from certain types of reservoirs under particular conditions. A successful application of the steam injection process requires a systematic investigation starting with preliminary screening and culminating with full-scale field development. Economics must be considered in each step. Rewards from a successful steam injection project will be substantial. 
Unsuccessful projects can be avoided if proper consideration is given to all aspects of the operation.

A good understanding of the reservoir and recovery process is essential for successful implementation of a steam injection project. Before starting a steam injection project, an operator should have a good estimate of the capital money required, have access to it, and be willing to spend it. The oferator should keep in mind that all investments involve a certain degree of risk, and steam injection projects are no exception. The risk of failure of a steam injection project is minimized if highly reliable and unbiased data are used in preparation and evaluation. In the final analysis, experience, judgement, and knowledge of the reliability of the input data should be used as a guide in deciding whether the proposed economic gains from a project justify the expected risk.

\section{REFERENCE}

1. Pursley, S. A., R. H. Healy and E. J. Sandvik. A Field Test of Surfactant Flooding, Loudon, Illinois, J. Pet. Tech., v. 25, No. 7, July 1973, pp. 793-802.

2. Smith, R. V., A. F. Bertuzzi, E. E. Templeton and R. L. Clampitt: Recovery of Oil by Steam Injection in the Smackover Field, Arkansas, J. Pet. Tech., v. 25, No. 8, August 1973, pp. 883-889. 


\section{CHAPTER 4 \\ ECONOMICS OF STEAM INJECTION}

\section{INTRODUCTION}

The basic advantage of steam injection over that of other recovery methods is increased ultimate recovery of lower gravity viscous oil in a shorter period of time. Steamed wells are usually allowed to produce to their maximum ability; hence, rapid payouts are possible. In addition, the process can be contained within a small area, thus making unitization unnecessary. Steam injection has evolved into a mature process over the past 30 years. This advancement in technology has removed many of the unknown factors associated with the process and has improved production forecasting. From the lending institution prospective, this has lowered the risks associated with the process and has permitted better evaluation of steam injection projects for loan purposes.

In spite of the technological advancements, steam injection projects are still considered as high-cost, low-profit operations. The production of heavy oil by steam injection is a more complex and expensive undertaking than conventional oil recovery practices. Steam injection requires high capital investments, and operating costs are high. Maintenance costs are generally high since reservoirs that make good steam injection candidates are usually very unconsolidated and lend themselves to sand production and require above normal workovers. Furthermore, the market price realized for the produced crude oil needs to be reduced for the lower quality product and any costs incurred for delivery to refineries. The very best steam recovery fields in California are barely profitable operations at current heavy oil prices. Hence, a careful analysis of the economics of the proposed project must be performed to determine feasibility. Assuming that the feasibility of a project had been established and that a flood has been started, many other factors will constantly arise that must be balanced against each other. Thus, a steam injection project requires a constant study of engineering and economics, and the task is not completed until the project is ready to be terminated.

The purpose of this chapter is to present an overview of the economics of a steam injection project. Some of the factors which govern the economics of a steam injection operation are outlined. Costs of steam injection operations are presented.

\section{Economic Factors in Steam Injection Operation}

An economic analysis of any injection operation whether it is waterflood or steam injection is largely a balancing of the costs for such an operation against the value of the additional oil recovery. The factors that govern the economics of individual steam injection operations are often numerous and varied. Many of these factors are peculiar to individual areas or operators, and it is not the purpose of this discussion to consider such factors and how they might affect economic 
conditions of steam injection. Likewise, there are factors that more or less frequently impact the economics of individual steam injection operations, and these will be presented briefly. These factors include (a) cost of the prospect, (b) reservoir depth, (c) oil content of the reservoir, (d) net production pay, (e) demand and price for the crude, ( $f$ ) abandonment, $(\mathrm{g}$ ) availability and quality of raw water, (h) availability and cost of fuel and power, (i) oil transportation facilities, (j) location, (k) size, (l) existing lease terms, (m) water disposal facilities, (n) local environmental regulations, and (o) availability and cost for labor and field service.

The order of importance of these factors is not necessarily the order of their listing. To illustrate how these factors influence the economics of an individual operation, a brief discussion of the related factors is in order.

The value of a thermal recovery prospect often is difficult to determine and may vary greatly. The effect of this factor is often disregarded in considering the economics of a steam injection operation. In areas where the possibilities of thermal recovery are not well established, stripper well properties can be acquired at little more than salvage value. Under such conditions, the cost of acquisition is of no significant importance, even though the true value of the prospect may be great. Conversely, in an area where steam injection operations are well established, and where the cost of such prospects more nearly reflect their true economic value, the cost of acquiring desirable steamflooding acreage is likely to be very high, almost prohibitive, to the average operator interested only in the production of oil. The thermal acreage of San Joaquin Valley is a good example of this later condition. Thus, the economic values of thermal recovery prospects may vary from salvage values to values representing a significant portion of the profit that is to be realized from the development of the prospect. This value should always be included in the economics of any steam injection operation.

In the development of a steam injection operation, perhaps the most important of all factors that affect the economics are: (1) the oil content of the reservoir-measured in terms of barrels of oil per acre-foot of reservoir; (2) the depth to the producing formation; and (3) the demand and wellhead price for the oil. The economic effects of these factors are interrelated, and one can hardly be considered without the others.

The oil content at the beginning of a steam injection operation is a key indicator of the likelihood of the economic success of the project. Steam injection recovery operations are energy intensive, and approximately one-third of the produced oil is used to generate steam. Total oil recovery must be sufficient to pay all costs of recovering that oil, at the prevailing oil price, plus provide an acceptable rate of return on the investment. Hence, minimum amounts are needed to permit significant incremental recovery and to exceed fuel requirements. Chances for an economically successful steamflood increase as oil-in-place increases above 600 barrels per acrefoot. 
The cost and efficiency of steam injection processes are strongly depth dependent. The average $1990 \mathrm{Kem}$ County, California, steam injection project well completion costs are shown as a function of depth in table 4.1. From this table, it is clear that well costs are largely controlled by depth. Deeper depths require higher injection pressures which means that high-pressure steaminjection equipment may be required. Also, the higher pressures required for deeper reservoirs may lead to higher steam temperatures and, therefore, higher reservoir heat losses. Furthermore, the latent heat content of high-pressure steam is low. Other disadvantages of high-pressure, hightemperature steam include casing or tubing failure in older wells and accelerated corrosion of well equipment. These factors increase operating and maintenance costs. Inasmuch as development, operation, and maintenance costs for intensive steam injection operations increase with depth, there is a minimum recovery per acre of oil for a given price that can be considered profitable. As the depth increases or the price of oil decreases, higher recoveries per acre are necessary to offset increased costs. In the same fashion, as the depth decreases or the price of oil increases, the minimum recovery per acre to obtain profit decreases. These are general relationships, the other factors being equal. In any proposed steam injection operation, however, these factors must be considered and carefully weighed to determine the probable economics of the operation.

Other factors encountered in the proposed development of a steam injection operation can be as important to the economics of the operation as the factors just described. In many old properties, particularly extremely old properties, many of the wells have been improperly plugged and long abandoned. The condition of these abandoned wells can be of major importance to a thermal operation. The old Midcontinent fields are good examples of this later condition. Geysers of steam, hot water and hot oil were formed at the surface after implementation of a steam

TABLE 4.1. - Kern County, California, New Steam Injection Well Costs, Excluding Well head injection equipment 1

\begin{tabular}{|c|c|c|}
\hline Well depeh. & $\begin{array}{l}\text { Enstern } \\
\text { Kerw County } \\
\text { inj. well cost, S }\end{array}$ & $\begin{array}{l}\text { Western } \\
\text { Kern County } \\
\text { inj. well cost, } \$\end{array}$ \\
\hline $\begin{array}{r}0-250 \\
251-750 \\
751-1,250 \\
1,251-1,750 \\
1,751-2,250 \\
2,251-2,750 \\
2,751-3,250\end{array}$ & $\begin{array}{r}37,000 \\
73,000 \\
89,000 \\
121,000 \\
160,000 \\
200,000 \\
240,000\end{array}$ & $\begin{array}{r}44,000 \\
79,000 \\
94,000 \\
141,000 \\
189,000 \\
236,000 \\
283,000\end{array}$ \\
\hline
\end{tabular}

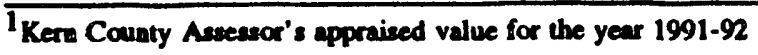

process at shallow depths in Missouri and Oklahoma as a result of communication to the surface via improperly plugged and abandoned wells. These unfortunate occurrences can be remediated at added cost by drilling new wells and changing injection patterns. Poorly plugged and 
undocumented abandoned wells are sources of tremendous loss of valuable oil and steam. Such losses reduce expected recovery and add materially to costs. When an operator is planning steam injection process implementation in old fields, a thorough investigation is necessary, with documentation, to try to locate ali old abandoned wells for the prevention of surface contamination and loss of recovery. With the increasingly stringent environmental regulations, such surface contamination materially affects the economics of an operation due to cleanup costs and penalties. While far from being universally practiced, it is recommended that any and all wells drilled within the area to be flooded, be reopened and replugged even the so called "dry holes," in order to prevent escape of oil and/or injected steam to the surface. Such a strategy in the long run will be less costly than cleanup and surface restoration costs. In view of the added costs of locating and replugging abandoned wells in older fields, it is obvious that the oil recovery per acre from such fields must be higher than that of younger properties for the process to be economical.

The availability of an adequate supply of good quality water at a reasonable cost for steam generation is important to steam injection operations. Large-scale steamflood operations require large volumes of good quality water, and usually a shortage of water seriously affects the rate of oil recovery and the economics of a operation. The cost of furnishing suitable water for steam generation varies considerably, depending upon the source of water and the amount of water treatment required. This varies not only from field to field but also from day to day, particularly if produced water is recycled. When sufficient volumes of water can be acquired at reasonable cost, the total cost of furnishing feed water for steam generation is usually small compared to steam generator fuel cost and has minimal effect on the economics of steam injection operations. In areas where water is scarce and extremely valuable, its cost could be prohibitive.

Steam injection operations are energy intensive, and fuel costs greatly affect the economics of an operation. Natural gas and lease crude are the most common types of fuels used to fire thermal EOR steam generators. In a typical California steam injection operation, fuel costs account for more than $50 \%$ of operation and maintenance costs. Gas-fired steam generators are less expensive to install and operate than oil-fired steam generators. In many areas, gas is not readily available, and lease crude is burned to generate steam. This reduces the volume of fuel available for sale. Since improvement in steam generator thermal efficiency reduces fuel requirements and reduces cooling loads of flue gas scrubbers, generator efficiency has an appreciable effect on the economics of an operation. For example, the fuel requirements of an oil-fired $50 \mathrm{MM}$ Btw/hr steam generator (the standard oil field unit) can be reduced roughly by 5,300 barrels of oil per year by increasing the thermal efficiency by about 5\%. Thus, even a marginal improvement in thermal efficiency can materially affect the economics of an operation and may result in prolonging its economic life.

The location and size of a steam injection operation also can affect overall economics. There are many factors inherent to the location of the property which affect development and operating 
costs. It is more expensive to implement a steamflood project in urban areas such as Los Angeles, California, than in rural area such as rural Kern County, California. Availability and cost of labor and oilfield services often depend on location. Oil pipeline outlets or other means of oil transportation often have an influence on the price received for oil at the wellhead. The size of the operation alone may have considerable effect. Usually, a large operation can be developed and operated for lower unit costs than a smaller operation. The shape and size of the area often affect development and operating costs. A square area usually is less expensive to develop than a long narrow area, such as that of the shoestring sands of eastern Kansas. Well spacing also affects development costs. Spacing controls the number of injection and production wells to be drilled and this, in turn, largely controls the development and operation cost per acre. In thermal operations, wells are closely spaced to minimize heat loss between injectors and producers and to improve areal and vertical sweep efficiency. In selecting the well spacing, the improvement in recovery must be balanced against development and operating costs.

Existing wells may or may not be used. One should not hesitate to use an old well as a producer, provided it is located not more than $10 \%$ off the desired geometrical location and provided, of course, that it is in good physical condition and can handle thermal stresses resulting from exposure to hot produced fluid. In most instances, old wells are not in good physical shape and require either cleaning out, replacement of tubing and casing, or some other major remediation. Since steam injection wells are subjected to high thermal stresses due to exposure to live steam, old wells should not be used as injection wells, unless they are worked over. The cost of this work seldom justifies the expense involved, even if it is very close to a proposed pattern input. Usually, it is less costly to drill and complete a new injection well than to convert an old exiting well to an injector.

Existing primary lease terms and obligation to non-operating interests are also important in thermal operations. Obviously, if royalty interests are high or nonoperating interests do not participate in the cost of the operation, the profit is materially reduced. Geology of the reservoir or field also significantly impact the economics of the thermal operation. For example, the shoestring reservoirs of southeast Kansas, though very high in oil saturation, unfortunately are highly compartmentalized and discontinuously bedded, allowing very little movement of steam through the producing formation. Such floods will seldom be a financial success. Steamflood is seldom economically viable in formations with a gas cap or in reservoirs with an underlying aquifer. Steam injected near the gas cap almost invariably moves preferentially through the gas cap, allowing little movement of steam through the zone of oil saturation. Similarly, in oil reservoirs with an under-lying aquifer-if steam enters the aquifer-all injected heat will be dissipated and the steam process may not be economical. Integrated engineering and geologic analysis prior to process implementation will improve the chances for success. 
Federal and local environmental regulations and requirements also significantly impact the economics of thermal operations. For example, in California the air emission standards are so stringent that the cost of compliance with the state air quality standards is becoming increasingly prohibitive for many steam injection operators. Obtaining necessary permits to operate the steam generators is the single most difficult and costly aspect of thermal recovery operations in California. Disposal of project-generated wastes such as scrubber liquor, scrubber sludge, water softener regeneration brine, etc. calls for special measures and can materially impact the economics of an operation. The cost of compliance with environmental regulations must be taken into consideration in any analysis of the economics of steam injection operations.

The brief factors which have been presented, not only control the economics of steam injection operations in general but also offer a sound basis for determining the profitability of the proposed operations. A thorough analysis of these and other factors, individually and collectively, not only determines the merit of thermal EOR in general but also the extent to which these operations are justified. Today, thermal recovery of oil is based on sound engineering and proven practices. It is usually possible to determine approximately how much oil can be recovered by a thermal method from a given reservoir. With this information on hand, thermal recovery is largely a problem of economics, i.e., balancing the total cost of recovery against the estimated value of the oil to be recovered. However, predicting the economics of thermal recovery is quite complex and requires extensive knowledge and experience. Although the literature on the theoretical and reservoir aspects of steam injection operation is voluminous, steam injection recovery costs are not as well documented. The published economic studies, ${ }^{2-5}$ of necessity, generally present overall costs rather than specific costs. In this report, an attempt is made to present a more detailed breakdown of equipment costs.

\section{Estimation of Economically Recoverable Oil}

It is obvious that the economics of any steam injection project are based on the simple formula:

\section{Gross Profit $=$ Gross Revenue - All Costs}

Estimation of gross revenue requires a reliable estimate of production. Several steamflood recovery models have been developed for use in estimating incremental ultimate oil recovery and potential producing rates under various operating conditions. The U.S. Department of Energy (DOE), through the DOE Bartlesville Project Office (BPO), has made available to interested operators and others four steam-drive enhanced oil recovery models that may be acquired free of charge. 8 The four models include algorithms for calculating oil and water production rates, optimum steam injection rates, surface and wellbore heat losses, and a basic economic analysis 
package. A brief description of the features of these models and their limitations is presented in appendix 4-A.

\section{Steam Injection Project Costs}

The total cost of steam injection operations includes many items, and the magnitude of each item varies between individual properties and operators. Steam injection project costs can be classified into two groups. The first group includes all costs pertaining to the development of a project and the second, all costs pertaining to the operation of a project.

Development costs should include not only all costs or investments for the installation of all equipment and facilities necessary for the successful operation of a steam injection project, but also all costs on investments made in the acquisition of a property. The acquisition cost should include the cost of a complete economic study of the thermal recovery possibilities of a property. This normally requires consultants or other experienced personnel to analyze all factors affecting the proposed operation including the cost of acquisition of necessary reservoir data, simulation costs, etc. The information-acquisition cost, although not large, is necessary and important in determining the magnitude of thermal recovery reserves and their economic value.

The direct developments for steam injection recovery represent the major portion of the total costs of such an operation. These costs are usually considered capital costs, and they include the drilling of wells, installation of injection and production systems, steam-generation and watertreatment equipment, and all additional equipment or facilities required for the successful operation of a project. These costs vary with location and many other factors, as previously discussed. The cost of acquiring necessary permits to implement a project is also included in the development costs.

The operating costs involved in steam injection operations include costs for water-treatment, fuel, operation and maintenance of injection and production wells, handling of oil, waste water disposal, administrative overhead, and taxes. These costs vary in different areas in relation to the size of the projects. The controlling portions of the operating costs are for fuel, labor, and supplies. The operating costs for steam injection operations are high and are paid out of current production and, to a considerable extent, are controlled by the amount of current production. On a per barrel basis, thermal operations require more engineering supervision and special services than primary or waterflooding operations. Intensive thermal recovery is a highly specialized operation, and good engineering supervision is a necessity for a successful operation. 


\section{Cost Estimate}

To determine whether a project will be economically successful, the costs specific to steam injection operation need to be analyzed in detail. These costs are grouped into development costs, operational costs, and acquisition/lease costs. Administrative costs are excluded. Steam injection project costs are detailed in the following. All costs are for a typical 1,000-ft, shallow, heavy oil well in California. Unless otherwise noted, all costs are in 1991 dollars.

\section{Development Costs}

\section{Well Costs}

The cost estimates for injection and production wells are shown in Tables 4.3 and 4.4. These cost estimates are based on the Kern County, California, assessors 1 estimation of the cost of drilling and equipping new steam injection and production wells (see Tables 4.1 and 4.2), and the Independent Petroleum Association of America (IPAA) Cost Study Committee ${ }^{1}$ Index of Drilling and Equipping Wells. ${ }^{6}$ The IPAA Drilling Index for the years of 1983 through 1989 is shown in Table 4.5.

Other capital costs associated with a steam injection project include: (1) source water wells and distribution lines; (2) water treatment facilities; (3) fuel supply facilities; (4) steam generator; (5) flue gas scrubber system; (5) steam distribution system; (6) wellhead injection facilities; and (7) surface facilities. The capital costs presented in the following section were gathered from various sources including equipment vendors and California steamflood operaturs.

\section{Water Treatment Facilities}

Water treatment facility costs are contingent upon the quality of source water. Depending on the raw water source, the system ranges from a simple zeolite ion exchange unit to a facility that includes clarifiers, filters, skimmers, oil separators, depurators, softeners, and deaerators. As a general rule, the poorer the water quality the more elaborate will be the treatment requirements and the higher will be the capital costs. For the purpose of this cost estimation, the source water is assumed to be fresh subsurface water containing less than $500 \mathrm{ppm}$ total hardness. Softening of such water, requires nothing more than a simple zeolite water softening unit. A packaged unit capable of softening about 3,500 bbl of water (capacity of a $50 \mathrm{MM} \mathrm{Btw/hr} \mathrm{steam} \mathrm{generator)} \mathrm{would}$ cost $\$ 100,000$. In Kern County, California, a source well drilled to about $300 \mathrm{ft}$ and completed in $200 \mathrm{ft}$ of water sands and equipped with a submersible pump and related equipment will cost $\$ 25,000$. The cost of a 5,000 -bbl raw water storage tank with gas blanket will cost $\$ 40,000$. Two-thousand feet of water distribution line; transfer pumps and drive will cost $\$ 20,000$. 
TABLE 4.2. - Kern County, California, New Production Well Costs, Excluding Downhole Pump ${ }^{1}$

\begin{tabular}{|c|c|c|}
\hline Well Depth. & $\begin{array}{l}\text { Eastern } \\
\text { Kern County } \\
\text { prod well cont } \$\end{array}$ & $\begin{array}{l}\text { Western } \\
\text { Kern County } \\
\text { prod. well cont, } \$\end{array}$ \\
\hline $\begin{array}{r}0-250 \\
251-750 \\
751-1,250 \\
1,251-1,750 \\
1,751-2,250 \\
2,251-2,750 \\
2,751-3,250 \\
3,251-3,750 \\
3,751-4,250 \\
4,251-4,750 \\
4,751-5,250\end{array}$ & $\begin{array}{r}35,000 \\
58,000 \\
78,000 \\
90,000 \\
130,000 \\
153,000 \\
180,000 \\
210,000 \\
242,000 \\
283,000 \\
322,000\end{array}$ & $\begin{array}{r}40,000 \\
63,000 \\
85,000 \\
100,000 \\
146,000 \\
180,000 \\
225,000 \\
270,000 \\
315,000 \\
360,000 \\
416,000\end{array}$ \\
\hline
\end{tabular}

Kern County Aseceser's appraised value for the year 1991-92

TABLE 4.3. - Cost to Drill and Equip a 1,000-ft Steam Injection Well (in 1991 Dollars)

\section{Drilling:}

Paymeet to drilling contractor

Site preparution

Tranportation and seup of ris

Finel

Drilling mod and additives

Orher expesditures

Toul drilling coets

$\$ 19,500$

6,500
2,600

700

5,300

70.0

35,300

Lomping:

Loge and wireline evaluntion services

3,500

Corims:

Side wall sampling, base chare

1,000

Sampling S6Oteample

for 50 ft zone, sample/5 fi 10 samples

600

Traneport

$\mathbf{2 , 2 0 0}$

Superviaion

Overheed

1,100

Completion:

Cemeat and cementing services

Tool reatals

Perforation and formation treating

Supervision

Overhead

Caving $T^{m}$, threaded and coupled, $\$ 12.3 / \mathrm{ft} 1.000 \mathrm{ft}$

Tubing and attachment 2-3/8" $\$ 4.0 \mathrm{hi} 1,000 \mathrm{ft}^{\circ}$

2,800

2.300

7,300

900

600

12,300

Dowahole equipmere

Caning and tubing centralizers, expansion joints, high

temperature safety joints, permanent thermal packers, retrievable packer etc.)

4,000

Total coet of injection well

Seem injection well injection couipment (etufiring box,

casing head, choke, nipples, ball joint asembly, valves.

lime pipe, tubieg, uaios, ells, etc)

$\$ 85,000$

Tot drilling, completion, and equipmen coets for the

25,000

ream injection well

$\$ 110,000$ 
TABLE 4.4. - Cost to Drill and Equip a 1,000-ft Production Well (in 1991 Dollars)

Drilling:

Payment to drilling contrector

Sile preperation

Trensportation and setup of ris

Puel

Drilling mud and additives

Other expenditures

$\$ 19,500$

6,500

2,600

700

5,300

700

Total drilling coots

$\$ 35,300$

$$
\text { or } \$ 35.3 / \mathrm{ft}
$$

Logring:

Logs and wireline evaluation services

Coring:

Side wall sampling, base charge

2,000

Sampling. \$60/sample

for $50 \mathrm{ft}$ zone, sample/5 ft, 10 samples

600

Transport

Supervision

2.200

Overhead

1,100

Comoletion:

Cement and cementing services

Tool rentals

Perforation and formation treating

Supervision

Overhead

Casing $7^{m}$ treaded and coupled, $\$ 12.3 / \mathrm{it} 1,000 \mathrm{ft}$

Production tubing 2-3/8", \$4.0/ft 1,000 ft

$\$ 2,000$

2,800

7,300

900

12,300

Domphole Equipment:

Telescoping expansion joints, production packers centralizer, gravel pack

$\$ 7.300$

Total cost of production well

$\$ 82,800$

Subsurface rod pump assembly with gas anchor, 3/4" API class C sucker rod $\$ 11,000$ 228,000 in lb-lorque API 228-213-86 pumping unit

$\$ 23,000$

Toed coet of production well

$\$ 116,800$ 
TABLE 4.5. - Index of Drilling and Equipping Wells Unadjusted for Depth6 $(1984=100)$

\begin{tabular}{|c|c|c|c|c|c|c|c|c|}
\hline \multirow{5}{*}{ 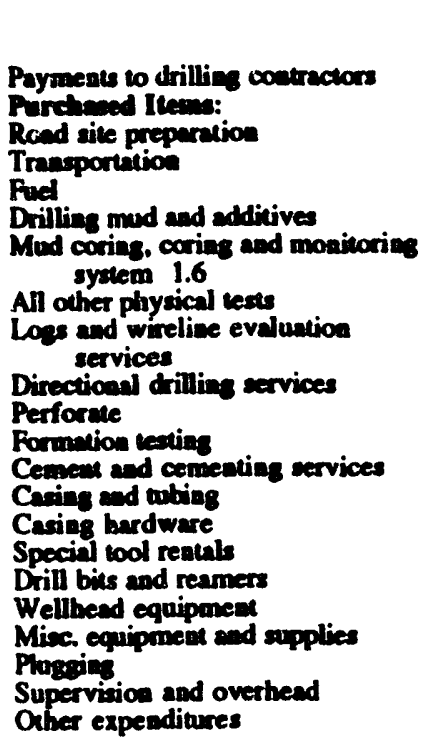 } & Weight & 1983 & 1984 & 1985 & 1986 & 1987 & 1988 & 1989 \\
\hline & 29.8 & 114.3 & 100.0 & 101.0 & 85.9 & 64.4 & 77.3 & 73.5 \\
\hline & $\begin{array}{l}6.3 \\
2.9 \\
1.2 \\
5.8\end{array}$ & $\begin{array}{r}96.7 \\
100.0 \\
101.8 \\
107.5\end{array}$ & $\begin{array}{l}100.0 \\
100.0 \\
100.0 \\
100.0\end{array}$ & $\begin{array}{r}101.7 \\
100.0 \\
95.3 \\
100.6\end{array}$ & $\begin{array}{r}103.6 \\
100.0 \\
58.4 \\
100.6\end{array}$ & $\begin{array}{r}106.2 \\
100.0 \\
65.4 \\
100.6\end{array}$ & $\begin{array}{r}108.5 \\
100.0 \\
58.8 \\
100.6\end{array}$ & $\begin{array}{r}110.1 \\
100.0 \\
68.8 \\
100.6\end{array}$ \\
\hline & $\begin{array}{r}100.0 \\
0.5\end{array}$ & $\begin{array}{l}100.0 \\
100.0\end{array}$ & $\begin{array}{l}100.0 \\
100.0\end{array}$ & $\begin{array}{l}100.0 \\
100.0\end{array}$ & $\begin{array}{r}87.4 \\
100.0\end{array}$ & $\begin{array}{r}88.9 \\
133.2\end{array}$ & $\begin{array}{l}104.6 \\
138.8\end{array}$ & 164.1 \\
\hline & $\begin{array}{r}4.1 \\
0.8 \\
2.0 \\
4.2 \\
4.3 \\
16.8 \\
0.7 \\
3.1 \\
1.6 \\
2.0 \\
2.5 \\
0.7 \\
3.0 \\
6.1\end{array}$ & $\begin{array}{r}95.6 \\
101.6 \\
100.0 \\
105.9 \\
107.4 \\
105.2 \\
105.2 \\
103.3 \\
99.9 \\
107.2 \\
100.9 \\
98.5 \\
100.3 \\
97.9\end{array}$ & $\begin{array}{l}100.0 \\
100.0 \\
100.0 \\
100.0 \\
100.0 \\
100.0 \\
100.0 \\
100.0 \\
100.0 \\
100.0 \\
100.0 \\
100.0 \\
100.0 \\
100.0\end{array}$ & $\begin{array}{r}89.9 \\
98.8 \\
100.0 \\
94.0 \\
92.7 \\
98.8 \\
98.8 \\
100.0 \\
100.4 \\
103.8 \\
100.8 \\
98.1 \\
103.3 \\
100.4\end{array}$ & $\begin{array}{r}67.4 \\
98.8 \\
100.0 \\
89.3 \\
86.5 \\
92.0 \\
92.0 \\
100.0 \\
98.8 \\
103.9 \\
99.1 \\
97.4 \\
108.1 \\
96.8\end{array}$ & $\begin{array}{r}73.0 \\
98.8 \\
100.0 \\
94.0 \\
90.8 \\
98.8 \\
98.8 \\
100.9 \\
101.2 \\
101.8 \\
99.8 \\
100.4 \\
106.5 \\
99.3\end{array}$ & $\begin{array}{r}79.5 \\
104.0 \\
151.7 \\
95.4 \\
97.5 \\
120.0 \\
120.0 \\
102.0 \\
116.5 \\
105.5 \\
103.6 \\
99.6 \\
109.3 \\
102.9\end{array}$ & $\begin{array}{r}75.7 \\
115.4 \\
182.3 \\
101.2 \\
102.3 \\
129.9 \\
129.9 \\
102.0 \\
118.8 \\
106.6 \\
106.0 \\
103.5 \\
115.2 \\
105.3\end{array}$ \\
\hline Sub-Toul Purchased liems & 70.2 & 102.4 & 100.0 & 98.7 & 94.4 & 97.5 & 106.4 & 111.8 \\
\hline
\end{tabular}

Source: IPAA Coat Study Committee

$\$ 20,000$. A $1,000-b b$ l soft water storage tank with gas blanket will cost $\$ 30,000$. Produced water treatment and disposal cost will total $\$ 80,000$.

\section{Steam Generation}

The operating characteristics of a steam generator are given in Table 4.6. Steam generator and accessories costs, excluding that of pollution control equipment, are given in Table 4.7. The steam generation operation cost, including water and fuel costs, are also shown in Table 4.7. Labor costs are taken from reference 7. A typical $50 \mathrm{MM}$ Btu/hr steam generator burns approximately $7 \mathrm{gpm}$ (gallons per minute) of crude oil and will require approximately $17 \mathrm{scf} / \mathrm{min}$ (standard cubic feet per minute) of air $(52,280 \mathrm{lbm} / \mathrm{hr}$ air) for complete combustion. A flue gas scrubber (pollution control equipment) to handle approximately $25 \mathrm{scfm}$ flue gas costs $\$ 360,000$. The operations and maintenance cost of the scrubber is approximately $\$ 200,000$ per year $(\$ 0.2$ per barrel of produced steam). 4 
TABLE 4.6. - Characteristics of Conventional Lease Crude Fired Steam Generator ${ }^{4}$

\begin{tabular}{|c|c|}
\hline $\begin{array}{l}\text { Heal input } \\
\text { Heat oututut } \\
\text { Design capacity } \\
\text { Average drily output } \\
\text { Anmual output } \\
\text { Steam quality } \\
\text { Steam conditions } \\
\text { Water requirement } \\
\text { Electricity requirement } \\
\text { Fuel requirement }\end{array}$ & $\begin{array}{l}\text { 62.5 MM Btu/hr } \\
50.0 \mathrm{MM} \text { Bui/hr } \\
3,500 \mathrm{bbl}-\text { steam/day } \\
2,800 \mathrm{bbl}-\mathrm{steam} \text { ( } 80 \% \text { capacity) } \\
1,022,000 \mathrm{bbl} \text {-steam } \\
80 \% \\
1,000 \mathrm{psi} \text {, saturated temperature } \\
1,022,000 \mathrm{bbl} / \mathrm{yr} \\
320,000 \mathrm{kwh} / \mathrm{yr} \\
10.2 \mathrm{bbl} / \mathrm{hr} \text { of lease crudes } \mathrm{hr} \\
\text { or } 74,000 \mathrm{bbl} / \mathrm{yr}\end{array}$ \\
\hline
\end{tabular}

$6.2 \mathrm{MM} \mathrm{Bu} / \mathrm{bbl}$.

TABLE 4.7. - Conventional Oil-Fired Surface Steam Generator Costs 4 (1991 Dollars)

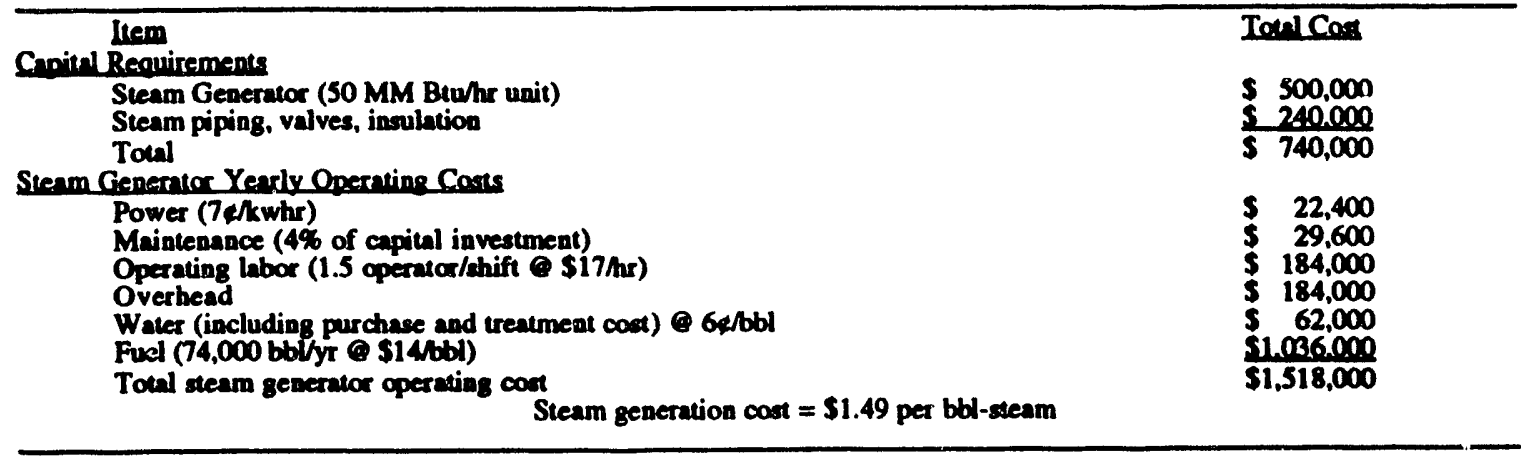

\section{Steam Distribution System}

Steam distribution lines include a main steam header and lateral lines. Steam headers range in size from 12 to 24 in. diameter depending on the steam zenerating capacity of the site and steam requirements in the area. Steam is transported from a steam header to individual injector wells by steam lateral lines. Typically, these lines range from 3 to $10 \mathrm{in}$. in nominal diameter. Diameter of lateral lines depends on injection rates of wells.

For cost estimation, the steam header was assumed to be constructed of 12-in. schedule 160 pipe and the lateral lines of 4-in. grade B seamless schedule 40 pipe. The pipes were assumed to be supported on pedestals and guided to control direction of expansion. Expansion loops and anchors were also installed at required intervals. Pipelines were insulated with magnesium silicate insulation and covered with aluminum jacket for weather proofing. The steam lines, including insulation, cost approximately $\$ 11.00$ per $\mathrm{ft}$ plus installation.

A complete 600 series flanged wellhead hookup, including chokes, master valve, 1500 series tubing valve, fittings, casing expansion flange, and swing joint would cost about $\$ 40,000$. 


\section{Other Surface Facilities}

Other surface fa ilities used in a typical steam injection project include free water knockout unit, heater treater, well testing unit, LACT unit, tank battery, pumps, etc.

\section{Free Water Knockout Unit}

An 8-ft-long unit capable of handling up to $27,000 \mathrm{bbl} /$ day of water would cost about $\$ 30,000$.

\section{Heater Treater}

A 6-ft horizontal heater treater, capable of handling $500 \mathrm{bbl} /$ day of produced fluid, would cost about $\$ 60,000$.

\section{Well-Testing Unit}

A well-testing unit is used to record the gravity of oil, gas/oil ratio, water/oil ratio, and total volume of fluid produced. A computerized automatic well testing unit costs about \$35,000.

\section{LACT Unit}

Lease automatic custody transfer (LACT) units are used to measure the volume of oil sold to a piryeline. A 2,000-BOPD LACT unit with 125 psi working pressure costs about $\$ 25,000$.

\section{Tank Battery}

Tanks of different sizes, six to eight in number, will be required for storage of produced fluids, treatment and storage of produced water, etc. These costs depend on the size of the units and accessories. For example, a 2,000-bbl (16 ft-dia. by 30-ft-high) 10-gauge, gas-tight, bolted steel tank would cost about $\$ 56,000$ installed.

Other costs should include production lines, miscellaneous pumps, valves, fittings, power line, sewer line, site office, etc.

\section{Operating Costs}

The operating costs for a typical steam injection project include costs for (1) raw water production and transportation, (2) water treatment, (3) fuel, (4) fuel heating and pumping (where lease crude is used), (5) power, (6) well pulling and repair, (7) aggravated oil treating problems, (8) waste disposal, and (9) labor.

\section{Raw Water Production and Transportation Costs}

These costs are usually included in the water treatment costs. In Kern County, California. it costs approximately 1 cent to produce 100 gallons of water from a subsurface well.

\section{Water Treatment}

The water treatment operational costs depend on the quality of raw water and generally include costs of salt for the regeneration of spent ion exchange resins, sodium sulfite for oxygen 
removal, pH control chemicals, and other chemicals as required. In Kern County, California, it costs approximately 4 cents to treat $1 \mathrm{bbl}$ of raw water containing 1,000 ppm (parts per million) tc tal dissolved solids. Details of water treatment costs can be found in Chapter 5.

\section{Steam Generation Operation Costs}

These costs include fuel costs, fuel heating and pumping costs (if needed), and labor. Details of steam generation operation costs are given in Table 4.7.

\section{Power}

Steam projects need electric power for lighting, controls, the burner blower, water and brine transfer pumps, chemical injection pumps, feedwater injection pumps, and operating various other miscellaneous equipment. Power requirements for operating steam generators are shown in Table 4.6. Purchased power in California costs about 7 cents per kilowatt hour.

\section{Well Pulling and Workover Costs}

Sand production problems associated with thermal recovery production wells require well repair costs. These costs depend on the severity of sand production and frequency of well pulling No definite costs can be given. One California thermal EOR operator estimates about $\$ 10,000$ per well per year as the well workover costs for his operation.

\section{Other Operating Costs}

Apart fror. the water treatment and steam generation costs, a steam injection project incurs numerous other costs such as surface facilities operational and maintenance, emulsion treatment, well servicing, produced water disposal, sand disposal, and steamflood monitoring costs (such as monthly temperature logs, miscellaneous other logs, tracer analysis, transient well testing, etc.), produced fluids analysis costs, well testing costs, etc. These costs vary with the size of the project and fluid produced. Detailed costs breakdowns are usually not possible.

\section{Financial Costs}

Royalties and taxes (federal and state income taxes) make up a substantial portion of the cost of thermally produced oil. Hence, they must be properly accounted for in economic analysis. Income and severance taxes vary from state to state. The current federal tax code must be consulted for federal income taxes, investment tax credits, intangible drilling costs (IDC), and depreciation on capital equipment.

Though royalties may range from 10 to $25 \%$, most steam injection projects are on old leases where a royalty rate of $12.5 \%$ on gross revenue usually applies. As previously mentioned, the profit potential of a steam injection project is severely impacted by a high royalty rate. 
The various oil-production-specific state taxes are shown in Table 4.8. These can be used to arrive at oil production economics on a state-specific basis. The federal corporate income tax for the year $1990-91$ is $34 \%$. The current federal tax law permits domestic independent producers to fully deduct intangible drilling costs (IDC).

An IDC is any cost that is necessary for the drilling and completion of a well but which in itself has no salvage value (e.g., wages, fuel, repairs, supplies, transportation, etc.)

Other charges that must be included in the financial analysis of a steam injection project include (a) cost of borrowing the necessary capital and (b) depreciation of capital equipment. Approximately one-third of the wellhead costs goes toward the financial costs of the operation. The suggested average life for steam injection operation related equipment is given in Table 4.10.

Capital charge rates, as arrived at by Rand Corporation 4 for steamflood projects, are given in Table 4.9. The annual capital charge rate accounts for (1) the cost of capital, (2) depreciation, and (3) federal and state income taxes including investment tax credits. This table is based on 1982 tax rates and presented here for illustration purposes only. The details of its calculation are presented in Appendix 4-B. This appendix should be consulted for estimating capital charges for new projects.

Table 4.9 is based on the following assumptions: (a) combined federal and state income tax assumed to be $50 \%$, (b) production and local tax rate assumed to be $10 \%$ of gross revenue. All investments are assumed to use $100 \%$ equity financing with $10 \%$ minimum acceptable real rate of return. Equipment life (book life) is assumed to be equal to project life. The tax life is assumed to be 5 years with straight line depreciation. A $10 \%$ investment tax credit is assumed in the calculation.

\section{SUMMARY}

Thermal recovery operations require a sizeable capital investment, and most components require much more maintenance than normal oilfield equipment. The success of an individual steam injection operation is affected by several factors. However, the principal factors are the oilsteam ratio (barrel of oil produced per barrel of feedwater injected as steam), the depth to the producing formation (deeper formations have larger heat losses and, at the same time, less latent heat content in the injected steam), and the price and demand for the oil. Other factors may become extremely important and affect the economics of the operation. As examples, in certain areas the quality of feedwater is so poor that the cost of water treatment may be excessive; or the cost of furnishing fuel for steam generation tends to make total operating costs higher. Hence, an evaluation of the different factors which could influence costs must be made before any steam injection operation is undertaken. A complete engineering and economic study of a prospect will, to a large extent, determine the probable degree of success of the operation. 
TABLE 4.8. - Comparisons of Economic Factors Affecting Oil Production From Selected Oil Producing States

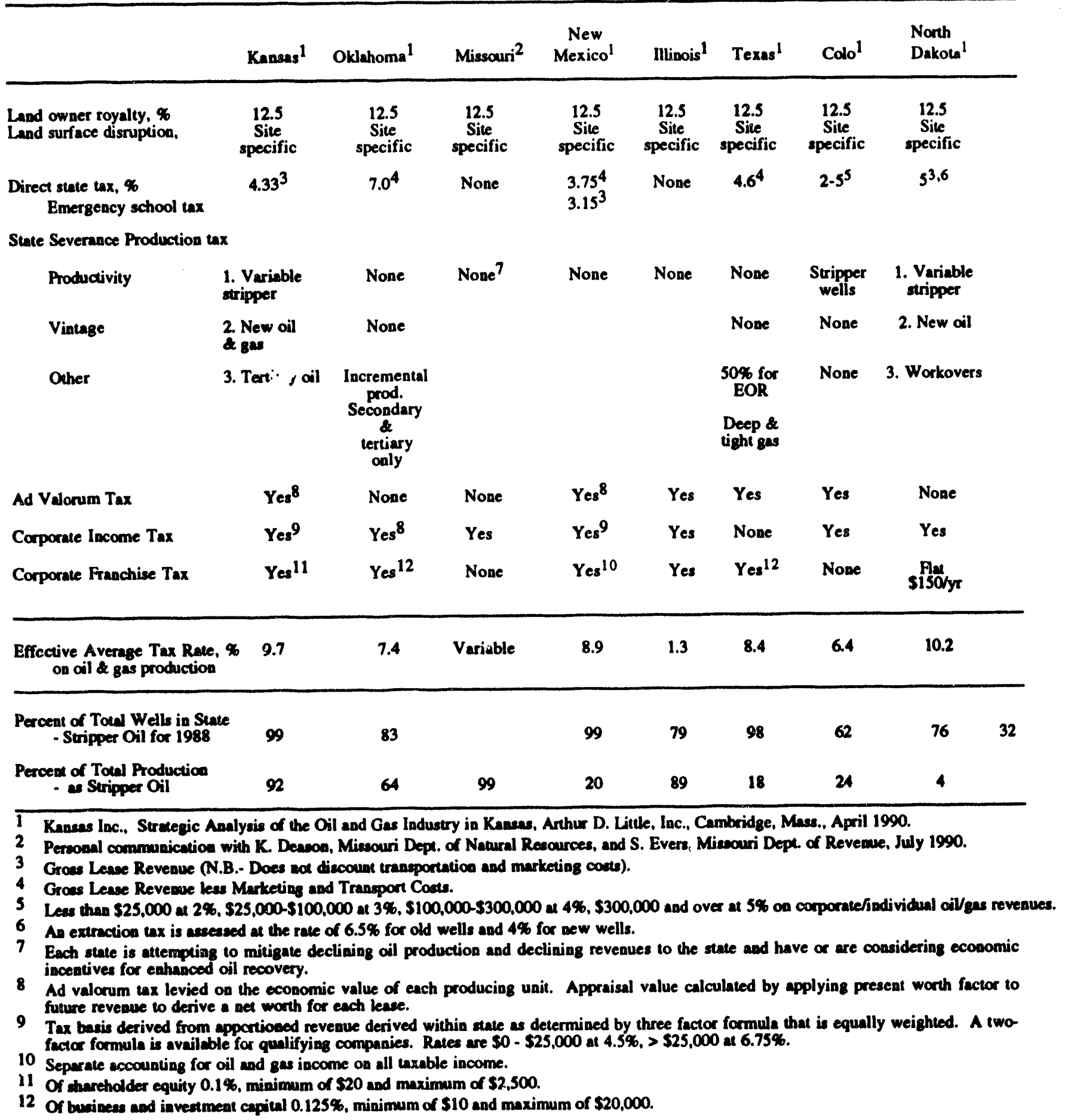


TABLE 4.94 - Capital Charge Rates

\begin{tabular}{cc}
\hline $\begin{array}{c}\text { Project life, } \\
\text { years }\end{array}$ & $\begin{array}{c}\text { Capital charge } \\
\text { rnte }\end{array}$ \\
\cline { 2 - 2 } 4.0 & 0.334 \\
4.5 & 0.304 \\
5.5 & 0.260 \\
6.0 & 0.243 \\
6.5 & 0.230 \\
7.0 & 0.218 \\
7.5 & 0.208 \\
8.0 & 0.199 \\
10.0 & 0.173 \\
11.0 & 0.163 \\
\hline
\end{tabular}

TABLE 4.10. - Suggested Average Life Tables for Oilfield Related Equipment ${ }^{1}$

\begin{tabular}{|c|c|}
\hline Descriotion & $\underset{\text { Lears }}{\text { Life. }}$ \\
\hline $\begin{array}{l}\text { Computers } \\
\text { Injection System } \\
\text { Collection System } \\
\text { Scrubber } \\
\text { Water Soflenet } \\
\text { Fillers } \\
\text { Preheaters } \\
\text { Steam Geserators }\end{array}$ & $\begin{array}{l}5 \\
10 \\
10 \\
10 \\
10 \\
10 \\
10 \\
10\end{array}$ \\
\hline $\begin{array}{l}\text { Office Furniture and Equipment } \\
\text { Heater Treater } \\
\text { Free Water Knock Out } \\
\text { Oil Treatiog } \\
\text { Transformers } \\
\text { Heat Exchanger } \\
\text { Casing Blow Syytem } \\
\text { Dehydration Unit } \\
\text { Separators }\end{array}$ & $\begin{array}{l}15 \\
15 \\
15 \\
15 \\
15 \\
15 \\
15 \\
15 \\
15\end{array}$ \\
\hline $\begin{array}{l}\text { Shipping, Boomer and Other Pumps } \\
\text { LA.C.P. Units } \\
\text { Compresacrs } \\
\text { Automatic Well Testing (AWT) Unit } \\
\text { Oil Analyzer } \\
\text { Vapor Recovery } \\
\text { Gauging Equipment } \\
\text { Flow Splituer } \\
\text { B.S. \&. Monitor } \\
\text { Air Exchanger } \\
\text { Electronic Panels } \\
\text { Waste Water Plant } \\
\text { Boiler Plant } \\
\text { Gas Plant } \\
\text { Cogeseration Plant }\end{array}$ & $\begin{array}{l}20 \\
20 \\
20 \\
20 \\
20 \\
20 \\
20 \\
20 \\
20 \\
20 \\
20 \\
20 \\
20 \\
20 \\
20\end{array}$ \\
\hline Tanks over $5,000 \mathrm{bbl}$ & 40 \\
\hline
\end{tabular}

The economic feasibility of thermal operations has been proved over and over again in California and other parts of the world for many years. In spite of higher capital and operating costs, thermal operations have proved profitable in these areas and have recovered large volumes of heavy oil which otherwise might have been abandoned. Successful steamflooding under a 
favorable geological setting is entirely dependent upon the three basic factors: engineering, economics, and experience.

\section{REFERENCES}

1. Maples, J. W. Kern County Assessor-Oil and Gas Properties Appraisal Parameters, 1991-92-Assessor, County of Kern Oil and Gas Division, Bakersfield, CA, March 1991.

2. Lewin and Associates-Economics of Enhanced Oil Recovery. U.S. Dept. of Energy Report No. DOE/ET/12072-2, May 1981.

3. Dowd, W. T., V. A. Kuuskraa, and M. L. Godec. A Technical and Economic Assessment of Domestic Heavy Oil. U.S. Dept. of Energy Report No. DOE/BC/10840-1, January 1988.

4. Nehring, R., R. Hess and M. Kamionski. The Heavy Oil Resources of the United States-A report prepared for the U.S. Dept. of Energy by the Rand Corporation. Report No. R-2946-DOE, Rand Corporation, Santa Monica, CA, February 1983.

5. Norton, J. F., J. D. Rouge, S. N. Husband, P. K. Beekley and W. R. Hearn. The Options for Increasing California Heavy Oil Production. A report to the California Energy Commission-Radiant Corporation, Sacramento, CA. Report No. DCN 81-250-008-07, November 1981.

6. IPAA Cost Study Committee-Index of Drilling and Equipping Wells. Oil \& Gas Investor, v. 9, No. 10, May 1990.

7. Trends and Statistics-Petroleum Independent, November-December 1990, p. 49.

8. Bartlesville Project Office, U.S. Department of Energy, P.O. Box 1398, Bartlesville, OK 74005 (Phone: 918-337-4293). 


\section{APPENDIX 4-A \\ REVIEW OF DEPARTMENT OF ENERGY \\ STEAM DRIVE PREDICTIVE MODELS}

\section{BACKGROUND}

Estimating the amounts of economically recoverable heavy oil requires the use of a sound, yet simple, thermal EOR model. For this, the Department of Energy (DOE) Bartlesville Project Office (BPO) currently maintains four steamdrive enhanced oil recovery models and one in situ combustion oil recovery model

This appendix reviews the publicly available thermal recovery DOE models and recommends the model most suitable for estimating oil production by steam injection.

\section{Review of Available Steamflood Models from BPO}

The four steamdrive thermal recovery models available through the BPO contain several common features. These features include algorithms for the determination of surface and wellbore heat losses, engineering costing algorithms, and a basic economic analysis package. The common technical features include a correlation for estimating residual oil saturation to steam, an optimum steam-injection rate calculation, and a method for calculating oil and water production rates, which includes fluid shrinkage and the presence of free gas. The models also use common routines for handling data input, data verification, and data output.

Each of the BPO steam drive models is discussed in more detail as follows:

1. SUUPRLModel. The SUPRI model, also called the Williams et al. model, ${ }^{1-2}$ utilizes the Marx and Langenheim ${ }^{3}$ method to predict the growth and volume of a steam zone created by continuous steam injection. These calculations assume that the growth of a steam zone and the volume of oil displaced by steam are controlled by heat losses to the adjacent overburden and underburden.

2. Jones Model. The Jones model ${ }^{4}$ is a steamdrive performance predictive model based on work by van Lookeren ${ }^{5}$ and by Myhill and Stegemeier. ${ }^{6}$ This model uses a steam-injection-rate optimization function based on a vertical conformance factor and a steamdrive algorithm based on the Marx and Langenheim ${ }^{3}$ equations as modified by Mandl and Volek. ${ }^{7}$ The model delays the arrival of the oil bank at the producing well and maintains ultimate oil recovery to less than the mobile oil in-place.

3. Gomaa Model. The Gomaa model ${ }^{8}$ predicts steamflood performance by utilizing a set of empirical correlations. These correlations are based on observed field performance data from the California Steamflood (notably Kern River) projects. The key correlation variables include vertical heat losses, vertical sweep, and fractional oil recovery as functions of reservoir thickness, heat injection rate per acre-foot of reservoir, bottomhole steam quality, and mobile oil saturation. The 
correlation curves are developed by regressing the results of a finite-difference steam drive reservoir simulator. A simple method of estimating water production rates has been added to the original Gomaa model by BPO.

4. Intercomp Model. The Intercomp model provides a more complex and thus more realistic description of steamdrive performance. The model utilizes the reservoir and injected steam properties to predict steamflood performance. The model calculations allow for the development and eventual production of three fluid banks created during steamflooding: (i) the cold liquid bank, (2) the hot oil, condensate, and water banks, and (3) the steam zone.

The cold liquid bank, created by the displacement of unheated oil and water by the steam and hot liquid banks, represents the initial response of a reservoir to steamdrive. The hot liquid bank contains heated oil and water and exists just ahead of the advancing steam zone front. The steam bank follows and generally overrides the hot liquid fluid bank. The model varies the densities, viscosities, residual saturations, and relative permeabilities of these banks with temperature. Heat losses from the reservoir to the overburden and underburden are calculated from simple heat balances, and heat is produced when the heated zone reaches the producing well. Initially the reservoir rock is assumed to be homogeneous, isotropic, and incompressible, in thermal equilibrium with the adjacent strata, and with uniform oil, water and gas saturations. A detailed description of this model is presented in references 9 and 10.

\section{Model Recommendation}

A comparative assessment of these models by Dowd et al. ${ }^{11}$ indicated that all of the models display reasonable and expected sensitivity to the steam injection rate, steam quality, and gross/net pay ratio. However, the simple Gomaa model exhibits no sensitivity to reservoir permeability or crude oil viscosity. Based on the model's ability to match simulation results and history match of field data, Dowd et al. recommend that the Intercomp model be used to predict steamflood recovery. However, it must be pointed out that the algorithm used in the Intercomp model to calculate residual oil saturation after steamflood often leads to an overprediction of oil recovery. Since this significantly affects the project economics, model results should be used with caution.

\section{REFERENCES FOR APPENDIX 4-A}

1. Williams, R. L., H. J. Ramey, Jr., S. C. Brown, and S. K. Sanyal. An Engineering Economic Model for Thermal Recovery Methods. Pres. at the 50th Annual California Regional Meeting of Soc. of Pet. Eng., Los Angeles, California, Apr. 9-11, 1980. SPE paper 8906.

2. Williams, R. L., S. L. Brown, and H. J. Ramey, Jr. A Method to Evaluate the Economics of Thermal Recovery Projects. Stanford University Petroleum Research Institute Technical Report No. 18 (SUPRI-TR-18), June 1980. 
3. Marx, J. W. and R. N. Langenheim. Reservoir Heating by Hot Fluid Injection. Trans. AIME, 216, 1959, pp. 312-315.

4. Jones, J. Steam-Drive Model for Hand-Held Programmable Calculators. J. Pet. Tech., v. 33, No. 9, September 1981 , pp. 1583-1589.

5. Van Lookeren, J. Calculation Methods for Linear and Radial Steam Drive in Reservoirs. Pres. at the 52nd Annual Fall Meeting of the Soc. of Pet. Eng., Denver, Colorado, 1977. SPE paper 6788.

6. Myhill, N. A. and G. L. Stegemeier. Steam Drive Correlation and Prediction. J. Pet. Tech., v. 30, No. 2, February 1978, pp. 173-182.

7. Mandl, G. and C. W. Volek. Heat and Mass Transport in Steam Drive Processes. Soc. Pet. Eng. J., March 1969, pp. 59-79.

8. Gomaa, E. E. Correlations for Predicting Oil Recovery by Steamflood. J. Pet. Tech., v. 32, No. 2, February 1980 , pp. 325-332.

9. Aydelotte, S. R., C. W. Paul, and R. M. Ray. Development and Verification of Simplified Prediction Models for Enhanced Oil Recovery Application: Steam Flood Predictive Model. U.S. Dept. of Energy, October 1984.

10. Aydelotte, S. R. and G. A. Pope. A Simplified Predictive Model for Steamflood Performance. J. Pet. Tech, v. 35, No. 5, May 1983, pp. 991-1,002.

11. Dowd, W. T., V. A. Kuuskraa and M. L. Godec. A Technical and Economic Assessment of Domestic Heavy Oil-Final Report. U.S. Dept. of Enargy Report No. DOE/BC/10840-1, January 1988. 


\section{APPENDIX 4-B \\ CAlCulation Of CAPITAL CHARge RATE ${ }^{4}$}

The methodology used to calculate the capital charge rate is as follows:

1. After-tax cost of capital (r):

$$
r=(1-\text { tax rate }) \times r_{b} f_{b}+r_{s} f_{s}
$$

2. Capital recovery factor based on $r$ and book life $\left(\mathrm{CRF}_{\mathrm{r}, \mathrm{B}}\right)$ :

$$
\mathrm{CRF}_{r, B}=\frac{r(1+r)^{\text {book life }}}{(1+r)^{\text {book life }}}
$$

3. Capital recovery factor based on $r$ and tax life $\left(\mathrm{CRF}_{\mathrm{r}, \mathrm{T}}\right)$ :

$$
\mathrm{CRF}_{\mathrm{r}, \mathrm{T}}=\frac{\mathrm{r}(1+r)^{\text {tax life }}}{(1+r)^{\text {tax life }}-1}
$$

4. Levelized depreciation factor $(\bar{d})$ based on straight-line depreciation method:

$$
\overline{\mathrm{d}}=[1 / \operatorname{tax} \text { life }] \times\left[\frac{\mathrm{CRF}_{\mathrm{r}, \mathrm{B}}}{\mathrm{CRF}_{\mathrm{r}, \mathrm{T}}}\right]
$$

5. Levelized investment tax credit factor (c):

$$
\overline{\mathbf{c}}=\frac{\text { investment tax credit }}{(1+\mathrm{r})} \times \mathrm{CRF}_{\mathrm{r}, \mathrm{B}}
$$

6. Capital charge rate $(\mathrm{CCR})$ :

$$
\mathrm{CCR}=\frac{\mathrm{CRF}_{\mathrm{r}, \mathrm{B}}}{(1-\text { tax rate })}-\left(\frac{\text { tax rate }}{1-\text { tax rate }}\right) \times \overline{\mathrm{d}} \frac{\overline{\mathrm{c}}}{(1-\text { tax rate })}
$$

where $r_{b}=$ required rate of return on debt (bonds)

$f_{b}=$ fraction of capital that is debt

$r_{S}=$ required rate of return on equity (stock)

$f_{S}=$ fraction of capital that is stock 


\section{CHAPTER 5 \\ WATER TREATMENT FOR STEAM GENERATION}

\section{INTRODUCTION}

Successful operation of steam generation equipment depends primarily upon a good source of feedwater combined with an effective water treating system. Quality of steam generator feedwater is of critical importance in steam injection projects. Field experience indicates that most steamer downtime is caused by water treating problems. Although a once-through steam generator can tolerate relatively high amounts of total dissolved solids (TDS), strict adherence to feedwater quality requirements is essential. Operating outside a design quality range can resuit in scale deposition in the water sides of steam generator tubes. Deposition of scale reduces heat transfer, reduces flow though the tubes, and results in tube failure through formation of localized hot spots on the tube walls. Corrosive components of the water also may cause tube failure. Therefore, it is imperative that the feedwater be properly conditioned to minimize downtime and costly maintenance.

Those embarking on steam injection projects should have an understanding of water quality requirements and the reason these requirements must be met for optimum operation of the steam equipment. Furthermore, since water provides a medium for trouble causing chemical reactions such as scaling and corrosion, it is essential that the operator at least have a rudimentary knowledge of water chemistry. In Appendix 5-A, oilfield water chemistry is briefly discussed.

In this chapter, the steam injection process water quality requirements, problems, and remedies are presented. Since the availability of fresh water for steam generation is becoming increasingly scarce in many locations, treatment and use of produced water as steam generator feedwater should be considered. A discussion on the treatment of produced water is also presented.

A list of feedwater treatment equipment and chemical vendors is included in Appendix 5-C. This list is included to serve as a reference and is not intended to be the recommended list of suppliers.

\section{WATER FOR STEAM GENERATION \\ Sources of Water for Steam Generators ${ }^{15}$}

Successful operation of conventional oilfield steam generators requires an adequate supply of good quality water. Depending upon the location, water for steam generation may be procured from many different sources. Some of the potential sources include: (a) municipal systems in the area, (2) freshwater wells, (3) lakes, rivers, creeks, dams, etc. In some fields where the potable fresh water sands are reserved for local community or agricultural use, brackish groundwater is used for steam generation. Produced water is another common source in many areas. 
The main point to consider before undertaking a steam injection pilot is that the available water supply is adequate to sustain a full-scale steamflood operation for a considerable length of time. It would be expensive to undertake a pilot program based on a limited supply of fresh water because if the pilot proved successful (and it should be favorable on paper before it starts) the ultimate need may be 20 tc 30 times the rate required by the pilot for several years to come. The pilot design should be based on the use of inferior quality water to assure the availability of an adequate supply of water for future expansion.

Naturally occurring water supplies contain considerable quantities of impurities. Water is such a superb solvent, that it has the power to dissolve virtually all inorganic substances to some extent. The impurities found in the water result from dissolving the various gases and mineral with which it comes in contact. Some of the typical impurities found in water sources are related to the origin of these sources. Moving suppies such as rivers and creeks generally contain mud, silt and other suspended matter, dissolved gases and minerals as well as bacteria, algae, and other organic matter. Because of natural settling, static sources are usually low in suspended matter. However, shallow lakes are easily disturbed by storms and are likely to contain higher amounts of suspended solids than deeper lakes.

Well waters, in general, are richer in dissolved mineral content, but poorer in suspended and organic matter and algae due to the filtration effect of the earth. As a rule, the mineral content of well water increases with depth. Typical analyses of subsurface waters used in California steamflood operations are shown in Table 5.1. Finally, produced water is usually contaminated with oil ard contains extremely high amounts of dissolved solids and organic matter. The dissolved mineral content of these waters often exceeds 20,000 ppm (see Table 5.2).

Since the type and amount of impurities found in ground and surface water supplies are considerably different, methods to produce the same end purity will vary with the source of water. Further, it is highly unlikely that water from any two surface sources in the same area would contain the same kind or amount of impurities. Therefore, it is essential that a specific water analysis be conducted before developing any water treatment plans. Additionally, source water should be monitored periodically to assure that changes which occur in a water supply due to usage are compensated by a water treating plant.

\section{Water Treating Consideration}

Although the impurities present in raw water are not necessarily troublesome, field experience indicates the use of poor quality feedwater results in frequent downtime and costly maintenance. In Table 5.3, oilfield steam generator feedwater requirements are presented.

Primary constituents most troublesome in steam generators are: (1) total hardness, (2) alkalinity, (3) oxygen, (4) sulfides, (5) dissolved solids, (6) suspended solids, (7) iron, (8) oil, 
(9) silica, (10) $\mathrm{pH},(11)$ carbon dioxide, and (12) biological growth. The following will discuss briefly how these impurities can affect steamflood equipment performance. For a more complete discussion, pleqse refer to Appendix 5-B.

TABLE 5.1. - Typical Analysis of Raw Waters Used in the San Jaoquin Valley, California, Steam Injection Projects 4

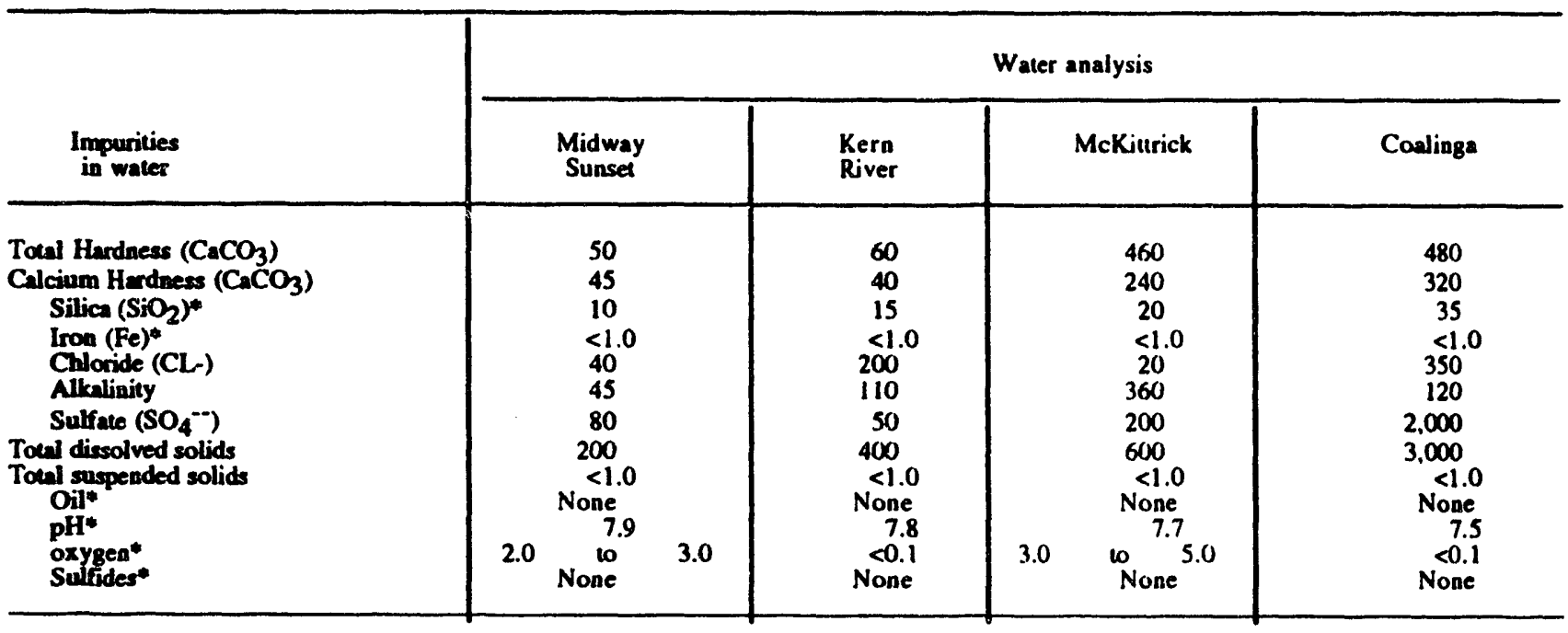

* Note: All values are in parts per million as $\mathrm{CaCO}_{3}$ except those indicated with an asterisk.

TABLE 5.2. - Approximate Total Dissolved Solid (TDS) Content and Hardness of California Oilfield Produced Water ${ }^{10}$

\begin{tabular}{|c|c|c|}
\hline Area-Field & $\begin{array}{c}\text { Hardness } \\
\text { ppm } \\
\left.\text { (2s } \mathrm{CaCO}_{3}\right)\end{array}$ & $\begin{array}{l}\text { TDS } \\
\text { ppm }\end{array}$ \\
\hline $\begin{array}{l}\text { Los Anyeles, Inglewood } \\
\text { Long Beach (Wilmingeon) } \\
\text { Venture } \\
\text { Sance Muria } \\
\text { Kern River } \\
\text { Behidge } \\
\text { Taft } \\
\text { Humtisgion Beach } \\
\text { Coalinga } \\
\text { Tulare }\end{array}$ & $\begin{array}{r}2.000 \\
3.000 \\
1.600 \\
800 \\
100 \\
300 \\
200 \\
1.500 \\
300 \\
500\end{array}$ & $\begin{array}{r}25,000 \\
30,000 \\
28,000 \\
10,000 \\
1,000 \\
6,000 \\
1,500 \\
25,000 \\
5,000 \\
8,000\end{array}$ \\
\hline
\end{tabular}


TABLE 5.3. - Steam Generator Feedwater Requirements

\begin{tabular}{|c|c|}
\hline $\begin{array}{l}\text { Conponent } \\
\text { Herdness } \\
\text { Total diseolved solids (TDS) } \\
\text { Allolinity } \\
\text { Silica } \\
\text { Diseclved oxygen } \\
\text { Chlorine } \\
\text { pH } \\
\text { ron } \\
\text { Hydrogen sulfide } \\
\text { Turbidity } \\
\text { O1 }\end{array}$ & $\begin{array}{l}\text { Permissible imosaicilimils } \\
<1 \mathrm{ppm} \\
<4.000 \mathrm{ppm} \\
<1.500 \mathrm{ppm} \\
<50 \mathrm{ppm} \\
<0.01 \mathrm{ppm} \\
<1 \mathrm{ppm} \\
9 .-11 \\
<0.05 \mathrm{ppm} \\
0 \\
0 \\
0\end{array}$ \\
\hline
\end{tabular}

Total Hardness: The hardness is the measure of the amount of calcium and magnesium ions contained in water. These ions are responsible for the steam generator scaling and their concentration in the boiler feedwater should be held below 1 part per million (ppm) to prevent scaling. This is normally accomplished with the aid of an ion exchange resin bed.

Alkalinity: Natural water contains carbonate and bicarbonate ions which, under the influence of heat, breakdown into hydroxide $\left(\mathrm{OH}^{-}\right)$and carbon dioxide causing the water to become alkaline. Although excess hydroxide alkalinity can result in caustic embrittlement, a moderate alkaline environment helps to reduce corrosion and keeps silica in solution. Therefore, alkalinity levels of less than $1,500 \mathrm{ppm}$ need not be treated.

Oxygen: Dissolved oxygen is the primary contributor to corrosion and should be excluded from feedwater. API recommends that the maximum amount of dissolved oxygen in the feedwater be kept below $0.01 \mathrm{ppm}$ and preferably at $0.0 \mathrm{ppm}$.

Sulfides: Sulfide is usually present in the feedwater in the form of dissolved hydrogen sulfide $\left(\mathrm{H}_{2} \mathrm{~S}\right)$ gas. $\mathrm{H}_{2} \mathrm{~S}$ is both corrosive and toxic and hence must be removed from the feedwater. $\mathrm{H}_{2} \mathrm{~S}$ is generally removed from the feedwater by deaeration, but chemical means such as chlorination may have to be used for complete removal.

Dissolved Solids: Dissolved solids will cause problems only if their concentration in the liquid phase exceeds their solubility limit. The practical limitation of dissolved solids generally comes as a result it water softener operating limitations. A dissolved solid concentration of less than $4,000 \mathrm{ppm}$ in the reedwater is acceptable.

Suspended Solids: The raw water should be free of suspencled solids since they contribute to softener fouling and formation of steam generator sludge. If the concentration of suspended solids in the raw water is high, the water must be filtered to reduce the suspended solid levels to an acceptable level (usually less than $5 \mathrm{ppm}$ ) before softening.

Iron: The iron content of the feedwater should be less than $0.05 \mathrm{ppm}$ to avoid contaminating the ion exchange resins. Iron can also precipitate as scale on the generator tube and cause hot spots to form. 
Qil: The presence of oil in the feedwater contributes to film formation and coking in the generator tube and results in their eventual failure. Oil also fouls the water softener resins. Therefore, the feedwater should be free of oil.

Silica: Silica is troublesome in oilfield steam generators because of its scaling tendency. However, the presence of hardness ions such as calcium and magnesium is necessary for the silica to form scale. Since these ions are usually removed by ion exchange process, silica removal is not necessary. Satisfactory operations with silica contents of $150 \mathrm{ppm}$ are possible in the absence of hardness ions.

$\mathrm{pH}$ : The $\mathrm{pH}$ of the feedwater should be maintained between 9 and 11 to keep silica in solution and to avoid corrosion of the steel parts of the system.

Biological Growths: If the total dissolved solids content of the raw water is high, bacteria may grow in the feedwater. Since bacteria and algae will foul the ion exchange system, their growth must be controlled. The most common method of controlling bacterial growth in oilfield water is by means of chlorine or other biocide agents. Chlorine will attack only the exposed organisms and will not penetrate slime. Biocides are effective in eliminating slime forming bacteria. Biocides should be chosen with the help of a vendor representative, since the type needed will depend on the organism, contact time, and temperature of the water to be treated, etc.

Table 5.4 summarizes the various methods of treating common feedwater impurities.

\section{FEEDWATER TREATING EQUIPMENT}

As noted previously, a wide variety of equipment is used in steamflood operations to treat and produce water of desired quality. The water source dictates the type of treatment equipment required. Some of the more common water treatment equipment used in steam injection operations include depurators, sedimentation basin, skimmers, filters, ion exchange units, and mechanical deaerators. Not all units are used in every operation. For example, only a few operations use deaerators to reduce oxygen. Almost all operations use "catalyzed" sodium sulfite to scavenge oxygen. However, in all steam injection projects, ion exchange systems are used to soften the water. Finally, all operations use automation to monitor the quality of treated water. The ion exchange units and their operational problems are discussed in detail in the following segments of this report. The difference between conventional cation exchange systems and those used in steam injection operations is outlined. A summary of the operation of other steam injection water treatment equipment is also provided.

\section{Ion Exchange Units}

In almost all steam injection operations, water is softened by ion exchange. As the name implies, an ion exchange system simply exchanges more of the desirable ions for the less desirable 
TABLE 5.4. - Methods for Removal of Common Raw Water Impurities ${ }^{1}$

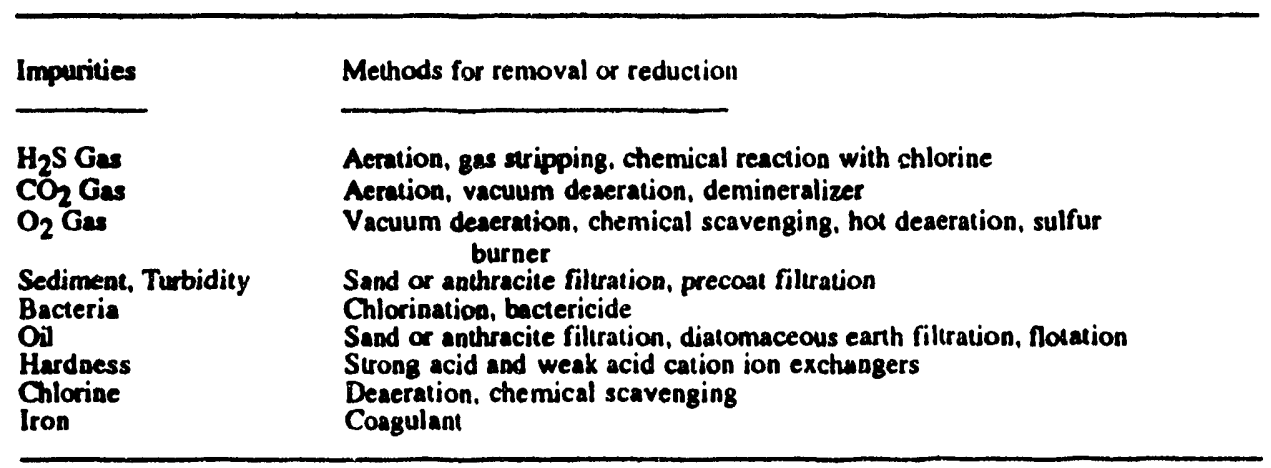

ions without reducing the total solids content. Inexpensive to purchase, operate, and maintain, the system consists of either a cation exchange resin which removes cations (such as calcium, magnesium, iron, and manganese) or an anion exchange resin which removes anions (such as carbonate, bicarbonate, chloride, and silica). For steam operations, most commonly used ion exchange system for softening water is the synthetic sodium zeolite cation exchange unit. The synthetic sodium zeolite resins are derivatives of sulfonic acids and are commonly referred to as strong acid resins. Strong acid resin softeners efficiently reduce the calcium and magnesium content of a raw water, but they do not affect the alkalinity, silica, or the total dissolved solids content of the water.

Many different types of ion exchange materials are used in water softening operations. The ion exchange material and method used to soften water will depend largely on the quality of raw water and the quality of water requirec' for a particular use. For example, the water quality required for steam generation calls for almost zero hardness, and a sodium zeolite softener alone is not satisfactory if the TDS content of raw water is greater than 2,000 ppm. ${ }^{10}$ Depending on the TDS content of raw water, other types of resins are used alone or in conjunction with sodium zeolite resins to obtain water of the required quality. The raw water quality and economics will dictate the resin choice. Weak acid resins are also used in steam injection operations. These resins exhibit a much greater capacity than conventional zeolite resins, are highly selective, and offer more efficient regeneration. Weak acid resins are discussed more fully in a later sertion.

Before discussing the details of ion exchange equipment, four terms describing resin efficiency are very important and should be remembered.

1. Capacity of an exchanger is defined as the amount of a specified ion that a given volume of resin can remove from a raw water at stated conditions. Exchanger capacities are used in characterizing ion exchange materials and in numerical calculations pertaining to ion exchange operations. The capacity of an ion exchange resin is expressed as 'grains per cubic foot' ( 1 grain $\mathrm{CaCO}_{3} / \mathrm{cu} \mathrm{ft}=2.29 \mathrm{ppm}$; see Appendix 5-A for definitions). For 
example, a resin is said to have a capacity of 2,500 grains per cubic foot, if 1 cubic foot of this resin upon saturation contains 2,500 grains $(5,725 \mathrm{ppm})$ of cations expressed as calcium carbonate. The capacity of ion exchange resins varies greatly. The capacities of naturally occurring zeolites vary between 2,500 and 5,000 grains per cubic foot. The capacities for synthetic zeolites range between 15,000 and 35,000 grains per cubic foot. In comparison, weak acid resins typically have a capacity as high as 70,000 grains per cubic foot, but the operating capacity is usually in the range of 20,000 to 40,000 grains per cubic foot. 10

2. Leakage is the quantity of unwanted ions present in the treated water, after its passage through the resin bed. Leakage is a function of raw water composition, resin capacity, regenerant concentration, and the condition of the lower levels of the exchanger bed. Leakage, as applied to an oilfield water, is discussed in a later section.

3. Elow Rate is expres $d$ as the volume of water passing per square foot of cross-sectional area of resin bed pe ninute. Flow rate must be regulated so as to allow proper contact time between the witer and resin. Since the flow rate can significantly effect the operating capacity of the resin beds, it should be limited to about six to eight gallons per square foot of resin beds.

4. Rate of Exchange is affected by resin type, flow rate, temperature, and resin particle size. For a given resin, a decrease in particle size results in increased rate of exchange and increased leakage. Higher temperatures increase the rate of exchange. For a given particle size, different resins exhibit different rates of exchange.

\section{Sodium Zeolite Softener}

Zeolite water softening is the oldest and simplest of the ion exchange processes. Zeolites are cation exchangers. Though in reality the name zeolite refers to naturally occurring alkali or alkaline earth aluminosilicates, in practice any synthetic organic or inorganic cation exchange resin is called a zeolite. Sodium cation exchange resins (sodium zeolites) used in the oilfield operations are organic cation exchange resins of the polystyrene variety. These are derivatives of strong sulfonic acids and are also commonly known as the strong acid resins. These resins are effective, durable, inexpensive and operable over virtually the entire $\mathrm{pH}$ range.

\section{Principles of Operation 4}

In the sodium zeolite water softening process, the hard water is passed through a bed of active sodium cation exchange resins. As the water flows through the resin bed, the resins replace the objectionable calcium and magnesium ions in the water with the nonobjectionable sodium ions. Using the symbol $\mathrm{Z}$ for the zeolite radical, the softening process can be summarized as follows: 


$$
\mathrm{Na} 2 \mathrm{Z}+\mathrm{Ca} \text { (or } \mathrm{Mg})\left\{\begin{array}{c}
\mathrm{Cl}_{2} \\
\left(\mathrm{HCO}_{3}\right)_{2} \\
\mathrm{SO}_{4}
\end{array} \rightarrow \mathrm{Ca} \text { (or } \mathrm{Mg}\right) \mathrm{Z}+2 \mathrm{Na}\left\{\begin{array}{c}
\mathrm{Cl} \\
\mathrm{HCO}_{3} \\
\mathrm{SO}_{4}
\end{array}\right.
$$

The resin now contains calcium and magnesium ions and a few residual sodium ions.

When the ability of the zeolite bed to remove hardness has been exhausted, the softener is temporarily taken out of service and backwashed for regeneration. The regeneration consists of passing sodium chloride brine through the units, replacing the calcium and magnesium ions with sodium ions. The regeneration step may be represented as follows:

$$
\mathrm{Ca} \text { (or } \mathrm{Mg}) \mathrm{Z}+2 \mathrm{NaCl} \rightarrow \mathrm{Ca} \text { (or } \mathrm{Mg} \text { ) } \mathrm{Cl}_{2}+\mathrm{Na}_{2} \mathrm{Z}
$$

The regenerating solution, along with water used to rinse the softener after regeneration, is discharged to waste. The process of regeneration of spent resins with sodium chloride is called "brining.'

It should be mentioned at this point, that no chemical reaction is involved in the ion exchange process. The softening or regeneration proceeds only because there is great excess of one ion in the water compared to the resin. Alth ough sodium zeolite treated water is nearly free of calcium and magnesium ions, some hardness leakage is inevitable. The term "leakage' implies a slipping of some of the unwanted ions into the effluent. Leakage occurs because the ion exchange process is in dynamic equilibrium, i.e., reactions 1 or 2 are reversible. The sodium ion in the raw water, plus the sodium ion released from the ion exchange bed by exchange of hardness ion, has a regenerating effect on the resin as it is removing hardness. This results in hardness leakage through the bed and into softened water. Hardness leakage increases with increasing TDS in the raw water.

The frequency of regeneration needed depends on the flow rate, the hardness content of the raw water, the exchange capacity of the resin, volume isf resin in the bed, and amount of salt used per regeneration. Of these, the operator can exercise control only on the quantity of salt used per regeneration. The other parameters are fixed by the system design and raw water hardness.

\section{Salt Requirements 11}

Zeolites have a greater affinity for divalent cations such as $\mathrm{Ca}^{++}$and $\mathrm{Mg}^{++}$than monovalent cations such as $\mathrm{Na}^{+}$. The divalent cation affinity increases with an increase in atomic weight. Thus, during the softening cycle, $\mathrm{Ca}^{++}$ions are more readily removed from raw water than $\mathrm{Mg}^{++}$. Therefore, magnesium hardness predominates in the softened water than calcium hardness. 
Since the zeolite more readily releases sodium in exchange for calcium and magnesium, an excess sodium chloride must be used for regeneration. This means the amount of sodium in the brine must exceed the total amount of equivalent calcium and magnesium in the exhausted resins.

The amount of salt needed for regeneration is determined by the acceptable effluent quality limit and plant capacity. By using greater quantities of salt for regeneration, the capacity of the softener can be increased. In figure 5.1, the effect of raw water hardness and salt dosage on resin capacity is depicted. However, capacity increase is not proportional to regenerant increase. The effect of salt level on the performance of a typical zeolite softener is shown in Table 5.5. Capacities in this table are stated in grains of $\mathrm{CaCO}_{3}$ per cubic foot of zeolite and salt consumptions in pounds per cubic foot of resin and also in pounds per kilograin of hardness. From this table, it is apparent that an increase in salt usage is out of propostion to the increase in softener yield. For example, increasing the salt dosage from six pounds per cubic foot of resin to $15 \mathrm{lb} / \mathrm{cu} \mathrm{ft}$ of resin (a $160 \%$ increase in salt usage) will result in about only a $50 \%$ increase in softener capacity. Thus, the higher the salt level, the less efficient is the exchange process and greater is the operating and waste handling costs. The effect of feedwater hardness and salt dosage on water softening costs is shown in figure 5.2.

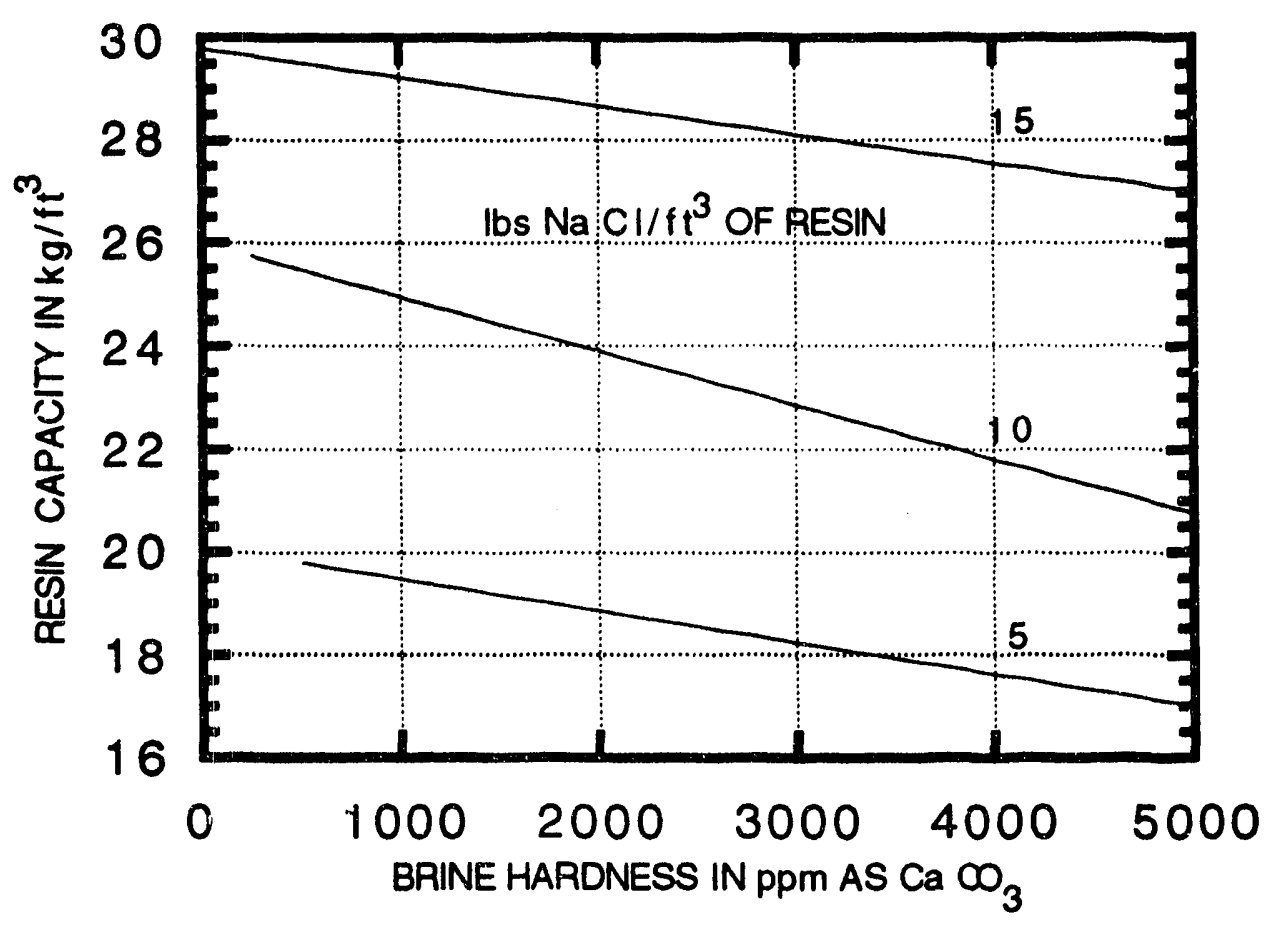

FIGURE 5.1. - Effect of feedwater hardness and salt dosage on resin capacity. ${ }^{11}$ 
TABLE 5.5. - Effects of salt level on the performance of a typical synthetic sodium zeolite exchanger 12

\begin{tabular}{|c|c|c|}
\hline $\begin{array}{l}\text { Pounds per cubic foot } \\
\text { of resin }\end{array}$ & $\begin{array}{c}\text { Pounds } \\
\text { per kilograin }\end{array}$ & $\begin{array}{l}\text { Resin capacily } \\
\text { (Grains of } \mathrm{CaCO}_{3} \text { per } \\
\text { cubic foot of resin) }\end{array}$ \\
\hline 6 & 0.33 & 18,000 \\
\hline 8 & 0.4 & 20,000 \\
\hline 10 & 0.42 & 24,000 \\
\hline 15 & 0.5 & 30.000 \\
\hline
\end{tabular}

Table 5.6 is a zeolite water softener sizing chart provided by one manufacturer. This chart provides a perspective on the relative size of the equipment and choice between salt dosage and capacity.

\section{Softener Equipment and Operation}

Although the sodium zeolite softener design features vary with vendor, in general the softener system consists of a vertical steel tank holding the ion exchange bed, piping and valves to permit the operations of softening, backwashing, brining, and rinsing. The system is usually instrumented to automate the operation. A typical softening unit is shown in figure 5.3.

The softener tank is a vertical pressure vessel with dished heads. The diameter of the tank depends on the flow rate and usually ranges from 2.5 to $10 \mathrm{ft}$. The height ranges between 6 and 8 $\mathrm{ft}$. The internal components of the tank include a raw water inlet distributor, a regenerant distributor, ion exchange resin bed, and an underdrain system. Ample room is also provided for the free expansion of the resin bed during backwash.

The raw water inlet distributor is housed in the top portion of the tank. It also serves as the rinse water inlet distributor, and wash water collector. It consists of a baffled arrangement which serves to introduce and deflect the incoming feed and rinse water. Deflection of the incoming water is necessary; otherwise the water will impinge on the bed and hollow out a portion of the upper part of the resin bed. Hollowing would cause the flow to channel and reduce the softener capacity.

The portion of the tank below the inlet distributor and above the resin bed is called the rising or free board space. The free board space permits the resin bed to expand freely during backwashing without loss of resin to the backwash drain. This expansion space is expressed as a percentage of the resin bed volume and ranges from 75 to $80 \%$.

The regenerant or the brine distributor is usually located about 6 in. above the resin bed. It usually consists of a header distribution system designed to distribute the salt solution evenly over the entire surface of the bed. 


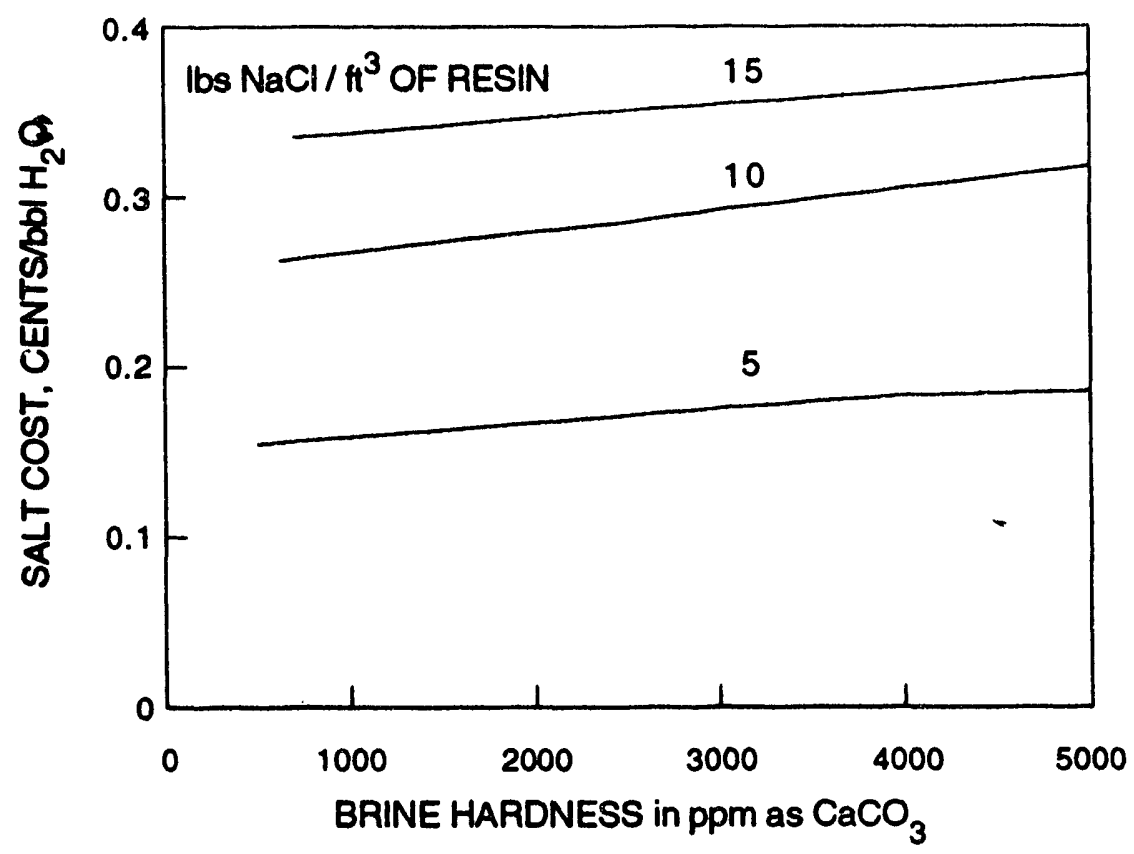

FIGURE 5.2. - Effect of brine hardness and salt dosage on water softening costs. 11

TABLE 5.6. - Zeolite Softener Selection Chart 12

\begin{tabular}{|c|c|c|c|c|c|c|}
\hline \multirow{2}{*}{$\begin{array}{c}\begin{array}{c}\text { Primary } \\
\text { tank }\end{array} \\
\begin{array}{c}\text { dimension } \\
\text { Dia x side. } \\
\text { inches }\end{array}\end{array}$} & \multirow{2}{*}{$\begin{array}{c}\begin{array}{c}\text { Polisher } \\
\text { tank }\end{array} \\
\begin{array}{c}\text { dimension } \\
\text { Dia } x \text { side. } \\
\text { inches }\end{array}\end{array}$} & \multirow[b]{2}{*}{$\begin{array}{c}\text { Service } \\
\text { fow rale. } \\
\text { GPM }\end{array}$} & \multirow{2}{*}{$\begin{array}{c}\begin{array}{c}\text { Total } \\
\text { resin } \\
\text { capacity. } \\
\text { kilograins }\end{array} \\
\begin{array}{c}\mathrm{CaCO}_{3} \\
\text { @ } 30^{\prime \prime} \text { bed. } \\
\text { depth }\end{array}\end{array}$} & \multicolumn{2}{|c|}{$\begin{array}{c}\text { Resin } \\
\text { volume, } \\
\text { cubic feet }\end{array}$} & \multirow[b]{2}{*}{$\begin{array}{c}\text { Salt } \\
\text { dosage, } \\
\mathbf{l b}\end{array}$} \\
\hline & & & & Primary & Polisher & \\
\hline $\begin{array}{r}30 \times 72 \\
48 \times 72 \\
60 \times 72 \\
72 \times 72 \\
90 \times 96 \\
120 \times 96\end{array}$ & $\begin{array}{l}24 \times 60 \\
42 \times 60 \\
48 \times 60 \\
60 \times 60 \\
78 \times 72 \\
96 \times 72\end{array}$ & $\begin{array}{r}55 \\
120 \\
190 \\
280 \\
440 \\
780\end{array}$ & $\begin{array}{r}480 \\
1.200 \\
1,800 \\
2.550 \\
4.800 \\
7.200\end{array}$ & $\begin{array}{r}16 \\
40 \\
60 \\
85 \\
160 \\
240\end{array}$ & $\begin{array}{r}8 \\
24 \\
32 \\
50 \\
90 \\
140\end{array}$ & $\begin{array}{r}240 \\
600 \\
900 \\
1,200 \\
2,400 \\
3,600\end{array}$ \\
\hline
\end{tabular}

1 Based on a TDS of $800 \mathrm{ppm}$ and $66 \mathrm{lbs} / \mathrm{ft}$ resin.

2 Based on 15 lbsfft primary bed. 


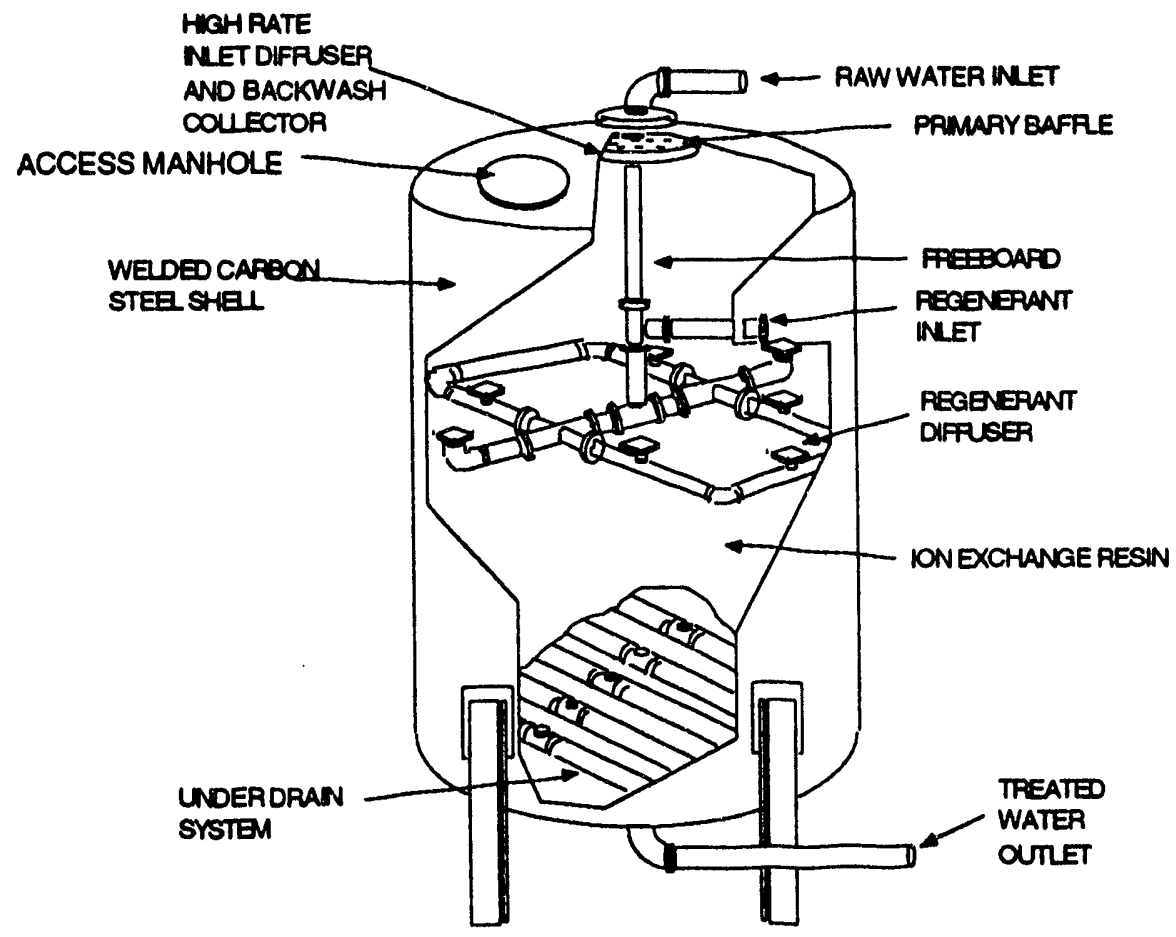

FIGURE 5.3. - Schematic of a typical ion exchange water softener. ${ }^{38}$

The resin bed contains a strong acid cation resin. The bed is leveled and hydraulically graded so that the coarse particles are in the bottom of the bed and the finest at the top. This arrangement permits even flow of water through the bed. The quantity of resin used will depend upon the exchange capacity of the resin, the hardness of the water being treated, and the amount of water to be softened between regenerations. The bed must also be of sufficient size to allow proper contact time between the water and the resin. A minimum depth of $30 \mathrm{in}$. is recommended for all systems.

The softened water is collected by the underdrain system, located at the bottom of the softener. This system also collects the waste brine and rinse water and distributes the backwash water during the backwashing operation. A well-designied underdrain system permits the even collection of softened, rinse, and salt waters from all portions of the bed and distributes the backwash water so that it flows evenly upward through all portions of the bed. A.n uneven distribution will lead to channeling and hardness leakage and cause loss of capacity. Uneven backwash can also result in loss of resin through carryover.

Although the underdrain system design varies with the vendor, most vendors use either a deflector plate type or a header-lateral type design. In the deflector plate design, a specially designed deflector plate housed inside a false bottom permits the even collection or distribution of water. 
Either a multiport valve or a valve nest is used to direct the flow of water and brine in and out of the softener. The valve nest is comprised of six valves: raw water inlet and outlet valves, brine inlet valve, rinse water outlet valve, and the backwash water inlet and outlet valves. In most installations, air, water, or motor-operated automatic valves are used to control the flow. Very few installations utilize manually operated gate valves. In large installations, a single multiport valve is used instead of a valve nest to control the flow of water through the softeners during the various cycles of operation. As the name implies, the multiport valve is comprised of several ports, and they are positioned precisely at the desired location by manipulating the valve motion. The positioned port then directs the flow of water in the same manner as the opening and closing of six separate valves. Automation is usually used in the operation of a multiport valve. Although more expensive, multiport valves are preferred over valve nests diue to the elimination of operational errors caused by opening or closing the wrong valves. The internal details of a typical ion exchange water softener are shown in figure 5.4 .

\section{Brining System}

The brining system ssually is comprised of an epoxy-lined salt storage tank in which saturated brine is formed. The saturated brine is then transferred to a small-diameter brine

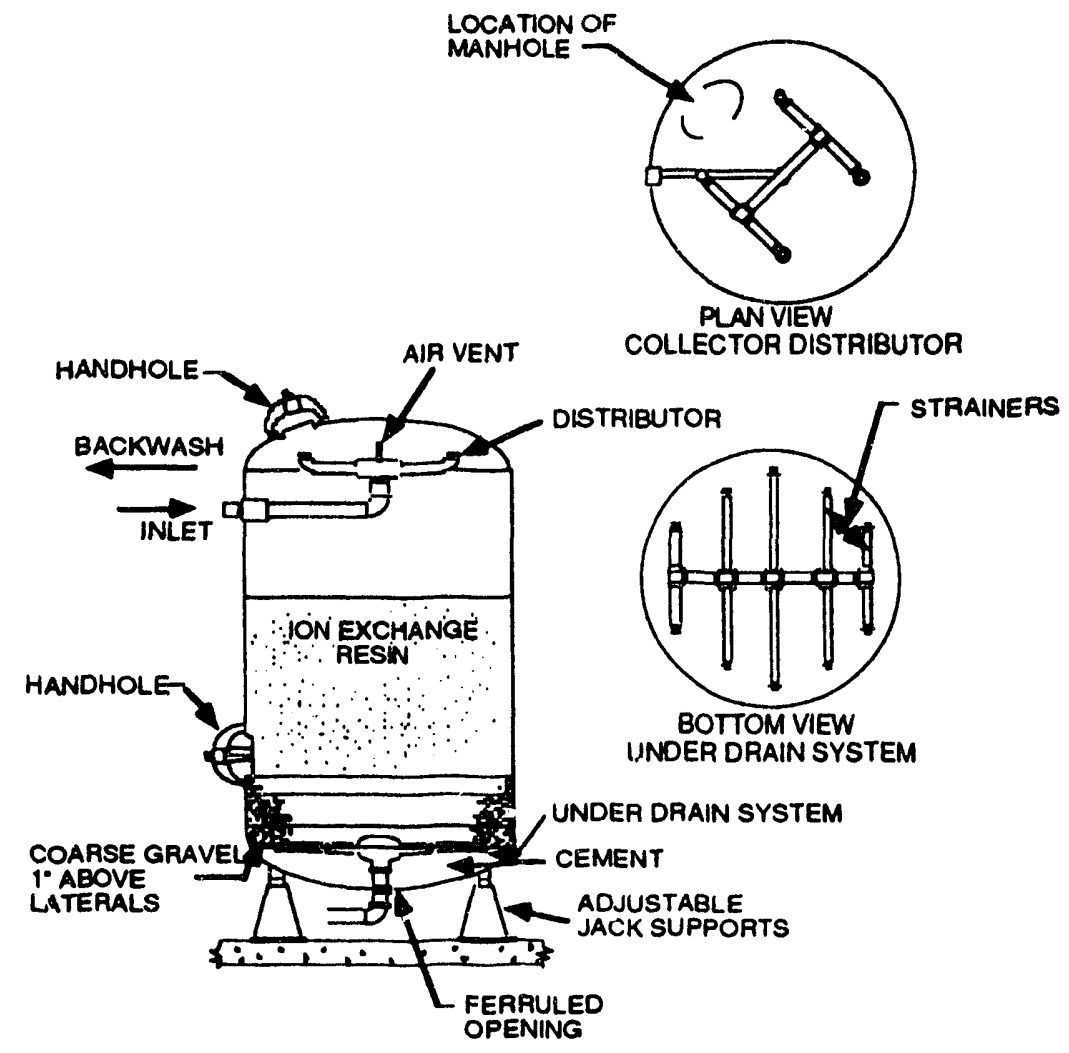

FIGURE 5.4. - Schematic of the internals of a typical zeolite softener unit. 
measuring tank where the brine is diluted to the desired concentration. The small-diameter measuring tank allows a deeper drawdown and gives a more accurate measurement.

In large steamflood operations, where considerable amounts of salt are being used to regenerate the spent resin, it is more cost-effective to purchase salt in truck loads than purchasing it bagged. A reduction in handling costs is another economic advantage of bulk salt usage. A typical design of a bulk salt storage facility for steamflood operation is shown in figure 5.5. It consists of a large subsurface concrete brine pit, usually located adjacent to a railroad track or roadway, where salt can be brought to the plant in bulk and simply dumped into a salt storage and brine preparation tank. An auger is usually available to unload the shipment of salt from the truck into a pit. This tank usually has a float-operated valve to control the addition of water into the tank. The saturated brine is pumped at intervals into a brine measuring tank from which it is pumped to the softener after dilution. Plastic pipes are usually used to transfer brine from the tank to softener.

\section{Softener Operation}

A sodium zeolite softener operates through two cycles: softening and regeneration. During the softening cycle, the raw water enters the softener through the inlet distributor and percolates

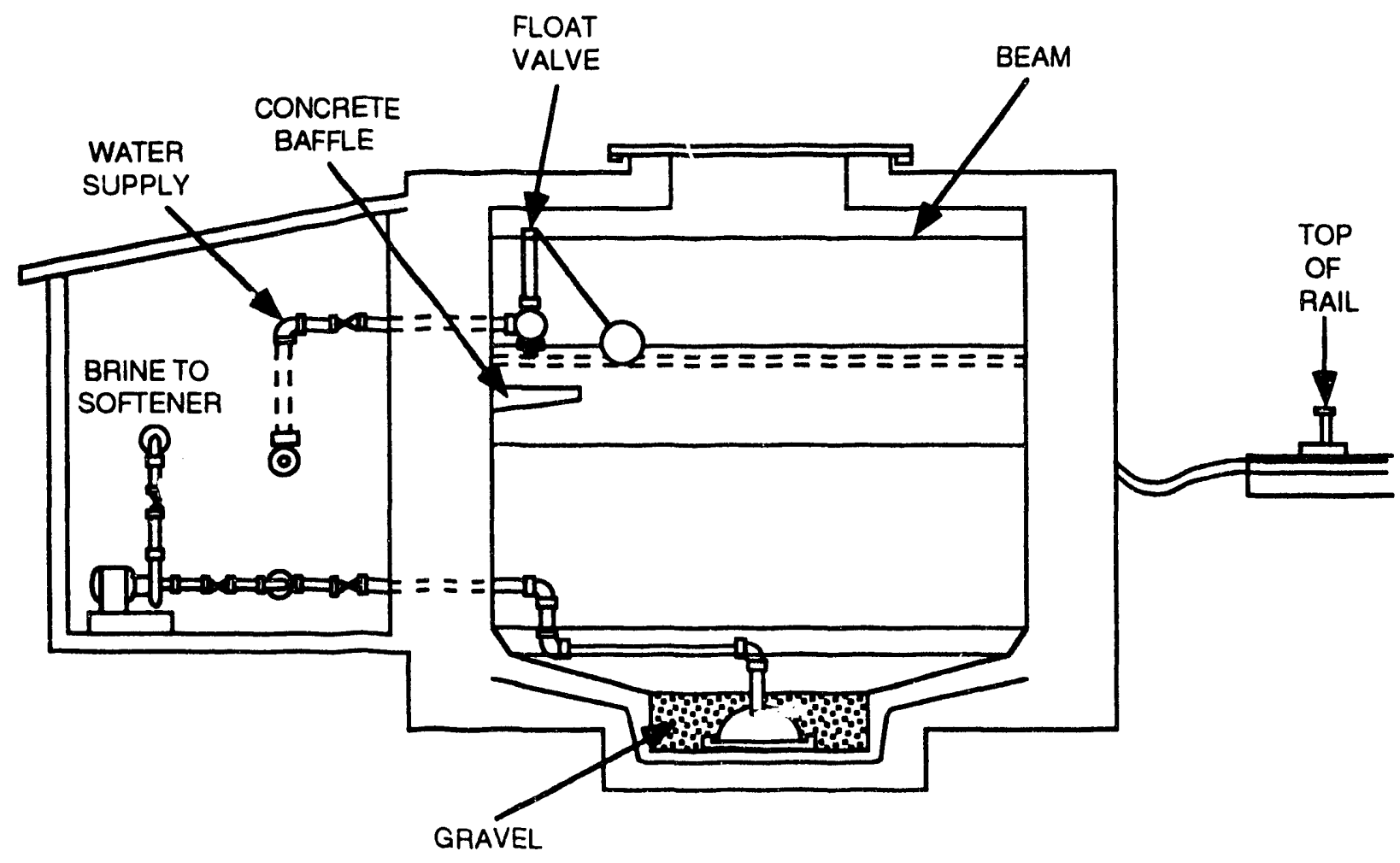

FIGURE 5.5. - Schematic of a bulk salt storage facility. 39 
through the zeolite bed. As it flows through the resin bed, the hardness-causing ions-calcium and magnesium - are taken up by the resin, and an equivalent amount of sodium is given up by the resin to the water. The softened water is collected by the underdrain system and transferred to the point of use.

When a softener is exhausted, it is regenerated. Several different approaches are used to signal the end of a softening cycle. Some plants regenerate after a fixed number of hours in operation. Others monitor the hardness of the sample-softened water and initiate regeneration when the hardness exceeds the desired level. Another common technique used to establish the need of regeneration is to monitor the quantity of water softened between regeneration. A metering device is used to initiate regeneration automatically when the preset numbers of gallons have been softened.

The regeneration cycle involves the following four steps: (1) backwash, (2) brining, (3) brine displacement and slow rinse, and (4) fast or final rinse.

Backwash - The purpose of backwash is to cleanse the resin bed of filtered particulates and resin fines and regrade the bed. Backwashing is accomplished by sending a strong flow of water through the underdrain system into the resin bed. As the water flows upward through the bed, it expands, cleanses, and hydraulically regrades the bed. The waste water is discharged to the waste through a raw water distributor.

The backwash regrades the bed by bringing the coarsest particles to the bottom of the bed and the finest to the top. This assures proper water distribution through the bed. Expansion fluffs the resin bed and improves the brine resin contact efficiency. Channeling and high pressure drop through the resin bed are eliminated through the removal of fines. Backwash must be carried out for a minimum of 15 minutes or until the backwash water effluent is clear.

The backwash flow rates depend on the water temperature, resin type, and height of the free board snace. The rate should not be excessive to cause resin loss, yet should be sufficient to produce a minimum of $50 \%$ bed expansion. Backwash rates usually vary from 6 to $8 \mathrm{gpm}$ at ambient temperature; however, manufacturers' recommendations should be carefully followed. A clear, suspended, matter-free water should be used for backwashing.

Brining - The purpose of the brining operation is to regenerate the spent resin. A strong salt solution enters the softener through the resin bed. As the brine trickles down through the bed, it removes the calcium and magnesium ions from the resin and simultaneously replaces them with an equivalent amount of sodium ions.

The brine flow rate must be slow enough to provide sufficient brine-resin contact time, yet fast enough to prevent channeling of the brine. To ensure optimum contact time and regeneration efficiency, one vendor recommended that a $10 \%$ brine be added at a rate of $1 \mathrm{gpm}$ per cubic foot of resin in the softener. 
Slow Rinse-The purpose of the slow rinsing operation is to displace the remaining brine through the resin bed and to wash out the excess salt. The rinse water enters the softener through the regenerant distributor and flows through the bed. The rinse water must flow through the bed at the same rate as the brine in the previous step. This ensures proper regeneration of the entire bed.

Fast Rinse-The final step in the regeneration cycle is fast rinse. Fast rinse is carried out to remove any residual brine from the resin bed and to eliminate the residual calcium and magnesium ions. A flow rate of 1.5 to $2 \mathrm{gpm}$ per cubic foot of resin bed is usually employed during the fast rinse.

At first, the fast rinse water will contain large amounts of calcium and magnesium chloride together with excess salt. Once the hardness ions are eluted and the excess salt is washed out by the rinse water, the bed is ready for operation. The unit is usually returned to service when the rinse water hardness falls below a desired value.

\section{Limitations of Strong Acid Resins 10}

Conventional strong acid resins do not hold the hardness ions very tightly, and a raw water containing sufficient sodium chloride will regenerate the resin while the resin is trying to remove calcium and magnesium. The result is hardness leakage even with a freshly regenerated resin bed. Thus, increased salinities affect strong acid softener performance by reducing the resin ion exchange capacity. Further, the hardness leaks through a strong acid resin bed are a function of TDS content of the feed and increase with the increase in raw water TDS. The hardness leakage from a conventional strong acid resin softener is shown in figure 5.6, as a function of raw water TDS for three different types of water. In figure 5.7, the capacity of strong acid resin is shown as a function of raw water TDS. From these it is clear that conventional strong acid resins cannot effectively soften water to zero hardness and that hardness leakage will occur even at low TDS.

Because of these limitations, regardless of added costs, other types of resins known to have sufficient affinity to remove hardness from high TDS water are increasingly being used in TEOR operations. These include weak acid resins and, to a lesser extent, chelating resins. Selectivity of chelating resins for hardness ions is several orders of magnitude higher than strong acid resins. However, unless the raw water is of such poor quality (highly brackish) that it is not possible to soften these waters economically using other resins, the use of chelating resins to soften water is not recommended. This is because these resins are very expensive, and their operating capacities are extremely low. These resins are not discussed in this report.

The selectivity of weak acid resins for divalent ions, though not as high as chelating resins, is much higher than the sodium zeolite resins. They are ideal for softening high TDS, high-hardness water such as the oilfield produced water. Weak acid resins, however, are relatively more 


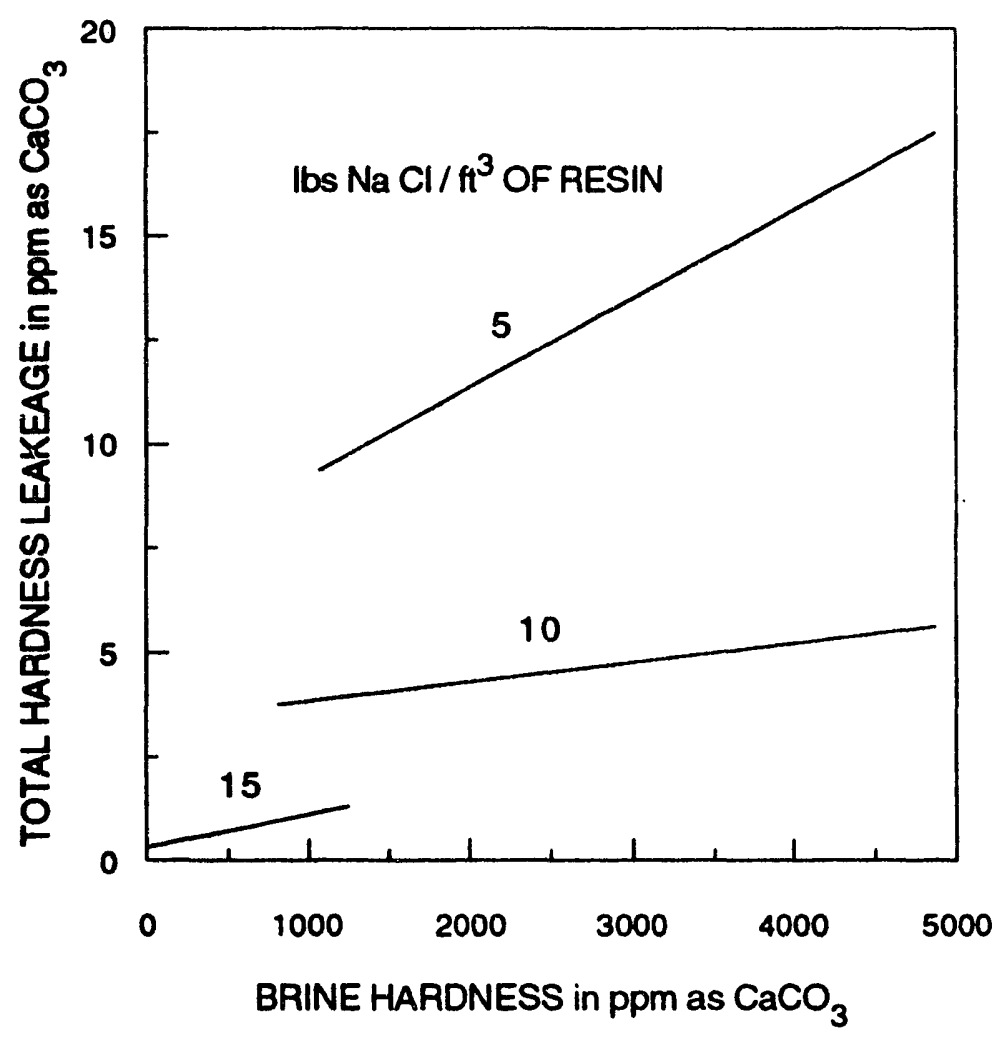

FIGURE 5.6. - Effect of water hardness and salt dosage on hardness leakage from primary beds. ${ }^{11}$

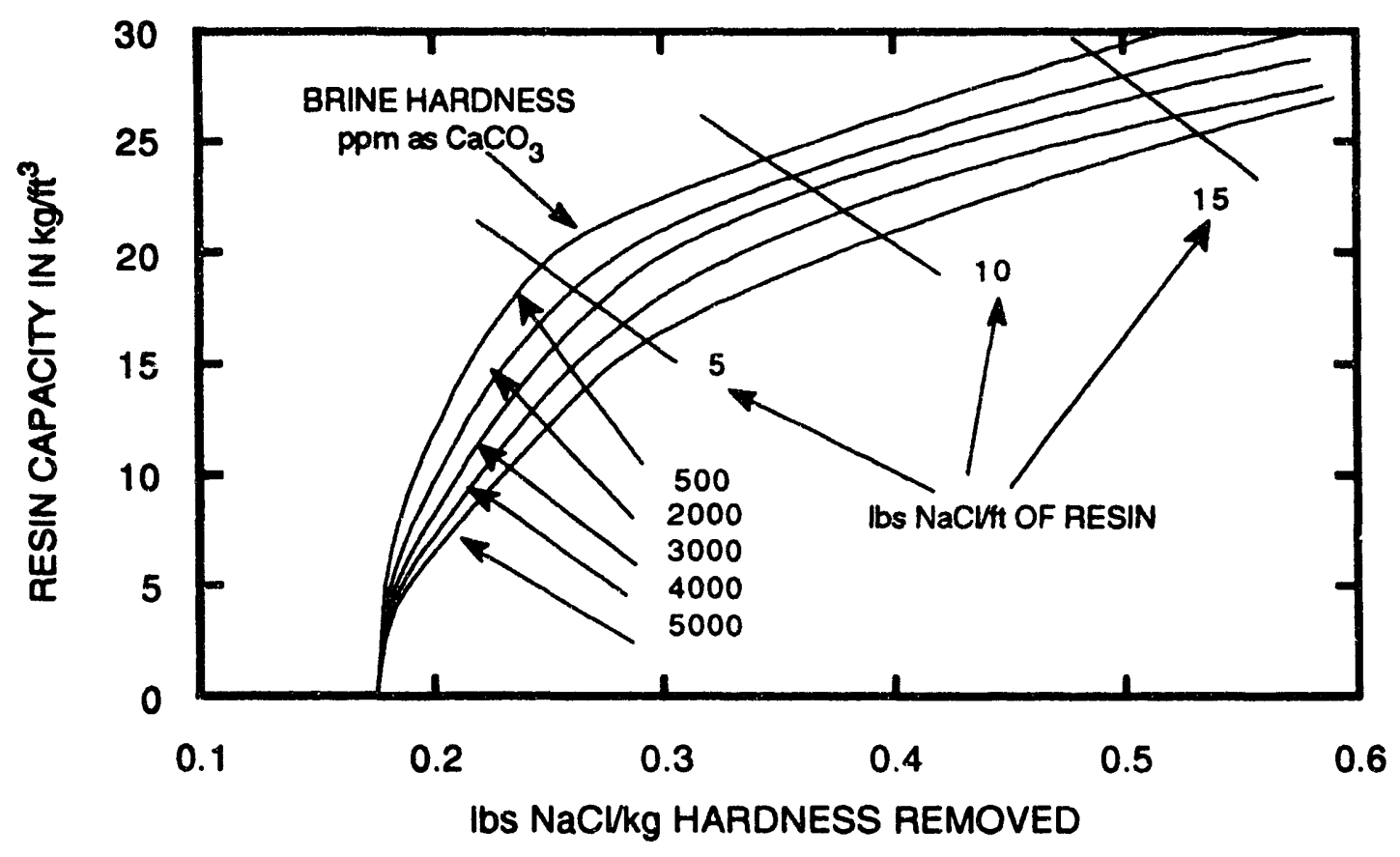

FIGURE 5.7. - Resin exchange capacity as a function of water hardness and salt dosage. ${ }^{11}$ 
expensive than the conventional strong acid resins and can be regenerated only with a strong acid such as hydrochloric or sulfuric acids. However, weak acid resins can be operated near $100 \%$ efficiency, and this will lower the regenerant requirements which generally results in a savings of regenerant and waste-handling costs. Since the goal is to obtain the most complete softening at minimum cost, raw water and softened water quality requirements usually dictate the resin choice.

\section{Weak Acid Resins 10}

Weak acid resins are derivatives of weak carboxylic acids such as acetic acid (vinegar) and are widely used in water-softening operations either in the sodium form or in the hydrogen form. The weak acid resins exhibit an immense selectivity preference for divalent (hardness) ions over monovalent (sodium) ions. The weak acid resins hold the hardness cations so tightly that they cannot be replaced by sodium. Since the most concentrated sodium chloride solution cannot dislodge the hardness ion from the resin, weak acid resins are very effective in removing hardness ions even in the presence of large quantity of sodium ions. Calcium and magnesium ions associated with a highly alkaline feedwater can be removed almost completely by weak acid resins.

Though both hydrogen and sodium forms of weak acid cation exchange resins are used in the water-softening industry, the sodium forms are preferable in oilfield water treatment applications because of their higher exchange capacity and selective preference for hardness ions. The weak acid cation exchange resins exhibit much higher affinity for hydrogen ions than for hardness ions; and hence, the hydrogen form of the resin is not as effective in lowering hardness ions from water as the sodium form. However, if the water is highly alkaline, it is possible to remove the hardness ions with the hydrogen form of the resin.

The hardness removal with the sodium form of weak acid cation resin can be expressed as follows:

$$
2 \mathrm{RCOO} \mathrm{Na}+\mathrm{CaCl}_{2} \Leftrightarrow(\mathrm{RCOO})_{2} \mathrm{Ca}+2 \mathrm{NaCl}
$$

The exhausted weak acid resins are usually regenerated with a strong acid such as hydrochloric acid or sulfuric acid. The resulting hydrogen form of the resin is then neutralized with sodium hydroxide to convert the resin to its sodium form. The regeneration reaction with hydrochloric acid and neutralization with sodium hydroxide is as follows:

\section{Regeneration}

$$
(\mathrm{RCOO})_{2} \mathrm{Ca}+2 \mathrm{HCl} \Leftrightarrow 2 \mathrm{RCOOH}+\mathrm{CaCl}_{2}
$$

\section{Neutralization}

$$
\mathrm{RCOOH}+\mathrm{NaOH} \rightarrow \mathrm{RCOONa}+\mathrm{H}_{2} \mathrm{O}
$$


Because of its strong preference for hydrogen ions, weak acid resins can be regenerated even with a very low acid concentration.

Hydrochloric acid is preferable to sulfuric acid as the regenerant. When sulfuric acid is used to regenerate the resin bed, calcium sulfate will precipitate. Because of the extreme insolubility of calcium sulfate, the cleaning will take considerable time. Calcium sulfate precipitation can be avoided by using a very dilute acid (below $1 \%$ ) and maintaining a very high flow rate. Regenerant efficiency, however, is rapidly lost at low concentration. Further, a high flow rate results in higher pressure drop and considerable force is exerted on the resin. The resin must have physical strength to withstand this force. Since most metal chlorides are water soluble, a high concentration of hydrochloric acid can be used in regenerating the bed. This not only eliminates the problems associated with sulfuric acid, but alsc lowers the regenerant storage and handling costs.

\section{Weak Acid Cation Exchange Resin Equipment and Operation}

The weak acid cation exchange unit is identical to the standard sodium zeolite unit. The only difference is that the weak resin system uses materials suitable for acid services. The resin tank, valves, piping, and fittings are fabricated out of acid resistant materials. The regenerant system is designed to handle acid, and several arrangements are provided for diluting the acids.

The operation of the weak acid resin bed is very similar to the sodium zeolite unit. The only major differences are the methods for determining the end of softening cycle and the use of hydrochloric (sulfuric) acid, rather than brine, as the regenerant.

\section{Limitation of Weak Acid Cation Exchange Resins 10}

Weak acid resin softeners are not very effective in removing the hardness from low alkaline water. The treated water will contain hardness if the raw water hardness exceeds the alkalinity. For example, when a raw water containing $100 \mathrm{ppm}$ alkalinity and $150 \mathrm{ppm}$ hardness is softened using weak acid resins, it will contain nearly 50 ppm hardness.

The sodium zeolite softener performance is not affected by the alkalinity of the raw water and is very effective in lowering the raw water hardness level. It is a common practice in steam injection operations for the sodium zeolite column to be followed by a weak acid softener to achieve total hardness removal. Since the hardness-to-alkalinity ratio of a sodium zeolite-treated water is much less than 1.0 , it is possible for complete hardness removal with a weak acid resin bed.

\section{Ion Exchange Unit Operation Problems $13-14$}

A properly designed and well-engineered ion exchange system normally operates troublefree, but problems can arise during the course of operation of the system. An abnormal loss of capacity of the resin bed, poor effluent quality, and decreases in chemical utilization efficiency are 
all indicative of ion exchange system operations problems. There are many possible causes for these problems, and corrective actions must be taken to alleviate them. In this section, ion exchange system-related operational problems and solutions are briefly reviewed.

The ion exchange system-related problems can be broadly grouped into the following classes: (a) ion exchange resin stability; (b) problems arising from changes in raw water quality; (c) problems associated with poor operational practices such as those resulting from the use of offspec regenerant and improper regeneration schedule; (d) mechanical problems; and (e) resin capacity failure due to fouling. Although hardness leakage is not an operational problem, it is discussed in this section because many of the operational problems result in hardness leakage.

\section{Resin Stability}

Cation exchange resins are highly stable and experience very little capacity loss during the life of an exchanger. Their useful life varies from 5 to 15 million gallons treated per cubic foot of resin. The resin degrades either due to physical breakdown by attrition or oxidation. Resin degradation will result in poor quality, treated water. In such cases, the resins must be replaced.

The life of the resins can be prolonged by minimizing or eliminating the oxidative conditions. The most frequently encountered oxidant in raw water is chlorine. When lake or river water is used as the feed, chlorine is usually added to the water to control slime and bacterial growth. Excess chlorine in raw water will oxidize the cation resin, causing the resin to become jelly-like. While oxidation does not affect the exchange sites, the mushy resins result in severe channeling and increased pressure drop. Excessive pressure drop through the bed or flow channeling results in significant reduction in ion exchange capacity and increased operational costs. Free chlorine in supply water should be measured and controlled to prolong resin life. Free chlorine concentration must be reduced to less than $1 \mathrm{ppm}$ by deaeration or chemical means. Resin breakdown can be minimized by avoiding excessive backwash. It is a good practice to replace annually about $10 \%$ of the resin bed to ensure trouble-free operation.

\section{Varying Water Quality}

It should be realized that the quality of raw water, particularly surface water (such as lake or river water), varies considerably between summer and winter and before and after rainfalls. These changes can affect the performance of an ion exchange unit. It is possible that the hardness of the water may have increased or a new troublesome ionic species has entered the raw water.

The resin capacity of each ion exchange system is determined by factors such as raw water hardness, resin volume, volume of water to be treated, and allowable hardness leakage. Hence, any change in the raw water hardness will disturb the hardness equilibrium between water and resin and affect the resin performance. For example, assume that a resin bed is designed to handle low hardness water of less than $500 \mathrm{ppm}$ as $\mathrm{CaCO}_{3}$. If the incoming raw water hardness is 
increased to $5,000 \mathrm{ppm}$, this would result in $10 \%$ loss in resin capacity. Otherwise, the hardness leakage through the bed would be increased by $10 \%$, and an expensive aftertreatment would be required to avoid generator tube scaling. Alternatively, by reducing the throughput in the bed or by increasing the salt dosage, the lost capacity can be restored. Hence, a periodic chemical analysis of the incoming water to the resin bed should be made for these difficulties to be anticipated.

\section{Poor Operational Practices}

Many times a loss of exchanger capacity can be traced to the use of poor quality regenerant chemical or incorrect chemical application. For example, use of mined salt containing less than 98\% sodium chloride as regenerant will lower the exchanger capacity. The use of a caustic soda containing high levels of iron in the neutralization step of the weak acid resin regeneration will result in chemically degraded resin. Specifications for regenerant chemical quality are given by the equipment manufacturer or the resin supplier. Only chemicals that meet these specifications should be used as regenerant.

Raw water flow rates and regenerant flow rates both influence the quality and quantity of water treated by ion exchange. Sometimes operators reduce the amount of salt used during the regeneration step to save a few dollars. This is poor economics and will result in high hardness leakage and generator tube scaling. There is an optimum concentration for each application, and manufacturers' recommendations should be followed.

\section{Mechanical Problems}

Mechanical failure or malfunctioning of ion exchange equipment may result in poor performance. Some of the more common mechanical problems are discussed in the following text.

Leaky valves are common sources of trouble in ion exchange system operation. Normally, raw water is used to backwash the system. Backwash water is introduced into the bed from the bottom at the same point where the effluent is normally withdrawn. An improperly seated multiport valve or a leaky backwash inlet valve could result in a bleeding of raw water into the effluent.

A broken or clogged distributor system is another trouble spot. Clogged distributors result in channeling and uneven distribution of water or regenerant. Poor water distribution results in premature breakthrough and off-quality effluent.

Underdrain system strainers and nozzles must be periodically inspected to ensure that they are not clogged or plugged. A clogged underdruin will restrict the backwash flow rate. A low backwash rate results in inadequate bed expansion and a dirty exchanger bed. The accumulated dirt will cause the bed to compact. Compaction results in severe channeling and increased pressure drop. High pressure drop across the unit will result in resin breakage. This problem compounds itself because the broken particles will further reduce bed permeability, causing additional 
compaction and more resin breakage and loss of capacity. A broken underdrain nozzle will result in excessive backwash flow and loss of resin.

The exchanger unit must be periodically inspected for mechanical deficiencies and corrective measures taken if needed. Since steamflood operation water treatment plant shutdown can be very costly, periodic checkouts are an insurance against trouble.

\section{Fouled Resins}

Ion exchange materials, at times, lose their effectiveness because of the accumulation of materials on their surfaces and in their pores. This accumulation of material, or fouling, is a result of an adsorption of contaminants present in the raw water, which is not completely removed during the normal backwash and regeneration steps. The substances that frequently foul ion exchange resins in oilfield operations include iron, oil, bacterial growth, and oxidants. The effects of these fouling agents on exchanger performance have been discussed in detail in a previous section. Fouling problems are best handled by good preventive measures.

Oxidant fouling agents such as free oxygen and chlorine can be eliminated at the source by adding a chemical scavenger such as sodium sulfite as far upstream as possible. Bacterial slime and algae can be controlled by closing the system to air and sunlight and adding a bactericide to the raw water. By eliminating oxygen pickup at the source, the iron pickup can be minimized. Injection of sodium sulfite will keep the iron in reduced form and eliminate iron fouling. Water containing excessive amounts of suspended matters must be filtered before softening. This is because the softening system has a limited ability to filter suspended matters and may be difficult to backwash. Fouled softener must be taken out of service periodically and backwashed several hours at the maximum permissible rate to dislodge and remove the adherent fouling agents. Iron fouled resins can be cleaned by washing the fouled resins with dilute hydrochloric acid or sodium hydrosulfite. Proper prewater treatment is the best insurance against fouling agent troubles.

\section{Hardness Leakage 5,7}

In the operation of a water softener, one of the first things that must be dealt with is the leakage of hardness ions through the ion exchange bed. As previously defined, the term hardness leakage implies a slipping of some of the hardness ions present in the feedwater into the softened water. Because of the nature of the sodium zeolite process, a certain amount of hardness leakage is inevitable; however, the leakage must be kept to a minimum. A small amount of hardness ion in boiler feedwater is acceptable because in the temperature range at which a steam generator operates, these ions remain in solution in the liquid phase of the wet steam. However, the degree of solubility of hardness ion varies according to the specific feedwater, and no generalization can be made. In some water, only $0.2 \mathrm{ppm}$ hardness leakage can be tolerated, while in others a $3 \mathrm{ppm}$ hardness can be tolerated. Reasons for these variations are unclear. Each feedwater must be 
checked to determine what hardness is tolerable at a given steam quality. A safe bet is to use zero hardness water, but complete elimination of hardness may not be economical in some installations.

Several factors are responsible for hardness leakage through a resin bed. Because of the need for the use of uneconomical excess regenerating chemical (salt) to completely regenerate the resin bed, the bed is never completely regenerated. Therefore, there is always some hardness ions present in the bed. These ions probably will leak during the subsequent softening cycle. Further, if the feedwater contains considerable sodium ion, the sodium will displace some of the calcium (hardness) ion previously removed from the feedwater. Consequently, the displaced calcium will be picked up by the softened water and hardness leakage occurs.

Sloppy operation and equipment malfunctioning also contribute to hardness leakage. Lessthan-satisfactory rinsing after regeneration will leave substantial amounts of hardness ions in the bed. These will show up in the effluent for a short time after regeneration. Additional rinsing is one way to solve this problem. A malfunctioning brine pump or meter can cause insufficient brine to flow through the bed during the brining operation and result in incomplete regeneration and hardness leak. A fouled resin bed will reduce the resin capacity and contribute to leakage. Poor backwash leads to bed compaction and channeling and results in hardness leakage.

Leakage is inevitable in the ion exchange system. Leakage, however, can be minimized by following prudent operating practices and improved design. By automating the zeolite water softener operation, operator errors can be eliminated, and the danger of hard water getting into the soft water lines can be avoided. Automation also permits each cycle to perform exactly the same way each time and eliminate insufficient backwashing or rinsing by maintaining proper flow rate and quantity. The system can also be made to shut down in the event of an equipment malfunction. In most large steam injection projects, the waier softening plant is fully automated and requires very little attention.

Leakage can also be minimized substantially and effluent quality improved by utilizing multistage units and by using strong acid-weak acid exchangers in tandem. Further, the resin bed should never be exhausted completely. The bed capacity begins to drop off and hardness leakage begins to increase as a greater fraction of the theoretical capacity of the bed is exhausted. Consequently, insofar as efficiency of regeneration is concerned, the bed should be operated only at a fraction of its designed capacity. While this will reduce hardness leakage, it also will increase the regeneration frequency and hence the operating cost. Therefore, a compromise must be reached between operating costs and the amount of hardness leakage that can be tolerated. It is recommended that the bed be exhausted to about $60 \%$ of its total capacity. This not only improves the performance and lowers regeneration chemical requirement but also prolongs the resin life. Also, by operating the exchanger below its rated capacity, the system will be able to accommodate 
a wide variation in the raw water quality. Pretreatment of raw water to remove suspended matter and to reduce soluble foulants will also improve resin capacity and reduce leakage.

\section{Water Treatment for Steam Injection Projects}

Source water determines the complexity of steam injection project water-treatment systems. Depending on the raw water source, systems range from a simple sodium zeolite ion exchange unit to a facility that includes clarifiers, coagulators, filters, skimmers, oil separators, coalescers, depurators, softeners, and deaerators. As a general rule, poorer water quality requires more elaborate treatments and higher treating costs.

The water sources and the water quality requirements for steam injection operations are discussed in previous sections. The general principles, operational techniques, and problems of ion exchange softeners, are outlined. The principal objectives of this section are (1) to explain the operational differences between the conventional cation exchange system and the one used in steam injection operations and (2) to summarize features of some other common water treating equipment and to offer some guidelines to their operation. Other topics discussed include: description of processes for the reclamation of produced water for steam generations, water treatment monitoring equipment, and water treatment costs.

\section{Steam Injection Water Softening System 12}

The oilfield cation exchange water softening system differs from the previously described conventional cation exchange system in two ways. Because of the stringent water quality requirements in steam injection operations, oilfield water-softening systems utilize a primarysecondary softener setup and a special upflow-downflow countercurrent regeneration technique to produce water with less than $0.25 \mathrm{ppm}$ hardness for steam generation. The steamflood water softening system consists of a primary exchanger which removes the bulk of the hardness from the water, followed by a polisher (secondary) unit which scavenges the last traces of hardness. Depending on the water requirements, two or more such trains (primary and polisher) are used to control water hardness. Oilfield water-softener systems are offered as fully self-contained, skidmounted units complete with two trains of softener vessels ( 2 primary and 2 polishers), brine meter, regeneraicion meter, valves and piping, control panel, and pumps.

The two trains are installed in parallel so that a continuous supply of softened water for steam generation is assured. Raw water passes through one of the primary exchangers and one of the polishing units in series to some point short of exhaustion of the resin in the primary bed. Then the used pair is regenerated automatically as the feedwater is diverted through the other pair. This operation is automated either by hardness-sensing devices or through an automatic time cycle. A schematic of the softeners and piping arrangement is shown in figure 5.8. The primary softeners 


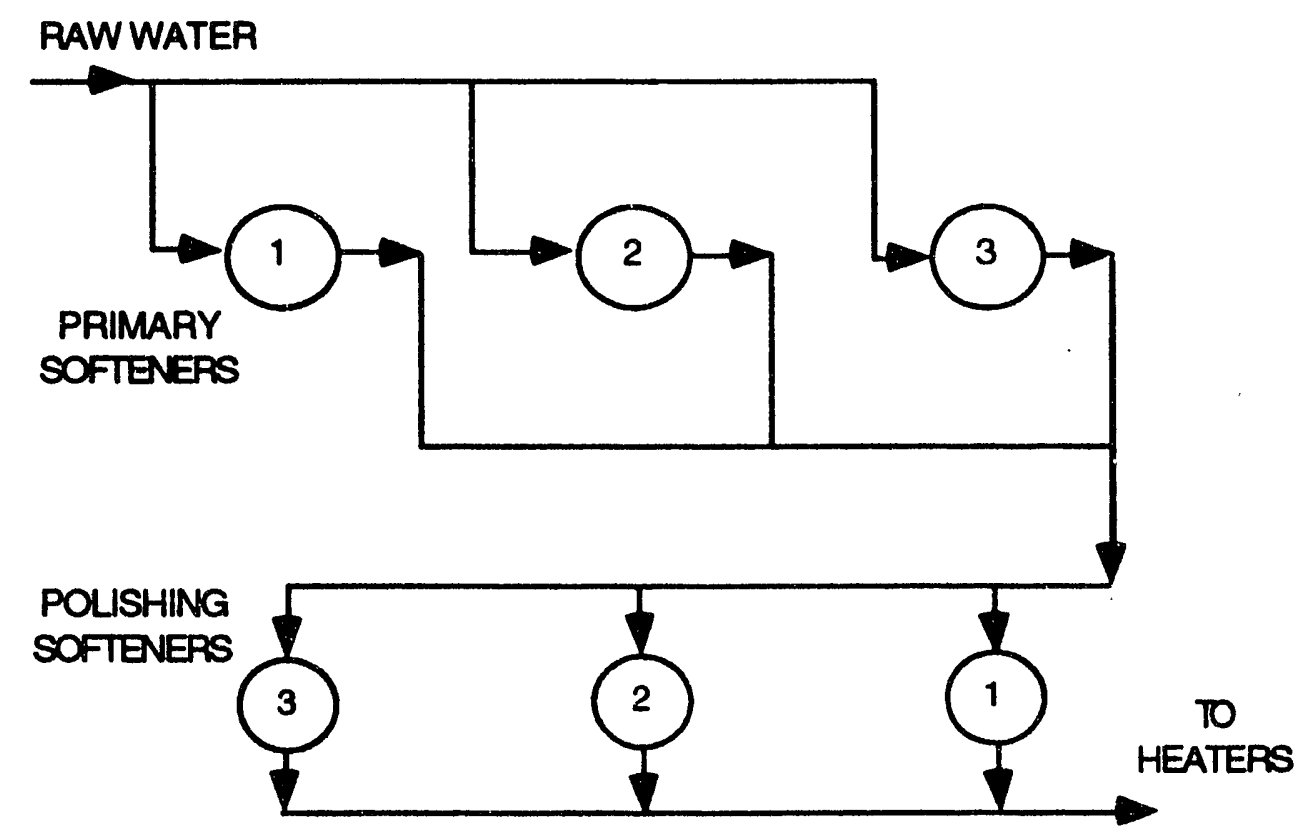

FIGURE 5.8. -Schematic of steam injection water softener piping arrangement.

produce into a common manifold. The polishing softeners receive the water from this manifold. Each primary and polisher train is regenerated independent of other trains. Flow schematics of the softening regeneration cycle is shown in figure 5.9. Note that soft water is used for backwashing and brining of polisher to minimize hardness leakage. Note also that countercurrent regeneration is used in the polisher to ensure complete regeneration at the bottom of the bed. Since portability is an important design factor, the softener train is usually oversized to cope with unexpected raw water quality changes. The softened water is usually stored in a galvanized or plastic-coated tank under a blanket of nitrogen to keep oxygen out. Water is usually gravity fed from this tank to a generator feed pump.

\section{Selection of Ion Exchange Resins 10}

Several factors influence the selection of ion exchange resins to be used in softening waters for thermal operations. These include the hardness and total dissolved solid contents of the raw water, the exchange capacity of the material, and the cost of regeneration. Both strong acid and weak acid cation exchange resins are used in a thermal operation water softening system. 


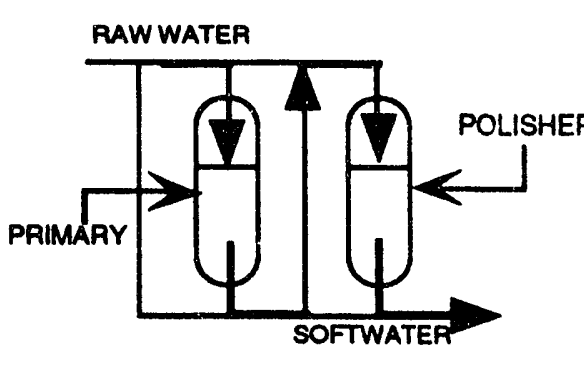

SOFTENING

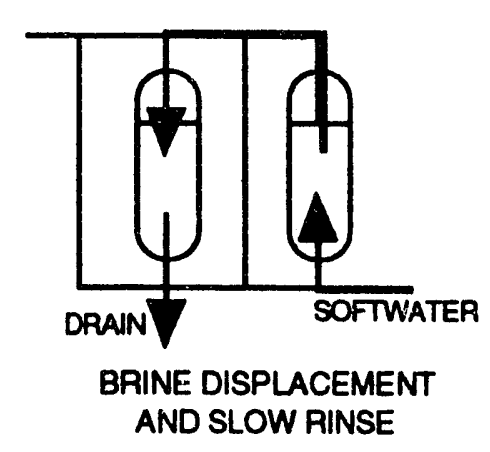

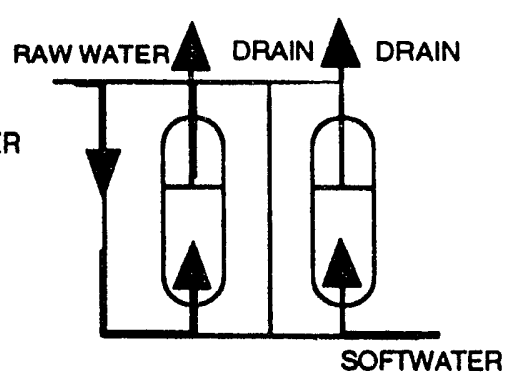

BACKWASHING

RAW WATER

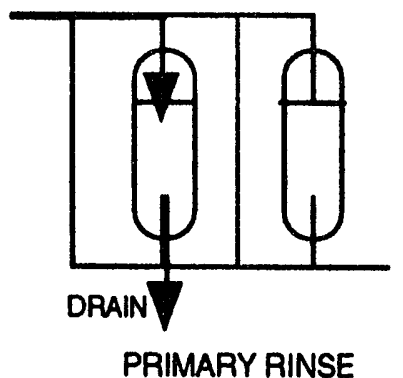

PRIMARY RINSE

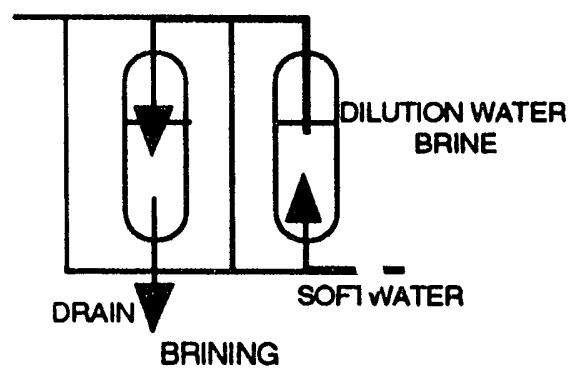

RAW WATER

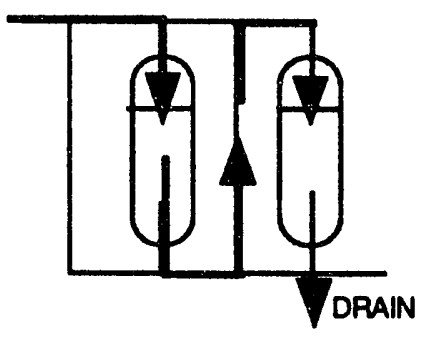

POLISHER RINSE

FIGURE 5.9. - Flow schematics of steamflood ion exchange softener regeneration cycle. 12

Experimental studies indicate that the strong acid cation exchangers are not satisfactory to soften waters containing greater than 5,000 ppm TDS. Weak acid cation exchange resins have much higher capacity and can be used to soften water containing up to 20,000 ppm TDS. Water containing up to 10,000 ppm TDS can be softened using a strong acid cation resin in the primary unit, followed by a weak acid cation resin in the polisher. Because of the effectiveness of the weak acid polisher, a higher than normal hardness leakage from the primary unit can be tolerated without sacrificing the quality of the final product from the polisher. The amount of salt, hydrochloric acid and sodium hydroxide (regenerant chemicals) required will depend on the extent of hardness breakthrough from the primary. Table 5.7 shows a general rule-of-thumb for selecting ion exchange resins for thermal EOR operations. This table can be used as a guideline in selecting a system. 


\section{Ion Exchange Calculations}

The basic calculations which will be needed for sizing an ion exchange system for a steam injection operation are given in Table 5.8.

\section{Use of Chelating Agents 6,9}

The present day ion exchange systems used in steam injection operations can reduce the total hardness below $0.1 \mathrm{ppm}$. However, even with this low hardness there is danger of scale formation in a steam generator, especially if silica is present (the problem of silica scaling is discussed in a later section). Some operators, who prefer zero hardness, use a chelating agent to pick up any remaining calcium or magnesium ions to assure a scale free operation, while others use nothing beyond the ion exchange.

Chelation is an equilibrium reaction between a metal ion and a complex organic chemical to form a soluble complex of metal ions in the presence of anions that would normally cause the cation to precipitate. The chelation reaction is generally referred to as sequestration and the chelating chemical, a sequestering agent. Many chemicals are known to form soluble complexes with calcium and magnesium ions. In steam injection operations, the most common chelating agent used to prevent the hardness ions from forming scales is the sodium salt of ethylenediamine-tetra

TABLE 5.7. - Rules-of-Thumb for Selection of Ion Exchange Resins for Oilfield Steam Generator Feedwater Softener 10

\begin{tabular}{rrl}
\hline \multicolumn{1}{c}{ TDS } & Hardness & \multicolumn{1}{c}{ Resin } \\
\hline$<2,000$ & $<700$ & Strong acid resin (no polisher) \\
$700-5,000$ & $<700$ & Strong acid resin with polishei unit \\
$5,000-10,000$ & $<500$ & Weak acid resin (no polisher) \\
$5,000-10,000$ & $500-1,500$ & Primary strong acid resin bed with weak acid \\
& & polisher unit \\
$50-15,000$ & $1,500-3,000$ & Weak acid resin (with polisher) \\
\hline
\end{tabular}


1. Sodium to hardness ratio $(\mathrm{Na} / \mathrm{H})$

$$
\mathrm{Na} / \mathrm{H}=2.17 \frac{\mathrm{Na}, \mathrm{mq} / \mathrm{L}}{\text { Hardness, } \mathrm{mg} / \mathrm{L} \text { as } \mathrm{CaCO}_{3}}
$$

2. Exchange capacity (EC), $\mathrm{kgr} / \mathrm{ft}^{3}$

$$
\mathrm{EC}=5.81 \times 10^{-3} \frac{\mathrm{FWV}(\mathrm{TH}-\mathrm{LH})}{\mathrm{RV}}
$$

where FWV $=$ feedwater volume, gallons

$\mathrm{TH}=$ total hardness in feedwater, $\mathrm{mg} / \mathrm{L}$ as $\mathrm{CaCO}_{3}$

$\mathrm{LH}=$ leakage hardness in softened water, $\mathrm{mg} / \mathrm{L}$ as $\mathrm{CaCO}_{3}$

$\mathrm{RV}=$ resin volume, $\mathrm{ft}^{3}$

and $\quad 5.81 \times 10^{-3}$ is a conversion factor

3. Regeneration cost (RC) $\% / b b l$ for both $100 \%$ strong acid resin systems and 100\% weak acid resin systems.

$$
\mathrm{RC}=\mathrm{RC}=0.00244 \frac{\mathrm{CR}(\mathrm{TH}-\mathrm{LH})}{\mathrm{EC}}
$$

where $\mathrm{CR}=$ cost of regenerants, $\mathrm{e} / \mathrm{ft}^{3}$

$\mathrm{TH}=$ total hardness in feedwater, $\mathrm{mg} / \mathrm{L}$ as $\mathrm{CaCO}_{3}$

$\mathrm{LH}=$ leakage hardness in softened water, $\mathrm{mg} / \mathrm{L}$ as $\mathrm{CaCO}_{3}$

$\mathrm{EC}=$ exchange capacity, $\mathrm{kgr} / \mathrm{ft}^{3}$

and 0.00244 is a conversion factor

4. Regeneration Cost ( $\mathrm{RCC}), \Varangle / b b l$ for combined strong acid resin/weak acid resin systems.

RCC, $₫ / \mathrm{bbl}=$ Cost for Strong Acid Resin + Cost for Weak Acid Resin

$$
=0.00244 \frac{\mathrm{CRS}(\mathrm{TH}-\mathrm{LH})}{\mathrm{ECS}}+0.00244 \frac{\mathrm{CRW}(\mathrm{LH})}{\mathrm{ECW}}
$$

where $\quad$ RS $=$ cost of strong acid resin regenerant, $₫ / \mathrm{ft}^{3}$

$\mathrm{TH}=$ total hardness of feedwater $\mathrm{mg} / \mathrm{L}$ as $\mathrm{CaCO}_{3}$

$\mathrm{LH}=$ hardness leakage from strong acid resin, $\mathrm{mg} / \mathrm{L}$ as $\mathrm{CaCO}_{3}$

$\mathrm{ECS}=$ strong acid resin exchange capacity $\mathrm{kgr} / \mathrm{ft}^{3}$

$\mathrm{CRW}=$ cost of weak acid resin regenerate, $\notin / \mathrm{ft}^{3}$

$\mathrm{ECW}=$ weak acid resin exchange capacity, $\mathrm{kgr} / \mathrm{ft}^{3}$

and 0.00244 is a conversion factor.

5. Bbl water softened $/ \mathrm{ft}^{3}$ resin $=409 \frac{\mathrm{EC}}{(\mathrm{TH}-\mathrm{LH})}$

where $\mathrm{EC}=$ exchange capacity, $\mathrm{kgr} / \mathrm{fl} 3$

$\mathrm{TH}=$ total hardness of feed water, $\mathrm{mg} / \mathrm{L}$ as $\mathrm{CaCO} 3$

$\mathrm{LH}=$ leakage hardness in softened water, $\mathrm{mg} / \mathrm{L}$ as $\mathrm{CaCO} 3$

and 409 is a conversion factor. 
acetic acid (EDTA). EDTA does not eliminate hardness, but only prevents it from forming scales. EDTA is preferred to other chelating agents because of its thermal stability.

The amount of EDTA necessary to complex $1 \mathrm{ppm}$ of calcium ion depends on which sodium salt of EDTA is used. The amounts of various EDTA ss:lts necessary to complex 1 ppm of hardness ion and the solvhility of the EDTA salts in water are shown in Table 5.9. Even though the amount of tetra sodium EDTA necessary to complex $1 \mathrm{ppm}$ of the cation is higher than the other varieties, it is used almost exclusively in the steam injection applications because of its higher solubility.

A 38\% solution of these salts is most commonly used in the steam injection application. To ensure complete chelation of the hardness ions, an excess (10 to $15 \mathrm{ppm}$ ) of the chelating agents is carried in the process water. The EDTA is diluted and stored in a 55-gallon polyethylene drum. A reciprocating metering pump is used to inject the EDTA directly into the waterline immediately upstream of the steam generator feedwater pump.

One important consideration in EDTA use is its effect on corrosion. EDTA, at generator pH. and reducing conditions, will chelate iron and corrode boiler tubes. Hence, addition of EDTA should be closely controlled to pievent excess. It should be added to the feedwater line so that it is well diluted before reaching the generator.

California steam injection field experience indicates that complete hardness removal is not necessary, and a small amount of hardness in the feedwater is acceptable. Unfortunately, the maximum acceptable level of hardness in the feedwater without scaling the generator varies with the feedwater and must be established for each feedwater. Chelating agent such as the EDTA. should be used only if the acceptable level of hardness cannot be achieved economically with the ion exchange process.

TABLE 5.9. - Concentration of EL'TA and its Sodium Salts Necessary to Complex 1 ppm of Hardness Ion 42

\begin{tabular}{|c|c|c|c|}
\hline \multirow[t]{2}{*}{ Chelating agent } & \multirow{2}{*}{$\begin{array}{c}\text { Solubility } \\
\text { in water } \\
80^{\circ} \mathrm{F} \\
\mathrm{gm} / 100 \mathrm{~cm}^{2} \mathrm{H}_{2} \mathrm{O}\end{array}$} & \multicolumn{2}{|c|}{$\begin{array}{l}\text { ppm necessary to complex } \\
\text { I ppm hardness ion }\end{array}$} \\
\hline & & $\mathrm{Ca}^{++}$ & $\mathrm{Mg}^{++}$ \\
\hline Ethylenediemine tetra actic acid & 0.02 & 7.4 & 12.0 \\
\hline $\begin{array}{l}\text { Disodium ethylenediaminetesra acetate } \\
\text { dihydrate }\end{array}$ & 11.1 & 9.5 & 15.4 \\
\hline $\begin{array}{l}\text { Trisodium effylenediaminetetra scetate } \\
\text { monobydrate }\end{array}$ & 57.0 & 9.6 & 15.6 \\
\hline $\begin{array}{l}\text { Tetra sodium ethylenediaminetetra acetate } \\
\text { dibydrate }\end{array}$ & 103.0 & 10.4 & 16.9 \\
\hline
\end{tabular}




\section{Hardness Monitors 17}

Monitoring hardness is essential for successful treatment. Tests for hardness should be run at least once each shift. Ideally, hardness should be monitored continuously, in addition to periodic manual tests.

A number of different approaches are used to monitor and control hardness. Th $\approx$ most basic and inexpensive is the analytical approach. The simplest hardness monitoring tool samples the softened water at frequent intervals (10 minutes or so) and indicates whether the measured hardness is above or below the setpoint. In most models, 1, 3, 5 and $7 \mathrm{ppm}$ are used as the setpoints.

Since this instrument is basically a titration apparatus, practically no maintenance is needed. However, technician must periodically check the instrument to assure its proper operation. The capacity of the reagent reservoir is sufficient to perform about 1,500 analyses and can be refilled in a matter of minutes.

A more useful hardness monitoring instrument is the one that not only monitors hardness, but also takes appropriate action to control it. A number of manufacturers market hardness monitors that are designed to regulate hardness. These instruments are basically automatic titrators fitted with an actuating mechanism designed to take appropriate action in the event the hardness exceeds the preset value. Depending on the model, the actuator will sound an alarm and/or actuate automatic regeneration equipment for zeolite softener. Some models will also shut down the steam generator. Units are usually calibrated for setpoints from 0.25 to $3.0 \mathrm{ppm}$ hardness.

A more sophisticated hardness regulator uses colorimetric principles to control hardness. These are simple single reagent colorimetric analyzers designed to measure the intensity of the color developed by the addition of reagent to the sample. The intensity is proportional to the hardness and is indicated on a direct reading meter as ppm hardness. A schematic of one such colorimetric analyzer is shown in figure 5.10. These instruments usually analyze and record hardness every 2 minutes. Most models are also equipped with a signal generator (pneumatic or electrical) to start automatic zeolite regeneration or to shut down the generator.

\section{Overview of Other Water Treatment Equipment18-19}

Besides ion exchange vessels, a wide variety of water-treating equipment is used in steam injection projects. The types of equipment depend very much upon the type of operation. Not all steam injection operators separate produced oil and water. A small operator may merely choose to produce the oil on his lease by steam injection and transfer the produced fluids for further processing to a facility equipped to handle the produced fluids. In such cases, no equipment other than an ion exchange system will be needed if the operator chooses to produce his own steam 


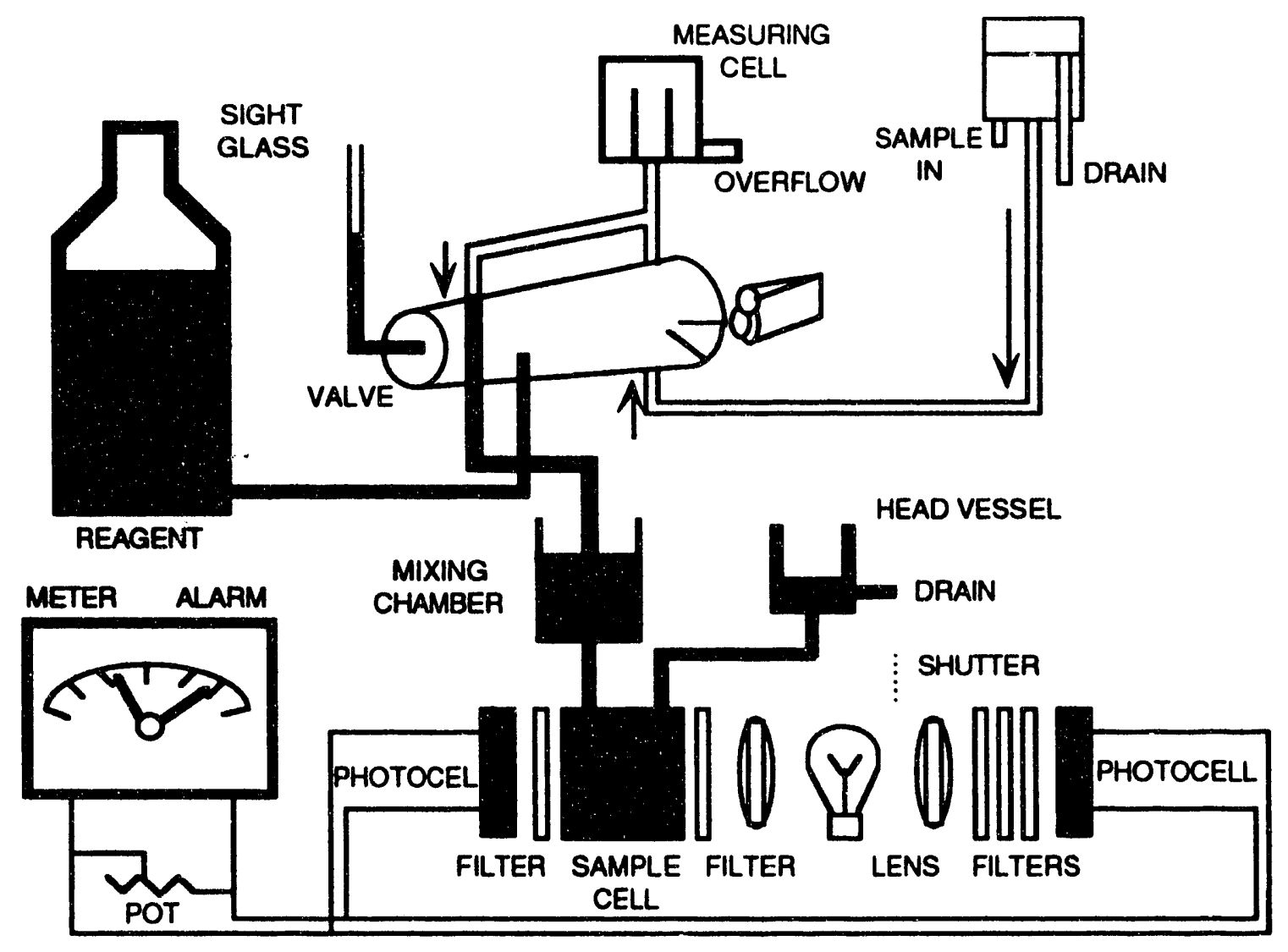

FIGURE 5.10. - Schematic of an automatic hardness monitor. ${ }^{17}$

using fresh water. On the other hand, in most larger steam injection operations, the produced water is usually reclaimed and used as the generator feed. Even when the produced water is not used as the generator feed, it must be processed and rendered suitable for disposal. In either case, an assortment of equipment will be needed to remove the impurities from the water.

The usage and operation of various water-treating equipment is summarized according to the process. Factors which must be considered in the equipment choice and/or design are enumerated. Processes covered include gravity separation, flotation, filtration, and dissolved gas removal.

\section{Oil and Solid Removals}

Produced water usually contains oil and suspended solids. These must be removed before the water can be properly disposed of. Oil removal is basic to all disposal processes involving oilfield water, although the necessary completeness of oil removal may vary widely depending on the end use. In California's San Joaquin Valley, much of the produced water is fresh enough that it is used as generator feedwater after proper treatment. Also, in Kern River oilfield, part of the produced water after treatment is used for irrigation of farm crops. 
Like the conventional waterflood operation, the produced fluids from the wellhead in the steam injection operations is sent to the oil dehydration plant for separation into oil and water. The separated water is sent to the water treatment plant for further processing. This discussion begins at this point, as this section is concerned with the treatment of produced water, not oil dehydration. Oil dehydration operations are discussed elsewhere in this report.

The degree to which the oil and solids must be removed from produced water depends on the ind use water quality requirements. If the water is to be used as steam generator feed, total removal of oil and solid is a must. If the waters are to be disposed of or used as irrigation water, complete oil and solid removal is not necessary. Depending on the local regulations, the oil content of treated water is permitted to vary from a low of $10 \mathrm{ppm}$ to as high as $40 \mathrm{ppm}$.

There are three practical methods of removing oil and solids from water. Each has its distinct place in water treatment. The three methods are gravity separation, flotation, and filtration.

\section{Gravity Separation}

When a mixture of oil and water is allowed to stand, it will separate into two distinct phases because of the differences in density between oil and water. This process is highly effective with low-density (high API gravity) oils but becomes less effective with low API gravity oils. This is because the density difference between water and oil determines the driving force causing separation of oil and water into two phases.

Oil and water are separated in settling basins. Settling basins were used in large California steam injection projects in the early 1970 s to clarify produced water from dehydration plants. The introduction of highly effective induced gas flotation cells (depurators) in 1970 for the removal of suspended oil from produced water practically eliminated the need for settling basins in steamflood operations. Unlike the settling basins, flotation cells require only a minimum of space for largecapacity throughput and can handle emulsions. Settling basins are rarely used in present day steam injection operations. However, it is advisable to use a small skid-mounted API type oil-water separator or skim tanks upstream of the depurator to handle any unexpected oil load in feedwater because of dehydration plant upsets.

The subject of gravity separation of oil and water has been covered in detail in an API publication. 20 This publication sets forth clearly the design and operational requirements of settling basins and should be consulted for details.

\section{Flotation}

Flotation is a process in which a gas is used in a mechanical system to give a lift to suspended oil or solids. Two types of flotation machines are used in the oilfield: (a) dissolved gas (or air) flotation (DGF) machine and (b) induced gas (or air) flotation (IGF) machine. 
Dissolved Gas Flotation: ${ }^{21}$ The dissolved gas tlotation (DGF) process has been used in the oilfield for a number of years in the removal of oil and suspended solids from produced water. The process involves contacting the water in a pressurized chamber with air or nitrogen. The volume of gas dissolved in the water is directly proportional to the applied pressure. Chemicals are usually added to the water to facilitate higher degrees of removal. Adequate retention time must be provided in the dissolving tank for the gas to dissolve in water. The operating pressure usually varies from 40 to $90 \mathrm{psi}$, depending on the application. Schematics of a typical DGF unit are shown in figure 5.11 .

After water has been saturated with gas, the gas-water mixture is transferred to the flotation chamber through a pneumatic pressure relieving valve. When the pressure is relieved, gas comes out of solution, forming minute bubbles. These bubbles then attach themselves to the suspended oil or solid particles. Adhesion of gas bubbles to the suspended particles results in the reduction of their specific gravity. This reduction of the effective specific gravity causes the particles to rise to the surface of the flotation cell. The accumulated surface mass is removed by rotating scraper arms into a launder for removal. The clarified water is discharged into an effluent tank. The efficiency of a DGF machine is of the order of 75 to $80 \%$.

Though DGF machines are very efficient in removing suspended oil from water, their efficiency suffers when the oil load exceeds $100 \mathrm{ppm}$ and emulsion exists. As the incoming oil load increases, increasing amounts of oil are left in the water. The disposal of sludges created by the DGF machine is a problem in itself. Since the maximum flow capacity of these types of machine is usually limited to aboli $2.0 \mathrm{gpm} / \mathrm{t}^{2}$ of surface area, they require large real estate.

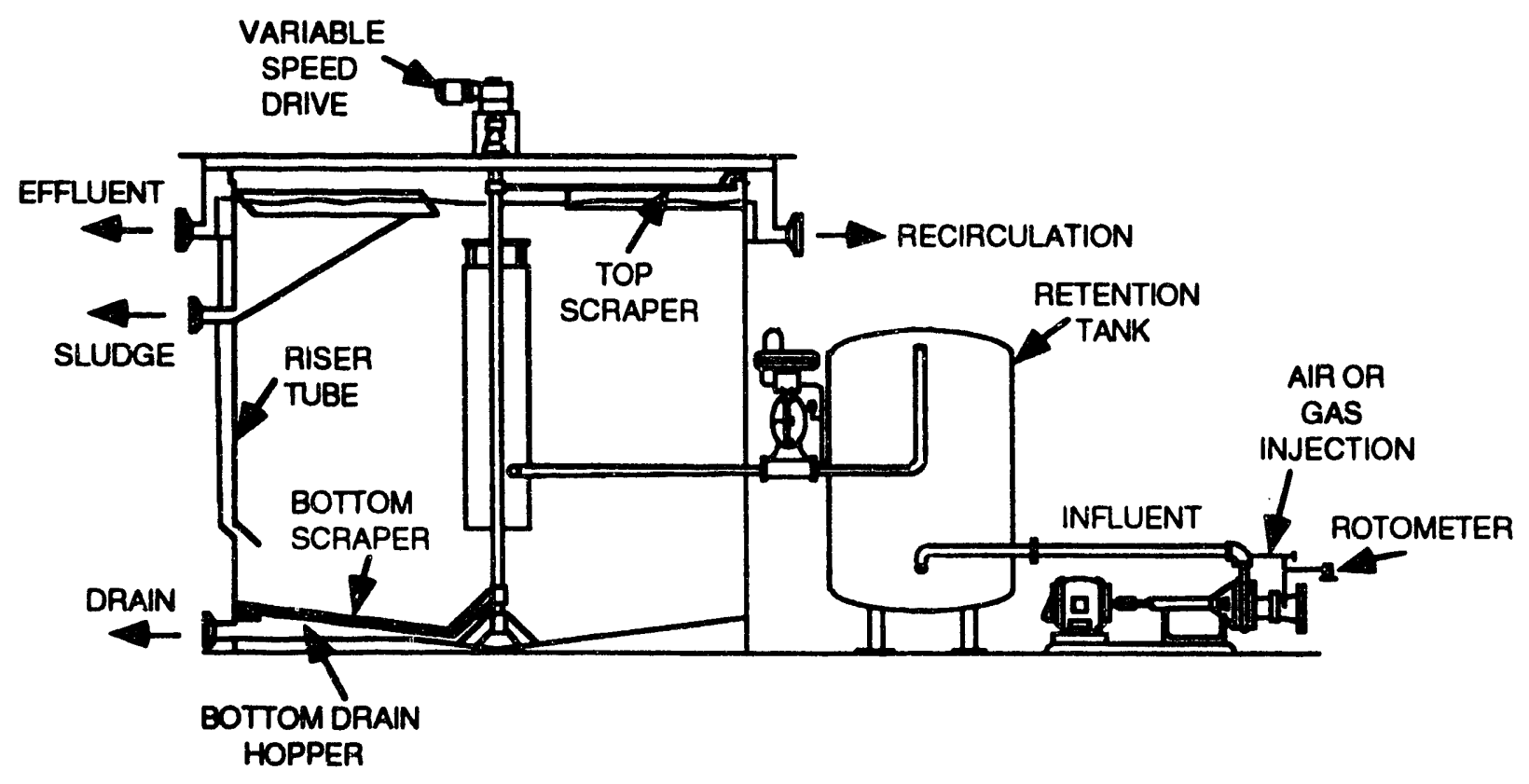

FIGURE 5.11. - Schematic of a typical dissolved gas flotation unit. 40 
Once popular in the oil patch, DGF machines are increasingly being replaced by induced gas flotation (IGF) machines, which are much more efficient than DGF machines and can handle much higher contaminant levels. The IGF machines do not create sludge and require much smaller space compared to DGF machines because of larger throughput.

\section{Induced Gas Flotation 22-23}

The shortcomings of the dissolved gas flotation cell, necessitated the need for a process that clarifies an emulsion-containing oilfield water efficiently and economically. This led to the development of the induced gas flotation process. An IGF cell is basically a froth flotation cell (used in the benefication of ore in the mining industry) modified for oilfield application. The induced gas flotation machine is a natural aspirating shear force flotation cell designed to lower the oil content of water efficiently. Since its introduction in late 1969 in a California steam injection operation, the IGF machine became the primary treatment unit for the clarification of produced water in steam injection operations. The induced gas flotation cells are commonly referred to as 'depurator' in the oil patch. The depurators are very effective in the removal of emulsified oil and suspended solids from produced water. They also lower the oxygen content of the water, if gas other than air is used in their operation. The depurator, together with a chemical flotation reagent, can remove oil and suspended solids from the water quickly and economically. Present day depurators can process in excess of 170,000 barrels of water per day containing up to $1,500 \mathrm{ppm}$ oil.

\section{Operation Principle 24}

The depurator typically consists of four flotation cells connected in series, with each cell having 1 minute retention time; 4 minute retention time for the entire machine. A schematic of a machine developed by WEMCO Corporation (the most popular IGF machine in the United States) is shown in figure 5.12. Table 5.10 shows the specifications and dimensions of these machines. These are included here to illustrate the range in capacities and overall dimensions of these units, but their inclusion does not necessarily imply endorsement.

Each cell is equipped with a motor-driven, self-aerating rotor mechanism. As the motordriven rotor spins rapidly, it acts as a pump and draws in gas from the gas blanket above the water, and the water from below and forces them through a dispenser at high velocity. This creates a shearing force and causes the gas to be broken up into a myriad of minute bubbles. As these bubbles rise to the surface, oil particles and solids attach to the interface of the gas bubbles. The oil and suspended solids gather in a dense froth at the surface and are removed from the cell by skimmer paddles into a float flume for collection and treatment. 


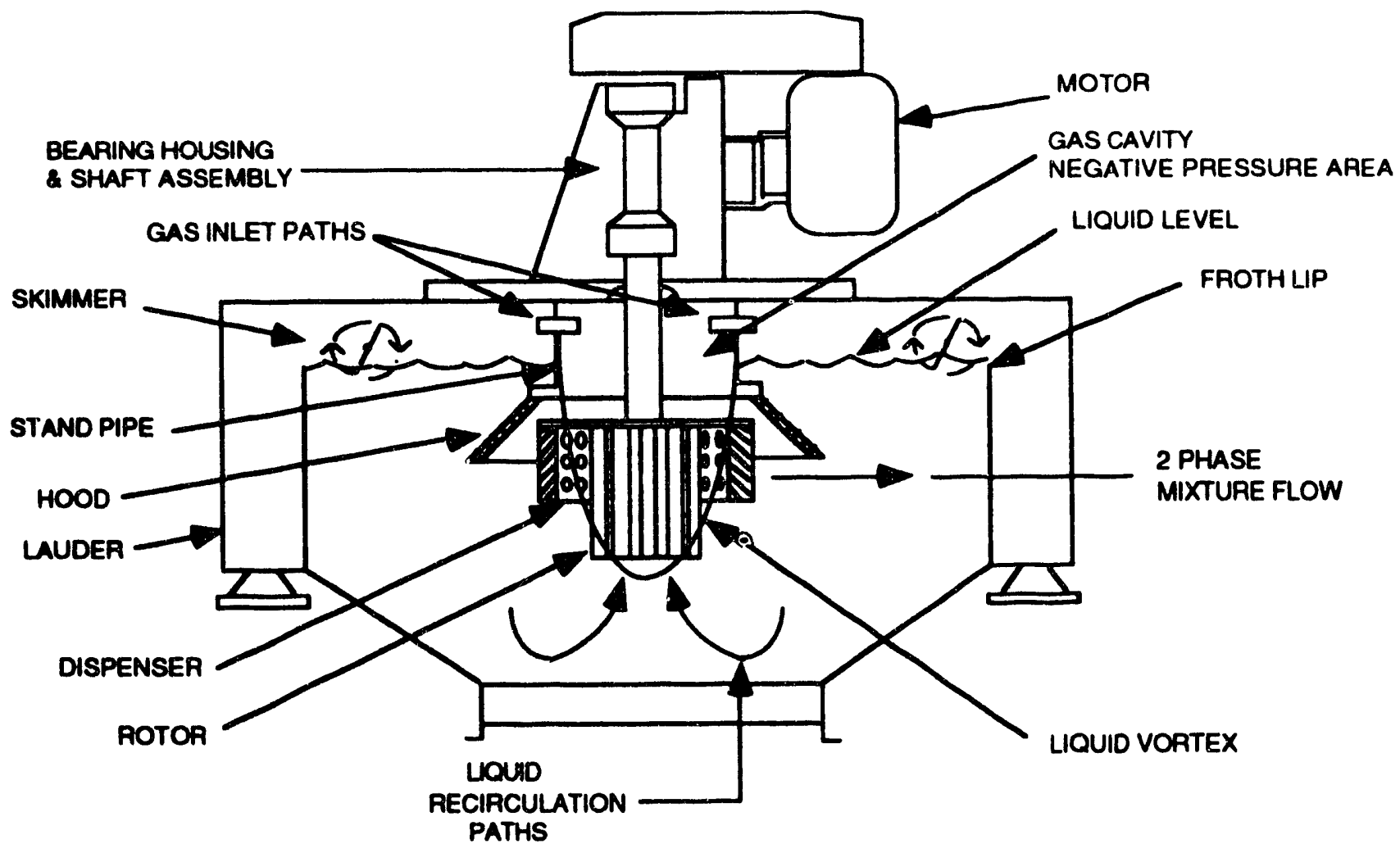

FIGURE 5.12. - Schematic of an induced gas flotation cell. 24

TABLE 5.10. - Induced Gas flotation Cell Selection Chart ${ }^{24}$

\begin{tabular}{|c|c|c|c|c|c|c|c|}
\hline \multicolumn{2}{|c|}{ Capagity } & \multirow{2}{*}{$\begin{array}{l}\text { Rotor, } \\
\text { rpm }\end{array}$} & \multirow{2}{*}{$\begin{array}{c}\text { Total } \\
\text { horsepower }\end{array}$} & \multicolumn{3}{|c|}{$\begin{array}{l}\text { Approx. } \\
\text { dimension }\end{array}$} & \multirow{2}{*}{$\begin{array}{l}\text { Approx. } \\
\text { Wt, lb }\end{array}$} \\
\hline & & & & L & $\mathbf{w}$ & H & \\
\hline $\begin{array}{r}50 \\
150 \\
300 \\
450 \\
750 \\
1,125 \\
2,250 \\
3,000 \\
5,000\end{array}$ & $\begin{array}{r}1,720 \\
5,150 \\
10,300 \\
15,450 \\
25,725 \\
38,585 \\
77,175 \\
103,000 \\
171,400\end{array}$ & $\begin{array}{l}559 \\
437 \\
380 \\
336 \\
289 \\
264 \\
220 \\
220 \\
194\end{array}$ & $\begin{array}{l}12.25 \\
12.5 \\
20.5 \\
30.5 \\
40.5 \\
60.5 \\
100.5 \\
100.5 \\
120.5\end{array}$ & $\begin{array}{l}14^{\prime}-5^{\prime \prime} \\
21^{\prime}-0^{\prime \prime} \\
26^{\prime}-6^{\prime \prime} \\
30^{\prime}-8^{\prime \prime} \\
35^{\prime}-8^{\prime \prime} \\
34^{\prime}-2^{\prime \prime} \\
40^{\prime}-8^{\prime \prime} \\
53^{\prime}-2^{\prime \prime} \\
64^{\prime}-2^{\prime \prime}\end{array}$ & $\begin{array}{r}3^{\prime}-7^{\prime \prime} \\
4^{4}-11^{\prime \prime} \\
6^{\prime}-9^{\prime \prime} \\
6^{\prime}-9^{\prime \prime} \\
7^{\prime}-11^{\prime \prime} \\
8^{\prime}-11^{\prime \prime} \\
11^{\prime}-11^{\prime \prime} \\
11^{\prime}-11^{\prime \prime} \\
11^{\prime}-11^{\prime \prime}\end{array}$ & $\begin{array}{c}6^{\prime}-10^{\prime \prime} \\
8^{\prime}-8^{\prime \prime} \\
9^{\prime}-7^{\prime \prime} \\
9^{\prime}-9^{\prime \prime} \\
9^{\prime}-9^{\prime \prime} \\
12^{\prime}-2^{\prime \prime} \\
14^{\prime}-10^{\prime \prime} \\
14^{\prime}-10^{\prime \prime} \\
15^{\prime}-2^{\prime \prime}\end{array}$ & $\begin{array}{r}5,500 \\
10,000 \\
12,500 \\
14,700 \\
19,000 \\
23,000 \\
39,000 \\
54,000 \\
59,000\end{array}$ \\
\hline
\end{tabular}


A polymer or other flocculation enhancer is often added upstream of the depurator to improve its efficiency. These compounds also break oil-in-water emulsions, gather suspended solids, and stabilize the gas bubbles to promote froth flotation. In thermal operations, nitrogen or natural gas instead of air are used to form the bubbles. A pressure of 0.5 to 1.0 ounce maintains a gas blanket between water level and the air-tight cover. The absence of oxygen prevents the bacterial growth and retards corrosion. The gas is recycled, requiring only about 0.1 to $0.2 \mathrm{cu} \mathrm{ft} / \mathrm{bbl}$ makeup gas.

The depurators are highly efficient in cleaning the oily water. The efficiency of an IGF machine is of the order of $95 \%$ and stays at that level even at high contamination levels. The oil concentration of the inlet water is usually lowered from about $400 \mathrm{ppm}$ to less than $20 \mathrm{ppm}$. Table 5.11 gives the oil reduction achieved in selected California steam injection operations using the depurator. These machines, however, do lose efficiency as the oil concentration in the coater exceeds 1,500 ppm and may fail completely if considerable amounts of oil (greater than 5,000 $\mathrm{ppm}$ ) come through. This is because the free oil inhibits the formation of foam which, of course, destroys the flotation action. If the produced water contains dissolved iron, it can be removed in the flotation process by using air in the first cell and nitrogen in subsequent cells. Methane is usually used to purge the air and maintain a positive gas pressure in the freeboard area of subsequent cells. The air will oxidize the dissolved iron and remove it as ferric hydroxide.

Since the IGF machines are very efficient in removing the oil from the produced water, they should be considered by operators contemplating the use of produced water for steam generation, or for surface discharge. Depurators offer maximum cleaning ability with minimum space requirement. However, before a depurator can be recommended for a specific application,

TABLE 5.11. - Feedwater Oil Reduction Achievable Using a Depurator ${ }^{24}$

\begin{tabular}{|c|c|c|c|c|c|}
\hline \multirow[b]{2}{*}{ Field location } & \multirow[b]{2}{*}{$\begin{array}{c}\text { Depurator } \\
\text { capacity, } \\
\text { bbl/d }\end{array}$} & \multirow[b]{2}{*}{$\begin{array}{c}\text { Feedwater } \\
\text { flow rate. } \\
\text { bbl/d }\end{array}$} & \multicolumn{2}{|c|}{ Oilcontent of } & \multirow{2}{*}{$\begin{array}{l}\text { Amount } \\
\text { of } \\
\text { chemical } \\
\text { added, } \\
\text { ppm }\end{array}$} \\
\hline & & & $\begin{array}{l}\text { Inlet water } \\
\text { ppm }\end{array}$ & $\begin{array}{l}\text { Exit water } \\
\text { ppm }\end{array}$ & \\
\hline Ventura, CA & 300 & 9.000 & $75-100$ & $10-15$ & 12 \\
\hline Wilmington, CA & 750 & 25,000 & $81-175$ & $6-10$ & 5 \\
\hline Kern River, CA & 450 & 13,000 & $60-350$ & $2-15$ & 0 \\
\hline Midway Sunset, CA & 77.175 & 70.000 & $100-400$ & $5-10$ & 15 \\
\hline
\end{tabular}


carefully monitored laboratory tests should be carried out to arrive at the proper size of machine and preferred flotation chemical. There are laboratory-size flotation cells available for bench testing, and often vendors of the depurators can conduct such tests and make recommendations.

\section{Filtration}

Filters are commonly employed in those steam injection operations that utilize surface or produced water for steam generation. Surface waters generally carry considerable amounts of suspended solids and must be removed before the water is softened. In such cases, primary filtration is necessary. Produced waters usually contain oil and no filterable solids. Oil and solids from such water can be removed more economically using flotation cells. In such cases, filtration should be viewed as a cleanup or polishing operation.

\section{Choice of Filters}

The choice of a filter should be based on a number of factors, which must be evaluated in each case. These include: (1) quality of effluent desired, (2) amount of suspended solids, (3) nature of the suspended solids, (4) capital cost vs. operational cost, (5) space available, (6) flexibility of operation, (7) variability in quality of incoming water, and (8) degree of reliability of operation required.

A wide choice of filters is available for the removal of suspended solids and other impurities from the water. These include: (1) slow sand filters, (2) gravity filters, (3) pressure filters, and (4) diatomaceous earth (DE) filters. Each has various characteristics limiting them to specific applications; therefore, the selection should be based on specific project requirements. In steam injection, both conventional pressure filters and precoat (diatomaceous earth) filters are used. Pressure filters are installed in operations handling waters containing large amounts of suspended solids. Precoat filters are very effective in removing suspended solids and oils. They are widely used in operations that recycle produced water for steam generation. They are usually installed downstream of depurators to remove the last traces of oil and solids from produced water prior to softening.

\section{Pressure Filters 25}

These filters use sand, antharcite or garnet, or a combination of the above as the filter media. Pressure filters are normally operated by forcing water down through a column of filter media such as sand. As the dirt builds up in the filter sand, the flow rate through the filter will decrease (or the pressure drop will increase). At some point, the flow is reversed and the accumulated solids are flushed to waste. As the filter is backwashed, the finest sand tends to accumulate at the top of the filter. 
During filtration, only the top inch or so of the sand acts as a filter. The remaining medium acts only as a support. Most modern filters operate at higher flow rates and pressures to drive the dirt down into the bed and make more use of the bed depth for filtration.

To improve the filtration efficiency, multimedia filters are increasingly being used in some steam injection operations. In these filters a combination of sand, anthracite, and garnet is used. The filter media is graded, so that the lightest and coarsest particles are at the top, and the finest and heaviest medium is at the bottom. With this type of arrangement, the coarsest particles are retained at the top of the filter, and the finer particles are driven deeper into the filter bed to be collected on the finer and more dense filter media. Thus, the whole filter bed takes part in the filtration operation and results in higher throughput and longer filtration cycles.

Both upflow and downflow arrangements are used in the operation of the multimedia filters. In the upflow arrangement, the flow is from bottom to top. The rated capacity of the upflow filter is 6 to $8 \mathrm{USGPM} / \mathrm{ft}^{2}$ and the backwash rates vary from 15 to $20 \mathrm{USGPM} / \mathrm{ft}^{2}$ for a period of about 10 minutes. Figure 5.13 shows an upflow filter arrangement. Upflow filters can remove particle sizes up to 10 microns without the use of a coagulant aid. Particle up to 2 microns in size can be removed with the help of a coagulant aid such as alum. Though upflow filters can be used to filter particles up to 2 microns, they are inherently unstable. A change in flow rate, pressure fluctuation, or vibration can result in channeling and poor filtration.

In the downflow filters, the raw water enters at the top and flows downward. The capacity of downflow filters are much higher than in upflow filters and are much more stable operational wise. Downflow filters are usually rated at 15 to $20 \mathrm{USGPM} / \mathrm{ft}^{2}$ and are backwashed at a rate of $15 \mathrm{USGPM} / \mathrm{ft}^{2}$ for 10 minutes. Particles size up to 1 micron can be effectively filtered out with the help of a filter aid. Because of its inherent stability and higher throughput, downflow arrangements are more popular in the oil patch.

\section{Diatomaceous Earth (DE) Filters 26}

Diatomaceous earth (DE) filters, also known as a precoat filter, are extensively used in major steam injection operations to remove very fine particles and oil from the recycled water. These filters are much more efficient than the pressure filters and are capable of removing particles down to 0.2 microns, along with all of the oil droplets.

Diatomite earth is nearly pure silica formed from fossilized, one-cell marine plants. In filtration, the diatomite forms a layer which contains about $90 \%$ void. The DE filters used in the oilfield are generally leaf-type pressure filters. The leaves consist of wire-wrapped screens housed inside a 4.5 -ft-diameter by 10 -ft-long horizontal pressure vessel. The vessel is equipped with retractable pressure casing for easy leaf access. ${ }^{27}$ 


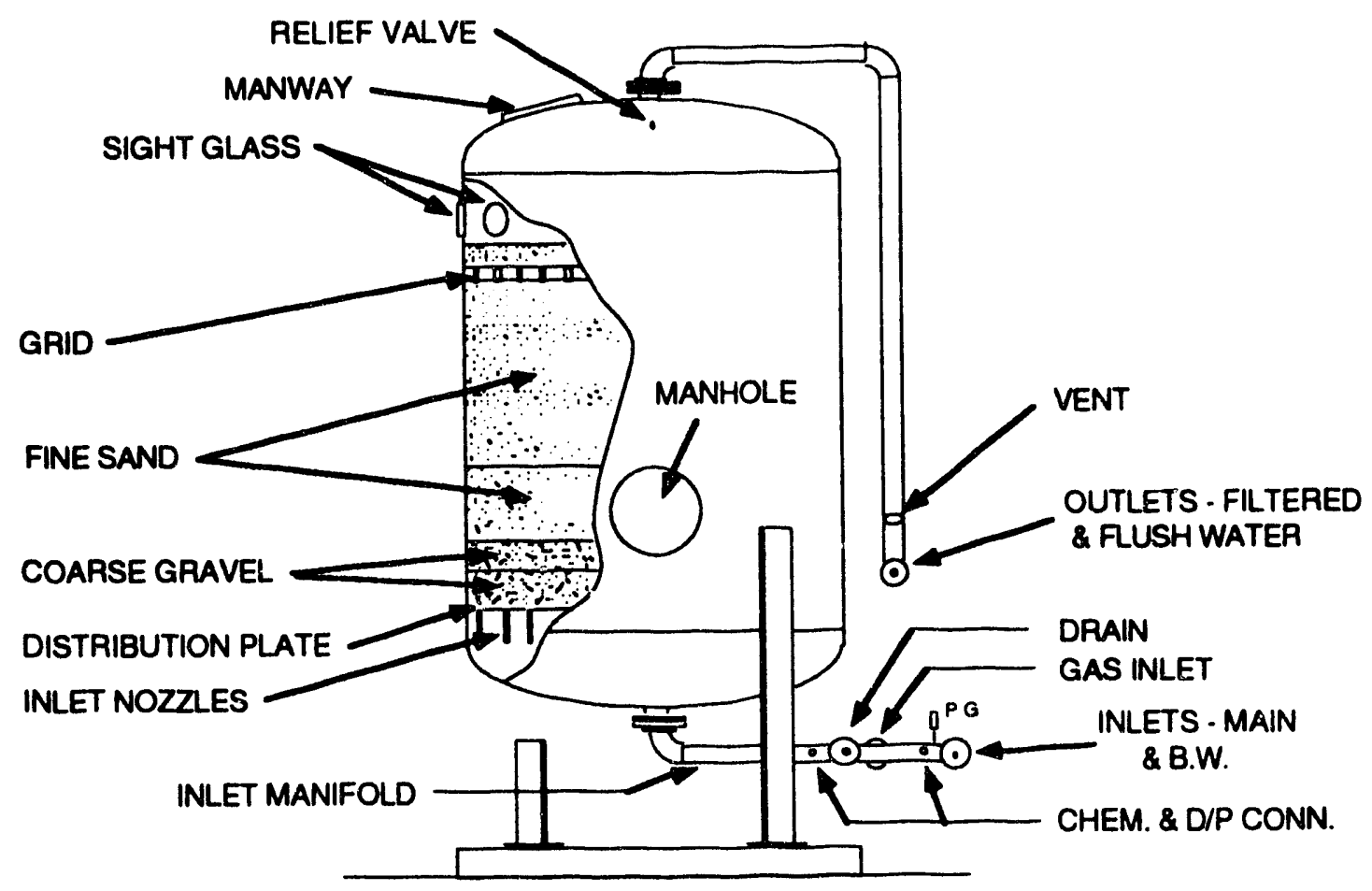

FIGURE 5.13. - Schematic of a typical up-flow sand filter. ${ }^{40}$

The DE earth filtration operation consists of three steps: (1) precoat, (2) body feed, and (3) sluicing.

The precoat is the first step in the filtration and involves coating the screens with a thin cake of fiber and diatomite. The fiber, which serves as a filter aid, is a finely ground cellulose and is circulated first to establish initial permeability and to aid in the quick release of the filter cake once the filtration cycle is completed. The fiber also serves to absorb the insoluble oil. The amount of fiber used depends upon the volume of water filtered. One steam injection operator employs about $800 \mathrm{lb}$ of fiber per $500,000 \mathrm{bbl}$ of water filtered. 27 The fiber is supplied in bagged quantities and mixed in the precoat slurry tank. The slurry then flows through the screen and the circulation stopped when the water passing through the screen is clear. A slurry of diatomite is next circulated through the filter, and the diatomite is added to the screen as a precoat. About $1 \mathrm{lb}$ of diatomite per $10 \mathrm{ft}^{2}$ of filter area is used as precoat concentration.

Once the screen is completely coated, the filter is placed in service. During filtration the raw water is pumped through the filter, to be cleaned by the precoat on the screen. When the filter is in service, the diatomite is continuously added to the incoming raw water line. This addition of diatomite is known as a 'body feed.' The amount of diatomite added to the raw water varies with the nature and quantity of solids and oil to be removed and with the operating characteristics of the system. Normally, it ranges from 0.01 and $0.05 \mathrm{lb} / \mathrm{bbl}$ of water to be filtered. The body is 
essential to maintain a loose pack in the filter cake and to prevent premature plugging of the filter cake. Without the body feed, the filtration efficiency will suffer. The higher the body feed rate, the greater is the filtration rate and higher will be the operating costs. Hence, an optimum body feed rate that results in highest filtration rate at the lowest cost should be used. In a typical thermal EOR operation, the filtration rate is maintained at about $2 \mathrm{gal} / \mathrm{min} / \mathrm{ft}^{2}$ of filtration area. The body feed concentration is maintained at about 0.7 part diatomite per part of suspended solid and oil. Usually, a material handling system consists of storage silos, shakers, and screw feeders are used to handle the volume of diatomite used in treating the raw water.

When the filter cycle is completed, the sluicing or washing cycle is initiated. The diatomite is cleaned by the use of high-velocity water jets to remove the cakes. After sluicing, the filter casing is opened, inspected and manually cleaned if necessary. The amount of backwash water needed to clean the DE filter is much less than the pressure filters.

\section{Selection of Diatomite}

Several grades of diatomite are available for use as a filter aid. The choice of grade depends entirely on the size and characteristics of the impurities to be removed and the effluent clarity requirements. The finest diatomite should be used for removing tight emulsions, ultra fine colloids, etc. The finest diatomite, however, has the lowest flow rate. The coarsest grade of diatomite yields the highest flow rate and should be used to filter water containing coarse particles. The final selection of filter aid (diatomite) should be made on the basis of field trials to $:$ "oid costly misapplications. Filter companies and diatomite suppliers can conduct such tests at small cost to prospective users and make recommendations.

\section{Diatomite Filter Problems}

Diatomite earth filters are very efficient in removing oil from water and have the advantage of high flow rate and low space requirements. They are capable of reducing the oil content of water from 20 to $0 \mathrm{ppm}$. Unfortunately, an improperly operated filter can be the biggest source of trouble. Diatomaceous earth filters require more closely monitored operator's attention than other types of filters. This is because an improper or inattentive operation will result in a poorly coated screen that results in holes, causing impurities and slurry feed to go through the filter and plug the ion exchange resin beds. Past experience indicates that most operational problems can be traced to poor operational practices. Some of the causes of DE filter failure in the past include the following:26,28

1. Operator leaves backwash valve open partially or completely after backwashing filter, resulting in partial or complete bypassing of the filter. This is worse than no filter at all, because in addition to bypassing the filter, diatomite is continuously fed to the water. 
2. Malfunctioning of the body feed devices will result in inadequate precoating of the screens and loss of filtration efficiency.

3. Temporary shutdown on a momentary pressure surge may cause part of the precoat to drop off the screen. Sutsequent operation of filter will result in all slurry feed and all suspended solids to go through the filters and plug the lines.

4. Failure to flush the lines containing slurry (body feed) during backwash will cause lines to plug and filter to fail.

Diatomaceous earth filters are very efficient in removing the oil from water and have the advantages of high flow rate and low space requirements. However, if the filter cake becomes oil saturated, some oil will leak through the filter. Hence to prevent the leakage the filtration is never carried to completion. This increases the cost of a filter run. It is sometimes necessary to install strainers or in-line filters downstream of a DE filter to strain out any solids going through the filter because of malfunction.

A properly designed and operated DE filter will produce high quality effluent consistently. Several filter companies offer a highly automated and packaged DE filter system that eliminates most of the operator related problems. ${ }^{41}$ Such a system, however, is not cheap; and the savings resulting from the reduction in labor, and cost of continuous attention, must be compared in a decision made against initial capital expenditure.

Diatomaceous earth filters are not recommended for use in small steam injection optrations because of the logistics involved in the supply of diatomite and high cost of disposal of used diatomite and the associated filtered solids.

\section{DEAERATION}

Deaeration of raw feedwater is critical to the control of corrosion of oilfield steam generators, piping, and equipment. The primary source of corrosion in steam injection operation is probably dissolved oxygen in raw water. Oxygen removal before water is heated is very important; its importance is second only to the removal of hardness.

\section{Oxygen Exclusion}

The first step in controlling oxygen is to eliminate it at the source, if possible. Subsurface source water does not contain oxygen; however, it is aerated inadvertently through improper handling. By taking the necessary steps, oxygen pickup from the surface can be eliminated. These steps include the use of a sealed type wellhead (with gas blanket) and use of packers to seal water wells. Since raw water is usually stored prior to treatment, storage tanks should be roofed and gas blanketed. The inlet to a tank must be submerged. An inlet (above water level) without a gas blanket can pick up 5 ppm or more of oxygen. Submerging entrance piping to a storage tank without gas blanket, while lowering the oxygen pickup, can still result in an oxygen pickup of 
about 2 ppm. The entrance piping must be equipped with check valves to prevent oxygen pickup if water wells are not operated continuously. Oxygen may also be picked up by a surface pump if the pressure is low enough for a vacuum to be created in the pump. If there is no water pressure on the seals, the pump will suck air making it necessary to have the water pump checked periodically.

\section{Oxygen Removal}

When every possible precaution is taken to exclude oxygen, small amounts of oxygen still are present in the water when the source water is other than subsurface water (for example, municipal or produced water). Water from such sources is usually oxygen saturated and the oxygen must be removed.

There are generally three methods of removing oxygen from softened waters. These include mechanical deaeration, chemical scavenging, or a combination of these two methods. Depending on the process, mechanical deaeration can restove the oxygen to about $0.1 \mathrm{ppm}$. Chemical scavenging is necessary to remove the trace residuals. Chemical scavenging can remove the oxygen completely, but an excess amount must be used.

Chemical scavenging is the most widely practiced oxygen-removal technique in steam injection operations and is recommended for smaller operations. However, in large operations, where large volumes of water are handled through a central plant, it may be more economical to use a deaerator followed by chemical scavenging to reduce chemical costs. Because of their higher operating costs and low efficiency, mechanical deaerators are not widely used in steam injection operations except in very large operations. The advantages and disadvantages of various deoxygenated systems are presented in Table 5.12.

\section{Mechanical Deaeration}

Several different processes are used to mechanically deaerate the water. They include (1) vacuum deaeration, (2) steam stripping, and (3) countercurrent gas stripping. The mechanical removal of oxygen from water is governed by (a) Dalton's law of partial pressures and (b) Henry's law.

Dalton's law states that the total pressure of a mixture of several gases is equal to the sum of the pressures which each gas would exert were it alone present in the volume occupied by the mixture.

Henry's law states that the concentration of the dissolved gas in the solution is directly proportional to the partial pressure of that gas in the free space above the liquid.

In accordance with the basic principles of Dalton's and Henry's laws, the dissolved oxygen from water can be removed by lowering the partial pressure of the oxygen in the surrounding atmosphere. This can be achieved by either (a) diluting water with a scrubbing gas or (b) by 
TABLE 5.12. - Summary of Advantages and Disadvantages of Water Deoxygenation Systems

\begin{tabular}{|c|c|c|}
\hline System & Advantages & Disadvantages \\
\hline A. Natural Gas Stripping & $\begin{array}{l}\text { 1. Mechanically simple and easy to operate. } \\
\text { 2. Flexible and reliable. } \\
\text { 3. Capable of reducing residual oxygen to } \\
\text { low levels. Some chemical scavengings } \\
\text { is necessary. } \\
\text { 4. Low operating cost if non-commercial gas } \\
\text { is used. }\end{array}$ & $\begin{array}{l}\text { 1. Gas evolved is water saturated. } \\
\text { at low pressure, and must be } \\
\text { flared generally. } \\
\text { 2. Requires "sweet" as free of } \\
\text { sulfur compounds. } \\
\text { 3. Amount of tolerable } \mathrm{CO}_{2} \text { in } \\
\text { the gas is limited by pH, } \\
\text { scaing and associated problems. }\end{array}$ \\
\hline B. Vacuum & $\begin{array}{l}\text { 1. Capable of reducing residual oxygen to } \\
\text { very low levels. } \\
\text { 2. Chemical scavenging may be neoded. } \\
\text { 3. May be used to overcome disadvantages } \\
\text { of gas stripping in (A) above. } \\
\text { 4. Reliabie (with careful design). }\end{array}$ & $\begin{array}{l}\text { 1. Slighuly mure complex than gas } \\
\text { stripping and normally more } \\
\text { expensive. } \\
\text { 2. More susceptible to operating } \\
\text { problems than gas stripping. } \\
\text { 3. Removal of } \mathrm{CO}_{2} \text { along with } \mathrm{O}_{2} \\
\text { and } \mathrm{N}_{2} \text { may introduce scaling } \\
\text { problems. }\end{array}$ \\
\hline C. Chemical Scavenging & $\begin{array}{l}\text { 1. Mechanically simple. } \\
\text { 2. Capable of reducing residual oxygen to } \\
\text { essentially zero. } \\
\text { 3. Minimum initial capital cost. }\end{array}$ & $\begin{array}{l}\text { 1. On large systems, cost of } \\
\text { chemical is very large. } \\
\text { 2. On large syjstems, logistics of } \\
\text { supplying and handling chemical } \\
\text { may be costly and present } \\
\text { difficulty. } \\
\text { 3. The chemical may present } \\
\text { problems with sulfate roducing } \\
\text { bacteria. } \\
\text { 4. Scavenger interaction with } \\
\text { other chemicals may present } \\
\text { some problems. } \\
\text { 5. Adequate contact time for } \\
\text { reaction must be provided. }\end{array}$ \\
\hline
\end{tabular}

lowering total pressure of the system. In the countercurrent gas stripping technique, the concentration of dissolved oxygen in the surrounding atmosphere is reduced by dilution with the scrubbing gas. In steam deaeration, the solubility is decreased by raising the water temperature.

\section{Vacuum Deaeration 29}

In the vacuum deaeration process, the partial pressure of oxygen, and hence its solubility in the water, is lowered by decreasing the system's total pressure.

It is well known that water boils at different temperatures, depending on the pressure which is maintained in the vapor space above the water. For example, water will boil at $60^{\circ} \mathrm{F}$, if the pressure reading is 0.5214 inches of mercury (0.256 psia) which corresponds to a vacuum of 
about 29.4 inches of mercury. It is usually assumed that the solubility of any gas is zero at the boiling point of the liquid. Therefore, by maintaining a vacuum of 29.5 inches of mercury, oxygen can be completely removed from the water. Since it is not economical to maintain water at boiling condition, complete removal of oxygen by vacuum deaeration is not possible. To maintain an oxygen content of about $1 \mathrm{ppm}$ in water at $60^{\circ} \mathrm{F}$, approximately 28 inches of vacuum must be maintained in the system.

For deaeration to be effective, two conditions must be met: (1) water must be kept in an agitated state and (2) a very large surface area should be available. In the vacuum deaeration operation, the water is sprayed onto a packed column maintained at about 28 inches of vacuum. As the water droplets cascade through the packing, it forms a thin film over the packing. It requires only a short distance for oxygen to travel for release in a thin film.

A properly designed and operated vacuum tower can reduce the oxygen content of water down to about $0.8 \mathrm{ppm}$. A schematic of a vacuum deaerator setup used in a steam injection operation is shown in figure 5.14. The dimensions of the tower will vary, depending on the volume of water to be deaerated and the flow rate desired. For example, the dimension of a typical tower used in one oilfield deaeration operation is $4 \mathrm{ft}$ diameter by $55 \mathrm{ft}$ high and is rated for 30,000 barrels of water per day.

Vacuum deaeration is seldom used in steam injection operations because of its high operating expenses and complexity of operation. Further, the deaerated water must be chemically treated to remove the residual oxygen.

\section{Steam Deaeration 30}

Steam can be used to remove oxygen from source water. The principle of removal is to (1) increase the temperature of the water (decreasing the oxygen solubility) and (2) put water vapor (steam) into the gas space over the water (which decreases the partial pressure of oxygen). The advantages of steam are as follows:

(1) It is readily available;

(2) it heats the water and reduces the oxygen solubility;

(3) does not contaminate the water; and

(4) most of the steam used to scrub the water is recovered as condensate and only a small portion of the steam utilized to remove the noncondensible gases is vented to the atmosphere.

Steam deaerators are widely used in power plants to deaerate boiler feedwater. The two major types of steam deaerators are the tray-type and spray-type. Only spray-type deaerators are used in the oilfield. Figure 5.15 is a schematic of a typical oilfield spray-type deaerator. 


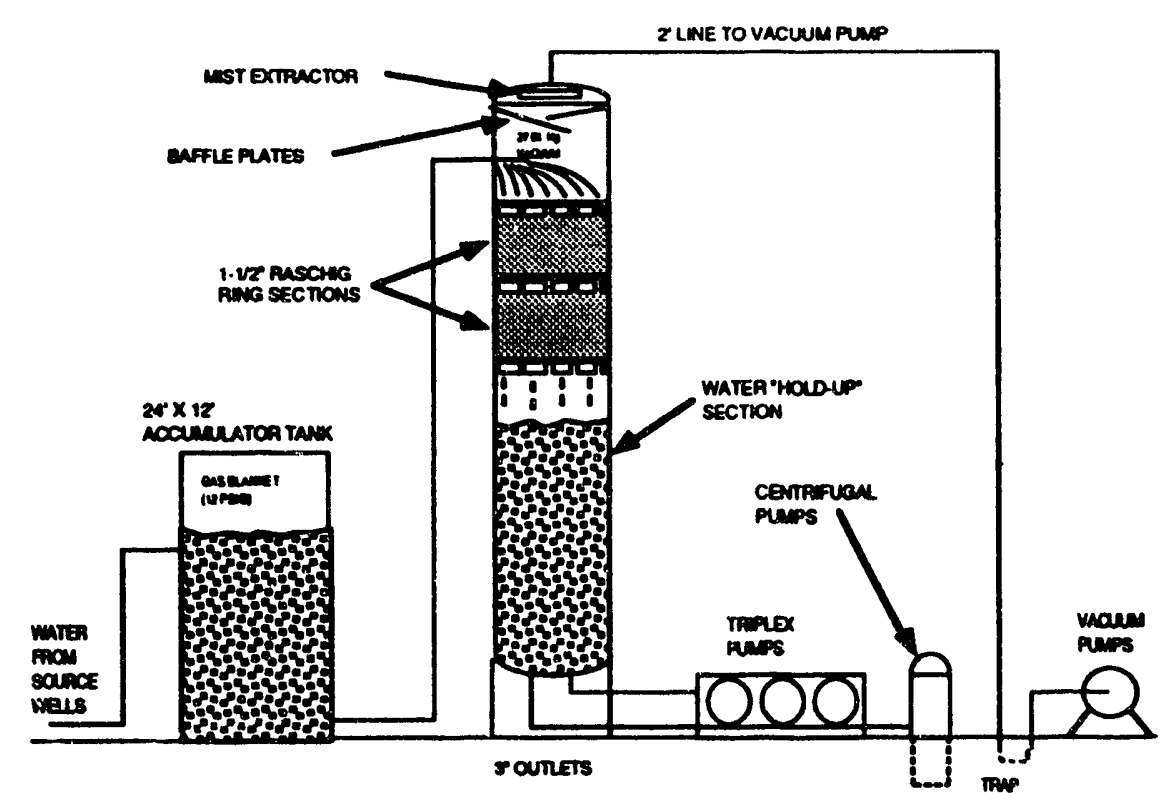

FIGURE 5.14. - Schematic of a vacuum deaerator. ${ }^{29}$

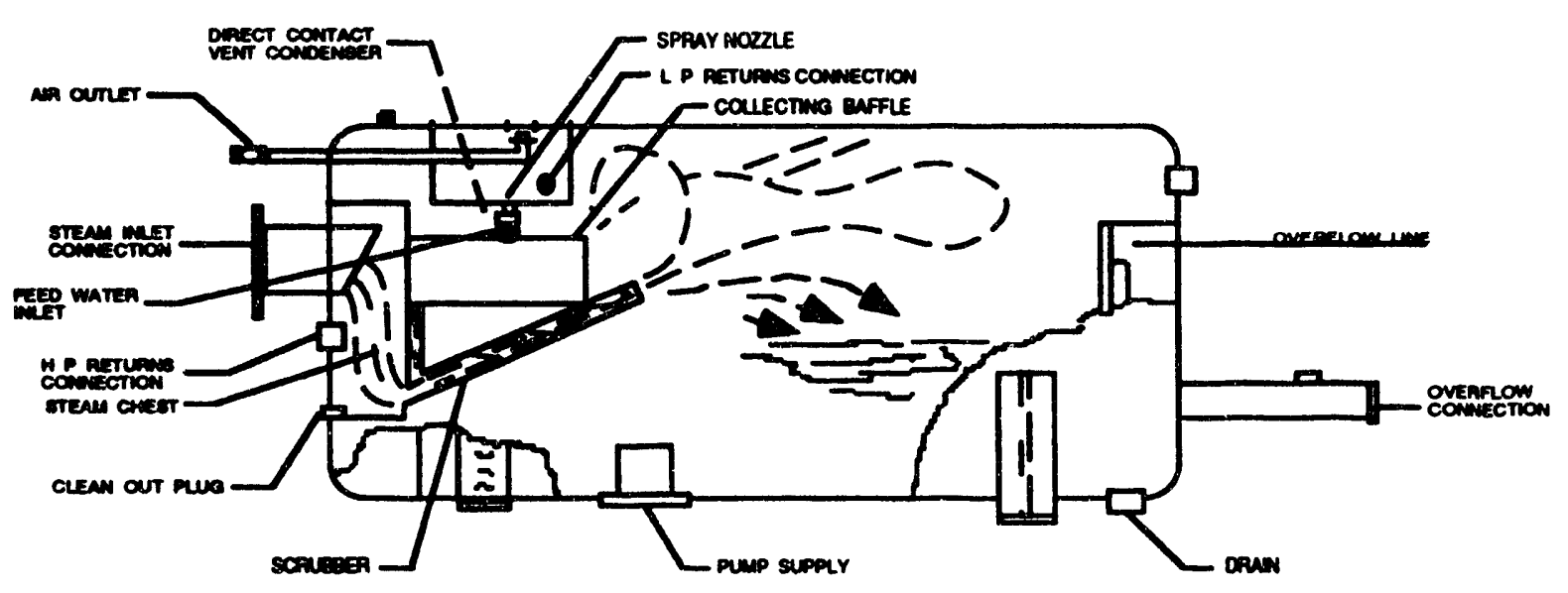

FIGURE 5.15. - Schematic diagram of a spray type steam deaerator. ${ }^{7}$ 
The major components of a spray-type steam deaerator include a carbon steel shell, springloaded inlet spray valve, direct contact vent condenser and a steam scrubber for final deaeration. The inlet spray valve and direct contact vent condenser section are fabricated out of stainless steel.

The incoming feedwater is sprayed in a finely divided state into an atmosphere of steam in the preheating section. The mist of water, upon coming into contact with the steam, is heated to near steam temperature. Most of the noncondensible gases are released to the steam and the heated water falls into a reservoir and drains to the lowest section of the steam scrubber. The heated water is then directed into the path of the incoming steam.

Steam enters the deaerator through the steam inlet nozzle and is directed to the scrubbing section via baffles. Here the large volume of steam scrubs and heats the water from the preheat section to the saturation temperature. The intimate contact between steam and water in the scrubber section results in the release of the remaining noncondensible gases. The deaerated water drops into the storage section below for pick up by the feedwater pump.

The steam, after flowing through the scrubber, passes into the preheating section and heats the incoming spray of water. Most of the steam condenses in the preheating section and becomes part of the deaerated water output. Finally, the noncondensible gases are expelled through a vent in the top of the deaerator, along with small amounts of steam into the atmosphere.

Though steam deaerators are capable of reducing the oxygen content of water to about 0.01 ppm, they are not widely used in steam injection operations because of capital equipment needs and operational and maintenance problems. Some of the operational problems include clogging of spray valves and the inlet distributors and scaling problems. Further, these units require constant operator's attention to ensure that the noncondensible gases are properly vented to keep the partial pressure if oxygen to a minimum. Use of large amounts of steam to deaerate the water increases the process steam demand and decreases the net steam available for injection because of fixed steam generation capacity. Further, the size and cost of the apparatus increases sharply with the volume of water to be deaerated. Since it is not physically possible to completely deaerate the water using a steam deaerator, the need for a chemical oxygen scavenging system is not eliminated; however, the scavenger requirements will be considerably less otherwise.

\section{Gas Stripping 31}

Use of natural gas to strip oxygen from water is practiced in large waterflood operations, but no steamflood operation using this technique has been reported. The underlying principle behind this deaeration technique is the reduction of the concentration of the dissolved oxygen in water by diluting it with the stripping gas. This reduces the partial pressure of oxygen in the gas mixture and causes oxygen to come out of the water. 
A schematic of a countercurrent gas stripping unit is shown in figure 5.16. Gas stripping is normally performed in bubble tray column. Bubble tray column promotes intimate contact between the water and gas by providing a large surface area.

Operation: The water enters near the top of the column and flows down through the trays passing across each tray and then down the staggered downcomers to the next tray. The stripping gas enters the column near the bottom and passes upward through the bubble caps on the trays. As it flows up the column, the gas bubbles go up through the downflowing water and remove a good portion of the oxygen. The gas leaves the top of the vessel through a stainless steel wire mesh mist extractor, through a gas outlet line, and a gas backpressure valve. The deaerated water collects in the bottom of the column. The discharge is controlled by a liquid level control and a large capacity diaphragm dump valve.

These columns are usually designed to operate at 50 psig or less. With higher operating pressure, more trays are required, and the cost will increase rapidly. Typical specifications for oxygen desorption towers are shown in Table 5.13. Gas stripping operations are not as efficient as vacuum deaeration and can lower the oxygen content of water to about $0.9 \mathrm{ppm}$. Gas stripping units, however, are less expensive to operate than a vacuum tower. Chemical scavenging must be used to remove the residual oxygen.

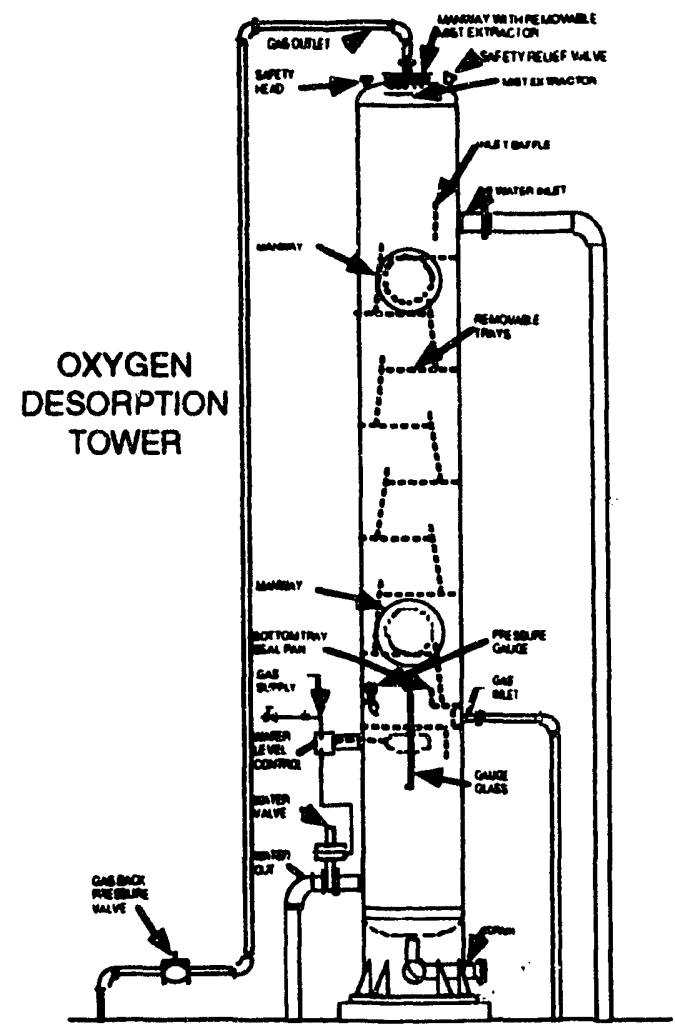

FIGURE 5.16. - Schematic of a counter current gas stripping unit. 25 
TABLE 5.13. - Oxygen Towers Selection Chart 25

\begin{tabular}{|c|c|c|c|c|c|c|c|}
\hline \multirow{2}{*}{$\begin{array}{l}\text { Tower } \\
\text { diameter, } \\
\text { in. }\end{array}$} & \multirow{2}{*}{$\begin{array}{c}\text { Tower } \\
\text { height, } \\
\text { ft }\end{array}$} & \multirow{2}{*}{$\begin{array}{c}\text { Working } \\
\text { pressure. } \\
\text { psi }\end{array}$} & \multirow{2}{*}{$\begin{array}{l}\text { No. and } \\
\text { type of } \\
\text { trays }\end{array}$} & \multicolumn{3}{|c|}{ Water canaciey ${ }^{2}$ bbl/day } & \multirow{2}{*}{$\begin{array}{c}\text { Gas } \\
\text { consumption, }{ }^{3} \\
\text { MSCF/day }\end{array}$} \\
\hline & & & & $\begin{array}{l}12^{\prime \prime} \text { tray } \\
\text { spacing }\end{array}$ & $\begin{array}{l}18 " \text { tray } \\
\text { spacing }\end{array}$ & $\begin{array}{l}24^{\prime \prime} \text { tray } \\
\text { spacing }\end{array}$ & \\
\hline 30 & 30 & 50 & 10 single pass & 4,400 & 6,600 & 8,800 & 44.0 \\
\hline 36 & 30 & 50 & 10 single pass & 6,340 & 9.510 & 12.680 & 63.4 \\
\hline 42 & 30 & 50 & 10 single pass & 8.680 & 13,020 & 17,360 & 86.8 \\
\hline 48 & 30 & 50 & 10 single pass & 11,350 & 17,030 & 22.710 & 113.6 \\
\hline 54 & 30 & 50 & 10 single pass & 14.460 & 21,70 & 28.930 & 114.7 \\
\hline 60 & 30 & 50 & 10 single pass & 27,690 & 26,540 & 35.390 & 117.0 \\
\hline 66 & 30 & 50 & 10 single pass & 21,350 & 32,030 & 42.710 & 213.6 \\
\hline 72 & 30 & 50 & 10 single pass & 25.390 & 38.080 & 50,780 & 253.9 \\
\hline
\end{tabular}

1 Based on using 10 trays on 24 " tray spacing.

2 Capacities based on $30 \%$ downcomer area, $80 \%$ of flood, and 4 second retention time in downcomers.

3 Gas consumption based on $5 \mathrm{cu} \mathrm{ft} / \mathrm{bbl}$ of water and maximum water capacity.

Mechanical deaeration systems may be cost-effective in operations handling large volumes of water. In such operations, mechanical deaeration followed by chemical scavenging will reduce the total chemical requirements.

\section{Chemical Deaeration 6}

Removal of oxygen from water by chemical means is the most popular and widely practiced technique in steam injection operations. Several methods of chemical scavenging exist. These include catalyzed sodium sulfite treatment, hydrazine treatment, and sulfur dioxide method.

The use of catalyzed sodium sulfite is cheaper than other chemical treatment methods and is the chemical of choice with steam injection operators. It is inexpensive and is very effective in removing oxygen from water. Theoretically, $8 \mathrm{ppm}$ of sodium sulfite is needed to remove each $1 \mathrm{ppm}$ of dissolved oxygen. The oxygen scavenging reaction is given by

$$
\mathrm{Na}_{2} \mathrm{SO}_{3}+\frac{1}{2} \mathrm{O}_{2} \rightarrow \mathrm{Na}_{2} \mathrm{SO}_{4}
$$

The above reaction is very slow at ambient temperature. For rapid removal of oxygen at ambient temperature, a small amount of catalyst (about 10 parts per billion, ppb, in the water) such as cobalt sulfate must be added to the sulfite solution. Catalyzed sodium sulfite will remove the oxygen in a matter of seconds as compared to minutes with the uncatalyzed compound. To be certain that all of the oxygen is removed, an excess sulfite is added to the water so that a sulfite residual of 20 to $30 \mathrm{ppm}$ is carried into the process water. It is recommended $10 \mathrm{lb}$ of catalyzed sodium sulfite be used per pound of oxygen. 6

The sodium sulfite is usually added to the water at a point downstream of water softener. Some operators inject the sodium sulfite solution upstream of the softener to provide adequate time 
for the chemical to react. The advantage of injecting ahead of the softeners is that it will protect the steel parts of the softeners and the steel piping against oxygen corrosion. However, addition of sodium sulfite ahead of the softener will increase the load on the softeners from the added sodium and will cause extra hardness leakage. Further, the excess may not be availabie to scavenge any oxygen that may enter the system due to leaky valve, pump failure, etc.

Both catalyzed and uncatalyzed sodium sulfite are readily available from water treatment chemical companies. Since uncatalyzed sodium sulfite is less expensive and the amount of catalyst needed ( $0.001 \mathrm{ppm}$ of cobaltous ion in water) is very small, it is recommended that uncatalyzed sodium sulfite be purchased in bulk from chemical supply companies and the catalyst be added in the field. The catalyst, cobaltous hexahydrate, can be purchased and fed with sodium sulfite as a catalyst without materially increasing the cost of sulfite. The equipment needed for sodium sulfite treatment includes storage vessels, mixing tanks, and chemical feed pumps.

Although sulfite is inexpensive and generally satisfactory for removing oxygen from the feedwater, there are times when hydrazine is used in preference to sulfite. If the oxygen content of the source water is consistently low, hydrazine may be economical to use because little excess is required for complete oxygen removal at high temperature. Only $3 \mathrm{ppm}$ of hydrazine is needed to remove $1 \mathrm{ppm}$ oxygen from the water. Further, at temperatures above $500^{\circ} \mathrm{F}$, the sulfite may decompose to give sulfur dioxide which is corrosive. Hydrazine is stable at these temperatures. Also, hydrazine does not require mixing or large storage vessels and is easy to feed.

Hydrazine is considerably more expensive and the reaction rate is very slow at room temperature but can be increased somewhat by using a catalyst. Even with the use of a catalyst, the rate of hydrazine-oxygen reaction is not fast enough to make use of hydrazine practical in many steam injection applications. Also, hydrazine is a hazardous chemical, and certain precautions in handling should be observed. In most thermal operations, the cost of hydrazine prevents it from being used where high concentrations of oxygen are present in the feedwater.

\section{Oxygen Scavenging by Sulfur Oxide 32}

When sulfur dioxide is absorbed into water, sulfurous acid is formed according to the reaction

$$
\mathrm{SO}_{2}+\mathrm{H}_{2} \mathrm{O} \rightarrow \mathrm{H}_{2} \mathrm{SO}_{3}
$$

The sulfite ion (sulfurous acid) thus formed can then be reacted with the dissolved oxygen to form sulfuric acid.

$$
2 \mathrm{H}_{2} \mathrm{SO}_{3}+\mathrm{O}_{2} \rightarrow 2 \mathrm{H}_{2} \mathrm{SO}_{4}
$$

Cobalt solution is usually fed into the solution as a catalyst. The economics favor this scavenging technique, provided sulfur dioxide could be produced on-site and a large volume of water can be treated at a central point. 
A large California steam injection operator utilizes this method to scavenge oxygen from feedwater. Theoretically, $4 \mathrm{lb}$ of sulfur dioxide is required to scavenge $1 \mathrm{lb}$ of oxygen from water. A sulfur burner is used to generate sulfur dioxide for scavenging oxygen. The sulfuric acid and the excess sulfurous acid is neutralized by the natural bicarbonate alkalinity of the water as follows:

$$
\begin{aligned}
& \mathrm{H}_{2} \mathrm{SO}_{4}+2 \mathrm{NaHCO}_{3} \rightarrow \mathrm{Na}_{2} \mathrm{SO}_{4}+2 \mathrm{H}_{2} \mathrm{CO}_{3} \\
& \mathrm{H}_{2} \mathrm{SO}_{3}+2 \mathrm{NaHCO}_{3} \rightarrow \mathrm{Na}_{2} \mathrm{SO}_{4}+2 \mathrm{H}_{2} \mathrm{CO}_{3}
\end{aligned}
$$

The use of a sulfur burner to generate sulfur dioxide for scavenging oxygen from boiler feedwater is well known and practiced since the early 1940s by the chemical process industries. ${ }^{32}$ However, this technique was not adopted by the oil industry until the early 1960s, when the first such unit was installed in a West Texas waterflood project to deoxygenate the process water. ${ }^{32} \mathrm{~A}$ schematic of the sulfur burner process used in the West Texas field is shown in figure 5.17.

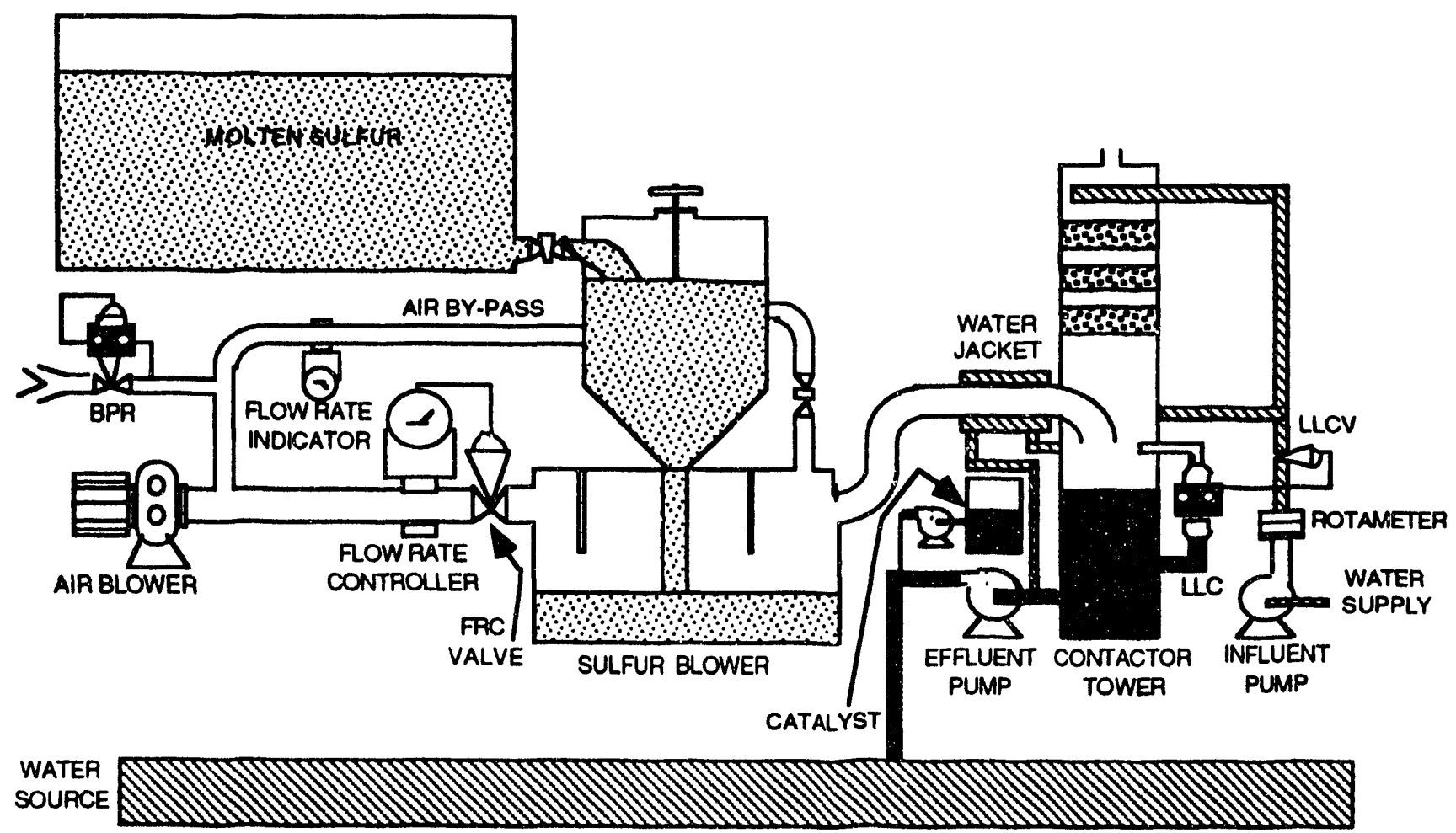

FIGURE 5.17. - Schematic of sulfur burner process for oxygen deaeration. 32 
The sulfur burning method of scavenging oxygen from feedwater was adopted by California steam injection operators in the early 1980 s. The overall process scheme used in steam injection operations is similar to those used in waterflood operations, but differs in the specifics because of the special needs of the steam injection operation. In this process, the sulfur is supplied to a sulfur burner as required to produce the sulfur dioxide necessary to scavenge oxygen in the incoming water. The hot sulfur dioxide is cooled to about $150^{\circ} \mathrm{F}$ by passing it through a water-cooled heat exchanger. The cooled sulfur dioxide is then introduced to the bottom of an absorption tower composed of ceramic packings. A side stream of source water taken from the source water storage tank is introduced into the top of the tower at the desired rate. The process water is sprayed onto the packing through the spray nozzles. The water reacts with the upflowing sulfur dioxide and converts it into diluted sulfurous acid which falls to the bottom of the tower. This solution is then pumped into the main stream of water. A dilute solution of cobalt chloride is added to the water to speed the reaction of sulfurous acid with the dissolved oxygen.

The absorption tower design, operation, and problems are similar to those of the generator flue gas scrubber. According to the operator, the installation costs for such a system were slightly over $\$ 175,000$ (1991 dollars), and the operating costs were about $1 \notin /$ barrel of water treated.

Another inexpensive source of sodium sulfite is the generator flue gas scrubber liquor. ${ }^{33}$ Depending on the sulfur content of the fuel oil burned in the generator, the scrubber liquor contains between $3 \%$ and $5 \%$ sodium sulfite which can be used to scavenge oxygen from the feedwater. The use of scrubber liquor to scavenge oxygen not only eliminates chemical requirements, but will also lower the spent liquor disposal cost. According to one California steam injection operator who utilizes scrubber wastes to scavenge oxygen, the total capital investments needed to implement such a system is slightly over $\$ 35,000$ (1991 dollars) and includes a 200-bbl fiberglass holding tank for scrubber liquor; a chemical feed pump; two 650-gpm cartridge filters; and associated pipes, valves, and fittings.

The requisite volume of scrubber liquor is transferred from the scrubber waste tank into the fiberglass holding tank. This allows the heavy metal precipitates and other debris to fall to the bottom of the holding tank. The clear supernatant liquor then flows through the cartridge filter and introduced into the upstream of the ion exchanger units. According to the operator, between 1 and $2 \mathrm{bbl}$ of scrubber effluent (containing 5\% sodium sulfite) was required to remove $4 \mathrm{ppm}$ oxygen from $1,000 \mathrm{bbl}$ of feedwater. The net savings in the operating and chemical costs were such that the operator was able to recover his investment in less than 6 weeks.

It should be realized, however, the benefits of using scrubber waste to scavenge oxygen may not be realized in all operations. This is because the scrubber waste contains high amounts of sodium (as high as $105,000 \mathrm{ppm}$ in some liquor) which makes an additional sodium load on the ion exchange resin and may cause increased hardness leakage. The scrubber liquor is also high in 
iron, which is harmful to the resin. Also, if the amount of oxygen in the steam generators is restricted in the burn process, sulfur, sodium sulfide, thiosulfate and hydrogen sulfide may also be generated. 1 Sulfur, sodium sulfide, and thiosulfate are known to inhibit the ability of sodium sulfite to remove oxygen from the generator feedwater. ${ }^{6}$ Hence efforts should be taken to ensure that generators operate with sufficient oxygen to minimize the harmful effects of oxygen deficiency. Also, a complete analysis of the scrubber waste must be performed and its oxygen scavenging potential established prior to its use as an oxygen scavenger. A typical $\mathrm{SO}_{2}$ scrubber waste analysis is shown in Table 5.14 .

\section{Reclamation of Produced Water For Steam Generation 18-19}

As discussed earlier steam injection operation requires large volumes of good quality water for steam generation. The availability of sufficient quantities of inexpensive, good quality water is becoming increasingly difficult in many parts of the country. This is especially true in the San Joaquin Valley, CA, the hub of U.S. steam injection activities. Steam injection operations also produce large volumes of water, with the crude oil creating a significant disposal problem. To solve the problems of fresh water requirements and waste water disposal, alternate water handling practices must be followed. Recycling represents the most efficient use of oilfield waters, practically eliminating waste water disposal and fresh water supply needs.

TABLE 5.14. - Typical $\mathrm{SO}_{2}$ Scrubber Waste Analysis

\begin{tabular}{lr}
\hline \multicolumn{1}{c}{ Constituent } & Concentration, \\
\hline Sodium & 105,000 \\
Calcium & less than 1 \\
Iron & 35 \\
Chloride & 2,400 \\
Carbonate & 0 \\
Bicarbonate & 44,000 \\
Sulfate & 53.000 \\
Sulfite & 84.000 \\
Bisulfite & 33.000 \\
Silica & 160 \\
Total dissolved solids & 225,000 \\
Total suspended solids & 5,600 \\
pH & 6.7 \\
\hline
\end{tabular}


However, before the produced water can be used for feedwater, the residual oil, suspended solids, and hardness must be removed. The required waste water treatment operations are more complex than conventional fresh water treatment techniques. The complexity and corresponding higher costs of produced water treatment have made reclamation uneconomical in many small operations. However, in larger operations, recycling is a viable alternative to conventional water handling practices due to high fresh water requirements and high disposal costs.

Before designing the treatment facility, the geochemical analysis of the produced water and its scaling tendencies must be investigated. Oilfield produced waters show a wide variance in the TDS and hardness content and contain significant amounts of oil and suspended matter. Experience indicates that conventional sodium zeolite softeners are not effective at a TDS level above $20,000 \mathrm{ppm}$, and weak acid softening resins must be utilized to remove the hardness. The TDS of oilfield produced water from thermal EOR fields in California varies from 1,500 ppm in the valley to more than $30,000 \mathrm{ppm}$ near the coasts. The TDS and hardness of the produced water can usually be lowered, and the softening costs reduced, by blending it with municipal or city water. The favorable economics depend on the ready availability of large volumes of city water at cheaper costs. Most major operators in California blend the produced water with city water before softening to reduce costs. Because of their high TDS content, produced waters are more likely to cause plugging problems in the generator tubes, if the steam quality is allowed to exceed the solubility limits of sodium salt. The use of produced water does require monitoring steam quality more closely.

\section{Silica Scaling}

Another major area of concern regarding produced water use has been the possibility of silica scaling. The produced water from a steamflood usually contains between 100 and $400 \mathrm{ppm}$ silica as $\mathrm{SiO}_{2}$. This silica is dissolved from the quartz present in the formation by the unvaporized and condensed water that has a $\mathrm{pH}>9$. Silica forms scales at high pressure in the presence of metal ions such as iron, aluminum, calcium, and magnesium. Although API recommendations permit up to $150 \mathrm{ppm}$ silica in generator feedwater, fields studied indicated that up to $9.9 \%$ of inlet dissolved silica will precipitate in one form or another in the convection and radiant sections of generators. ${ }^{37}$ Even a trace amount of metal ion will result in silicate scale formation in boiler tubes. Factors that contribute to silicate precipitation include not only the silica level but also salinity, alkalinity $\left(\mathrm{HCO}_{3}^{-}\right), \mathrm{pH}$, and trace amounts of metal ions.

Depending on the vapor velocity, entrained liquid droplet, and water film thickness, silicate scale can be mobilized and cause erosion and eventual failure of the tubes. ${ }^{30}$ Field studies indicated that irrespective of the steam quality, silica precipitation will occur, and the metal loss is higher at higher quality steam due to greater rate of transport of the deposit present. Further, 
neither the acceptable level of silica concentration in the feedwater required to produce $75 \%$ or higher quality steam, nor a water treatment process to achieve this concentration, is known.

Since the solubility of silica increases rapidly above $\mathrm{pH} 10$, it is suggested that silica deposition can be prevented by $\mathrm{pH}$ modification; however, adding caustic to buffered waters is difficult to control. ${ }^{9}$ If soda ash is used to increase $\mathrm{pH}$ of the water, it may decompose in the generator and release carbon dioxide to accelerate corrosion.

To mitigate silicate scale problems, high silica waters should generally be avoided in steam generation processes. If the use of high silica water cannot be avoided, silica must be removed by precipitation or by total demineralization (anion exchangers) to avoid scaling problems. Since the formation of silica scales requizes the presence of metal ions such as iron, calcium, and magnesium, complete removal of these ions is technically and economically more attractive than silica removal.

Reclamation of produced water for steam generation involves the following steps:

(a) Flotation Process: The induced gas flotation process further reduces the oil and suspended solids to about $20 \mathrm{ppm}$ and $80 \mathrm{ppm}$, respectively.

(b) Filtration: DE filters reduce the oil and suspended solids in the produced water to 0 ppm.

(c) Oxygen Scavenging: Chemical scavengers are used to eliminate the dissolved oxygen.

(d) Ion Exchange Softener: Softening is done in two stages-primary and polisher-to reduce the hardness to $0 \mathrm{ppm}$.

Figure 5.18 summarizes the sequence in which the unwanted constituents of the produced water are removed. Operational details of the equipment used in these steps were discussed in a previous section.

Daily monitoring should form an integral part of produced water reclamation plant operation. Monitoring provides adequate warning of possible upset conditions. The following components of the produced water must be monitored constantly. ${ }^{18}$

- Oil concentration in incoming water

- Filter pressures

- Dissolved oxygen and iron

- Water hardness

- Plant inflow and outflow volumes.

The oil concentration is probably the most critical factor since high concentrations will increase filter differential pressure and reduce filter cycle length. A significant reduction in filter cycle would curtail generator feed supply and may result in generator shutdown. 


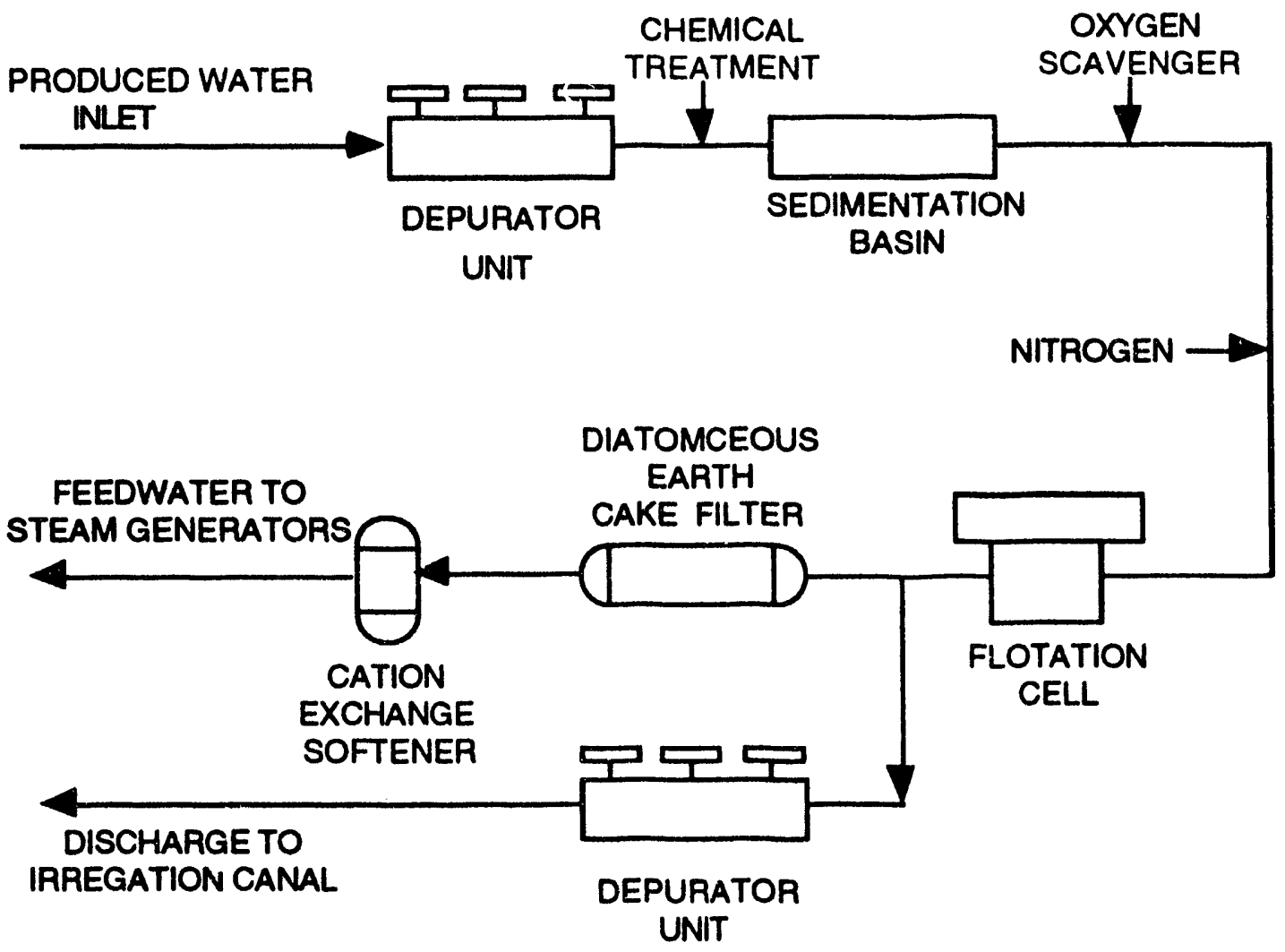

FIGURE 5.18. - Flow diagram for a Kern River, CA, steamflood produced water reclamation plant. ${ }^{18}$

Higher filter pressure is an indication not only of high oil concentration but may also indicate bacterial growth in the settling tanks. High oil concentrations are controlled by ensuring proper operation of the upstream dehydration plant. Bacterial growth is controlled by periodic biocide treatment of the holding tanks.

Dissolved oxygen and iron are monitored as corrosion control indicators.

Monitors are utilized for identifying hardness leakage and to indicate when corrective action is warranted.

Plant inflow and outflow volume monitoring is needed to ensure efficient plant operation.

\section{Disposal of Excess Produced Water}

The excess produced waters are usually disposed of by subsurface injection. Federal and most state environmental regulations require that the produced fluid be disposed of in an environmentally safe manner. Underground injection wells represent a safe environmental practice for disposal of produced water and hydrocarbon-containing wastes. Underground injection of produced fluids is subject to state and federal underground injection control regulations. 
Underground injection wells associated with the disposal of oilfield produced waters are classified by the U.S. Environmental Protection Agency (FPA) as Class II wells.

Produced water must be treated before its disposal. For example, current federal regulations require that the oil content of produced water not exceed $48 \mathrm{ppm}$. The methods of treatment and equipment used for produced water disposal are similar to those used in the reclamation of produced water for steam generation. Treatment of produced water need not be elaborate. The operator's objective should be to provide only sufficient treatment to meet the regulatory requirements and render the water suitable for injection into formations without decreasing the injective capacity of disposal wells. It is essential that thorough laboratory studies be conducted on the proposed injection water, thereby determining the minimum water treatment requirements; scrubber wastes must be neutralized and filtered before injection. If the produced water is to be discharged to a surface facility such as a canal, a more thorough treatment may be in order.

The treatment and disposal of steamflood produced water in a pollution-free manner is an essential part of operational expenses and must be so recognized. With proper planning, design, and operation, produced water may be disposed of at a minimum cost. Produced water disposal system design, operation, and economics are beyond the scope of this report. Steam injection produced water treatments are covered in a previous section of this report. Disposal of the produced water by underground injection is similar to that for oilfield produced brines and is covered thoroughly in an API publication ${ }^{34}$ which should be consulted.

\section{Water Treating Casts}

The cost of treating water depends on the quality of the feedwater. Good quality fresh waters containing minimum amounts of hardness ions and other impurities require the least amount of treatment and hence, the treatment costs will be nominal. At the other extreme, if the feedwater is brackish or the produced water is to be recycled, the treatment costs will be much higher. The chemical costs associated with the treatment of produced water increases with TDS concentration. At any given TDS level, costs become a function of hardness concentration. 30 The chemical costs account for nearly half the water treatment expense. Beckett ${ }^{35}$ allocated the expenses as follows:

Chemicals......................................... $49.2 \%$

Power ........................................... $\quad 7.6 \%$

Supervision and labor............................ $37.0 \%$

Repair and maintenance........................... $6.2 \%$

Elias et al. ${ }^{19}$ concluded that although the chemical costs associated with softening raw water are substantial, they are small compared with steam generation fuel costs. The chemical costs associated with softening the high TDS feedwater amounts to about $5 \%$ of the fuel costs. Fresh 
TABLE 5.15. - Typical Water Analysis for Water Treatment Cost Estimation 18

\begin{tabular}{|c|c|c|}
\hline Impurities & Fresh water (ppın) & Produced water (ppm) \\
\hline $\begin{array}{l}\text { Dissolved solids (TDS) } \\
\text { Bicarbonate } \\
\text { Hardness as } \mathrm{CaCO}_{3}\end{array}$ & $\begin{array}{l}640 \\
260 \\
570\end{array}$ & $\begin{array}{r}5,000 \\
960 \\
270\end{array}$ \\
\hline $\begin{array}{l}\text { Calcium } \\
\text { Magnesium } \\
\text { Silica } \\
\text { Sulfate } \\
\text { Chloride } \\
\text { Sodium } \\
\text { Iron } \\
\text { pH } \\
\text { Oil, ppm }\end{array}$ & $\begin{array}{l}90 \\
15 \\
45 \\
95 \\
70 \\
60 \\
60 \\
7.5 \\
\cdots\end{array}$ & $\begin{array}{c}75 \\
20 \\
20 \\
270 \\
170 \\
2,000 \\
1,540 \\
7.4 \\
20\end{array}$ \\
\hline \multicolumn{3}{|c|}{ Fresh and produced water treatment costs are based on the following chemical prices: } \\
\hline $\begin{array}{l}\text { Diatomaceous earth. too } \\
\text { Chlorine gas, ton } \\
\text { Oxygen scavenger, lb } \\
\text { ( } 25 \% \text { sodium sulfite solution) } \\
\text { Sodium chloride (salt), ton } \\
\text { Hydrochloric acid (HCl), ton } \\
\text { Sodium hydroxide ( } \mathrm{NaOH}) \text {, ton }\end{array}$ & $\begin{array}{l}\$ 300 \\
\$ 270 \\
\$ 0.75 \\
\$ 39 \\
\$ 92.5= \\
\$ 325\end{array}$ & \\
\hline
\end{tabular}

* 35\% HCl by wt solution.

water chemical costs amount to about $1 \%$ of the steam generation fuel costs. A typical water analysis for the water treatment cost estimations (in 1991 dollars) are shown in table 5.15.

In Tables 5.16 and 5.17, published water treatment costs are shown. Most of the data were published in 1980-83. These data have been updated to 1991 dollars using the U.S. Producer Price Index. From this, it is clear that softening produced waters is more expensive than softening fresh water. However, recycling of produced water will substantially reduce the cost of acquiring fresh water and will result in a decrease in cost of waste water disposal. One California steam injection operator indicated that waste water recycling will result in a savings of about 1.5 cents per barrel over that of conventional water handling practices. ${ }^{36}$ However, this savings can be realized only in large operations. For small operations, waste water recycling may not be economical and efforts should be made in acquiring good quality feedwater for steam generation.

\section{Guidelines to Water Treatment System Design and Operation}

Proper plarining, design, and operation of the water-handling system is a very important part of the overall picture in a steam injection project. Becuuse of the usually uneventful operation of a water treatment plant, coupled with the fact that water acquisition and treatment costs constitute a very small percentage of total operating costs, there has been a tendency on the part of operators to minimize the importance of water-handling systems to the success of a project. Yet the economic 
TABLE 5.16. - Fresh Water Treatment Costs

(All costs are for processing $1 \mathrm{bbl}$ of fresh water containing impurities shown in Table 5.15)

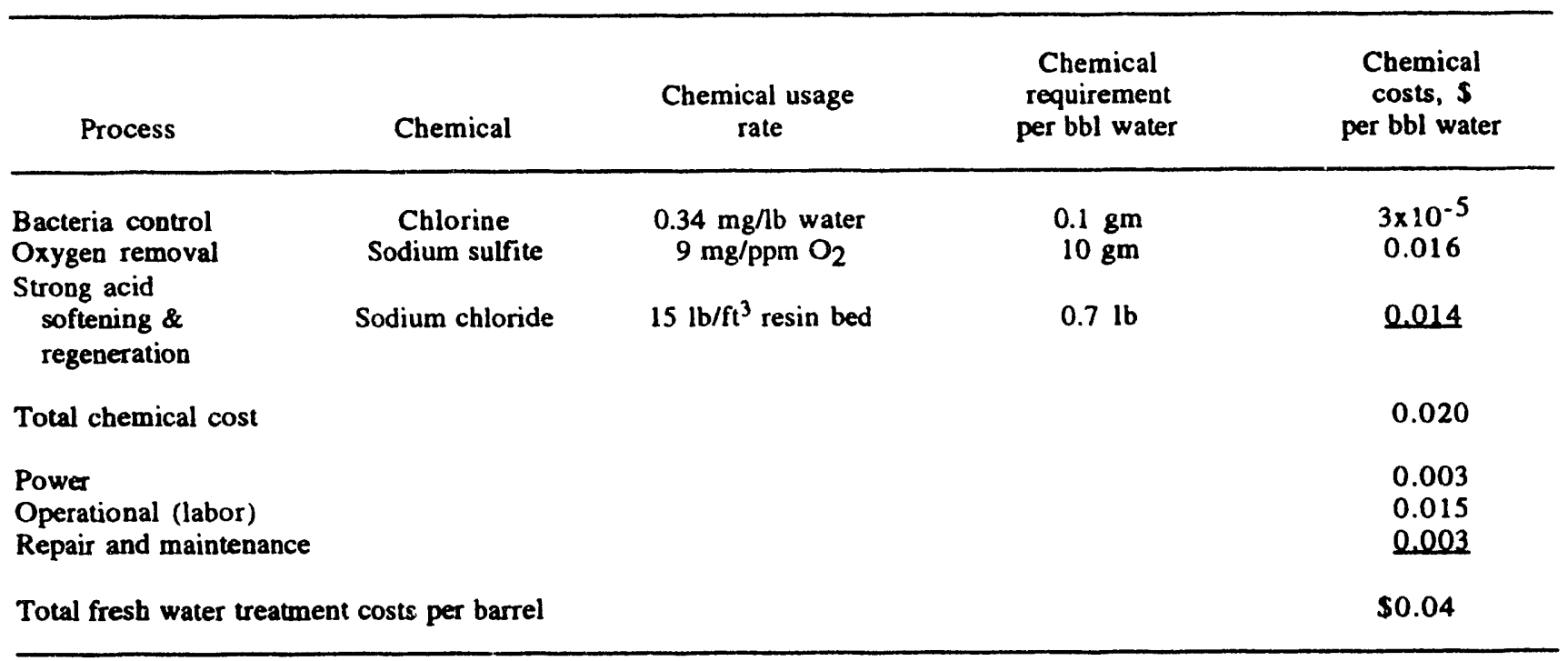

TABLE 5.17. - Produced Water Treatment Costs

(All costs are for processing $1 \mathrm{bbl}$ of produced water containing impurities shown in Table 5.15.)

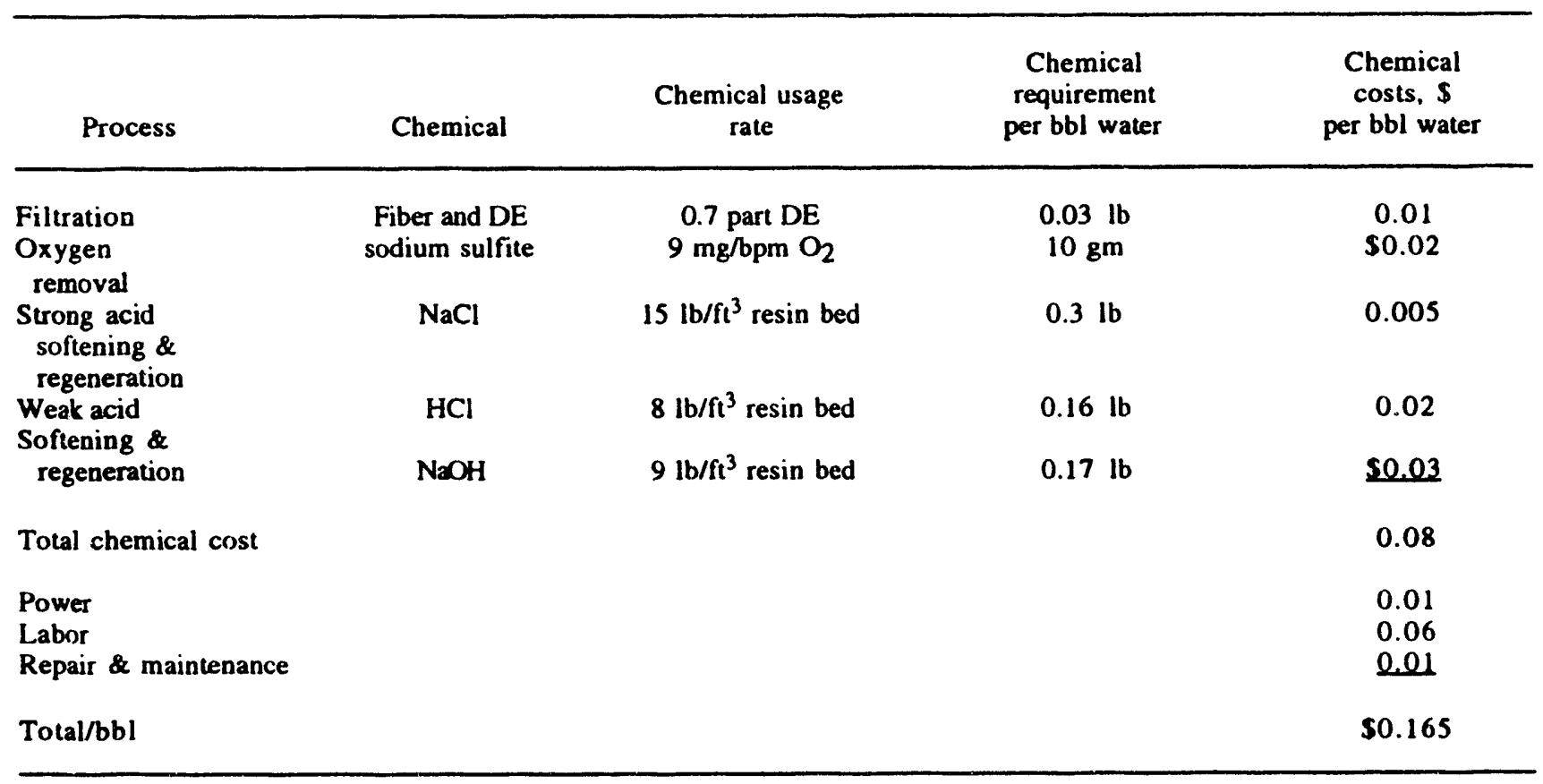


success of a steam injection project can be just as dependent on water handling practices as on such items as steam generation, reservoir performance, and sweep and displacement efficiency. As previously mentioned, a problem-plagued water treatment system will result in costly steamer downtime and loss of production. A properly engineered and operated water treatment system can result in a more profitable operation than otherwise. The purpose of this section is to outline what needs to be considered in the design and operation of water treatment system to ensure maximum benefits from the installed equipment.

\section{Design Concept}

Design of a water treatment system for steam injection requires careful planning and engineering. It may require more technical effort initially, but will assure relatively trouble-free operation over the life of the project. There is no such thing as a standard water system design. 1 Each project is unique and has its own water processing requirements. A treatment facility must be tailored realistically to meet anticipated needs, with provision for addition or expansion when required. In designing the process, the objective should be to keep it simple. The simpler the system, the better chance it will be operated successfully. During the planning and design stage, major potential problems should be identified and taken into account. Since everything cannot be foreseen, no attempt should be made to anticipate all problems and provide for all contingencies.

The approach to the planning and designing of a water treatment system for steam generation can be broken into three steps, and certain minimum information is required for each step. In general terms, the timing of items that need to be considered are as follows:

(a) Eeasibility Studies: The planning of the water treatment system should coincide with other early work on the project. At this stage, identify all water sources capable of meeting the project's water requirements. More often than not there is only one adequately sized water source existing at a given site. In cases where multiple water sources exist, it is necessary to consider them separately to determine the procurement (either drilled, purchased, or piped in) and processing costs for each source. The main objective at this step is to select the most likely water source and rough-in expected treatment equipment requirements and order-of-magnitude costs. The quality of feedwater will determine the equipment requirements and operating costs. The analyses of several typical source waters used in the California steam injection projects are shown in Table 5.2. Each type of water presents a different set of problems.

(b) Preliminary Design: In this step, water quality data are refined, and comparative economics of alternatives are made using firmer numbers. More exact determination of equipment requirements, materials, and operating costs should be considered.

(c) Einal Design: This step must cover such items as exact equipment sizing, location, and brand names. Installation drawings should be reviewed to locate sampling and coupon monitoring 
points, drain and flushing locations, etc. While these details may seem insignificant, they are extremely important to the profitable operation of the project.

\section{Source Water Properties and Problems}

Water treatment system design must be tailored to both the source water characteristics and steam generator feedwater requirements. The source water may be surface waters from streams or lakes or subsurface fresh water, or it may be produced water from the field operation. Whatever the source may be, the water treatment system must be able to take the supply water and improve its quality to meet steam generator feed specifications. The method of treatment and equipment needed to process these waters depends on the feedwater characteristics.

Surface waters tend to have a high concentration of suspended solids and dissolved oxygen and often contain bacteria. It is usually necessary to employ flocculation, coagulation, and sedimentation upstream of filtration to achieve a quality suitable for an ion exchange process. The water must be rendered noncorrosive by utilizing oxygen-scavenging, chemical, or other processes designed to remove oxygen from the water. Bacterial activity can be controlled through the use of biocide on an intermediate basis. Treatment of surface water involves relatively high initial costs.

Subsurface water is rich in dissolved solids but contains reduced amounts of suspended and organic matters. It is also lean in dissolved gases, but oxygen leakage into a source well annulus is a frequent problem. Subsurface source water requires relatively fewer pieces of equipment to treat and is preferred over surface water.

Produced waters are high in dissolved solids and rich in oil and suspended solids. The total dissolved solids in steam injection produced waters can vary from a low of about 500 ppm to as high as 30,000 ppm (see Table 5.3). Produced waters are more difficult and expensive to treat than water from other sources. The amount of hardness and TDS in the feedwater dictates the type of ion exchange resins employable in the softener.

The complexity of the water treatment system depends on the quality of the source water. The better the quality of raw water the less complex the system will be. Subsurface sources of water usually require less equipment to treat and are preferred over other sources. Steam injection demands the handling of large volumes of water. For various reasons, a single source may not be able to meet a project's water demand, and it is a poor practice to design a water handling system based on a single source. Overall plans should include the handling of water from different sources. Flexibility should be built into the initial design to provide for the handling of less than desirable water. As a generality, the water treatment system should be designed to treat the readily accessible and inexpensive water that is available in sufficient quantities, with provisions for addition of supplementary equipment if and when necessary. Most water can be treated with a reasonably simple system, if sufficient emphasis is placed on careful planning during design. 


\section{Equipment Consideration}

At each step prior to the final plans of a steam injection project, the type of equipment believed necessary to produce water of acceptable water quality should be reviewed. Since it is not possible to predict with certainty all of the possible problems which can arise in a 15- to 20-year steam injection project, provisions should be made for possible future additions of water-handling equipment. Only that equipment needed to start plant operation should be installed initially. If additional problems arise regarding water quality after a plant is in operation, a detailed study must be conducted to identify the causes and possible solutions. If the study indicates the need for new equipment and/or chemical treatment to achieve the desired boiler feedwater quality, then the system should be modified accordingly. Installation of each piece of new equipment must be justified economically.

In the design of pipelines, consideration should be given to the possibility of hydraulic shock and surge which may damage pipes of low tensile strength. Provisions should be made for the use of cleanout pigs for removal of scale and other fouling materials. Air pocket vents should be included. Leak-testing equipment should be available. If separators are to be used, they should be selected based on the volume of suspended solids and type of oil that must be removed, the reactivity of the water, and the value of the land on which they would be located. Separators, however, should be used only if the amount of free oil is expected to exceed the handling capacity of the depurators. This can occur when the dehydration equipment malfunctions. Efforts should be made to prevent upsets of dehydration equipment. Installation and operation of deaeration equipment is very expensive. Before considering deaeration equipment, other methods of control of oxygen should be thoroughly evaluated. In the case of dissolved oxygen, elimination of the source of oxygen can be the most profitable approach. Even the shallow water sands do not contain dissolved oxygen, and the oxygen found in these waters is from the surface. Oxygen pickup from the surface can be eliminated by proper design and gas blanketing of the supply well.

All chemicals, which may include bactericide, oxygen scavengers, de-emulsifiers etc., should have a mix hopper provided with a transfer arrangement to a feed tank. In the case of sodium sulfite, the tanks should be closed and blanketed to prevent oxygen contamination. All chemicals should be fed into the system through a variable metering type injection pump. Materials should be selected for corrosion resistance to chemicals in the concentrated and dilute states.

\section{Operation of a Water System}

The objective of a water treatment system is to obtain and/or maintain the water at the quality suitable for steam generation. Certain operating techniques are required to achieve this goal, and specific monitoring procedures must be used to assure the success of the operation. 
Frequently, once a system is installed, put on stream, and 'debugged,' the operation and maintenance of the water-handling system is relegated to the backburner until trouble developssoftener resin deterioration, equipment scales, corrosion failures etc. Considerable amounts of money are usually spent on remedial work that often destroys a project's profit picture.

As with other preventive maintenance, water-treatment system monitoring can go a long way towards reducing such problems. A few thousand dollars spent on monitoring has a large potential payout in decreased operating costs. A systematic review and evaluation of water quality will help detect changes and conditions before serious problems develop. Automatic and manual hardness and oxygen monitoring should be made to periodically determine and follow water treatment plant performance. Oxygen content at the discharge of each piece of equipment should be checked periodically. Performance of the ion exchange bed should be monitored carefully. Excessive pressure-drop through the bed and poor quality treated water are indications of resin degradation. As a rule, about $10 \%$ of the resin bed should be replaced annually. Using such a systematic approach, the efficiency of water treatment equipment and its operation may be monitored. Such information, in conjunction with the steam generator performance and the injection well performance data, can be utilized to evaluate the flood performance.

Apparently, insignificant items can greatly influence water quality. In a well designed and operated water-handling system, most of these can be classed as "good housekeeping" items. Yet the importance of good maintenance programs cannot be over-emphasized. Routine maintenance schedules and reporting procedures should be set up and periodically reviewed. Last, but certainly not least, is the importance of operator's training. Many operating problems can be avoided or minimized by personnel who understand the what, why, and how of good maintenance management.

Finally, it should be kept in mind that the steam injection process is, above all, an oilfield operation. Each project is unique and has its own problems. Circumstances, when fully understood, will dictate the best course of action.

\section{SUMMARY}

Quality of boiler feedwater is of critical importance in steam injection projects. Past field experience indicates that the majority of steamer downtime is caused by water treating problems. Therefore, it is imperative that feedwater problems be examined with care. This chapter discusses in detail the feedwater treating requirements for a single-pass steam generator and the effect of specific impurities on steamflood equipment performance. Guidelines to water treatment system design are also provided. Water treatment softening-unit operations and problems are detailed. Process requirements for reclaiming produced water for steam generation are also detailed. 


\section{REFERENCES}

1. Burns, W. C. Water Treatment for Once Through Steam Generators. J. Pet. Tech., v. 17, No. 4, April 1965, pp. 417-421.

2. Hagist, F. C. and D. R. Fincher. What You Ought to Know About Water Treatment for Thermal Recovery. Oil \& Gas J., v. 63, No. 46, Jan. 11, 1965, pp. 64-70.

3. Fincher, D. R., F. C. Hagist and D. L. Gallaher. How to Treat Feedwater on Steam Injection Projects. World Oil, v.166, No. 1, January 1968, pp. 53-57.

4. Fieber, C. E. How to Treat Water for Steam Flooding. Pet. Engineer, v. 36, No. 11, November 1964, pp. 94-100.

5. Fincher, D. R. and F. C. Hagist. Handling Water Treating Problems in Steam Injection Projects. Pres. at the 40th Ann. Fall meeting of the Soc. of Pet. Eng., Denver, CO, Oct. 3-6, 1965. SPE paper 1265.

6. Walker, C. L. The Chemical Treatment of Water Used in Steam Injection Systems. J. Can. Pet. Tech., v. 4, No. 2, April-June 1965, pp. 107-110.

7. Burns, W. C. What Kind of Water Treatment for a Successful Steam Flood? Pres. at the 39th Ann. Fall meeting of the Soc. of Pet. Eng., Houston, TX, Oct. 11-14, 1964. SPE paper 1000 .

8. Roberts, J. C. and J. W. Williams. Steam Injection, Oil Recovery Techniques and Water Quality. J. Water Pollution Control Federation, v. 42, No. 8, Part 1, August 1970, pp. 14371445.

9. Haseltine, N. G. and C. M. Beeson. Steam Injection Systems and Their Corrosion Problems. Materials Protection, v. 4, No. 10, October 1965, pp. 57-61.

10. Reyes, R. B. Softening of Oilfield Produced Water by Ion Exchange for Alkaline Flooding and Steamflooding. Pres. at the California Regional meeting of the Soc. of Pet. Eng., Ventura, CA, Mar. 23-25, 1983. SPE paper 11706.

11. Bradley, B. W. Influence of Salt Dosage and Hardness on Series Softener Performance. Pres. at the 42nd Ann. Fall Tech. meeting of the Soc. of Pet. Eng., Houston, TX, Oct. 1-4, 1967. SPE paper 1951.

12. Serck Baker-Water Softener Systems-Oil Field Steam Generation and Other Enhanced Recovery Techniques. Tech. Bulletin, Serck Baker Inc., Huntington Beach, CA, 1982.

13. Owens, M. E. and B. G. Bramley. Performance of Equipment Used in High Pressure Steam Floods. J. Pet. Tech., v. 18, No. 12, December 1966, pp. 1525-1531.

14. Brusset, M. J., A. N. Edgington and R. F. Gilmour. Equipment Performance in an Alberta High Pressure Steam Injection Project. Paper pres. at the 18th Ann. Tech. meeting of the Pet. Soc. of CIM, Banff, Alberta, Canada, May 24-26, 1967.

15. Bealessio, M. Sources of Fresh Water for Steam Generators. Producers Monthly, v. 32 , No. 9 , September 1968 , pp. 8-10. 
16. Bradley, B. W. and L. K. Gatzke. Steamflood Heater Scale and Corrosion. J. Pet. Tech., v. 27, No. 2, February 1975, pp. 171-178.

17. Welder, B. Q. Automation Does Well in Steam Injection: The Oil \& Gas J., v. 63, No. 46 , Nov. 15,1965 , pp. 164-173.

18. Carrell, M. A. Reclaiming Produced Water for Steam Generation in the Kern River Field. Pres. at the 54th Ann. Fall Tech. Conf. of the Soc. of Pet. Eng., Las Vegas, NV, Sept. 2326, 1979. SPE paper 8411 .

19. Elias, R., J. R. Johnstone, J. D. Krause, J. C. Scanlan, and W. A. Young. Steam Generation With High TDS Water. Pres. at the 50th Ann. California Regional meeting of the Soc. of Pet. Eng., Los Angeles, CA, Apr. 9-11, 1980. SPE paper 8819.

20. American Petroleum Institute. Manual on Disposal of Refinery Wastes-Volume on Liquid Wastes-Chapter 6-Construction Details of Gravity-Type Separators. 1st Edition, 1969, American Petroleum Institute, Washington, D.C.

21. Katz, W. J. Dissolved Air Flotation as Applied to the Treatment of Oil-Production Water and of Refinery Wastes. API Drilling and Production Practices, 1960, pp. 140-144.

22. Bessett, M. G. WEMCO Depurator System. Pres. at the Rocky Mountain Regional meeting of the Soc. of Pet. Eng., Billings, MT, June 2-4, 1971. SPE paper 3349.

23. Eddins, W. N. Induced Gas Flotation Process Performance. Pres. at the 26th Ann. Southwestern Petroleum Short Course, Lubbock, TX, Apr. 19-20, 1979, pp. 371-375.

24. WEMCO. WEMCO Depurator 1+1 Flotation Machine. Bulletin F8-B6 (5/88 6500M), 1987. WEMCO, Sacramento, CA.

25. Sivalls, R. C. Water Treating Equipment Design Manual. Sivalls Inc., Tech. Bulletin, Sivalls Inc., Odessa, TX, 1969.

26. Olmsted, B. C. and G. R. Bell. Diatomite Filtration of Water for Injection. Paper presented at the Third Biennial Symp. on Microbiology, sponsored by API Pacific Coast District Study Committee on Treatment and Control of Injection Waters, Nov. 29-30, 1964, Anaheim, CA, pp. 201-219.

27. Smith, M. L. Waste Water Reclamation for Steam Generator Feed, Kern River Field, California. Pres. at the 42nd Ann. California Regional meeting of the Soc. of Pet. Eng., Los Angeles, CA, Nov. 4-5, 1971. SPE paper 3689.

28. Baumann, E. R. and R. L. LaFrenz. Optimum Economical Design for Municipal Diatomite Filter Plants. J. of American Water Works Association, v. 55, January 1963, pp. 4858.

29. Adams, G. H. Vacuum Deaeration In Waterflood Operations, Paper No. 851-51-H, pres. at the API Mid-Continent District's Spring meeting, Division of Production, Oklahoma City, OK, May 1967. API Drilling and Production Practices, 1967, pp. 159-163.

30. Fanaritis, J. P. and J. D. Kimmel. Review of Once-Through Steam Generators, J. Pet. Tech., v. 17, No. 4, April 1965, pp. 409-416. 
31. Weeter, R. F. Desorption of Oxygen From Water Using Natural Gas for Countercurrent Stripping, J. Pet. Tech., v. 17, No. 5, May 1965, pp. 515-520.

32. Perry, L. N. and W. J. Frank. Sulfur Burning Method of Scavenging Oxygen From Water. Paper 906-11-E, pres. at the API Southwestern District Spring meeting, Division of Production, Hobbs, NM, March 1966. API Drilling and Production Practices, 1966, pp. 70-73.

33. Williams, R. L. and A. Harris. Use of Scrubber Waste as an Oxygen Scavenger in Thermal Water Plant Operations. Pres. at the California Regional meeting, Ventura, CA, Apr. 810, 1987. SPE paper 16368.

34. American Petroleum Institute. Subsurface Salt Water Disposal. Book 3 of the Vocational Training Series. American Petroleum Institute, Division of Production, Dallas, TX, 1960.

35. Beckett, J. K. Low-Cost Water Treatment Solves Disposal Problems. World Oil, v. 173, No. 6, November 1971, pp. 64-67.

36. Burton, R. Waste Water Recycling in Steamflood Operations. Pres. at the California Regional meeting of the Soc. of Pet. Eng., Ventura, CA, Mar. 23-25, 1983. SPE paper 11710.

37. Khatib, Z. J., E. E. Olson and M. C. Place Effect of High Silica Content on Scale Deposition and Pipe Wall Loss in Oilfield Steam Generators. Pres. at the 64th Ann. Tech. Conf. and Exhib. of the Soc. of Pet. Eng., San Antonio, TX, Oct. 8-11, 1989. SPE paper 19760.

38. BETZ Handbook of Industrial Water Conditions, 8th Ed., Chapter 8: Ion Exchange, p. 54. BETZ Laboratories Inc., Trevoise, PA, 1980.

39. Kemmer, F. N.: The NALCO Water Handbook-Chapter 12: Ion Exchange, pp. 11, McGraw Hill Book Company, New York, 1979.

40. Battle, J. L.: Salt Water Disposal. Pres. at the 15th Ann. Southwestern Petroleum Short Course, Lubbock, TX, Apr. 18-19, 1968, pp. 193-206.

41. Maloney, G. F.: Diatomite Filters-Methods of Automation. Paper pres. at the Third Biennial Symp. on Microbiology, sponsored by API Pacific Coast District Study Committee on Treatment and Control of Injection Waters, Nov. 29-30, 1964, Anaheim, CA, pp. 170-186.

42. Ostroff, A. G.: Introduction to Oilfield Water Technology, pp. 88, Prentice-Hall Inc., Englewood Cliffs, NJ, 1965.

\section{GENERAL REFERENCES}

BETZ Laboratories. BETZ Handbook of Industrial Water Conditioning, 8th Ed., Chapters 6, 8 and 9. BETZ Laboratories, Inc., Trevoise, PA, 1980.

Crawford, P. B. Water Processing For Thermal Oil Recovery Programs. Producers Monthly, v. 29, No. 4, April 1965, p. 18.

Crawford, P. B. Water Treatments For Steamfloods-Part II-Hardness Removal by Ion Exchangers. Producers Monthly, v. 29, No. 11, November 1965, p. 28. 
Crawford, P. B. Regeneration of Ion Exchangers Used in Steam Recovery Programs. Producers Monthly, v. 29, No. 11, November 1965, pp. 16-17.

Crawford, P. B. Effect of Ion Exchange Properties on Thermal Water Treatment Quality. Producers Monthly, v. 29, No. 1, January 1965, pp. 8-9.

Crawford, P. B. Importance of $\mathrm{pH}$ in Treating Water For Thermal Recovery Programs. Producers Monthly, v. 29, No. 6, June 1965, p. 4.

Crawford, P. B. Water Deionization for Steam Injection. Producers Monthly, v. 28, No. 10, October 1964, pp. 21-22.

Crawford, P. B. Silica Removal in Thermal Recovery Water Treatment Programs. Producers Monthly, v. 29, No. 5, May 1965, p. 2

Crawford, P. B. Catalyzed Sodium Sulfite For Oxygen Removal From Injection Water. Producers Monthly, v. 30, No. 1, January 1966, pp. 12-13.

Crawford, P. B. Water Deaeration With Steam Ejectors. Producers Monthly, v. 25, No. 8, August 1961, p. 10.

Gras, E. H. Portable Steam Generating Equipment. Pres. at the 40th Ann. Fall meeting of the Soc. of Pet. Eng., Denver, CO, Oct. 3-6, 1965. SPE paper 1169.

Kemmer, F. N., Editor. The NALCO Water Treatment Handbook, Chapters 3, 12 and 14. McGraw Hill Book Company, New York, 1979. 


\section{APPENDIX 5-A \\ WATER CHEMISTRY}

\section{Definition}

The purpose of this appendix is to define terms frequently encountered in oilfield water chemistry. The treatment by necessity is very simplistic, but sufficiently accurate for our purposes.

Elements are chemical substances which cannot be cheinically decomposed to give two or more simpler substances. Examples of elements of importance in oilfield water chemistry (and their symbols) include: hydrogen $(\mathrm{H})$, sodium $(\mathrm{Na})$, calcium $(\mathrm{Ca})$, magnesium $(\mathrm{Mg})$, oxygen $(\mathrm{O})$, and carbon (C).

Elements are made up of matter called atoms. An atom is the smallest particle of an element that can enter into a chemical reaction.

An atom is made up of electrons, protons and neutrons. An electron carries a negative electrical charge and has negligible mass. The proton carries a positive electrical charge and has a unit mass. The neutron carries no charge and also has unit mass.

The nucleus of an atom is made up of protons and neutrons. Thus, the nucleus is positively charged. In an atom the electrons move about the nucleus. The positive charges in the nucleus are balanced by the negatively charged electrons orbiting it. Thus, an atom is electrically neutral. Since the mass of an electron is negligibly small, for all practical purposes, the mass of an atom is considered to be the mass of its nucleus. The mass of an atom is equal to the sum of the number of protons and neutrons in the nucleus.

The number of electrons in an atom is always equal to the number of protons in the atom, but the number of neutrons in the nucleus of an atom may or may not be the same as the number of protons in it. When the number of protons and neutrons in an atom are different it is called an isotope of an element.

For the purpose of this report, the number of protons and neutrons in a nucleus are assumed to be the same. An exception to this is the nucleus of the hydrogen atom. The nucleus of the element hydrogen contains one proton and no neutron. Only the electrons in an atom take part in a chemical reaction.

Atoms are identified by name, atomic number and atomic mass. The atomic number is the number of electrons moving around the nucleus of an atom. It is also the number of protons in the nucleus. The mass of an atom is the sum of protons and neutrons in the nucleus. The atom hydrogen has one electron orbiting about a nucleus made up of one proton and no neutron. Thus, its atomic number is 1 and its atomic mass is also 1 . The nucleus of a calcium atom is composed of 20 protons and 20 neutrons. Thus, its atomic number is 20 and its atomic mass is 40 . 
The atomic weight of an element is the ratio of the mass of an element to that of an arbitrary standard element, the carbon atom. The atomic mass of a carbon atom is 12 . Therefore, when we say that the atomic weight of hydrogen is 1 , it actually means that a hydrogen atom weighs $1 / 12$ as much as an atom of carbon.

Molecules and compounds: Elements combine to form molecules. For example, an oxygen molecule is comprised of two oxygen atoms. Molecules made up of a number of different atoms are called compounds. A compound is formed by chemically combining two or more elements in definite proportion by weight. It is not possible to identify individual elements in a compound, unless the compound is chemically separated.

Molecular weight is the weight of a single molecule and is equal to the sum of the weights of its constituent atoms. Molecular weights, like atomic weights are also relative weights. When we say that the molecular weight of water is 18 , we mean that a molecule of water weights $18 / 12$ times the weight of a carbon atom.

When the molecular weight of a substance is expressed in grams, it is termed as gram molecular weight or simply gram-mole or mole.

\section{Ions, Valence and Radicals}

As previously stated, an atom has an equal number of electrons and protons and is therefore electrically neutral. However, if an atom is allowed to gain an electron, it will have net negative charge, since the number of protons in the nucleus remains the same. On the other hand, if an atom loses an electron, it will have a net positive charge. Thus, whenever an atom loses or gains an electron, it becomes electrically imbalanced. An electrically imbalanced atom is called an ion. Thus, an ion is defined as an atom or group of atoms containing an electric charge.

A positively charged ion is called a cation and a negatively charged ion is called an anion. The amount of charge an ion carries is called a valance. Valance is a measure of an element's chemical combining power.

A radical is a group of atoms found in certain compounds that react as a unit as if it were a single atom or ion. For example, if the compound calcium carbonate $\left(\mathrm{CaCO}_{3}\right)$ were ionized, we would find the group of atoms $\mathrm{CO}_{3}$ behaves as an ion and carries two negative charges. Thus, the anion $\mathrm{CO}_{3}{ }^{2-}$ is called a radical.

Equivalent weight of an element is given by:

Equivalent weight $=$ Atomic weight

Valance

For a radical

Equivalent weight $=$ Molecular weight

Valance 
The elements and radicals present in water combine with each other on an equivalent basis to form a salt. For example, one equivalent weight of $\mathrm{Na}^{+}$combines with one equivalent weight of $\mathrm{SO}_{4}^{--}$to form the salt sodium sulfate $\mathrm{Na}_{2} \mathrm{SO}_{4}$.

\section{pH}

A pH of solvent such as water is the measure of its acidity or alkalinity. A pure water molecule dissociates itself into hydrogen ions $\left(\mathrm{H}^{+}\right)$and hydroxyl ions $\left(\mathrm{OH}^{-}\right)$according to the equation

$$
\mathrm{H}_{2} \mathrm{O} \Leftrightarrow \mathrm{H}^{+}+\mathrm{OH}^{-}
$$

The extent to which water dissociates is given by the dissociation constant $k$. The dissociation constant is defined as the product of the number of hydrogen and hydroxyl ions present in one liter of water. Thus,

$$
\mathrm{k}=\frac{\left[\mathrm{H}^{+}\right] \mathrm{X}\left[\mathrm{OH}^{-}\right]}{\left[\mathrm{H}_{2} \mathrm{O}\right]}=10^{-14}
$$

Thus, there are $10^{-7}$ moles of $\mathrm{H}^{+}$ions present in 1 liter of water. Since this is such a small number, it is more convenient to express the hydrogen ion concentration in terms of a logarithmic function. This expression is called a $\mathrm{pH}$ and defined as

$$
\mathrm{pH}=\log \left[\frac{1}{\mathrm{H}^{+}}\right]=-\log \left[\mathrm{H}^{+}\right]
$$

Thus, $\mathrm{pH}$ is a measure of the hydrogen ion concentration of a solution and is a number between 0 and 14. A solution is said to be acidic if its $\mathrm{pH}$ is less than 7 and basic if its $\mathrm{pH}$ is greater than 7 . $\mathrm{A} \mathrm{pH}$ of 7 indicates neutrality. The $\mathrm{pH}$ is measured using a pH meter.

Since $\mathrm{pH}$ is a logarithmic function, a solution having a pH of 6.0 is 10 times more acidic than one with a pH of 7.0. Similarly, a solution having a pH of 8.0 is 10 times more alkaline than one with a $\mathrm{pH}$ of 7.0 .

\section{Water Analysis}

Water Analysis is merely a listing of the concentration of various chemical species present in the water. The results of the water analysis are expressed in several ways. Some of the more common ways of reporting water analysis include: parts per million (ppm); milligram per liter $(\mathrm{mg} / \mathrm{L})$, milliequivalent per liter (meq/L), and ppm as $\mathrm{CaCO}_{3}$. These are defined as follows:

Parts per million (ppm) means one part in a million part, for example, 1 gram in a million grams of water, or 1 pound in a million pounds of water.

Milligram per liter $(\mathrm{mg} / \mathrm{L})$ expresses the weight of an ion or radical in 1 liter of water. For fairly fresh water, $1 \mathrm{mg} / \mathrm{L}$ is approximately equal to $1 \mathrm{ppm}$. In water analysis, the units $\mathrm{mg} / \mathrm{L}$ and ppm are often used interchangeably. 
Milliequivalents per liter (meqiL) - Some laboratories report water analysis results in milliequivalent per liter:

$$
\text { meq } / \mathrm{L} \text { of an ion }=\mathrm{mg} / \mathrm{L} \div \text { equivalent weight of the ion }
$$

\section{$\mathrm{PPM}$ as $\mathrm{CaCO}_{3}$}

Steamflood water analysis reports are frequently expressed in this unit. When the concentration of a species is expressed in ppm as $\mathrm{CaCO}_{3}$, it means that the concentration of the ion (or radical) is given as though it were calcium carbonate $\left(\mathrm{CaCO}_{3}\right)$. For example, $\mathrm{ppm} \mathrm{Mg}^{++}$ expressed as $\mathrm{CaCO}_{3}$ is given by

$$
\text { ppm } \mathrm{Mg}^{++} \text {as } \mathrm{CaCO}_{3}=\mathrm{ppm} \mathrm{Mg}^{++} \times \frac{\text { equivalent weight of } \mathrm{CaCO}_{3}}{\text { equivalent weight of } \mathrm{Mg}^{++}}
$$




\section{APPENDIX 5-B \\ OILFIELD STEAM GENERATOR WATER QUALITY REQUIREMENTS}

\section{INTRODUCTION}

Oilfield steam generator water quality requirements are much more stringent than those required for the conventional power boilers. Poor quality feedwater can result in steam generator tube failure. The following discussion is directed toward how specific impurities can affect steam generator performance.

\section{Totai Hardness ${ }^{16-17}$}

Hardness is a measure of the amount of calcium and magnesium salts contained in water. The salts of calcium and magnesium are the most common source of scale in steam generator tubes because the solubility of many calcium and magnesium salts in water decreases with increases in temperature. Probably the most common source of scale is a breakdown of calcium bicarbonate with heat to form calcium carbonate, illustrated as:

calcium bicarbonate + Heat $\rightarrow$ calcium carbonate + water + carbon dioxide

Other calcium salts that may deposit are calcium sulfate and calcium silicate. The most common magnesium salts expected to scale are magnesium hydroxide and magnesium silicate.

Since the solubilities of these scale-forming salts are so low at tube wall temperatures, they tend to precipitate at tube walls and plug the tubes. This results in reduced heat transfer and flow through the tube causing hot spots to develop. Hot spots result in localized overheating and subsequent tube rupture. The breakdown of bicarbonates also releases carbon dioxide which can react with steam condensate to form carbonic acid and cause metal corrosion and tube failure.

The most trouble-free steam generator operation is achieved by maintaining boiler feedwater hardness to near zero level. This is critical because, at typical steamflood operations temperatures of $400^{\circ}$ to $600^{\circ} \mathrm{F}$, the solubility of calcium carbonate in distilled water is from 4 to $7 \mathrm{ppm}$. At $70 \%$ steam quality, the hardness would be concentrated three and one-third times. At $80 \%$ steam quality, there will be a fivefold concentration, and at $90 \%$ a tenfold concentration. Thus, theoretically the solubility of calcium carbonate in $80 \%$ steam ranges between 0.8 and $1.4 \mathrm{ppm}$, and at $90 \%$ the solubility reduces to 0.4 to $0.7 \mathrm{ppm}$. Obviously, the higher the steam quality desired, the more carefully must feedwater hardness be controlled. Operating a steam generator with hardness values exceeding these limits for as little as $\mathbf{5}$ hours can result in tube scaling. Therefore, it is important to monitor the feedwater hardness level continuously to detect any hardness leakage. Since the solubility limits given above vary according to the chemical composition of the feedwater, each feedwater must be analyzed to determine what hardness level is tolerable for a given steam quality. 
By far, the most common method of removing hardness for steam generation is through sodium cation exchange. In the ion exchange method, all of the objectionable calcium and magnesium ions in the feedwater are replaced by nonobjectionable sodium ions. The sodium salts are highly soluble in water and contribute to the total dissolved solids (TDS) content of the feedwater.

\section{Total Dissolved Solids (TDS)}

The TDS content of feedwater becomes a cause for concern only when their level is extremely high. California steam injection operators have satisfactorily utilized feedwater containing $6,000 \mathrm{ppm}$ of TDS in steam generators without any problem. The practical limitation on TDS generally comes as a result of water softener operating limitations. The resins used in most oilfield water softeners limit the feedwater TDS to about 7,000 ppm. However, newer resins pernit TDS levels up to $30,000 \mathrm{ppm}$, but their operating costs are several times that of the older resins.

However, the operator should ensure that the TDS content of the feedwater does not exceed their solubility limits in the liquid phase. Therefore, a generator producing $80 \%$ quality steam should be able to tolerate feedwater salts in concentrations approaching $20 \%$ of their solubility limits. ${ }^{1}$

\section{Alkalinity}

In feedwater, alkalinity may exist in several forms - carbonate, bicarbonate, and hydroxide. Silicate, borate, and phosphate ions are also sometimes classed as alkaline. In natural water, the bulk of alkalinity is usually carbonate and bicarbonate. Under the influence of heat, the alkaline water in a steam generator decomposes to form carbonate and hydroxides, as illustrated by

$$
\begin{aligned}
& 2 \mathrm{HCO}_{3}^{-}+\mathrm{Heat} \rightarrow \mathrm{CO}_{3}^{2-}+\mathrm{CO}_{2}+\mathrm{H}_{2} \mathrm{O} \\
& \text { Bicarbonate carbonate } \\
& \begin{array}{l}
\text { carbon water } \\
\text { dioxide }
\end{array} \\
& \mathrm{CO}_{3}^{2-}+\mathrm{H}_{2} \mathrm{O}+\mathrm{Heat} \rightarrow \underset{\text { hydroxide }}{2 \mathrm{OH}^{-}+\mathrm{CO}_{2}}
\end{aligned}
$$

The carbonates and hydroxides will combine with hardness and other divalent ions to form scale deposits. However, since the ion exchange system removes all hardness, scale formation will not be a problem.

With pressures above $600 \mathrm{psi}$, a feedwater containing $2,000 \mathrm{ppm}$ of sodium bicarbonate could theoretically form nearly $5,000 \mathrm{ppm}$ of sodium hydroxide in the water phase of $80 \%$ quality steam, and corrosion or caustic embrittlement of tubes would be likely. However, for this to occur, the following three conditions must exist at the same time. ${ }^{2}$ 
(1) Metal must be under stress;

(2) generator water must contain hydroxide; and

(3) there must be a crevice, seam, etc. permitting the generator water solids to concentrate on the stressed metal.

Since the presence of all of these three conditions at the same time is unlikely, high alkalinity of the feedwater is of little concern. However, as a matter of precaution, feedwater containing greater than 2,000 ppm alkalinity should be avoided.

Moderate levels of hydroxide alkalinity in feedwater; however, are beneficial because they tend to keep silica in solution and reduce corrosion. Further, the free $\mathrm{CO}_{2}$ formed during the decomposition of bicarbonates and carbonates dissolves in the unvaporized water and forms carbonic acid. However, since this carbonic acid is neutralized by the sodium hydroxide present in water, condensate corrosion is unlikely. In light of the above factors, alkalinity less than 2,000 ppm need not be treated.

\section{Suspended Solids}

Common suspended solids found in an oilfield water include mud, silts, and corrosive products. The presence of these materials can cause plugging and fouling of steam generator tubes, water treating plants and injection wells. In most field operations, filtration is all that is required to control suspended solid buildup. Suspended solid levels in the feedwater should be maintained below $5 \mathrm{ppm}$ and preferably below $1 \mathrm{ppm} .^{2}$

\section{Oxygen}

Dissolved oxygen can exist in surface waters as a result of contact with the atmosphere and in subsurface waters as a result of equipment suction leaks as well as pulling a vacuum on a well because of falling water levels. Dissolved oxygen can be extremely corrosive in steam generators. Field experience shows that even a small amount of oxygen (less than $1 \mathrm{ppm}$ ) can cause nonuniform pitting. ${ }^{3}$ Therefore, as for hardness, the dissolved oxygen content of the feedwater must be reduced to zero.

Since improper handling of an initially oxygen-free water source can result in aerated water, monitors should be utilized to detect oxygen leakage. To minimize the treatment necessary to remove dissolved oxygen, the operator should take steps to eliminate unnecessary oxygen pickup. Unnecessary oxygen pickup can be avoided by using packers to seal water wells, gas blanketing storage tanks as well as water wells, submerging entrance piping to storage tanks and by maintaining adequate pressure on the suction side of the pumps. ${ }^{3}$ Oxygen from feedwater can be removed either by a deaerator and/or by chemical means. 


\section{Sulfides 1}

Sulfide is unacceptable in steam generator feedwater because of the high rate and severe nature of the corrosion it produces. Sulfides also cause plugging problems upstream of a generator. The presence of hydrogen sulfide $\left(\mathrm{H}_{2} \mathrm{~S}\right)$ in the steam phase could cause corrosion and perhaps plugging of injection wells because of precipitation. For these reasons, as well as the hazardous nature of $\mathrm{H}_{2} \mathrm{~S}$, sulfides should be reduced to nearly zero (less than $0.1 \mathrm{ppm}$ ). The presence of bacteria in many freshwater sources is the cause of $\mathrm{H}_{2} \mathrm{~S}$ in these waters. If the source of sulfide is indigenous to the water source and another source cannot be located, treatment could be very expensive and the process quite complex. Hydrogen sulfide is generally reduced with deaeration, but chemical means such as chlorination have to be used for complete removal. If chlorination is used, it must be carefully controlled to avoid added corrosion potential and to avoid oxidizing effects of chlorine on ion exchange resin.

\section{$\operatorname{Iron}^{5}$}

The natural iron content of feedwater is quite low. Its presence is usually indicative of corrosion. Feedwater picks up iron either from a gathering system as a result of corrosion of steel piping or can acquire it through contact with formation minerals. Irrespective of its origin, the presence of iron in feedwater is troublesome and should be kept below $0.05 \mathrm{ppm}$.

Iron may exist in solution as a ferric $\left(\mathrm{Fe}^{+++}\right)$or ferrous $\left(\mathrm{Fe}^{++}\right)$ion. Depending upon the form in which it exists, iron in feedwater can cause difficulties in the ion exchange process by fouling the resin bed or can form scale deposits in the generator tubes. To prevent scale deposits in steam generator tubes, the iron content of feedwater should be kept below $0.05 \mathrm{ppm}$. The ion exchange systems are extremely efficient in lowering the feedwater iron content to this level. Both the $\mathrm{Fe}^{++}$and $\mathrm{Fe}^{+++}$ions are removed by the resin in a manner analogous to calcium and magnesium ions. The ferrous ions can be removed from the resin bed by backwash. However, the ferric ion fouls the resin bed by forming a gelatinous precipitate on or in the resin. This results in capacity loss and makes the unit difficult to backwash. Special backwash and regeneration techniques must be employed to restore the exchange capacity of the bed. These techniques are expensive and increase water treatment costs. ${ }^{2}$

The ferric ion is formed by the oxidation of ferrous ion. Hence, iron should be kept in the reduced form (ferrous form) as water is being softened. Oxidation of ferrous ion can be avoided by removing dissolved oxygen with a reducing agent (such as an excess amount of sodium sulfite) upstream of the resin bed. This will act to reduce the ferric ion to ferrous ion and, thus, keep the resin unfouled. The reducing agent should be added to the water before caustic is added for $\mathrm{pH}$ control. After the iron has been removed, it is highly desirable to avoid iron pickup in long pipelines between a softener and a steam generator. One way of accomplishing this would be to 
keep residual sodium sulfite in the water to avoid oxygen contamination and iron pickup. Another method of avoiding iron pickup is to use plastic pipes or internally plastic coated pipes.

\section{$O i l^{4}$}

The presence of free oil in feedwater can result in the formation of hard asphaltic scales on steam generator tube walls. Deposition of scale reduces heat transfer and causes tubes to fail through formation of localized hot spots on tube walls. Oil is especially troublesome in the fouling of ion exchange resins. From the viewpoint of the resin bed, the oil content should be reduced to zero ppm. Coarse media filtration can remove oil up to $50 \mathrm{ppm}$. Above this limit, pretreatment by induced clarification, air flotation, and diatomaceous earth filtration may be required.

\section{$p H^{5}$}

The $\mathrm{pH}$ of feedwater plays a very important role in thermal recovery operations. The solubility of many common ions varies greatly with the $\mathrm{pH}$ of water. The concentration of calcium ion in water goes through a minimum at a pH of 9 to 10 . Above a pH of 10 , the concentration of calcium ion in water increases rapidly due to the formation of soluble calcium hydroxide. The concentration of magnesium ion in water decreases rapidly with increase in $\mathrm{pH}$ and approaches zero at a pH of around 10.6. The solubility of iron in water also decreases with increase in $\mathrm{pH}$ and approaches zero at a pH of 9 . Thus, at a pH of approximately 10, both magnesium and iron ions would precipitate out. Since calcium, magnesium, and iron ions are the most troublesome impurities in feedwater, problems resulting from these ions can be minimized by assuring that the steam generator feedwater is slightly alkaline.

Field experience indicates satisfactory operations can be obtained by maintaining the $\mathrm{pH}$ of feedwater between 9 and 11. This alkaline environment also keeps silica dissolved and reduces the corrosion of steel. However, higher operation pressure will lower the optimum operating range to between 10 to 10.5 . The $\mathrm{pH}$ control is usually done by adding sodium hydroxide $(\mathrm{NaOH})$ into the water systems at some point between the softener and feedwater injection pump. This is done to prevent the neutralizing of oxygen scavengers which may have also been added.

\section{Silica 6}

Silica is present in most water supplies and is a much greater problem in power boilers than in oilfield steam generation systems. Silica is troublesome in oilfield steam generators because of its scaling tendency. Silica can produce scaling, both directly and as a constituent of complex mineral scales. However, formation of complex scales requires the presence of metal ions such as iron, calcium, and magnesium. Elimination of these ions will effectively prevent the formation of complex silicate scales. 
Control of silica problems in steam generator systems consists primarily of maintaining silica solubility. Silica solubility is a function of temperature, alkalinity, and concentration of other ions with which silica forms complex scales. By maintaining the hardness of the feedwater near zero level and $\mathrm{pH}$ around 11, silica can be kept in solution. Satisfactory operations have been maintained with silica content of as much as $150 \mathrm{ppm}$. Steam generated by the system must contain enough liquid to prevent silica from precipitating. Tolerable limits of silica in feedwater vary from $100 \mathrm{ppm}$ at pressures to $50 \mathrm{psi}$ to $50 \mathrm{ppm}$ at pressures up to $1,500 \mathrm{psi}$. It is recommended that the silica concentration in feedwater be maintained around $40 \mathrm{ppm}$.

Suspended or colloidal silica can be effectively eliminated by a coagulation process. Soluble silica can be removed by a strong base anion exchange to almost any level. Since silica content of fresh water is much less than the tolerable limit, no silica removal is required. However, it is suggested that before any equipment expenditures are made for silica removal, a very critical look at all operating conditions and water analysis data be made to decide if such expenses are justified.

\section{Biological Growths $7-8$}

Feedwater used for steaming operations are usually rich in total dissolved solid content and are conducive to growth of organic matter. If left untreated, these organic growths can foul and plug an ion exchange resin bed.

Some of the common bacteria found in oilfield waters include sulfate-reducing bacteria, iron bacteria, and slime-forming bacteria.

Sulfate-reducing bacteria are anaerobic bacteria. However, they are quite capable of thriving in oxygenated systems, provided they find some scale to congregate under. These bacteria reduce sulfate ions in water to sulfide ions and produce $\mathrm{H}_{2} \mathrm{~S}$ as a byproduct. They cause corrosion, and the iron sulfide produced as a byproduct of corrosion reaction is an excellent plugging material.

Iron bacteria are aerobic bacteria and grow well even with only trace amounts of oxygen. Iron bacteria precipitate a sufficient quantity of ferric hydroxide to cause severe plugging problems. As discussed previously, ferric ions foul ion exchange resins readily and are expensive to remove.

Slime-forming bacteria are aerobic bacteria and produce dense masses of slime on solid surfaces. They are magnificent pluggers and contribute to corrosion.

One method of controlling aerobic bacteria is to seal and gas blanket water supply wells. The other and the most common method of controlling bacterial growth in vilfields is by chemical means. Chlorine is the most widely used inorganic chemical to kill bacteria. Chlorine, however, attacks only exposed organisms and will not penetrate slime or scale masses which often hide sulfite-reducing bacteria. There are other biocides (a chemical which kills other forms of life, in addition to bacteria) available which will control sulfate-reducing bacteria. 
Since chlorine is a very strong oxidizing agent, it will oxidize iron and hydrogen sulfide. Once it reacts, it is no longer available to kill bacteria. Hence, to determine the total amount of chlorine needed it is necessary to establish how much chlorine will be used by reaction with other materials. The amount used by the system is called the chlorine demand. The amount of chlorine in excess of that required to control bacteria and meet chlorine demand is the excess chlorine. The excess chlorine concentration in the feedwater must be less than $1 \mathrm{ppm}$ because chlorine can oxidize ion exchange resins and reduce its effectiveness. Excess chlorine concentration in feedwater can be reduced to less than $1 \mathrm{ppm}$ by chemical deaeration upstream of an ion exchange unit.

Other biocides should be chosen with the aid of vendor representatives, since the type needed will depend on contact time, $\mathrm{pH}$, and temperature of the water treated. These biocides should be of the nonionic type as others will clog filters and softeners.

\section{Turbidity}

The turbidity of water being fed into steam generators should be zero. Softening systems have a limited ability to filter out turbidity. If the turbidity is high, a separate means must be used for its reduction. A combination of coagulation, flocculation, and sludge removal is generally required.

\section{Carbon Dioxide ${ }^{9}$}

Although fresh sources of water contain carbon dioxide $\left(\mathrm{CO}_{2}\right)$, its major corrosive effect, as far as steam generation is concerned, comes from the decomposition of sodium bicarbonate. In theory, the bicarbonates break down at high temperatures and release carbon dioxide. The $\mathrm{CO}_{2}$ then reacts with steam condensate to form carbonic acid and cause of the metal condensate system to corrode. In a typical oilfield steam generator, the tubes carry both steam and water not flashed to steam. The water phase is usually highly alkaline due to sodium carbonate and hydroxide in solution. On the other hand, the steam phase carries free $\mathrm{CO}_{2}$ which redissolves in the condensate forming carbonic acid. If the velocities in the boiler tubes are high and if there is a lot of turbulence in the flow stream, then the two phases are intimately mixed, the acid is neutralized by the alkalinity, and minimal corrosion occurs. However, if the velocity is low, the vapor can condense without intimate contact with the alkaline water and cause corrosion.

There is much disagreement among operators as to which situation actually occurs. This led to two different approaches to handle the $\mathrm{CO}_{2}$ problem. One group feels that treatment is not necessary because $\mathrm{CO}_{2}$ will eventually be neutralized by the alkaline water. This group, however, carefully excludes oxygen (which can accelerate $\mathrm{CO}_{2}$ corrosion) from the system and closely monitors corrosion rates. The other group feels that treatment for $\mathrm{CO}_{2}$ corrosion is necessary. One method of treatment is to use sodium hydroxide or volatile filming amines (such as 
cyclohexylamine) to neutralize $\mathrm{CO}_{2}$ as it is formed. The other approach would be to use a nonvolatile filming amine (such as octadecylamine) which establishes a water insoluble protective film on metal surfaces and, thus controls corrosion. In either case, the treatment chemical should be injected into the system immediately downstream of the water softening equipment to protect as much of the system as possible. 


\section{FEEDWATER TREATMENT EOUIPMENT AND CHEMICAL VENDORS}

\section{A. Packaged Ion Exchange Units}

1. LA Water Treatment Corporation 17400 T. E. Chestnut Street City of Industry, CA 91749 Telephone: (818) 912-5411

2. Serck Baker Inc. 5352 Research Drive Huntington Eeach, CA 92649 Telephone: (714) 898-3474

3. Saltech Corporation 1035 Diesel Drive P.O. Box 26872

El Paso, TX 79907

Telephone: (915) 592-7982

4. Permutit Company 30 Technology Drive

Warren, NJ 07059

Telephone: (908) 668-1700 1-800-631-0878

5. Graver Water 2720 U.S. Highway No. 22

Union, NJ 07083

Telephone: (908) 964-2400

6. Illinois Water Treatment Company 4669 Shepherd Trail

P.O. Box 560

Rockford, IL 61105

Telephone: (815) 877-3041

7. Culligan Industrial Water Company 119 Paulson

San Antonio, TX 78219

Telephone: (512) 227-9729

8. NATCO

Division of National Tank Company P.O. Box 1593

4550 Pierce Rd.

Bakersfield, CA 93308

Telephone: (805) 325-4146
9. Daniel En-Fab Systems Inc. 3905 Jensen Drive P.O. Box 21361 Houston, TX 77226-1361 Telephone: (713) 225-4913

B. Ion Exchange Resins and Water Treatment Chemical Suppliers

1. Betz Labs Inc. 4636 Somerton Road Trevoise, PA 19047 Telephone: (215) 355-3300

2. Nalco Chemical Company, Visco Division 4851 Stine Road Bakersfield, CA 93313 Telephone: (805) 834-6590

3. LA Water Treatment Corporation 17400 T.E. Chestnut Street City of Industry, CA 91749 Telephone: (818) 912-5411

4. Rohm and Hass Company Independence Mall West Philadelphia, PA 19105 Telephone: 1-800-338-1205

5. Wolcott Water System Inc. 2007 Wolcott Court Columbia, MO 65202 Telephone: (314) 449-0011 1/800-325-0104

6. Culligan Commercial Industrial Systems

1 Culligan Parkway

Northbrook, IL 60062

Telephone: 1-800-451-3260

7. Techni Chem Inc. 6853 Indy Drive Belvidere, IL 61008 Telephone: (805) 547-5900 
C. Emulsion Treatment and Corrosion Control Chemicals

1. Nalco Chemical Company, Visco Division 4851 Stine Road

Bakersfield, CA 93313

Telephone: (805) 834-6590

2. Petrolite Corporation Oilfield Chemical Group 16010 Barker's Point Lane

Suite 600

Houston, TX 77079

Telephone: (713) 558-5200

3. Champion Chemicals Inc. Oilfield Chemicals Division 6321 District Blvd.

Bakersfield, CA 93308

Telephone: (805) 834-0454

4. Champion Chemicals Inc. Oilfield Chemicals Division 11000 Richmond, Suite 400 Houston, TX 77042

Telephone: (713) 782-3333

D. Produced Water Reclamation Plant

1. Modulur Production Equipment Inc.

P.O. Box 690965

Houston, TX 77269-0965

Telephone: (713) 320-8796

2. Daniel En-Fab Systems Inc. 3905 Jensen Drive

P.O. Box 21361

Houston, TX 77226-1361

Telephone: (713) 225-4913

Other Water Treatment Equipment

E. Pressure and Multimedia Filters

1, LA Water Treatment Corporation 17400 T. E. Chestnut Street City of Industry, CA 91749 Telephone: (818) 912-5411

2. Serck Baker Inc. 5352 Research Drive Huntington Beach, CA 92649 Telephone: (714) 898-3474
3. Saltech Corporation 1035 Diesel Drive El Paso, TX 79907

Telephone: (915) 592-7982

4. WEMCO

1796 Tribute Road

P.O. Box 15619

Sacramento, CA 95852

Telephone: (916) 929-9363

5. Graver Water 2720 U.S. Highway No. 22 Union, NJ 07083

Telephone: (908) 668-1700

6. Daniel En-Fab Systems Inc. 3905 Jensen Drive P.O. Box 21361 Houston, TX 77226-1361

Telephone: (713) 225-4913

7. Permutit Company 30 Technology Drive

Warren, NJ 07059-0920

Telephone: (908) 668-1700 1-800-631-0878

F. Precoat Filters (Diatomaceous Earth Filters)

1. LA Water Treatment Corporation 17400 T. E. Chestnut Street City of Industry, CA 91749 Telephone: (818) 912-5411

2. Celite Corporation P.O. Box 519 Lompoc, CA 93438 Telephone: 1-800-654-3103

3. Liquid-Solid Corporation 185 Le Grand Avenue P.O. Box 9

North Vale, NJ 07647

Telephone: (201) 784-1570

G. Chemical Feed System

1. Saltech Corporation 1035 Diesel Drive El Paso, TX 79907 Telephone: (915) 592-7982 
2. Permutit Company

30 Technology Drive

Warren, NJ 07059

Telephone: (908) 668-1700 1-800-631-0878

3. Graver Water 2720 U.S. Highway No. 22 Union, NJ 07083

Telephone: (908) 964-2400

4. Daniel En-Fab Systems Inc. 3905 Jensen Drive P.O. Box 21361 Houston, TX 77226-1361 Telephone: (713) 225-4913

H. Clarifier. Deaerators (Mechanical, Vacuum, Steam)

1. Permutit Company 30 Technology Drive Warren, NJ 07059

Telephone: (908) 668-1700 1-800-631-0878

2. Graver Water 2720 U.S. Highway No. 22 Union, NJ 07083

Telephone: (908) 964-2400

3. LA Water Treatment Corporation 17400 T. E. Chestnut Street City of Industry, CA 91749 Telephone: (818) 912-5411

4. Sivalls Inc.

P.O. 2792

Odessa, TX 79760

Telephone: (915) 337-3571

5. Daniel En-Fab Systems Inc. 3905 Jensen Drive P.O. Box 21361 Houston, TX 77226-1361 Telephone: (713) 225-4913

I. Oil-Water Separator. Skimmers. Hydrocyloncs. etc.

1. Modulur Production Equipment Inc. P.O. Box 690965

Houston, TX 77269-0965

Telephone: (713) 320-8796
2. ACS Environmental 303 Silver Spring Road Conroe, TX 77303 Telephone: (409) 856-4515

3. AFL Industries Inc. 3661-B West Blue Heron Blvd. Riviera Beach, FL 33404 Telephone: (407) 844-5200

J. Dissolved and Induced Gas Elotation Cells

1. WEMCO P.O. Box 15619 1796 Tribute Road Sacramento, CA 95852 Telephone: (916) 929-9363

2. Modulur Production Equipment Inc. P.O. Box 690965 Houston, TX 77269-0965 Telephone: (713) 320-8796

3. Serck Baker Inc. 5352 Research Drive Huntington Beach, CA 92649 Telephone: (714) 898-3474

4. Permutit Company 30-T Technology Drive Warren, NJ 07059

Telephone: (908) 668-1700 1-800-631-0878

K. Water Treatment Plant Controls (Multi Port Valves, Hardness Monitors, Oxygen Monitor, etc.)

1. Saltech Corporation 1035 Diesel Drive El Paso, TX 79907 Telephone: (915) 592-7982

2. Permutit Company 30 Technology Drive Warren, NJ 07059

Telephone: (908) 668-1700 1-800-631-0878 
L. Diatomaceous Earth and Filter Aids

Suppliers

1. Universal Diatoms Inc.

1024, 1st Street N.W.

Albuquerque, NM 87107

Telephone: (505) 247-3999

2. Celite Corporation

P.O. Box 519

Lompoc, CA 93438

Telephone: 1-800-654-3103

M. Used Water Treatment Plants Supplier

1. Virgles Steam Service

Renfro Road

Bakersfield, CA 93312

Telephone: (805) 589-2597 


\section{CHAPTER 6 \\ STEAM GENERATION}

\section{INTRODUCTION}

Steam for thermal recovery is usually generated in direct-fired, forced-circulation, oncethrough generators. Since a typical steam injection operation requires large quantities of steam for continuous injection, the cost of treating the feedwater for steam generation must be kept low. The once-through design permits the use of low quality feedwater that is essentially free of hardness and suspended solids, but of relatively high level of total dissolved solids (TDS). Oilfield steam generators are usually rated in millions of BTUs per hour of heat output. Some manufacturers also rate them in terms of pounds per hour of steam output, or in terms of boiler horsepower.

Typical oilfield steam generators range in size from 10 to 180 million BTU/hr (MPM BTU/hr) heat output. The smaller size generators are generally used in pilot projects and in steam soak applications, whereas the larger units are used in continuous steam injection operations. In fact, the $50 \mathrm{MM} \mathrm{BTU} / \mathrm{hr}$ unit has become the industry standard for steamflood applications. While all oilfield steam generators are offered as skid-mounted units, smaller units (up to $40 \mathrm{MM} \mathrm{BTU} / \mathrm{hr}$ ) are also offered as fully self-contained trailer-mounted units. The size of a fully-assembled skidmounted $50 \mathrm{MM}$ BTU/hr unit is about $11 \mathrm{ft}$ by $80 \mathrm{ft}$ and its weight ranges from 170,000 to 230,000 pounds. 2,19 The $50 \mathrm{MM}$ BTU/hr unit is the largest skid-mounted unit that can be transported easily by rail to an oil lease. A list of steam generator vendors is included in Appendix 6-F.

\section{General Features of Oil Field Steain Generators}

The oilfield steam generator, also known as the wet steam generator, thermal recovery heater, oil field heater, etc., differs from conventional power boilers, in that is specifically designed to produce low quality steam from saline feedwater with minimum treatment. Oilfield steam generators can handle zero hardness feedwater containing up to 6.000 ppm TDS and generate up to $80 \%$ quality steam. The cap on the quality is set to prevent the precipitation and deposition of dissolved solids on the boiler tubes.

Basically, in a generator of this type, water enters, one end of a heated tube and leaves the other end as wet steam. This type of constructior perm.its a great deal of flexibility in operation, allows quick response to load changes, and does not require constant supervision. Further, since the water storage capacity of the generator is small, only a small amount of steam-water mixture is released if the heating coil fails. Thus, these units are safe to operate under continuous operating conditions. However, in order to respond to quickly to changing load conditions, it is important to control precisely the rate of flow of water through the tube, the fuel injection rate, and the air flow. Figure 6.1 is an isometric view of a skid-mounted oilfield steam generator showing the major 


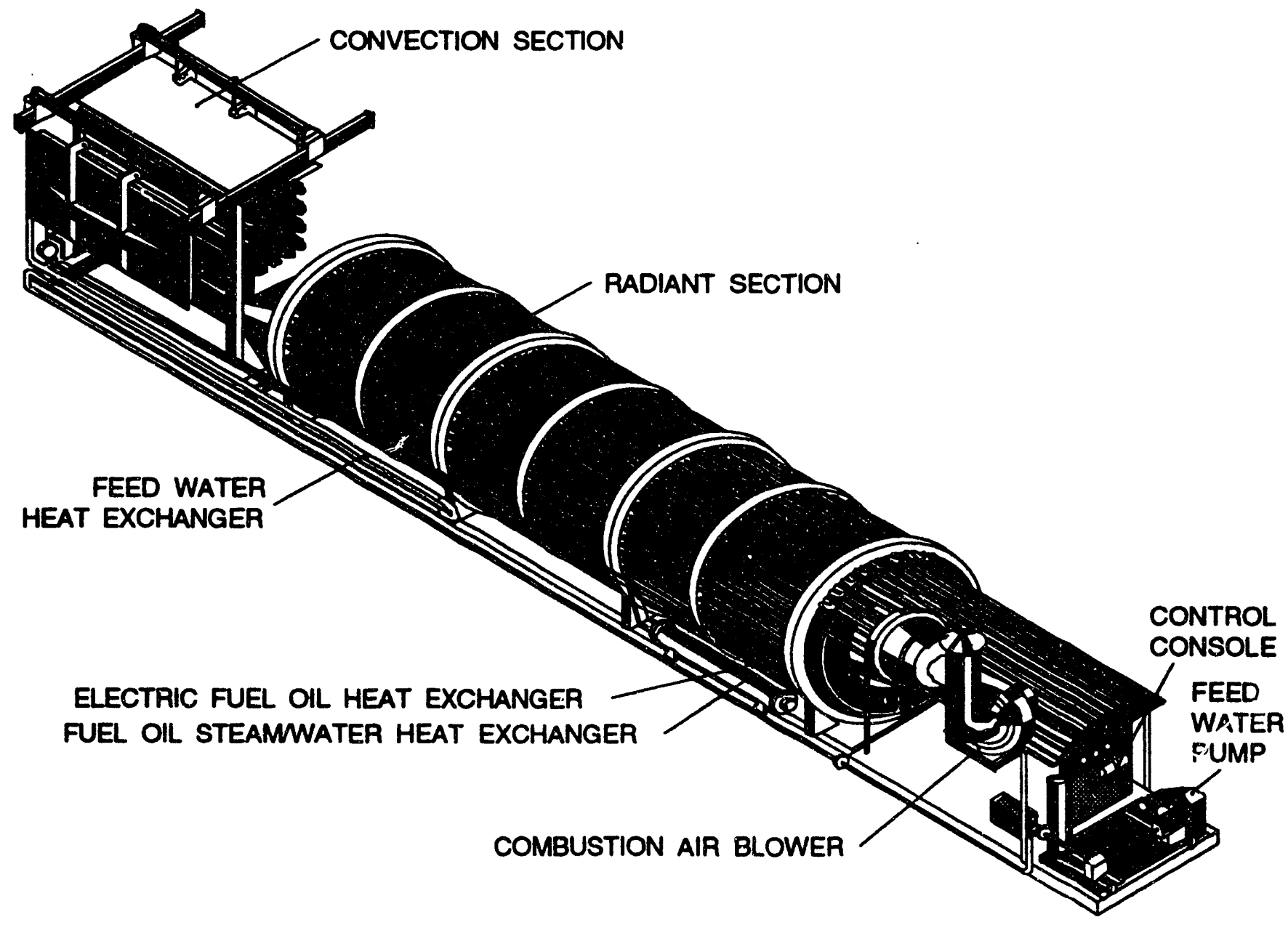

FIGURE 6.1. - Iosmetric view of a skid-mounted oilfield steam generator.1

components on the supporting skid. 1 The generator is fully self-contained and equipped with necessary controls and instrumentation to monitor operating pressures, flows, temperatures, etc. The standard oilfield steam generator flow chart is shown in figure 6.2.

A self-contained unit is ready for operation, and the only field work required to prepare a generator for operation after transportation consists of connecting unit's discharge pipe to the well, connecting feedwater to pump, connecting electrical power, and connecting fuel supply to the generator. 


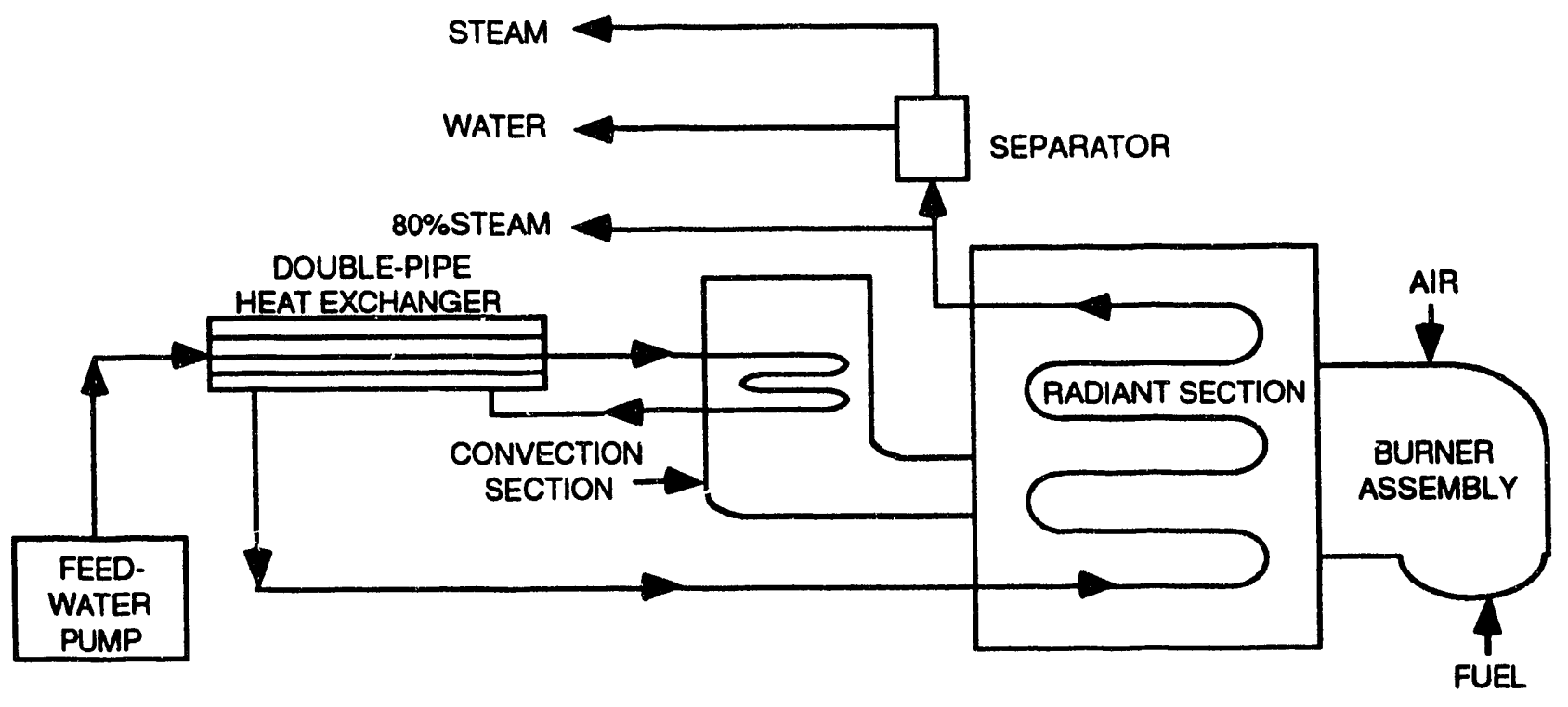

FIGURE 6.2. - Schematic of oilfield steam generator.

\section{Generator Selection}

Generator capacity must be carefully chosen for each application to avoid idle steam capacity. Oilfield steam generators are available with pressure ratings of 1,000,1,500 and 2,500 psig, based on coil pressure capability. They come in a range of standard sizes from 10 to $150 \mathrm{MM} \mathrm{BTU} / \mathrm{hr}$ heat output (approximately equivalent to 650 to $9,864 \mathrm{bbl}$ of water (as steam) per day) and are designed to burn both gas and oil.

Steam rates in the United States are normally reported in barrels of steam per day (BSPD) regardless of steam pressure or quality. This is also the 'cold water equivalent' (CWE) rate. The CWE rate is much smaller than the actual volumetric rate for wet steam and is equivalent to the mass flow rate. The term BSPD originates from the early day steam injection practice when the generator feedwater meter indicator was calibrated in barrels and it was the most convenient place to measure the amount of steam injection.

Tabis 6.1 is a generator selection chart provided by one manufacture. ${ }^{2}$ Table 6.2 presents the capacities and fuel requirements for these units. The electrical requirements for selected units are depicted in table 6.3. The capacity and fuel requirements in these tables are based on feedwater temperature of $100^{\circ} \mathrm{F}$ and $80 \%$ quality steam at $1,000 \mathrm{psig}$. The approximate steam generator 
TABLE 6.1. - Oilfield Steam Generator Selection Chart ${ }^{2}$

\begin{tabular}{|c|c|c|c|c|}
\hline \multirow{3}{*}{$\begin{array}{l}\text { Size } \\
\text { of the } \\
\text { unit } \\
\text { boiler, hp. }\end{array}$} & \multicolumn{4}{|c|}{ Boiler capacity ${ }^{a, b}, c$} \\
\hline & \multirow{2}{*}{$\begin{array}{l}\text { Absorted henl } \\
\text { BTU } \times 10^{6} \\
\text { per hour }\end{array}$} & \multirow{2}{*}{$\begin{array}{l}\text { Sleam@80\%. Qualiix } \\
\text { Pounds } \\
\text { per hesur }\end{array}$} & \multicolumn{2}{|c|}{ Cold waler equivalenl } \\
\hline & & & $\begin{array}{l}\text { Barrels } \\
\text { Mer hour }\end{array}$ & $\begin{array}{l}\text { Barrels } \\
\text { per day }\end{array}$ \\
\hline 314 & 10 & 9.600 & 27.4 & 657 \\
\hline 553 & 18 & 17.280 & 49.3 & 1,183 \\
\hline 657 & 22 & 21.120 & 60.3 & 1.447 \\
\hline 747 & 25 & 24.000 & 68.5 & 1.644 \\
\hline 896 & 30 & 28.800 & 82.2 & 1,972 \\
\hline 1.195 & 40 & 38.400 & 109.6 & 2.630 \\
\hline 1.494 & 50 & 48.000 & 137.0 & 3.288 \\
\hline 2.100 & 70 & 67.200 & 191.8 & 4.603 \\
\hline 3,000 & 100 & 96,000 & 274.0 & 6.576 \\
\hline 4.500 & 150 & 144,000 & 611.0 & 9.864 \\
\hline
\end{tabular}

- Feedwater Temperature $=100^{\circ} \mathrm{F}$.

b Steam Pressure $=1,000$ psig.

c Generator Efficiency $=\mathbf{9 0 \%}$.

TABLE 6.2. - Oilfield Steam Generator Fuel Requirements ${ }^{2}$

\begin{tabular}{|c|c|c|c|c|}
\hline \multirow{2}{*}{$\begin{array}{l}\text { Size } \\
\text { of the } \\
\text { unit } \\
\text { boiler.ho }\end{array}$} & \multicolumn{2}{|c|}{$\begin{array}{c}\text { Fuel oila,b.c } \\
\text { Basis: } 130,000 \text { BTU/GAL }\end{array}$} & \multicolumn{2}{|c|}{$\begin{array}{c}\text { Gas a,b,c } \\
\text { Basis: } 1000 \text { BTU/SCE }\end{array}$} \\
\hline & $\begin{array}{l}\text { Gallons } \\
\text { per hour }\end{array}$ & $\begin{array}{l}\text { Barrels } \\
\text { Derday }\end{array}$ & MSCF'Mour & MMSCF/day \\
\hline 314 & 79 & 44.8 & 11.36 & 0.2727 \\
\hline 553 & 141 & 80.6 & 20.45 & 0.4909 \\
\hline 657 & 172 & 98.5 & 25.00 & 0.66 \\
\hline 747 & 196 & 112.0 & 28.41 & 0.6818 \\
\hline 896 & 235 & 134.4 & 34.10 & 0.8182 \\
\hline 1,195 & 314 & 179.1 & 45.45 & 1.09 \\
\hline 1.494 & 392 & 223.9 & 56.82 & 1.3636 \\
\hline 2,100 & 549 & 313.5 & 79.55 & 1.9091 \\
\hline 3,000 & 784 & 447.8 & 113.64 & 2.7273 \\
\hline 4,500 & 1.176 & 671.8 & 170.46 & 4.0009 \\
\hline
\end{tabular}

a Feedwater Temperature $=100^{\circ} \mathrm{F}$.

b Stcam Pressure $=1,000$ psig.

c Generator Efficiency $=90 \%$. 
TABLE 6.3. - Oilfield Steam Generator Electrical Requirements, ${ }^{1} \mathrm{kw}$

\begin{tabular}{c|ccc|ccc}
\hline $\begin{array}{c}\text { Size } \\
\text { of the } \\
\text { unit } \\
\text { boiler, hp }\end{array}$ & \multicolumn{3}{|c|}{ Oil fired. psi } & \multicolumn{3}{c}{ Gas fired. psi } \\
\cline { 2 - 7 } & 1,000 & 1.500 & 2,500 & 1.000 & 1.500 & 2,500 \\
\hline 314 & 41 & 47 & 60 & 19 & 25 & 36 \\
657 & 60 & 72 & 95 & 34 & 50 & 80 \\
896 & 89 & 100 & 137 & 65 & 76 & 114 \\
1.195 & 116 & 134 & 172 & 91 & 110 & 146 \\
1.494 & 160 & 179 & 216 & 134 & 154 & 194 \\
\hline
\end{tabular}

$1480 \mathrm{~V}, 3$-phase, 60 cycles with $110 \mathrm{~V}$ control circuit.

output in pounds of water evaporated per hour for other operating pressures, steam quality, and feedwater temperatures is shown in figure 6.3. The approximate fuel cost for operating various capacity generators by burning $10^{\circ}$ to $20^{\circ}$ API California crudes is shown in figure 6.4. This figure is based on Table 6.2 and can be used to estimate approximate fuel cost for the generation of steam. In figure 6.5 , the cost of steam generation by burning natural gas $(1,000 \mathrm{Btu} / \mathrm{scf})$ is depicted.

ACTUAL EVAPORATION-LBS./HRS./B.H.P.

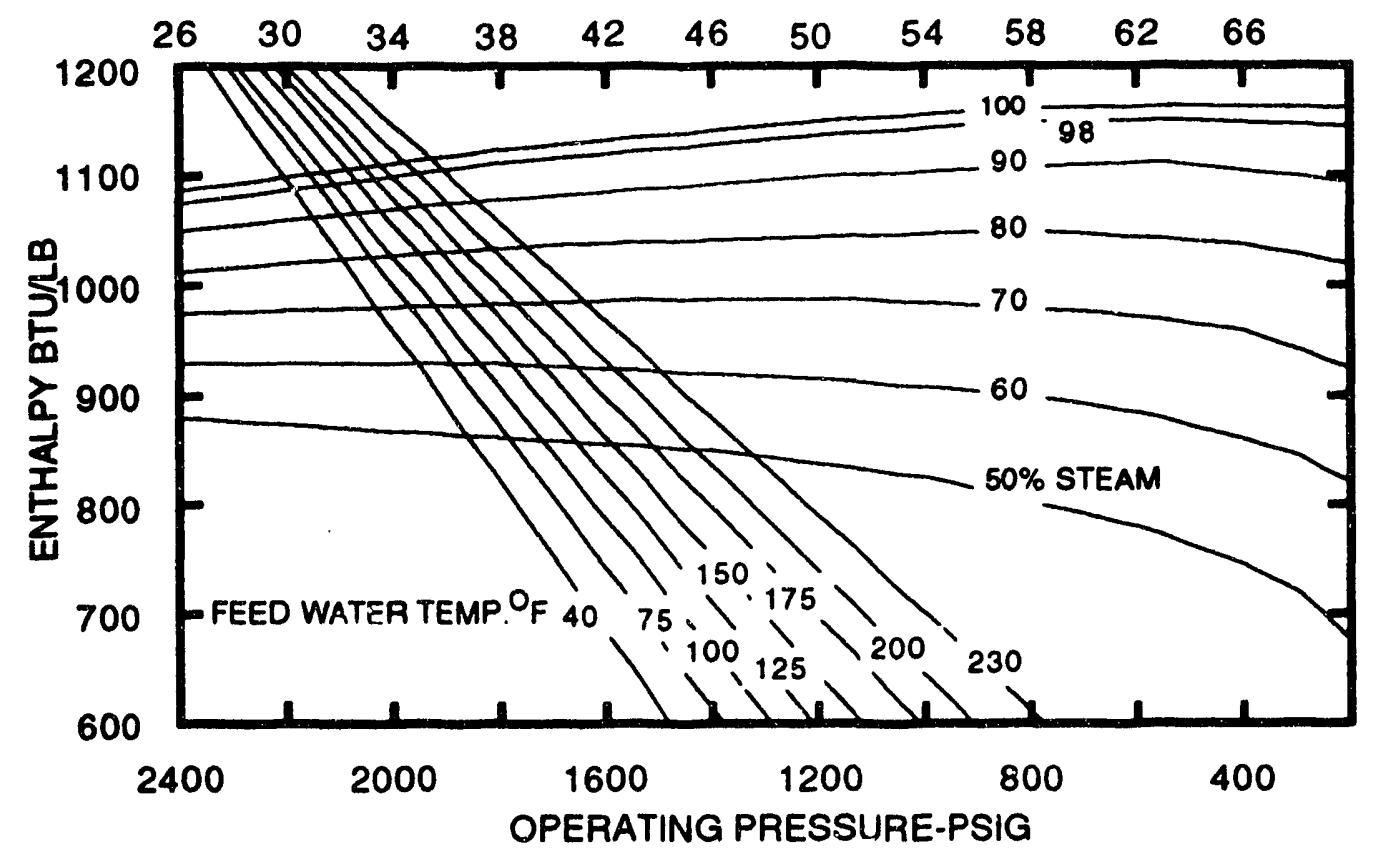

FIGURE 6.3. - Approximate steam generator output (lb/hr/bhp) at various pressures, steam quality and feedwater temperature. 


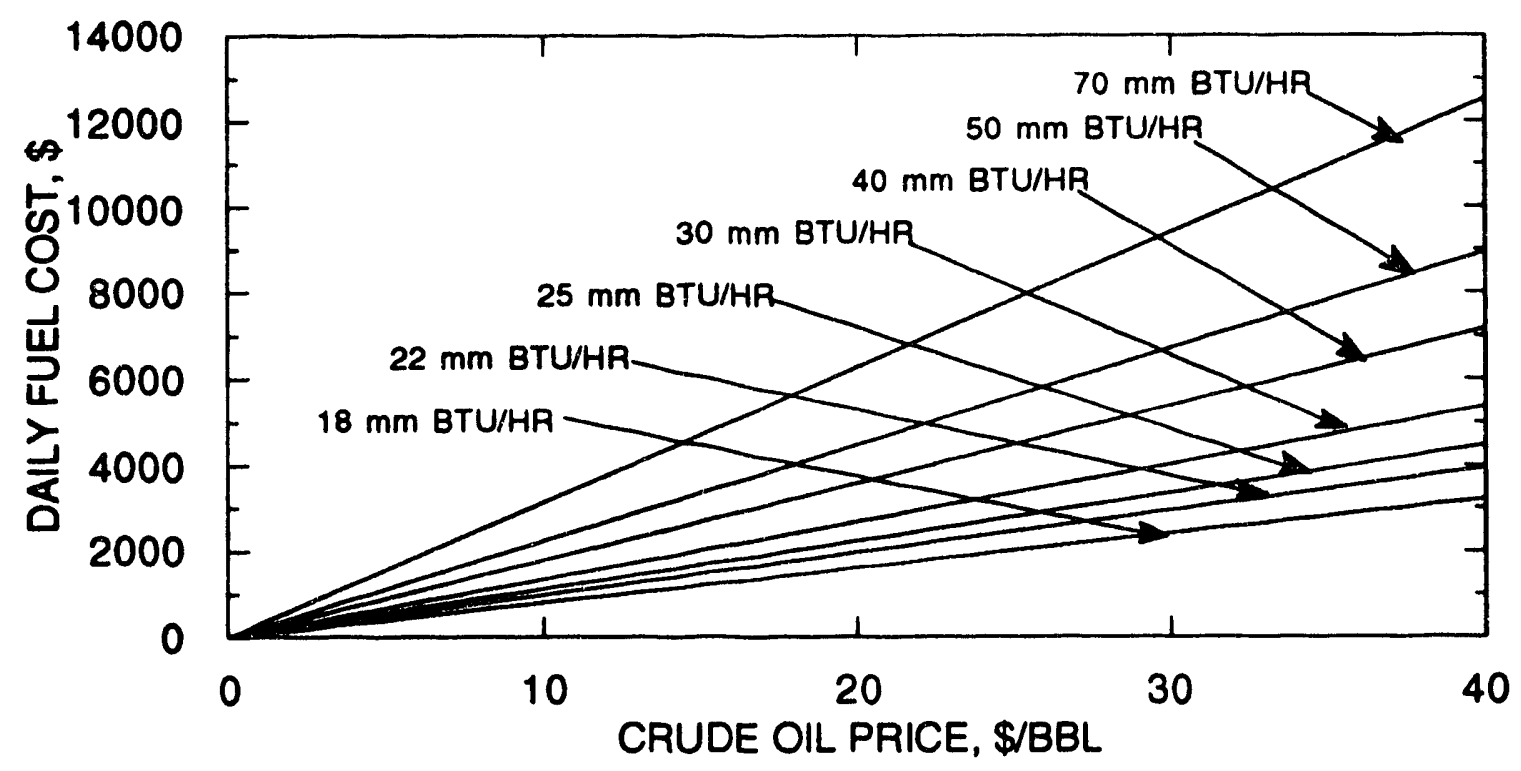

FIGURE 6.4. - Daily fuel (lease crude) cost for operating various capactiy generators.

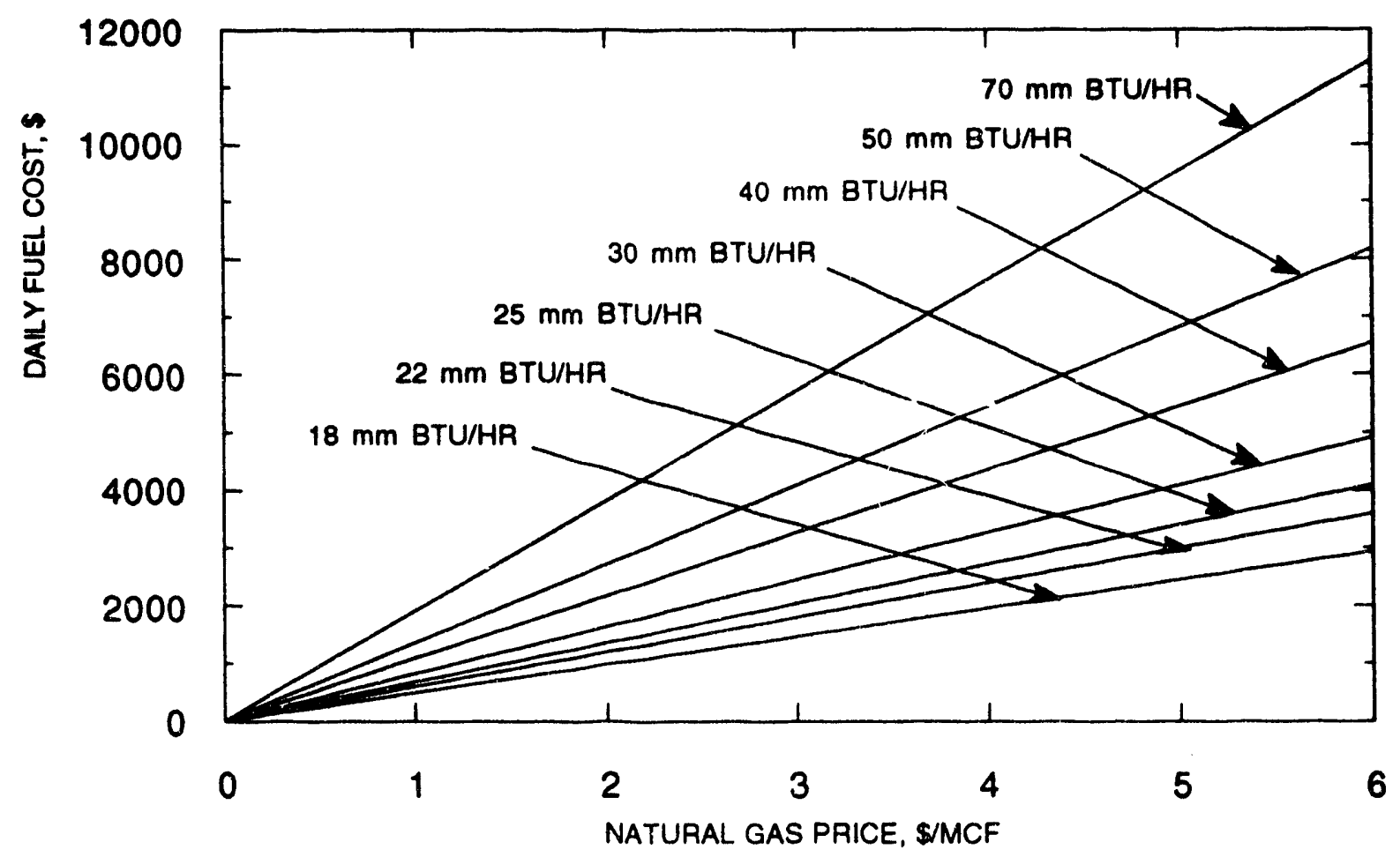

FIGURE 6.5. - Daily fuel (natural gas) costs for operating various capacity steam generators. 
Figure 6.3 assumes steam generator efficiency as $90 \%$. The following procedure is employed to graphically determine the steam generator capacity from Fig. 6.3. To determine the capacity of a $50 \mathrm{MM} \mathrm{Btu/hr}$ generator delivering $80 \%$ quality steam at $1,500 \mathrm{psig}$ (feedwater temperature assumed to be $100^{\circ} \mathrm{F}$ ), enters the chat at 1,500 psi and proceeds vertically to $80 \%$ quality line. Then proceeds horizontally to locate the $100^{\circ} \mathrm{F}$ feedwater temperature line and then goes vertically to read off the evaporation capacity as $33 \mathrm{lb} / \mathrm{hr} / \mathrm{bhp}$. From Table 6.1 , the boiler horsepower corresponding to a $50 \mathrm{MM} \mathrm{Btu/hr}$ generator is 1,494 and hence generator output in $\mathrm{lbs} / \mathrm{hr}$ is approximately $49,300 \mathrm{lb}(=33 \times 1,494)$ per hour.

Since the steam requirements for thermal operation are not uniform and vary with time, it is important to size steam generators properly, especially for small projects. It is important to bear in mind that in any operation there will be downtime for maintenance, and it is unlikely that all injectors will be in service at any given time. Hence, to avoid idle steam capacity, selection should be based on maximum expected steam injection rate per injector and the number of injectors expected to be in service at any given time. A minimal size generator that fulfills this requirement with some spare capacity to meet unexpected demands should be specified. Selection based on the steam requirements to start an entire project at one time should be avoided. Further, in small projects where steam requirements are small, consideration should always be given to having two or more smaller units instead of one large unit. This permits more flexibility in operation as steam demands change by bringing in or removing from service one or more units. This strategy also ensures that at least some steam is available all the time, in the event of failure of one or more units.

In steam stimulation projects, excess steam capacity can be avoided by steaming the wells in rotation. For example, consider a steam soak operation involving 20 wells to be steamed at the rate of 3,200 barrels of equivalent steam per cycle, two cycles per year. Also, assume that the duration of each injection cycle is 3 weeks. If all of the wells are to be steamed simultaneously, this operation will need about 3,050 barrels of steam per day. From table 6.1 , to satisfy this requirement, the operator must specify a $50 \mathrm{MM} \mathrm{Btu} / \mathrm{hr}$ unit. On the other hand, if only 5 wells are to be steamed at a time, the maximum steam requirement reduces to 763 barrels of steam per day, and smaller $18 \mathrm{MM} \mathrm{Btu/hr}$ unit would be sufficient to meet the peak demand with ample spare capacity. Such a generator is also small enough to be trailer-mounted and can be moved from well to well; thus, minimizing heat losses in distribution lines. Another advantage of adopting a staggering steaming policy in steam soak operations is that the production decline from the wells steamed first is offset by the production rise from wells steamed later.

In large steamflood operations, due to continuous steam injection requirements, steam demand is large and several steam generators are employed. Since steam requirements decrease with time as injected steam reaches producers, steam demand fluctuates, and the operator must bear this in mind while sizing steam generating capacity. Choice of steam generator size should be 
based primarily on the overall expected oil-steam ratio. ${ }^{3}$ As noted previously, generators should not be sized based on total project steam requirement, but should be based on the desired steam injection rate per injector and the number of injectors to be used at any one time. For this reason, it is preferable in steamflood operations to undersize steam generation capacity relative to total project requirement. Also, it is preferable to have a few standby portable units to take care of any unexpected surge in demand or to provide steam to peripheral wells that are too far away from the main unit.

\section{Design Requirements For Oilfield Steam Generators ${ }^{2}$}

A well-designed oilfield steam generator must meet the following minimum criteria:

- Must handle zero hardness feedwater containing an appreciable amount of TDS without significant scale deposit on the tubes.

- Must operate largely unattended with a minimum of operator attention.

- Must lend itself to outdoor installation with minimum of weather protection required in the more severe climates.

- Must be readily portable for ease in relocution at other sites.

- Must have the ability to operate over a wide range of thermal efficiency.

- Must operate efficiently over a wide steam pressure range up to the design pressure.

- Must have the ability to deliver steam of any desired quality.

\section{Steam Generator Components}

A standard oilfield steam generator has the following basic components:

\section{Feedwater System}

The feedwater system of a single-pass steam generator consists of positive displacement pumps, a bypass system, and controls to record and regulate the flow of water to the generator. The positive displacement pump boosts the water from the softener operating pressure to the pressure required by the steam distribution system.

\section{Feedwater Preheater}

Feedwater preheaters are usually a double pipe heat exchanger, whose function is to preheat the incoming feedwater using the hot effluent from the convection section. The purpose of preheating is to elevate the inlet feedwater to a temperature slightly above the 
predicted flue gas dewpoint temperature, thus eliminating the condensation of acid gas components of the flue gas.

\section{Fuel System}

Modern oilfield steam generators are designed to burn different fuels including natural gas, fuel oil, lease crude, compressed natural gas (CNG), etc. The lease crude (fuel oil) fuel system normally includes fuel oil strainer, steam-fuel oil heat exchanger, electric oil heater, fuel oil temperature controller, pressure regulators, bypass system, air and steam atomizing systems, burner assembly, and safety shut-off valves.

\section{Combustion Air System}

The combustion air system provides the air needed for the combustion and includes a high-pressure, forced draft-type air blower and associated controls to regulate the discharge of the blower.

\section{Convection Section}

Flue gas exiting the radiant section contains a large amount of heat. The purpose of the convection section is to capture the bulk of this heat and thereby improve the thermal efficiency of the generator. The convection section is essentially a heat exchanger designed to transfer the heat from the flue gases to the feedwater.

The convection section is made of two parts: the lower bare tube section and the upper finned tube section. The preheated feedwater enters the convection section at the top through the finned tubes and travels to the bottom section. The hot tlue gases from the radiant section enter the convection section at the bottom and leaves from the top. This countercurrent flow results in efficient heat transfer from the hot gases to the water. Since the bare tubes are the first to be exposed to hot flue gases, they are subjected to thermal shock and hence known as the shock tubes.

Typically, in a $50 \mathrm{MM} \mathrm{BTU/hr}$ unit, there are six to ten rows of shock tubes. In each row there are 12 tubes, each $12 \mathrm{ft}$ long. The principal function of the shock tube is to reduce the flue gas temperature and to shield the finned tubes from exposure to direct radiant heat. Usually there are six to ten rows of finned tubes in the upper section. In each row, there are nine tubes located on 6-in. centers.

In oil burning units, the convection sections are equipped with removable side panels to facilitate cleaning of the soot that accumulates. A drain is usually located at the bottom of the transition zone (a zone where the bare tube is replaced by finned tube) to drain away wash water from the desooting operation. The tubing arrangements in a typical convection section are shown in figure 6.6. 


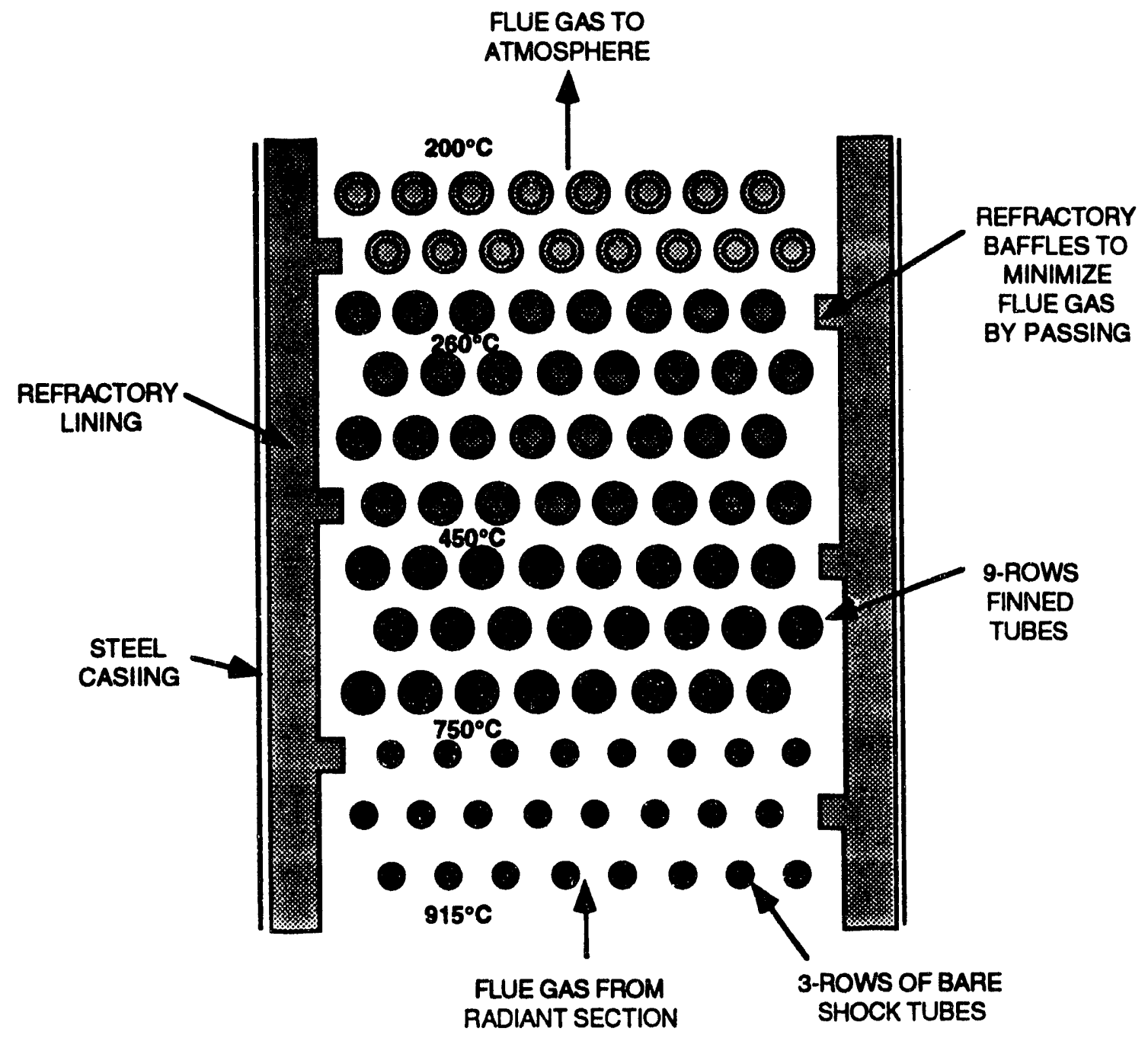

FIGURE 6.6. - Tubing arrangements in the steam generator flue gas convection section. ${ }^{2}$

\section{Radiant Section}

The radiation section is comprised of a cylindrically shaped combustion chamber housing the radiant section tubes, tube hanger support systems and the burner assembly. The dimensions of a $50 \mathrm{MM}$ BTU/hr unit radiant section as provided by one manufacturer is $11 \mathrm{ft}$ in diameter and $40 \mathrm{ft}$ long. The tubes within the radiant section are 3 in. in diameter and are held in place by primary hangers in the endplate and by three or four rows of secondary hangers attached to the curved wall. Depending on the outlet pressure ratings, schedule 40,80, or 160 pipes are used. These tubes are arranged in rows and travel the length of the generator. In most cases, they penetrate the two ends of the radiant section. The burner is located in the center of one flat end. On the other end, the transition section connects the radiant section to the convection section. The radiant section shell wall is lined with light-weight refractory bricks to protect it from the high-temperature corrosive 
combustion gases. The type of refractory used depends upon the nature of fuel burned and the environment.

\section{Steam Generator Controls}

Controls and instruments are integral parts of a steam generator that ensure its safe operation. These include pressure relief and safety valves, alarms of various types, such as a high and low steam discharge pressure alarms, low and high steam discharge temperature alarm, flame failure alarm, low fuel oil pressure alarm, low burner blower pressure alarm, low fuel oil temperature alarm, low feedwater flow alarm, high tube wall temperature alarm, and low and high atomizing pressure alarm. These temperature, pressure, and flow monitoring devices are designed to ensure safe operation of a generator and to keep steam generator failure to a minimum. In addition, controls to monitor steam quality, exhaust stack oxygen content, combustion air dampers, etc. are also provided.

\section{Process Description}

Figure 6.7 is a typical oilfield steam generator layout showing the feedwater system, fuelcombustion air system, and associated controls and instrumentation. 19

The feedwater system of a single-pass steam generator consists of a triplex or quintaplex positive displacement pump and a bypass system to control water flow rate and to proportion the water flow rate with fuel input. The positive displacement pump boosts the water from the softener operating pressure to the pressure required by the steam distribution system. The bypass loop around the pump connects the pump discharge with pump suction. A motor valve on this line controls the fraction of total pump discharge to be routed back to pump suction, and thereby controls the feed rate to the steam generator. The orifice in the feedwater line measures the flow and is connected to a differential pressure cell that supplies the control signal for the firing rate. In this way, the fuel injection rate and air flow are adjusted to correspond with water flow rate.

The feedwater under pressure is first forced through a feedwater preheater. The preheater is a double pipe heat exchanger where the feedwater is heated to about $260^{\circ} \mathrm{F}$ by water on its way from the convection section to radiant section. Preheating the feedwater assures that the outside tube temperature in the convection remains above the dewpoint temperature of the sulfur trioxide and/or sulfur dioxide in the flue gases. Condensation of these gases along with the moisture in the flue gas will result in the formation of corrosive sulfuric acid and leads to rapid corrosion of convection section tubes and fins.

The dewpoint temperature of the flue gas and, therefore, the required feedwater preheat temperature, is a function of the sulfur content of the fuel burned in the generator. In general, a low-gravity, high-sulfur-content crude will have a high dewpoint temperature; thus requiring higher feedwater preheat temperature. 


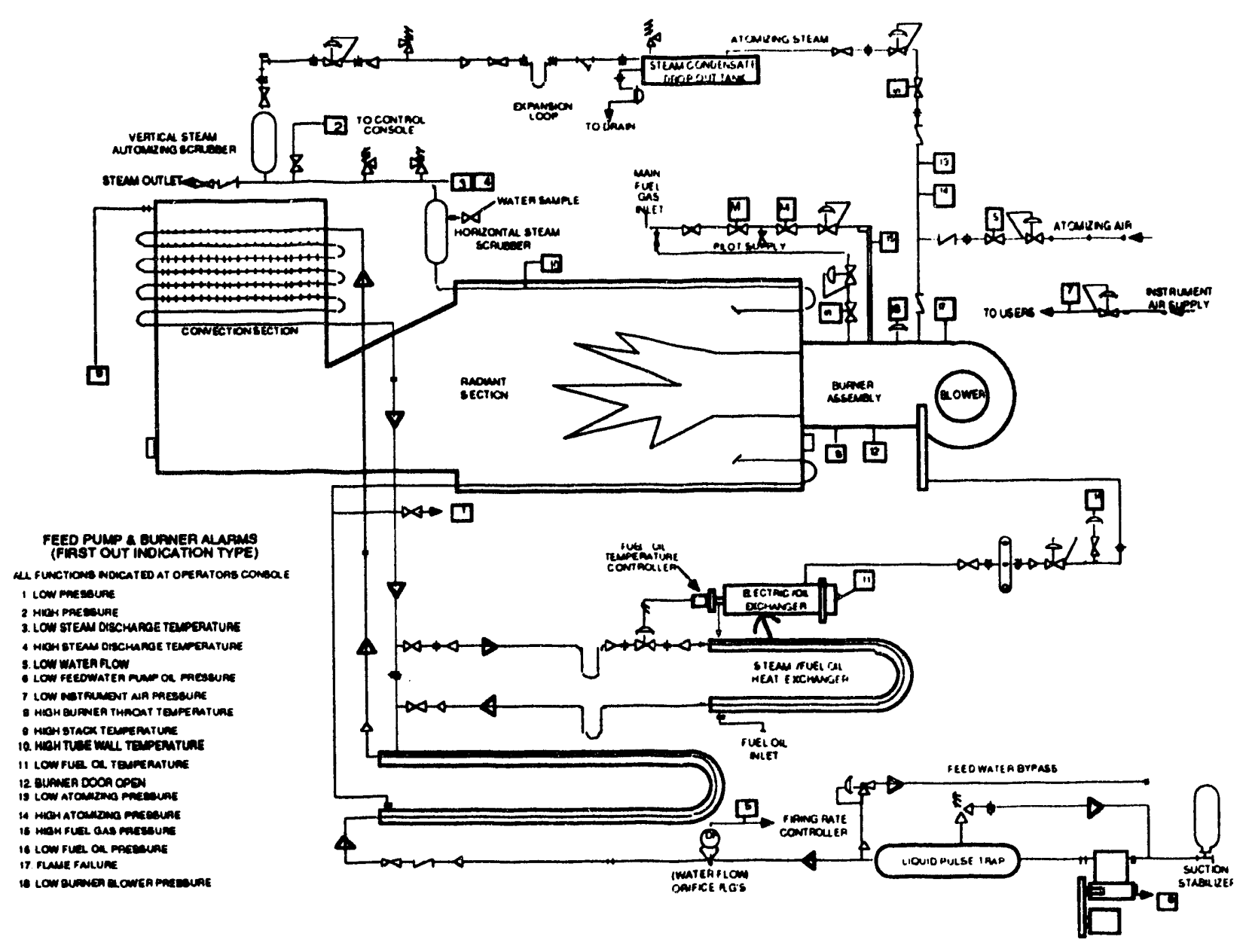

FIGURE 6.7. - Layout of a typical oilfield steam generator burning lease crude. ${ }^{19}$

The preheated feedwater enters the top of the convection section and flows downward and countercurrently to the hot flue gases from the radiant section. The $1,600^{\circ} \mathrm{F}$ hot flue gases from the radiant section enter the convection section at the bottom and contact the lower, most-bare tubes of the convection section. These bare tubes are chosen to withstand the hot flue gas temperatures and are located $4.5 \mathrm{in}$. apart. The flue gas, after losing part of its heat to the bare tube, then contacts a series of finned tubes at the upper section at a reduced temperature. The flue gas then exits the top of the convection section at a temperature of $300^{\circ}$ to $600^{\circ} \mathrm{F}$.

The finned tubes, which increase the heat transfer rate between the feedwater and flue gas, cannot be used in the bottom section because of increased corrosion at the high temperature. The transition between finned tubes and bare tubes is carefully chosen to ensure that the maximum permitted fin tip temperatures are not exceeded. Since burning of lease crude results in an accumulation of soot in the convection section heat transfer surfaces, operation of the generator at 
optimum performance will require regular cleaning of the convection section tube surfaces. The cleaning cycle varies from 3 weeks to 3 months, depending on the fuel oil.

After supplying the heat requirements of the feedwater preheater, and usually the heat needed to preheat the fuel oil, the effluent from the convection section enters the radiant section of the steam generator. The tubes within the radiant section are heated by direct radiation from the combustion gases and radiation from the refractory lining behind the tubes. The heat transfer process at work in the radiant section is not simple. To guarantee that the correct heat flux is delivered to the tubes, manufacturers use sophisticated computer programs to calculate tube spacing and tube placement from the refractory wall. Heat flux rates of 20,000 BTU/hr- $\mathrm{ft}^{2}$ are typical in oilfield steam generators. Failure to model correctly the heat flux rates can result in poor generator efficiency and premature tube failures.

Design and construction practices, which are common for oilfield steam generators, include closely spaced tubes to minimize heat absorbed by the refractory, and reducing tube size to minimize the heat release in the event of a tube failure. The feedwater leaves the radiant section as $80 \%$ quality steam.

Since some formations are susceptible to swelling, it is not possible to inject wet steam into such reservoirs. For these, the effluent steam and water from the generator must be separated and only dry steam injected. The separated water can be utilized to preheat feedwater.

\section{Fuel System}

Although only the fuel oil system is shown in figure 6.7, oilfield steam generators are designed to burn different fuels, including lease crude, natural gas, liquefied petroleum gas (LPG), etc. To provide efficient combustion of fuel oil, they must be pumped into the burner, divided into small droplets and intimately mixed with air before burning. The process of dividing the fuel oil into small droplets is called atomization.

Steam or compressed air is generally used as the atomizing agent. The atomization takes place in the burner nozzle. The atomization is accomplished by forcing the crude through the fuel oil nozzle at sufficient pressure to guarantee a well-dispersed pattern. An atomizing air compressor and/or an atomizing steam system is used to atomize the fuel. To assure the formation of proper droplet size and spray pattern shape at the nozzle exit, the oil must enter the nozzle at correct viscosity. Most nozzles are designed to function correctly at an oil viscosity of 100 to 150 Saybolt Second Unit (SSU).

A typical $14^{\circ}$ API Kern River, CA, crude must be preheated to about $250^{\circ} \mathrm{F}$ to reach the proper nozzle viscosity. Hence, oilfields are equipped with a fuel oil preheater to preheat the fuel oil. Electricity, hot water, or steam is used to preheat fuel oil. In figure 6.7, both electricity and steam are used to preheat fuel oil. In many leases, produced oil is hot enough to fire a generator. 
Close control of the temperature of the oil pumped to the burner is critical. Close temperature control is needed to provide oil at constant pressure and viscosity. If the oil were to overheat and become less viscous, the burner could overfire. If the oil were too cool and become more viscous, it would be difficult to handle and impossible to atomize and burn. The oil pump and piping between oil storage tank and steam generator must also be insulated to maintain correct oil temperature. For proper nozzle operation, the fuel oil must be delivered to the nozzle at the correct pressure. For a $50 \mathrm{MM} \mathrm{BTU/hr}$ generator, the fuel oil must be delivered to the nozzle at 100 psi at the rate of about $6.5 \mathrm{gpm}$.

The basic components of a generator fuel system burning lease crude include fuel pressuring pump, fuel oil heater, atomizing equipment, and heated fuel storage. A fuel oil system supplied by the generator manufacturer usually includes a bypass system to bypass any fuel in excess of that required by the nozzle. Gear pumps are often used for fuel oil service. However, the lubricity of the fuel oil should be considered before specifying the fuel pumping equipment.

When natural gas is used as the fuel in an oilfield steam generator, a separate fuel system is used. Instead of a fuel nozzle, a pipe ring is used at the transition firum the burner throat to the radiant section. Natural gas is supplied to this ring at approximately 10 inches of water column. The natural gas is released into the combustion chamber through small nozzles (holes) in the ring, where they mix with combustion air and burn. The flame pattern of the gas flame is more stable than the oil flame and hence are more easily controllable. Typical gas fuel requirements for a 50 MM BTU/hr generator are about 1,000 standard cubic feet per minute (SCFM) of 1,000 Btu/SCF gas.

\section{Combustion Air System}

The air needed for the combustion of the fuel is provided by a high-pressure air blower. A typical $50 \mathrm{MM}$ BTU/hr generator burning $6.5 \mathrm{gpm}$ of crude will require approximately 17 SCFM or $52,280 \mathrm{lb} / \mathrm{hr}$ of air. This air is not filtered unless the atmosphere is dust laden. Filtering will entail additional blower horsepower.

The combustion air system includes a forced-draft type air blower and associated controls to regulate the discharge of the blower. The air blower system must be designed for local operating conditions. The BTU output of a steam generator at sea level is higher than that of higher altitudes. Also, if the generator is installed inside an ill-ventilated building (to protect it from harsh winter), the blower is likely to suck hot air from inside the building, resulting in efficiency degradation. Hence, the blower must be located in a well-ventilated area.

The blower delivers air to the radiant section of the generator through the burner nozzle throat. The air and the atomized fuel are turbulently mixed at the transition from the throat to the radiant section, and combustion is initiated. 
The rate of air delivery to the combustion process is determined by the 'shutters' placed at the blower discharge. The amount of excess oxygen in the flue gas, as it leaves the radiant section, controls the position of these shutters. Excess oxygen concentration for normal operations is between $1.5 \%$ and $3 \%$. Excess oxygen outside this range causes the shutter controller to take appropriate action.

To assure complete combustion, steam generation equipment has to be operated with about 3\% excess air. Any excess air above this amount will lower the steam generator efficiency, because the additional excess air robs the heat from the combustion process that otherwise could be used to generate steam. Otherwise, the use of less than $1.5 \%$ excess air will probably cause incomplete combustion.

As part of the efficient operation of th; unit, the stack gases released by the generator should be monitored to assure that complete combustion is occurring and no undue air is being used. The quantitative determination of total air ( $100 \%+$ excess air) admitted to an actual combustion process requires a complete flue gas analysis for $\mathrm{CO}_{2}, \mathrm{O}_{2}, \mathrm{CO}$ and $\mathrm{N}_{2}$. However, $\mathrm{N}_{2}$ is usually determined by difference. No oxygen in the flue gas indicates incomplete combustion with resultant fuel wastage. Too much excess oxygen indicates needlessly high stack losses. By performing these analyses and adjusting generator operation when necessary, the operator can save fuel.

\section{Steam Generator Specifications 4}

Since steam injection operations are site specific, oilfield steam generators must be custom designed to meet the requirements of a specific site. Operators must provide certain minimum information to steam generator vendors, to assure that minimum design, safety and environment considerations are met. The American Petroleum Institute (API) recommends that steam injection operators include the following minimum information in steam generator specification sheets:

(a) Fuel oil analysis (see appendix 6-A for fuel oil analysis specification sheet)

(b) Fuel gas analysis (see appendix 6-B for fuel gas analysis specification sheet)

(c) Other fuels analysis (if any)

(d) Feedwater analysis (see appendix 6-C for feed water analysis specification sheet)

(e) Utilities specification

(i) Electric power: $\mathrm{V}-\mathrm{Ph}-\mathrm{H}_{\mathrm{z}}$ (e.g.,. $440 \mathrm{~V}, 3 \mathrm{Ph}, 60 \mathrm{H}_{\mathrm{z}}$ )

(ii) Compressed air: _ SCFM _ Psig _ ${ }^{\circ} \mathrm{F}$ dewpoint

(iii) Pilot fuel: Type SCFM Psi

(f) Site conditions:

(i) Ambient Air Temperature, ${ }^{\circ} \mathrm{F}$ : $\operatorname{Max}$ Min Design 
(ii) Wind velocity, MPH: _ Max _ Min _ Design

(iii) Elevation, $\mathrm{ft}$ Above mean sea level

(iv) Seismic zone:

(v) Rainfall, in./yr: Avg.

(vi) Humidity, \%: Max Min Design

(vii) Atmospheric conditions: List unusual condition, such as $\mathrm{H}_{2} \mathrm{~S}$, sand, dust, salt, air, etc.

(g) Environmental consideration:

(i) $\mathrm{SO}_{2}$ emission limits

PPM: _ current _ future

(ii) $\mathrm{NO}_{\mathrm{x}}$ emission limits:

$\mathrm{Lb} / \mathrm{hr}$ : _ current _ future

(iii) Particulate emission limit:

$\mathrm{Gr} / \mathrm{SCF}$ : current future

$\mathrm{Lb} / \mathrm{hr}$ : current _ future

(iv) Waste liquid discharge limits.

(h) Transportation

Operators must list any unusual transportation problem that vendors may encounter while transporting a generator from the shop to the site. These may include such obstacles as tunnels, narrow or weak bridges, restrictive roads, etc. Any special local permits required for the transport of heavy equipment on county roads must also be spelled out.

(i) Safety Instrumentation and Equipment:

Operators must spell out any desired special safety features that have to be included with the generators to assure maximum safety of operating personnel and equipment. Any special safety equipment required to comply with state and local codes must also be listed. At the minimum, generators have to be equipped with the following safety instruinentation to meet the code standards.

(i) ASME code required safety valves.

(ii) Electronic flame monitoring device and combustion controller. This includes prepurge, proof-of-pilot, proof-of-rnain flame, and postpurge sequence.

(iii) Steam pressure controller

(iv) Feedwater flow rate transmitter and controller

(v) Feedwater pump relief valve

(vi) Burner firing rate controller

(vii) Temperature and pressure indicating devices 
(j) Safety Limit Devices:

API recommends that oilfield steam generators be equipped with the following safety shutdown switches. Upon malfunction, one or more of these devices should shut burner fuel valve(s) and require manual restart. Many of these switches are also required by Federal and most State Codes.

(i) Flame failure

(ii) High steam pressure

(iii) High tube temperature

(iv) High stack temperature

(v) High burner throat temperature (oil fired only)

(vi) High/low atomizing pressure switch (oil fired only)

(vii) High fuel gas pressure switch (gas tired only)

(viii) Low fuel oil pressure switch (oil fired oniy)

(ix) Low fuel oil temperature switch (oil fired only)

(x) Low feedwater flow rate control

(xi) Low combustion air pressure switch

(xii) Low instrument air pressure

(xiii) Low steam pressure

(xiv) Power failure

(k) Hook up

If special design considerations are required for connections, operator should specify service, size, rating and locations for the following:

(i) Feedwater inlet

(ii) Steam outlet

(iii) Fuel inlets

(iv) Elećrical connection

(v) iny other special requirements.

\section{Fuels For Oilfield Steam Generators}

Oilfield steam generators burn a variety of fuels, the most common being natural gas and lease crudes. Other generator fuels include industrial fuel oil and LPG. The main criterion for the selection of a fuel or fuels is the availability at a particular site and at a reasonable cost. Because of the fluctuating nature of costs of delivered fuel due to price, freight rates, seasonal variations in availability and temporary shortages, an operator must plan for the use of more than one fuel to ensure continuous operation at a reasonable cost. 


\section{Natural Gas}

If natural gas is readily available, it is the most convenient fuel because it can simply be metered to the burner at a pressure that assures the desired vo!ume feed rate. Other advantages of gas are cleanliness of operation, relative simplicity of heat input control and fewer operating problems. However, if the gas is allowed to accumulate in faulty valves or fittings which are not readily detectable, explosions can occur. The explosion hazard can be minimized with well-trained operators. Some of the problems associated with the use of natural gas as generator fuel are: water in gas supply lines, inadequate gas pressure, and flow rate as well as excessive pressure drop under maximum demand operations. Typical gas consumption rates for different sizes of steam generators are shown in table 6.2.

\section{Liquefied Petroleum Gas (LPG)}

Light hydrocarbons such as propane and butane are distributed and stored under pressure as liquefied gas. When the pressure is released, the liquid boils producing gaseous fuels. Use of LPG has most of the advantages of natural gas, but does require storage capacity and vaporizers to convert LPG into gaseous form for combustion. Liquefied petroleum gases are more expensive than natural gas. Typical consumption rates for propane range from about 1,500 gallons per day (2,520 BTU/SCF) for $5 \mathrm{MM} \mathrm{BTU/hr}$ heat release rate to 15,000 gallons per day for $50 \mathrm{MM}$ BTU/hr units.

\section{Lease Crude}

Lease crude is the most commonly used steam generator fuel in the oil patch. However, the operating difficulties and hence the costs associated with burning lease crude are significantly higher than those associated with burning natural gas. Lease crudes contain water which is corrosive and susceptible to sludge formation upon storage. Additives must be added to the crude to minimize these problems.

The following requirements must be met before crude oil can be used as generator fuel..$^{5}$

1. Oil properties such as the API gravity at $60^{\circ} \mathrm{F}$, viscosity from $100^{\circ}$ to $300^{\circ} \mathrm{F}$, percentage of basic sediment and water (BS \& W), and flash point must be known to successfully control burning. The flash point is defined as the temperature at which the oil begins to vaporize. These vapors will flash when ignited.

2. The burner control system must be evaluated to assure that it is compatible with the oil pump.

3. The atomizing medium must be able to vaporize the oil. 


\section{Steam Generation Operations and Problems}

The oilfield steam generation system is a complex web of many interconnected mechanical devices that are outfitted with various instruments and safety devices to ensure the safe and efficient delivery of steam. As with any mechanical device, breakdowns are inevitable, and steam generator failure can be kept to a minimum by adopting good operational practices and mechanical maintenance schedules. In this section, steam generator related operation problems and solutions are reviewed. Maintenance practices will be discussed in the next section.

\section{Tube Failure}

Even though steam generator tubes decay and fail with use and require periodic replacements, premature tube failures can be prevented by knowing the causes of tube failures and avoiding them. Some of the causes of tube failure are direct impingement of flame on tubes, improper feedwater temperature, improper water-to-fuel ratio, and poor burner operation resulting from a too high or too low fuel preheat temperature.

Direct impingement of flame on tubes or tube hanger results in hot spots and eventual tube burnout. This problem can be avoided by adjusting the flame to minimize impingement on tubes or tube hangers. A clean fuel nozzle, proper air-fuel ratio and correct radiant section pressure all contribute to a good flame pattern. In an oil-fired steam generator, good flame pattern can be achieved and maintained by ensuing correct fuel pressure and viscosity and employing right quality steam at suitable pressure for atomization.

Use of improperly heated feedwater to generate steam will also result in tube failures. When cold feedwater is used to generate steam in a generator designed for preheated feedwater, it will result in increased heat load on the unit. This :icreased load causes hot spots to develop and lead to eventual tube failure. Further, if the temperature of the feedwater entering the convection section is low, the tube temperature can become less than the dewpoint temperature of the hot flue gases. This will produce acid precipitation on the tubes and results in premature fouling of their heat transfer surfaces, as well as corrosion of tubes and fins. These, in turn, will result in premature tube failures.

Tube failures can also occur through the formation and buildup of scales insic. 5 ie tubes. Scale buildup will occur if the feedwater and fuel flow rate are not matched. If the water-to-fuel ratio is low, it will cause concentration of the dissolved solids in the liquid phase to increase and result in scale formation. Scale formed inside the water tubes will lower the overall heat transfer rate and cause hot spots. If left unchecked, scale buildup will diminish the life expectancy of the tubes. Often, formation of scale can be detected by keeping a careful record of feedwater pressure. By checking and adjusting the water-fuel ratio periodically, scale buildup can be minimized and tube life prolonged. 
Tube failure can also occur as a result of improper burner operation. In oil-fired generators burning lease crude, the fuel oil must be preheated to the right temperature before burning. Too high or too low a preheating temperature can result in erractic burner operation and poor flame pattern. Hampton 6 has pointed out that the following problems can result from too high or too low a preheating temperature.

1. Poor atomization will result in poor combustion.

2. Too high a preheat temperature will result in preignition and erratical firing of burner.

3. Too low a preheat temperature makes ignition of fuel almost impossible, especially on a cold start.

4. Improper preheating of fuel oil will result in soot and carbon formation on burner throats and in the combustion area.

5. Improper preheating also will result in oil pump cavitation.

6. Fuel oil pump r qvitation will result in reduced fuel input to burners and poor burner pressure regula on.

\section{Other Operation Problems}

Modern oilfield steam generators are highly instrumented to ensure safe operations and to shut down if an unsafe condition exists. Because of this high degree of automation, steam generators experience frequent shutdowns and reactivation. Such frequent shutdowns and restarts result in cyclic thermal stresses on the refractory material and tubes. ${ }^{7}$ As a result, the refractory lining of the inner surface of a generator will decay and fail. The loss of the insulating properties of the refractory will permit the corrosive combustion gases to come in contact with the outer shell of a generator and can result in skin failure due to corrosion. Further, the expansion and contraction of radiant section tubes will cause tube sealing packings in the tube hanger to fail. In addition, the tubes within the radiant section of a generator will suffer material loss from their outer surface because of the erosive action of the hot combustion gases. Tubes within the convection section will deteriorate with time due to aging and corrosive attack by the products of combustion. Hence, steam generators must be rebuilt periodically.

California field experience has shown that on an average a $50 \mathrm{MM} \mathrm{BTU} / \mathrm{hr}$ steam generator burning lease crude must be rebuilt once every 7 years. In general, the first rebuilt requires the replacement of all the ref:actory and a portion of the tubes. The second rebuilt requires the replacement of refractory and all tubes.

Other mechanical components of the steam generation system will also fail, mostly as a result of poor maintenance. The rotating parts of the blower will fail prematurely, if it is not aligned properly. Accumulation of soots on generator tubes will cause blower motors to overload and eventually fail. Presence of excessive water in the lease crude will result in burner failure. The 
fuel oil nozzle is another troublesome area requiring fiequent cleaning. The seals of the fuel and feedwater pumps also fail frequently and require repair. Field experience will better define other areas of frequent repair. Most of the steam generation system problems, however, can be kept to a minimum with good and well thought out maintenance.

\section{Steam Generation System Maintenance}

Field experience has indicated good maintenance is a key to the technical and economic success of a steam injection project. It is recommended that a routine mainienance schedule be established and maintenance and inspection be perfermed daily, monthly, and yearly. All repairs and maintenance should be documented. Forms should be designed for each specific application. API recommended formats are shown in appendix 6-D. The manufacturer's recommendations should be an integral part of the maintenance and inspection schedules. The environment in which a generator operates dictates certain types of checks and maintenance.

Based on field experience, the $\mathrm{API}^{4}$ recommends the following maintenance schedules:

\section{Daily Maintenance and Inspectio'.}

Routine inspection and recording of all instrument readings once each shift are recommended. The instrument readings that should be recorded include: feedwater pump discharge pressure, feedwater flow rate, feedwater inlet temperature, steam outlet temperature, steam outlet pressure, radiant tube skin temperature, stack temperature, radiant section pressure, fuel nozzle pressure, fuel rate, and excess air.

In addition, the operator must visually inspect all tlames during each shift to ensure that the flame is clean, bright, and smokeless and centrally placed in the radiant section. This is done to detect burner malfunction and take corrective action. The following comments are offered as a guide for better burner operation in oil-fired steam generatirs. 6

(i) A properly adjusted and operated oil burner will result in a clean bright yellow flame with no trace of smoke and will verge on whiteness.

(ii) Insufficient combustion air and/or insufficient atomizing steam will result in a long smoky flame.

(iii) Too much atomizing steam and/or too much combustion air will result in a dazzling white flame.

(iv) Too much atomizing steam will also lead to a thin fluttery flame.

(v) Insufficient combustion air will result in a reddish dusty looking flame with flocks of smoke over the bright part of the flame.

(vi) Presence of too much water or solid in the fuel will cause the flame to spark or flutter.

(vii) A plugged fuel valve or too low a fuel pressure will result in an uneven flame.

(viii) A plugged fuel valve or too low a fuel pressure will cause the flame to be put out. 
(ix) Since conditions such as too cold a fuel oil temperature, too wide a flame angle, too much excess air, or too much fuel supply will all result in excessive flame impingement on tubes and rapid coke formation, they should be avoided.

In addition, the operator must monitor and record daily those parameters needed for calculations and efficient operation of the steamflood. These include: water quality, steam quality, lubricating oil levels of the feedwater pump and air compressors, and filter and strainer conditions. The API recommended steam generator daily $\log$ is shown in table 6.4. Also, since the single most expensive activity in steamflood operation is the production of steam by burning fuel, a daily record of fuel use should be part of every steamflood operations. This will be discussed in some detail in a subsequent chapter on tools for monitoring steamflood performance.

\section{Monthly Maintenance and Inspection}

In addition to the daily maintenance log, monthly maintenance schedules should be established. The API recommends that the operator adopt the following monthly maintenance and inspection schedules:

(i) The operator should follow the manufacturer's recommended maintenance procedures and inspect feedwater pump and drive systems once a month. The crankcase oil should be inspected and replaced.

(ii) All motors should be inspected and lubricated as specified by the manufacturer.

(iii) Fuel, water, and air filters and strainers should be cleaned and serviced.

(iv) Steam generator should be shutdown and the condition of the convection section and radiant section tubes should be noted and recorded. Any fouling, soot buildup, or fin deterioration and the condition of the refractory surfaces should be recorded.

TABLE 6.4. - API Recommended Steam Generator Daily $\log ^{4}$

\begin{tabular}{|c|c|c|c|c|c|c|c|c|c|c|c|}
\hline $\begin{array}{l}\text { Date } \\
\text { or } \\
\text { time }\end{array}$ & $\begin{array}{l}\text { Water } \\
\text { Inlet } \\
\text { temp. }\end{array}$ & $\begin{array}{l}\text { feedwater } \\
\text { flow rate }\end{array}$ & $\begin{array}{l}\text { Feedwater } \\
\text { pump disch. } \\
\text { pressure }\end{array}$ & $\begin{array}{c}\text { Sieam } \\
\text { outlet press. }\end{array}$ & $\begin{array}{l}\text { Stean } \\
\text { outlet temp }\end{array}$ & $\begin{array}{l}\text { Stack } \\
\text { temp. }\end{array}$ & $\begin{array}{l}\text { Radiant } \\
\text { tube } \\
\text { skin temp. }\end{array}$ & $\begin{array}{c}\text { Fuel } \\
\text { nozzle } \\
\text { press. }\end{array}$ & $\begin{array}{l}\text { Radiant } \\
\text { Section } \\
\text { pressure }\end{array}$ & $\begin{array}{l}\text { Fuel } \\
\text { rate }\end{array}$ & \begin{tabular}{|} 
Excess \\
$0_{2}$
\end{tabular} \\
\hline & & & & & & & & & & & \\
\hline & & & & & & & & & & & \\
\hline & & & & & & & & & & & \\
\hline
\end{tabular}

(v) The condition of the burner tip, burner throat, fuel nozzle, flame diffuser, and air blower vanes should be inspected and cleaned as required. 
(vi) It is also recommended that the convection section heat transfer surface (inside and outside) be cleaned regularly to reduce stack temperature and improve generator efficiency. Soots should be removed from the outside surface and any scale buildup inside the tubes must be removed by circulating a weak solution of hydrochloric acid through the tubes at room temperature.

The API recommended monthly steam generator inspection checklist is shown in table 6.5.

\section{Annual Inspection}

In addition to the monthly inspection, all components of steam generation systems (water, fuel, instrument, air, safety devices, etc.) should be thoroughly inspected once a year and permanent records should be kept. External inspection should include calibration and replacement of pressure and temperature instruments; inspection of safety relief valves for the accumulation of rust, dirt, or foreign matter; and inspection of electrical equipment, damaged insulation, broken wires, and corrosion. Internal inspections should include inspection of all tube surfaces for erosion, corrosion, deformation, bulging, cracks and sagging, and inspection of tube hangers, yokes and hanger bolts for cracks and stress deformation and inspection of refractory material for cracks. The API recommended annual steam generator inspection list is included in appendix 6-E.

The above recommended practices should be considered only as the starting point for a good and thorough maintenance schedule. Assistance of the manufacturer of steam generation equipment must be enlisted in developing a good flexible and optimum maintenance schedule.

\section{Operational Problems Because of Poor Maintenance}

Failure to follow manufacturer's recommended maintenance schedules may cause several operational problems and result in costly downtime. Some of these problems are detailed in the following paragraphs.

A trouble-free steam injection operation begins with the use of good quality feedwater for steam generation. Ideally, the feedwater must have less than $1 \mathrm{ppm}$ hardness, less than $0.05 \mathrm{ppm}$ dissolved oxygen, a pH value between 9 and 11 , and less than 4,000 ppm TDS. Failure to use a good quality feedwater will result in formation of scales inside the tubes and cause tubes to corrode. Scale formed inside the tubes can cause a variety of problems in addition to lowering the overall heat transfer rate and formation of hot spots. Feedwater should be free of oil. Oil contamination of the feedwater may lead to asphaltene deposition inside the tubes. Oil and other suspended matter are removed from the feedwater by flowing it through a mechanical filtering system. Such filters should be backwashed every 24 hours to minimize cake buildup and prolong their life. 
TABLE 6.5. - API Recommended Steam Generator Monthly Maintenance and Inspection Check List $^{4}$

\begin{tabular}{|c|c|c|c|c|c|c|c|c|}
\hline \multirow[b]{2}{*}{ Description of item } & \multicolumn{2}{|c|}{ Inspected } & \multicolumn{3}{|c|}{ Condition } & \multirow[b]{2}{*}{$\begin{array}{l}\text { Date of service } \\
\text { gr inspection }\end{array}$} & \multirow[b]{2}{*}{ Inspector } & \multirow[b]{2}{*}{ Comments } \\
\hline & Yes & No & OK & Faulty & Replaced & & & \\
\hline \multicolumn{9}{|l|}{$\begin{array}{l}\text { Feedwater pump } \\
\text { crankcase-drain and } \\
\text { refill as specified by } \\
\text { manufacturer. }\end{array}$} \\
\hline \multicolumn{9}{|l|}{$\begin{array}{l}\text { Feedwater purnp motor }{ }^{1} \\
\text { lubricate as specified by } \\
\text { manufacturer. }\end{array}$} \\
\hline \multicolumn{9}{|l|}{ Convection coil $^{2}$} \\
\hline \multicolumn{9}{|l|}{ Radiant coil } \\
\hline \multicolumn{9}{|l|}{$\begin{array}{l}\text { Fuel oil filters and } \\
\text { strainers } \\
\text { Water filters } \\
\text { Air filters }\end{array}$} \\
\hline $\begin{array}{l}\text { Burner blower motor }{ }^{1} \\
\text { Miscellaneous motors } \\
\text { Burner stabilizer/diffuser } \\
\text { plate }\end{array}$ & & & & & & & & \\
\hline
\end{tabular}

1 Keep all motors clean and ventilation openings clear of dust, dirt and other debris. Do not over grease. WARNING: Disconnect all power sources to the unit and discharge all parts which inay retain an electrical charge before attempting any maintenance or repair. Screens and covers must be maintained in place when unit is in operation.

Some small motors have sealed-for-life type bearings which require no relubrication.

Motors that do require lubrication, can be regreased by stopping the motor. remuving the Jrain plug and pumping new grease into fillhole. Run the motor with the cirain plug removed, for a short period, to discharge excess grease. Replace the árain plug.

Motors that operate at speeds greater than 1,800 RPM should be lubricated on a more frequent maintenance schedule depending on duty cycle.

2. On occasion it may be necessary to remove deposits from between the fins on the tubes in the convection section. The frequency of cleaning the fin tubes will be determined by the type of fuel oil being used.

The convection section fin tubes may require cleaning when increase in backpressure of approximately 2 in w.c., above new and clean condition, is indicated on the radiant section manometer.

3. The frequency of service required for the filters and strainers is determined by operating time using fuel oil and the quality of the fuel oil being used. One indication of a dirty element is a drop in oil pressure to the burner (as indicated on pressure gauge).

Every effort should be made to burn only clean fuel in the generator. If field gas is used as fuel, it should be oil-free. Oily gas will cause a gas pilot solenoid valve to become sticky and result in solenoid pilot valve failure. 
When firing lease crude, the oil should be filtered to remove sand, sludge, and other solid material. Dirty fuel causes nozzle plugging and contributes to erratic flame pattern and eventual tube failure. Presence of sand in the fuel will lead to excessive wear of the pump, pressure regulators, and nozzle. Heavy sludges give rise to erratic burning and eventual flame failure. Sludge problems can be alleviated by adding additives to the crude. Lease crude should also be free of excessive free water. Up to 3\% water, as long as it is dispersed in the oil, is not detrimental to combustion. Excessive water can lead to burner failure and refractory deterioration.

Thus, good maintenance practices should be an integral part of a steam injection operation not only to lower operating costs and increase thermal efficiency, but also to ensure the safety of field personnel.

\section{Steam Generator Efficiency}

Typical thermal efficiency of an oilfield steam generator ranges between 80 and $85 \%$ and with special design can exceed $90 \%$. The oilfield steam generator thermal efficiency is given by: Generator thermal efficiency $=$

(Heat released by burning of the fuel) - (Heat loss to the surroundings)

Heat released by burning of fuel

The above definition is the most widely accepted and most reliable procedure for the determination of oilfield steam generator thermal efficiency.

The API recommends that steam generator thermal efficiencies be based on the higher heating value of the fuel. However, it also allows the efficiencies to be based on the lower heating value of the fuel. It is the accepted practice in the oilfield to base the generator's thermal efficiency on the lower or net heating value of the fuel. The difference between the higher and lower heating values of a fuel is the heat necessary to vaporize the water formed in the combustion reaction. This heat can be recovered only by cooling the combustion gases to a temperature at which the water formed during combustion will condense. Since it is not practical to cool the flue gases to this temperature, it is standard practice to base steam generator efficiencies on the lower or net heating value of the fuel.

The basic heat losses to the surroundings from an oilfield steam generator consist of the heat lost in the flue gases exhausted to the atmosphere, plus the heat lost by radiation from the steam generator setting. The thermal efficiency of the oilfield steam generator is affected by the amount of excess oxygen (air) used in the combustion process and the flue gas exit temperatur (stack temperature). The temperature and excess air content of the flue gases are determined by actual measurement during the operation of the generator. The net heating value of the fuel can be determined by using a calorimeter or by a calculation based on the chemical composition of the fuel. 
Since the flue gases heat content accounts for the major portion of generator heat losses, steam generator efficiency can be improved by reducing the stack heat losses. The amount of heat lost via flue gases is proportional to the temperature of the flue gases and to the mass flow rate of the vented gases. To the extent possible, flue gas heat is recovered in the convection section and indirectly in the feedwater preheater.

Since steam generators are mostly fired with sulfur bearing fuels, such as the California crude oils, the flue gases contain corrosive sulfur oxides. The amount of heat recoverable from the flue gases is limited by the dewpoint temperature of these corrosive acid gases. If cooled below the dewpoint, these gases condense and form highly corrosive sulfuric acids. Thus, the exhaust gases cannot be cooled below the acid dewpoint which is about $r 00^{\circ} \mathrm{F}$ under typical operating conditions. Therefore, steam generator thermal efficiencies are limited by stack gas dewpoint temperatures.

The approximate flue gas dewpoints for heavy oils are shown in figure 6.8 as a function of percent sulfur in the fuel oil and percent excess air used for combustion. As can be seen for a given amount of sulfur in the fuel, the stack gas dewpoint increases with percent of excess air. Further, the greater the excess air used in the combustion process, the lower will be the thermal efficiency because the additional air traveling through the generator robs heat from the combustion process that otherwise could be ccnverted to steam energy. Typical net thermal efficiencies (as defined by equation 1) for three different fuels are shown in figures 6.9 through 6.11 , as a function of the flue gas temperature and percent excess air. ${ }^{2}$ These charts assume a $2 \%$ radiation heat loss. As can be seen from these plots, the thermal efficiency increases as stack gas temperature and percent excess air decrease.

A knowledge of thermal efficiency is essential for the proper operation of a steam generator. A drop in thermal efficiency is usually an indication that either the tubes are fouled and/or too much excess air is being used for combustion. A stack gas analysis for $\mathrm{CO}_{2}$ will give an indication of excess air being used. Steam generation equipment is not normally operated with excess air above 7\%. Any amount greater than that will result in greater heat losses and lower thermal efficiency. Otherwise, if too little excess air is used for combustion, it will result in incomplete combustion and sinoking and soot deposition on the surface of the tubes. In gas-fired steam generators, where soot should not be a problem, loss in thermal efficiency generally indicates that scale has formed inside the tubes. The presence of scale is indicated by an increase in flue gas temperature. Scale buildup is also indicated by an increase in the feedwater pump outlet pressure. Accumulation of soot on the external surfaces of the tube also reduces the heat transfer rate to the feedwater and increases the flue gas temperature. 


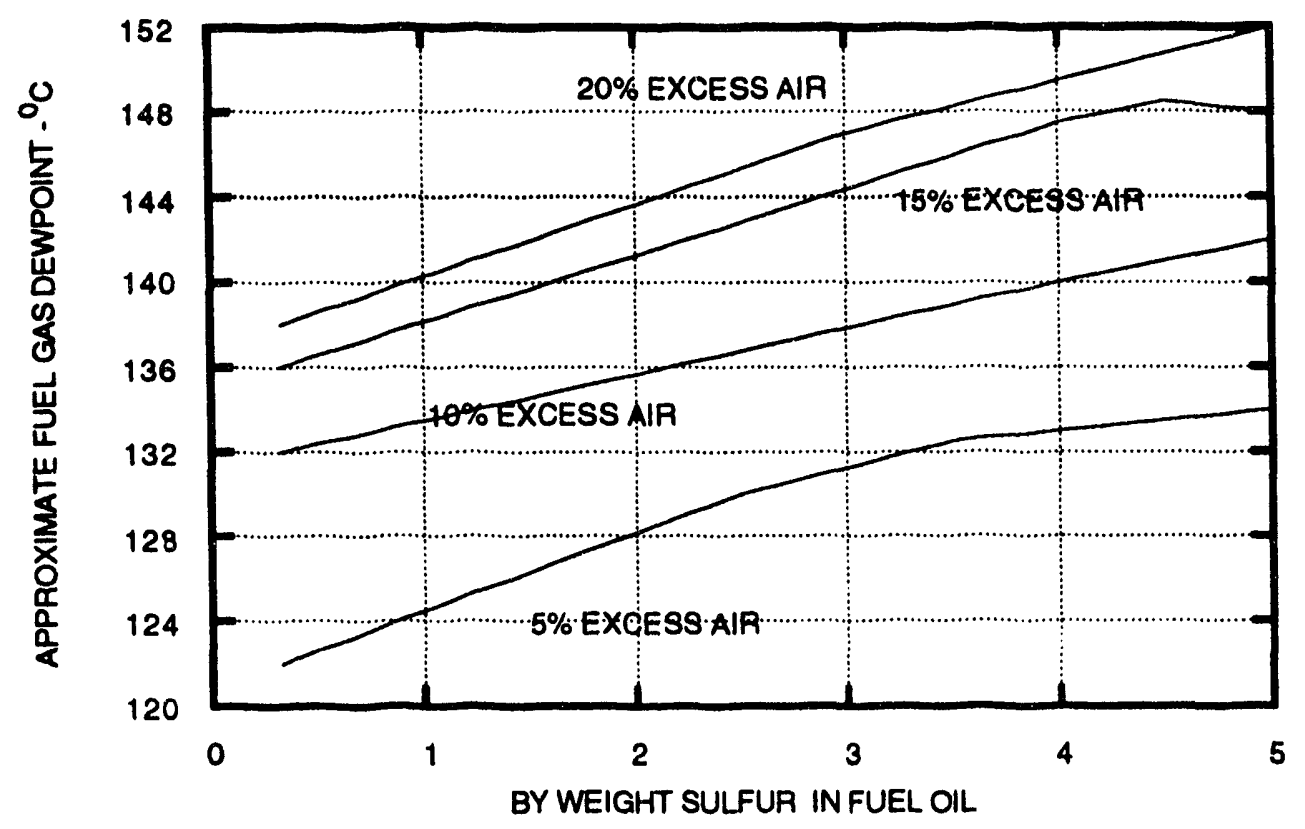

FIGURE 6.8. - Approximate flue gas dewpoints for heavy oils. ${ }^{2}$

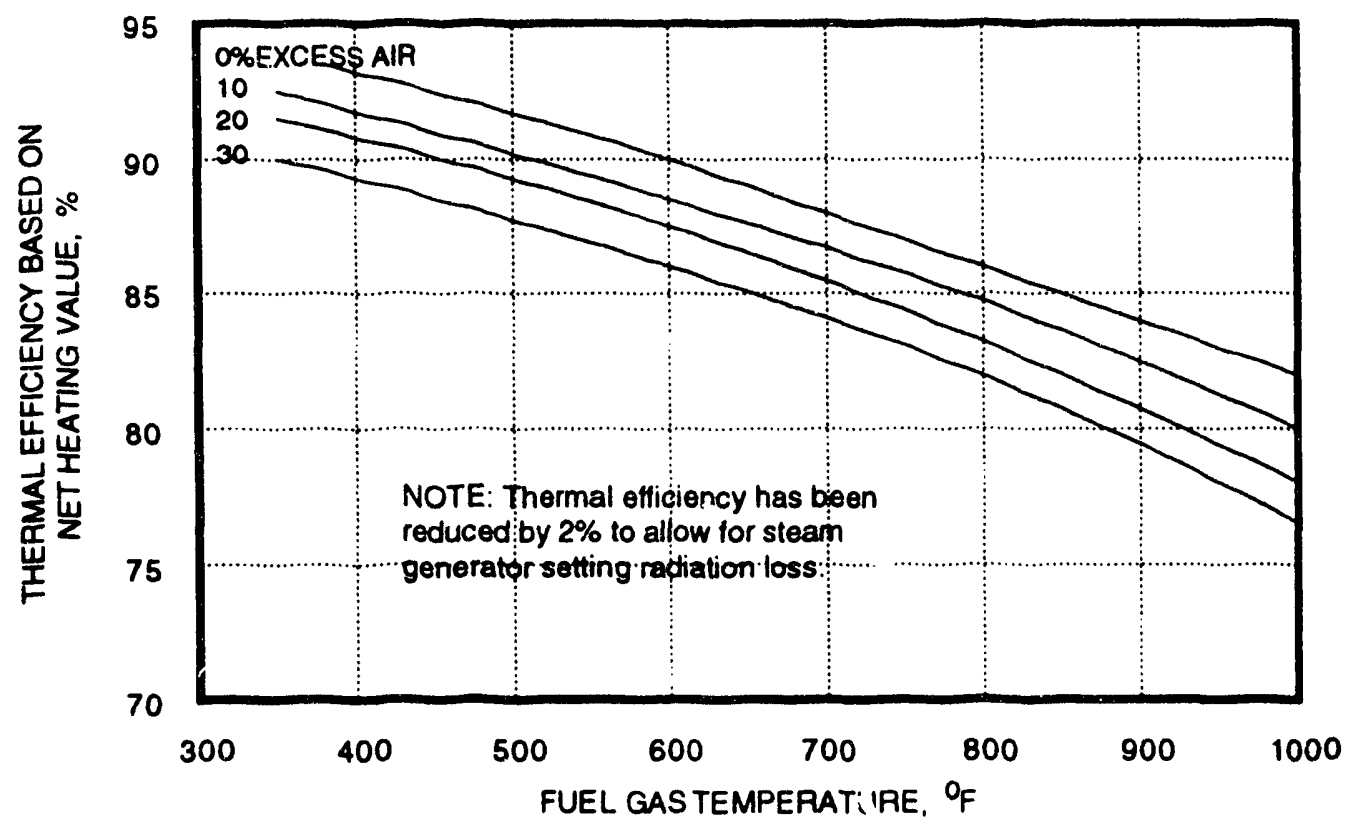

FIGURE 6.9. - Thermal efficiency versus flue gas temperature for $10^{\circ}$ API crude. ${ }^{2}$ 


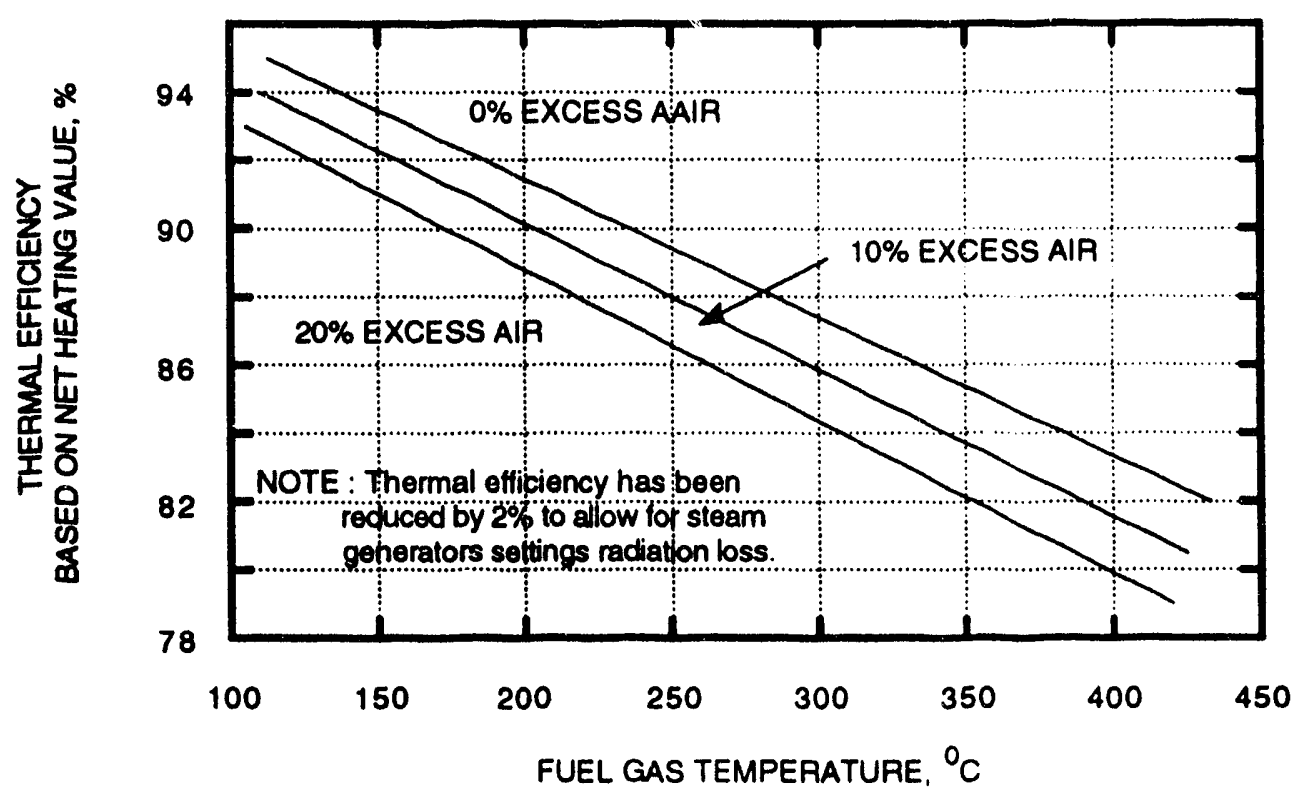

FIGURE 6.10. - Thermal efficiency versus flue gas temperature for $15^{\circ}$ API crude. ${ }^{2}$

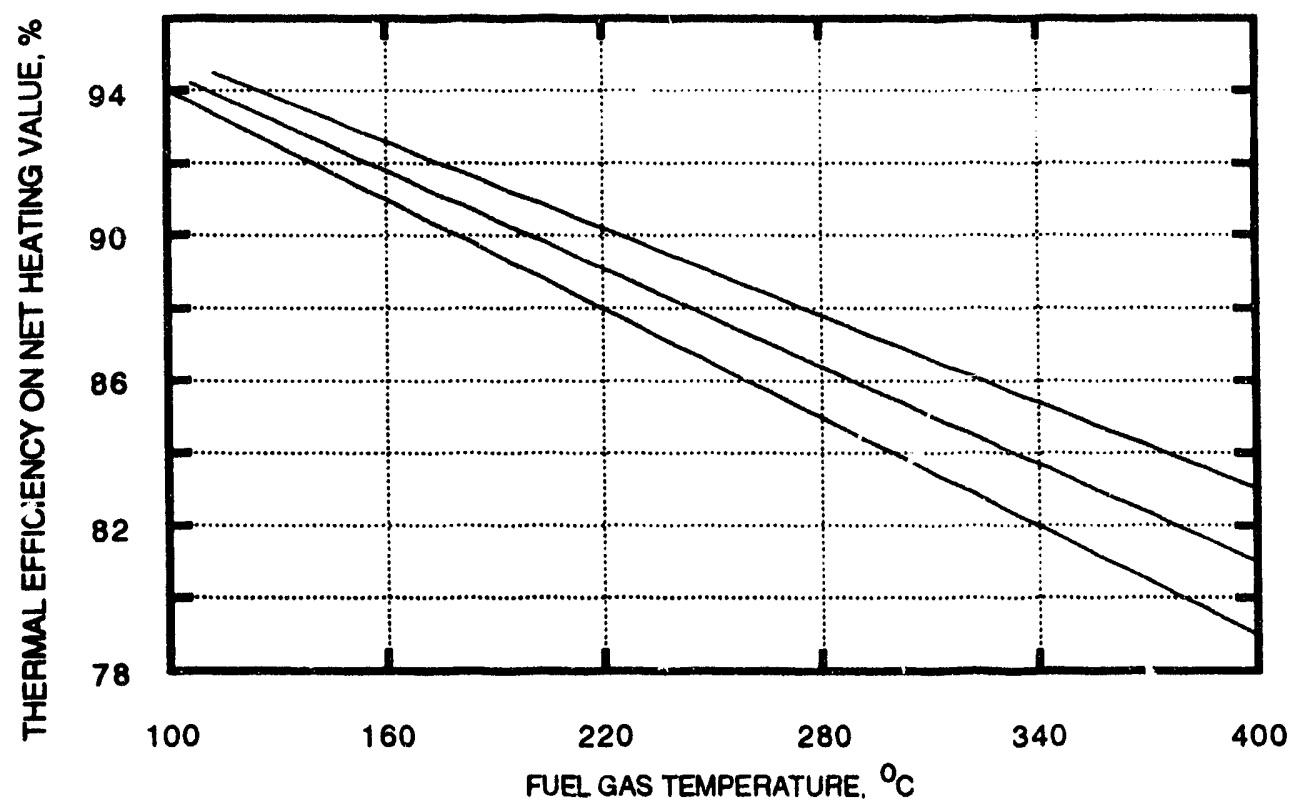

FIGURE 6.11. - Thermal efficiency versus flue gas temperature for natural gas $(1,000 \mathrm{Btu} / \mathrm{SCF}) .^{2}$ 
Any increase in the steam generator thermal efficiency reduces the fuel requirements of the steam generator and sharply reduces the cooling load on the sulfur dioxide scrubbers (where they are used). For example, the fuel requirements of an oil-fired $50 \mathrm{MM}$ BTU/hr steam generator can be reduced roughly by about $5,300 \mathrm{bbl}$ of oil per year by increasing the thermal efficiency $5 \%$. For this reason, one manufacturer offers steam generators equipped with special add-on convection sections. Corrosion-resistance, plastic-coated heat exchange tubes are used in this section to capture heat from the corrosive flue gases. This arrangement permits the cooling of sulfur oxide containing flue gases to about $150^{\circ} \mathrm{F}$ (well below their dewpoint temperature) and increases the thermal efficiency by about $8 \%$.

\section{Flue Gas Scrubbers}

In the United States, most steam generators are fired with lease crudes. These crudes contain sulfur which is converted to sulfur oxides during combustion in a steam generator. Environmental regulations prohibit the discharge of these flue gases without lowering their sulfur content. For example, in Kern County, California, the emissions of sulfur from a standard $50 \mathrm{MM} \mathrm{BTU/hr}$ steam generator is limited to less than $1 \mathrm{lb} / \mathrm{hr}$. Wet scrubbers are used in the oilfield to remove sulfur oxides from steam generator flue gases. The sulfur oxides in the flue gases exist principally as sulfur dioxide, with traces of sulfur trioxide. The sulfur dioxide (and trioxide) from the flue gases is removed by passing through a wet scrubber where it is absorbed into an aqueous scrubbing liquor followed by reaction with the active alkaline constituents of the liquor. The reaction products are sulfur-containing salts. These are purged from the scrubber in small batches and sent to disposal.

Different types of internals are used in the scrubber tower to aid the absorption and reaction of sulfur oxides with scrubber liquor. These include tray towers, packed towers, spray towers, and ejector venturi. Each of these has its own advantages and disadvantages, and in designing a scrubber system a compromise must be made between absorption efficiency, operating reliability, and cost. Most of the scrubbers in current use in oilfields are made of packed bed and bubble cap tray to yield very good mass transfer and turndown characteristics. A good turndown character dictates that the scrubber should be capable of operating efficiently over a relatively wide range of gas flow rate.

\section{System Description}

Figure 6.12 shows the basic components of a most commonly used oilfield flue gas scrubber system. These include a forced draft fan, scrubber tower, caustic feed system, recirculation tank and pump, bluwdown pump and tank, $\mathrm{pH}$ meter control system and makeup water system. 


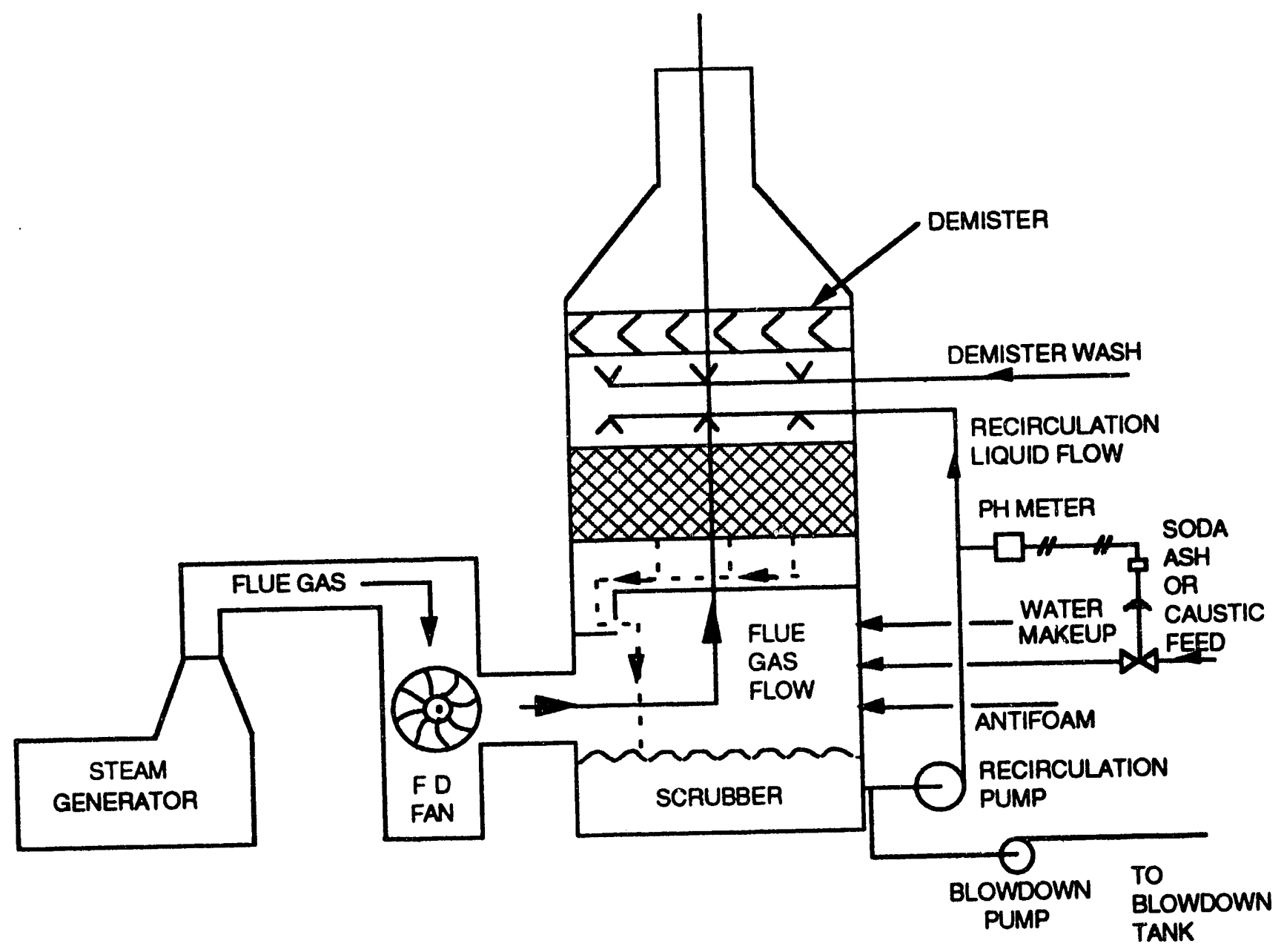

FIGURE 6.12. - Schematic of a typical steamflood flue gas scrubber system.

Flue gas from the generator, instead of being exhausted directly into the atmosphere, is ducted to the inlet at the bottom of the scrubber via a forced draft fan. Flue gases pass upward, first through a humidification section, where it is cooled by a spray of water. The water also removes the larger particles from the gas stream. The cooled gas then passes through the absorption section where it comes in contact with scrubbing liquor. The absorption section consists of one 316 stainless steel bubble cap tray and a packed column. The scrubbing liquor (aqueous sodium carbonate) is passed over the bubble cap tray as the gas is forced upward. The scrubbing liquor reacts with the sulfur dioxide in the flue gas and converts it to water soluble sodium salts of sulfur (sodium sulfite, sodium bisulfite and sodium sulfate).

As a result of the vigorous liquid-gas contact in the absorption section, some of the liquor is entrained in the gas. Prior to exiting to atmosphere, the gas passes through a mist elimination device to remove the entrained droplets. Failure to remove these droplets could not only corrode 
and scale downstream equipment, but also result in particulate pollutants such as sodium salts left after evaporation of the scrubbing liquor mist. The two most common mist eliminators are the wire mesh pad, and the chevron mist eliminator. The chevron mist eliminator is a set of slats set in such a way to impart a zigzag flow to the gas over a distance ranging from a few inches to few feet.

\section{Other Types of Steam Generation Equipment}

While once-through type steam generators are used almost exclusively in oilfields, steam generators with special design features are also available for oilfield use. These include generators having the capability to handle feedwater with a very high TDS content (up to $24,000 \mathrm{ppm}$ ), generators with a capability to burn low BTU or sour gas as fuel in conjunction with crude oil, generators that work on solid fuel such as coal or petroleum coke, generators that utilize an intermediate heat transfer fluid to provide heat necessary to produce steam from treated water in a shell, and tube type heat exchanger and generators that are designed to burn any fossil fuel and to generate steam from brackish water. Although these types of steam generators have not gained wide acceptance, they may find application in unusual situations. The key features of a few such generators are described in the following section.

\section{Vapor Tech Steam Generator 8}

Vapor Tech steam generators are small, light-weight, inexpensive, trailer-mounted steam generators developed to generate steam using brackish or untreated water. This steam generator is designed to burn any type of fossil fuel including pulverized coal. lease crude, natural gas, low BTU gas, or biomass.

The key feature of the vapor tech steam generator is a resonant burner that creates a sonic resonance at a temperature of about $2,500^{\circ} \mathrm{F}$. As a result of the burner resonance, the combustion gases are pulsed. This pulsating action of the combustion gases results in a scrubbing effect on the surface of the free-floating steam coil and homogenizes the steam-water mixture inside the tube. This homogenization prevents the formation of the insulating steam layer on the inside surface of the tubes and results in higher heat transfer. Also, the scrubbing action of the combustion gas prevents the formation of a cooled gas insulating layer outside of the tube. As a result of the absence of any insulating boundary layer, a steep temperature gradient across the metal wall is achieved and makes it possible to reduce the length of steam coil necessary to achieve a given heat transfer rate. This, in turn, reduces the size and weight of the unit.

The pulsating flue gas also results in the resonance and vibration of the free-floating steam coil. This vibrating coil keeps the salt precipitates and other scale-forming chemicals in suspension in the pulsating steam. As a result, the generator successfully operates on brackish water or oilfield brine without any buildup of scale. The largest unit offered by the manufacturer is a 10 
MM BTU/hr trailer-mounted unit. Since the unit is modular in nature, a number of such units can be manifolded together to achieve the desired output capacity.

These units are light-weight, portable, inexpensive, and need no water treatment. According to the manufacturer, a $10 \mathrm{MM}$ BTU/hr unit costs less than $\$ 40,000$.

\section{Fluidized Bed Combustion (FBC) Steam Generator 9}

Conventional oilfield steam generators use oil or gas as fuel. In fields where a coal source is readily accessible, it may be more economical to use inexpensive and more plentiful coal as fuel. One vendor offers a steam generator whose design features a fluidized bed combustion with an inbed steam generating coil and economizer section. These generators permit the burning of high sulfur coal and various solid fuels to generate steam in an oilfield environment. The fluidized bed design has the potential for providing uniform and low heat fluxes, minimum heat retention and quick response to load changes and low fouling tendencies. This type of steam generator was field tested in a South Texas steamflood project where steam was injected into a tar sand to recover a heavy $-2^{\circ}$ API gravity tar. ${ }^{10}$ This type of generator was a natural fit for this project due to the existence of an abundance source of low BTU coal and limestone in the project vicinity.

Operation Principle: Figure 6.13 is a schematic of the FBC steam generator. The crushed solid fuel (coal, lignite, petroleum coke, waste wood, etc.) is mixed with limestone and fed into the combustion chamber, where air is circulated at high velocity to agitate and suspend the burning solids. The limestone reacts with the sulfur in the coal to limit the production of sulfur dioxide. Feedwater is pumped through the theat exchanger coils in the combustion chamber where it is heated and converted to steam. The operating conditions of the combustion are such that production of nitrogen oxides and carbon monoxide are also minimized. Emissions from the FBCtype steam generator are kept within stringent environmental standards without using external cleanup equipment.

The economics of the FBC steam generator depends upon the cost of solid fuel and the capacity of the generator. It is unlikely that the generator will be economical to operate at capacities less than $50 \mathrm{MM}$ BTU/hr. This system should be considered only if a ready and reliable source of inexpensive solid fuel is assured and stringent air quality standards have to be met.

\section{The Wet Air Oxidation Boiler \\ Wet Oxidation Concept ${ }^{11}$}

The term wet oxidation as used here refers to a flameless combustion process capable of releasing enormous amounts of heat under certain conditions. Around the turn of the century, it was discovered that dissolved oxygen will attack water-wetted fuels directly from the liquid phase 


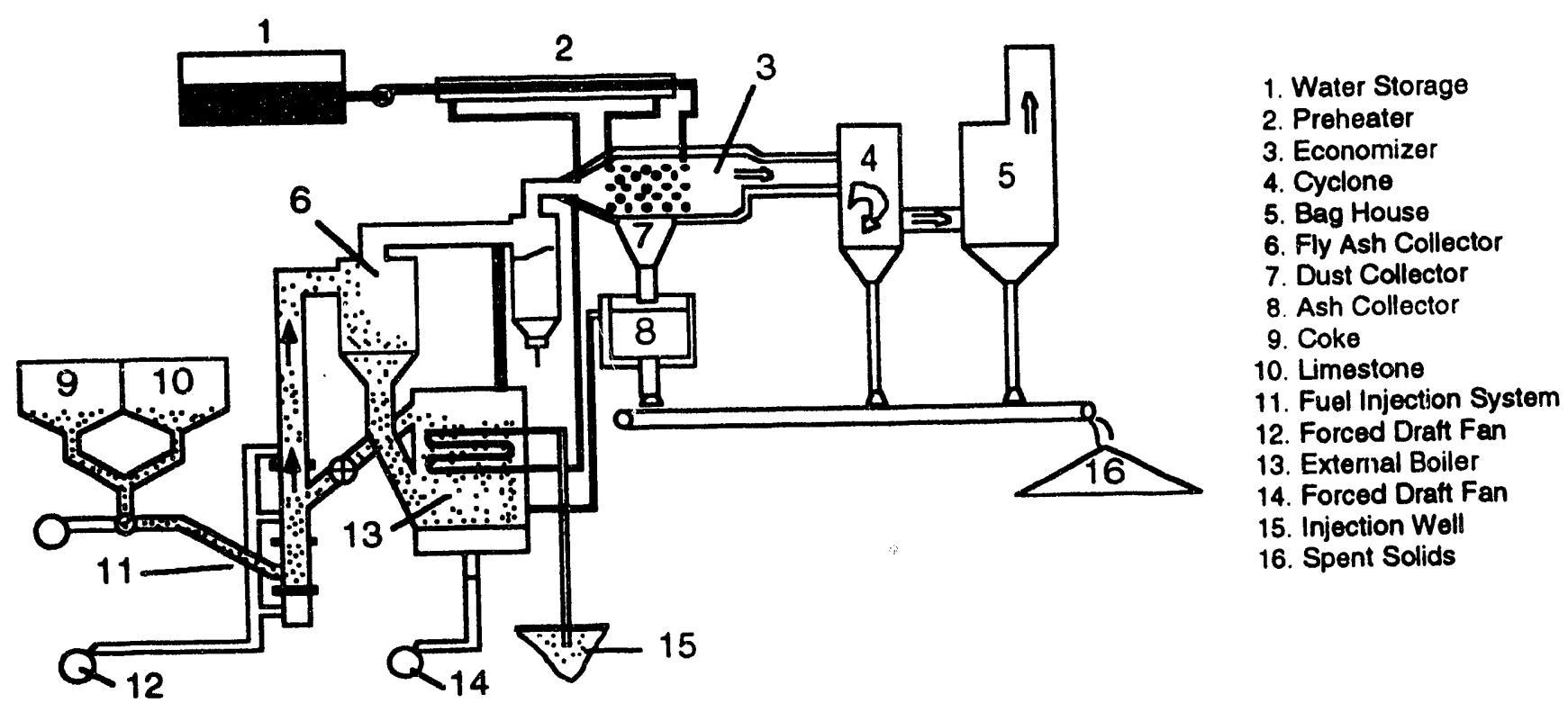

FIGURE 6.13. - Schematic of a fluidized bed combustion steam generator. ${ }^{9}$

if the materials are pressurized to 300 to $3,000 \mathrm{psi}$. Under these conditions the flameless oxidation process generates temperatures of $300^{\circ}$ to $700^{\circ} \mathrm{F}$ as compared with conventional combustion which produces flame of $1,800^{\circ} \mathrm{F}$ at atmosphere pressure. However, the total number of BTUs released by wet oxidation is the same as that released by conventional combustion. The principal reaction products are also the same: carbon dioxide and water.

\section{WAO Boiler ${ }^{12}$}

Although wet air oxidation reactors generate enormous amounts of heat and are used extensively in the waste disposal industry for the treatment of aqueous wastes and sludges, they have not been used in the oil patch. Their inherent characteristics, however, make them ideal for thermal EOR applications.

Figure 6.14 shows the schematic of one WAO arrangement for steam injection application. The feed to the WAO boiler consists of fuel slurry, water, and compressed air (or oxygen). It oxidizes the fuel and produces steam, $\mathrm{CO}_{2}$, and $\mathrm{N}_{2}$ which can then be injected into the reservoir. The rational behind the suggestion to use WAO process in steam injection application is that steam contributes thermal energy to the reservoir, while the gas phase $\left(\mathrm{CO}_{2}\right.$ and $\left.\mathrm{N}_{2}\right)$ contributes both thermal energy and gas drive/solubility effects to the process. Since by its inherent nature, the process does not produce any $\mathrm{SO}_{2}, \mathrm{NO}_{\mathbf{x}}$, or particulate, and no emission control is necessary, and the process can be used at locations where stringent air quality standards have to be met. 


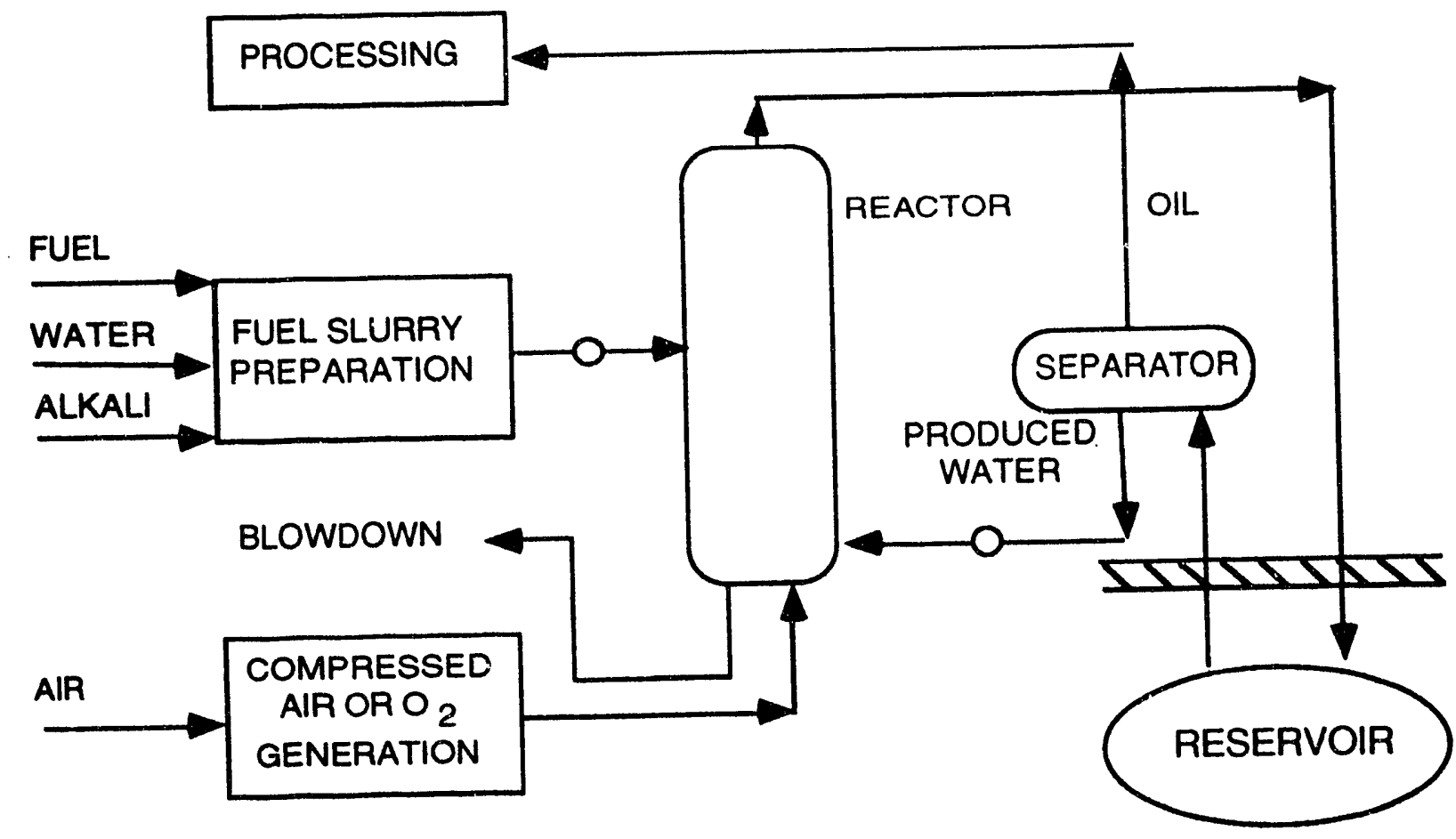

FIGURE 6.14. - Schematic of a wet air oxidation boiler arrangement for steamflood application. 12

Other advantages of a WAO boiler for steam injection application are as follows:

(a) Inexpensive fuels such as high sulfur petroleum coke, high sulfur coal, lignite, high sulfur crude-water emulsion, wood wastes, or any other solid waste product can be used as feed to the reactor.

(b) Feedwater requires no treatment. Brackish or oilfield brine or produced water can be used as the source of water. Dissolved feedwater solids are concentrated and removed in the blowdown.

(c) The steam produced in the WAO unit is essentially $100 \%$ quality; hence, the water requirement per unit heat injected into the reservoir is significantly lower.

The major disadvantages of the WAO boiler are that it requires the use of an air compressor or a compressed oxygen source to generate steam, and the process is corrosion prone. Hence, it is more expensive to generate steam using the WAO boiler than a conventional boiler. Another disadvantage of the WAO boiler is the problem of the disposal of reactor blowdown sludge.

The WAO process is a well-developed technology. However, the present economic situation and the absence of field performance data are apparently the compelling reasons for the lack of interest in WAO boilers. Because of increasing costs of meeting stringent air and water quality 
regulation requirements, WAO boilers with their emission and water usage advantages may prove to be cost-effective in steam injection applications.

\section{Vapor Therm System 13}

Like the WAO process, the 'Vapor Therm' system also involves the generation and direct injection of combustion gases and steam into heavy oil bearing formations. Unlike WAO boilers, Vapor Therm generators are designed to burn high pressure liquid fuels or natural gas and utilize prefiltered but untreated water to generate steam.

Figure 6.15 is a schematic of the Vapor Therm process showing the major equipment and process flow. The Vapor Therm generator is composed of (1) a high pressure air compressor system, (2) a high pressure combustiun chamber, and (3) a steam drum where steam is formed, harmful combustion products are removed, and solids removed. In addition, there are water and chemical injection pumps, fuel feed pumps, and attendant instrumentation and control systems.

The air is compressed to the desired operation pressure ( 900 psig maximum) and mixed with a fuel source at the entrance to the combustion chamber. The combustion reaction takes place in excess of $2,500^{\circ} \mathrm{F}$ in a refractory lined combustion chamber. The hot combustion gases flow from the combustion chamber into a steam generation drum where the hot combustion gases are quenched with high pressure water, producing a mixture of steam and inert gases. In addition to its function as a steam generator, the drum also acts to scrub the combustion gases. The scrubbing action of water absorbs the acid gases such as $\mathrm{SO}_{2}$ and $\mathrm{NO}_{\mathrm{x}}$ which, in turn, are neutralized by addition of chemicals to the drum. The effluents from the steam drum, steam, $\mathrm{CO}_{2}$, and $\mathrm{N}_{2}$ are then carried to the wellhead through the insulated pipes and injected into the reservoir. The steam drum is periodically blown to remove aqueous concentrate of acid salts and other so!ids.

The Vapor Therm process requires water filters, air compressors, liquid fuels, and chemicals to operate. The process has been successfully field tested in two different and distinct reservoirs. The process is currently available on the market. Vapor Therm works best in a dipping reservoir, where a gas cap can be formed, adding drive energy to the reservoir.

Both WAO and Vapor Therm processes have the potential of producing more oil than a

conventional steam generator. However, they cost more than a conventional steam generator and do not eliminate the inherent limitation of a surface steam generation facility: heat losses in surface lines and wellbores. The major competitor to these process is the downhole steam generator which will be discussed in the next section.

\section{Downhole Steam Generator}

The downhole steam generator was developed to overcome the two major limitations of conventional steam operations: (1) line and wellbore heat losses and (2) exhaust emissions. Steam 


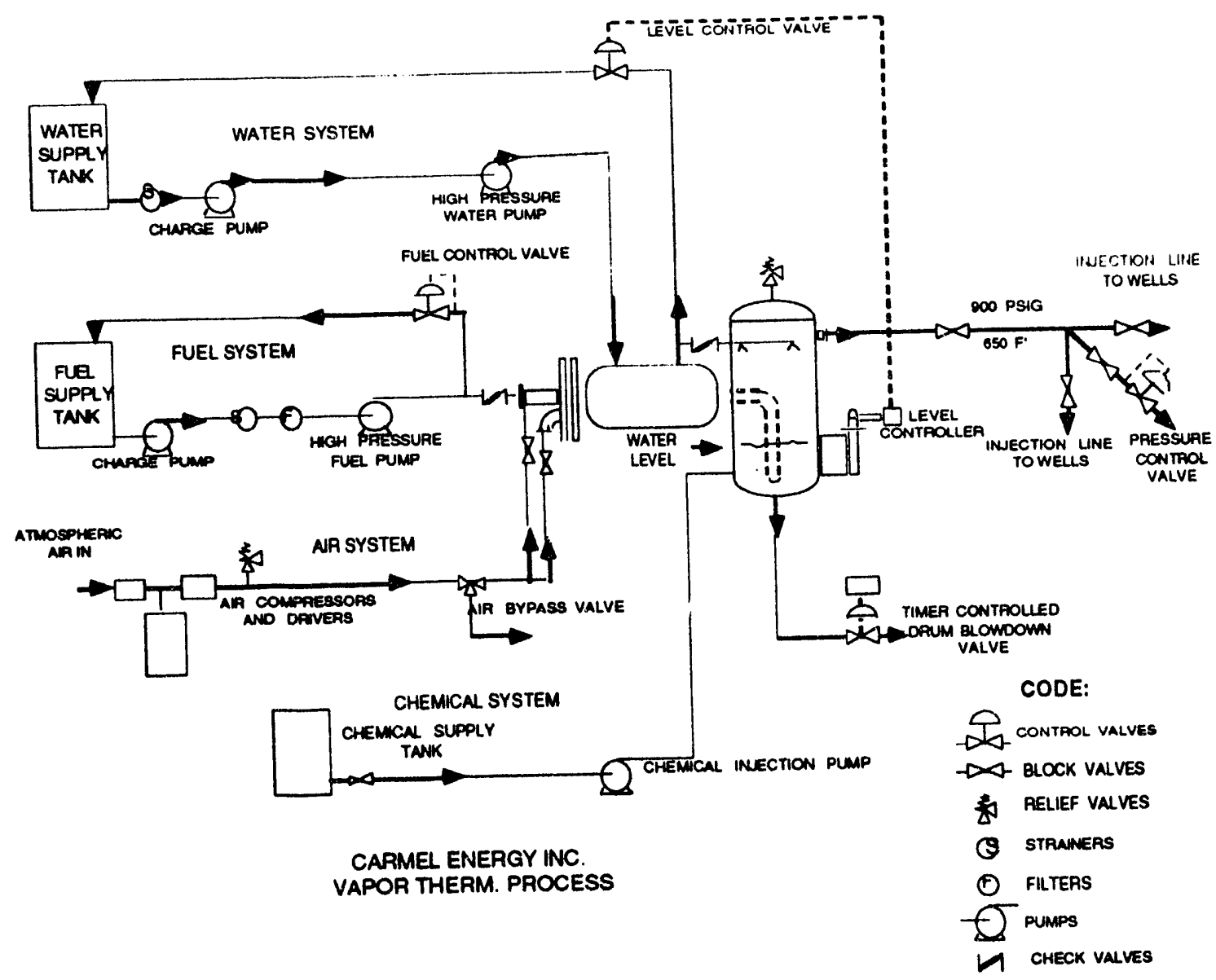

FIGURE 6.15. - Schematic of Vapor Therm system. ${ }^{13}$

generated in conventional surface steam generators loses a significant portion of its heat as it flows through surface piping and into injection wellbores. Wellbore heat losses have limited the applicability of conventional steam generators to formations shallower than $3,000 \mathrm{ft}$ with uninsulated tubing and not much deeper than $5,000 \mathrm{ft}$ with insulated tubing.

Downhole steam generators (DSG) are designed to eliminate surface and wellbore heat losses and to deliver high quality steam at the sandface with high thermal efficiency. In addition, certain DSG design permits the reinjection of combustion gases with steam, thereby eliminating the emission problems associated with surface generation and provides some of the advantages of a steam additive process. Further, for the same heat injection rate into an oil-bearing formation, a DSG will require less generator fuel and combustion air than a surface level generator. However, this reduction is achieved at the expense of the air compressor and its associated energy utilization. Some of the advantages and disadvantages of DSG are listed in table 6.6. A schematic of a downhole steam generation system arrangement is shown in figure 6.16. 
TABLE 6.6. - Advantages and Disadvantages of Downhole Steam Generators

Advantages

Disadvantages

1. Significantly minimize heat losses.

2. Reduction of air pollution.

3. Has potential to extend steam injection to deeper wells.

4. Have applicability to offshore and arctic environments.

5. Injected combustion gases have the potential to enhance the oil recovery.

6. Low capital investments per BTU of heat injected.

7. Eliminate the need for surface steam distribution and quality monitoring systems.
1. Their output capacity is limited.

1. Not well suited for cyclic steam injection application, since it adds significantly to operating costs.

2. Maintenance costs for DSG is higher than conventional steam generator.

3. Difficult to control combustion at high pressures.

4. Corrosion of burner components is a major problem.

5. Results in frequent packer failures.

6. High compression costs

7. Lack Nexibility in that it can only serve the well in which it is installed. Surface generators on the other hand can readily adapt to serve multiple injection wells.

8. For wells requiring higher steam injection rates, larger casing may be required to install a DSG of suitable size; thus adding significantly to capital investment cosis.

9. Additional standby air compressor is needed to avoid generator shutdown in the event of a compressor breakdown.

10. Response to load changes is not as quick as a surface generator. 


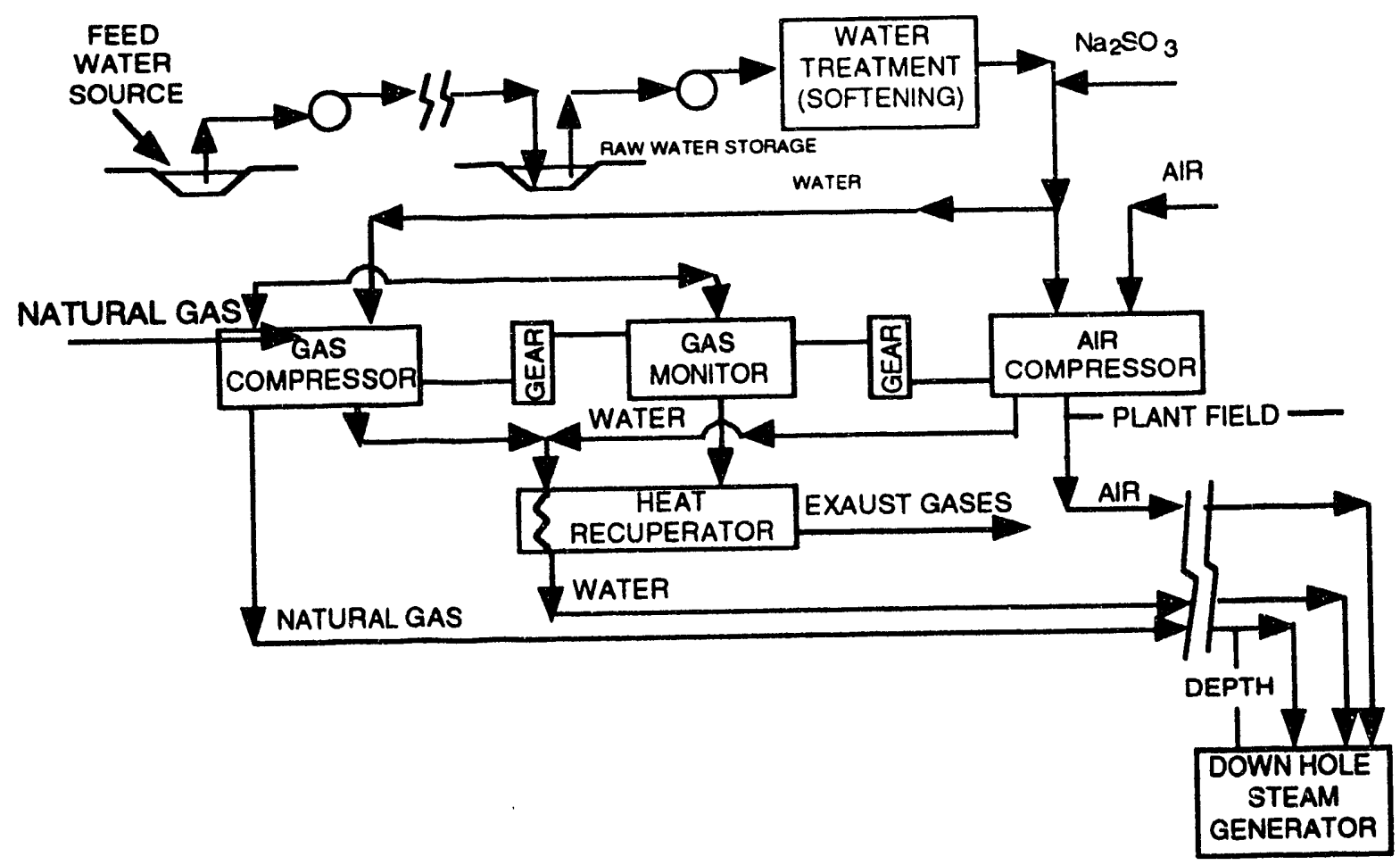

FIGURE 6.16. - Schematic of a downhole steam generation system. ${ }^{13}$

There are nearly a dozen different DSG designs in existence. Much research has gone into the development of DSG without significant success. Existing DSG can be broadly classified into two groups: (1) low-pressure generators or indirectly fired DSG and (2) high-pressure generators or directly fired DSGs. Here the terms 'high' and 'low' refer to the combustion pressure, not the injection pressure. The two designs differ in the method of transferring heat from hot combustion gases to produce steam.

\section{Low-Pressure DSG}

The key features of this generator are as follows:

(a) Energy is transferred to the water through a heat exchanger, thus, enabling the combustion process to be conducted at a pressure less than the injection pressure.

(b) Smallest well in which the generator can be placed is 10 in. in diameter.

(c) The combustion products are returned to the surface where they must be cleaned up. 
Figure 6.17 is a schematic of a low pressure DSG developed by Sandia National Laboratory. ${ }^{14}$ The typical operating parameters for this system are shown in table 6.7. In the Sandia design, the fuel and air are transported from the surface through tubes to the combustion chamber and ignited. After ignition, the combustion is sustained by maintaining the proper air/fuel ratio. The hot combustion products upon leaving the combustion chamber preheat the incoming feedwater and return to the surface as exhaust gases. The preheated feedwater flows around the combustion chamber where it picks up additional heat and converts it into steam. The steam at a pressure higher than the reservoir pressure is injected into the formation. A high-temperature, high-pressure packer is used to prevent the steam from entering the annulus between the casing and the generator.

The thermal efficiency of a low-pressure DSG is extremely high. They deliver greater than $90 \%$ of the energy available in the fuel to the formation. In comparison, conventional surface steam generators deliver only about $65 \%$ of the energy input to the formation. The major drawbacks of a low-pressure DSG are its large size and exhaust emissions similar to those of a surface system. Because of these limitations, industry interest in downhole steam generation is almost exclusively centered on the high-pressure version.

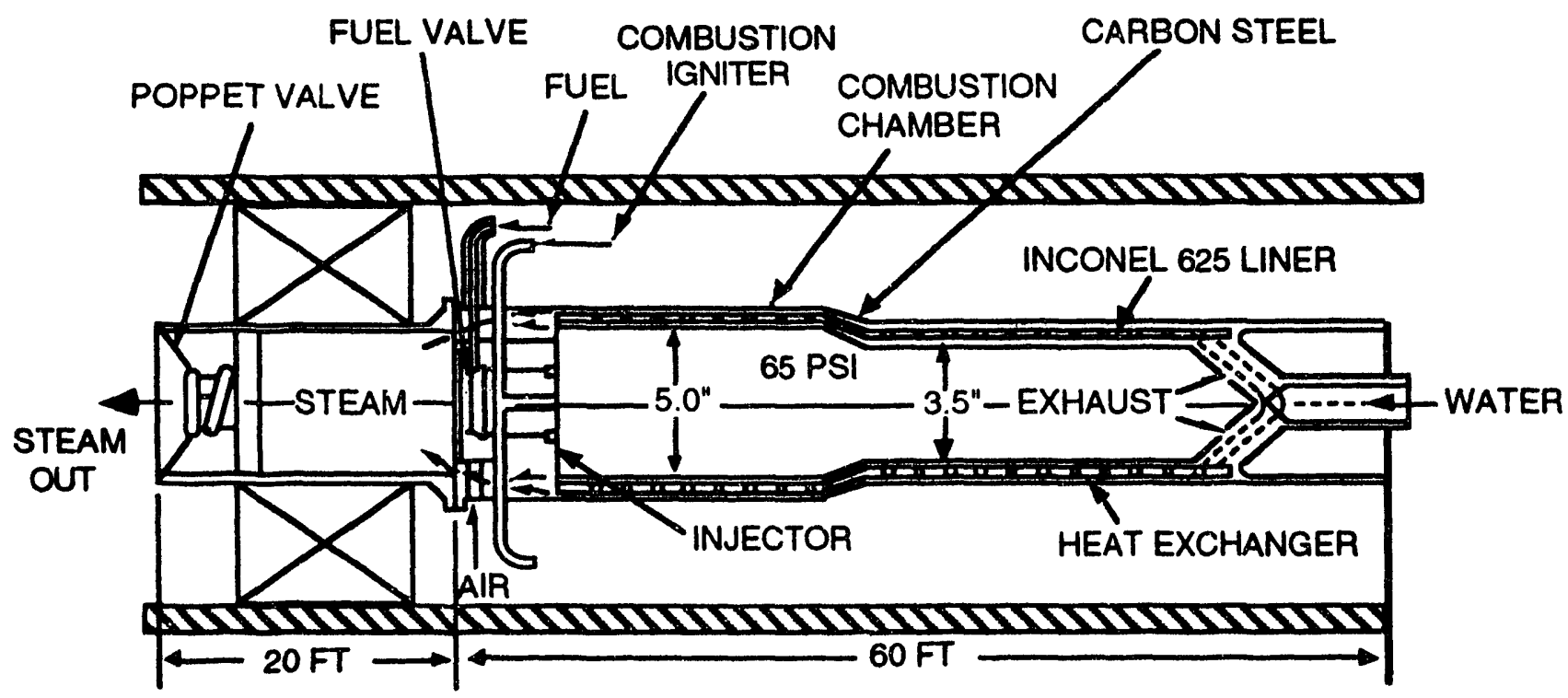

FIGURE 6.17. - Low pressure downhole steam generator. ${ }^{14}$ 
TABLE 6.7. - Typical Operating Parameters for a Low-Pressure DSG

\begin{tabular}{ll} 
Heat rate, MM BTU/hr & $1(0-20)$ \\
Injection pressure, psia & $1,00()-2,5(0)$ \\
Operating depth, $\mathrm{ft}$ & $2,50(-5,()) 0$ \\
Fuel & No. 2 dicsel \\
Maximum sandface & \\
$\quad$ steam quality, $\%$ & 85 \\
Emissions & Normal \\
Combustion pressure, psia & 100 \\
Minimum casing size, in. & 60 \\
Generator length, $\mathrm{ft}$ & 60 \\
\hline
\end{tabular}

\section{High-Pressure DSG}

The distinguishing features of this generator are as follows:

(a) Steam is produced by direct contact with high-pressure combustion gases, which eliminates the need for any heat exchangers.

(b) The overall size of the generator is considerably smaller than a low-pressure version and this permits the installation of the generator in existing injection wells.

(c) The hot combustion products are injected into the formation and repressurize the reservoir. This repressuring can enhance recovery by improving flow characteristics.

Figure 6.18 is a schematic of a high-pressure DSG developed by Sandia National Laboratory. ${ }^{14}$ The typical operating parameters for this system are shown in table 6.8. In the Sandia design, fuel and air are injected and mixed in the upper portion of the combusticn chamber. Since the combustion operates at the injection pressure, a large air compressor is required at the surface to provide high-pressure air for the combustion. The fuel and air are thoroughly mixed at high pressure in the combustion chamber prior to ignition. Once sustained combustion is achieved, high-pressure feedwater is sprayed directly into the flame through spray nozzles. The water is flashed into steam, and the mixture of steam and combustion products is injected into the formation.

The overall thermal efficiency of a high-pressure DSG is about $80 \%$. Even though the efficiency is not as high as that for the low-pressure DSG, it is considerably higher than that for a conventional surface generator.

Results of the field tests conducted to date in evaluating the reliability of high-pressure DSG under oilfield conditions have indicated a number of technical problems. Corrosion of burner components seems to be the most severe and common problem among all DSGs. Other major problems encountered include difficulties in controlling combustion at high pressure and frequent packer failures resulting from the harsh DSG operating environment. 


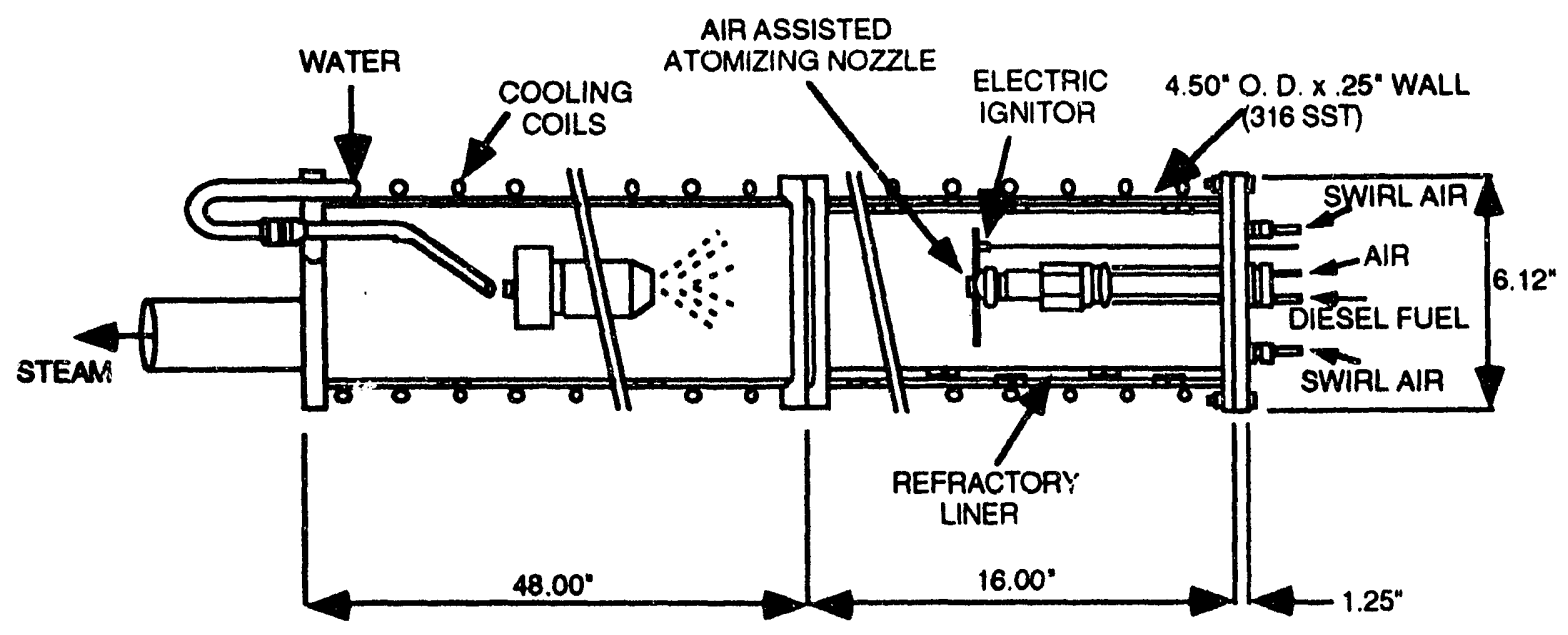

FIGURE 6.18. - High-pressure downhole steam generator. ${ }^{14}$

TABLE 6.8. - Typical Operating Parameters for a High-Pressure DSG

$\begin{array}{ll}\text { Heat rate, MM BTU/hr } & 10-20 \\ \text { Injection pressure, psia } & 1,000-3,000 \\ \text { Operating deptb, } \mathrm{ft} & 2,500-5,000 \\ \text { Fuel } & \text { No. } 2 \text { diesel } \\ \text { Maximum sandface } & \\ \quad \text { steam quality, } \% & 80 \\ \text { Emissions } & \text { Very low } \\ \text { Combustion pressure, psia } & 1,000-3,000 \\ \text { Minimum casing size, in. } & 7 \\ \text { Generator length, ft } & 8\end{array}$

Even though DSGs have been field tested successfully, these tests are of short duration-the longest being 6 months. The DSG needs to be field tested over an extended period of time ( 2 to 3 years) to establish its reliability and identify operational problems.

The economic advantage of DSG over surface generation is debatable. Even though DSG has higher thermal efficiency, this efficiency does not always translate into dollars and cents because the cost of fuel used to drive compressors often exceeds the savings in heat. Further, since most heavy oils of interest in the U.S. are found in shallow reservoirs $(<4,000 \mathrm{ft})$, a surface generator with insulating tubing may be more cost-effective in delivering unit heat input to the reservoir. The advantage of DSG over surface generators in reducing the cost of compliance with environmental regulations is also debatable because the injected combustion gases more than likely will break through to the producing wells and thereby reduce the economical advantage of DSG. 
Based on a heat-balance study of a conventional surtace steam generation system and the downhole steam generation system, Sandia National Luboratory concluded that DSG has a lower appeal to low-injectivity shallow reservoirs and high-injectivity deeper reservoirs. ${ }^{15}$ Figure 6.19 depicts the steam genemtor system selection chart recommended by Sandia. This graph, however, excludes any consideration of investment and operating costs. The costs of energy injected into a reservoir (1981 dollars) as a function of depth for surface and downhole steam generators are shown in figure 6.20 .

A fair comparison of the economics of the DSG versus surface steam generation is difficult because such studies involve the comparison of an unproven rechnology with that of an established technology. Published comparative economic evaluations are all preliminary and generic in nature and reflect author's bias. To arrive at an honest conclusion, a site-specific process economic study of the options is necessary. In table 6.9. the published equipment cost data are shown. Most of the data were published in 1980-82. These are updated to 1991 da.:.:urs using the U.S. Producer Price Index. Note that the equipment costs vary with improvement in technology, effect of inflation, and the general state of the economy.

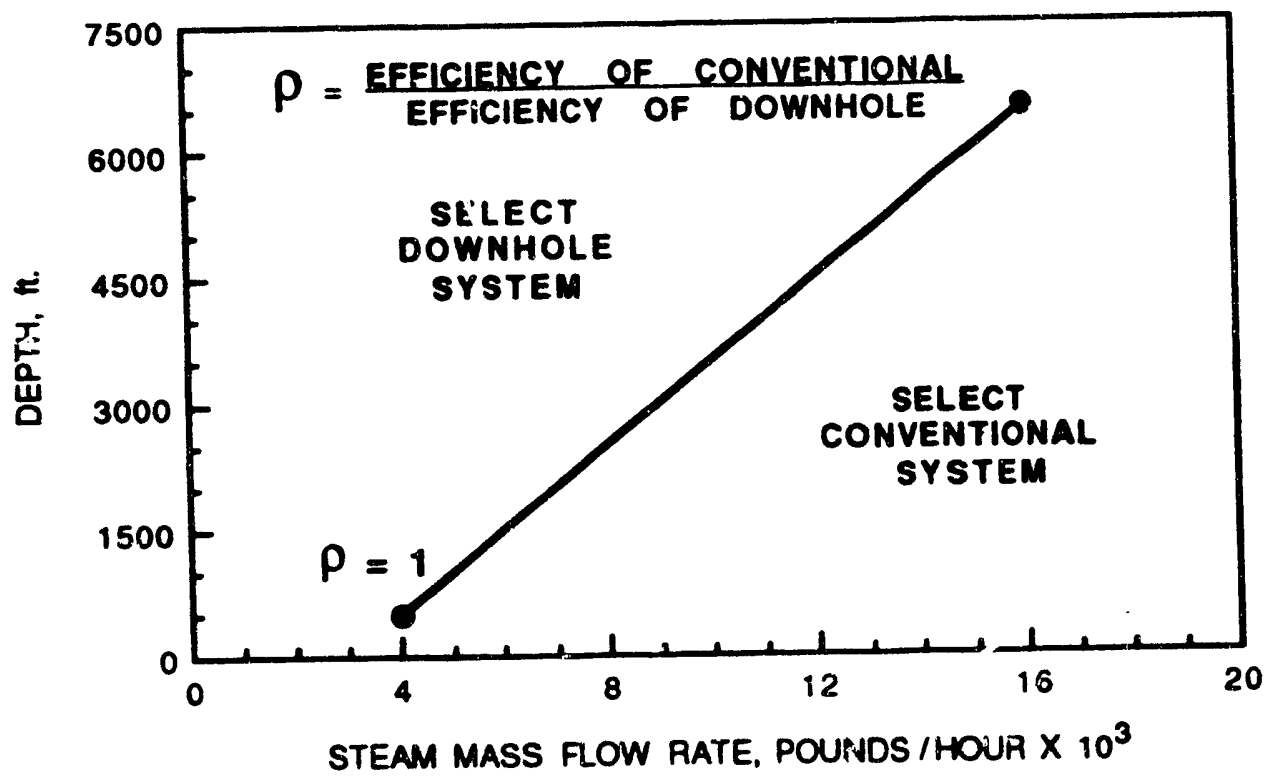

FIGURE 6.19. - Downhole steam generator selection chart. ${ }^{15}$ 


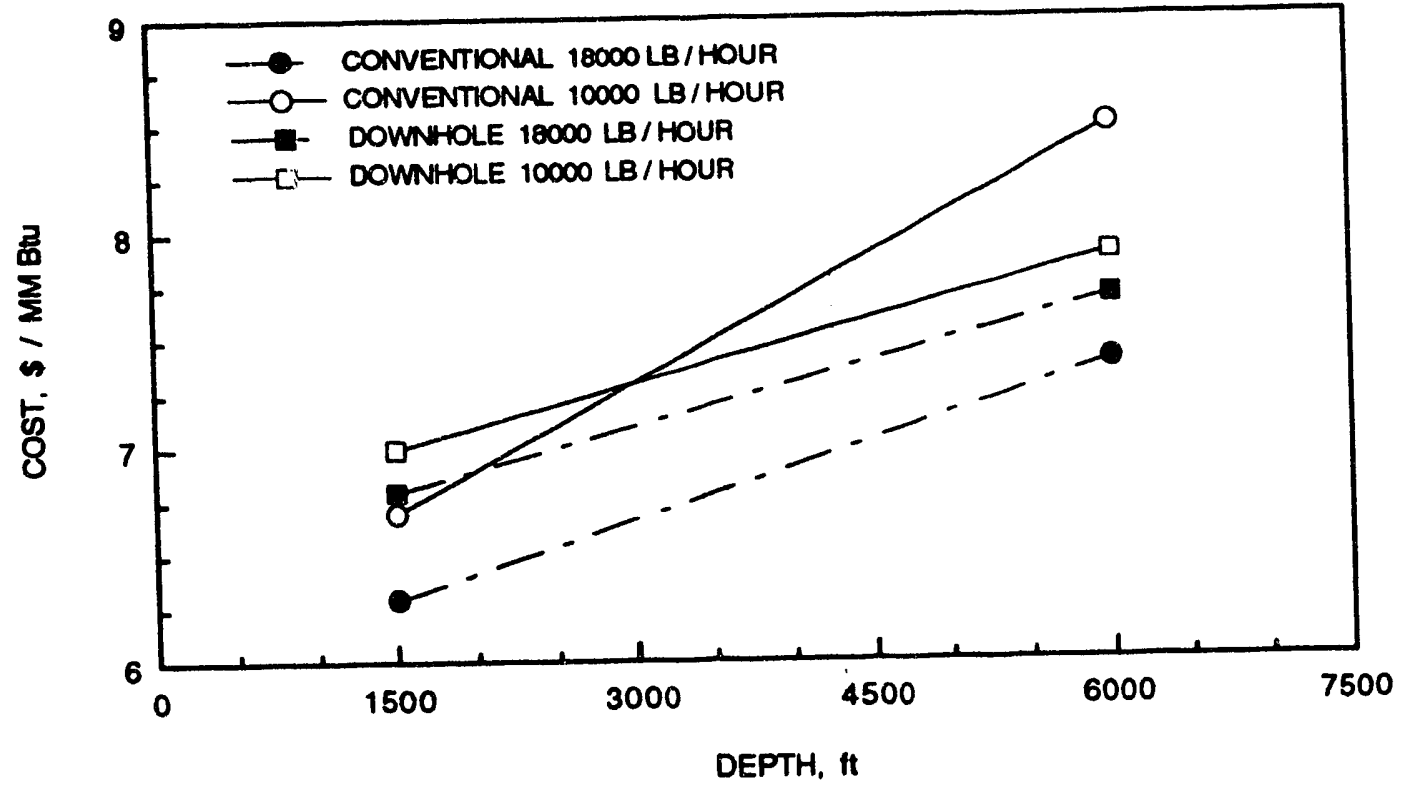

FIGURE 6.20. - Cost of energy injected into reservoir versus reservoir depth. ${ }^{15}$

TABLE 6.9. - Comparison of Surface and Downhole Steam Generator Costs 20

\begin{tabular}{|c|c|c|c|c|c|c|c|}
\hline \multirow[b]{2}{*}{$\begin{array}{l}\text { Author } \\
\text { and } \\
\text { Reference }\end{array}$} & \multirow[b]{2}{*}{ Year } & \multicolumn{3}{|c|}{ Surface steam generator } & \multicolumn{2}{|c|}{ Downhole steam generator } & \multirow[b]{2}{*}{$\begin{array}{l}\text { Well drilling } \\
\text { and } \\
\text { completion } \\
\text { costs. } \\
1991 \text { \$ }\end{array}$} \\
\hline & & $\begin{array}{c}\text { Generator costs. } \\
1991 \text { S per } \\
\mathrm{MM} \mathrm{Btu/hr}\end{array}$ & $\begin{array}{c}\text { Water } \\
\text { treatment } \\
\text { plant costs, } \\
1991 \text { S per } \\
\text { MM Btwhr }\end{array}$ & $\begin{array}{l}\text { Well drilling } \\
\text { and } \\
\text { completion } \\
\text { costs. } \\
1991 \text { S }\end{array}$ & $\begin{array}{l}\text { Generator } \\
\text { costs, } \\
1991 \text { \$ per } \\
\text { MM Btu/hr }\end{array}$ & $\begin{array}{c}\text { Water } \\
\text { treatment } \\
\text { plant costs, } \\
1991 \text { \$ per } \\
\text { MM Btu/hr }\end{array}$ & \\
\hline Hart $^{15}$ & $1982^{2}$ & 15,900 & 5,600 & $\begin{array}{r}\$ 81 / \mathrm{ft} \\
+\$ 8,000\end{array}$ & $\begin{array}{r}1_{38,200} \\
26,360 \\
3_{2,650}\end{array}$ & $\begin{array}{c}6,900 \\
- \\
-\end{array}$ & $\begin{array}{l}{ }^{4} \$ 100 \text { per } \mathrm{ft} \\
+\$ 12,600 \\
5 \$ 90 \text { per } \mathrm{ft} \\
+\$ 10,600\end{array}$ \\
\hline $\mathrm{CORCO}^{2}$ & 1981 & 10.600 & 8,200 & 一 & $1_{74,000}$ & - & - \\
\hline Eson $^{21}$ & 1982 & 14.575 & 4.000 & - & 159,200 & 1.200 & - \\
\hline
\end{tabular}

1 High pressure DSG including compressor.

2 Low pressure DSG - generator only.

3 High pressure DSG - generator only.

4 Low pressure DSG.

5 High pressure DSG. 
At the present time, because of the current economic situations and the unproven nature of the technology, there is lack of interest in the vil patch for DSG. It is unlikely that the DSG will be used in the shallow California reservoirs. DSG applications may be limited to special situations such as steamflooding of heavy oil reservoirs in Alaska where the fragile nature of the environment and arctic climate preclude the use of surface steam generation facilities. It may also find a practical application offshore where its compact size would be an asset.

\section{Cogeneration}

Another method of steam generation currently in use, principally in California, involves the use of a heat-recovery steam generator (HRSG) as an integral component of a process known as cogeneration. In the cogeneration process, the fuel (such as natural gas) is burned in a gas turbine to generate electricity and the heat from the hot exhaust gas is recovered in a HRSG to generate steam. Figure 6.21 shows a schematic of a steam injection cogeneration facility.

Cogeneration is defined by the U.S. Government as the simultaneous production of electricity and thermal energy (steam) from the same fuel source. Cogeneration technology has been used since the 1950 s by the petroleum industry in such facilities as natural gas processing

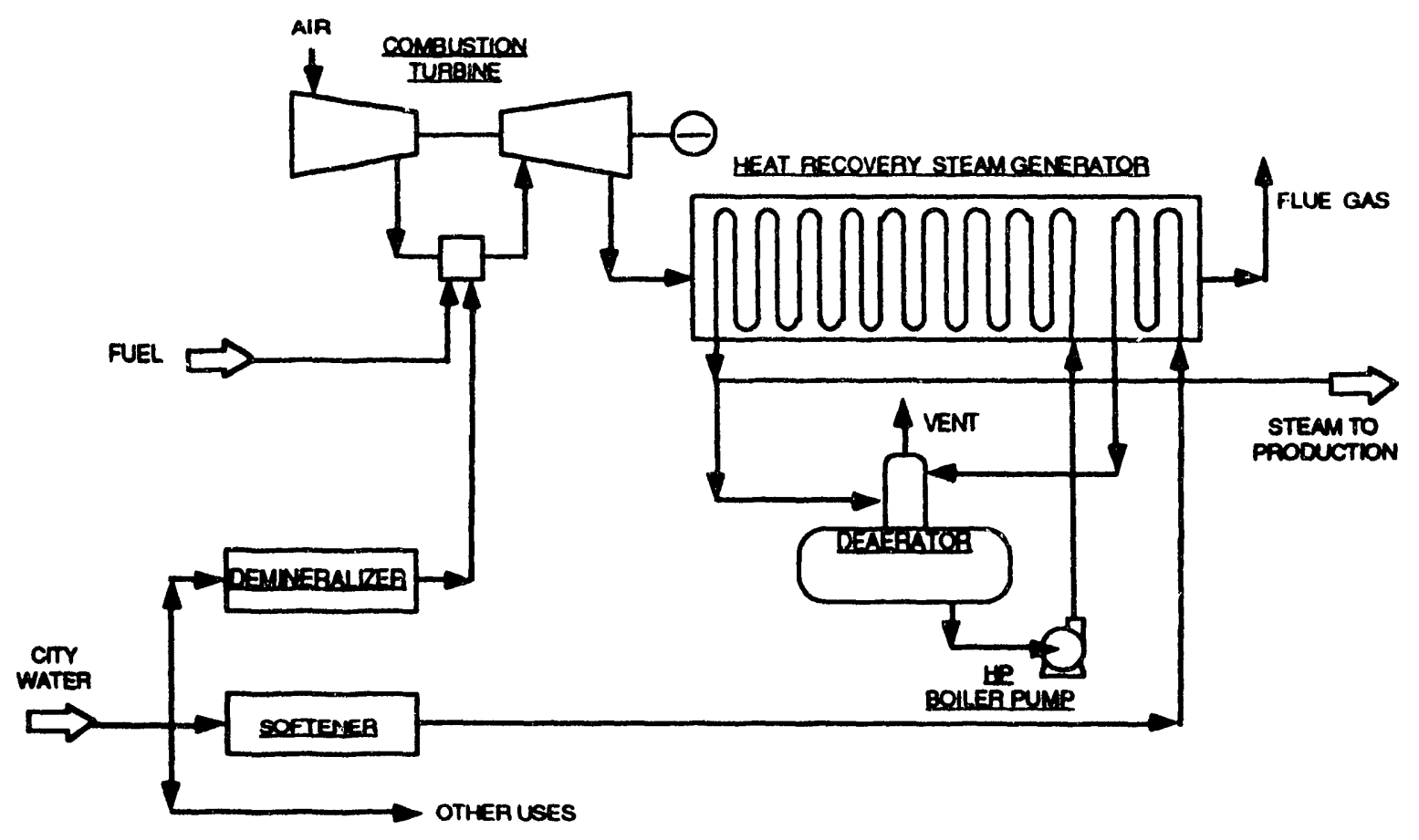

FIGURE 6.21. - Schematic layout of a cogeneration facility. ${ }^{18}$ 
plants, offshore oil platforms, and crude oil pipeline applications. Steam injection operators did not utilize cogeneration technology until the late 197()s, principally due to economic reasons. In the past, the low oil price and the larger capital expenditure for cogeneration equipment combined with the absence of a ready market for the excess generated electricity made cogeneration economically unattractive for steam injection operators. However, the passage of the "Public Utility Regulatory Policy Act" (PURPA) in 1978 and the rising prices of crude in the 1970s improved the attractiveness of cogeneration for steam injection operations. One of the provisions of PURPA requires that state utility agencies must mandate local public utility companies to purchase any excess power that a cogenerator has to offer. The contract with the electric utility company is a key factor in ensuring the economic success of a large cogeneration system. In California, the public utility commission has arranged for "standard offers." Cogenerators can take advantage of them or can negotiate a special contract with the utility, if they so choose.

In California, most cogeneration systems are owned by the operators or by companies specially formed for this purpose. These cogeneration plants are large units with a power generating capacity of $80 \mathrm{MW}$ or more. In table 6.10 , the capital cost itemization of an $80 \mathrm{MW}$ California cogeneration project is shown. ${ }^{18}$ These data are included here to indicate the capital investment requirements for large size cogeneration plants. Small steam injection operators can merely purchase steam from these companies. The constraints to such an arrangement are heat loss from the steam piped long distances prior to injection and long-term purchase commitments. Long-term purchase commitments, while they assure a steady supply of steam at a negotiated price for the duration of a project, also require operators to pay for steam not used due to project shutdown. For this reason, most small steam injection operators in California prefer to generate the steam themselves.

TABLE 6.10. - Capital Cost Itemization of a California Cogeneration Project (All Costs are in 1989 Dollars) ${ }^{18}$

\begin{tabular}{rrr}
\hline & \multicolumn{1}{c}{$\begin{array}{c}\text { Cost. } \\
\text { MS of }\end{array}$} & $\begin{array}{c}\text { Total cost } \\
\text { TS }\end{array}$ \\
\hline 1. Power generation & 25.637 & 50.5 \\
2. Steam generator & 8.900 & 17.5 \\
3. General facilities & 7.578 & 14.9 \\
4. Switchyard \& transmission & 1.385 & 2.7 \\
5. Emission offsets & 1.170 & 2.3 \\
6. Startup & 2.051 & 4.0 \\
7. Project engineering \& management & 2.160 & 4.3 \\
8. Construction interest & 565 & 1.2 \\
9. Offsite pipelines & 1.320 & 2.6 \\
10. Total & 50.766 & \\
\hline
\end{tabular}


Small operators who do not wish to enter a contract with large cogenerators yet wish to avail themselves to the benefits of cogeneration can do so by installing small custom-designed skidmounted cogeneration units. These are designed for unattended operation in a dusty outdoor environment and generate approximately $2.5 \mathrm{MW}(8.53 \mathrm{MM} \mathrm{BTU} / \mathrm{hr}$ ) of electricity and $40 \mathrm{MM}$ BTU/hr $(2,600 \mathrm{bbl} / \mathrm{d})$ of $80 \%$ quality steam at $1,500 \mathrm{psig}$. One vendor's economic summary of a packaged cogeneration unit (updated to 1991 dollars using the U.S. CPI) is shown in table 6.11.16 These cogeneration economic data are included here for illustration only, and the actual vendor quote may differ from these 'off-the-cuft' estimates. The net cost shown in the table is the cost of the system minus the cost of the steam generator that would have been required if the cogeneration system had not been installed.

According to one steam injection operator who installed such a system (in the mid-80s) on his lease, the generated power cost from cogeneration units were about $25 \%$ of purchased power costs and the payout was about 2.4 years. ${ }^{17}$ His annual maintenance expense averaged about $5 \%$ of the initial turbine investment.

With the exception of the turbine and the electric generator, a cogeneration facility is designed and operated to produce steam similarly to a standard oil field steam generator. Both require essentially the same feedwater quality (zero hardness and low TDS) and operate within the same pressure ranges. Since a cogeneration steam generator is designed to recover the waste heat from the hot exhaust gases $\mathrm{cf}$ a turbine, only a convective heat transfer section is used in a cogeneration facility. Since cogeneration units are designed to burn sweet natural gas, no $\mathrm{SO}_{2}$ is formed. The $\mathrm{NO}_{\mathrm{x}}$ emissions are usuaily controlled by injecting demineralized water into the turbine combustion chamber.

The operating problems of cogeneration steam generators are similar to those of standard oil field steam generators. The discussion of the operation and problems of a turbine generator set is beyond the scope of this report.

\section{SUMMARY}

Steam generators used in oilfields differ from conventional power boilers. Oilfield steam generation equipment and techniques have evolved over the past 30 years to a highly specialized state. This chapter reviewed the once-through wet steam generators that are used almost exclusively in oilfields. Essential operating and maintenance techniques are discussed. The importance of good operation practices and mechanical maintenance schedules that reduce the overall maintenance and operating costs are emphasized. Salient features of other specialized oilfield steam generation equipment are detailed. 
TABLE 6.11. - Economic Summary for a Skid-Mounted Cogeneration Unit. ${ }^{16}$

Capital investment

$\$ 3,000,000$

Water treatment plant

\$ 200,000

Total capital investments

$\$ 3,200,000$

Operating costs 2

Turbine fuel, $37 \mathrm{MM}$ BTU/hr

Supplemental fuel, $36 \mathrm{MM}$ BTU/hr

Demineralized feedwater

Treatment and disposal of waste water

Operation and maintenance

Total operating costs

s 32,000 per month

s 31,000 per month

\$ 21,000 per month

S 12,000 per month

s 30.000 per month

$\$ 129,000$ per month

Value of output ${ }^{2}$

Electric power, $2,500 \mathrm{kw} / \mathrm{hr}$

Steam produced, $48,000 \mathrm{lb} / \mathrm{hr}$

S126,000/month

Total

Monthly savings

$=\$ 100.000 /$ month

$=\$ 226,000 /$ month

\$ $97,000 /$ month

Initial capital cost

$\$ 3,200,000$

Alternative cost

$\$ 700.000$

Net cost

$\$ 2,500.000$

Pay back $=2.2$ yeaps

1. Capital investment includes the following

(a) Gas turbine/generator set

(b) Switch gear, controls, relays and substation equipinent and housing

(c) Waste heat recovery steam generator and associated components. These include:

Diverter valve/bypass stack, duct burner, airblower, steam generator, feedwater prebeater, feedwater pump, burner controls, and steam generator control panel.

2. Assumptions:

Steam generator capacity, $\mathrm{lb} / \mathrm{hr}$

Power generator capacity, $\mathrm{kw} / \mathrm{hr}$

Utilization, hr/month

Fuel value (natural gas), 5 per MM BTU

Electric power value, $\mathbf{S}$ per $\mathbf{k w}-\mathrm{hr}$

Steam generator efficiency

Feedwater utilization rate, bbl/hr

$$
\begin{array}{r}
38,000 \\
2.500 \\
700 \\
1.2 \\
0.07 \\
0.8 \\
110 \\
0.31
\end{array}
$$

Feedwater treatment cost, $\$$ per bbl

Steam value is computed as steam value $=$

Pounds steam produced/hr $\times 954 \mathrm{BTU} / \mathrm{lb} \times 10^{-4} \times$ fuel cost $\$ / \mathrm{MM}$ BTU

Steam generator efficiency

\section{REFERENCES}

1. Warren, K. W. Advances in Oil Field Steam Generation. Meyer, R. F., J. C. Wynn and J. C. Olson, eds. The Future of Heavy Crude and Tar Sands. Second International UNITAR Conference in Caracas, Venezuela, February 1982, McGraw-Hill, New York, pp. 685-693.

2. Struthers-Thermo-Flood Corporation: Enhanced Oil Recovery Steam Generators. Bulletin No. TF 100-79-7-5000, 1979. 
3. Peachey, B. R. Design Consideration for Very Large Oilfield Steam Generators. Pres. at the 35th Ann. Tech. Meeting of the Pet. Soc. of CIM, Calgary, Canada, June 10-13, 1984. Paper No. 84-35-81.

4. American Petroleum Institute. API Recommended Practice for Installation and Operation of Wet Steam Generators. API Publication API RP IIT, 1st Ed., March 1983. American Petroleum Institute, Production Dept., Dallas, TX, 1983.

5. Gjerde, E. Raw crude: A Heat Source for Steam Flooding. Pet. Engr. v. 36, No. 13, December 1964, pp. 92-94.

6. Hampton, L. A. How various Fuels Affect the Design and Operating Costs of Steam Generators. Pres. at the 19th Ann. Tech. Meeting of the Pet. Soc. of CIM, Calgary, Canada, May 7-10, 1968. Paper No. 6812.

7. Prats, M. Operational Aspects of Steam Injection Processes. In: Donaldson, E. C., G. V. Chilingarian and T. F. Yen, eds. Enhanced Oil Recovery II-Processes and Operations, Elsevier Science Publishing Co., New York, 1989, p. 359.

8. Modular Steam System: Vapor Tech Steam Generator-A Lightweight Steam Generator for In-field Steam Flooding-Modular Steam System. Technical Bulletin, Earth Resources Technology Services, Phoenix, AZ.

9. Martin, W. L., M. W. Britton and R. A. Harmon. Conoco's South Texas Tar Sands Project . In: Meyer, R. F., J. C. Wynn and J. C. Olson, eds. The Future of Heavy Crude and Tar Sands. Second International UNITAR Conf., Caracas, Venezuela, February 1982. McGrawHill, New York, pp. 987-997.

10. Jones, O. and J. S. Davis. Solid Fuels Proven for Oil Field Steam Generation. Oil \& Gas J., v. 81, No. 8, Feb. 27, 1983, pp. 189-192.

11. Clark, S. W. Wet Oxidation Downhole Steam Generator for Recovery of Deep Heavy Oil. Pres. at the Third International UNITAR Conf. on Heavy Crude and Tar Sands, Long Beach, CA, July 22-31, 1985. Proceedings v. 3, pp. 1,116-1,119.

12. Balog, S. E., R. K. Kerr and L. A. Pradt. The Wet Air Oxidation Boiler for Enhanced Oil Recovery. J. Can. Pet. Tech., v. 21, No. 5, September-October 1982, pp. 73-79.

13. Sperry, J. S. Development and Field Testing of the Vapor Therm Process. Pres. at the Third ERDA Symp. on Enhanced Oil \& Gas Recovery and Improved Drilling, Tulsa, OK, Aug. 30-Sept. 1, 1977. Proceedings, v. 1, pp. D-2/1-D-2/14.

14. Bader, B. E., R. L. Fox, D. R. Johnson, A. B. Donaldson and D. A. Krueger. Deep Steam Project. Quarterly Report Oct. 1-Dec. 31, 1978. Sandia Laboratories Report SAND-79$0562,1979$.

15. Hart, C. M. Comparative Analysis of Steam Delivery Cost for Surface and Downhole Steam Drive Technologies. Sandia National Laboratories Report No. SAND-81-0758, 1981.

16. Solt, J. C. and I. R. McNeill. Cogeneration in the Oil and Gas Industry Solar Turbines Technical Publication No. TTS 43, Solar Turbines Inc., Div. of Caterpillar, Oak Brook, IL, 1986. 
17. Livesay, J. D. Long-Term Performance of Small Cogeneration Units in Oil Field and Gas Plant Operation. Pres. at the Pet. Soc. of CIM and the Soc. of Pet. Engineers International Technical Meeting, Calgary, Canada, June 10-13, 1990. Paper CIM/SPE 90-14. 1989.

18. Harbor Cogeneration Project Fact Sheet - Union Pacific Resources, Wellmington, CA,

19. NATCO: "Therma Drive" Steam Generator. Technical Bulletin No. 1701, National Tank Company, Tulsa, OK, 1990.

20. Nguyen, D., S. Singh and S. Wong. Technical and Economic Criteria for the Selection of Downhole Steam Generators in Alberta. Pres. at the 38th Ann. Tech. Meeting off the Pet. Soc. of CIM, Calgary, Canada, June 7-10, 1987. Paper No. 87-38-04.

21. Eson, R. L. Direct Fired Downhole Steam Generator-Field Tests. Meyer, R. F., J. C. Wynn and J. C. Olson, eds. The Future of Heavy Crude and Tar Sands. Second International UNITAR Conf., Caracas, Venezuela, February 1982, McGraw-Hill, New York, pp. 737-743.

22. Schirmer, R. M. and R. L. Eson: A Direct-Fired Downhole Steam Generator-From Design to Field Test. J. Pet. Tech., v. 37, No. 10, October 1985, pp. 1903-1908.

\section{Bibliography}

\section{Wet Steam Generators}

Brusset, M. J., A. N. Edgington and R. F. Gilmour. Equipment Performance in an Alberta High Pressure Steam Injection Project. Pres. at the 18th Ann. Tech. Meeting of the Pet. Soc. of CIM, Bannf, Alberta, May 24. J. Can. Pet. Tech, Oct.-Dec. 1967.

Crawford, P. B. Combustion Calculations for Steam and Hot Water Generators. Prod. Monthly, v. 31, No. 1, January 1967, pp. 16-17.

Crawford, P. B. Fuel Calculations for Steam Generators. Producer's Monthly, v. 31, No. 2, February 1967, p. 23.

Crawford, P. B. Firing Crude or Fuel Oil in Steam Generators. Producer's Monthly, v. 31, No. 3, March 1967, p. 29.

Crawford, P. B. Combustion Furnaces for Steam Generators. Producer's Monthly, v. 31, No. 4, April 1967, pp. 29-30.

Crawford, P. B. Controls for Steam Generators for Thermal Oil Recovery Programs. Producer's Monthly, v. 31, No. 5, May 1967. pp. 22-23.

Fanaritis, J. P., and J. D. Kimmel. Review of Once-Through Steam Generators. J. Pet. Tech., v.17, No. 4, April 1965, pp. 409-416.

Gras, E. H. Portable Steam Generating Equipment. Pres. at the 40th Ann. Fall Meeting of the Soc. of Pet. Eng. Denver, CO, Oct. 3-6, 1965. Paper SPE 1169.

Khatib, Z. I., E. E. Olson and M. C. Place. Effect of High Silica Content on Scale Deposition and Pipe Wall Loss in Oilfield Steam Generators. Pres. at the 64th Ann. Tech. Meeting of the Soc. of Pet. Eng., San Antonio, TX, Oct. 8-11, 1989. Paper SPE 19760. 
Owens, M. E., and B. G. Bramley. Performance of Equipment Used in High Pressure Steam Floods. J. Pet. Tech., v. 18, No. 12, December 1966, pp. 1,525-1,531.

Sams, G. W. and J. D. Hunter. Performance Improvement of Direct and Indirect Fired Heaters. Pres. at the 61 st Ann. Tech. Meeting of the Soc. of Pet. Eng., New Orleans, LA, Oct. 58, 1986. Paper SPE 15398.

Struthers Thermo-Flood Corporation, Operating and Maintenance Practice for Struthers Thermo-Flood Oilfield Heaters, Winfield, KS, 1980.

\section{Flue Gas Scrubbers}

Bardet, C. K., L. A. Stuebinger and D. E. Wittig. Williams Holding Lease Steamflood Demonstration Project, Cat Canyon Field, U.S. Dept. of Energy. Report No. DOE/ET/12058-6, July 1983, pp. 71-75.

Sachtschall, J. R. and J. F. Dydo. Operation and Performance of a Double Alkali Scrubber. J. Pet. Tech., v. 34, No. 11, November 1982, pp. 2,630-2,636.

Siemak, J. B. and M. P. Gelbs. Operating Experience With a Two Stage H2S Scrubber Using Caustic Soda. Pres. at the California Regional Meeting of the Soc. of Pet. Eng., Bakersfield, CA, Mar. 27-29, 1985. Paper SPE 13640.

Slack, A. V. and G. A. Hollinden. Sulfur Dioxide Removal From Waste Gases. Noyes Data Corporation, Park Ridge, NJ, 1975, pp. 176-178.

Wendt, R. E. Review of Stack Gas Scrubber Operating Experience on an Oil Fired Steam Generator. Pres. at the California Regional Meeting of the Soc. of Pet. Eng. San Francisco, CA, April 12-14, 1978. Paper SPE 7125.

\section{Downhole Steam Generators}

Bader, B. E., R. L. Fox and J. J. Stosur. The Potential of Downhole Steam Generation to the Recovery of Heavy Oils. Meyer, R. F., J. C. Wynn and J. C. Olson, eds. The Future of Heavy Crude and Tar Sands. Second International UNITAR Conf., Caracas, Venezuela, February 1982, McGraw-Hill, New York, pp. 369-377.

Davis, J. S. and J. P. Fanaritis. The Application and Economics of the Use of Insulated Injection Tubing With Oilfield Steam Generators. Meyer, R. F., J. C. Wynn, and J. C. Olson, eds. The Future of Heavy Crude and Tar Sands. Second International UNITAR Conf., Caracas, Venezuela, February 1982, McGraw-Hill, New York, pp. 675-684.

Stosur, J. J. G. Downhole Steam Generator-A Potential Breakthrough in Heavy Oil Recovery. Meyer, R. F., J. C. Wynn and J. C. Olson, eds. The Future of Heavy Crude and Tar Sands. Second International UNITAR Conf., Caracas, Venezuela, February 1982, McGraw-Hill, New York, pp. 744-748.

Wright, D. E. and R. L. Binsley. Feasibility Evaluation of a Downhole Steam Generator. Pres. at the SPE/DOE Second Joint Symp. on Enhanced Oil Recovery, Tulsa, OK, Apr. 5-8, 1981. Paper SPE 9775.

Ware, C. H. An Evaluation of Alternatives in Downhole Steam Generation. U.S. Dept. of Energy Report DOE/PO/10879-1, September 1981. 


\section{Cogeneration}

Anon. Cogeneration Unit to Assist Heavy Oil Recovery. Oil \& Gas J., v., 81, No. 44, Nov. 7,1983 , pp. 68-69.

Davis, J. S. and W. W. Young. Cogeneration Could Provide Economic Benefits in Steamflood EOR Operations. Oil \& Gas J., v. 82, No. 18, May 5, 1984, pp. 81-86.

Dedrick, C. T. and J. S. Ahuja. Cogeneration and Enhanced Oil Recovery. Meyer, R. F., J. C. Wynn, and J. C. Olson, eds. The Future of Heavy Crude and Tar Sands. Second International UNITAR Conf., Caracas, Venezuela, February 1982, McGraw-Hill, New York, pp. 510-515.

Western, E. R. and D. W. Nass. Cogeneration Improves Thermal EOR Efficiency. Oil \& Gas J., v. 88, No. 40, Oct. 15, 1990, pp. 41-43.

\section{Other Types of Steam Generators}

Davis, J. S., W. W. Young and C. J. Lyns. Use of Solid Fuels Possible for Field Steam Generation. Oil \& Gas J., v. 79, No. 22, June 8, 1981, pp. 129-134.

Sperry, J. S., R. S. Poston and F. S. Young. Development and Field Testing of the Vapor Therm Process in the Carlyle Pool-Allen County, Kansas. Pres. at the Fourth Ann. DOE Symp. on Enhanced Oil \& Gas Recovery \& Improved Drilling Methods, Tulsa, OK, Aug. 29-31, 1978. Proceeding, v. 2, No. 1B, pp. D-2/1-D-2/29.

Sperry, J. S., F. S. Young and R. S. Poston. Development and Field Testing of a Process for Recovering Heavy Crude Oil in the Carlyle Pool-Allen County, Kansas Using the Vapor Therm Generator. U.S. Dept. of Energy Report No. DOE/BETC-2880-1, September 1980.

Young, F. S. and R. W. Krajicek. The Vapor Therm Process for Oil Recovery of Viscous Crude Oil. In: Meyer, R. F., J. C. Wynn and J. C. Olson, eds. The Future of Heavy Crude and Tar Sands. Second International UNITAR Conf., Caracas, Venezuela, February 1982, McGrawHill, New York, pp. 466-468. 


\section{APPENDIX 6-A}

\section{API RECOMMENDED FUEL OIL ANALYSIS SPECIFICATION SHEET ${ }^{4}$}

Higher Heating Value (HHV)

BTU/lb.

Lower Heating Value (LHV)

BTU/lb.

Density, $60^{\circ} \mathrm{F}$

$\mathrm{Lb} / \mathrm{ft}^{3}$

Specific Gravity, $60^{\circ} \mathrm{F}$

or

API Gravity, $60 / 60^{\circ} \mathrm{F}$

Viscosity @ $60^{\circ} \mathrm{F}$

$$
\begin{aligned}
& 122^{\circ} \mathrm{F} \\
& 200^{\circ} \mathrm{F} \\
& \text { Other }
\end{aligned}
$$

Conradson Carbon Residue

Ash

Carbon (C)

Hydrogen (H)

Sulfur (S)

Ditrogen $(\mathrm{N})$

Water $\left(\mathrm{H}_{2} \mathrm{O}\right)$

Sediment

Vanadium (Va)

Iron (Fe)

Magnesium (Mg)

Sodium (Na)

Chloride as $\mathrm{NaCl}$

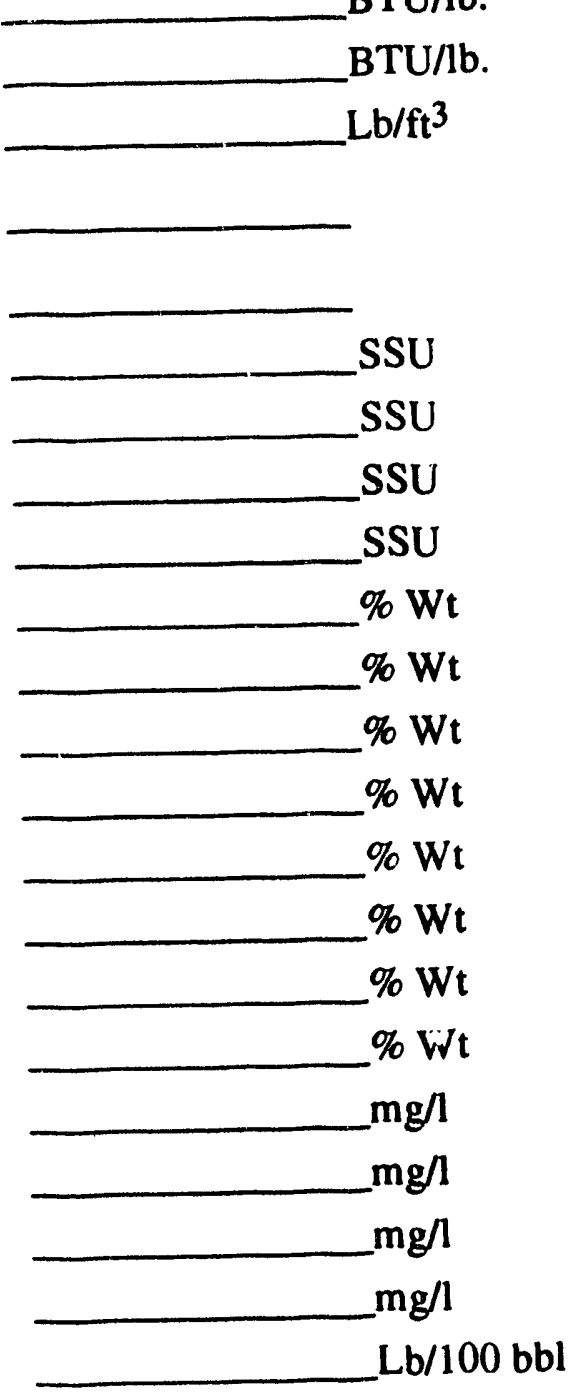


APPENDIX 6-B

\section{API RECOMMENDED FUEL GAS ANALYSIS SPECIFICATION SHEET ${ }^{4}$}

Higher Heating Value

Lower Heating Value

Molecular Weight

or

Density, $60^{\circ} \mathrm{F} \& 14.696$ psia

Temperature

Supply Pressure

Components (Mol \%)

Carbon Dioxide $\left(\mathrm{CO}_{2}\right)$

Hydrogen Sulfide $\left(\mathrm{H}_{2} \mathrm{~S}\right)$

Nitrogen $\left(\mathrm{N}_{2}\right)$

Oxygen $\left(\mathrm{O}_{2}\right)$

Methane $\left(\mathrm{CH}_{4}\right)$

Ethane $\left(\mathrm{C}_{2} \mathrm{H}_{6}\right)$

Propane $\left(\mathrm{C}_{3} \mathrm{H}_{8}\right)$

Butanes $+\left(\mathrm{C}_{4}+\right)$
BTU/SCF

BTU/SCF

$\mathrm{Ft}^{3} / \mathrm{lb}$.

${ }^{\circ} \mathrm{F}$

_psig

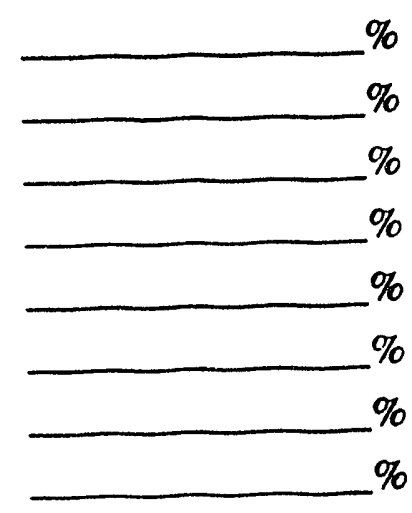


APPENDIX 6-C

\section{API RECOMMENDED WATER ANALYSIS SPECIFICATION SHEET ${ }^{4}$}

Source:

Pressure:

Temperature.

Components

*Calcium, (Ca)

*Magnesium, (Mg)

*Oxygen, $\left(\mathrm{O}_{2}\right)$

Barium, (Ba)

*Iron, (Fe)

*Sodium, (Na)

Copper, $(\mathrm{Cu})$

Potassium, (K)

Ammonium, (NH4)

*Chloride, (Cl)

Iodide, (I)

Bicarbonate, $\left(\mathrm{HCO}_{3}\right)$

Carbonate, $\left(\mathrm{CO}_{3}\right)$

Silica, $\left(\mathrm{SiO}_{2}\right)$

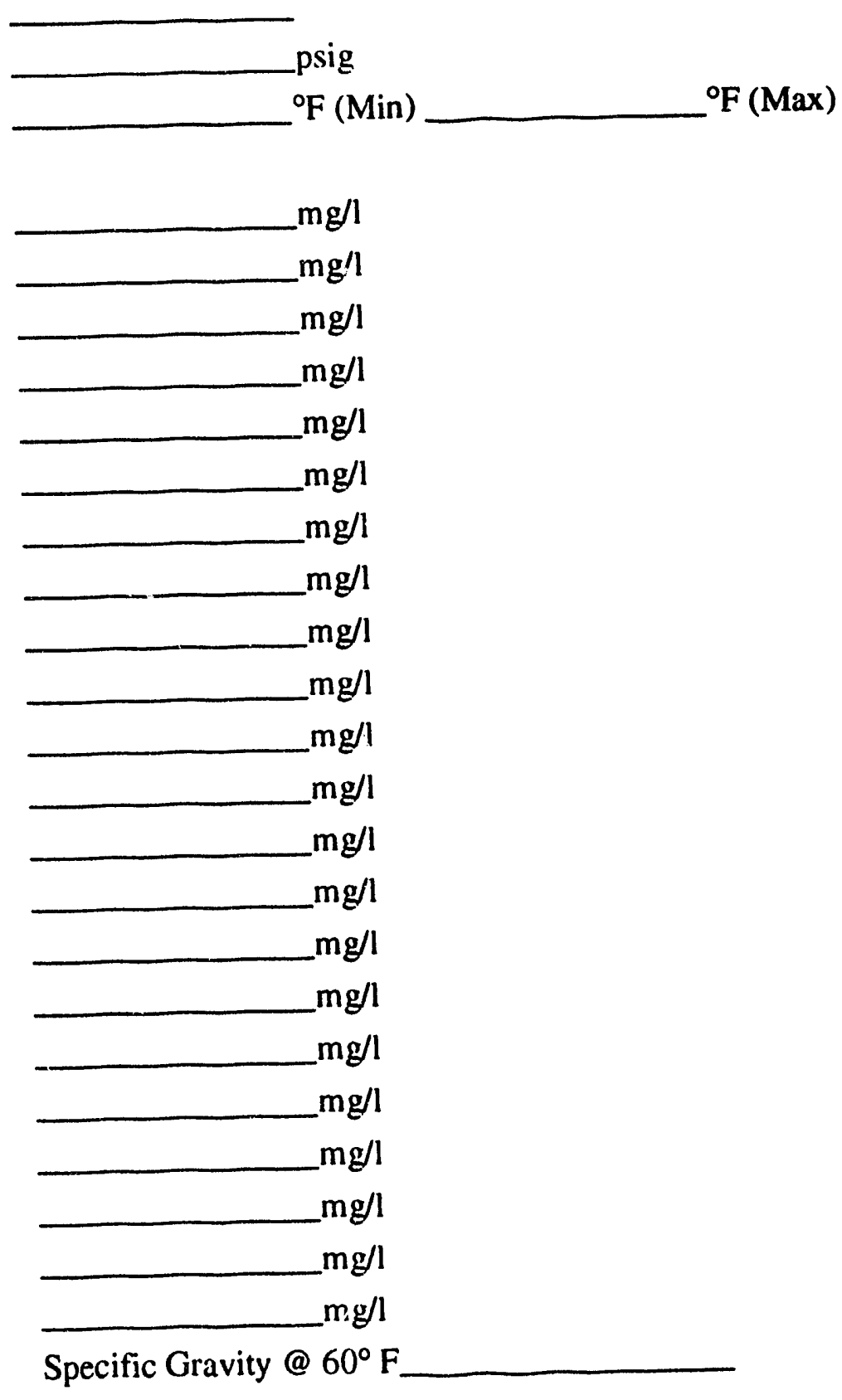

Sulfate, $\left(\mathrm{SO}_{4}\right)$

Hydroxide, $(\mathrm{OH})$

Hydrogen Sulfide $\left(\mathrm{H}_{2} \mathrm{~S}\right)$

Organic Acids

*Total Alkalinity

*Total Hardness, $\left(\mathrm{CaCO}_{3}\right)$

*Total Dissolved Solids

*Total Suspended Solids

*pH

Specific Gravity@60 F

Color

*Oil $\mathrm{mg} /$ Resistivity @ 75 $\mathrm{F}$ Ohm-meter

*Minimum Data Required 


\section{APPENDIX 6-D \\ API RECOMMENDED MAINTENANCE PRACTICE FOR OILFIELD STEAM GENERATOR ${ }^{4}$}

6.1 It is recommended that maintenance and inspection procedures be performed daily, monthly and annually. All repairs and maintenance should be documented. The manufacturer's recommendations should always be a part of maintenance and inspection, and forms should be designed for each specific application. Consider the environment in which a generator operates. Severe environments may require special maintenance and inspection.

\subsection{Daily Maintenance And Inspectuon}

6.2.1 A minimum daily routine of inspecting and recording of all instrument readings is recommended and the following is a list of the minimum readings that should be recorded (See Table 6.4):

a. Feedwater pump discharge pressure

b. Feedwater flow rate

c. Steam outlet pressure

d. Steam outlet teinperature

e. Hater inlet temperature

f. Rociant tube skin temperature

8. Fuel nozzle pressure

h. Stack temperature

i. Radiant section pressure

j. Fuel rate

k. Excess air or $\mathrm{O}_{2}$

6.2.2 In addition there are other parameters that require testing, calculations, or judgment. and should also be monitored and recorded. The following items are recommended:

a. Water quality

b. Steam quality

c. Flame pattern

d. Visual internal and external inspection

e. Lubricating oil levels of the feedwater pump prower end.

f. Lubricating oil level of the air compressor

g. Filter and strainer efficiency

6.3 Monthly Maintenance And Inspection (See Table 6.5)

6.3.1 Feedwater pump, fluid and power ends and drive systems sbould be inspected. The inanufacturer's recommended maintenance procedures should be followed. The crankcase oil should be inspected and replaced as specified by the manufacturer.

6.3.2 All motors should be inspected and lubricated as specified by the manufacturer.

6.3.3 Fuel, water, air strainers and filters should te cleaned and services, as required.
C.3.4 If the Wet Steam Generator is shut down the condition of the convection section and radiant section tubes should be noted. Fin loss deterioration or fouling should be noted and ricorded.

6.3.5 If the Wet Steam Generator is shut down, the flame siabilizer/diffuser and fuel nozzle, used with heavy oil burners should be inspected and cleaned as required.

6.4 Safety Inspection (See Table 6-D-1)

6.4.1 It is recommended that all safety devices be tested at a minimum of once each sixty days. State and local codes may require more frequent testing.

6.4.2 Some regulations require a minimum of five safely shutdeswn devices to be responsive.

a. High steam pressure

b. High tuhe temperature

c. Flame failure

d. Low combustion

e. Low ficedwater flow rate

6.4.3 Mosi manufacturers and purchasing companies require additional safeties, and local codes may require others. Any additional safeties should be tested and the results recorded.

6.4.4 Where possible always lest both the electrical and sensing portions of any safety device.

6.4.5 Any safety that does not function must be replaced or repaired.

6.4.6 The following is a listing of the safety devices that should be tested each 60 days.

a. Flame failitre

b. High steam temperature

c. High sleam pressure

d. High tube temperature

e. High stack temperature

f. High burner throat temperature (oil fired only)

g. Swing out burner switch

h. High/Low atomizing pressure (oil fired only)

i. High fuel gas pressure

j. Low fuel pressure

k. Low fuel oil temperature

l. Low leedwater flow rate

$m$. Low combustion air pressure

n. Low instrument air pressure

o. Low steam pressure 
TABLE 6-D-1 - Steam Generator Safety Inspection Check Sheet ${ }^{4}$

Unit No.

Make of Unit \& Fuel Used
State Serial No.

Location
Inspection Date

Inspector's Signature

1. Enter OK or failed in column headed "Proper Operation"

2. Enter set point of control in column headed "Set Point"

3. Describe any safety failure under "Comments" and describe repairs made

4. Draw line through any safety listed that is not on this unit

\begin{tabular}{l|l|l|l}
\hline & $\begin{array}{c}\text { Proper } \\
\text { Operation }\end{array}$ & $\begin{array}{c}\text { Set } \\
\text { Point }\end{array}$ & Comments \\
\hline High steam pressure & & & \\
\hline High tube temperature & & & \\
\hline Elame failure & & & \\
\hline Low combustion air viressure & & & \\
\hline Low water flow & & & \\
\hline Low fuel pressure & & & \\
\hline Ligh fuel gas pressure & & & \\
\hline Low steam pressure & & & \\
\hline Bumer throat temperature & & & \\
\hline Swing out burner switch & & & \\
\hline High stack temperature & & & \\
\hline Low atomizing pressure & & & \\
\hline Sow fuel oil temperature & & & \\
\hline
\end{tabular}

Visual check of external wiring, conduit, piping, tubing and fittings for obvious leaks or defects. All gauges must be checked for proper calibration.

* Consult state and local codes for test procedures.

\begin{tabular}{l}
\hline Electrician \\
\hline Mechanic \\
\hline Operator \\
\hline
\end{tabular}

Foreman

\begin{tabular}{c}
\hline Date \\
\hline Date \\
\hline Date \\
\hline Date
\end{tabular}

Date 
6.5 Annual Maintenance And Inspection (See Appendix 6-E)

6.5.1 Permanent and progressive records should be maintained for each Wet Steam Generator. It is recommended that the following documents and information be included:

a. All ASME Manufacturers' Data Reports.

b. Drawings showing the location and thickness of monitored or critical inspection locations.

c. If material loss is found within the piping system the maximum allowable working pressure and temperature should be recomputed by a qualified person and the Wet Steam Generator derated or repaired accordingly. All calculations should be made a part of the annual record. All name plates, permits, etc., must reflect the change. In addition, a name plate rubbing should be included in the records.

d. Hydrotest the steam piping from the feedwater pump discharge to the stean outlet at the time of inspections. If applicable record the hydrotest pressure.

e. Schedule date of next inspections.

f. Date of any significant changes in service conditions.

g. Complete pressure relieving device information including safety relief valve spring data and dates of latest and next inspection.

h. The completion of a performance data sheet (see Ref. 4. pg. 10) is recommended. The data can be a useful inspection/maintenance tool.

i. The Wet Steam Generator Mechanical Design Data Sheet (see Ref. 4. pg. 11) should be completed and become a part of the initial records. It should be checked and updated annually to reflect any changes.

6.5.2 A safety check should coincide with an annual maintenance procedure and in addition to the items inspected daily and monthly, the following points should be inspected for proper anuual maintenance:

a. External Inspections. Any evidence of steam or water leaks should be investigated. Leakage from behind insulation. coverings or supports should be investigated and corrective action taken.

1. All pressure and temperature instruments should be calibrated and replaced as required.

2. Safety relief valves should be carefully examined at each inspection and there should be no accumulations of rust, scale or other foreign substance in the valve body which will interfere with the free operation of the valve. It is recommended that annually the safety valves be removed from the unit, tested and reset at an approved safety valve testing facility or by the valve manufacturer. State or losal regulations may require mor frequent inspection or testing.

3. Flectrical. The continuity and condition of all electrical components should be checked.

b. Internal Inspections. Where there is evidence of insulation or refractory failure the material should be repaired or replaced.

1. The surface of all tubes should be carefully examined for any evidence of corrosion, erosion, deformation, bulging. sagging, cracks or de-fective welds. The radiant coil or tubes and the convection section should be spot checked for wall thickness by a non-destructive test. If repairs are made to the code sec-tions of the Wet Steam Generator, a record of the repair must be made. A partial data sheet, ASME form P.3 for the material or piping used, is to accompany the repair form.

2. Tube hangers, yokes and hanger bolts should be inspected for thinning, cracking, stress or deformation.

3. THE HYDROSTATIC TEST PRES. SURE SHOULD BE 1-1/2 TIMES THE MAXIMUM ALLOWABLE WORKING PRESSURE AND SAFETY PRECAU-TIONS MUST BE EXERCISED. 
APPENDIX 6-E. - Steam Generator Annual Check List ${ }^{4}$

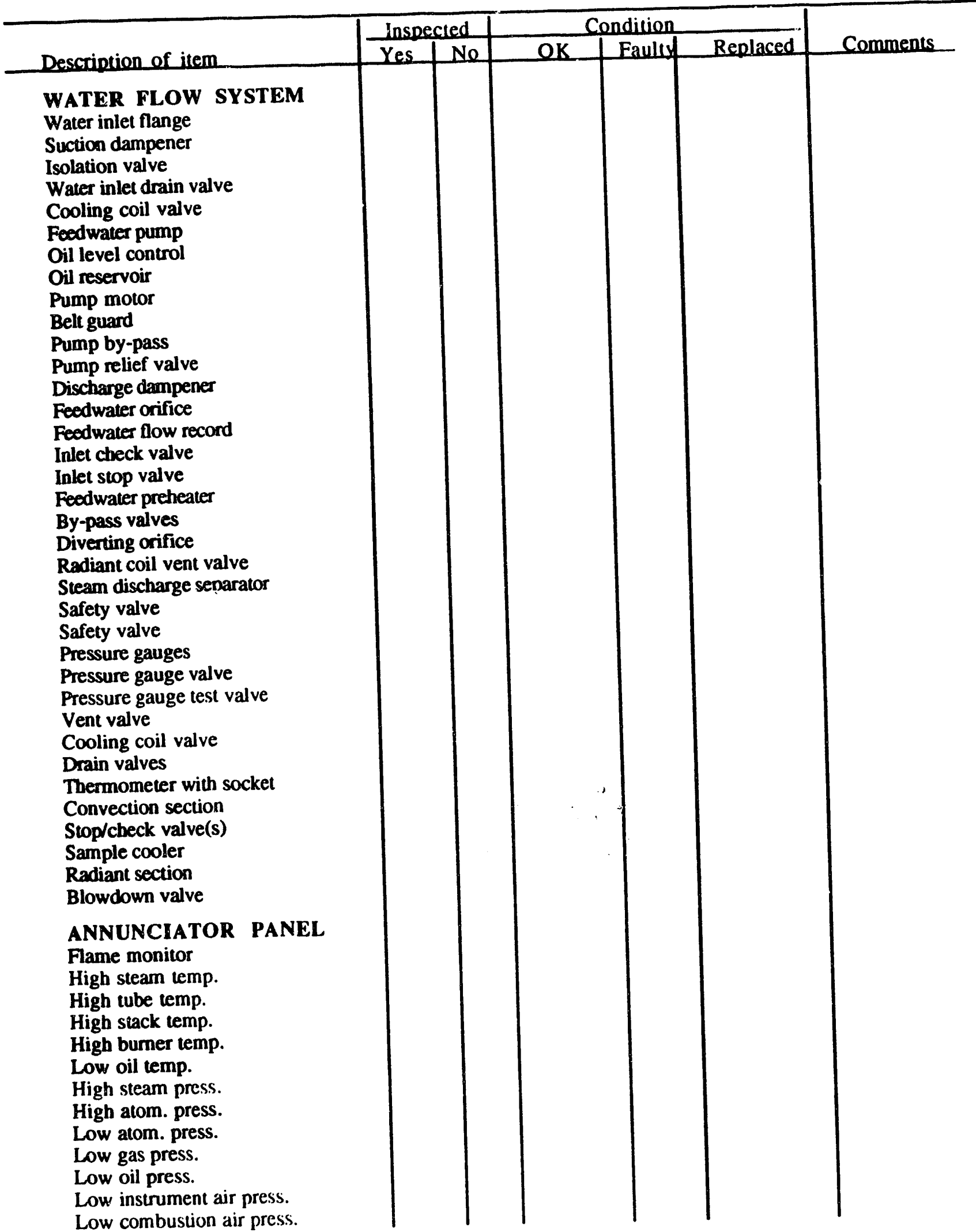


APPENDIX 6-E. - Steam Generator Annual Check List ${ }^{4}$-Continued

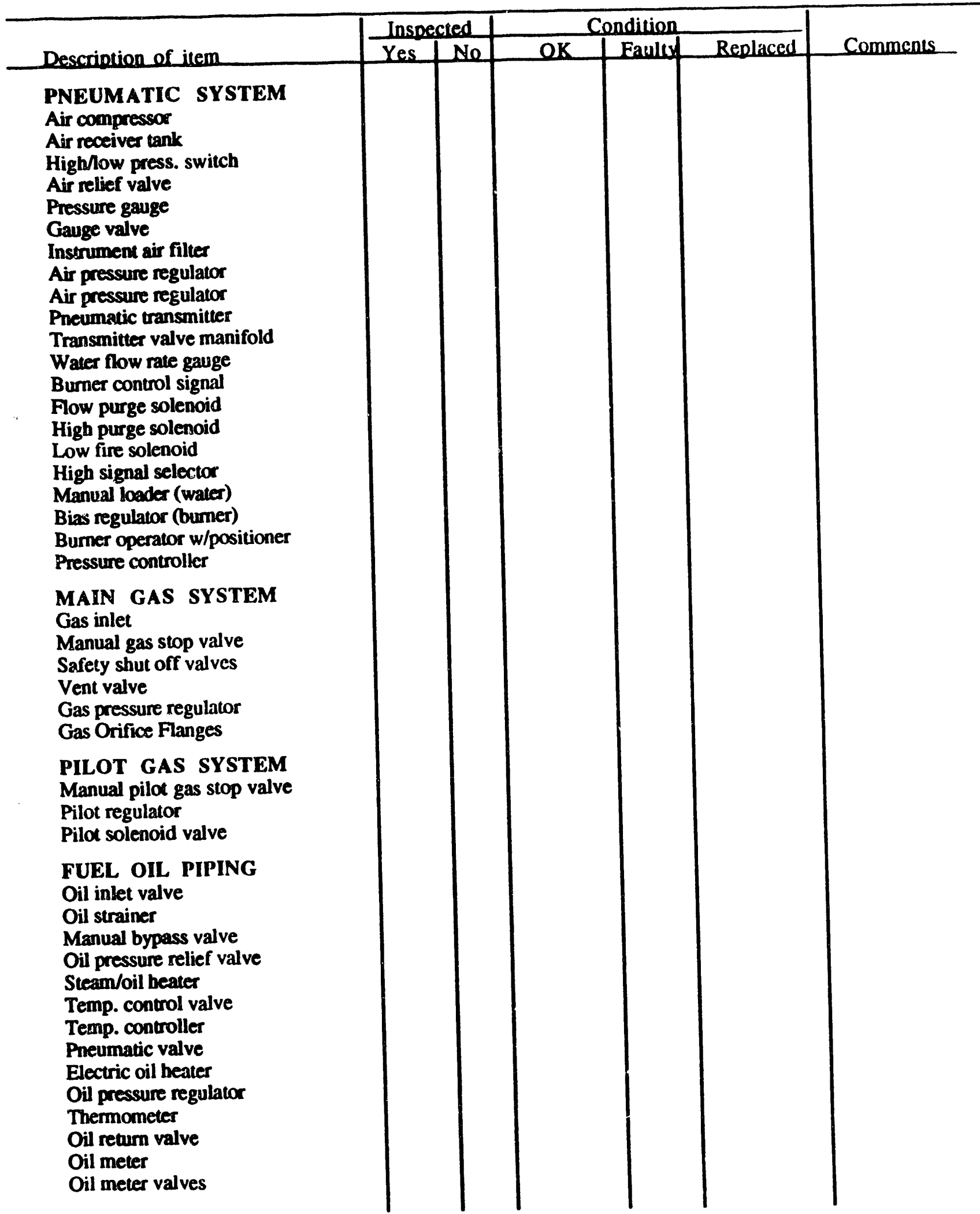


APPENDIX 6-E. - Steam Generator Annual Check List ${ }^{4}$-Continued

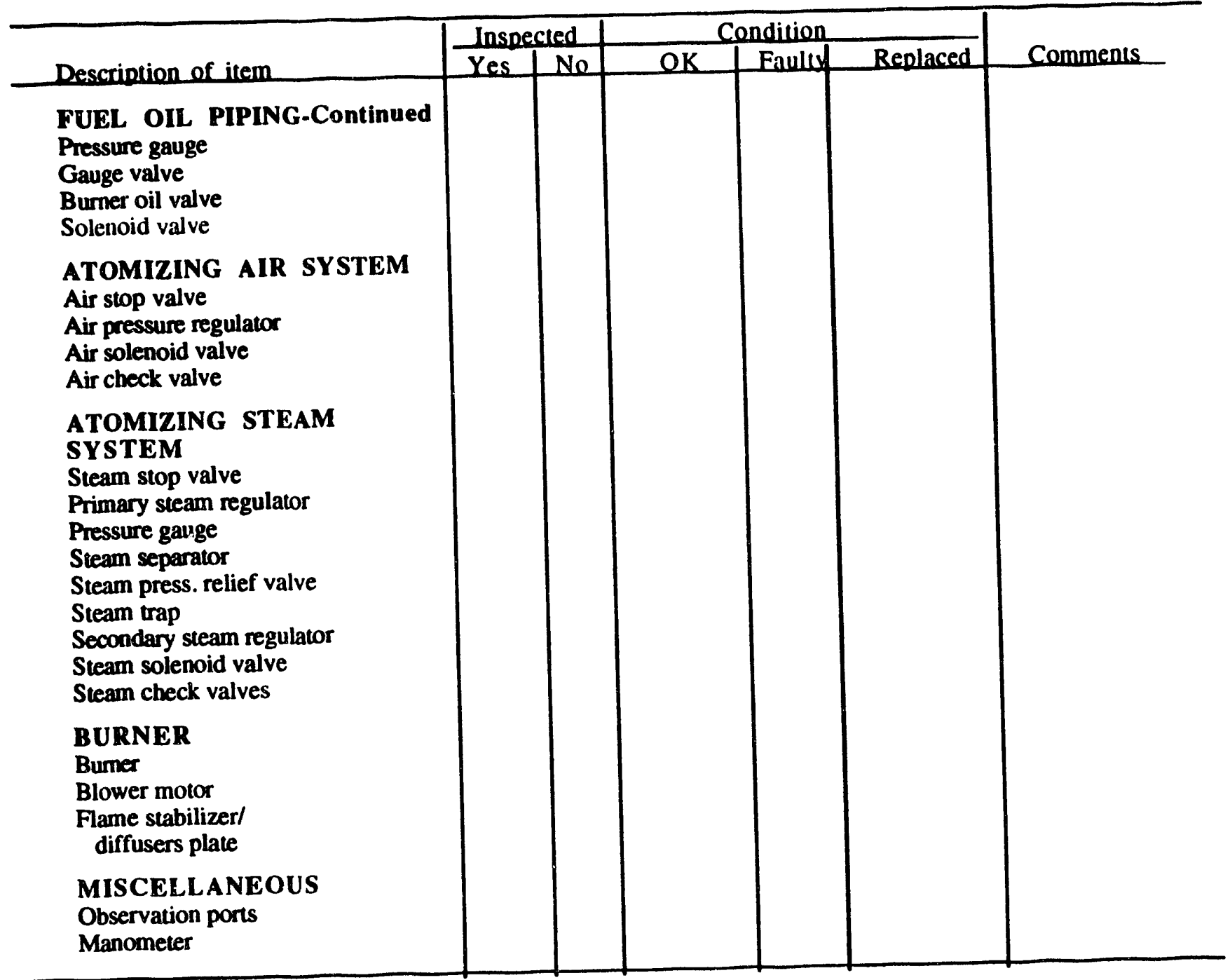




\section{APPENDIX 6-F \\ STEAM GENERATOR VENDORS}

A. Oilfield Steam Generators

1. Babcock \& Wilcox ST Co. Struthers Thermo-Flood Division 8900 Fourche Dam Pike Road P.O. Box 1901

Little Rock, AR 72203

Telephone: (501) 490-2424

Contact: J. D. McNeal

2. NATCO

Division of National Tank Company 4550 Pierce Road

Bakersfield, CA 93308

Telephone: (805) 325-4146

Contact: Bert Miles

3. Daniel En-Fab Systems Inc.

3905 Jensen Drive

P.O. Box 21361

Houston, TX 77226-1361

Telephone: (713) 225-4913

B. Cogeneration Units (Self-contained Units)

1. Solar Turbines Inc.

Division of Caterpillar

2625 Butterfield Road, Suite 315 W

Oak Brook, IL 60521

Telephone: (708) 572-0303

Contact: Cort Van Rensselger

2. Vogt Machine Company

Dept. 24A

P.O. Box 1918

Louisville, KY 40201-1918

Telephone: (502) 634-1500

C. Elue Gas Scrubber

1. NATCO

Division of National Tank Company 4550 Pierce Road

Bakersfield, CA 93308

Telephone: (805) 325-4146
2. Babcock \& Wilcox ST Co.

Struthers Thermo-Flood Division 8900 Fourche Dam Pike Road P.O. Box 1901

Little Rock, AR 72203

Telephone: (501) 490-2424

D. Used Oilfield Steam Generator Supplier

1. Virgles Steam Service Renfro Road

Bakersfield, CA 93312

Telephone: (805) 589-2597 


\section{CHAPTER 7 \\ STEAM DISTRIBUTION}

\section{INTRODUCTION}

Steam leaving generators is directed to injection wells through a network of pipelines called the steam distribution system. The high temperature and pressure of the steam to be injected influences the size and installation of lines transmitting it. In the past, a steam distribution system was considered merely a pipeline between steam generators and injection wells. However, experience of the past decade indicated that the network can behave as an unpredictable phase separator delivering near $100 \%$ quality steam to one well and at the same time deliver hot water to another well on the same distribution line. Hence, the steam distribution network must be designed not only for appropriate pressures and temperatures, but also to provide desired steam quality at a desired flow rate to each injection well in the network. Consideration must be given to maintaining optimum line velocities and provide for the measurement of steam quality at points other than the generator outlet.

The objective of this chapter is to present an overview of the features and requirements of a steam distribution network in a modern steam injection project. The basic function of the steam distribution network in a steam injection project is to deliver steam reliably and safely to injection wells at a desired rate and quality.

\section{Components of a Steam Distribution Network}

A steam distribution network consists of the following major components: (a) main headers; (b) lateral steam lines; (c) wellhead steam rate controls, and (d) wellhead assembly. The design of a steam distribution system is based on the following factors:

1. The expected rate of delivery of steam to each injection well.

2. The expected system operating pressure (This will be principally a function of the expected reservoir injection pressure).

3. The desired steam quality at each injection well.

4. Minimize the effects of phase-splitting.

The principles of operation of a steam distribution system are simple and straightforward. Figure 7.1 shows a schematic of a typical steam distribution system employed in a steam injection project. The steam generator(s) deliver steam to the main header usually at a steam quality of 70 to $80 \%$. These steam headers range in size from 12 to 24 inches, depending on the steam generation capacity of the project and project steam requirements.

Steam is transported from a steam header to individual injector well lines by a steam lateral system. The lines making up this system typically range between 3 and 10 inches in nominal diameter. 


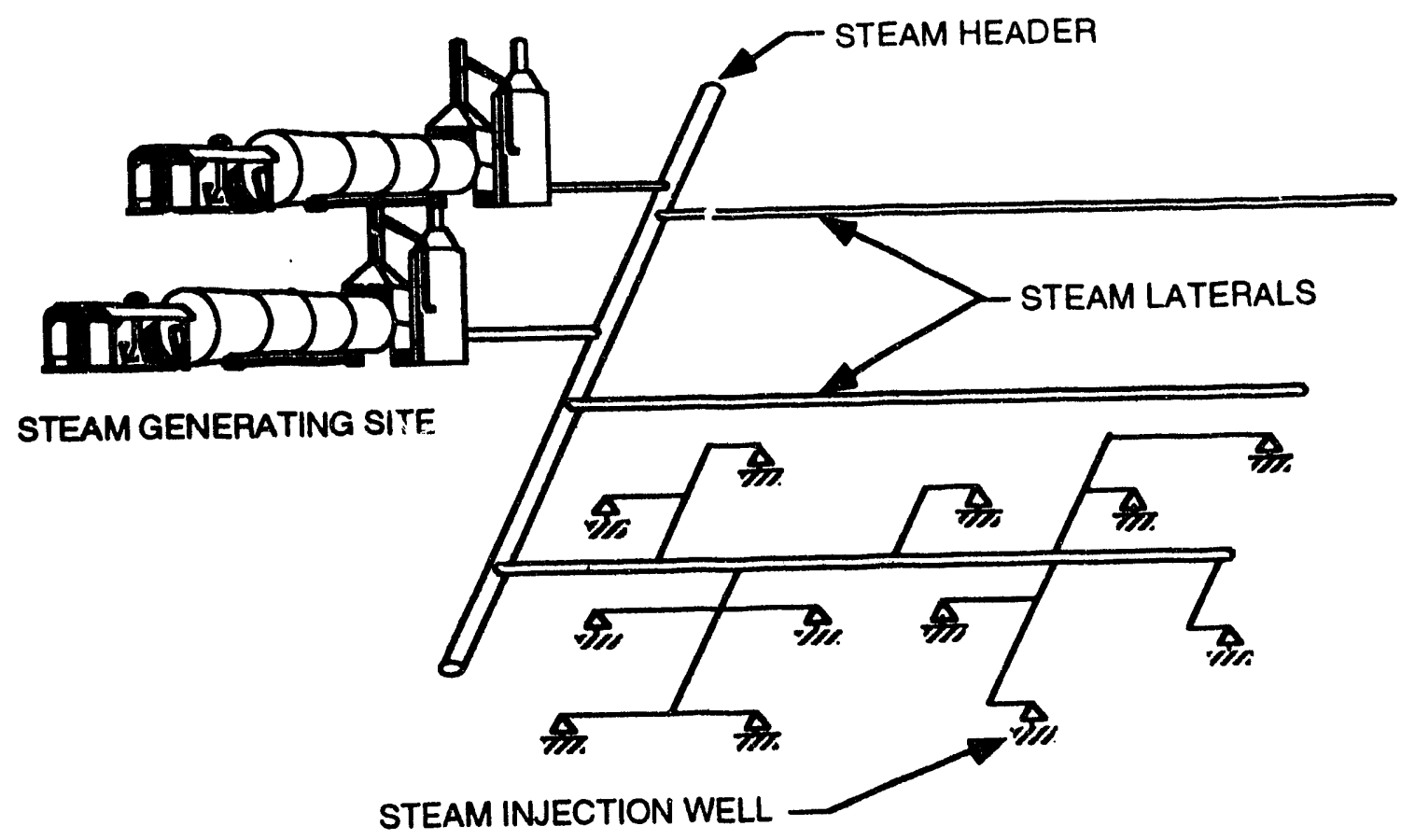

FIGURE 7.1. - Schematic of a typical steam distribution system layout.

The rate of delivery of steam to each individual well is controlled by the installation of some form of rate control, in general at the wellhead itself. These control devices are currently of two forms. The first is merely a static choke driven by system pressure to critical (or sonic) flow. The second device widely used is a manually adjustable choke or control valve operated in the subcritical flow regime. Both forms of control are discussed in detail later in this chapter.

Finally, the steam injector downhole tubing can be expected to expand and contract as its temperature rises and falls. Since it has become common practice to install a downhole tubing packer, the movement of the expanding tubing downhole can become somewhat restricted. The movement of the tubing through the wellhead can become considerable. It is the purpose of the wellhead assembly not only to deliver the steam from the distribution network to the injection well tubing, but also to provide for the expected tubing movement at the wellhead.

The discussion within this chapter is organized into the following sections:

(a) General system pressure and temperature design requirements;

(b) Main steam headers;

(c) Lateral steam lines; 
(d) Expansion of steam lines;

(e) Support for steam lines;

(f) Insulation and heat losses;

(g) Effects of branching on steam quality;

(h) Wellhead assembly;

(i) Wellhead steam rate control devices:

(j) Control of individual well steam quality; and

(k) Maintenance and monitoring.

A list of steam distribution network component suppliers is included in Appendix 7-A.

\section{General System Pressure and Temperature Design Requirements}

The distribution of steam to several wells on an oil property does not pose any unusual engineering problem, and the design of the network is straightforward. The elevated temperature of steam to be injected, however, influences the size and installation of the network. Hence, careful adherence to recognized engineering and operating practices should be observed. The distribution system should be designed for the expected maximum operating temperatures and pressures within the system. Table 7.1 shows the working pressures recommended for steam transmission lines. This table should be used to select the appropriate line size after determining the maximum allowable frictional pressure drop. Table 7.1, taken from reference 1 , is based on ANSI (American National Standard Institute) standards 31.3 and 31.8. The temperature and pressure ratings for steel flanges based on ANSI Standard 16.5 are shown in table 7.2. It is recommended that design of the steam transmission lines be based on ANSI standards as these allow for an ample margin of safety.

Temperature increases cause steam transmission lines to expand, as shown in table 7.3. Hence, thermal expansion must be accounted for in the design of steam transmission lines. If thermal expansion of the steam distribution lines is not adequately compensated for, the lines will be subjected to thermal and bending stresses. Thermal stresses accelerate the corrosion of the lines and weaken the pipe walls. Bending stresses may result in line splitting or rupture. Failure is unlikely to occur until part of the metal wall has been removed by corrosion.

The bending stress can usually be eliminated by providing for the expansion of the lines. Incorporation of expansion loops or swivel joints in the lines is the most practical way to relieve bending stresses. According to table 7.3, a pipe heated from $60^{\circ}$ to $460^{\circ} \mathrm{F}$ expands $3.336 \mathrm{in} . / 100$ $\mathrm{ft}$. Thus, an expansion loop on a line with $250 \mathrm{ft}$ between anchors would require a loop that would handle $8.4 \mathrm{in.}$ of pipeline expansion. Expansion of steam lines is discussed more fully in a later section. 
TABLE 7.1.- Design Properties and Allowable Working Pressures (psig) for Piping 1

ASTM A 106, grade B seamless pipe - petorleum tefinery piping code

for pressure piping ANSI B31.3-1966. Comosion allowance $=0.05$

\begin{tabular}{|c|c|c|c|c|c|c|c|c|c|c|c|c|c|}
\hline \multirow{2}{*}{$\begin{array}{l}\text { Nom } \\
\text { pipe } \\
\text { size, } \\
\text { in. }\end{array}$} & \multirow{2}{*}{$\begin{array}{l}\text { Sch. } \\
\text { No. }\end{array}$} & \multirow{2}{*}{$\begin{array}{l}\text { Wt of } \\
\text { pipe. } \\
\text { Ib/ft }\end{array}$} & \multirow[b]{2}{*}{$\underset{\text { in. }}{O D}$} & \multirow{2}{*}{$\begin{array}{l}\text { Wall } \\
\text { thk. } \\
\text { in. }\end{array}$} & \multirow{2}{*}{$\begin{array}{l}\text { I D. } \\
\text { (d) } \\
\text { in. }\end{array}$} & \multicolumn{8}{|c|}{ Alluwable working pressures for temperatures (in ${ }^{\circ} \mathrm{F}$ ) not to exceed } \\
\hline & & & & & & $\begin{array}{c}2010 \\
100\end{array}$ & 200 & 300 & 400 & 500 & 600 & 700 & 800 \\
\hline $1 / 2$ & S40 & 0.851 & 0.840 & 0.109 & 0.622 & 2.260 & 2.160 & 2.050 & 1,950 & 1.8 .50 & 1.750 & 1.630 & 1,220 \\
\hline $3 / 4$ & $\begin{array}{r}\mathbf{S} 40 \\
\mathbf{X 8 0}\end{array}$ & $\begin{array}{l}1.131 \\
1.474\end{array}$ & 1.050 & $\begin{array}{l}0.113 \\
0.154\end{array}$ & $\begin{array}{l}0.824 \\
0.742\end{array}$ & $\begin{array}{l}1.940 \\
3,460\end{array}$ & $\begin{array}{l}1.850 \\
3.300\end{array}$ & $\begin{array}{l}1.760 \\
3.140\end{array}$ & $\begin{array}{l}1,670 \\
2,980\end{array}$ & $\begin{array}{l}1.590 \\
2.830\end{array}$ & $\begin{array}{l}1.500 \\
3.680\end{array}$ & $\begin{array}{l}1.390 \\
2.480\end{array}$ & $\begin{array}{l}1.050 \\
1,870\end{array}$ \\
\hline 1 & $\begin{array}{r}\mathbf{S 4 0} \\
\mathbf{X 8 0} \\
\mathbf{1 6 0} \\
\mathbf{X X}\end{array}$ & $\begin{array}{l}1.679 \\
2.172 \\
2.844 \\
3.659\end{array}$ & 1.315 & $\begin{array}{l}0.133 \\
0.179 \\
0.250 \\
0.358\end{array}$ & $\begin{array}{l}1.049 \\
0.957 \\
0.815 \\
0.599\end{array}$ & $\begin{array}{l}2.110 \\
3.470 \\
5.720 \\
9.540\end{array}$ & $\begin{array}{l}2.010 \\
3.320 \\
5.470 \\
9.110\end{array}$ & $\begin{array}{l}1.910 \\
3.1 .50 \\
5.200 \\
8.660\end{array}$ & $\begin{array}{l}1.820 \\
3.000 \\
4.940 \\
8.230\end{array}$ & $\begin{array}{l}1.730 \\
2.840 \\
4.680 \\
7.800\end{array}$ & $\begin{array}{l}1.640 \\
2.690 \\
4.440 \\
7.390\end{array}$ & $\begin{array}{l}1.510 \\
2.490 \\
4.110 \\
6.850\end{array}$ & $\begin{array}{l}1.140 \\
1.880 \\
3.090 \\
5.150\end{array}$ \\
\hline $1-1 / 2$ & $\begin{array}{r}S 40 \\
\mathbf{X} 80 \\
160 \\
X X\end{array}$ & $\begin{array}{l}2.718 \\
3.632 \\
7.445 \\
6.409\end{array}$ & 1.900 & $\begin{array}{l}0.145 \\
0.200 \\
0.343 \\
0.400\end{array}$ & $\begin{array}{l}1.610 \\
1.500 \\
1.687 \\
1.100\end{array}$ & $\begin{array}{l}1.680 \\
2.780 \\
4,600 \\
7.230\end{array}$ & $\begin{array}{l}1.600 \\
2.660 \\
+.400 \\
6.910\end{array}$ & $\begin{array}{l}1.520 \\
2.530 \\
4.180 \\
6.560\end{array}$ & $\begin{array}{l}1.450 \\
2.400 \\
3.970 \\
6.240\end{array}$ & $\begin{array}{l}1.370 \\
2.280 \\
3.770 \\
5.910\end{array}$ & $\begin{array}{l}1.300 \\
2.160 \\
3,570 \\
5.610\end{array}$ & $\begin{array}{l}1.200 \\
2.000 \\
3.310 \\
5.190\end{array}$ & $\begin{array}{r}910 \\
1,510 \\
2.490 \\
3,910\end{array}$ \\
\hline 2 & $\begin{array}{r}\mathbf{S} 40 \\
\mathbf{8} 80 \\
160 \\
\mathbf{X X}\end{array}$ & $\begin{array}{l}3.653 \\
5.022 \\
6.445 \\
9.030\end{array}$ & 2.375 & $\begin{array}{l}0.154 \\
0.218 \\
0.343 \\
0.436\end{array}$ & $\begin{array}{l}2.067 \\
1.939 \\
1.687 \\
1.503\end{array}$ & $\begin{array}{l}1.470 \\
2.490 \\
+.600 \\
6.290\end{array}$ & $\begin{array}{l}1 .+10 \\
2,380 \\
+.400 \\
6.010\end{array}$ & $\begin{array}{l}1.340 \\
2.260 \\
4.180 \\
5.710\end{array}$ & $\begin{array}{l}1.270 \\
2.150 \\
3.970 \\
5.420\end{array}$ & $\begin{array}{l}1.210 \\
2.040 \\
3.770 \\
5.140\end{array}$ & $\begin{array}{l}1,140 \\
1,930 \\
3,570 \\
4,880\end{array}$ & $\begin{array}{l}1.060 \\
1,790 \\
3,310 \\
4.510\end{array}$ & $\begin{array}{r}800 \\
1,350 \\
2,490 \\
3,400\end{array}$ \\
\hline 3 & $\begin{array}{r}S 40 \\
\mathbf{X} 80 \\
160 \\
\mathbf{X X}\end{array}$ & $\begin{array}{r}7.58 \\
10.25 \\
14.33 \\
18.58\end{array}$ & 3.500 & $\begin{array}{l}0.216 \\
0.3 n 0 \\
0.438 \\
0.600\end{array}$ & $\begin{array}{l}3.068 \\
2.900 \\
2.624 \\
2.300\end{array}$ & $\begin{array}{l}1.640 \\
2.560 \\
4.130 \\
6.050\end{array}$ & $\begin{array}{l}1.570 \\
2.440 \\
3.940 \\
5.820\end{array}$ & $\begin{array}{l}1.490 \\
2.320 \\
3.750 \\
5.530\end{array}$ & $\begin{array}{l}1.420 \\
2.210 \\
3.560 \\
5.260\end{array}$ & $\begin{array}{l}1.350 \\
2.090 \\
3.370 \\
4.980\end{array}$ & $\begin{array}{l}1.280 \\
1.980 \\
3.200 \\
4,720\end{array}$ & $\begin{array}{l}1.180 \\
1.840 \\
2.960 \\
4.370\end{array}$ & $\begin{array}{r}890 \\
1.380 \\
2,230 \\
3.290\end{array}$ \\
\hline 4 & $\begin{array}{r}\mathbf{S} 40 \\
\mathbf{X} 80 \\
160 \\
\mathbf{X X}\end{array}$ & $\begin{array}{l}10.79 \\
14.99 \\
22.51 \\
27.54\end{array}$ & 4.500 & $\begin{array}{l}0.237 \\
0.337 \\
0.531 \\
0.674\end{array}$ & $\begin{array}{l}4.026 \\
3.826 \\
3.438 \\
3.152\end{array}$ & $\begin{array}{l}1.440 \\
2.280 \\
3.980 \\
5.310\end{array}$ & $\begin{array}{l}1.380 \\
2.180 \\
3.800 \\
5.070\end{array}$ & $\begin{array}{l}1.310 \\
2.070 \\
3.620 \\
4.820\end{array}$ & $\begin{array}{l}1.250 \\
1.970 \\
3.440 \\
4.580\end{array}$ & $\begin{array}{l}1.180 \\
1.870 \\
3.260 \\
4.340\end{array}$ & $\begin{array}{l}1.120 \\
1.770 \\
3.090 \\
4.120\end{array}$ & $\begin{array}{l}1,040 \\
1,640 \\
2,860 \\
3,810\end{array}$ & $\begin{array}{r}780 \\
1.230 \\
2.150 \\
2.870\end{array}$ \\
\hline 6 & $\begin{array}{r}\mathbf{S} 40 \\
\mathbf{X 8 0} \\
160 \\
\mathbf{X X}\end{array}$ & $\begin{array}{l}18.98 \\
28.58 \\
45.30 \\
53.17\end{array}$ & 6.625 & $\begin{array}{l}0.280 \\
0.432 \\
0.718 \\
0.864\end{array}$ & $\begin{array}{l}6.065 \\
5.761 \\
5.187 \\
4.897\end{array}$ & $\begin{array}{l}1.210 \\
2.070 \\
3.760 \\
+.660\end{array}$ & $\begin{array}{l}1.160 \\
1.970 \\
3.5(0) \\
4.460\end{array}$ & $\begin{array}{l}1.100 \\
1.880 \\
3.410 \\
4.230\end{array}$ & $\begin{array}{l}1.050 \\
1.780 \\
3.240 \\
+1.020\end{array}$ & $\begin{array}{r}990 \\
1.690 \\
3.070 \\
3.810\end{array}$ & $\begin{array}{r}940 \\
1.600 \\
2.910 \\
3.620\end{array}$ & $\begin{array}{r}870 \\
1.480 \\
2.700 \\
3.350\end{array}$ & $\begin{array}{r}660 \\
1.120 \\
2.030 \\
2.520\end{array}$ \\
\hline 8 & $\begin{array}{r}S 40 \\
X 80 \\
160 \\
X X\end{array}$ & $\begin{array}{l}28.56 \\
43.4 \\
45.30 \\
74.7\end{array}$ & 8.625 & $\begin{array}{l}0.322 \\
0.500 \\
0.718 \\
0.906\end{array}$ & $\begin{array}{l}7.981 \\
7.625 \\
5.187 \\
6.813\end{array}$ & $\begin{array}{l}1.100 \\
1.870 \\
3.760 \\
3.700\end{array}$ & $\begin{array}{l}1.050 \\
1.790 \\
3.590 \\
3.540\end{array}$ & $\begin{array}{l}1.000 \\
1.700 \\
3.410 \\
3.360\end{array}$ & $\begin{array}{r}950 \\
1.610 \\
3.2+0 \\
3.200\end{array}$ & $\begin{array}{r}900 \\
1.530 \\
3.070 \\
3.030\end{array}$ & $\begin{array}{r}860 \\
1.450 \\
2.910 \\
2.870\end{array}$ & $\begin{array}{r}790 \\
1,340 \\
2.700 \\
2.660\end{array}$ & $\begin{array}{r}600 \\
1,010 \\
2,030 \\
2,000\end{array}$ \\
\hline 10 & $\begin{array}{r}S 40 \\
\mathbf{X 8 0} \\
160\end{array}$ & $\begin{array}{r}40.5 \\
54.7 \\
115.7\end{array}$ & 10.750 & $\begin{array}{l}0.365 \\
0.500 \\
1.125\end{array}$ & $\begin{array}{r}10.020 \\
9.750 \\
8.500\end{array}$ & $\begin{array}{l}1.030 \\
1.490 \\
3.740\end{array}$ & $\begin{array}{r}980 \\
1 .+20 \\
3.570\end{array}$ & $\begin{array}{r}930 \\
1,350 \\
3.4(00\end{array}$ & $\begin{array}{l}890 \\
1.280 \\
3.230\end{array}$ & $\begin{array}{r}840 \\
1.220 \\
3.060\end{array}$ & $\begin{array}{r}800 \\
1.160 \\
2.900\end{array}$ & $\begin{array}{r}740 \\
1.070 \\
2,690\end{array}$ & $\begin{array}{r}560 \\
810 \\
2.020\end{array}$ \\
\hline 12 & $\begin{array}{r}S 40 \\
\times 80 \\
160\end{array}$ & $\begin{array}{r}49.6 \\
65.4 \\
160.3\end{array}$ & 12.750 & $\begin{array}{l}0.375 \\
0.500 \\
1.312\end{array}$ & $\begin{array}{l}12.000 \\
11.750 \\
10.126\end{array}$ & $\begin{array}{r}890 \\
1.250 \\
3.700\end{array}$ & $\begin{array}{r}850 \\
1.190 \\
3.540\end{array}$ & $\begin{array}{r}810 \\
1.140 \\
3.360\end{array}$ & $\begin{array}{r}770 \\
1.080 \\
3.200\end{array}$ & $\begin{array}{r}730 \\
1.020 \\
3.030\end{array}$ & $\begin{array}{r}690 \\
970 \\
2.870\end{array}$ & $\begin{array}{r}640 \\
900 \\
2.660\end{array}$ & $\begin{array}{r}480 \\
680 \\
2.000\end{array}$ \\
\hline 14 & $\begin{array}{r}S 40 \\
\times 80 \\
160\end{array}$ & $\begin{array}{l}36.7 \\
62.6 \\
72.1\end{array}$ & 14.000 & $\begin{array}{l}0.250 \\
0.375 \\
0.500\end{array}$ & $\begin{array}{l}13.500 \\
15.250 \\
13.000\end{array}$ & $\begin{array}{r}486 \\
810 \\
1.1 .40\end{array}$ & $\begin{array}{r}465 \\
780 \\
1.090\end{array}$ & $\begin{array}{r}+12 \\
7+0 \\
1.030\end{array}$ & $\begin{array}{l}+20 \\
700 \\
980\end{array}$ & $\begin{array}{l}398 \\
670 \\
930\end{array}$ & $\begin{array}{l}377 \\
630 \\
880\end{array}$ & $\begin{array}{l}349 \\
580 \\
820\end{array}$ & $\begin{array}{l}263 \\
437 \\
620\end{array}$ \\
\hline 16 & $\begin{array}{r}S 40 \\
\mathbf{8} 80 \\
160\end{array}$ & $\begin{array}{l}42.1 \\
62.6 \\
82.8\end{array}$ & 16.000 & $\begin{array}{l}0.250 \\
0.375 \\
0.500\end{array}$ & $\begin{array}{l}15.500 \\
15.250 \\
15.000\end{array}$ & $\begin{array}{l}+26 \\
710 \\
990\end{array}$ & $\begin{array}{l}407 \\
680 \\
950\end{array}$ & $\begin{array}{l}387 \\
650 \\
900\end{array}$ & $\begin{array}{l}368 \\
610 \\
860\end{array}$ & $\begin{array}{l}349 \\
580 \\
810\end{array}$ & $\begin{array}{l}331 \\
550 \\
770\end{array}$ & $\begin{array}{l}306 \\
510 \\
710\end{array}$ & $\begin{array}{l}231 \\
382 \\
540\end{array}$ \\
\hline 18 & $\begin{array}{r}S 40 \\
\times 80 \\
160\end{array}$ & $\begin{array}{l}47.4 \\
70.6 \\
93.5\end{array}$ & 18.000 & $\begin{array}{l}0.250 \\
0.375 \\
0.500\end{array}$ & $\begin{array}{l}17.500 \\
17.250 \\
17.000\end{array}$ & $\begin{array}{l}378 \\
630 \\
880\end{array}$ & $\begin{array}{l}361 \\
600 \\
840\end{array}$ & $\begin{array}{l}344 \\
570 \\
800\end{array}$ & $\begin{array}{l}327 \\
540 \\
760\end{array}$ & $\begin{array}{l}310 \\
520 \\
720\end{array}$ & $\begin{array}{l}293 \\
486 \\
680\end{array}$ & $\begin{array}{l}272 \\
450 \\
630\end{array}$ & $\begin{array}{l}205 \\
339 \\
474\end{array}$ \\
\hline
\end{tabular}


TABLE $7.1^{1}-$ Continued

\begin{tabular}{|c|c|c|c|c|c|c|c|c|c|c|c|c|c|}
\hline \multirow{2}{*}{$\begin{array}{l}\text { Nom } \\
\text { pipe } \\
\text { size. } \\
\text { in. }\end{array}$} & \multirow{2}{*}{$\begin{array}{l}\text { Sch. } \\
\text { No. }\end{array}$} & \multirow{2}{*}{$\begin{array}{l}\text { Wt of } \\
\text { pipe, } \\
\text { lb/it }\end{array}$} & \multirow[b]{2}{*}{$\underset{\text { in. }}{O}$} & \multirow{2}{*}{$\begin{array}{l}\text { Wall } \\
\text { thk. } \\
\text { in. }\end{array}$} & \multirow{2}{*}{$\begin{array}{l}\text { ID. } \\
\text { (d) } \\
\text { in. }\end{array}$} & \multicolumn{8}{|c|}{ Allowable working pressures for temperatures (in ${ }^{\circ} \mathrm{F}$ ) not to exceed } \\
\hline & & & & & & $\begin{array}{c}-2010 \\
100\end{array}$ & 200 & 300 & 400 & 500 & 600 & 700 & 800 \\
\hline 20 & $\begin{array}{r}\$ 40 \\
\times 80 \\
160\end{array}$ & $\begin{array}{r}52.7 \\
78.6 \\
104.1\end{array}$ & 20.000 & $\begin{array}{l}0.250 \\
0.375 \\
0.500\end{array}$ & $\begin{array}{l}19.500 \\
19.25 \\
19.000\end{array}$ & $\begin{array}{l}340 \\
570 \\
790\end{array}$ & $\begin{array}{l}325 \\
540 \\
760\end{array}$ & $\begin{array}{l}309 \\
520 \\
720\end{array}$ & $\begin{array}{l}294 \\
485 \\
680\end{array}$ & $\begin{array}{l}278 \\
460 \\
650\end{array}$ & $\begin{array}{l}264 \\
4.6 \\
620\end{array}$ & $\begin{array}{l}244 \\
404 \\
570\end{array}$ & $\begin{array}{l}184 \\
304 \\
426\end{array}$ \\
\hline 24 & $\begin{array}{r}S 40 \\
\times 80 \\
160\end{array}$ & $\begin{array}{r}63.4 \\
94.6 \\
125.5\end{array}$ & 24.000 & $\begin{array}{l}0.250 \\
0.375 \\
0.500\end{array}$ & $\begin{array}{l}23.500 \\
23.250 \\
23.000\end{array}$ & $\begin{array}{l}282 \\
468 \\
660\end{array}$ & $\begin{array}{l}270 \\
447 \\
630\end{array}$ & $\begin{array}{l}256 \\
425 \\
600\end{array}$ & $\begin{array}{l}244 \\
404 \\
570\end{array}$ & $\begin{array}{l}231 \\
383 \\
540\end{array}$ & $\begin{array}{l}219 \\
363 \\
510\end{array}$ & $\begin{array}{l}203 \\
336 \\
470\end{array}$ & $\begin{array}{l}153 \\
253 \\
354\end{array}$ \\
\hline
\end{tabular}

TABLE 7.2. - Pressure-Temperature Ratings for Low Carbon Forged Steel Pipe Flanges ${ }^{1}$

ANSI Standard B $65.5 \cdot 1968$

\begin{tabular}{|c|c|c|c|c|c|c|c|}
\hline $\begin{array}{l}\text { Flange rating } \\
\text { service } \\
\text { temperature. }{ }^{\circ} \mathrm{F}\end{array}$ & $150-1 b$ & $300-16$ & $\begin{array}{l}400-1 b \\
\text { aximum. }\end{array}$ & $\begin{array}{l}600-1 b \\
\text { shock, se }\end{array}$ & $\begin{array}{l}\text { 900-lt } \\
\text { pressure }\end{array}$ & $\begin{array}{l}\text { 1,500-lb } \\
\text { ings, psig }\end{array}$ & $2.500-1 \mathrm{~b}$ \\
\hline $\begin{array}{l}100 \\
200 \\
300 \\
400 \\
500 \\
600 \\
700\end{array}$ & $\begin{array}{l}275 \\
240 \\
210 \\
180 \\
150 \\
130 \\
110\end{array}$ & $\begin{array}{l}720 \\
700 \\
680 \\
665 \\
625 \\
555 \\
470\end{array}$ & $\begin{array}{l}960 \\
930 \\
910 \\
890 \\
835 \\
740 \\
635\end{array}$ & $\begin{array}{r}1.440 \\
1.400 \\
1,365 \\
1,330 \\
1,250 \\
1.110 \\
940\end{array}$ & $\begin{array}{l}2.160 \\
2.100 \\
2.050 \\
2.000 \\
1.875 \\
1.660 \\
1.410\end{array}$ & $\begin{array}{l}3.600 \\
3.500 \\
3.415 \\
3.330 \\
3.125 \\
2.770 \\
2.350\end{array}$ & $\begin{array}{l}6,000 \\
5,830 \\
5,690 \\
5,550 \\
5,210 \\
4,620 \\
3,920\end{array}$ \\
\hline
\end{tabular}

TABLE 7.3. - Thermal Expansion of Steel Pipe²

\begin{tabular}{cccc}
$\begin{array}{c}\text { Change } \\
\text { temperature. }\end{array}$ Ff & $\begin{array}{c}\text { Expansion. } \\
\text { in./100 fi }\end{array}$ & $\begin{array}{c}\text { Change in } \\
\text { temperature. } \\
\text { qf }\end{array}$ & $\begin{array}{c}\text { Expansion, } \\
\text { in./100 ft }\end{array}$ \\
\hline 10 & 0.145 & 340 & 2.862 \\
20 & 0.293 & 360 & 3.029 \\
40 & 0.430 & 380 & 3.211 \\
60 & 0.593 & 400 & 3.375 \\
80 & 0.725 & 420 & 3.566 \\
100 & 0.898 & 440 & 3.740 \\
120 & 1.055 & 460 & 3.929 \\
140 & 1.209 & 480 & 4.100 \\
160 & 1.368 & 500 & 4.296 \\
180 & 1.528 & 520 & 4.487 \\
200 & 1.691 & 540 & 4.670 \\
220 & 1.851 & 560 & 4.860 \\
240 & 2.020 & 580 & 5.051 \\
260 & 2.183 & 600 & 5.247 \\
280 & 2.350 & 620 & 5.437 \\
300 & 2.519 & 640 & 5.627 \\
320 & 2.690 & 660 & 5.831 \\
\hline
\end{tabular}




\section{Main Steam Headers}

The purpose of the main steam headers is to collect steam produced by one or more steam generators at one or more sites and deliver this steam to various steam laterals for distribution. The steam collected by the main headers will vary in steam quality from generator to generator. In addition, the quality of the steam delivered by a generator during its initial start-up may approach zero.

Depending on the volume of steam it is expected to carry, the main header size may vary from 12 to $24 \mathrm{in.} \mathrm{Steam} \mathrm{headers} \mathrm{usually} \mathrm{have} \mathrm{extra} \mathrm{strong} \mathrm{wall} \mathrm{thickness-more} \mathrm{than} \mathrm{that} \mathrm{required}$ by the code - to allow for extra margin of safety. The size of the steam pipe is usually determined using empirical steam flow equations such as the Unwin formula (Eq. 7.1) or Fritzsche's formula (Eq. 7.2)6

The Unwin formula for steam flow is

$$
\Delta P=\frac{0.002705\left(1+\frac{3.6}{d}\right) V L W^{2}}{74,500 d^{5}}
$$

The Fritzsche formula for steam flow is

$$
\Delta P=\frac{0.00000021082 V L W^{1.85}}{d^{4.97}}
$$

where

$\mathrm{d}=$ internal diameter of the pipe, in.

$L=$ length of pipe, in.

$\mathrm{P}=$ pressure in lb per sq in. gauge

$\mathrm{W}=$ rate of flow of steam in $\mathrm{lb}$ per $\mathrm{hr}$

$\mathrm{V}=$ specific volume of steam, cu ft per $\mathrm{lb}$

The Fritzsche formula is believed to give more accurate results for pipes 10-in. and larger, carrying steam at high velocities.

The headers are usually sized based on the minimum acceptable pressure drop in the header. If the available steam pressure is lower than the acceptable pressure drop, the header should have been sized larger than normal to minimize pressure losses. Since the headers carry large volumes of steam and are located adjacent to the generators where there is greater exposure to personnel, they should be designed and fabricated using the most stringent standards. Construction practices should be based on accepted standards, and pipe welds should be subjected to more frequent X-ray inspections. 
A shut-off valve must be provided at each steam lateral connection to the header. This will facilitate the isolation of any lateral for repair or maintenance. A bypass valve should also be installed in parallel with the shut-off valve to allow for slow preheating of the lateral.

Because a steam generator can introduce significant amounts of cold water to the steam header during the startup and shutdown phases, it is a common field practice to install a "blowdown" line. This line permits the operator to divert the discharge from the generator to atmosphere and to a sump during the startup or shutdown phases. By using this line, the operator can minimize the stresses placed on the steam header system.

\section{Lateral Steam Lines}

\section{Steam Flow Rates and Pressure Drop}

The purpose of the steam lateral system is to deliver steam from the headers, located at the generation sites to the steam injection wells. The necessury steam lines can vary in size from 3 to $10 \mathrm{in.}$ in diameter although lateral line sizes may reach 18 in. diameter or more. The steam lateral system resembles very much the branches of a tree. Larger lines leaving the steam headers branch into smaller and smaller lines until the system ultimately delivers steam to the wellhead assembly. The size of these lines is determined by the design engineer based on the Unwin steam equation or other steam flow equations (see Eqs. 1 and 2).

Like headers, steam laterals are sized based on the pressure drop that can be tolerated by existing pipe or based on allowable steam velocities. Steam velocities that are typical in oilfield steam distribution networks are between 35 and $70 \mathrm{ft} / \mathrm{sec}$, with normal velocities in the range of 40 to $55 \mathrm{ft} / \mathrm{sec}$. Velocities beiow $35 \mathrm{ft} / \mathrm{sec}$ will result in increased phase separation, and velocities exceeding $70 \mathrm{ft} / \mathrm{sec}$ will result in high pressure losses and curtail the system's ability to deliver steam to remote wells. ${ }^{8}$

In addition to the use of the Unwin and similar equations for steam flow calculations, newer steam distribution networks are being designed with the use of commercial pipe network analysis computer programs. These programs permit the design engineer to try out "on paper" various piping networks or layouts.

\section{Steam Shut-off Valves}

The designer of the steam lateral system should include a steam shut-off valve at the beginning point of any branch. This valve should be of sufficient pressure and temperature rating for the expected steam service. In addition, on any of the branch lines that are 6 in. or larger, a 2 in. steam bypass valve should be placed in parallel with the shut-off valve. This bypass valve will be useful in "preheating" the branch line prior to placing the line in service. By bleeding steam through the 2-in. bypass, not only can the line be slowly preheated and thereby expanded without 
shock, but liquids left in the line as a result of construction and testing can be delivered to the injection wells at low and therefore safe velocities. During the steam bypass operation, injection wells may be, opened and closed in sequence beginning with the wells nearest the beginning of the branch. The presence of flowing liquid in the lines may be detected by the audible differences at the well rate control device (the steam choke or the control valve).

In laying out the steam lateral system, the designer should avoid the use of circular paths or steam flow loops, for example, terminating one lateral branch into another. Although this might be attractive in minimizing pressure losses, it can lead to hazardous situations when a portion of the system must be isolated and depressurized for repair or maintenance.

\section{Expansion of Steam Lines}

Temperature variations in the steam flow line cause expansion and contraction that can be relieved by expansion loops. An expansion loop or anchor should be installed at each point where the line changes direction vertically (i.e., at the crest of a hill or at the bottom of a ravine). If the steam lines are buried, the pipe shculd be brought to the surface for a distance great enough to accommodate an expansion loop, then returned to underground. The buried line should be brought to the surface at least every $300 \mathrm{ft}$ to provide for expansion.

If a steam manifold is used to supply several wells, an expansion loop should be located at the manifold for each line leaving the manifold. ${ }^{2}$

Three techniques are available to deal with the expansion of steam lines. They are as follows:

1. Manufactured bellows-type expansion joints. These are more expensive and their use is usually restricted to the headers.

2. Vertical pipe loops. These are generally field fabricated and installed vertically to conserve surface area for wells and facilities.

3. Z-Bends. These are the least costly of the three alternatives. They are usually field fabricated and installed. Z-bend type expansion joints also allow one to take advantage of surface terrain and piping layout during installation.

Figure 7.2 illustrates the typical vertical and Z-bend type expansion loops used in steam injection operations. Figure 7.3 shows several methods of providing for expansion.

Figures 7.3a and 7.3b show buried lines in which expansion takes place above ground. In the case of figure 7.3a. the extra weight of covering forces the expansion to occur only at the loop. When an expansion loop is used at the wellhead with the buried line, as in figure $7.3 \mathrm{~b}$, the line should be heated by passing steam through the line and the.. covered while heating. ${ }^{2}$ Figures $7.3 \mathrm{c}$ and 7.3d show surface lines in which expansion is controlled by placing the line on supports or on hanging chains that allow the line to move in several directions. 

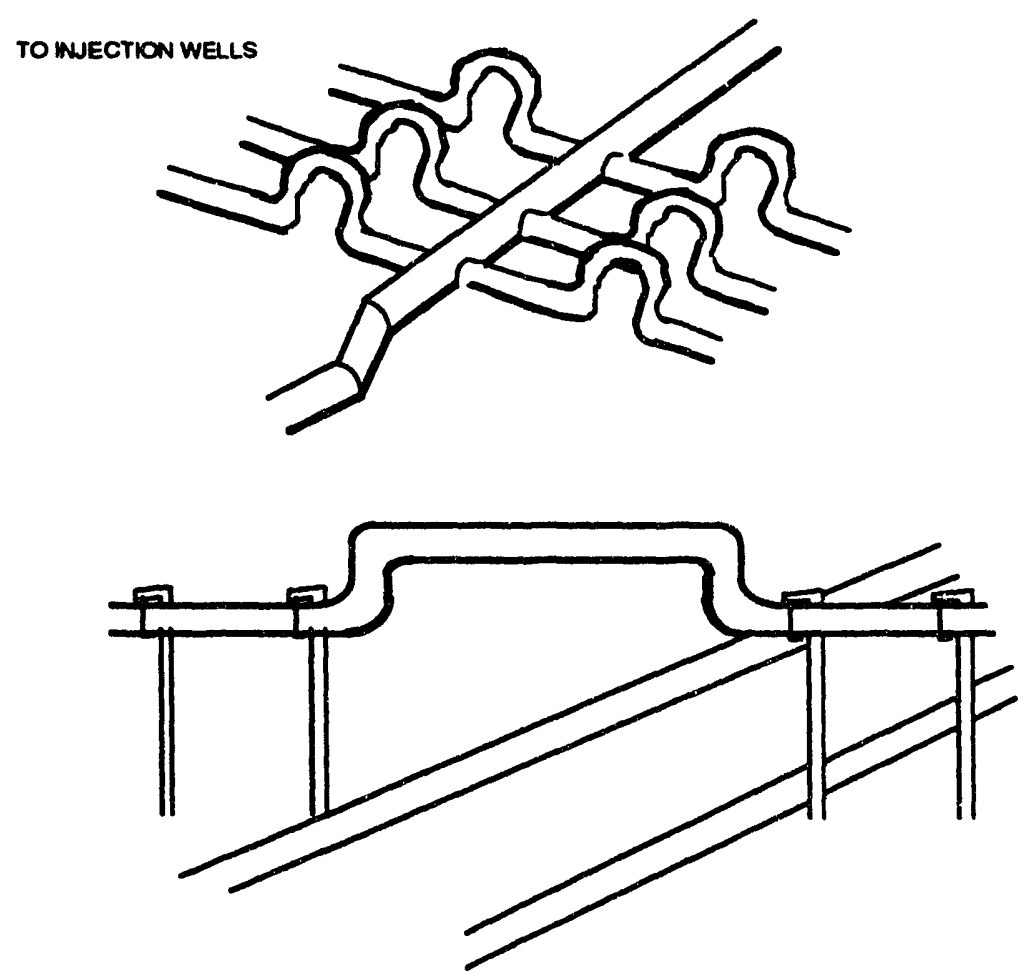

FIGURE 7.2. - Typical expansion loops used in steam injection operations to relieve steam flow line thermal stresses. ${ }^{3}$

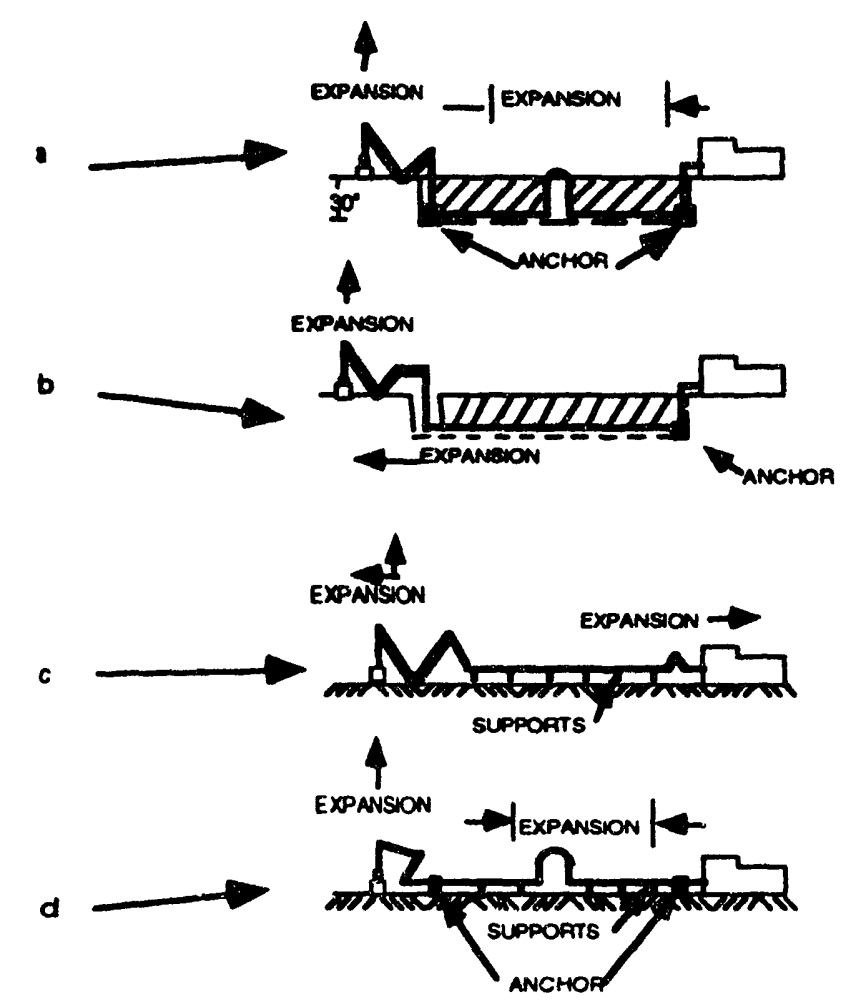

FIGURE 7.3. - Schematics of different expansion methods for steam injection lines. 2 
Dead anchors must be installed between expansion devices to force the pipe movements to the expansion device. The location of the dead anchors is largely determined by the piping layout. The expansion devices are usually installed approximately midway between two anchors. Table 7.4 can be used to select the loop size and anchor spacing for vertical loops. Z-bend type expansion joints can be sized using figure 7.4.

TABLE 7.4. - Loop Size vs. Spacing

\begin{tabular}{|c|c|c|c|}
\hline \multirow[b]{2}{*}{ Pipe Size, in. } & \multirow[b]{2}{*}{ Spacing, ft } & \multicolumn{2}{|c|}{ Loop Size, ft } \\
\hline & & Height & Width \\
\hline $2^{n}$ Sch. 40 & $\begin{array}{l}150 \\
200\end{array}$ & $\begin{array}{l}7 \\
8\end{array}$ & $\begin{array}{l}7 \\
8\end{array}$ \\
\hline $3^{n}$ Sch. 40 & $\begin{array}{l}250 \\
150\end{array}$ & $\begin{array}{l}9 \\
9\end{array}$ & $\begin{array}{l}9 \\
8\end{array}$ \\
\hline & 200 & 10) & 9 \\
\hline 4" Sch. 40 & 2500 & $\begin{array}{l}11 \\
12\end{array}$ & $\begin{array}{l}11 \\
10\end{array}$ \\
\hline 6" Sch. 40 & 250 & it & 12 \\
\hline $6.39 n .40$ & $\begin{array}{l}200 \\
250\end{array}$ & $\begin{array}{l}15 \\
16\end{array}$ & $\begin{array}{l}13 \\
16\end{array}$ \\
\hline 8" Sch. 40 & 200 & 17 & is \\
\hline & $\begin{array}{l}250 \\
200\end{array}$ & $\begin{array}{l}18 \\
19\end{array}$ & $\begin{array}{l}18 \\
18\end{array}$ \\
\hline 100 Sch. 40 & 250 & 20 & 20 \\
\hline $12^{n} \operatorname{Sch} .40$ & $\begin{array}{l}200 \\
250\end{array}$ & $\begin{array}{l}20 \\
22\end{array}$ & 20 \\
\hline
\end{tabular}

NOTE: Use longest spacing possible.

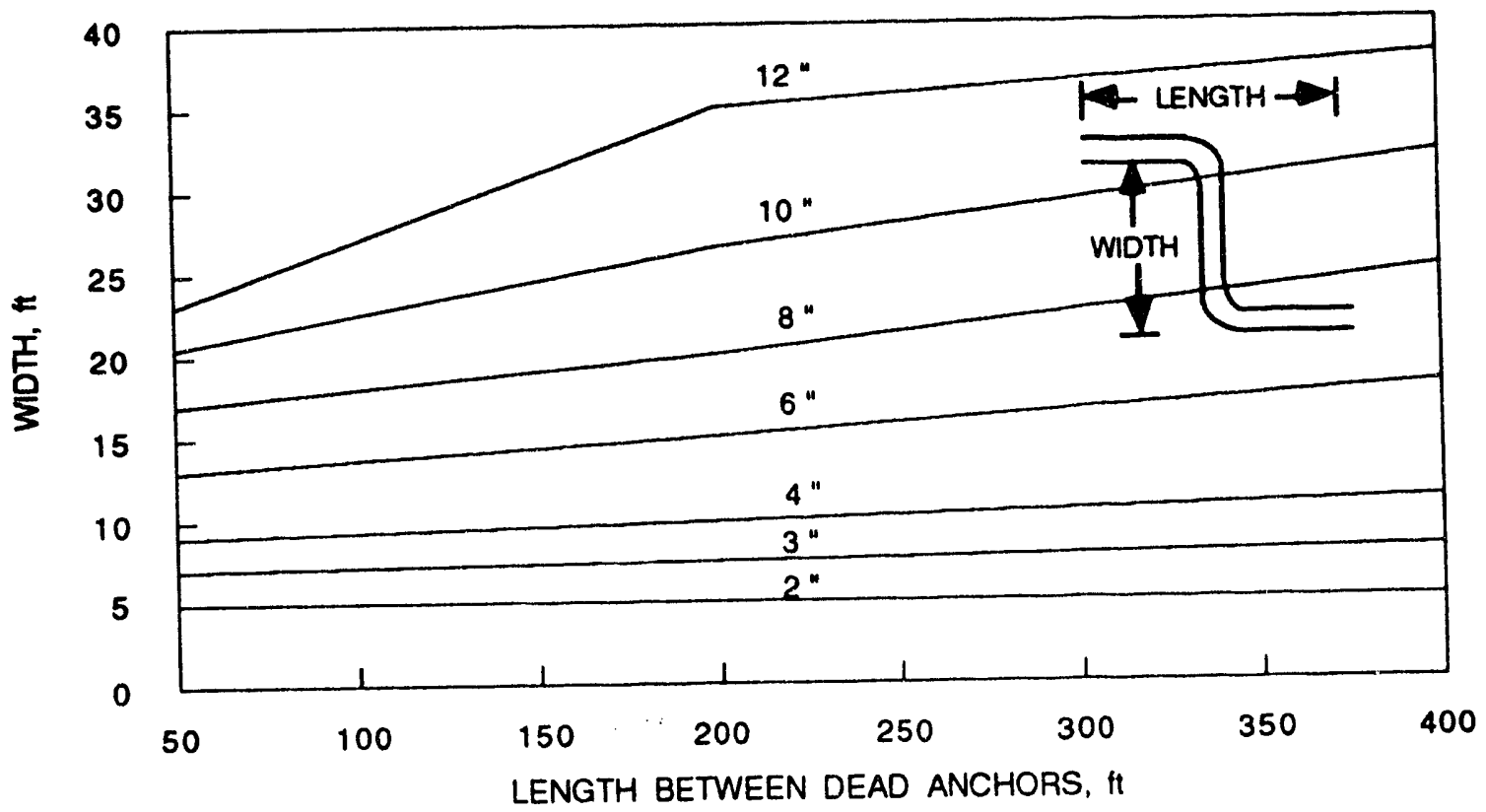

FIGURE 7.4. - Z-bend expansion loop sizing chart. 
Expansion loops must be equipped with bleed valves at the upstream side 5 so that it is possible to do the following:

(a) Bleed off the line when any shutdown occurs. This is very important in cold climate, where the lines may otherwise freeze during winter.

(b) Bleed off liquid, if two-phase flow becomes a problem.

(c) Provide for warmup of the line.

\section{Expansion of the Steam Headers}

The manufactured bellows type expansion joint is the preferred expansion device for steam headers because of its greater reliability and safety. These devices, however, permit only a limited amount of pipe movement. Hence, the expected amount of pipe expansion and contraction must be accurately calculated prior to selecting the expansion joint. If the header is not properly supported, it may laterally deflect enough under pressure to "pull" in its length and over travel the expansion joints.

Both the laterals and the individual steam generator discharge lines which connect with the header must be equipped with an expansion joint to facilitate the expected movement of the header. This is generally accomplished by installing lateral line supports near the header which allow for lateral (sideways) movement.

\section{Wellhead Connection}

Temperature changes affect the wellhead connections because of both vertical expansion of the casing and tubing and horizontal movement of the steamline supplying the well. This problem can be overcome by a variety of ways. For example, a flexible connection, such as a steam hose can be used in low-temperature and pressure steam injection applications. However, when higher temperatures and pressures are required, expansion joints and swivel joints must be used between the line and the wellhead. Figure 7.5 shows a typical swivel joint used at the injection wellhead which permits vertical movement of tubing and horizontal movement of steam line. Figure 7.6 shows an expansion manifold used to connect the Christmas tree and flow line of a steam injection well. The dotted part of this figure indicates movement of tree and manifold due to thermal expansion.

\section{Support of Steam Lines}

An expansion is not effective unless both lines to the loop are supported. Otherwise, the line may creep toward one loop and not return to its original position upon cooling. The determination of the spacing between these supports should be based on basic statics and the assumption that the longitudinal pressure stress in a pipe is no more than one-half the allowable stress. This 


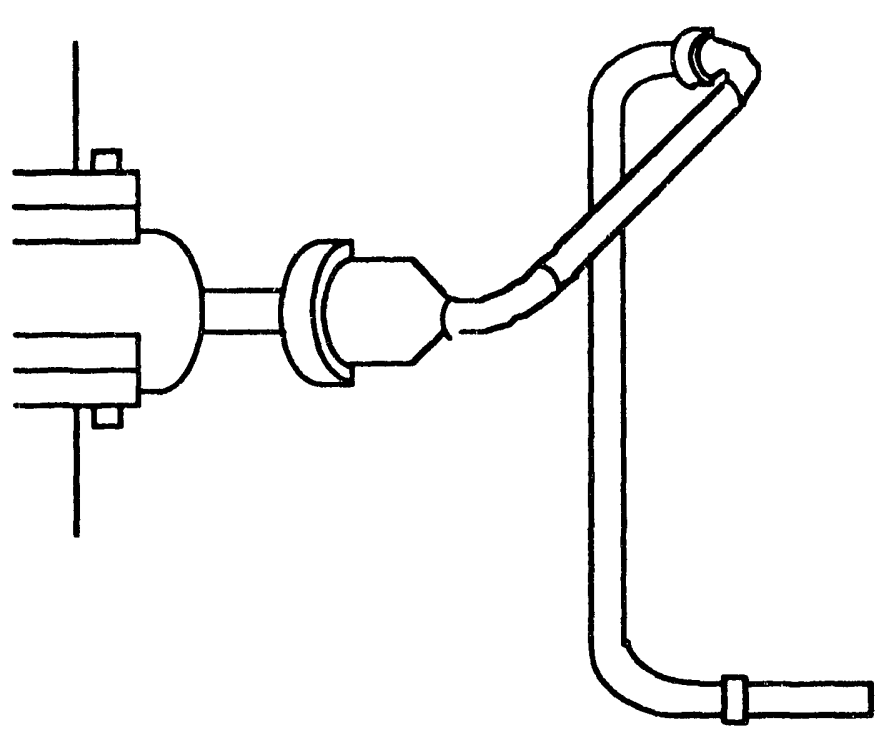

FIGURE 7.5. - Schematic of a typical swivel joint used at the steam injection wellhead. ${ }^{3}$

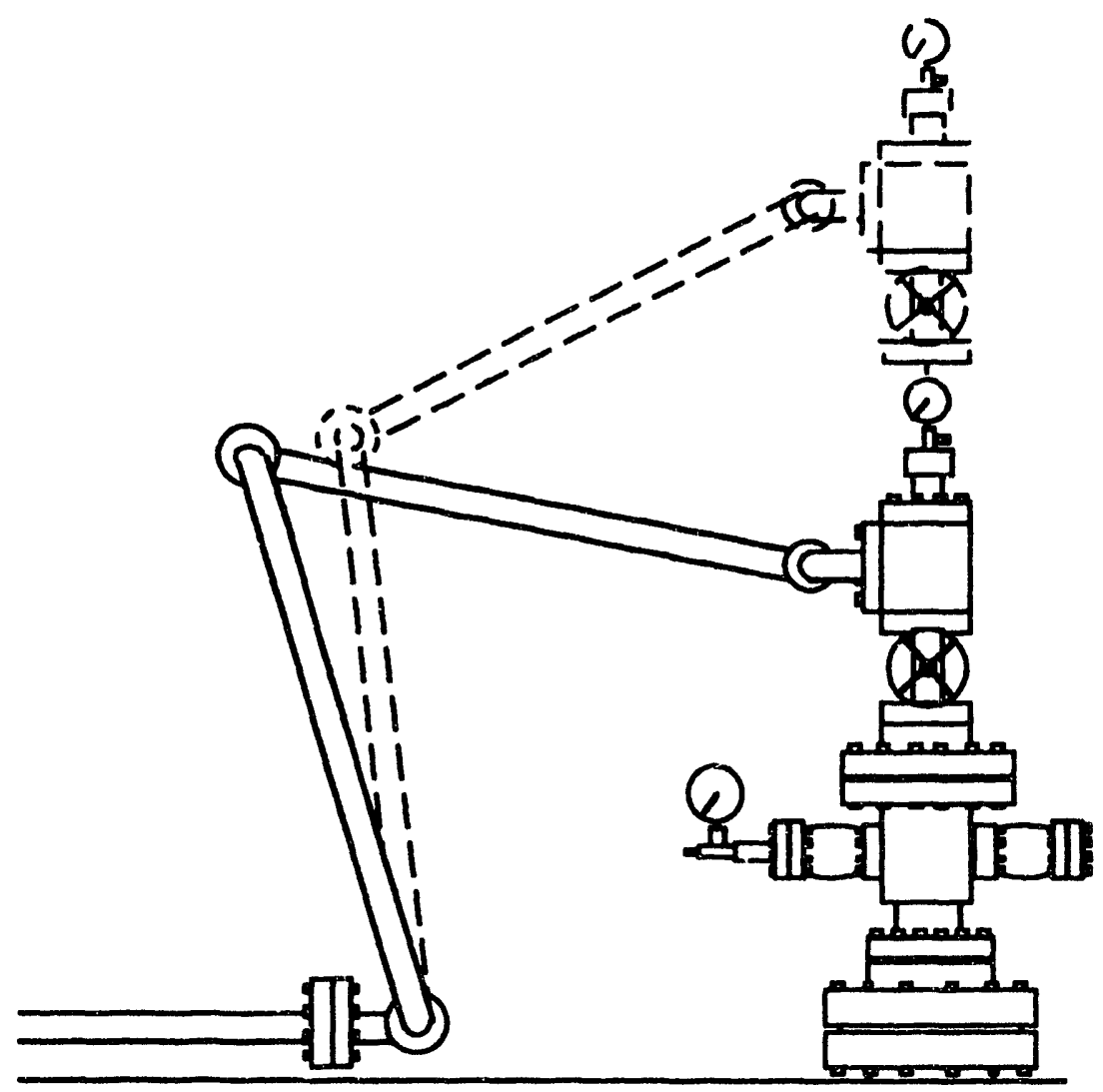

FIGURE 7.6. - Schematic of expansion manifold connection to steam injection well Christmas tree. ${ }^{4}$ 
assumption would allow the bending stresses due to weight loading to be as much as one-half the allowable stress. Since the effects of thermal expansion on bending stress are rarely completely known, a span length that produces bending stress no more than one-quarter the allowable stress is preferred. The formulas for support spacing $N(\mathrm{ft})$ are:

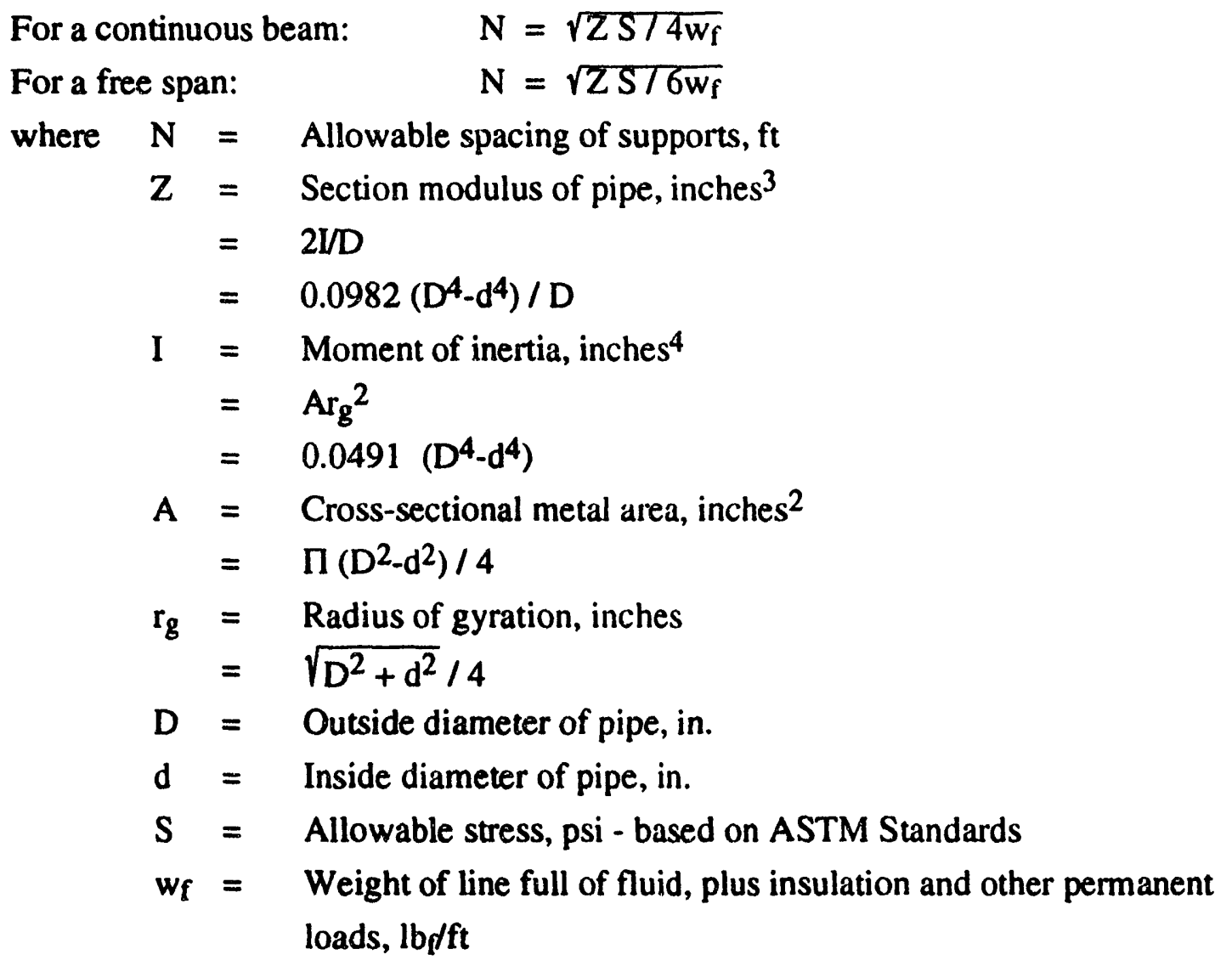

A free-span condition is rarely, if ever, encountered, and the assumption of a continuous beam is also not representative of typical conditions. As a result, it has become practice to use a span length between the two calculated extremes. A chart or graph is generally developed (based on the before mentioned equations) and provided to the field construction personnel.

The construction of the pipe support varies widely from field to field and operator to operator. Some operators make extensive use of the chain type pipe hanger. Its advantages are that it is easily field fabricated and therefore inexpensive. In other fields a guided sleeve support is commonly used. The advantage is a cleaner appearance as well as a more controlled pipe movement. This may be of particular importance in areas of high piping congestion. The disadvantages of the guided support are (1) it is more expensive and (2) the piping insulation may be damaged as the line moves through the guide.

A more conservative approach to supporting steam headers should be taken than that recommended for steam lateral lines. The startup or shutdown of a steam generator may introduce 
cold water to the steam header. If this should occur, "water hammering" of the header can be expected. This will result in very high instantaneous pressures within the header. These pressures will act to place the header in a stressed condition similar to that of a loaded structural column. The Euler equation, which predicts the failure load for structural columns, suggests that the strength of the column can be increased by "pinning" the column at points along its length. Properly designed guided supports can serve to "pin" the header. The equations descritied under the laterals section should be used as a guide for selecting header pipe support spacing, but in no case should the spans calculated using these equations be exceeded.

\section{Insulation and Heat Loss}

The economic successes of a steam injection process is measured in terms of oil-steam ratio or barrels of oil recovered per barrel of steam injected. As a general rule, the oil-steam ratio can be improved by delivering higher quality steam to the sandface. The sandface steam quality depends on the amount of heat lost from the surface and subsurface tubings. Heat losses can be minimized by insulating surface steam lines and employing insulated tubing downhole. Subsurface insulated tubulars are discussed in detail in a later chapter. In this section, surface steam pipe insulation requirements are addressed.

Even though heat losses from the surface lines in steam injection operations may be a small fraction of total heat injected, it is generally worthwhile to insulate them to lower fuel costs, and as a safety precaution. Heat losses from bare, buried, and insulated steam pipes are shown in Table 7.5 as a function of temperature for various pipe sizes. ${ }^{2}$ A bare 3-in. line will lose 1,496 $\mathrm{Btu} / \mathrm{hr} / \mathrm{ft}$ length of pipe at a temperature difference of $400^{\circ} \mathrm{F}$. With $1.5 \mathrm{in}$. of $85 \%$ magnesia insulation, the heat loss is reduced to $184 \mathrm{Btu} / \mathrm{hr} / \mathrm{ft}$ length. Figure 7.7 shows the cash loss per year per foot of line as a function of injection line heat loss in Btu/hr/ft length. Steam costs were assumed as $\$ 2.22 / \mathrm{MM}$ Btu (based on an oil price of $\$ 12.00$ per barrel and an assumed oil heat content of $130,000 \mathrm{Btu} / \mathrm{gallon})$. From this figure, reduction of heat loss from 1,496 to 184 $\mathrm{Btu} / \mathrm{hr} / \mathrm{ft}$ length results in a savings of $\$ 25.50 \mathrm{per}$ year per ft length. Assuming the cost of insulating a 3-in. pipe as $\$ 11.00$ per $\mathrm{ft}$, (see chapter 4 ), heat loss savings amounts to $\$ 14.50$ per $\mathrm{ft}$ per year or equivalence of one additional barrel of oil production per year per ft length. Hence, significant savings in fuel consumption can be realized by insulating the surface lines. Accordingly, surface lines, especially those from steam generators, are usually insulated in steam injection operations. 
TABLE 7.5 - Heat losses from pipes Btu/hr/ft length (steady state)

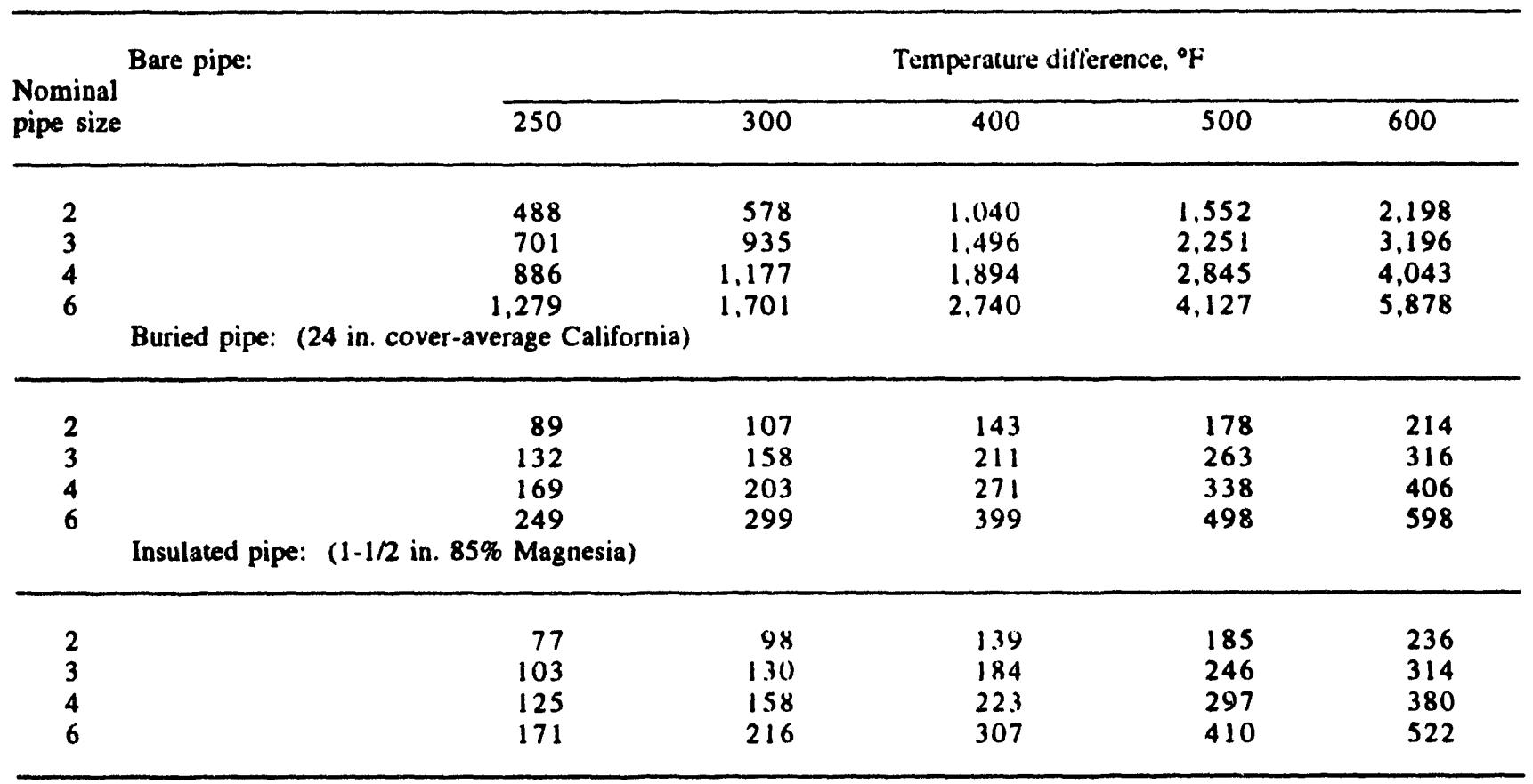

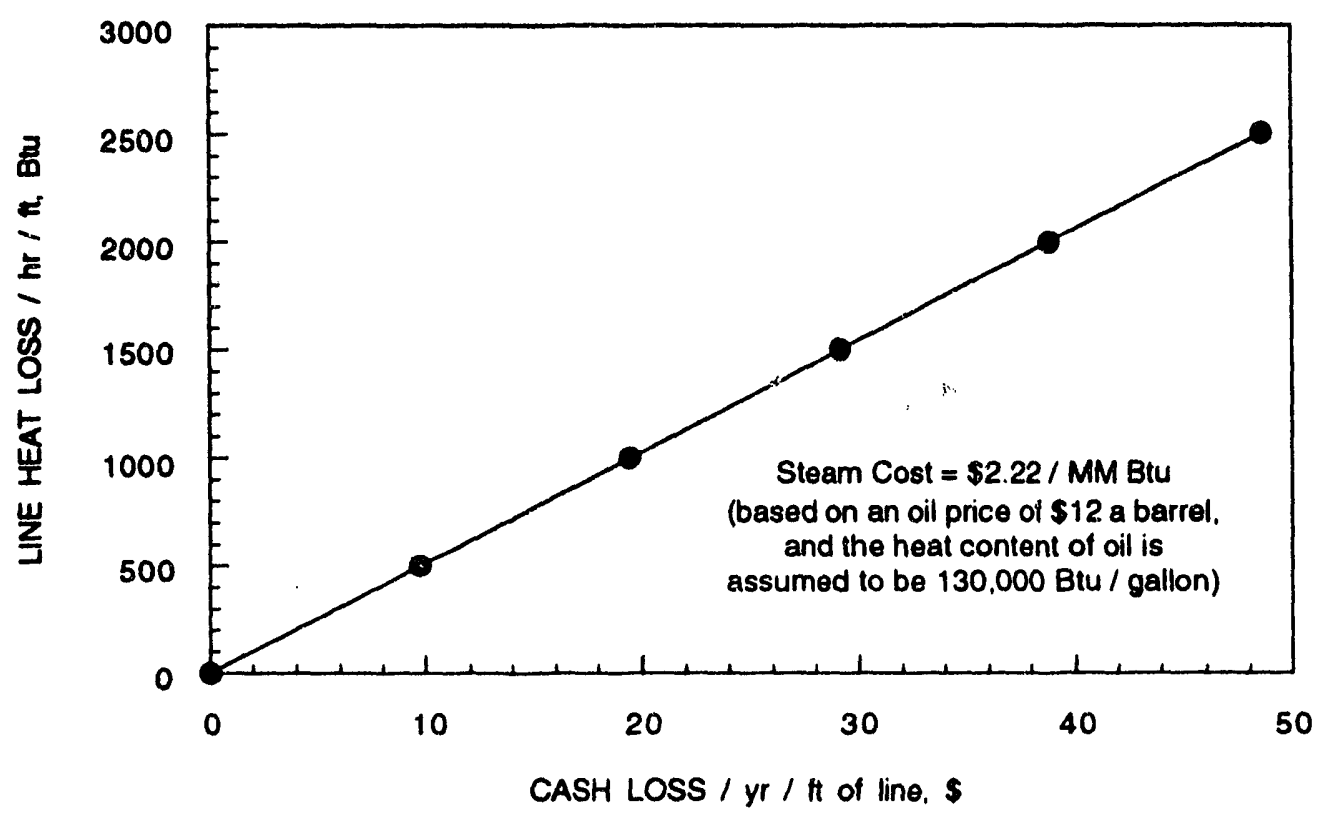

FIGURE 7.7. - Steam injection line heat loss versus cash loss. 
Depending on the expected operating pressure of the steam distribution system, the internal operating temperature of the system can be expected to range between $350^{\circ}$ and $600^{\circ} \mathrm{F}$. At these temperatures, the decision on the type and thickness of the pipe insulation becomes a question of economics. Two types of pipe insulation are commonly used in steamflood operations:

1. Fiber glass wool wrapped with a thin skin of sheet metal (usually aluminum) - the thermal conductivity of the fiber glass wool is $0.022 \mathrm{Btu} / \mathrm{hr}-\mathrm{ft}-{ }^{\circ} \mathrm{F}$.

2. Calcium silicate wrapped with an impervious barrier followed by a thin skin of sheet metal (usually aluminum) - the thermal conductivity of the calcium silicate is 0.017 Btu/hr-ft- ${ }^{\circ} \mathrm{F}$.

The convection coefficient for heat transfer from the outside skin of the insulation surface is generally taken to be in the range of 2 to $5 \mathrm{Btu} / \mathrm{hr}-\mathrm{ft}^{2}-{ }^{\circ} \mathrm{F}$.

The rate of heat transfer from a unit length of pipe may be calculated by referring to figure 7.8 and the following radial heat transfer equation.

$$
\begin{aligned}
& q / L=U_{o}(A / L) \Delta T=2 \pi\left(T_{i}-T_{o}\right) /\left(\left(\ln \left(r / r_{i}\right) / k\right)+1 / h r\right) \\
& \text { where } q / \mathrm{L}=\text { Rate of heat transfer per unit length of the pipe, Btu/hr-ft } \\
& \mathrm{U}_{\mathrm{o}}=\text { Overall heat transfer rate, } \mathrm{Btu} / \mathrm{hr}-\mathrm{ft}^{2}{ }^{\circ}{ }^{\circ} \mathrm{F} \\
& \text { A }=\text { Heat transfer surface area, } \mathrm{ft}^{2} \\
& \Delta \mathrm{T}=\text { Temperature difference between the pipe wall and the } \\
& \text { air, }{ }^{\circ} \mathrm{F} \\
& \mathrm{T}_{\mathrm{i}}=\text { Pipe wall temperature-assumed to be the same as the } \\
& \text { internal steam temperature, }{ }^{\circ} \mathrm{F} \\
& \mathrm{T}_{\mathrm{o}}=\text { Air temperature, }{ }^{\circ} \mathrm{F} \\
& r=\text { Inside radius of the insulation, } \mathrm{ft} \\
& r_{i}=\text { Outside radius of the pipe, } \mathrm{ft} \\
& \text { k }=\text { Thermal conductivity of the insulation, Btu/hr-ft- }{ }^{\circ} \mathrm{F} \\
& \text { h }=\text { Convective heat transfer coefficient, Btu/hr- } \mathrm{ft}^{2}{ }^{\circ} \mathrm{F} \text { - } \\
& \text { commonly taken to be in the range of } 2 \text { to } 5 \mathrm{Btu} / \mathrm{hr}-\mathrm{ft}^{2}{ }^{2} \mathrm{~F}
\end{aligned}
$$

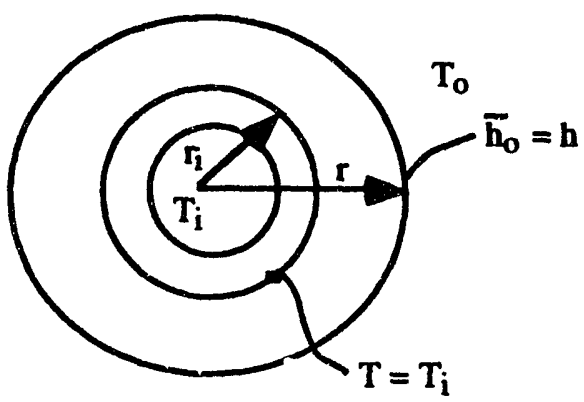

FIGURE 7.8. - Schematic of insulated pipe for heat loss transfer estimation. 
If $r=r_{c r i t}=k / h$ in the above equation, a critical insulation thickness is reached. Adding insulation until this critical thickness is reached will decrease heat losses. Adding insulation beyond this critical thickness will increase the rate of heat loss. More insulation, at least in the case of pipe, is not always the best solution to reducing heat losses.

To maintain the insulating properties of either of the two materials recommended above, several general practices should be observed. First, the insulating material should be installed without undue compression of the material. It is, after all, the trapped air spaces within the insulating material which provides the desired insulating properties of the material. Second, the insulation must be kept moisture free. This begins with the installation of the material under dry conditions only. The thin metal skin applied to the outside surface of the insulation should be installed in a manner such that rain water will not run into the insulation. One of the biggest problems in using piping insulation in oilfield service is that the metal skin and the insulation it protects are often damaged by well workover crews or by heavy equipment used in daily operation of the field. In addition, field personnel often find that insulated steam lines make convenient steps or working platforms. This should be discouraged because of the resulting damage to the insulation, and also the safety risks. The proper siting of steps and pipeline crossings can help to reduce this kind of damage. If the oilfield is in an area that is frequented by either grazing wildlife or domestic stock, a means must be provided to prevent damage to the insulation, and the piping system as well, by these animals. In some cases this involves strengthening the outer protective skin and in others it will mean erecting barriers to prevent the animals from coming into contact with the piping system.

Calcium silicate insulation is generally the preferred insulating material for header use because of the higher human traffic volume around the steam generator site.

\section{Effects of Branching on Steam Quality}

Until the late seventies, it was common practice to assume that steam delivered to a steam lateral system at $80 \%$ quality would, after traveling through the various branching points of the steam distribution network, arrive at each wellhead at $80 \%$ quality or less after any adjustments for heat losses in the lines. In 1978, Chevron published a research paper which demonstrated that this was not the case. They demonstrated that in laboratory tests steam quality was not being evenly distributed between two branches of a pipe tee but rather, depending on flow rate (and some other parameters as well), the liquid phase would favor flowing through either branch and was rarely split evenly between the two.

Chevron went on to demonstrate that the usual practice of installing the pipe tee in a "straightthrough" fashion (refer to Figure 7.9) further provoked the problem of unequal phase splitting. As a result of further research into the problem of phase splitting at pipe tees, the installation of pipe 
tees in the "dead-end" fashion of Figure 7.9 is preferred. In addition, an even split into the two branches is preferred with a 30-70) split considered the maximum acceptable uneven split. It is also considered good practice to install the pipe tee as level as possible.

The problem of unequal phase splitting at steam distribution system branches is unfortunately very complex. No less than six flow regimes have been identified for the combined flow of liquid and gases (vapors), and some authors have identified seven or more. The flow regime of a vaporliquid mixture can be very unstable and therefore very difficult to predict. As a result, computer pipe network models which properly account for the phase splitting phenomenon are currently being developed. Their further development will require modeling of existing steam distribution networks and comparison of the modeling results with actual field measurements. To further complicate the problem, steam distribution systems currently in operation seem to demonstrate a tendency towards less than stable delivery of constant steam qualities. That is, at times a given system may deliver a relatively high quality of steam to a particular well and a short time later the same well may be delivered a low quality. For the present, the designer will be left with only the guidelines of good engineering practice as previously described (dead-end tees with relatively even flow splits between branches).

\section{Wellhead Equipment}

Wellhead design for a steam injection well depends on depth, temperature, and pressure of the steam and casing and tubing sizes. The wellhead pressure and therefore the system pressure depend on the maximum steam injection rate that the well can sustain.

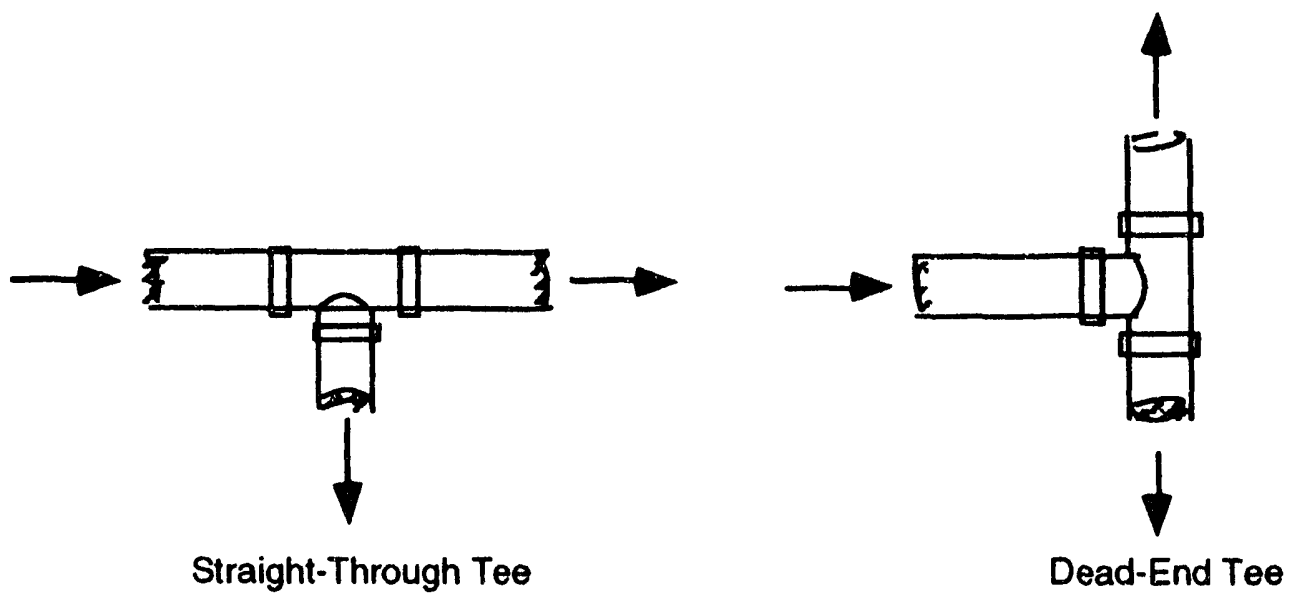

FIGURE 7.9. - Schematic of pipe tee installations in steam injection lines. 
Figure 7.10 illustrates a typical wellhead assembly used in a steam injection project. Figure 7.11 shows the wellhead details for a typical steam injection well.

As previously discussed, all tubular goods in an injection well will expand as temperature increases. But the amount of expansion will not be the same for the tubing, casing, and surface pipe. The reason for this uneven expansion is that these strings are of different lengths, and at different temperatures. Hence, provisions for this differential expansion must be made at the wellhead, unless a packer or an expansion joint is able to accommodate the tubing movement. Downward expansion of tubing and casings are discussed in a later chapter. Surface expansion of casing and tubings are usually handled by wellhead stuffing boxes. Figure 7.12 shows a typical thermal wellhead stuffing box that allows casing to expand and contract as required when a well is steamed. A tubing stuffing box for steam injection well is shown in figure 7.13. A tubing stuffing box is similar in design to a casing stuffing box except that it has provisions to allow for installation of a packer.

A variety of stuffing box designs are used in steam injection applications, depending on the amount of expansion anticipated, depth, temperature, and pressure. Two such designs are shown in figure 7.14. The wellhead shown in figure 7.14a provides for upward expansion of casing and downward expansion of tubing with the rise in temperature. The wellhead shown in figure 7.14b provides upward expansion of both casing and tubing. This wellhead design contains two separate

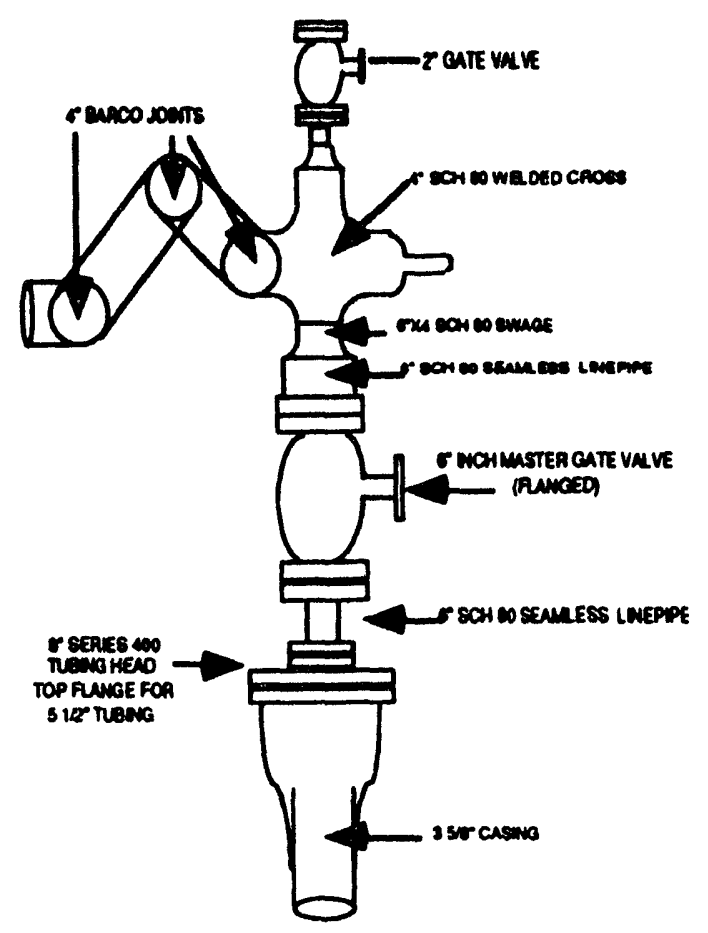

FIGURE 7.10. - Schematic of typical steam injection wellhead arrangement. 


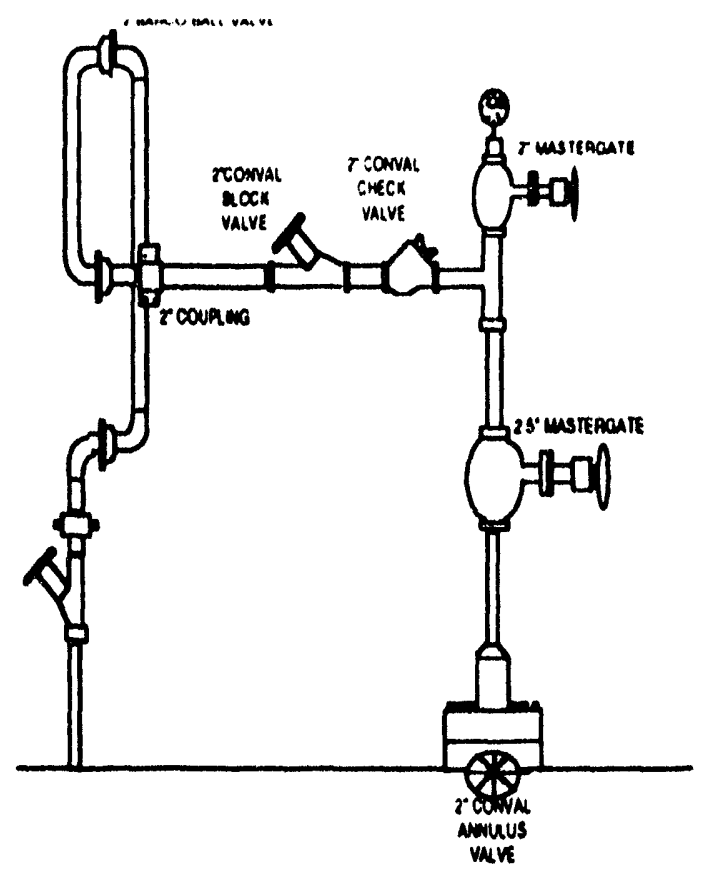

FIGURE 7.11. - Schematic of steam injection wellhead details.

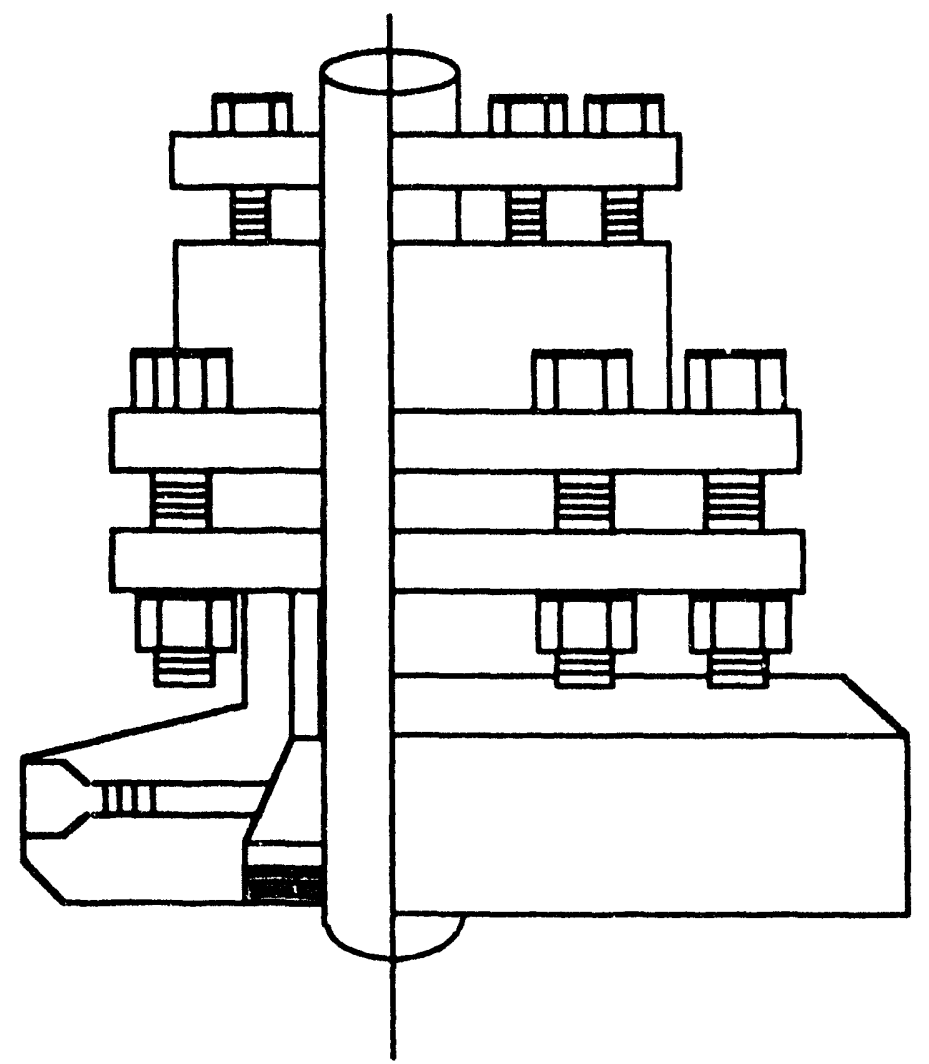

FIGURE 7.12. - Schematic of a typical steam injection well casing stuffing box. ${ }^{4}$ 


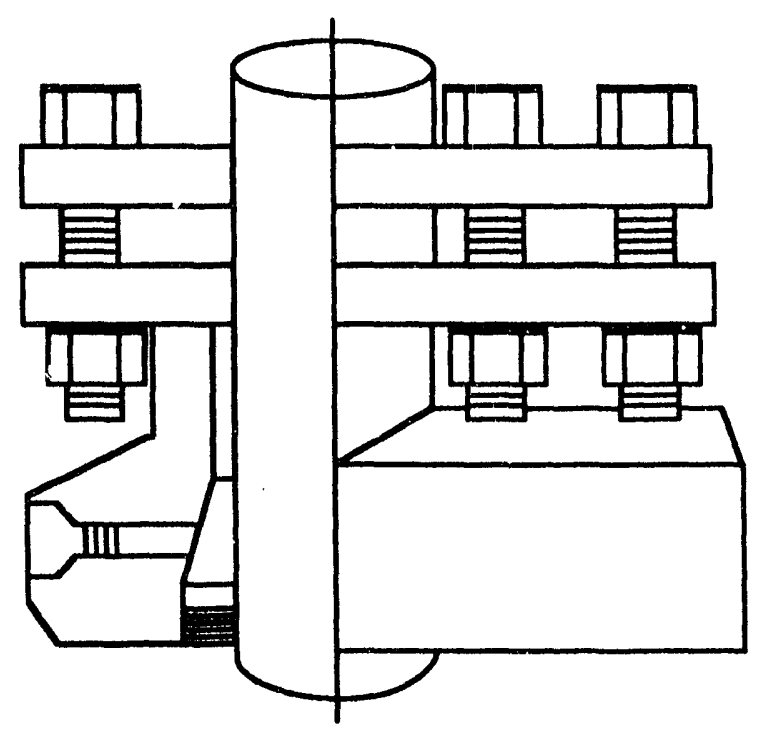

FIGURE 7.13. - Schematic of a typical steam injection well tubing stuffing box. ${ }^{4}$

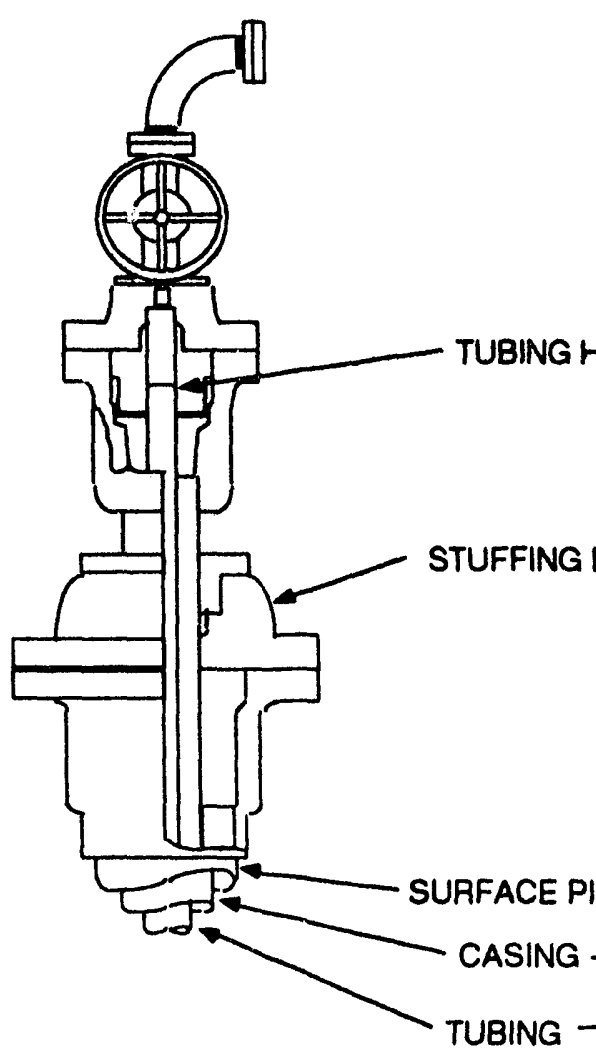

(a)

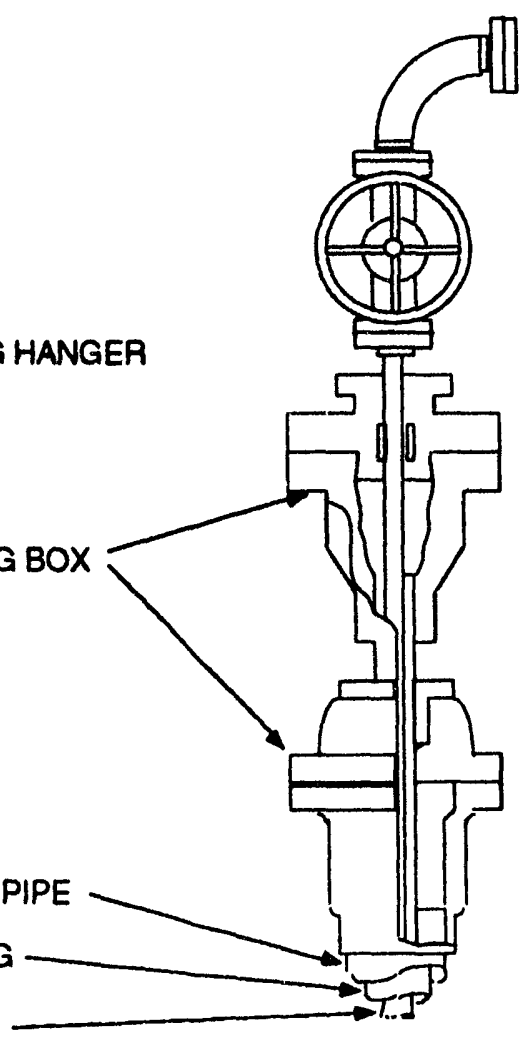

(b)

FIGURE 7.14. - Schematic of steam injection wellhead assembly showing casing and tubing stuffing box arrangement. ${ }^{3}$ 
stuffing boxes, an upper tubing stuffing box and a lower casing stuffing box for the tubing and casing expansion. Since this arrangement shows all the tubing weight is set on the packer, this design is not recommended for use in steam injection wells deeper than $1,0(0) \mathrm{ft}$. Use of such a design in deeper wells may cause the tube to buckle because of its own weight and result in mechanical failure.

The wellheads used in cyclic steam wells should be equipped to handle fluid production in addition to the free tubing and casing expansion facility. One such wellhead design is shown in figure 7.15. This wellhead is equipped with a combination stuffing box-packoff unit that not only allows free movement of tubing and casing through the wellhead, but also allows steam to be injected without pulling the rods. To steam the well, the pump is lifted off its seat, and the packoff unit is tightened to provide a seal around the polished rod. ${ }^{5}$ At the end of the steaming period, the packoff unit is loosened, the pump is seated, the stuffing box is checked for leakage, and the well is put on production. A three-way, two-position valve is usually used in huff 'n puff operations to permit steam injection and oil production through the same wellhead outlet. At the end of the steaming cycle, the valve is simply turned to the production line as soon as the packoff unit is loosened and the pump is seated.

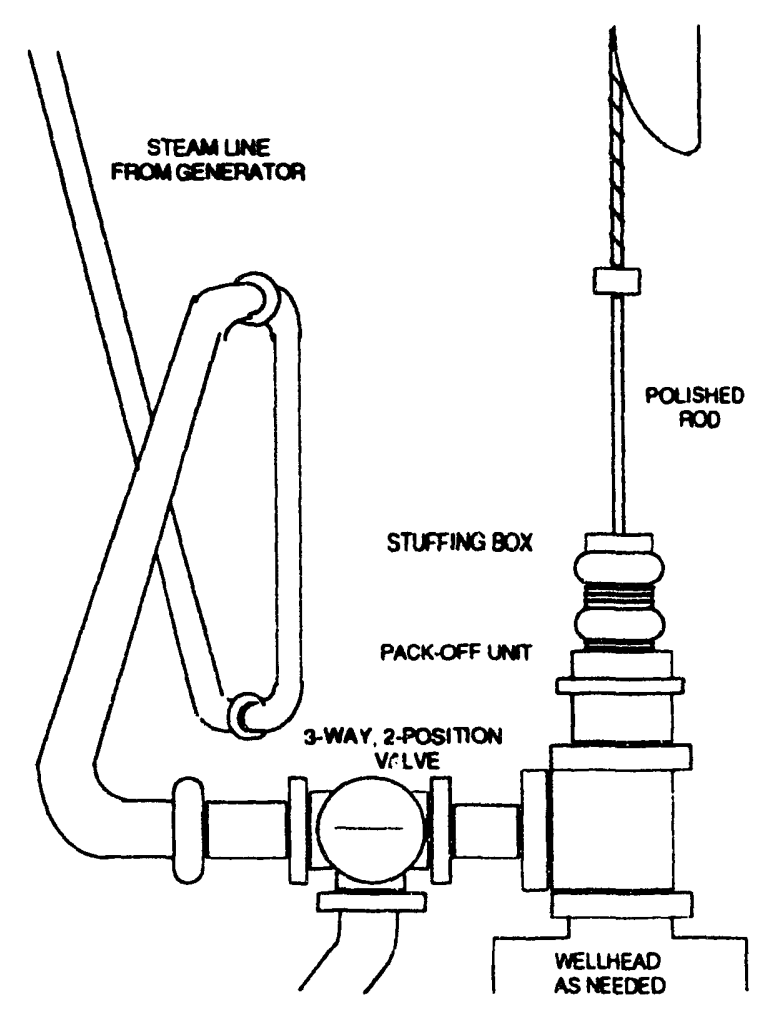

FIGURE 7.15. - Schematic of steamflood production wellhead arrangement showing the facilities for pur:p hookup. ${ }^{3}$ 
As pointed out in a previous section, wellhead assembly must be equipped with a moveable connection to allow for the free horizontal expansion of the flow line and vertical expansion of tubing and casing. This is accomplished through the use of three swivel joints (see figure 7.10). Grease packed swivel joints such as those offered by Barco are the most widely used swing joints in thermal EOR fields. These joints are designed to accommodate all expansion and temperature ranges.

Liberal use of hammer unions should be included in the wellhead assembly design to provide for not only well service and workover, but also for future maintenance and replacement of swivel joints and the flow rate control device.

\section{Wellhead Steam Rate Control Devices}

In all steam distribution systems, it is necessary to control the rate of delivery of steam to each well on an individual basis. Because the wellhead injection pressure on any well can vary significantly with time (as the result of wellbore fill for example) and because these pressures can vary significantiy from one well to the next (as the result of differences in formation permeability as an example), it is desirable that the device selected to control these steam rates either: (1) be capable of adjusting to varying wellhead injection pressures or (2) be uncoupled from wellhead pressures.

Two devices are currently in use for steam injection rate control. They are as follows:

1. A static choke drive to critical or sonic flow

2. A manually adjusted control valve operated in the subcritical flow regime

\section{Static Chowes in Critical Flow}

The use of the static choke device most often finds application in those steamflood projects which are fortunate enough to have low wellhead injection pressures. This device takes advantage of the shock wave developed in the throat of a converging nozzle when a vapor (in this case steam) is forced across the nozzle with a sufficiently high upstream pressure (for steam the upstream pressure must be in excess of 1.72 times the downstream pressure). The effect of the shock wave is to decouple the rate of flow across the nozzle from the downstream pressure. This is particularly advantageous in steamfloods.

The following equation recommended by one choke manufacturer is generally used in the field to determine critical steam flow rate. ${ }^{7}$

$$
W=59 d^{2} C_{d} \sqrt{P_{1}} / V_{1} \text { if: } P_{2}<0.577 P_{1}
$$

$$
\text { where } \begin{aligned}
& \mathrm{W}=\text { Flow rate, bbl/d of steam (cold water equivalent) } \\
& \mathbf{d}=\text { Choke diameter, in. } \\
& \mathrm{C}_{\mathbf{d}}=\text { Coefficient of discharge, approximately } 1-0.00705 \mathrm{~L} / \mathrm{d}
\end{aligned}
$$




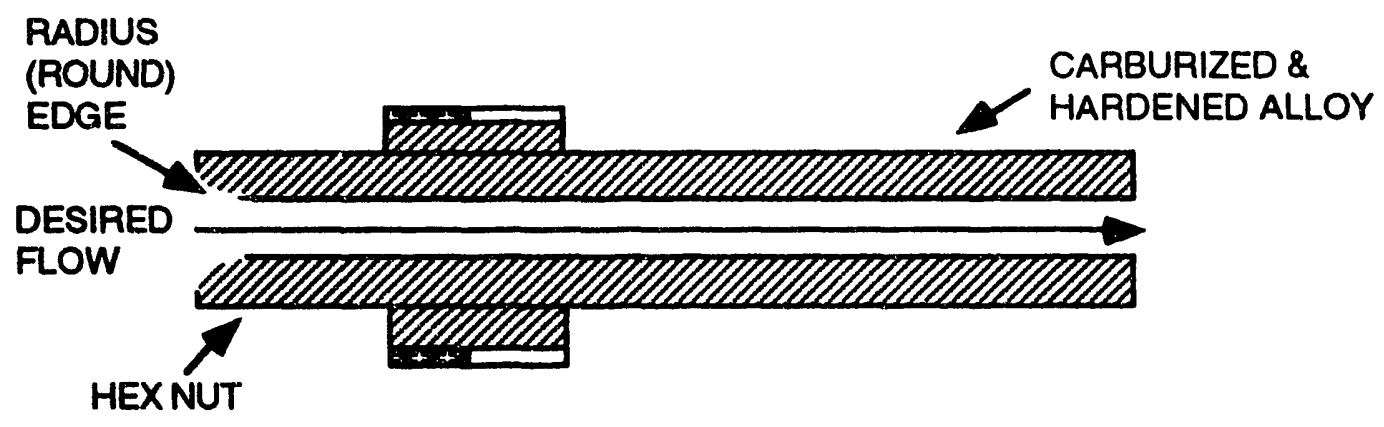

\section{ACCEPTABLE CHOKE BEAN}

ROUND EDGE "FLOW THRU THE NUT"

NOTE: INSIDE DIAMETER MUST BE THE SAME

THROUGHOUT THE LENGTH OF THE BEAN

- NO INSERT ACCEPTABLE

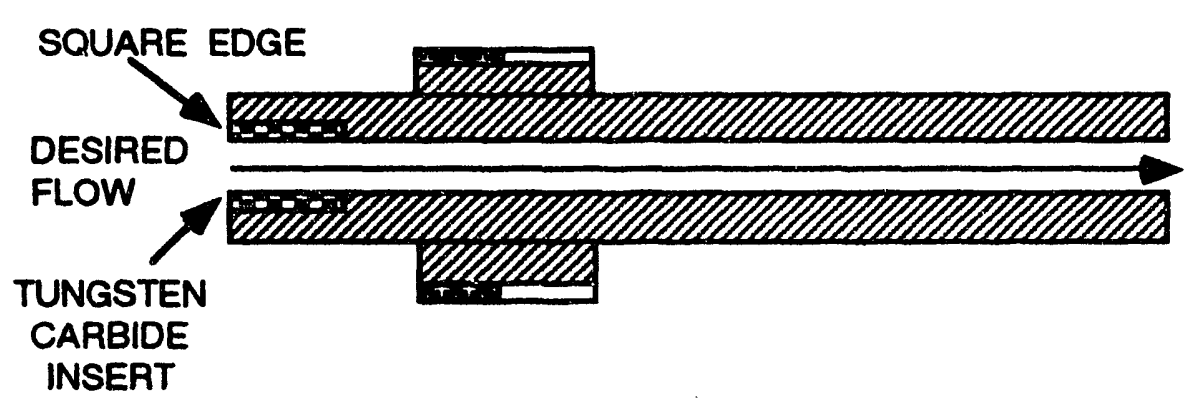

RED

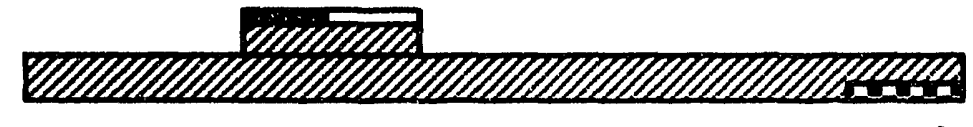

FLOW
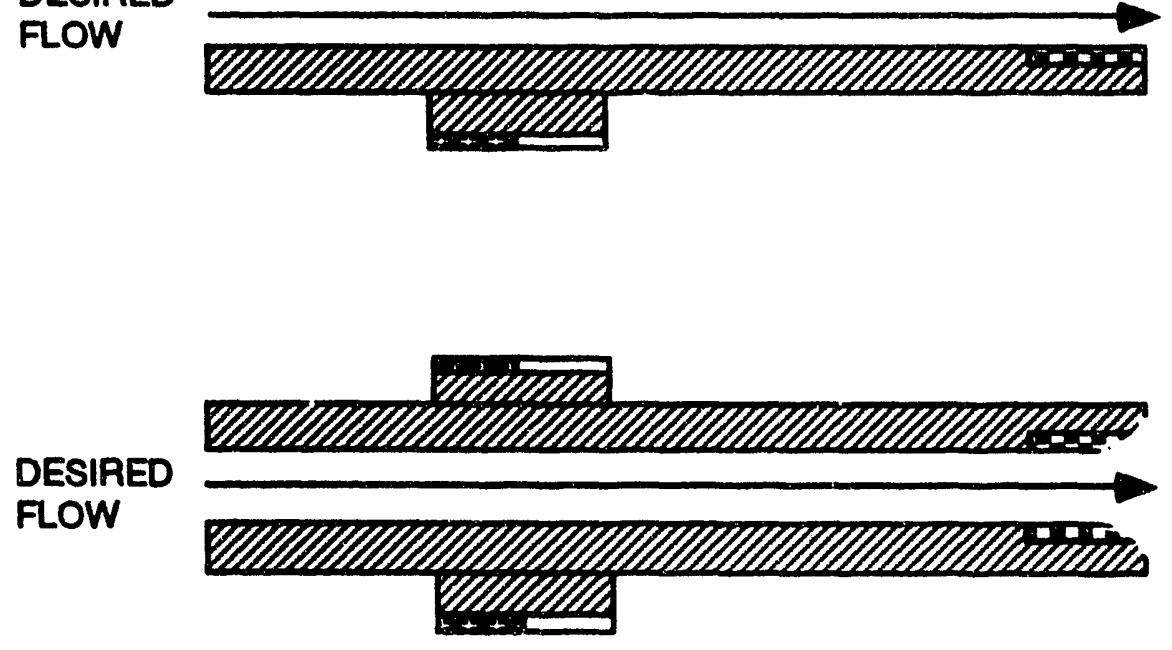

NOT ACCEPTABLE CHOKE BEAN

FIGURE 7.16. - Schematic of acceptable and nonacceptable choke inserts for steam injection rate control choke bean. 
L = Length of choke, in., normally 6 in.

$P_{1}=$ Upstream pressure, psia

$P_{2}=$ Downstream pressure, psia

$\mathrm{V}_{1}=$ Upstream steam specific volume $\mathrm{ft}^{3} / \mathrm{lbm}$

The specific volume of steam is given by the general equation of steam properties as:

$$
\text { where } \begin{aligned}
& \mathbf{x}=\mathbf{x} V_{\mathbf{g}}+(1-\mathrm{x}) \mathrm{V}_{\mathrm{f}} \\
& \mathbf{v}_{\mathbf{g}}=\text { Steam quality, fraction } \\
& \mathbf{v}_{\mathbf{f}}=\text { Specific volume of the vapor phase @ } \mathrm{P}_{1}, \mathrm{ft}^{3} / \mathrm{lbm}
\end{aligned}
$$

Notice that as long as the upstream pressure is more than 1.72 times greater than the downstream pressure both of the above equations apply and that neither is a function of any of the downstream conditions (in the case of steam injection operations, the wellhead pressure).

It is particularly important when using the static choke method of rate control to make certain that the chokes themselves are installed with the rounded radius of the choke insert facing the incoming steam and also that the inside surface of the choke is smooth over its entire length (usually 6 in.). Figure 7.16 illustrates several types of choke inserts available and it further indicates those choke inserts which are considered acceptable. During the life of a steam injection operation, it may be expected that these choke inserts will be changed several times. The inserts should be carefully inspected with each change, and as new shipments are received, they also should be carefully inspected to guarantee that they possess the desired round entrance and smooth interior.

General field practice is to measure the upstream and downstream pressures across each choke at 2-week intervals. This allows a technician to determine that the choke is or is not operating at critical flow (subcritical flow is an indication that well work is required because the perforations have become plugged or blocked, usually by sand fill). The pressure readings also allow a technician to calculate the current rate of delivery of steam to the well and make a choke insert size change to either decrease or increase the rate. This allows adjustment or trimming of the steam system to provide the desired rate of flow to all wells in the system. In large steamflood projects, the injection well pressure is monitored and controlled with the help of computers. ${ }^{8}$

The use of static flow chokes under critical flow is attractive for steam injection service because of their simplicity and ease of maintenance and also because they are relatively immune to the condition of injection wells. If injection pressures should become higher than about 250 psi, a significant amount of power is consumed to raise generator feedwater pressure to provide the pressure upstream of the static choke to guarantee critical flow. As a result, adjustable chokes or 
control valves operating in the subcritical flow regime are often used where injection pressures are expected to be high.

\section{Adjustable Chokes Operated in the Subcritical Flow Regime}

In steam injection projects where the steam injection pressures are expected to exceed 250 psi, the adjustable choke, or control valve, is selected as the means of controlling the rate of steam delivery to the injector. The principle of operation is the same as that of any control valve. The adjustable choke is placed in the path of flow, and the variable orifice within the choke is adjusted to sufficiently restrict flow to achieve the desired rate. The rate of flow across the choke or control valve can then be determined using the standard control valve equations for gas or steam. The following equation can be used to size a control valve for steam flow.

$$
\begin{aligned}
& \mathrm{Q}=1.06 \sqrt{\mathrm{d}_{1} / \mathrm{P}_{1}} \mathrm{C}_{\mathrm{g}} \operatorname{SIN}\left(\left(3471 / \mathrm{C}_{1}\right) \sqrt{\left(\Delta \mathrm{P} / \mathrm{P}_{1}\right)}\right) \\
& \text { where } \begin{aligned}
& \mathrm{Q}=\text { Rate of flow of steam, } \mathrm{lb}_{\mathrm{m}} / \mathrm{hr} \\
& \mathrm{d}_{1}= \text { Steam density, } \mathrm{lb}_{\mathrm{m}} / \mathrm{ft}^{3} \\
& \mathrm{P}_{1}= \text { Valve inlet pressure, psia } \\
& \mathrm{C}_{\mathrm{g}}= \text { Gas sizing coefficient; this value is generally published by } \\
& \text { the valve manufacturer as a curve versus valve stem position } \\
& \mathrm{C}_{1}= \text { Liquid sizing coefficient; this value is also provided by the } \\
& \Delta \mathrm{P}= \text { manufacturer and is also a function of valve stem position } \\
&
\end{aligned}
\end{aligned}
$$

Note: The argument of the sine function in this equation should be evaluated in degrees.

It would seem from this equation that measurement of the rate of flow across the valve in field service is easily made by measuring the differential pressure across the valve and the static pressure upstream of the valve. But, although this equation is very useful in initially sizing the control valve, it is nearly impossible to make use of this equation to estimate the current rate of delivery across the valve. This difficulty arises because the exact position of the valve stem must be known in order to determine both $C_{g}$ and $C_{1}$. As the valve stem position is changed in an effort to adjust steam rate, the values of both $C_{g}$ and $C_{1}$ must both be re-evaluated.

To solve the difficulties associated with the use of the above equation, an orifice plate is generally installed with the adjustable choke. The static and differential pressures across the static choke are then measured, an estimate of the steam quality is made, and the orifice plate flow equation is used to calculate the rate of steam delivery across the orifice plate. By monitoring the differential and static pressures across the orifice as the valve stem position of the choke is 
adjusted, the desired rate of steam flow may be obtained. The orifice plate flow equation is repeated as follows:

$$
\begin{aligned}
& Q_{s}=C F_{x} F_{s} \sqrt{h} \sqrt{P} \\
& \text { where } Q_{S}=\text { Rate of delivery of steam across orifice plate, } \mathrm{lbm} / \mathrm{hr} \\
& \mathrm{C}=\text { The orifice coefficient } \\
& \mathrm{F}_{\mathrm{X}}=\text { Correction factor based on wet steam, specific volumes } \\
& =\sqrt{v_{B} / v_{x}} \\
& \mathbf{v}_{\mathbf{g}}=\text { Specific volume of the saturated vapor, } \mathrm{ft}^{3} / \mathrm{lbm} \\
& v_{x}=\text { Specific volume of the saturated steam at } \mathrm{x} \text { quality, } \mathrm{ft}^{3} / \mathrm{lbm} \\
& =x v_{g}+(1-x) v_{f} \\
& F_{S}=\text { Correction factor for density and the difference in measurement } \\
& \text { units between steam and gas } \\
& =1.062 \sqrt{W / P} \\
& W=\text { Density of the saturated steam, } 1 \mathrm{bm} / \mathrm{ft}^{3} \\
& \mathbf{P}=\text { Pressure of steam upstream of the orifice plate, psia } \\
& \mathrm{h}=\text { Differential pressure across the plate, in. of water column }
\end{aligned}
$$

A hand held calculator may be programmed to make the necessary field calculations for the adjustment of these chokes. In addition, at least one manufacturer is currently marketing a microprocessor based device which when attached to the proper differential pressure and static pressure transducers, will calculate the flow rate across the orifice plate.

As in the case of the static choke in critical flow, the performance of each flow rate control device should be checked at least once every two weeks and, in addition, a check should be made anytime a change in the steam distribution system pressure occurs. These changes may occur for a variety of reasons including the following:

1. Steam generator shutdown;

2. Well work on other wells within the system; and

3. Adjustment of steam rates on any of the other injection wells on the system.

The adjustable choke system of steam injection rate control is in all cases tedious and difficult to operate consistently at the desired flow rates. This is because the rate of flow across the adjustable choke is dependent (in noncritical flow) on not only the upstream system operating pressure but also the downstream well injection pressure. The adjustable choke method of rate control becomes the system of choice only when the additional operating pressure needed for a system of critical flow chokes becomes high enough to cause either unacceptable operating 
pressures or the cost of power necessary to raise feedwater pressure to the required system pressure becomes unacceptable.

\section{The Effect of Steam Quality on Injection Rate Control}

To make use of either steam rate control system properly, the steam quality at the control device should be accurately known. This results from the square root of the density term which is present in both equations describing the rate of flow across either the choke or the control valve. The accurate estimation of steam quality delivered to the wellhead and therefore across the control device is by no means a simple task. The problem is made more difficult because no reliable procedure or equipment has yet been developed to accurately measure the steam quality at the wellhead. Current steam quality measurement techniques and practices are discussed in detail in chapter 8.

In the past, field practice has been to calculate steam quality at the wellhead as the steam quality at the steam generator site less the effects of heat loss in the distribution system. While this makes the solution of the steam rate equations possible, it does not accurately reflect the true quality delivered to the wellhead, and the rate of delivery of steam across the control device cannot be accurately calculated. Current research and field testing is directed at the following:

1. A better understanding of how the steam distribution system delivering steam to the wellhead operates in regard to steam quality.

2. Techniques to measure the steam quality at the wellhead.

Recent laboratory tests have shown that it is possible to design and operate the steam distribution system to provide more reliable steam quality values to each wellhead.

\section{Control of Individual Well Steam Quality 8}

Recent advances in steam injection field practices have led to the use of a "variable" quality steam injection. This requires that the steam distribution system deliver $80 \%$ quality steam at the beginning of the project and then gradually reduce this quality to near zero value towards the end of the economic life of the project.

It is a common practice in large steam injection operations to develop different sections of the field at different times. As a result, the individual sections are at different stages of flood and their steam quality requirements are also different. For example, the steam quality requirement of a section where the steam injection has just been started may be $80 \%$, while the quality requirements of a matured neighboring section may be $30 \%$. Since the steam quality requirements of different sections are different, means must exist to satisfy this requirement.

One of the simplest ways to produce adjustable steam quality is to produce steam at the maximum quality required by an injector in the system (usually $80 \%$ ) and then mix hot water ( $0 \%$ 
quality) with steam to produce desired quality. The problem remains as to the most desirable location for the mixing of steam and hot water.

Mixing hot water with steam results in a two-phase mixture. Phase separation will result if this mixture is transported over long horizontal distances. Further, since steam velocities in the distribution system usually range from 30 to $70 \mathrm{ft} / \mathrm{sec}$, the presence of liquid slug in steam can result in line failure at tees and ells. Hence, it is preferable to mix steam and hot water at the wellhead to avoid the liquid slug problems.

The mixing chamber is usually located at the downstream side of the steam rate control device (usually a critical flow choke). Steam and water are introduced into the chamber through metering devices and intimately mixed before being injected into the well. A turbine meter installed at the water line measures the volume of water introduced into the chamber. Steam rate is measured using the static choke.

Though this device is satisfactory for formulating steam of desired quality, the inlet steam quality must be known accurately if it is to be effective. Since the quality of the steam entering the mixing chambers is usually not precisely known, this limits the usefulness of this device. To overcome this limitation, the steam is first passed through a separator located upstream of the mixing chamber. The steam leaving the separator is then metered through a choke into the mixing chamber and mixed with a known quantity of water. Since the steam leaving the separator would be of $100 \%$ quality, the quality of steam entering the well can be closely controlled.

\section{Steam Distribution System Maintenance and Monitoring}

A properly designed and implemented steam distribution system requires very little maintenance and can be operated relatively trouble free. Problems related to steam distribution include corrosion of buried pipes, leaky valves, and injection wellhead stuffing box packer failure. The most troublesome maintenance problem is the replacement of insulation material which is likely to be damaged due to normal oilfield activities.

Steam distribution system monitoring includes manual reading of downstream and upstream choke pressure to determine the current steam injection rate. The well rate chokes will require regular adjustment to maintain acceptable injection rate control. Wellhead steam quality should also be regularly monitored to assure that specified quality steam is delivered to each injection well.

\section{SUMMARY}

A properly designed and installed steam distribution system is relatively trouble free to operate and requires very little maintenance. The steam distribution system must be designed, not only for the appropriate pressures and temperatures, but must also provide the desired steam quality and flow rate to each injection well in the system. The major component of a steam 
distribution network includes main steam headers, lateral steam lines, wellhead assembly, and wellhead steam rate controls.

Steamheader and lateral steam lines must be designed and constructed in accordance with recognized standards such as ANSI Standard 31.4. Expansion loops must be incorporated in steam lines to provide for the expansion and contraction of these lines due to temperature changes. Since temperature changes also affect the wellhead connections, they must be equipped with stuffing boxes to allow for the free movement of tubing and casing and tubing setting with steam temperatures. The rate of delivery of steam to each individual well is controlled using a static or adjustable choke. The performance of the controlled devices must be checked at least once a week to assure proper functioning. In addition, a check should be made whenever a change in the steam distribution system pressure occurs. The integrity of the steam line insulation must be periodically evaluated and the insulation replaced as warranted.

\section{REFERENCES}

1. Natural Gas Processors Suppliers Association. Engineering Data Book, 9th Edition. Natural Gas Processors Association, Tulsa, OK, Section 10, 1972.

2. Fitzgerald, B. M. Surface Injection and Producing Systems for Steam Operations. Producer's Monthly, v. 31, No. 12, December 1967, pp. 18-23.

3. Bleakley, W. B. The Hardware of Steam Injection. Producer's Monthly, v. 29, No. 8, August 1965, pp. 2-27.

4. Eckert, L. A. Solving Mechanical Problems In Steam Stimulated Wells. World Oil, v. 161, No. 7, December 1965, pp. 89-96.

5. Brusset, M. J., A. N. Edgington and R. F. Gilmour. Equipment Performance in An Alberta High Pressure Steam Injection Project paper presented at the 18th Annual Technical Meeting of the Petroleum Society of CIM, Banff, Alberta, Canada, May 1967.

6. Crocker, S. Piping Handbook, 4th Ed. Chapter 2, Flow of Steam in Pipes, pp. 246253. McGraw Hill Book Company, New York, 1945.

7. Chien, S. F. Critical Flow of Wet Steam Through Chokes. J. Pet. Tech., v. 42, No. 3, March 1990, pp. 363-370.

8. Schoen, D. M. and T. L. Frazier. Operational Review of a Large-Scale Saturated Steam Delivery System. Paper presented at the Soc. of Pet. Eng. California Regional Meeting, Ventura, CA, Apr. 4-6, 1990. Paper SPE 20026. 


\section{APPENDIX 7-A \\ STEAM DISTRIBUTION NETWORK COMPONENTS SUPPLIERS}

A. Injection Wellhead Control Equipment (X-mas tree, flow chokes, control valves, etc.)

1. Flow Control Cooper Industries 16500 S. Main Missouri City, TX 77489

Telephone: (713) 499-85! 1

2. Gardner Denver Petroleum Equipment 3325 S. Rice Avenue

Houston, TX 77056

Telephone: (713) 626-2220

3. Cameron Iron Works Inc. 13013 Northwest Freeway Houston, TX 77060

Telephone: (713) 939-2211

4. FMC Corporation Petroleum Equipment Group 1777 Gears Road Houston, TX 77067

Telephone: (713) 448-0211

5. Hydril Company P.O. Box 60458 3300 N. Beltway 8 Houston, TX 77032-3411 Telephone: (713) 449-2000

6. Trico Industries Inc. 3040 E. Slauson Avenue Huntington Park, CA 90255 Telephone: (213) 588-1271

7. Daniel Flow Products Inc. 9720 Katy Road Houston, TX 77224 Telephone: (713) 467-6000

B. Turn Key Steam Distribution System Supplier

1. Daniel En-Fab Systems Inc. 3905 Jensen Drive P.O. Box 21361 Houston, TX 77226-1361 Telephone: (713) 225-4913
C. Steam Pipe Fabricators

1. Piping Technology \& Products Inc. P.O. Box 34506

Houston, TX 77234-4506

Telephone: (713) 731-0030

2. Sunland Fabricators Inc. 30103 Sunland Drive Walker, LA 70785 Telephone: (50.4) 667-1000

3. LaBarge Pipe \& Steel Company 901 N. 10th Street

St. Louis, MO 63101

Telephone: (314) 231-3400

4. Progressive Fabricators 6882 N. Broadway St. Louis, MO 63147 Telephone: (314) 385-5477

D. Piping Insulation

1. Manville Mechanical Insulation Division

P.O. Box 5108

Denver, CO 80217

Telephone: 1-800-654-3103 


\section{CHAPTER 8 \\ STEAM QUALITY}

\section{INTRODUCTION}

The term steam quality is commonly used to describe the vapor content of a two-phase steamwater mixture. It is a dimensionless quantity and defined as the mass ratio of vapor to the total mass of liquid and vapor. ${ }^{1}$ Thus, an oilfield steam generator is said to produce $80 \%$ quality steam, if the produced steam contains $80 \%$ by weight steam and $20 \%$ by weight water.

A knowledge of steam quality is essential for the efficient operation of a steam injection operation. Steam quality is one of the operator-controlled parameters that can impact the economics of a steam injection project. Steam quality enters into the calculation of steam generator efficiency and steamflood performance.

Steam generator output quality is required for several reasons. The output quality affects the steam generator energy output. It is desirable to know the energy output of a generator, so that it can be compared with the total energy injected at wells. If a reasonable energy balance cannot be obtained, this is an indication that one or more of the metering devices is not functioning properly and maintenance is required. Second, steam quality from each generator is required by plant operators to ensure that generator firing rates are properly set and stay in adjustment. Third, it is desirable to compare energy output from a generator with fuel consumption on a regular basis to detect generator efficiency. Any such change is usually the result of a change in operating conditions, which can be corrected to provide good generator efficiency.

The performance of a steam injection operation is commonly measured in terms of oil-steam ratio, i.e., barrels of oil recovered per barrel of steam injected. The oil-steam ratio generally improves, if the heat content of the injected steam is high. The enthalpy or total heat of steam is strongly dependent on the steam quality, especially at lower pressures. At a given pressure a higher quality steam carries more heat than a lower quality steam and, other things being equal, a higher quality steam can recover more oil than a lower quality steam. Steam quality must also be known to calculate accurately the wellhead injection rate using devices such as the critical choke.

Ideally, it would also be desirable to have a knowledge of steam quality at the bottom of the injection string, as it enters the sandface. This would give the exact amount of energy entering the formation and, in conjunction with the surface steam quality, would also allow an evaluation of the effectiveness of the tubing insulation, if present.

The steam quality can be measured using a number of techniques. However, these techniques are only approximate, since in general the steam quality varies considerably with the operating conditions. In this chapter, some of the various methods currently available for the measurement of steam quality have been evaluated. Only techniques of interest to steam injection operation are reviewed. Some of the more recent techniques developed to measure steam quality at 
wellheads in multiple well distribution systems are discussed. Limitations of each of the methods reviewed are also given.

\section{SURFACE STEAM QUALITY MEASUREMENT}

Several different methods are used in oilfield operations to measure steam quality in surface lines. These include: (a) separator method, (b) orifice metering method, (c) total dissolved solids method, (d) electric conductivity method, (e) stack gas analysis method, (f) fixed heat rate method, and $(g)$ enthalpy determination method.

\section{Separator Method}

This method, based on the mechanical separation of liquid and vapor phases, is one of the techniques widely used in steam injection projects to determine steam quality at the wellhead. The technique is simple and yields values comparable to those of other methods.

The separator system can be used when large moisture contents are encountered in the twophase mixtures. The separator itself consists of an insulated cylindrical vessel (usually configured in a vertical position) which is used to physically separate the liquid phase from the vapor phase. Measurement of the mass rate of flow of each of the two phases as they leave the separator gives a direct indication of quality. After separation, any suitable method of metering the two phases is acceptable. Most systems use orifice meters on both streams, but an orifice meter in the vapor line and a positive displacement or turbine meter on the liquid side is also satisfactory, if correction is made for possible temperature difference between the streams.

A separator used by a large California steam injection operator is shown in figure 8.1. The separator can be trailer-mounted and consists of the following:

1. Liquid vapor separator vessel;

2. Vessel level controller with valve;

3. Vapor line adjustable throttle (choke);

4. Vapor flow orifice and computer; and

5. Liquid flow orifice and computer.

At each well, the trailer is installed in the injection line downstream from the rate control device. In this manner, the steam quality delivered to the wellhead can be measured. The liquid and vapor phases are separated and measured. They are then recombined and delivered to the wellhead assembly for injection. The phase mass flow rates are computed automatically by flow rate computers. 


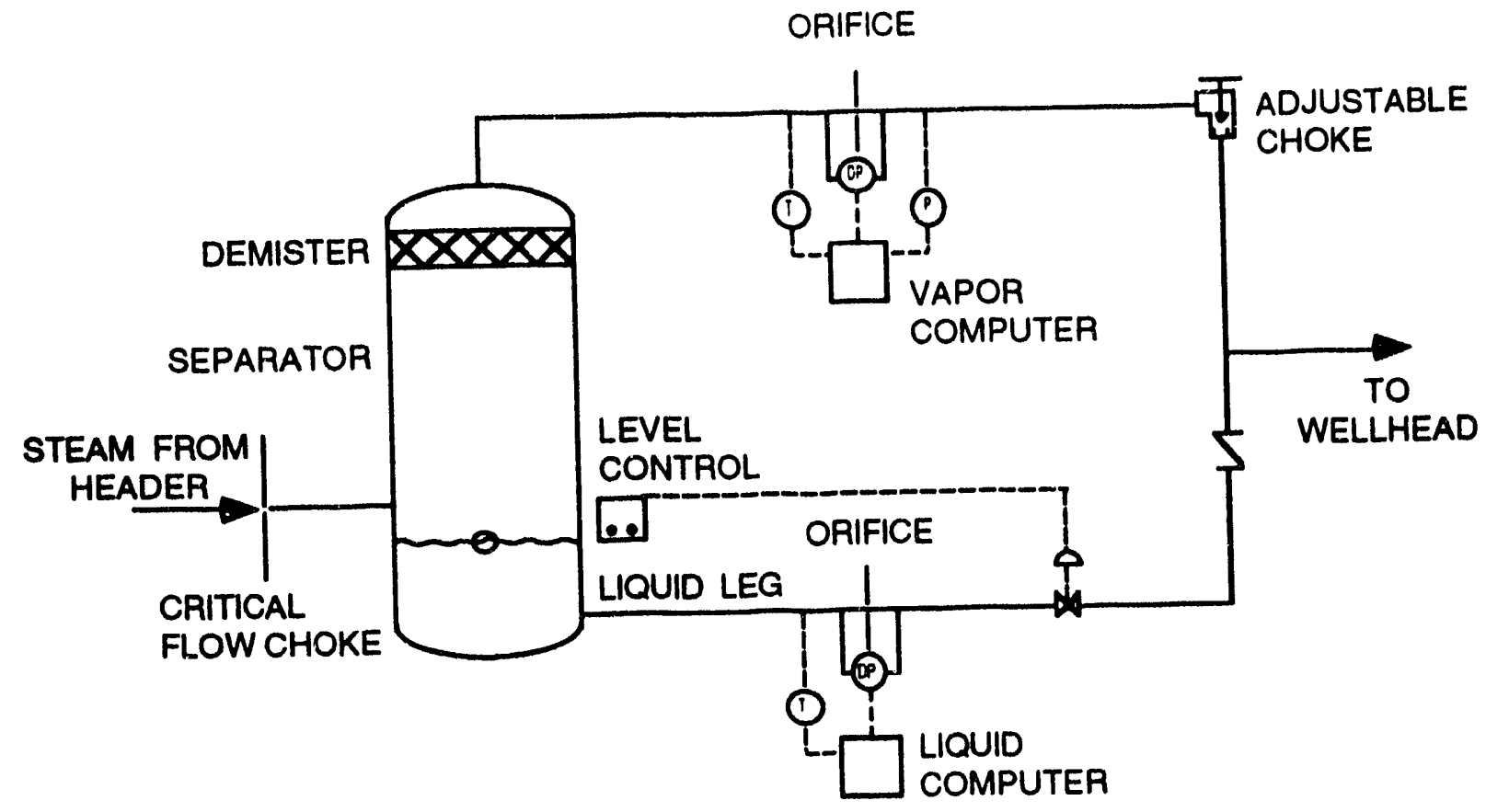

FIGURE 8.1. - Schematic of equipment arrangement for steam quality measurement by the vaporliquid separation technique.

To obtain reliable results, the separator chamber must be thoroughly warmed to avoid any steam condensation. If not, dilution of the liquid phase would occur and give a lower apparent quality. In addition, insulation should be provided generously throughout the flowing chambers to approach an adiabatic condition (no net gain or loss of heat to the surrounding area) as much as possible. Quality can be calculated by dividing the mass rate of vapor flow by the sum of the mass rates of vapor and liquid streams.

Tests performed by Hodgkinson ${ }^{2}$ indicated that a separator system could provide accurate measurements of steam quality in the range of 40 to $80 \%$. The measured values deviate from standard chemical titration tests (discussed later) by only about 5 to $7 \%$.

Mahon ${ }^{3}$ has evaluated the separator sampling techniques. He recommends samples to be taken at distances of several pipe diameters (50-100) downstream of any elbow, tees, valves, or other flow constrictions. It is also essential that pressure drops through the separator be kept to a minimum to avoid flashing of the water phase. Before taking samples, the separator must be allowed to warm up and stabilize for a period of at least 15 minutes.

\section{Orifice Metering Method}

Orifice meters, commonly used in oilfields to measure gas and liquid flow rates, can be used to estimate steam quality. The flow of wet steam through an orifice meter, and its relation to the 
measurement of steam quality, has been investigated by several authors. ${ }^{4-9}$ This technique is preferred by many TEOR operators, since it does not require sampling or phase separators. The standard equation for single-phase flow through sharp-edge orifice plates or flow nozzles is

$$
W_{h}=C\left(\frac{\Delta P_{w}}{V}\right)^{1 / 2}
$$

where

$\mathrm{W}_{\mathrm{h}}=$ mass flow rate of fluid $\mathrm{lb} / \mathrm{hr}$

$\Delta \mathrm{P}_{\mathrm{w}}=$ pressure drop across the device, inches of water

$\mathrm{V} \quad=$ specific volume, $\mathrm{cu} \mathrm{ft} / \mathrm{lb}$

$\mathrm{C}=$ meter factor

The meter factor, $C$, is an empirically determined flow constant which depends on the size and geometry of the orifice plate and the flow conditions. It is normally considered to be constant for a range of fluid properties and flow rates. This is a reasonable assumption provided the Reynold's number stays above $10^{5}$ for all flow conditions.

For metering flow of a wet steam through the orifice, the specific volume in Eq. 1 must he adjusted to account for the degree of wetness. The specific volume of a two-phase steam.water mixture (assuming the mixture to be homogeneous) is given by

$$
V=(x) V_{g}+(1-x) V_{f}
$$

where

$\mathbf{x}=$ steam quality, fraction of mass in vapor phase

$V_{g}=$ specific volume of saturated steam, $\mathrm{tt}^{3} / \mathrm{lb}$

$\mathrm{V}_{\mathrm{f}}=$ specific volume of saturated liquid, $\mathrm{ft}^{3} / \mathrm{lb}$

Although this correction is appropriate for very high qualities, it is known to introduce significant errors for sharp-edged orifices as the flowing stream becomes wetter. Wilson ${ }^{4}$ determined that errors in mass throughput in the 1,500 to 2,000 psia range were about $5 \%$ at $80 \%$ quality, $10 \%$ at $60 \%$ quality, and 15 to $20 \%$ at $4.7 \%$ quality.

James ${ }^{10}$ determined experimentally that Eq. 1 could be used directly if the specific volume term is calculated from Eq. 2 using an apparent or pseudo-quality that is related to the true quality by

$$
\mathrm{x}_{\text {apparent }}=\mathrm{x}_{\text {true }}{ }^{1.5}
$$


Eq. 1 then hecomes

$$
W_{h}=C\left(\Delta P_{w} /\left(V_{g} x^{1.5}+\left(1-x^{1.5}\right) V_{f}\right)\right)^{0.5}
$$

or, rewriting to solve for quality,

$$
x=\left(\left(\left(C^{2} \Delta P_{w} / W_{h}^{2}\right)-V_{f}\right) /\left(V_{g}-V_{f}\right)\right)^{2 / 3}
$$

Quality can then be calculated directly when the mass throughput rate is known from some independent source, such as the boiler input feedwater meter. The parameter $\mathbf{C}$ is determined as if all fluid flowing was saturated vapor, the pressure drop across the orifice is measured, and $\mathrm{V}_{\mathrm{g}}$ and $\mathbf{V}_{\mathbf{f}}$ are determined from steam tables at the operating pressure level of the orifice. James' work encompassed a broad range of conditions, so Eq. 5 should be applicable for even very wet high pressure steam, where the vapor to liquid volume ratio is not particularly high.

Though steam qualities obtained from the orifice meter method compared reasonably well with other methods such as the total dissolved solids method, the method is only approximate and has limitations. As increasingly wet steam flows through the orifice, the recorded differential pressure fuctuates. Wilson 5 found that the magnitude of these fluctuations to be at least $1 \%$, and more often $3 \%$ of full scale deflection. Consequently, the value of the $\Delta P_{w}$ term in Eq. 5 is only approximacie. In addition, orifice meter measurements should be made after at least 10 minutes of steady-state flow. Attempts to determine steam quality on an instantaneous basis, while the variables are changing have proved to be unsuccessful.

In spite of its limitation, use of the orifice plate technique to measure steam quality is widespread in steam injection operations. This is because the technique can measure steam quality continuously and no samples of two-phase mixtures are required. Further, it is one of the few methods that provides on-line indication of steam quality changes. Instruments that measure differential pressure across the orifice and convert it to signals suitable for computer interfacing are being marketed. 12 At least one vendor markets a computer program to calculate steam quality using an orifice plate correlation. The program requires the following information to estimate steam quality: minimum line pressure (psig), maximum line pressure (psig), differential pressure range (inches of water), orifice plate internal diameter (inches), pipe internal diameter (iaches), and minimum and maximum steam mass flow rates (lb/day).

\section{Total Dissolved Solids Method}

The total dissolved solids method of measuring steam quality consists of comparing the concentration of soluble solids in the feedwater to the enriched concentration in the liquid fraction of the boiler discharge. The chloride ion, $\mathrm{Cl}^{-}$, and sometimes the sodium ion $\mathrm{Na}^{+}$concentration 
provides a convenient tool for this check. By chemical titration, the concentration of $\mathrm{Cl}^{-}$in the liquid part of the steam-water mixture is compared with the concentration of the same ion in the feedwater, and, assuming good quality water samples, the results obtained can be very accurate. This method is, at present, the most widely used technique for obtaining steam quality in the field.

The sampling technique for obtaining a specimen of the water fraction from the two-phase flowing mixture is one of the most critical steps in the procedure. This liquid fraction sample is obtained from separators or traps in the output line of the generator and must be drawn through a cooler to avoid flashing. If the sample is drawn off too quickly, vapor may also be withdrawn and condensed, with a subsequent dilution of the liquid phase, therefore implying less water evaporation in the generator and a lower output quality. On the other hand, if liquid is withdrawn too slowly, the liquid obtained will be some composite of the effluent liquid previously left in the separator, also giving incorrect results.

Ion concentrations are found by adding a dilute acid to the water samples. A phenolphthalein color indicator is used to determine when sufficient acid solution has been added. More acid solution must be added to the outlet sample than to the feedwater sample, and the ratio of the acid added to each sample determines the quality of the outlet sample. For example, if the effluent sample requires an acid volume five times greater than the feedwater sample, then the final dissolved solids concentration is five times the original, or what is the same, four-fifths of the feedwater has been vaporized, and the steam quality is $80 \%$.

Chemical titration techniques suffer the same limitations as all other techniques requiring samples to be taken from the flowing two-phase pipeline; that is, the need to take a sample from a representative cross section of the pipe and in a segment of the line located far away from any discontinuities. Errors will be introduced into the measurement if a sample is taken very close to a tee, elbow, or any pipe fitting.

\section{Electric Conductivity Method}

The electric conductivity of a solution of water with dissolved salts depends on the concentration of the salts. By noting the increase in the conductivity between the feedwater and liquid fraction of the boiler's discharge, the amount of vaporized water can be determined. This method is similar to the chemical titration-chloride ion determination method, except that all dissolved salts are considered instead of only one. In general, the electric conductivity method of obtaining steam quality is a simpler and quicker method than the chloride ion measurement technique, although it is also somewhat less dependable.

The steam quality determined by this method has several potential sources of error. First, in using the ratio of input and effluent liquid conductivities, it is assumed that the dissolved solids are concentrated only by the evaporation of the liquid phase as the water passes through the steam 
generator. This, however, is not always the case. The effluent liquid phase contains carbonate and hydroxyl ions produced by the thermal decomposition of bicarbonate ions in the feedwater. The hydroxyl ions in the effluent liquid provide a conductivity out of proportion to the concentrated total dissolved solids and when this conductivity is used directly, the calculated quality is too high. To avoid this situation, both input and effluent liquid samples must be neutralized to a pH of 7 with a weak acid. Over- or underneutralization of either sample can lead to erroneously calculated steam qualities. Secondly, because conductivity varies substantially as a function of temperature, it is necessary to correct conductivities of feedwater and effluent samples to a common temperature base if they have not been measured at the same temperature originally.

\section{Stack Gas Analysis Method}

A stack gas analysis may be used in conjunction with the feedwater rate and the fuel consumption rate to check the approximate Btu content of the steam-water output of the boiler. To use this method, the following information is required:

1. Feedwater input rate

2. Fuel consumption rate

3. Btu content of fuel

4. Stack gas analysis for carbon dioxide and oxygen content

5. Stack gas temperature me asurement

Commercial portable stack as analysis kits are available for $\mathrm{CO}_{2}$ and $\mathrm{O}_{2}$ determination. From the $\mathrm{CO}_{2}, \mathrm{O}_{2}$, and temperature values, combustion efficiency and heat losses from the stack can be determined. The following calculation can then be made (assuming that the boiler heat losses are negligible):

$$
\mathrm{H}_{3}=\mathrm{H}_{1}-\mathrm{H}_{2}
$$

where

$\mathrm{H}_{1}=$ total heat input in fuel to burner, Btu/hr

$\mathrm{H}_{2}=$ heat loss from stack determined by analysis, Btu/hr

$\mathrm{H}_{3}=$ heat content of generator water output, Btu/hr

The value of the specific heat content is:

$h_{3}=\mathrm{H}_{3} / \mathrm{W}$

$h_{3}=$ specific heat cuntent of steam-water output, Btu/lb

$\mathrm{W}=$ feedwater rate, from meter, $\mathrm{lb} / \mathrm{hr}$

The value of the $h_{3}$, compared to the steam table values for saturated water and steam enthalpy at the steam line pressure, will establish steam quality.

The stack gas analysis method does not require any sample from the flowing two-phase mixture; furthermore, it does not require any information, other than the flow rate, from the 
flowing mixture. However, the quality obtained from this method is only applicable to the outlet of the steam generator. It cannot be used at either the wellhead or downhole locations.

Even when intended for measurement of steam quality at the generator outlet, this method is not in standard use because it is error prone, more time-consuming, just as involved as the chemical titration method, and yields less accurate values.

\section{Fixed Heat Rate Method 11}

This method is an attempt to fix steam quality in advance, rather than measure it. At constant heat input rate (fuel rate to the burner), the feedwater rate is gradually reduced while observing pressure and temperature of the discharged steam. As soon as the temperature begins to increase, at constant pressure, the water input rate is noted. Since neither temperature nor pressure alone can be changed as long as both liquid and vapor are present in the system, an increase in temperature at constant pressure mist mean that all liquid is vaporized, and that the steam has entered the superheated region. By repeating this test under several different conditions, an approximate relation can be obtained between the feedwater input and the heat input required to produce saturated steam. The output steam quality from the boiler will then be in inverse proportion to the additional water throughput above the value that will produce only saturated steam.

This calibration process must be used with extreme caution, particularly if the feedwater contains a large percent of dissolved solids. Extended periods of operation at low water rates (forming superheated steam) will deposit scale on the water tubes, reducing thermal efficiency and inviting corrosion. If the method must be used, feedwater rate should be increased to a safe level as soon as it is noted that the steam generator is producing superheated steam, and the water rate recorded.

This technique of measuring, or rather fixing, the steam quality is not in standard use by any steam injection thermal recovery project. The method should only be considered under those conditions where no other provisions such as throttling calorimeter, separators, or orifice techniques have been provided, and where no possibility exists for performing dissolved solids, electric conductivity, or stack gas analysis evaluations.

\section{Enthalpy Determination Method}

The enthalpy determination technique for measuring steam quality is another relatively crude method which should only be employed when none of the more acceptable methods are available. The method has been discussed by Hodgkinson, et al. ${ }^{2}$

The enthalpy of a sample from the steam-mixture is first transfierred into an absorbing medium. There are two methods available to transfer the enthalpy into this medium. One is indirectly, by the use of a heating coil, and the other is directly, by allowing the steam-water 
sample to mix with the absorbing medium. Then, the temperature rise of the absorbing medium is measured, and from this measurement the enthalpy of the steam-water sample is calculated. Knowing the enthalpy of the steam-water mixture, its quality can be obtained by comparison with the values for saturated liquid and vapor at the flowline pressure. The absorbing medium with known thermal properties must be selected and its flow rate measured accurately. The rate of flow of the steam-water mixture must also be measured and this can be done by noting the amount of condensate if the indirect technique (with a heating coil) is used.

Although available, this technique is not in common use because calibration of the enthalpy transfer chamber requires very precise measurement, and the criteria assuring simple design and ease of operation have not been met.

\section{Wellhead Steam Quality}

The techniques described in the previous sections provide a means to measure surface steam quality but require an independent means of measuring the total mass flow rate or require that the mass flow be held constant from a point of known quality (usually zero) to the point at which the quality is being measured. Further, beyond the first split in the surface lines, there is no easy way to determine steam quality with any degree of confidence because beyond the first junction steam splitting can be extremely uneven and difficult to predict. This uneven splitting of phases between the branches results in a wide variation in wellhead steam quality. A fieldwide check of wellhead steam quality made by one major California steam injection operator, indicated that individual wellhead quality can vary from near zero to $100 \%$. Table 8.1 lists the measured wellhead steam quality. 13 Measurement of steam quality at the wellhead is very difficult because no reliable procedure or equipment has been developed to date. Because of this, most operators assume the wellhead steam quality to be no more than the steam generator outlet steam quality less the effects of heat loss in the distribution system.

As indicated in table 8.1, this method of estimating wellhead steam quality does not reflect the true quality of steam delivered to the weilhead. Since a knowledge of steam quality is essential for the calculation the rate of flow of steam across the wellhead control device, the well injection rates are suspect. In recent years, however, significant effort has gone into the development of tools that can reliably measure the actual wellhead steam quality. Some of the devices currently being marketed include the following:

(a) Vibrating densitometer;

(b) gamma ray absorption technique; and

(c) neutron densitometer.

These devices are expensive, require extensive calibration, and are still under development. Following is a brief overview of the operating principles of these devices. 
TABLE 8.1. - Steam injection wellhead steam quality 13

\begin{tabular}{|c|c|c|}
\hline Well No. & $\begin{array}{c}\text { Flow rate, } \\
\text { bbl/day }\end{array}$ & $\begin{array}{c}\text { Steam quality, } \\
\%\end{array}$ \\
\hline 1 & 425.3 & 62.1 \\
\hline 2 & 453.9 & 78.1 \\
\hline 3 & 19.1 & 100.0 \\
\hline $\begin{array}{l}4 \\
5\end{array}$ & 600.7 & 4.2 \\
\hline $\begin{array}{l}5 \\
6\end{array}$ & 727.4 & 6.3 \\
\hline 7 & $\begin{array}{l}301.4 \\
398.6\end{array}$ & $\begin{array}{l}52.7 \\
53.4\end{array}$ \\
\hline 8 & $\begin{array}{l}398.6 \\
247.2\end{array}$ & $\begin{array}{r}53.4 \\
100.0\end{array}$ \\
\hline 9 & $\begin{array}{l}247.2 \\
283.5\end{array}$ & $\begin{array}{r}100.0 \\
81.6\end{array}$ \\
\hline 10 & $\begin{array}{l}283.5 \\
365.1\end{array}$ & $\begin{array}{l}81.6 \\
88.3\end{array}$ \\
\hline 11 & 530.1 & $\begin{array}{l}88.3 \\
43.2\end{array}$ \\
\hline 12 & 188.3 & $\begin{array}{l}43.2 \\
66.5\end{array}$ \\
\hline 13 & 379.4 & $\begin{array}{r}66.5 \\
100.0\end{array}$ \\
\hline 14 & 100.3 & $\begin{array}{r}100.0 \\
95.1\end{array}$ \\
\hline 15 & 293.8 & $\begin{array}{l}95.1 \\
93.4\end{array}$ \\
\hline 16 & 251.3 & $\begin{array}{l}93.4 \\
68.3\end{array}$ \\
\hline 17 & 507.5 & 48.5 \\
\hline 18 & 486.3 & 85.7 \\
\hline 19 & 278.7 & 89.9 \\
\hline 20 & 113.0 & 95.1 \\
\hline 21 & 478.8 & 64.6 \\
\hline 22 & 276.0 & 72.7 \\
\hline 23 & 256.1 & 89.0 \\
\hline 24 & 226.7 & 93.3 \\
\hline 26 & 432.2 & 56.2 \\
\hline 27 & 333.5 & 73.7 \\
\hline 28 & 395.9 & 63.8 \\
\hline 29 & 308.9 & 91.3 \\
\hline 30 & 251.3 & 95.6 \\
\hline 31 & 397.9 & 95.8 \\
\hline
\end{tabular}

\section{Vibrating Densitometer}

The vibrating densitometer operates on the principle that the natural or resonant frequency of a vibrating tube containing a two-phase mixture depends on the bulk density of the two-phase mixture. Hence, by measuring the resonant frequency, the bulk density of the two-phase mixture can be calculated. The bulk density, along with the pure vapor and liquid density at the operating temperature, can be utilized to calculate the steam quality.

Figure 8.2 shows a schematic of a vibrating densitometer which consists of a pair of sensor tubes made of magnetic material and are vibrated by an electromagnet. When the frequency of vibration of the tubes corresponds to its natural or resonant frequency, a large amplitude 


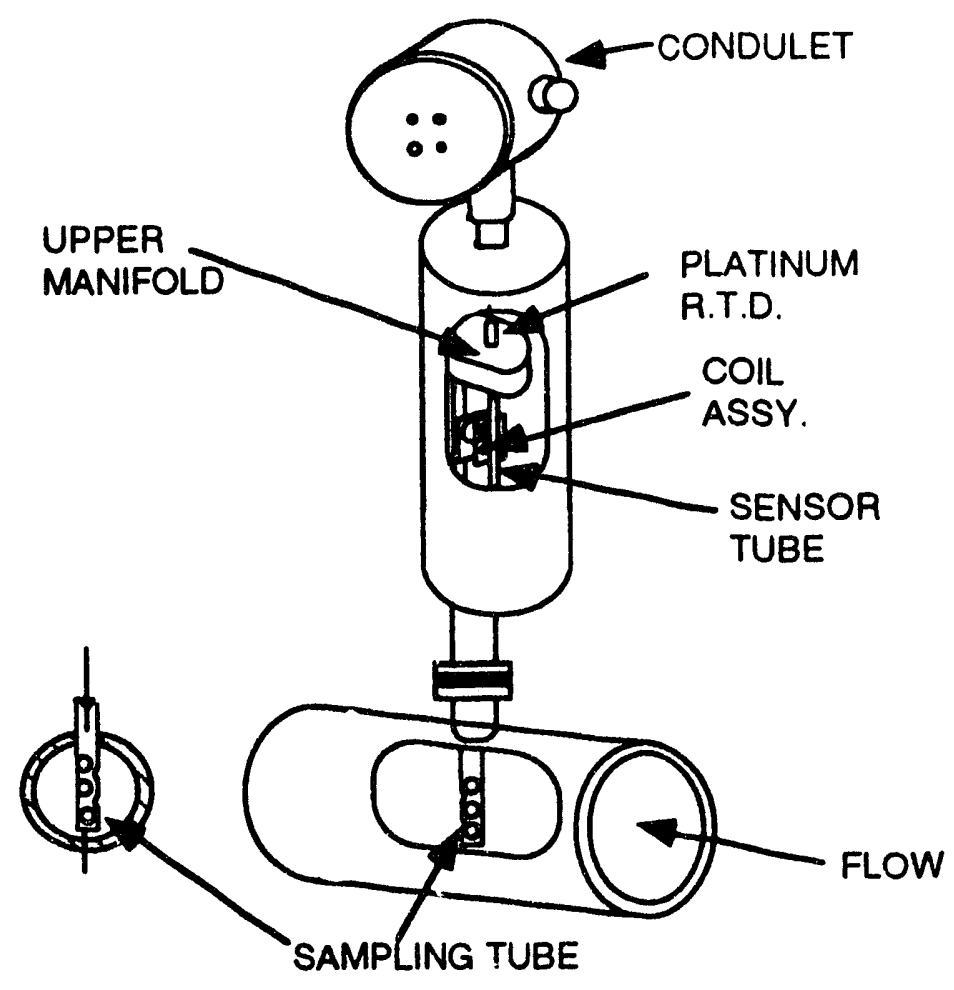

FIGUKE 8.2. - Schematic of a vibration densitometer for steam quality determination. ${ }^{1}$

in the tube vibration results. A strain gauge mounted on one of the tubes is used to detect the resulting amplitude and a microprocessor correlates this amplitude response with the vibrating frequency.

The resonant frequency of the tube is a function of the mass of the tube (i.e., the mass of the tube itself plus the mass of the two-phase mixture inside the tube). Depending on the bulk density of the liquid-vapor mixture inside the tube, the natural or resonant frequency of the tube will vary. The bulk density and the natural frequency are related by the equation,

$$
\bar{\rho}=\left(A / f^{2}\right)+B
$$

where

$\bar{\rho}=$ Bulk density of liquid vapor mixture

f = Natural or resonant frequency of the vibrating tube

$\mathrm{A}, \mathrm{B}=$ Constants determined by calibrating the meter.

A platinum resistance thermometer mounted on the tube can be used to measure the temperature of the fluid inside the tube. From the temperature measurement and steam table, the density of pure vapor and pure liquid can be established. Knowing the bulk density from the densitometer and the vapor and liquid densities from the steam table, the steam quality can be calculated using the following expression 


$$
x=\left[\frac{1}{\rho}-\bar{V}_{f}\right] /\left(\bar{V}_{g}-\bar{V}_{f}\right)
$$

where

$$
\begin{aligned}
& \frac{x}{\rho}=\text { Steam quality } \\
& \bar{V}_{f}=\text { Bulk density of two-phase mixture }\left(1 \mathrm{bm} / \mathrm{ft}^{3}\right) \\
& \bar{V}_{\mathrm{g}}=\text { Specific volume of liquid }\left(\mathrm{ft}^{3} / \mathrm{lbm}\right) \\
& \text { Specific volume of vapor }\left(\mathrm{ft}^{3} / \mathrm{lbm}\right)
\end{aligned}
$$

Vibrating densitometer technique is still being evaluated. Its accuracy, reliability and ease of operation are not known at this time.

\section{Gamma Ray Absorption Technique 14}

This steam quality monitoring system operates on the principle of attenuation of gamma rays by matter. The attenuation of gamma rays through a pipe filled with wet steam is related to steam density and ience to the steam quality.

A schematic of the gamma ray steam quality monitoring system is shown in figure 8.3. Steam is passed through a pipe section containing a two-phase mixer, where it is homogenized. Low level gamma ray energy emitted from a gamma ray source is beamed in a precise shape through the walls of the pipe and measured on the other side. The detector (measuring device) is an ionization chamber filled with a pressurized gas. When ionized, a current is generated and sent to the transmitter.

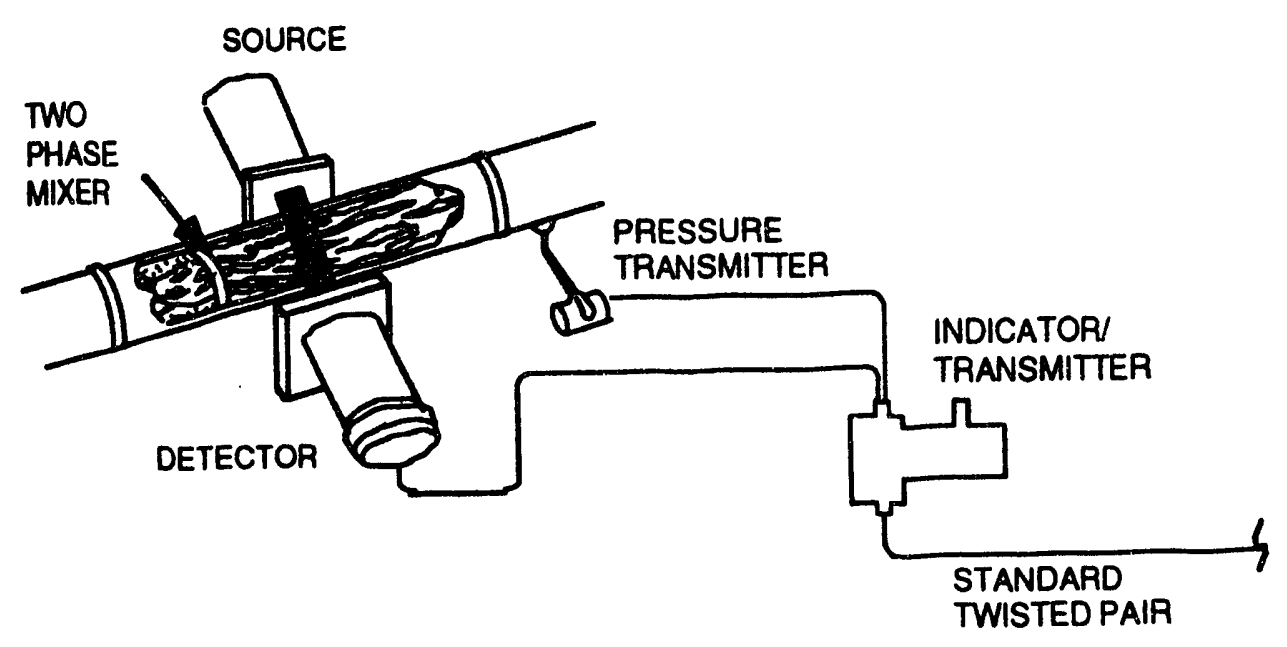

FIGURE 8.3. - Schematic of gamma ray steam quality measurement technique. ${ }^{14}$ 
The gamma steam transmitter calculates steam quality from data supplied by the density sensor and by a downstream pressure transmitter and outputs to an indicator.

To obtain reliable steam quality, the system must be calibrated over a wide range of conditions and the calibrations must be checked periodically. The system is drift prone and hence accuracy suffers.

\section{Neutron Densitometer Steam Quality Measurement System 15,16}

The principle of operating this system is identical to that of the gamma ray steam quality monitoring system. The meter is based on the fact that a beam of thermal neutrons is strongly scattered by hydrogenous material, such as water. The attenuation of a beam of thermal neutrons through a pipe filled with wet steam is related to the average density of the steam-water mixture inside the pipe, and for this reason the system is referred to as a neutron densitometer steam quality measurement system.

The average density of the wet steam $\bar{\rho}$ is related to the gas phase density, $\rho_{g}$, the liquid phase density, $\rho_{1}$, and the void fraction, $\alpha$, by

$$
\bar{\rho}=\alpha \rho_{g}+(1-\alpha) \rho_{1}
$$

The void fraction, $\alpha$, is the volume occupied by the gas-phase in a wet steam mixture. The steam quality, $x$, which is defined as the ratio of the mass flow rate of the gas-phase steam to the mass flow rate of the wet steam, is related to $\alpha$ by

$$
\alpha=\frac{1}{1+\frac{s(1-x)}{x \rho_{1}}}
$$

where $s$ is the slip ratio. The slip ratio is defined as the ratio of average gas-phase velocity to average liquid-phase velocity. Hence, if the slip ratio and pressure are known, the steam quality can be determined from Eqs. 10 and 11. However, the slip ratio, s, depends on pressure, mass flux, steam quality, flow pattern, and orientation of flow. These relationships are not well established and, therefore, calibration of the system over a wide range of conditions must be undertaken. The principle of operation of a neutron densitometer is shown schematically in figure 8.4 .

The neutron densitometer steam quality measurement system is shown schematically in figure 8.5. To measure steam quality accurately, the meter must be calibrated. The system is usually calibrated with the steam pipe empty and with the pipe full of water. Measurement of 

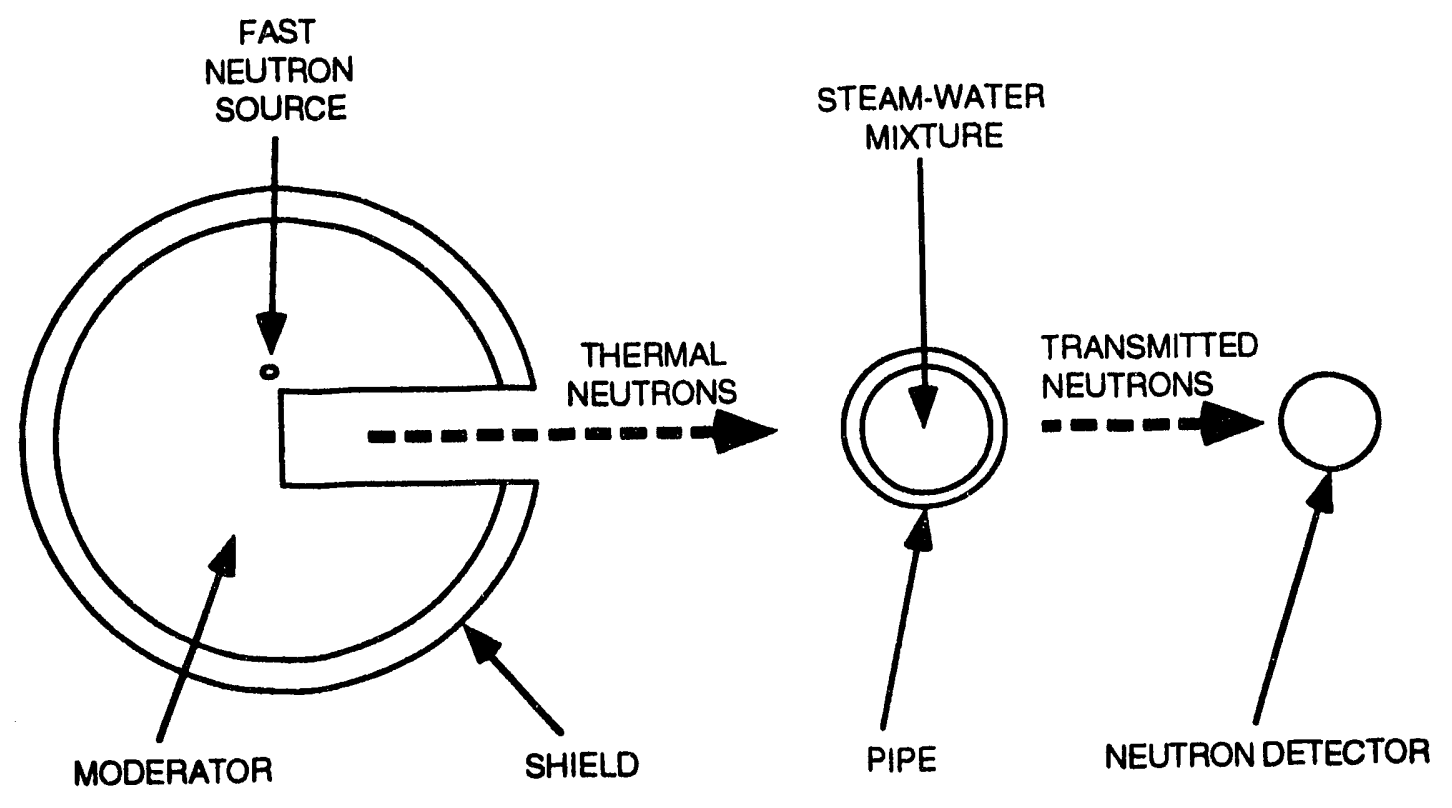

FIGURE 8.4. - Schematic of the principles of operation of a neutron densitometer. ${ }^{15}$

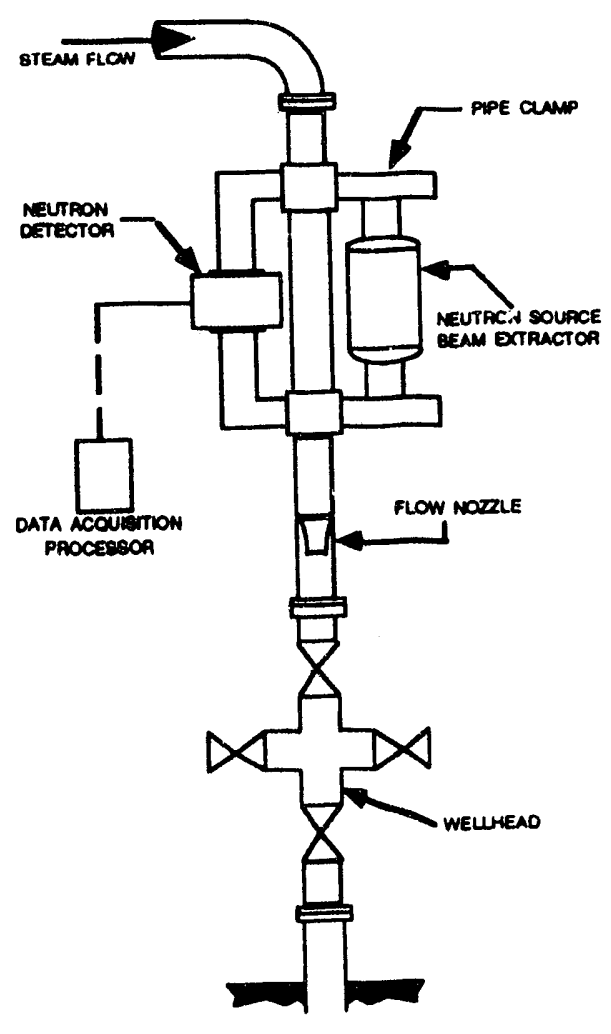

FIGURE 8.5 - Arrangements for steam quality measurement using a neutron densitometer. ${ }^{16}$ 
steam quality also requires knowledge of steam pressure and an approximate mass flow rate. The mass flow rate can be determined by measuring the pressure drop across a flow nozzle. The flowing steam pressure is determined using a pressure transducer. The steam quality is determined using the information provided by the neutron densitometer and flow nozzles. A data acquisition system interfaced with an on-line computer is utilized to calculate and display steam quality, mass flow rate, and enthalpy delivery rate to the well. Further details on the system can be found in references 15 and 16.

The system is still in developmental stage and has been field tested to a limited extent in Canada. No units have been installed to date in the United States.

\section{Downhole Steam Quality Measurement}

To date, no reliable tools or techniques for measuring steam quality at the sandface have been developed. Several downhole steam quality sampler designs have been proposed to collect a representative sample of liquid-phase of steam at any depth in an injection well; $17-18$ however, the collection of a truly representative sample is very difficult and will require an extensive calibration program to ensure accurate measurements. At the present time, sandface steam quality is estimated from wellhead steam quality, steam flow rate, and wellbore heat losses. Special computer programs for the calculation of downhole steam qualities from wellhead qualities are available.

\section{SUMMARY}

Accurate measurement of steam quality in an oilfield environment is both cumbersome and difficult because steam distribution through manifolds, laterals, and tees results in uneven splitting, and no easy way exists to determine steam quality with any degree of confidence. Some of the techniques currently used in oilfields to measure surface steam quality include the orifice plate method, dissolved solids technique, liquid-vapor separator method, enthalpy determination method, and stack gas analysis technique. All of these techniques have limitations and do not lend themselves to continuous, real time measurement of steam quality. Newer techniques, such as those based on the vibration densitometer and thermal neutron densitometer are promising but are expensive and require extensive calibration. No technique is available to measure steam quality at the sandface. At the present time, downhole steam quality is inferred firom wellhead steam quality measurements. A list of vendors that can assist in steam quality measurement are shown in Appendix 8-A.

\section{REFERENCES}

1. Strome, R. K. and D. M. McStravick. Continuous Steam Quality Measurement in a Steam Distribution System Quality Measurement. Presented at the Soc. of Pet. Eng., California Regional Meeting, Ventura, California, Apr. 8-10, 1987. SPE paper 16348. 
2. Hodgkinson, R. J. and A. D. Hugli. Determination of Steam Quality Anywhere in the System. In: D. A. Redford and A. G. Winestock, Eds. The Oil Sands of Canada-Venezuela, CIM Special v. No. 17. The Canadian Institute of Mining and Metallurgy, Edmonton, Alberta, Canada, June 1977, pp. 672-675.

3. Mahon, W. A. J. Sampling of Geothermal Drillhole Discharges. United Nations Conference on New Sources of Energy, Conf. Proceedings, v. 2, 1964, pp. 269-278.

4. Pryor, J. A. Orifice Meter Measures Steam Quality. The Oil \& Cas J., v. 64, No. 22, May 30, 1966, pp. 86-88.

5. Wilson, T. M. Steam Quality and Metering. The Journal of Canadian Pet. Tech., v. 15, No. 2, April-June, 1976, pp. 33-38.

6. Mattar, L. Nicholson, M., K. Aziz, and E. A. Gregory. Orifice Metering of Two-Phase flows. Journal of Pet. Tech., v. 31, No. 8, August 1979, pp. 955-961.

7. Bennett, M. D. and K. Martin. Calibration of a Small Venturimeter for Wet Steam at Low Reynolds Number. Proc. Instn. Mech. Eng., London, v. 184, Pt. 3C, 1970, pp. 151-153.

8. Palm, J. W., W. H. Anderson, and J. W. Kirkpatrick. Determination of Steam Quality Using an Orifice Meter. Pres. at the Soc. of Pet. Eng. 42nd Ann. Fall Meeting, Houston, Texas, Oct. 1-4, 1967. SPE paper 1941..

9. Collins, D. B. and M. Gacesa. Measurement of Steam Quality in Two-Phase Upflow with Venturimeters and Orifice Plates. ASME Transactions, Journal of Basic Engineering, March 1971, pp. 11-21.

10. James, R. Metering of Steam/Water Two-Phase Flow by Sharp-Edged Orifices. Proceedings of the Instn. Mech. Eng., London, v. 180, Pt. 1, No. 23, 1965-1966.

11. Bleakley, W. B. How to Find Steam Quality. The Oil \& Gas J., v. 63, No. 9, Mar. 1, 1965, pp. 76-77.

12. Anderson, J. L., S. E. Falke and D. N. Clum. A Microprocessor Based Steam Generator Quality Controller. Pres. at the Soc. of Pet. Eng. 59th Ann. Tech. Conf. \& Exhib., Houston, Texas, Sept. 16-19, 1984. SPE paper 13022.

13. Jones, J. and R. L. Williams. A Two-Phase Flow-Splitting Device That Works. Pres. at the Soc. of Pet. Eng., International Thermal Operations Syinposium, Bakersfield, California, Feb. 7-8, 1991, SPE paper 21532.

14. Kay-Ray Inc. Steam Quality Measurement System. Tech. Bulletin KR484-789, 1986. Kay-Ray Inc. Division of Rosemont, Mt. Prospect, Illinois 60056.

15. Woiceshyn, G. E., P. S. Yuen, H. John and J. J. Manzano-Ruis. Measurement of Steam Quality, Mass Flow Rate and Enthalpy Delivery Rate Using Combined Neutron Densitometer and Nozzle. Pres. at the Fifth SPE/DOE Symp. on Enhanced Oil Recovery of the Soc. of Pet. Eng., Tulsa, Oklahoma, Apr. 20-23, 1986. SPE/DOE paper 14907.

16. Wan, P. T. Measurement of Steam Quality Using a Neutron Densitometer. Pres. at the Pet. Soc. of CIM and Soc. of Pet. Eng. Joint International Tech. Meeting, Calgary, Canada, June 10-13, 1990. Paper CIM/SPE 90-88. 
17. Fox, R. L. and A. J. Mulac. Downhole Steam Quality Tool. Sandia National Laboratory Internal Report SD-3877, 1980.

18. Mulac, A. J. Summary of Steam Quality Measurement Program at Sandia National Laboratories. Paper pres. at the U.S. DOEJINTEVEP Joint meeting, Caracas, Venezuela, January 1981. 


\section{APPENDIX 8-A}

\section{STEAM OUALITY MEASUREMENT SYSTEM VENDORS}

A. Steam Quality Measurement System

1. Kay-Ray/Sensall Inc. Division of Rosemont 1400 Business Center Drive Mt. Prospect, IL 60056 Telephone: (708; 803-5100

2. Daniel En-Fab Systems Inc. 3905 Jensen Drive P.O. Box 21361

Houston, TX 77226-1361

Telephone: (713) 225-4913

\section{B. Orifice Plate Vendors}

1. Lambda Square Inc.

P.O. Box 1119

Bay Shore, NY 11706

Telephone: (516) 587-1000

2. Airtrol Components Inc. 17400 W. Library Lane New Berlin, WI 53146-2107

Telephone: (414) 786-1711

3. Metals for Industry Inc. 9800 S. 219th E. Avenue Broken Arrow, OK 74014 Telephone: (918) 455-1778

4. Oil \& Gas Specialities Company

P.O. Box 55306

Houston, TX 77255

Telephone: (713) 686-3444 


\section{CHAPTER 9 \\ THERMAL WELL COMPLETION PRACTICES}

INTRODUCTION

Thermal well completions, while basically the same as those for conventional wells, differ in mechanical aspects. The main difference between completing a steam injection well and a conventional well is the handling of the problems associated with elevated temperatures. High temperatures cause tubular goods in an injection well to expand. If the injection or production of hot fluids is interrupted for some reason such as mechanical failure of a steam generator or a well workover to correct an unexpected downhole problem, the wellbore temperature will fall causing the tubing to contract. The heating and cooling of the tubular goods lead to severe thermal stresses. If these stresses are allowed to exceed the design stress of the tubular goods, casing and tubing failure may result. In addition, the effect of temperature on downhole completion equipment must be considered in equipment selection.

Movement of sand particles into a production wellbore from semiconsolidated or unconsolidated sands, as fluid is produced, can be a major production problem in thermal wells. The sand production mechanism can be extremely complex and is influenced by all completion operations ranging from first bit penetration to the start of production. The problems of sand control in thermal recovery wells are especially troublesome because of high production rates of reservoir fluids that result from the high volume of fluid injected in these processes. The greatest single problem in steam injection operation is that of making lasting, high productivity well completions resistant to erosion and corrosion at elevated temperatures.

Thus, thermal well completions must be designed to withstand elevated temperatures without damaging to wellbore equipment. In brief, the severe service seen by thermal wells calls for specific thermal completion designs. This chapter describes and recommends certain well completion practices currently used in the industry.

Provided in Appendix 9-A is a list of vendors that deal in thermal weli completion tools and services. This list is not intended to be the recommended vendors; it is included here so that a prospective operator can contact these or other vendors for adcisional information.

\section{CASING DESIGN}

\section{Temperature Effects on Casings and Tubings}

Steam operations impose severe stress on casing. Casing tends to elongate when heated. In shallow wells, casing seldom fails if it has been cemented back to the surface and if the steam temperature and pressures are low during injection. However, many casing string failures have been reported in wells deeper than $1,500 \mathrm{ft}$, under temperatures of $400^{\circ}$ to $650^{\circ} \mathrm{F}$ and pressures of 
250 to 3,200 psi. Most of these failures have occurred at the couplings. ${ }^{1}$ Examination of failed casings show extensive compression damage to the joints in the form of telescoping or buckling to the point of collapse or breaking. ${ }^{1}$

It is important that the temperatures effect on the yield strength, ultimate tensile strength, and modulus of elasticity of casing materials be considered prior to preparing specifications for casing. Quantitatively, casing will expand or contract with temperature changes in an amount determined by the following expression,

$$
\Delta \mathrm{L}=\alpha \Delta \mathrm{TL}
$$

$\alpha=$ coefficient of linear expansion per degree $\mathrm{F}$

$\Delta \mathrm{L}=$ linear expansion, $\mathrm{ft}$

$\Delta \mathrm{T}=$ change in temperature, ${ }^{\circ} \mathrm{F}$

$\mathrm{L}=$ length of the casing, $\mathrm{ft}$.

An excellent rule of thumb is that the unstressed casing will elongate 0.83 inch per $100 \mathrm{ft}$ of length per $100^{\circ} \mathrm{F}$ increase in temperature. Thus, a $2,000-\mathrm{ft}$ tubing string subjected to a $500^{\circ} \mathrm{F}$ temperature will elongate about 83 in. or almost $7 \mathrm{ft}$. The casing will also contract during a cooling period.

If the shoe of the casing is cemented and the top is free to expand. the casing will expand out of the ground, thus relieving casing stress. If the casing is not free and the top is securely fastened at the bradenhead, changes in temperature will set up thermal stress in the casing. This stress will result in the slackening of the tension generally transmitted and concentrated in the lowermost free section of the string in the form of compression buckling. ${ }^{2}$ A good rule of thumb for estimating thermal compressive forces in tubular goods is that the compression changes by about 207 psi per ${ }^{\circ} \mathrm{F}$ change in temperature. ${ }^{3}$

Thermal stress, if it exceeds the elastic limit of the tubular goods, will cause both tubing and casing to buckle helically, like a coil of spring. The magnitude of the stress depends largely on the moment of inertia of the pipe and the radial clearance between pipe wall and any straightening suppist. ${ }^{3}$ The support structure for casing is the open hole; for tubing, the supporting structure is the casing. In all but very shallow wells, hole deviations and formation sloughing will cause compressive stresses to build up at intermittent joints and may cause heated casing and tubing to fail.

An obvious way to avoid compressive casing failure is to ensure that the compressive stresses do not exceed the yield strength of the casing material. In new wells, this can be achieved by employing an appropriate grade of casing; by cementing the casing under tension; and by controlling casing temperature through the use of thermal packers. 


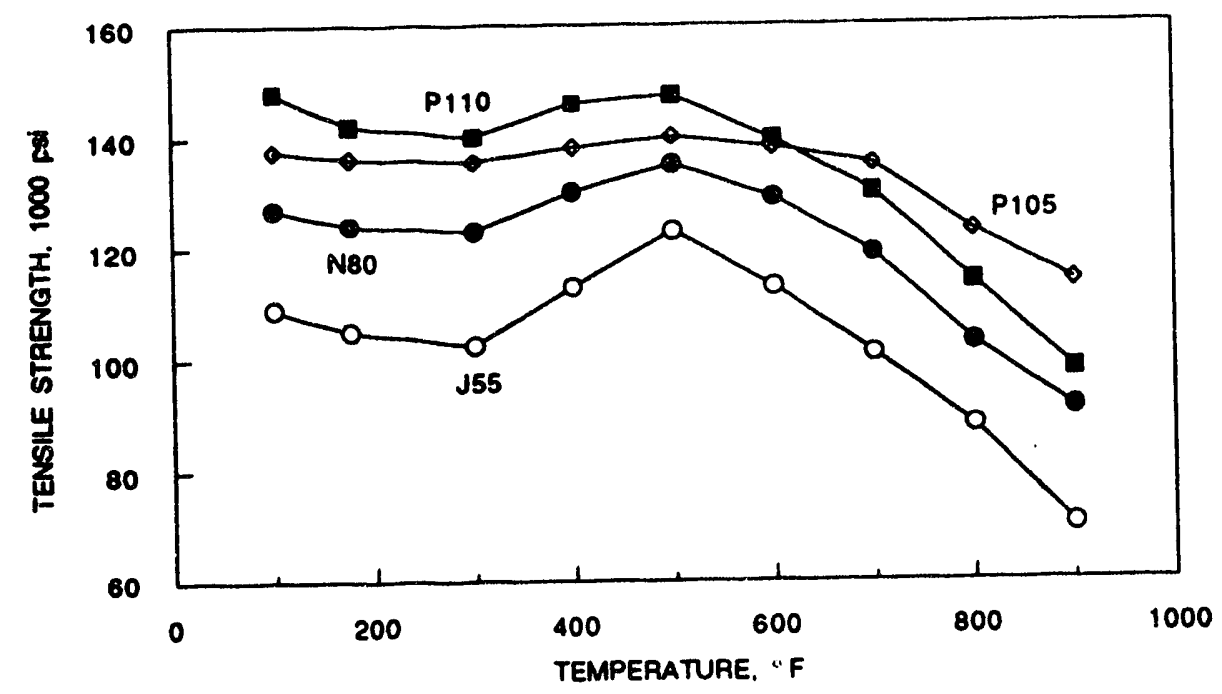

FIGURE 9.1. - Tensile strength of casing versus temperature. ${ }^{4}$

Gates $^{4}$ and Willhite 5 discussed in detail the nature of casing stress failure. Both Gates and Willhite propose that casing failure can be avoided by selecting a casing strong enough to avoid yielding in compression at the maximum expected temperature. Holliday ${ }^{6}$ noting that the tensile strength of steel is at a maximum of $500^{\circ} \mathrm{F}$ (see figure 9.1) proposes that one need not be unduly concerned about casing stress exceeding its yield point at steam temperature. However, casing strength must be high enough to avoid tension failure upon subsequent cooling. A review of reported casing failure indicates that casings generally fail in tension, than in compression. ${ }^{7}$ Hence, compressive casing stresses are normally tolerable. Holliday's criteria permit much higher allowable casing temperatures and steam pressures than those of Willhite or Gates. The recommended maximum casing temperature for various grades of casing reported by these authors are shown in table 9.1

TABLE 9.1 - Recommended operating temperature range for thermal well tubular goods

\begin{tabular}{lccc}
\hline \multicolumn{1}{c}{ Casing } & \multicolumn{3}{c}{ Permissible surtiace steam temperature. ${ }^{\circ} \mathrm{F}$} \\
\cline { 2 - 4 } (API Grade) & Willhite & Gates & Holliday \\
\hline H-40 $270-300$ & $270-330$ & 350 & 450 \\
J-55 & $240-275$ & $350-410$ & 595 \\
N-80 $350-400$ & $470-580$ & $620-7.30$ & 750 \\
P-110 &.-- & & 450 \\
\hline
\end{tabular}


Table 9.2 lists physical properties of four grades of seamless tubing and casing at various temperatures. ${ }^{4}$ The ultimate tensile strength of these steels decreases slightly up to $300^{\circ} \mathrm{F}$, increases to a maximum at $500^{\circ} \mathrm{F}$, then rapidly decreases with temperature as shown in figure 9.1. The yield strengths and elastic limits are shown as function of temperature in figures 9.2 and 9.3, respectively.

In some shallow reservoirs, steam is injected directly down the casing. These wells are usually less than $600 \mathrm{ft}$ deep, so the steam temperatures are low and casing failure is unlikely. In deep wells, steam is rarely injected down the casing. The probability of casing failure in deep wells is much higher due to higher steam temperatures and pressures. In deep steam injection

TABLE 9.2. - Tensile properties of various grades of seamless casing and tubing 4

\begin{tabular}{|c|c|c|c|c|c|c|c|c|}
\hline \multirow[b]{2}{*}{ Grade } & \multirow[b]{2}{*}{ Condition } & \multirow[b]{2}{*}{$\begin{array}{c}\text { Outside } \\
\text { diameter, } \\
\text { in. }\end{array}$} & \multirow[b]{2}{*}{$\begin{array}{l}\text { Wall. } \\
\text { thickness } \\
\text { in. }\end{array}$} & \multirow{2}{*}{$\begin{array}{c}\text { Tensile } \\
\text { test } \\
\text { temp.. } \\
\text { of }\end{array}$} & \multicolumn{3}{|c|}{ Tensile Properties ${ }^{1}$} & \multirow{2}{*}{$\begin{array}{c}\text { Sodulus } \\
\text { of } \\
\text { elasticity } \\
1,000 \mathrm{psi}\end{array}$} \\
\hline & & & & & $\begin{array}{c}\text { Yield } \\
\text { strength, } \\
\text { psi }\end{array}$ & $\begin{array}{c}\text { Tensile } \\
\text { strength. } \\
\text { psi }\end{array}$ & $\begin{array}{c}\text { Elastic } \\
\text { limit. } \\
\text { psi }\end{array}$ & \\
\hline J55 & $\begin{array}{l}\text { Hot } \\
\text { rolled }\end{array}$ & $13-5 / 8$ & 0.313 & $\begin{array}{l}\text { RT } \\
300 \\
500 \\
700 \\
900\end{array}$ & $\begin{array}{l}59.320 \\
55.820 \\
57.870 \\
53.130 \\
44.445\end{array}$ & $\begin{array}{r}107.950 \\
100,040 \\
122.125 \\
98.490 \\
68.030\end{array}$ & $\begin{array}{l}52,350 \\
50,750 \\
42,050 \\
37,925 \\
28,800\end{array}$ & $\begin{array}{l}25,750 \\
24,650 \\
23,800 \\
21,550 \\
24,000\end{array}$ \\
\hline N80 & Normalized & $13-3 / 8$ & 0.500 & $\begin{array}{l}\text { RT } \\
300 \\
500 \\
700 \\
9(0)\end{array}$ & $\begin{array}{l}83.750 \\
80.150 \\
83.970 \\
74.415 \\
62.715\end{array}$ & $\begin{array}{r}124.050 \\
120.675 \\
133.500 \\
116.775 \\
85.000\end{array}$ & $\begin{array}{r}69.550 \\
65.9850 \\
59.850 \\
51.900 \\
40.850\end{array}$ & $\begin{array}{l}27,900 \\
25,400 \\
21.600 \\
16.300 \\
15.700\end{array}$ \\
\hline P105 & $\begin{array}{l}\text { Normalized } \\
\qquad \& \text { tempered }\end{array}$ & $10-7 / 8$ & 0.375 & $\begin{array}{l}\text { RT } \\
300 \\
500 \\
700 \\
900\end{array}$ & $\begin{array}{r}106.800 \\
102.100 \\
104.830 \\
95.900 \\
86.640\end{array}$ & $\begin{array}{l}136.275 \\
131.600 \\
139.100 \\
129.100 \\
107.375\end{array}$ & $\begin{array}{r}78,050 \\
73,500 \\
70,950 \\
678,500 \\
59,500\end{array}$ & $\begin{array}{l}27,600 \\
26,500 \\
26,200 \\
25,200 \\
18,700\end{array}$ \\
\hline P110 & $\begin{array}{l}\text { Quenched } \\
\qquad \& \text { tempered }\end{array}$ & $10-3 / 4$ & 0.547 & $\begin{array}{l}\text { RT } \\
300 \\
500 \\
700 \\
9(1)\end{array}$ & $\begin{array}{r}128.825 \\
114.850 \\
110.025 \\
100.310 \\
78.545\end{array}$ & $\begin{array}{r}145.500 \\
139.100 \\
146.050 \\
124.650 \\
92.145\end{array}$ & $\begin{array}{r}120.200 \\
95,000 \\
86,750 \\
76.800 \\
51.400\end{array}$ & $\begin{array}{l}27,900 \\
27,300 \\
25,500 \\
24,100 \\
19,200\end{array}$ \\
\hline
\end{tabular}

\footnotetext{
${ }^{1}$ Average for two tests.
} 


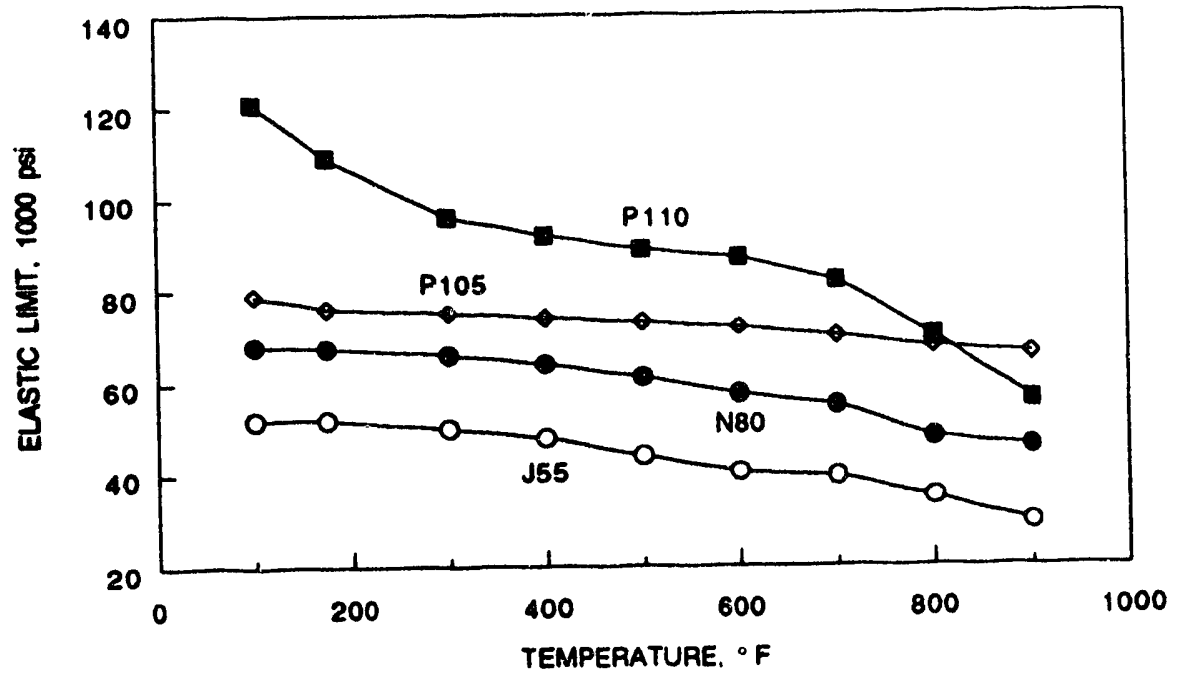

FIGURE 9.2. - Yield strength of casing versus temperature. ${ }^{4}$

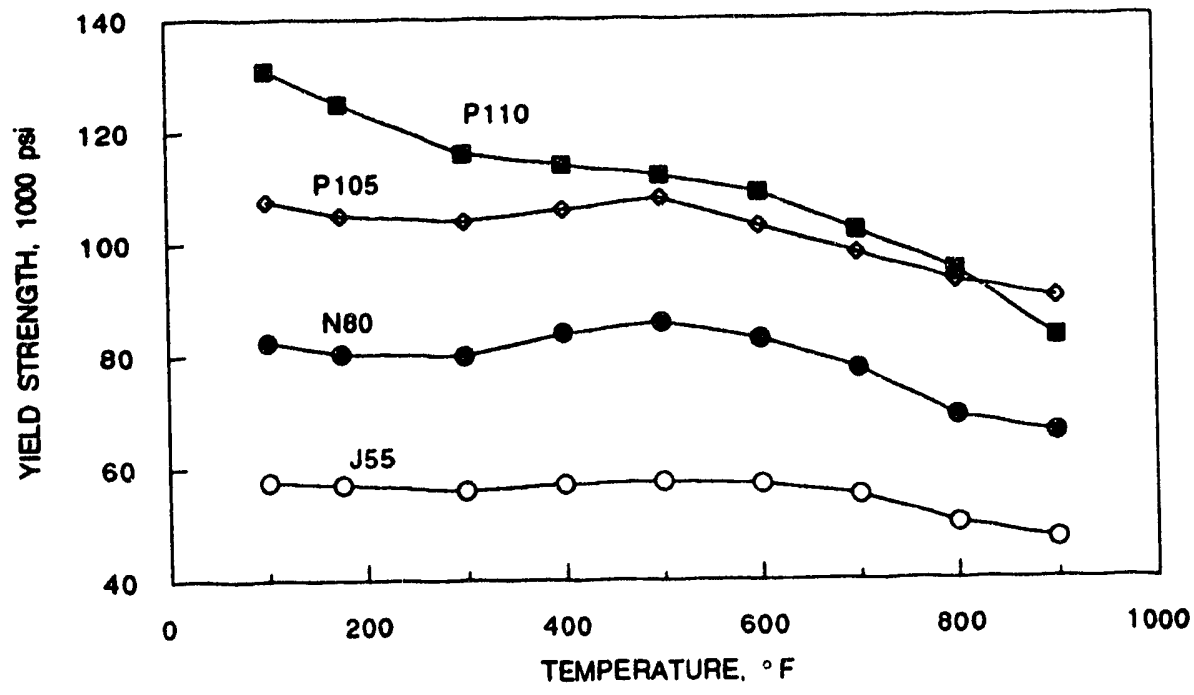

FIGURE 9.3. - Elastic limit of casing versus temperature. ${ }^{4}$ 
wells, steam is rarely, if ever, injected down the casing for the fear of risking casing failure due to thermal stresses. In deep wells, casing temperatures can be maintained below the injected steam temperature by injecting the steam down the tubing and by preventing the steam from entering the tubing-casing annulus through the use of thermal packers. 8

\section{Thermal Well Casing Design}

Design of casing strings for thermal wells requires careful study. Engineers designing steam injection well casings must consider other operator's experience in the area, service company recommendations, the potential cost of any failure, expected cement quality, amount of cycling (for stimulation processes), well life, erosion and corrosion.

To prevent casing failure due to thermal stresses, two criteria must be considered during casing selection:

1. The compressive stress generated by the change in casing temperature should not exceed the yield strength of the casing material.

2. The fiber stress at the maximum casing temperature should not exceed the yield strength of the casing material for reasonable clearances and uncemented intervals.

These criteria can be met through the use of the following techniques:

1. Prestress the casing-prestressing the casing involves placing enough tension on the casing before cementing in order to prevent the casing from exceeding yield strength in compression during steam injection. As casing temperature increases, temperaturegenerated compressive forces relieve the initial tension. Further heating passes the casing through a neutral point and into compression. Prestressing requires a shoe job on the casing to provide an anchor. The casing then needs to be pulled with hydraulic jacks (drilling rigs usually cannot handle the amount of pull required), and then the casing is cemented while in its stressed state.

2. Anchor the casing at the bottom and allow it to move freely-the casing can be anchored at the bottom with a small cennent job. The casing is allowed to rise through a packing gland at the surface. This is the simplest method; $r$ swever, in many cases it is impractical as sloughing of the formation may hinder full movement of the casing.

3. Increase the yield strength of the casing-if complete compensation is not possible, some insulation may be needed between the tubing and casing to keep the casing temperature within limits.

Maruyama et al., on the basis of laboratory studies, recommend heavy weight K-55 casing with premium connection for high-temperature steam injection wells. ${ }^{9}$ Typical California thermal well casing completions are shown in table 9.3. The shallow Califomia thermal wells are generally 
TABLE 9.3. - Typical casing completions in California thermal wells 16

\begin{tabular}{|c|c|c|c|c|c|c|}
\hline \multirow[b]{2}{*}{ Field Operator } & \multirow[b]{2}{*}{$\mathrm{ft}$} & \multirow[b]{2}{*}{$\begin{array}{l}\text { Depth, } \\
\text { psig }\end{array}$} & \multirow{2}{*}{$\begin{array}{l}\text { Max } \\
\text { Pressure. } \\
\text { in. }\end{array}$} & \multicolumn{3}{|c|}{ Casing } \\
\hline & & & & $\begin{array}{c}\text { Diameter } \\
\text { Grade }\end{array}$ & $\begin{array}{l}\text { Type } \\
\text { type }\end{array}$ & Coupling \\
\hline Kern River & Chevron & 700 & 350 & 7.0 & K-55 & STC \\
\hline Midway-Sunset & Chevron & 1,200 & 450 & 7.0 & $K .55$ & STC \\
\hline Mt. Poso & Shell & 1.800 & 600 & $85 / 8$ & K.55 & BUTT \\
\hline San Ardo & Texaco & 2.350 & 800 & $85 / 8$ & $K .55$ & STC \\
\hline Guadalupe & Union & 3,000 & 1.800 & 7.0 & N.80 & BUTT \\
\hline
\end{tabular}

completed using K-55 grade casings with buttress threads and landed in tension. Canadian operators generally use $\mathrm{N}-80$ grade casing because of the higher injection pressures and temperatures. Casing grades should be selected based on expected operating conditions and anticipated thermal stresses. Since most field experience shows that casing failures occur at a coupling, use of buttress or other premium couplings is recommended. However, this will increase the initial costs of completion. In shallow wells, where the operating pressures and temperatures are lower, the standard short threads and couplings (STC) may be used without the risk of failure. Many operators in the shallow Kern River (CA) fields, still uses the less expensive short threads and couplings. Hence, the steam injection completion practice for a given field should be a compromise between the initial completion costs and the cost of risking failure of the well. Engineering judgement plays a large role in arriving at a safe completion design. Since failures usually occur at the joint, the engineer should rate the joint first, apply a safety factor, and then select the casing based on anticipated maximum casing temperature.

Casings are usually landed in tension after prestress to protect the casing from elevated temperature. Studies indicate that a prestressed casing is less subjected to buckling than a conventionally run string. By placing high tensile stress initially, it is possible to absorb a higher temperature increase and still remain below the yield point in compression. ${ }^{10}$ For example, if the safe operating temperature limit for a stress free $\mathrm{N}-80$ casing were set at $500^{\circ} \mathrm{F}$, this limit can be increased by another $100^{\circ} \mathrm{F}$, by stressing the casing. The higher operating temperature allows for higher injection pressure, since the saturated steam pressure increases from 681 psig at $500^{\circ} \mathrm{F}$ to 1,543 psia at $600^{\circ} \mathrm{F}$.

Casings are normally prestressed while cementing. The casing is run and cemented through a shoe with a small volume of quick setting thermal cement. The shoe is anchored to about $200 \mathrm{ft}$ 
to the bottom to facilitate the stretching operation. 10 The rig is moved off and casing jacks stress the casing while the remainder of the cement sets up. In this way, as the casing heats up, it merely relieves the tensile forces already in the structure, and thermal elongation is eliminated.

The amount of prestress is a function of steel grade, coupling strength, mud weight, and collapse resistance. To prevent crushing when the load is distributed over the slip area, the prestressed casing must be landed on a reinforced cellar designed for the load. ${ }^{11}$ In the past, a two-stage cement job was used to stress the casing. Only a few operators currently use this technique. Though the two-stage technique is less expensive (about $\$ 5,000$ per job), the operator risks casing failure when the overburden sloughs in and holds the pipe or when the tail section does not hold. 11

\section{Tubing Strings Consideration}

In steam injection wells, steam is often injected through the tubing to reduce heat losses through the casing and to prevent well failures. Injection of steam through the tubing often results in tubing temperatures approaching steam temperatures and this causes the tubes to elongate. The tubing elongations, together with the relatively large clearances between tubing OD and casing ID, results in thermal conditions that lead to high stress levels in the outer fibers of the tubing strings. 12 Since these stress levels often exceed those of conventional oilfield steel grades, it is obvious that these stresses must not be allowed to develop. Use of tubing expansion joints can relieve the thermal stresses. Tubing expansion joints are installed either at the surface or downhole. Surface installation, especially for deeper wells, is more expensive and involves placement of centralizing guides on the string to improve its columnar characteristics and to avoid friction locks between tubing and casing due to elastic instability. ${ }^{12}$ In most applications, expansion joints are placed at the packer. In many cases, the expansion joint is designed as an integral part of a retrievable packer. The expansion joint seal is subjected to considerable stress because of joint movement. The joint moves considerably when injection starts or when the well cools. Many types of sealing materials are used in the oilfield. Present day expansion joint seals are made of high temperature EPDM rubber reinforced with carbon fibers. These elastomers, though rated to $650^{\circ} \mathrm{F}$, field experience suggests that sealing is likely to fail above $550^{\circ} \mathrm{F}$.

\section{Thermal Well Completion}

After the selection of casing material, drilling and completion of the well should be the next consideration. Steamflood injection and production well drilling and completion programs must be carefully designed and executed properly. Any failures in drilling, underreaming, casing, cementing, or the perforating program could be detrimental to well productivity. Steam injection wells may be completed with or without a packer. Casing size ranges from 5-1/2 to $8-5 / 8$ in. in 
diameter with 7 in. common in deeper wells. California regulation requires a packer in continuous steam injection wells to protect the casing. Expansion joints are needed to accommodate the differential expansion and contraction of the tubing when heated or cooled. Expansion joints are usually placed at the packer. Thermal packers are discussed more fully in a later section. This section describes certain thermal well completion practices used in the industry. It should be noted, however, that well completion practices for steam injection can and do vary from field to field and operator to operator in specifics, depending on the circumstances, and no generalization is possible. Examples of typical steam injection, production, and observation well completion features are shown in figures 9.4, 9.5 and 9.6, respectively. The discussions in the following section, however, are generic in nature and should be of assistance to the engineer designing a thermal well completion program.

\section{Drilling Fluids}

Both productivity and injectivity can be adversely affected by washouts through the production interval and by reduction in permeability due to fresh water invasion into the formation and resultant swelling of water sensitive clays. Drilling fluids, therefore, have to be inhibited against clay hydration, generally with 1 to $10 \%$ brine or $\mathrm{KCl}$ solutions and/or other clay stabilizing compounds, such as hydroxy-aluminum.

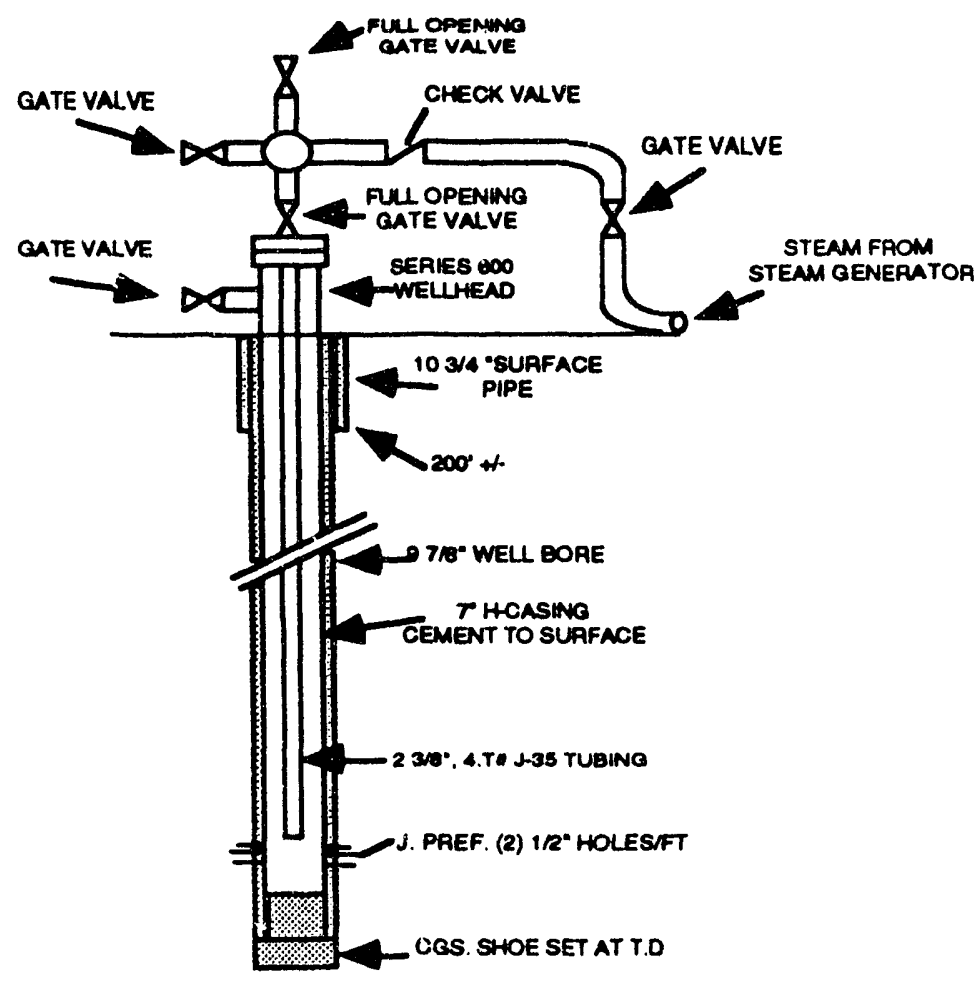

FIGURE 9.4. - Schematic of a typical steam injection well completion. 


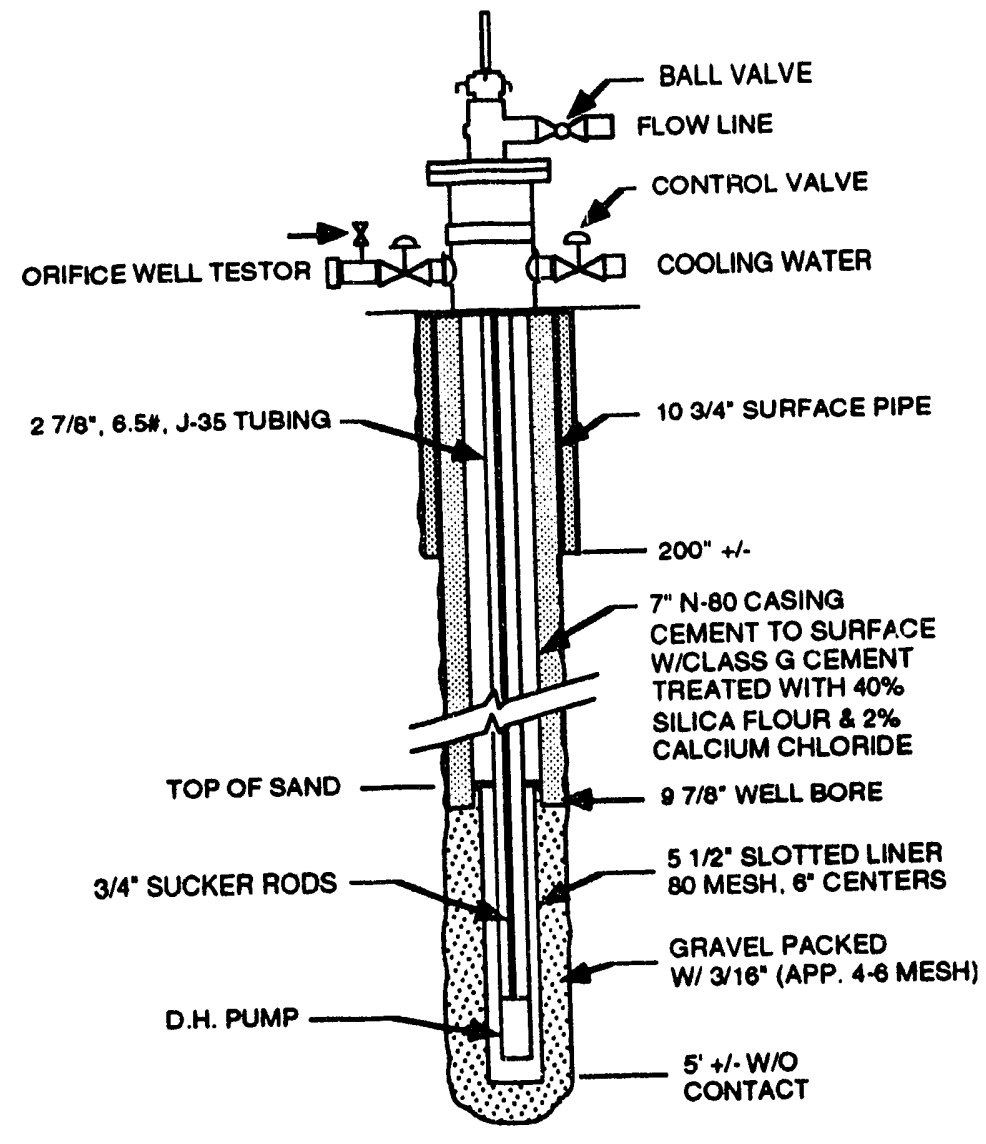

FIGURE 9.5. - Schematic of a typical steamflood production well completion.

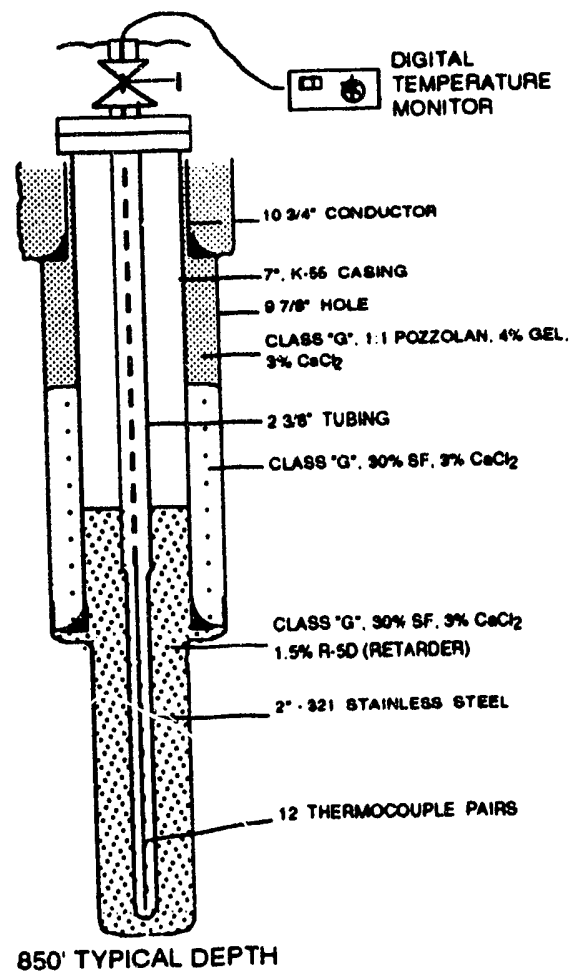

FIGURE 9.6. - Schematic of a typical steamflood observation well completion. 


\section{Cementing}

Poor cementing techniques could cause channeling and may contribute to excessive water or gas production in certain wells. Formation damage from cement particle invasion into the production zone could be a severe problem in certain enhanced recovery wells. For this reason, open-hole completions or a cement "puddling" technique, designed to minimize column height or head while cementing casing through the production zone, is sometimes recommended. In most areas, casing is set through and cemented with high silica flour cement. For an open-hole completion operation, the well is drilled to gauge to the top of the producing formation and then cemented in accordance with the best available cementing practices; i.e., the cement should possess low-fluid loss, and the casing string should be centralized, equipped with scratchers, and rotated or reciprocated during the cementing operation. A high-silica flour cement is recommended for all zones experiencing high temperature.

During the cement "puddling" operation, cement with proper water loss and setting time additives is spotted in open hole through the production interval while pumping through the drill string equipped with scratchers. The drill string is usually rotated and withdrawn slowly through the production zone during the cementing operation to remove, or scratch, mud cake from the side of the wellbore and to prevent the formation of pickets of mud in the cement. After the cement has been "puddled in," the drill string is removed from the well; centralized casing is run to the top of the cement posl and then slowly through the cement to the bottom of the well. The cement is then permitted to set prior to perforating. Thermal well cementing practices are discussed in more detail in chapter 10.

\section{Perforating}

Jet perforating is a piercing and pulverizing process that creates a flow path through the casing, cement sheath, and into the formation. However, cement, copper, lead and carbon from the jet charge can penetrate and mix with crushed formation material. sometimes causing significant perforation damage and restrictions on productivity and injectivity.

Perforations should be gravel packed with properly sized sand to prevent the "tunnel" from being filled with formation fines when the well is placed on production. If gravel is not sized properly, sand will enter the perforated area. become trapped in the gravel, and cause a prohibitively high pressure drop across the perforations.

Completion fluids flowing across the interval at the time of casing perforation should be free of solids because they can be driven into the perforation by the force of the charge. Perforation debris removal methods include underbalance, backflow, perforation washing, acid stimulation, and swz ${ }^{2}$ bing. Underbalance, backflow, and perforation washing, for the most part, are effective remedial measures, but are not always $100 \%$ successful. Acid stimulation under certain conditions could be responsible for reduced permeability and compressive strength of the formation, 
sometimes resulting in abnormal production decline shortly after treatment. Swabbing is undesirable in soft formations because of excessive sand removal and the uncertainty that all perforations have been properly cleaned.

\section{Well Completion and Workover Fluids}

Colloids, brine, and bridging solids impart effective fluid loss control, excellent suspension properties, and low friction loss to well completion and workover fluids. These colloids generally consist of calcium lignosulfonate, hydroxyethyl cellulose and other polymers. In addition, special fluids, such as oil base, inverted emulsion, and chalk emulsion systems have been used successfully to protect sensitive clay bearing formations from fresh water. The chalk emulsion is actually a water-in-oil emulsion containing acid-soluble bridging and weighting materials which have been stabilized by finely divided acid-soluble chalk solids.

In many shallow low-pressure reservoirs in California, a stable preformed foam has replaced mud, oil, and water as a circulating medium in well completion and remedial operations. The foam, with a density as low as $0.3 \mathrm{ppg}$, is preformed at the surface to a consistency of aerosol shaving cream by blending detergent, fresh or salt water, compressed air or gas, and sometimes other special additives such as surfactants. The foam has been used in California wells to core the completion interval; stabilize severe sanding and shale sloughing problems; retrieve open-hole liners; complete old, low pressure wells by drilling in new liners; and recover sanded-up equipment and cement liners in lost circulation zones. Advantages include low hydrostatic head, elimination of formation damage, high carrying capacity for cuttings removal, low circulation pressures, and simple installation.

\section{Open-Hole Completion}

Most cyclic steam wells in California are completed open-hole with a slotted liner through the production interval. In open hole completion the casing is set on top of a producing interval. The main advantage of open-hole completion is the increased productivity over that of perforated completions. For example, theoretically it would require tour perfect $1 / 2$-in. diameter holes per $\mathrm{ft}$ to penetrate the casing, cement sheath, and $8 \mathrm{in}$. of the formation to equal open hole productivity. In addition, these openings in unconsolidated sand must be held open by gravel or by chemical consolidation of the surrounding formation. In the following sections, some sand-control methods for open-hole completion are outlined. Sand-control techniques are discussed more fully in chapter 13.

\section{Screens}

Slotted liners, wire wrapped screens and pre-packs, have been used effectively in certain areas to control sand production. However, it is not recommended that the well be permitted to create its own pack around a screen placed across the producing interval. This procedure will generally result in a disturbance of the formation, possibly causing excessive fine sand production 
or plugging before the screen or pack stabilizes. All screens, therefore, should be used in conjunction with gravel packs to retain gravel packing material which, in turn, supports the formation sand.

The all-welded, wrapped-on-pipe screen has the highest flow capacity. Wire and pipe are normally 304 stainless steel, but for extremely corrosive atmospheres special alloys such as Inconel 625 and Incoloy 825 are available. Some laboratory corrosion tests have shown that Inconel 625 has a better high-temperature corrosion and oxidation resistance than Incoloy 825 .

A slot or wire width opening of two times the 10 percentile diameter of the formation sand has been proved effective in areas containing sand with broad size distribution. In areas with relatively uniform sand size, slots equal to the 10-15 percentile formation sand diameter have been used satisfactorily. The self cleaning, keystone type slot or wire opening is recommended over that of parallel sided slots in which particles $1 / 2$ the slot width tend to wedge and plug.

\section{Pre-Packs}

Pre-packs are designed to bridge fine formation sands without the need for gravel packing. They are fabricated with an outer cylinder of either unconsoliduted or resin-consolidated sand which is supported by a slotted mandrel. Since pre-packs necessarily must be somewhat smaller than the wellbore into which they are positioned, the formation may subsequently shift and cause productivity impairment. Pre-packs may plug when (1) the formation contains large quantities of clay, (2) asphaltenes or paraffins are precipitated by viscous, low gravity crude oils, (3) emulsions are formed, and (4) carbonate or sulfate scale is deposited. They offer the following advantages: (1) large surface area for filtering, (2) compatible with most well fluids, (3) high permeability (50 to 100 darcies), (4) high compressive strength $\left(5,000\right.$ psi at 15()$\left.^{\circ} \mathrm{F}\right),(5)$ can be run on a wire line or tubing, and (6) withstand temperatures to $500^{\circ} \mathrm{F}$.

To reduce the chances of formation movement around the pre-pack and the risk of plugging with formation fines or clay, this device should be used in conjunction with underreaming and conventional r consolidated sandpacks.

\section{Open-Hole Gravel Packing}

Open-hole gravel packs should provide higher productivity than inside gravel packs because restrictive casing perforations are eliminated, and the underreamed wellbore improves radial flow into the well. Open-hole gravel packing are preferred over other completion techniques in stratas of clay and shale since the gravel should prevent migration of the shale or clay to the screen and sealing it off.

Gravel packing consists of underreaming the wellbore 6 to $12 \mathrm{in}$. larger than the casing diameter; running and hanging the wire wrapped liners; packing with gravel using a viscous, highgravel concentrated ( $15 \mathrm{lb} / \mathrm{gal}$ ) slurry at low circulation rates to prevent intermixing of the sandpack with formation sand; washing to remove gravel bridges; and then reficking, if necessary. During 
the foregoing operations, a nondamaging completion fluid should be used as suggested earlier. Also, preflushes of clay stabilizing material should be used prior to both underreaming and gravel packing as will be discussed later. In addition, the hole should be enlarged slowly to prevent corkscrewing; a caliper log should always be run in the underreamed hole to determine if sloughing has occurred; and debris should be removed from the well prior to running the liner.

The ratio of gravel size to formation sand size should be estimated from Karpoff's rule which states that gravel size should range from 5 to 10 times the 50 percentile or median formation sand diameter. Sand movement should be properly restrained under these conditions since the gravel pore openings, theoretically, are properly sized relative to the sand particle diameter.

Effectiveness of gravel packs can sometimes be determined by radioactive tracer methods. Gravel packs in open hole injection wells sometimes tend to slump soon after the start of injection, and logging may indicate that repacking is required.

\section{Consolidated Pack}

The consolidated pack is a slurry consisting of a carrier fluid, resin (or other type of bonding agent), coupling agent, sand, and catalyst, which is blended at the surface and pumped behind a liner or in open hole where the resin or bonding agent is permitted to cure. This process is designed to achieve gravel packing and sand consolidation in a single injection step. If a liner is used, any consolidated material remaining in the wellbore is simply drilled out. In most open hole completions, no liner is used and the consolidated pack is redrilled through the entire producing zone with a regular bit. All the same rules and precautions associated with conventional open-hole gravel packing and drilling also apply to this particular technique.

The main advantage of the consolidated pack treatment is that consolidation of the sand is assured in all areas where the sand laden sluiry can be pressure packed. The pack possesses excellent strength (5,000 psi) and permeability (60 darcies) and is stable in most well environments up to $500^{\circ} \mathrm{F}$. The process works well with clay bearing formations, and excess resin can be used to consolidate a portion of the formation behind the pack to stabilize both sand and clay when $q$ special clay stabilized compound, such as Halliburton's Claylok or Claysta, is injected ahead of the resin.

\section{Cased-Hole Completion}

Cased-hole completions in steam injection operations generally are recommended only for injection wells although they may be used for producers under certain circumstances. If it is found that open-hole completion cannot be satisfactorily performed, or is not desired for some reason, then setting the casing with the best cementing technology should be implemented along with the best available well completion, perforating, gravel packing. and/or chemical sand consolidation methods. 
In unconsolidated formatior. the sand immediately behind the perforation must be stabilized, as previously discussed, either with a sandpack or with chemical or artificial consolidation. Another technique is to gravel pack a wire wrapped liner inside and across the perforated interval of the long string of casing.

\section{Clay Stabilization}

Serious reductions in permeability of the formation can occur when clay minerals restrict flow by either expanding to fill the pore volume or dispersing and lodging in restrictions. The expanding force acting on clays is caused by the affinity of exchangeable interlayer cations and surfaces for fresh water. The inherent negative charge on almost all clay minerals is neutralized by adsorption of cations, producing a positive surface charge with a negative inner charge. These clay particles with an eiectric double layer repel each other and, thus, disperse.

Chemicals are now available which stabilize many water-sensitive formations. One such compound, a positively charged hydroxy-aluminum ion which is prepared in the field by reacting aluminum chloride and sodium hydroxide in a high shear device, is absorbed and polymerized on the negatively charged clay mineral surface to form a stabilizing network that prevents further migration. This chemical, Claylok, a trademark of Chevron Research Company, has been successfully used to improve permeability following acid treatments, stabilize formation fines, desensitize clay bearing formations prior to steam injection, and reduce formation damage during perforating and gravel packing. Most field brines and fresh water will not remove the treatment, but mixtures having $\mathrm{pH}$ values below 4 or above 9 will damage its effectiveness.

Halliburton has a process that uses an organic, oil-soluble chemical, trade name SFD-3, to shrink water-swollen clays and then surround them with a hard furan-type resin which increases permeability and stabilizes clay in some dirty formations. Another Halliburton product, Claysta, is organic in nature and stabilizes clay in a manner similar to Claylok, but has the added advantage that it is stable to subsequent acid or caustic treatments.

It appears that these clay stabilizing compounds have possible application in open hole as well as in cased hold completions. Injection of these chemicals prior to underreaming and gravel packing may eliminate or significantly reduce formation damage caused by clay swelling. Incorporating these inhibitive chemicals into the gravel pack slurry, drilling fluid, and/or other completion fluids may also prove to be advantageous. All possibilities should be evaluated in the laboratory before implementation. 


\section{Well Workover Practices}

Treatments for some typical situations are described as follows:

A. Case 1

Assumptions

1. Well has not been previously steamed.

2. Sand production problem.

3. Formation sensitive to fresh water.

General Procedure

1. Bail out and clean up well.

2. Run injectivity test with filtered ( 1 micron) $2 \%$ potassium chloride $(\mathrm{KCl})$ solution. Adequate injectivity should be approximately $2 \mathrm{bbl} / \mathrm{min}$ at no more than $300 \mathrm{psi}$ surface pressure.

3. Run cement bond $\log (\mathrm{CBL})$, temperature $\Delta \mathrm{t}$ and/or spinner survey with $2 \% \mathrm{KCl}$ solution.

4. If formation is not taking fluid uniformly, acidize with $100 \mathrm{gal} / \mathrm{ft} * 15 \%$ hydrochloric acid $(\mathrm{HCl})$, followed by $200 \mathrm{gal} / \mathrm{ft}$ mud acid,** followed by $100 \mathrm{gal} / \mathrm{ft} 3 \% \mathrm{HCl}$, and then followed by $600 \mathrm{gal} / \mathrm{ft} 1 \%$ filtered $\mathrm{KCl}$ solution (spacer between acid and hydroxy aluminum).

5. Inject $5 \mathrm{bbl} / \mathrm{ft}$ hydroxy aluminum.***

6. Run spinner survey or profile to determine if all perforations are taking solution.

7. Overflush with $5 \mathrm{bbl} / \mathrm{ft}$ filtered $1 \% \mathrm{KCl}$ solution.

8. Install injection well wellhead or pumping well wellhead and pumping unit.

9. Shut-in well and age 24 to 48 hours.

10. Start steam injection in injection well or place production well on production.

* Per $\mathrm{ft}$ of perforated interval.

** Mud acid consists of $12 \% \mathrm{HCl}+3 \%$ hydrofloric acid (HF) $+0.3 \%$ inhibitor $+0.3 \%$ surfactant $+0.3 \%$ iron sequesterant $+0.3 \%$ anti-sludging agent (Dowell products)

*** Injected hydroxy aluminium should be 0.3 Molar and, therefore, must be diluted 20 -fold with $1 \% \mathrm{KCl}$ water. Always add $1 \% \mathrm{KCl}$ to concentrate. 


\section{B. Case 2}

\section{Assumption}

1. Well has not been previously steamed.

2. Sand production problems.

3. Formation sensitive to fresh water.

4. Well needs to be gravel packed or re-gravel packed.

\section{General Procedure}

1. Bail out, clean up well, and acidize, if necessary (Steps 1-4 in Case 1).

2. If well is perforated, shoot additional perforations ( 8 shots per $\mathrm{ft}$ ) under $2 \% \mathrm{KCl}$ solution.

3. Install gravel pack in hydroxy aluminum while keeping well full with hydroxy aluminum. Pack fluid should incorporate hydroxy aluminum, or $2 \% \mathrm{KCl}$ solution when possible.

4. If open hole, remove old liner, install new liner, and gravel pack in hydroxy aluminum.

5. Run steps 5-9 in Case 1.

C. Case 3

\section{Assumptions}

1. Well has been previously steamed.

2. Sand production problems

3. Clay and sand migration are problems.

4. Formation sensitive to fresh water.

\section{General Procedure}

1. Bail out and clean up well.

2. Cool well with filtered ( 1 micron) $2 \% \mathrm{KCl}$ solution until temperature of formation around wellbore is less than $200^{\circ} \mathrm{F}{ }^{*}$ Twenty-five barrels of cooling water per perforation is usually a sufficient quantity for cooling.

*Temperatures greater than $200^{\circ} \mathrm{F}$ will cause aluminum chloride to precipitate in formation.

\section{Screening}

Certain preliminary tests should be run in the laboratory to determine which completion technique is most likely to be successful. The following is an outline of proposed tests which should be run for the purpose of designing the best or optimum well completion:

1. Permeability, porosity, and water sensitivity.

2. Clay content and types of clays present, if any. 
3. Grain size distribution - to be used for the proper selection of slotted liner size and/or conventional or consolidated grain size.

4. Effect of steam condensate - permeabilities before and after injection.

5. Fluid penetration studies - determine depth of fluid penetration in core and resultant damage from conventional mud, extremely low water loss mud, invert emulsion, chalk emulsion and fluids containing bridging material of calcium carbonate, and oil soluble resins.

6. Degree of clay or fine sand migration in core samples during fluid or steam injection.

7. Effectiveness of clay stabilizing compounds, such as Claylok, Claysta, and SFD-3-furan resin combination, in native cores.

8. Compatibility of clay stabilizing compounds in presence of and as a part of well completion fluids.

9. Chemical consolidation and compressive strength of consolidated native cores and compare with clean sand chemical consolidation.

\section{Suggested Steam_Injection and Production Well Drilling and Completion \\ Procedures}

In the following section, the drilling and completion procedure followed by a California steam injection operator is outlined. 14 These procedures detail the steps involved in the drilling and completion of steam injection and production wells. These procedures are meant only to be a guide for the engineer in designing such well completions.

\section{Steam Injection Well}

a. Drill the well with "best" low-water loss drilling mud using current drilling practices for that area.

b. Run 2-4 joints (depending on thickness of reservoir) of casing and set the casing with a high-silica flour cement, using centralizers and scratchers, while rotating or reciprocating the casing to remove mud cake and pockets of mud from annulus during the cementing operation. A synthetic lubricant should always be used on threads while making up casing.

c. Plug back well with 20-40 mesh sand and cement plug or standard bridge plug to depth 1-2 $\mathrm{ft}$ below intended perforation.

d. Install BOP. Pressure test casing to 3,000 psi with fresh water.

e. Run neutron, gamma ray, $\mathrm{CCL}$, and other desired well surveys.

f. Run open-ended 2-7/8 in. O.D. EUE tubing, ${ }^{*}$ equipped with casing scraper, to plugback and reverse-circulate well with $10 \mathrm{bbl}$ diesel fuel followed by $2 \%$ caustic and $1 \%$ detergent solution until returns are clean. Displace cleaning solution with fresh 
water followed by $5 \%$ Nitrox** solution. Circulate $1-2$ well volumes. Displace $5 \%$ Nitrox solution with filtered $0.2 \%$ Nitrox solution.

g. Pull tubing and perforate casing with one hole using suitable jet shot (3/4-in. diam. hole and 9-11 in. penetration) at a depth determined from electric log. To prevent flowback of sand in unconsolidated regions, perforating should be done with pressure differential from wellbore into formation. After perforating, keep hole full of $0.2 \%$ Nitrox solution.

h. Run injectivity and pressure fall-off tests with $0.2 \%$ Nitrox solution. Injectivity should be at least 1 BPM at pressure less than fracture pressure. Pressure falloff should be at least $500 \mathrm{psi} / \mathrm{min}$.

i. If injectivity test is unsatisfactory, either reperforate at same depth or clean up existing perforation with mud acid. Before reperforating or using mud acid, however, tag bottom to make certain there is no sand fill. Repeat injectivity and pressure fall-off tests.

j. Repeat steps $g$ to $i$ until adequate injectivity and fall-off are attained.

k. Run 2-7/8-in. O.D. EUE tubing with pup joint(s), crossover, packer, and telescoping union. Space out and set packer to $5 \mathrm{ft}$ above perforation. Packer should be set in special alloy casing no closer than 25 ft from pertoration.

1. Remove BOP and install wellhead.

$\mathrm{m}$. Purge all surface lines and equipment with $5 \%$ and $0.2 \%$ Nitrox solution. Install and pressure test to 3,000 psi all injection lines and Christmas tree.

o. Commence injecting steam.

p. Steam injection will continue over the life of the project at various increased rates, depending on the size of the steamtlood.

* Again, always use synthetic grease while making up tubing.

** Nitrox consists of 2 parts sodium nitrite and 1 part sodium hydroxide.

\section{Production Well}

a. For liner type completions, drill to the top of the producing formation with standard drilling mud using current drilling practices for that area. For "set through" completions, skip steps a, c, and e.

b. Set the casing with standard low-water loss cement, using centralizers and scratchers, while rotating or reciprocating the casing to remove mud cake and pockets of mud from annulus during the cementing operation. 
c. Drill through the production sand with the "best" completion fluid as determined from laboratory screening tests. Clay stabilizing agents should be incorporated into the completion fluid, if needed.

d. If required, inject clay stabilizer through entire production interval.

e. Underream formation 6-12 in. using "best" completion fluid to circulate out cuttings.

f. Run caliper log and other desired logs with "best" completion fluid.

g. Run properly designed prefaced liner or wire wrapped perforated pipe and perform tailored gravel pack or consolidation pack with clay stabilized completion fluid, or

h. Perform properly tailored open hole consolidation pack with clay stabilized completion fluid. Permit bonding agent to cure sufficiently, and drill through with standard bit, using best completion fluid. A slotted liner used only to properly guide the bit could be incorporated into this process.

i. Lower tubing to bottom and reverse circulate, and clean with $4 \% \mathrm{KCl}$ solution.

j. Set retrievable bridge plug, install steam quality expansion type casing head, install BOP, and recover bridge plug. In place of expansion type casing head, a telescoping union or expansion joint could be run above packer if packer is used. If no packer is used, no expansion joints are required; however, downhole cooling may be required during production of hot well fluids.

k. Run 2-7/8-in. O.D. tubing, packer (if required), 2 joints special alloy tubing, expansion joint (if required), and seating nipple.

1. If packer is used, space out to set packer inside special alloy casing at least $20 \mathrm{ft}$ above pay zone, gravel pack, or consolidated pack. If no packer is used, position bottom of tubing at top of pay. Tubing should be lined with straight phenolic coating. All materials below packer and including packer should be fabricated from special alloy material. If no packer is used, the bottom 8 joints of tubing should be special alloy.

m. If packer is used, displace annulus fluid with salt water containing 80-100 ppm cobalt catalyzed sodium sulfide oxygen scavenger and Tretolite $\mathrm{KW} 12$ or Visco 938 film coating chemical at $0.5 \%$ by volume.

n. Set packer, remove BOP and install wellhead.

o. Run rods and pump with coupon rack on bottom.

p. Test well. When it is evident that well will flow, recover rods, pump, and coupon rack.

q. Set coupon rack in seating nipple and swab well if necessary.

r. After well has cleaned up and stabilizes, conduct static BHP and BHT surveys. 


\section{DOWNHOLE EQUIPMENT}

After successful drilling and completion of the wells, the next important step is to install a set of downhole equipment to minimize thermal stresses on casing and improve steamflood (stimulation) efficiency. Downhole equipment includes thermal packers and expansion joint and steam deflectors.

\section{Thermal Packers}

The injection tubing string should be equipped with a thermal packer. The thermal packer provides a seal between the injection tubing and the inside of the casing, closing the annulus to steam injection. In the case of an open hole completion, packers seal against the formation. Use of packer with an expansion joint will: (1) reduce thermal stress, (2) reduce primary cement failures, (3) reduce wellbore heat loss to the casing and formation, and (4) prevent the casing from bursting if injection pressures become too high. A thermal packer will normally reduce the average temperature of the casing and cement sheath by approximately $120^{\circ} \mathrm{F}$ and reduce thermal stress by approximately 20,000 psi. To obtain the full benefits of the packer, the annulus must be vented early in the heating period to remove any steam formed by evaporating water in the annulus. Not all steam injection wells are completed with thermal packers. Many cyclic steam injection wells and a few steamflood injectors in California are completed without packer to reduce well servicing and workover costs. These are discussed in a later section.

Packer selection for thermal recovery wells is primarily a problem of selecting retrievable or permanent equipment. This decision is influenced by such considerations as pilot or large scale flood, soak, or drive etc. Whenever long periods of uninterrupted injection are planned, permanent completion is preferred. Retrievable packers are the preferred choice if long interruptions of the injection well are anticipated, so that the packer is available for use in another well.

Retrievable thermal packers come in either single or double grip models. Single grip models are used for steam injection below the packer and are usually tension set. This way pressire from below tends to further set the packer. Double grip packers are used for pressure control above and below the packer. Many thermal well retrievable packers come with an integral expansion joint. Thermal packers come in a variety of sizes to fit casing from 4-1/2 to 13-3/8 in. OD, and most are designed with an operating limit of 2,100 psia and $640^{\circ} \mathrm{F}$.

Packers should be located as high as possible in the well to permit downward tubing expansion, but close enough to the formation to confine the steam coming from the tubing. Typical retrievable and permanent packer locations for steam injection wells are shown in figure 9.7.13 Packer installation for a multiple zone steam injection well is shown in figure 9.8.13 


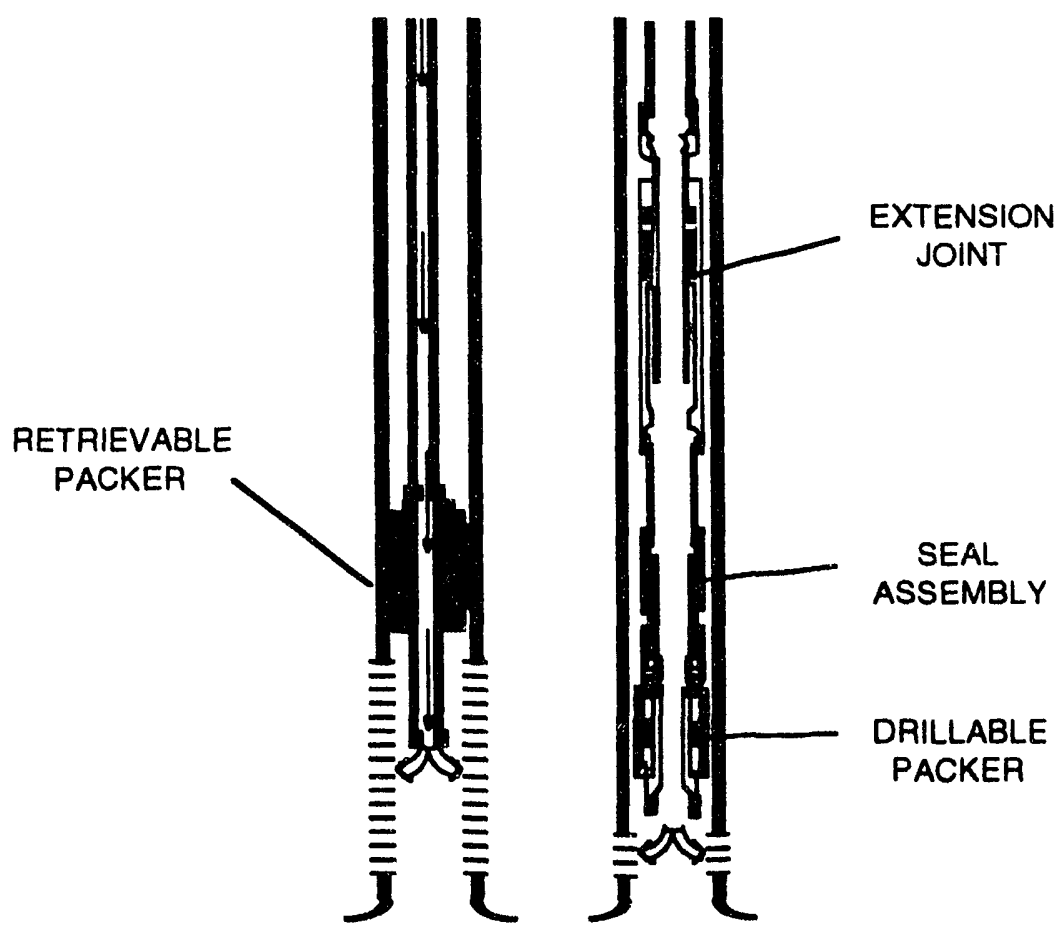

FIGURE 9.7. - Schematic showing retrievable and permanent packer position in steam injection well. 13

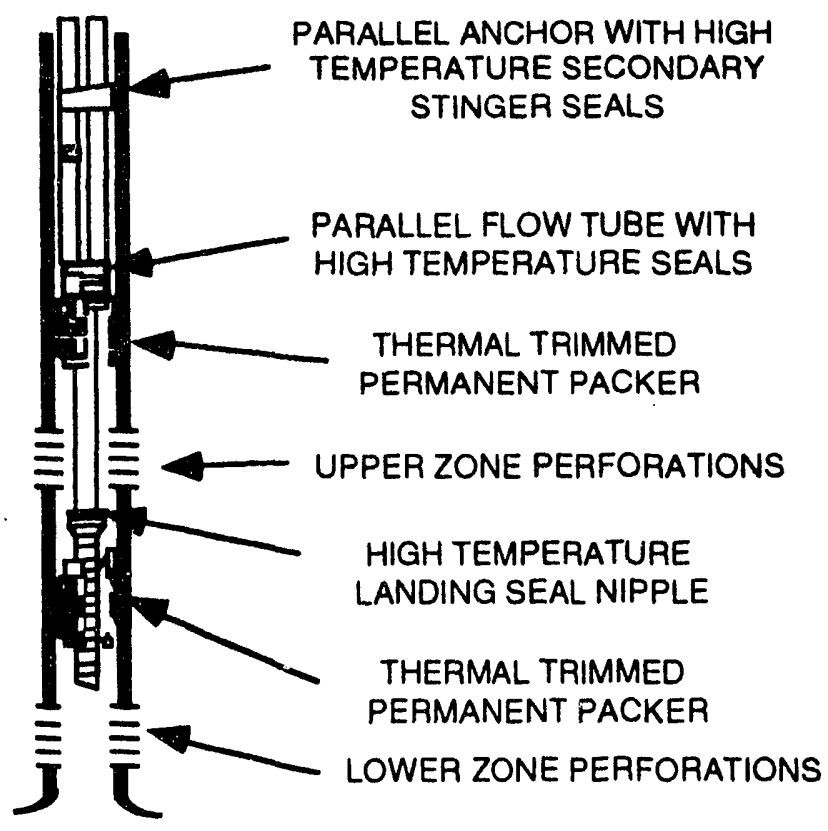

FIGURE 9.8. - Schematic detailing packer installation for multizone completion. 13 
The performance of a packer tubing system plays a major role in the success of any steam injection project. Continued high injection rates without excessive heat losses are necessary for efficient utilization of injected heat and sustained oil production. In this respect, packer plays a crucial role in the economic success of the project. This is because: (a) The cost of replacing failed wells, packers and tubing is high in terms of capital and lost production; (b) The price of a packertubing system is large and it must provide sufficient increased earnings or savings to justify their installation; and (c) The selected packer should be able to lower the wellbore heat losses (and they usually do). The cost of heat loss can be high in terms of operating costs, if steam costs (fuel, water, labor) are high, or oil production, if steam generating capacity is restricted.

Packers do fail-packer failures in high pressure injection wells (pressure $>700 \mathrm{psi}$, temperature $>500^{\circ} \mathrm{F}$ ) are generally caused by expansion joint assembly failure (seal failures).

Details of a packer system used by a California thermal EOR operator to alleviate the casing stress problems associated with high pressure steam injection $\left(1,400 \mathrm{psi}\right.$ and $\left.588^{\circ} \mathrm{F}\right)$ in shallow wells (less than 3,000 ft) are shown in figure 9.9.14 The major components of the system are a

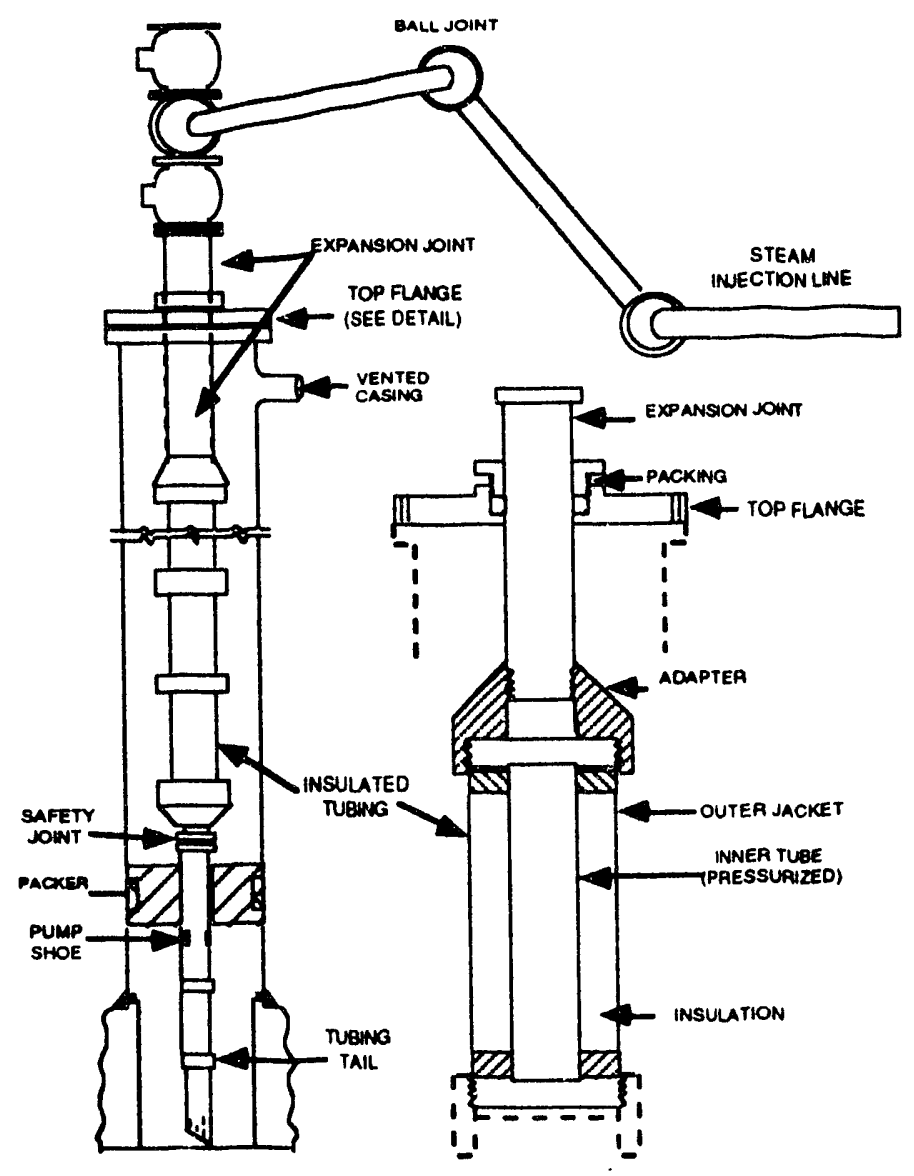

FIGURE 9.9. - High-pressure steum injection well packer details. ${ }^{14}$ 
locking type compression set packer, insulated tubing, and a surface expansion joint. Use of custom packers such as this and those offered by major packer vendors (Guiberson-Dresser and Otis) have practically elininated the well failures.

The most common operational problem associated with the packers include leakage or sticking of packers and thermal expansion joints. These problems can be minimized by carefully running and setting the packers. Sufficient slip area must be provided; Otherwise, danger of ruining the casing exists when high pressures are applied 15

\section{Packer Installation}

The reliability of a thermal packer can be enhanced and costly workovers avoided, if certain precautions are followed prior to the packer installation. Gates ${ }^{4}$ advocates the following:

1. Scrape the casing to remove any cement or scale to provide a clean, smooth surface on which to set the packer.

2. Displace fluid in the hole below the packer setting depth by bailing or by dumping water down the annulus. To obtain the full benefits of the packer, the annulus must be vented during the early heating so as to remove any steam which occurs by evaporation of water in the annulus.

3. Provisions must be made for the expansion and contraction of the tubing.

\section{Seal Systems}

One of the keys to successful steam injection operation is the ability to seal against high pressure, high temperature steam. Downhole sealing points include (1) casing to open hole; (2) tubing to casing annulus; (3) packer to casing, and (4) tubing to packer.

Casing to open hole and tubing to casing annulus seals involve thread connections. By design, threaded joints on oil country tubular goods will not be pressure tight because of the rootcrest clearance, unless coated with a suitable thread compound. Thread seal reliability depends heavily on the mechanical properties of the fillers used in these compounds. In steam injection applications, special high temperature sealing compounds with nonmetallic fillers must be used to prevent leakage. Present day thermal well thread sealing compounds, though expensive (about $\$ 8.00$ per pound), are highly reliable and contain fillers that retain their physical properties even after long periods of exposure to the steam injection environment. These sealants are rated to $1,200^{\circ} \mathrm{F}$ and employ a blend of copper, molybdenum disulfide, and teflon as the filler material.

Packer to casing and tubing to packer sealing depends on the reliability of elastomers used in the thermal packers. Present day packer sealing elements are fabricated out of EPDM elastomers with carbon fiber reinforcements. Though packer vendors rate these seals to about 60()$^{\circ} \mathrm{F}$ and $3,000 \mathrm{psi}$, field experience indicates these seals usually fail at temperatures above $525^{\circ} \mathrm{F}$. Hence, before selecting a particular packer, its temperature and pressure limitations must be investigated. 


\section{Packerless Completion}

Thermal packers are expensive and cost several thousand dollars; and, as pointed out previously, their use must be justified in terms of increased earnings or savings. In the United States, most steam injection wells are shallow and heat losses in such wells are small (less than 5\% at high injection rate). Further, the use of packers in wells increases the well servicing and workover costs. Also, the relatively shallow depths do not provide sufficient hold down weights for conventional weight set packers. Thermal expansion (and contraction) of the tubing preclude the use of packers set in tension. For these reasons most shallow cyclic wells in California are completed without a packer. California regulations, however, require a packer in continuous steam injection wells to protect the casing.

\section{SUMMARY}

Steamflood injection and production well completion practices, while basically the same as those used for conventional waterflood injection and production wells, differ in mechanical aspects related to the heat factor. Thermal well completions are more expensive but are necessary to avoid failures due to the stress caused by steam injection temperatures. A carefully engineered well completion program for steam injection may make the difference between economic success and failure of a seemingly attractive project. Downhole mechanical problems and excessive heat loss can be minimized if the well completion is given as much technical consideration as the surface equipment.

Thermal production well completion practices are similar to those of injection wells from a tubing and casing consideration. The primary factor in selecting casing size is the size of production equipment to be placed inside the casing. In the United States, most production wells are completed open-hole with a slotted liner through the production interval. Careful consideration should be given in selecting thermal packers, and temperature and pressure limitations of the packer should be investigated.

\section{REFERENCES}

1. Nelson, C. G. Program is Designed to Analyze Casing Buckling in Thermal Recovery. Oil \& Gas J., v. 73, No. 49, Dec. 8, 1975, pp. 79-82.

2. Holmquist, D. E. Prestressed Casing Tolerates High BHT's. World Oil, v. 173, No. 6, November 1971, pp. 80-82.

3. Humphrey, H. C. Casing Failures Caused by Thermal Expansion. World Oil, v. 151, No. 6, November 1960, pp. 105-108.

4. Gates, C. F, and B. G. Holmes. Thermal Well Completions and Operation. Proceedings of Seventh World Petroleum Congress, Mexico City, 1967, pp. 419-429. 
5. Willhite, G. P. and W. K. Dietrich. Design Criteria For Completion of Steam Injection Wells. J. Pet. Tech. v. 19, No. 1, January 1967, pp. 15-21.

6. Holliday, G. H. Calculation of Allowable Maximum Casing Temperature to Prevent Tension Failures in Thermal Wells. Pres. at the ASME Petroleum Mechanical Engineering Conference, Tulsa, Oklahoma. Sept. 21-25, 1969. Paper 69-PET-10.

7. Prats, M. Thermal Recovery. Soc. of Pet. Eng.. Monograph No. 7, Soc. of Pet Eng., Dallas, 1982, p. 142.

8. Bleakley, W. B. The Hardware of Steam Injections. Producers Monthly, v. 29, No. 8, August 1965, pp. 2-27.

9. Maruyama, K., E. Tsuru, M. Ogasawara, Y. Inoue and E. J. Peters. An Experimental Study of Casing Performance Under Thermal Recovery Conditions. Pres. at the Soc. of Pet. Eng., California Regional Meeting, Bakersfield, California, Apr. 5-7, 1989. SPE paper 18776.

10. Dietrich, W. K. and G. P. Willhite. What Conoco Learned From Steam Stimulating Deep Wells. World Oil, v. 162, No. 7, June 1966, pp. 107-114.

11. Dietrich, W. K. and G. P. Willhite. Solving Cat Canyon Casing Problems. Pet. Eng., v. 39, No. 9, August 1967, pp. 55-61.

12. Leutwyler, K. and H. L. Bigelow. Temperature Effects on Subsurface Equipment in Steam Injection Systems. J. Pet. Tech., v. 17, No. I, January 1965, pp. 93-101.

13. Thermal Recovery. Guiberson-Dresser Technical Bulletin 5337, GuibersonDresser, Houston, Texas.

14. J. Mondragon. Union Pacific Resources. Welmington, California. Personnel Communication, April 1991.

15. Leutwyler, K. How Temperalure Affects Thermal Well Completions. Pet. Eng., v. 36 , No. 12 , November 1964 , pp. 84-89.

16. Chu, C. State-of-the-Art Review of Steamflood Field Projects. Pres. at the Soc. of Pet. Eng. California Regional Meeting, Ventura, CA, Mar. 23-25, 1983. SPE paper 11733. 


\section{THERMAL WELL COMPLETION TOOLS AND ACCESSORIES SUPPLIERS}

A. Casings and Tubings

1. Kilsby-Roberts

P.O. Box 9500

Brea, CA 92622

Telephone: (714) 579-8823

2. Trico Industries Inc. 15707 S. Main Street

Gardena, CA 90247

Telephone: (213) 516-5000

3. Hydril Company

P.O. Box 60458

Houston, TX 77205-0458

Telephone: (713) 449-2000

B. Subsurface Flow Control Equipment (Landing Nipples, Lock Mandrels, etc.)

1. Hydril Company

P.O. Box 60458

Houston, TX 77205-0458

Telephone: (713) 449-2000

2. Otis Engineering Corporation 2601 Beltline Road

P.O. Box 819052

Dallas, TX 77381-9052

Telephone: (214) 418-3000

C. Thermal Packers and Expansion Joints

1. Guiberson Division

Dresser Industries Inc.

P.O. Box 6504

Houston, TX 77265

Telephone: (713) 750-2301

2. Otis Engineering Corporation

2601 Beltline Road

P.O. Box 819052

Dallas, TX 77381-9052

Telephone: (214) 418-3000

3. Baker Hughes Inc.

3900 Essex Lane, Suite 1200

Houston, TX 77073

Telephone: (713) 439-8600
D. Well Completion and Workover Services

1. Baker Hughes Inc.

3900 Essex Lane, Suite 1200

Houston, TX 77073

Telephone: (713) 439-8600

2. Baker Service Tools

P.O. Box 40129

Houston, TX 77240

Telephone: (713) 466-8600

3. BJ-Titan Services Company 5500 Northwest Central Drive Houston, TX 77210

Telephone: (713) 462-4239

4. Halliburton Services

1015 Bois d' Arc, Drawer 1431

Duncan, OK 73536

Telephone: (405) 251-3760

5. Schlumberger Well Services 5000 Gulf Freeway

P.O. Box 2175

Houston, TX 77252-2175

Telephone: (713) 928-4000 


\section{CHAPTER 10 \\ THERMAL WELL CEMENTING PRACTICES}

\section{INTRODUCTION}

Cement is almost exclusively used to fill the annular space between casing and open hole in a well completion operation. The primary functions of any cementing job are (1) to restrict fluid movement between formations and (2) to support the casing. ${ }^{1}$ Good cement jobs are essential for the successful operation of a well. In thermal wells it is even more critical. Steam injection wells present special challenges when one designs a cement job for such wells. In most cases, the cement slurry is subjected to relatively low temperatures during the cement job and early curing. However, after the cement sets, it must withstand the thermal shock associated with the initiation of steam injection. Another complicating factor is the problematic weak and unconsolidated formation often encountered with thermal wells. This chapter presents an overview of current steam injection well cementing practices. Vendors such as those listed in Appendix 10-A should be consulted for additional information.

\section{Steam Injection Well Cementing Requirements}

Although cements used in thermal wells are subject to thermal shock at the initiation of steam injection, they must retain adequate compressive strength and low permeability during the life of the well. Thermal stress on the cement and casing requires uniform high quality bonding throughout the well. It is also advantageous to have low thermal conductivity cement such that the injected heat goes predominantly to the oil bearing sand rather to the overburden.

Good cementing practices, such as the use of spacers, centralizers, and mud conditioners are also very important. However, such practices are wasted unless the cement is properly designed for long-term stability and adequate performance characteristics. Two kinds of cement, with additives, are routinely used in the completion of steam injection wells: Portland cement (API Class $\mathrm{A}, \mathrm{G}$ or $\mathrm{H}$ cement) and high alumina cement. In general, Portland cement is useful in applications up to about $650^{\circ} \mathrm{F}$; however, beyond $600^{\circ} \mathrm{F}$, use of high alumina cement is recommended. ${ }^{2}$

\section{THERMAL CEMENT CHEMISTRY3,5-6}

\section{Portland Cement}

Conventional oilfield Portland cement cannot be used in thermal well completion applications because it begins to lose its compressive strength at abcut $230^{\circ} \mathrm{F}$. Silica flours are usually added to the cement to halt strength retrogression. The silica flour plays an important role in improving the cement's strength. 
Ordinary Portland cement is essentially a calcium silicate material, the primary components being dicalcium silicate and tricalcium silicate. When water is added to the cement, it hydrates to form a calcium silicate hydrate gel. It is this gel that is responsible for the strength and integrity of the set cement at ordinary temperatures. In addition, a substantial amount of calcium hydroxide is also liberated.

The calcium silicate hydrate gel provides good binding at lower temperatures, but at about $230^{\circ} \mathrm{F}$, this gel undergoes a phase transition and converts to a phase called "alpha dicalcium silicate hydrate' ( $\alpha$-gel). The $\alpha$-gel is, unfortunately, a much denser material that is prone to shrinkage. The shrinkage is accompanied by a loss of compressive strength and an increase in permeability. Though the amount of strength reduction is severe (from about 4,000 psi to 2,800 psi in one week), it is still sufficient to support the casing in a well (the minimum API acceptable compressive strength is about $500 \mathrm{psi}$ ). However, the real problem is the drastic changes in permeability. The changes in permeability may create greater problems. Cements exhibiting $0.01 \mathrm{mD}$ permeability after one day at $320^{\circ} \mathrm{F}$ can exhibit $1 \mathrm{mD}$ permeability after one month. Normally, this permeability increase is of little importance in the high permeability reservoirs associated with the steamflood operations. However, this permeability increase will cause steam to migrate to zones behind the casing and weaken the casing-cement bond. This weakened bond is easily broken by the thermal expansion of the casing. Thermal well cement studies indicate, that for the prevention of interzonal communication, the water permeability must not exceed $0.1 \mathrm{mD}$ at steam injection temperatures. 4 In figures 10.1 and 10.2, the compressive strength and permeability performance of neat Portland cements at $400^{\circ} \mathrm{F}$ are shown, respectively. ${ }^{7}$

Portland cement slurries are usually made suitable for steam injection applications by stabilizing them with the addition of silica flour. When silica flour is added to the cement, a portion of the additive reacts with the calcium hydroxide to form alpha dicalcium silicate hydrate $(\alpha$-gel). The remaining silica reacts with the $\alpha$-gel to form what is known as the tobermorite phase. ${ }^{5}$ The tobermorite phase is a better cementing binder than $\alpha$-gel and retains the high compressive strength and low-permeability characteristics of the Portland cement. In figures 10.3 and 10.4, the compressive strength and permeability performance of silica flour augmented Portland cements are shown, respectively. ${ }^{7}$

For steam injection weli cementing applications, normally 30 to $60 \%$ (by weight of dry cement), silica flour is added to the Portland cement. The average being about $40 \%$. The minimum temperature at which silica flour should be used is $230^{\circ} \mathrm{F}$. Recent research indicates that regular silica flour is the best additive for temperatures ranging from $230^{\circ}$ to $600^{\circ} \mathrm{F} .{ }^{6}$ Above $650^{\circ} \mathrm{F}$, these mineral phases begin to dehydrate to form calcium oxide. In steam injection operations, the dehydrated cement will begin to rehydrate in the presence of steam and begin to disintegrate due to volume increase. 


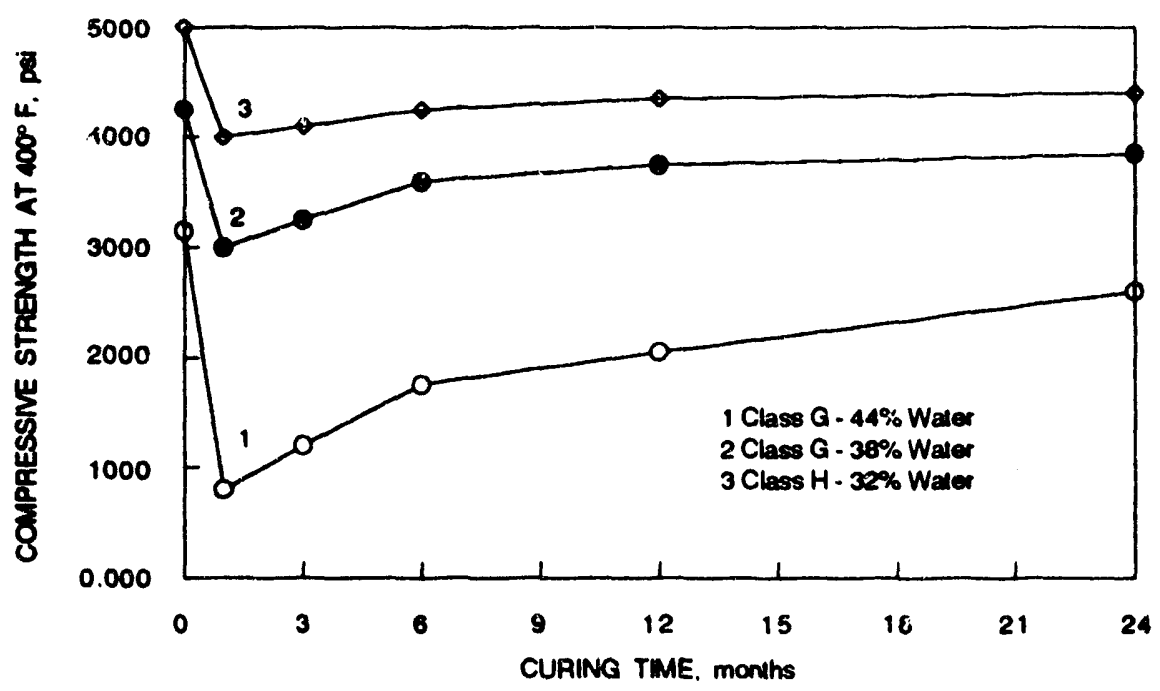

FIGURE. 10.1. - Compressive strength of neat Portland cement at $400^{\circ}$ F. ${ }^{7}$

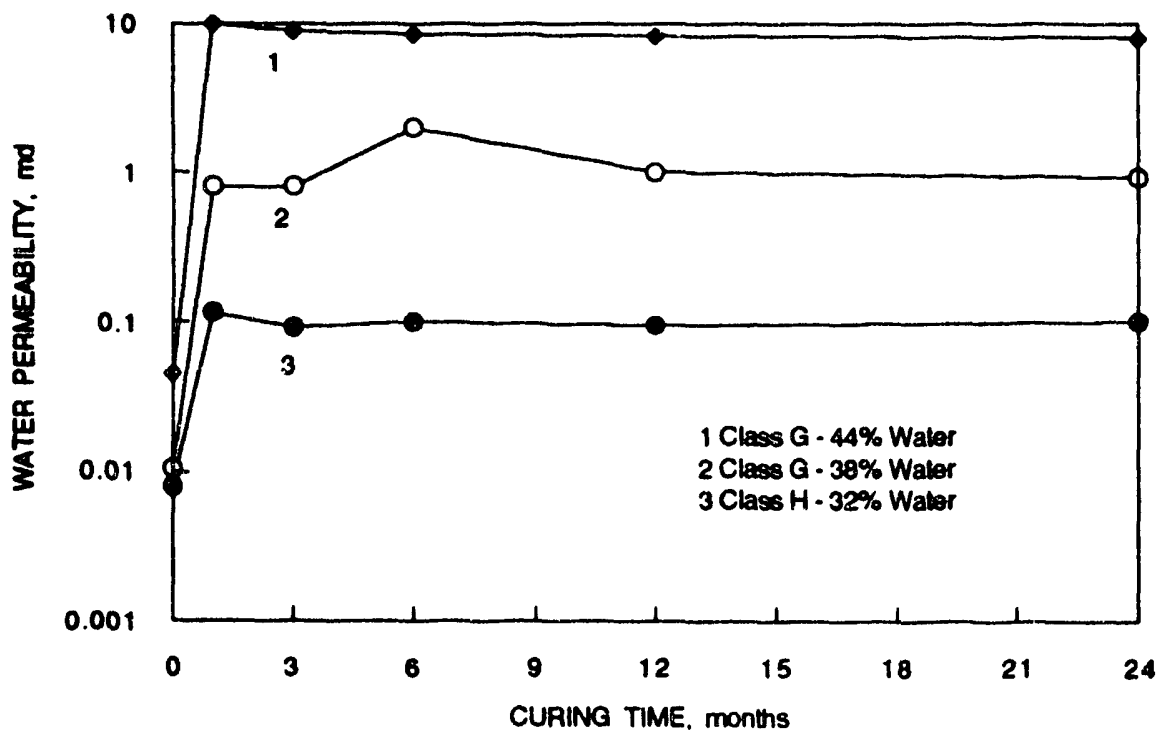

FIGURE 10.2. - Permeability behavior of neat Portland cement at $400^{\circ}$ F. ${ }^{7}$ 


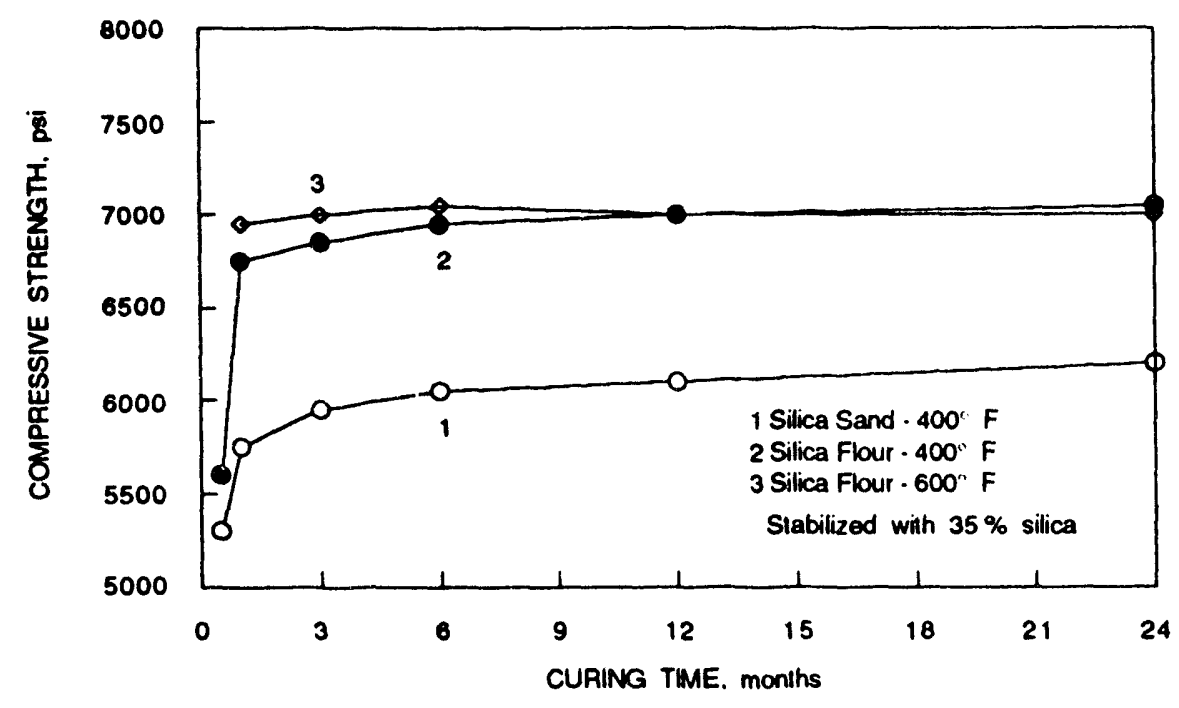

FIGURE. 10.3. - Compressive strength of Portland cement stabilized with $35 \%$ silica flour at various temperatures. ${ }^{7}$

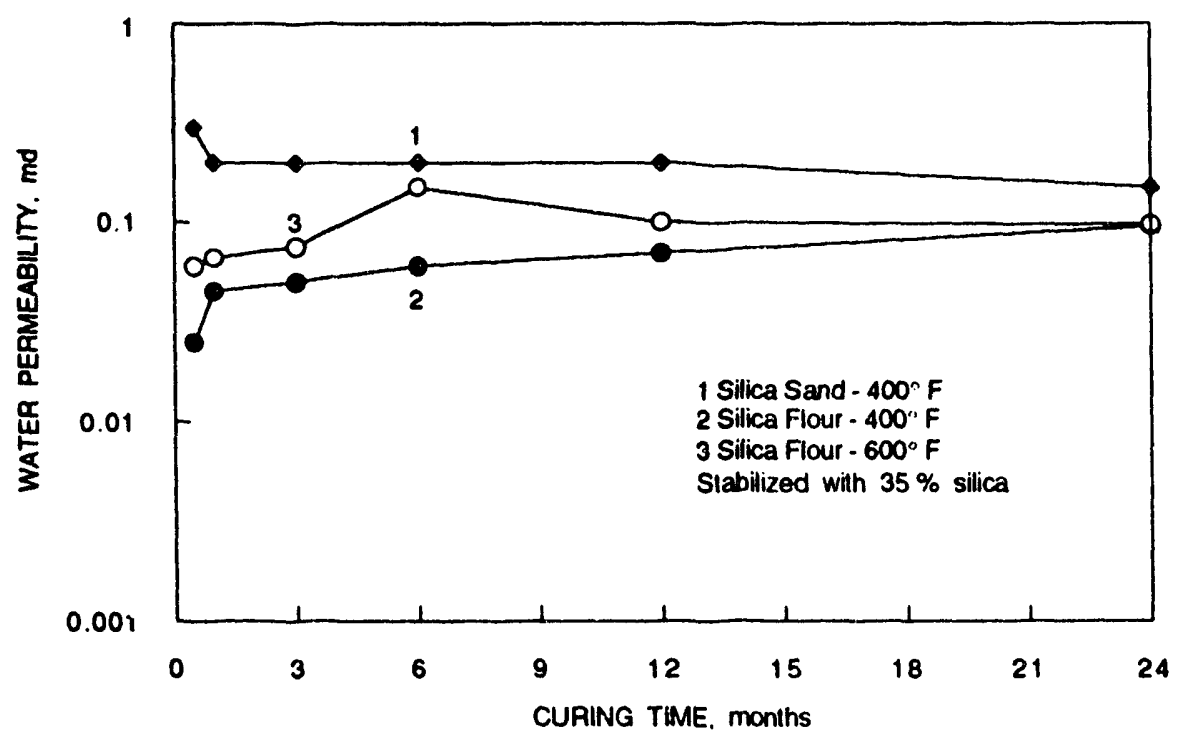

FIGURE. 10.4. - Permeability behavior of Portland cement stabilized with $35 \%$ silica flour at various temperatures. ${ }^{7}$ 
Alumina silicate cements such as the "Pozzolan" cements, which contain fly ash, can chemically bind the free calcium hydroxide in Portland cements ${ }^{5}$ but are often unreliable at the high temperatures associated with a steam well, and their use is not recommended. ${ }^{3}$ Thus, for all practical purposes, the Portland cements are satisfactory for steam injection well completion up to $600^{\circ} \mathrm{F}$, if sufficient silica flour is added to the cement. Since very few steum injection operators inject steam above $600^{\circ} \mathrm{F}$, silica flour augmented Portland cement is satisfactory for most steam injection applications. Silica flour is also inexpensive and is compatible with all commonly used retarders, friction reducers, low water loss additives, and lost circulation materials.

\section{High Alumina Cement}

In applications where a refractory binder is required, high alumina cement can be used. These are speciality cements whose primary cementitious constituent is monocalcium aluminate. When water is added to the high alumina cement, it forms three metustable calcium aluminate hydrates (mono-, di- and tetra-calcium aluminate hydrate), which eventually converts to tricalcium aluminate hydrate. Unlike the Portland cement, the high alumina cement does not produce calcium hydroxide as one product of the reaction. Above $440^{\circ} \mathrm{F}$, the tricalcium aluminate hydrate begins to dehydrate and above $525^{\circ} \mathrm{F}$, it begins to decompose with formation of calcium oxide and calcium aluminate.

Because of their excellent resistance to thermal shock, these cements are widely used to cement in situ combustion wells where the temperature often exceeds $1,0(0)()^{\circ} \mathrm{F}$. Their stability at such temperatures is mainly due to the absence of calcium hydroxide. The strength and durability of high alumina cements are primarily controlled by the water-to-cement ratio. The durability decreases with the increase in water-cement ratio. Hence, the addition of water should be kept at a minimum necessary to obtain a pumpable slurry. A variety of materials are used as extenders in high alumina cement slurries to obtain desirable characteristics. These include high alumina crushed firebricks, fly ashes, diatomaceous earth, and perlite.

High alumina cements are recommended for cementing those wells where the steam injection temperature is expected to exceed $600^{\circ} \mathrm{F}$. These cements, however, are expensive and cost much more than Portland cement plus silica flour. Further, its behavior under steam injection conditions is hard to predict. Laboratory tests are recommended before its use in a steam well.

\section{STEAMFLOOD CEMENTING PRACTICES}

\section{Steam Well Problems}

Steam injection wells are frequently less than 4,(0)(0) $\mathrm{ft}$ in depth; and, as such, these wells generally have normal formation temperatures (less than $125^{\circ} \mathrm{F}$ ). These temperatures do not affect 
primary cementing. After the cement has set, however, a steam injection well must withstand temperatures up to $650^{\circ} \mathrm{F}$, but not until steam injection begins.

The formations associated with steam injection wells are usually unconsolidated, weak and have low fracture gradients. Hence, lost circulation of cement and fluid loss problems are often present. To avoid fracturing the weak formations with cement and the associated cement loss, low density cement slurries are necessary. Another problem associated with the thermal well is the thermal expansion of the casings and wellhead growth. This calls for a cement with good expandable properties. To minimize heat loss to the over- and underburdens, the cement should have good insulating properties.

These unique characteristics of thermal wells and the associated performance requirements of cementing materials are often at cross purposes. For example, as mentioned previously, thermal well cement must retain the strength and low-permeability characteristics of ordinary cement at elevated temperatures. This requirement can be met through the use of high density cement slurries. Unfortunately, since the formations associated with steam wells are weak, high density slurries are generally not suitable because of the loss circulation problem. Further, thermal well completion calls for cements with good insulating properties (i.e., low thermal conductivity characteristics), but high density cements are poor insulators. Therefore, considerable research has been performed to formulate cements with the above desired properties.

Until a few years ago, low density Portland cement slurries were prepared by adding light weight filler materials (such as perlite, gilsonite, powdered coal and diatomaceous earth) or water absorbing thickeners such as bentonite and sodium silicate. The performance of selected low density slurries are shown in figures 10.5 through $10.8 .^{7}$ These figures indicate that high compressive strength and low water permeability are not linked. Further, field experience indicates that conventional, filler cements with densities less than 12.5 pounds per gallon (ppg) perform poorly in steam injection wells due to permeability increase. ${ }^{8}$

Recently, two new methods of preparing low density slurries have been developed. These methods not only reduce the slurry density to a very low level, they were also able to retain the compressive strength and low-permeability characteristics of the cement 2 t elevated temperatures. The method includes (1) addition of hollow glass or ceramic micro spheres ${ }^{9}$ and (2) foamed cement. 10 Of these two techniques, foam cements are preferred for thermal applications due to their superior performance. ${ }^{7}$

With the addition of proper surfactants and stabilizers, it is now possible to prepare low density slurries with high compressive strength and extremely low-permeabilities. Foamed cement made from a base slurry stabilized for high temperatures exhibits excellent performance 


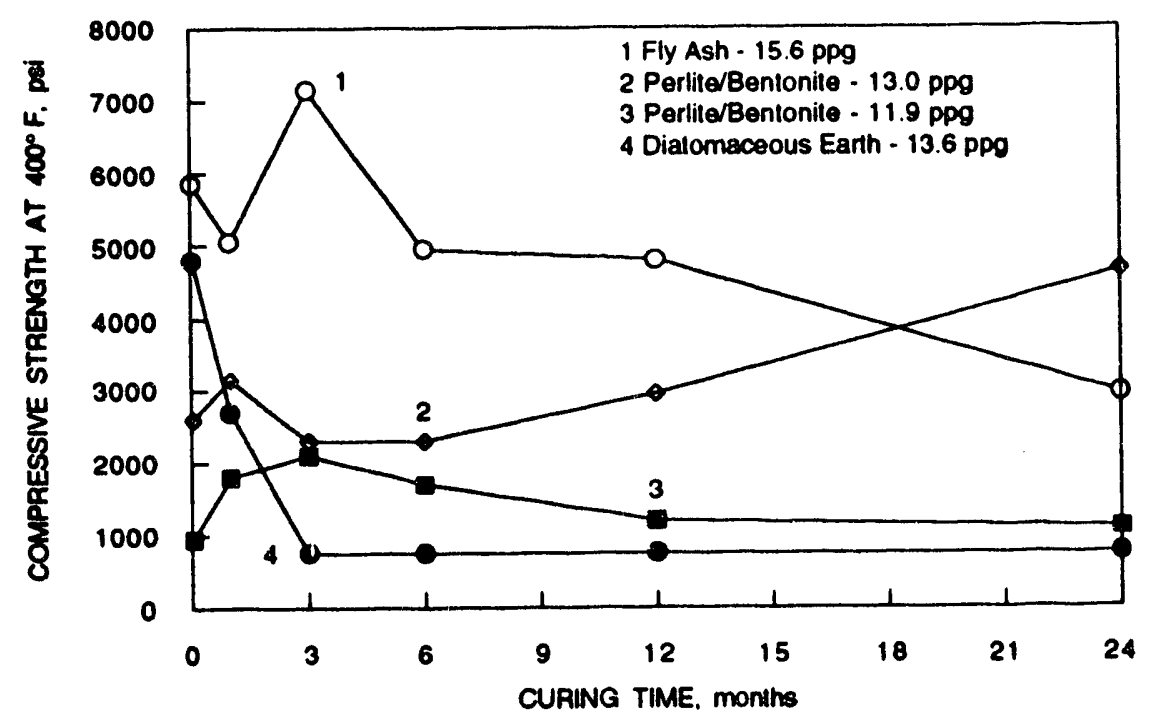

FIGURE. 10.5. - Compressive strength of conventionally extended Portland cement at $400^{\circ} \mathrm{F} .^{7}$

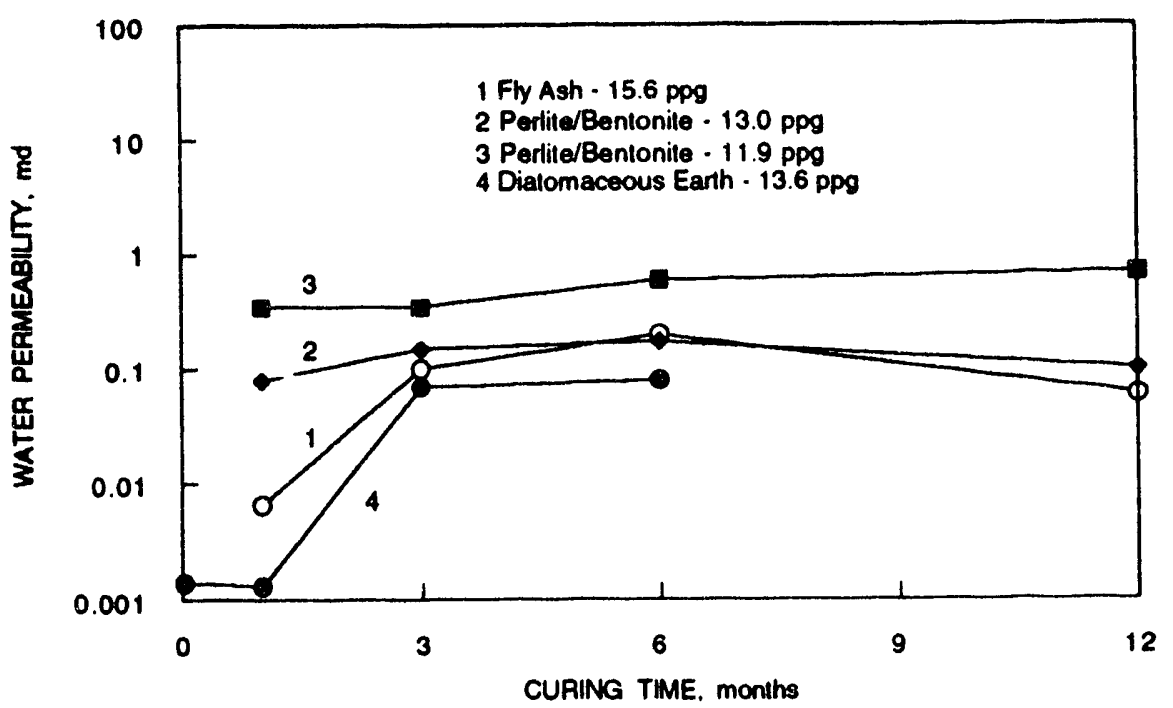

FIGURE. 10.6. - Permeability performance of conventionally extended Portland cement at $400^{\circ} \mathrm{F}^{7}$ 


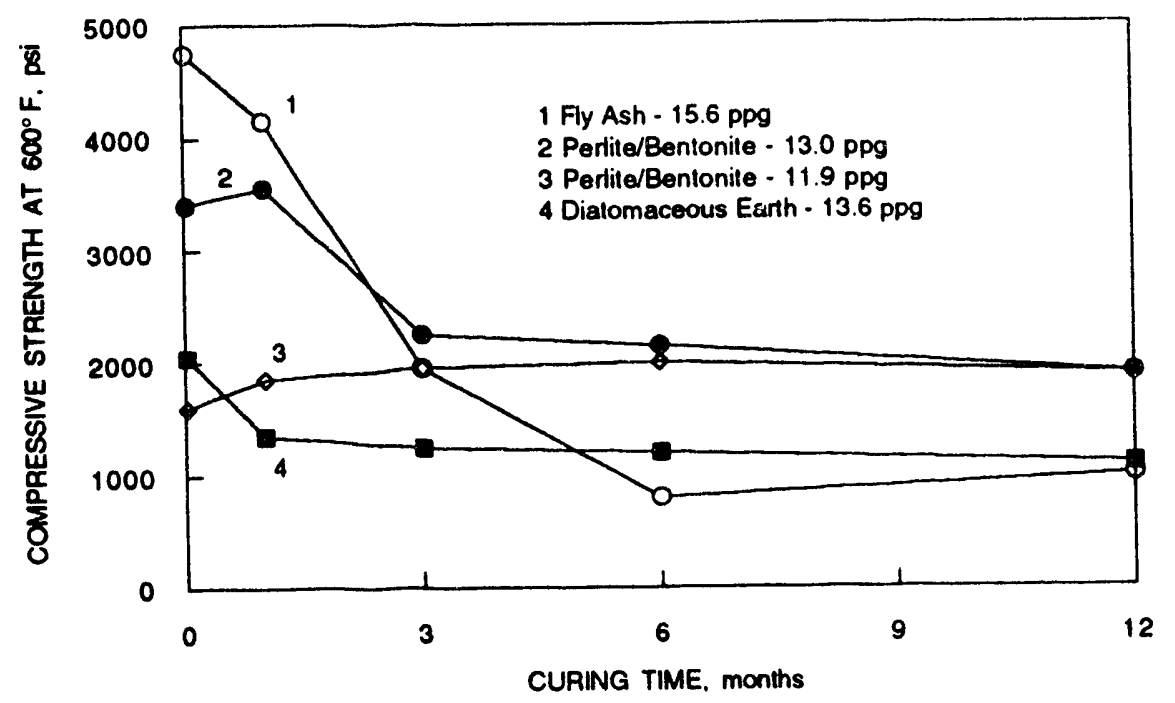

FIGURE. 10.7. - Compressive strength of conventionally extended Portland cement at $600^{\circ} \mathrm{F}^{7}$

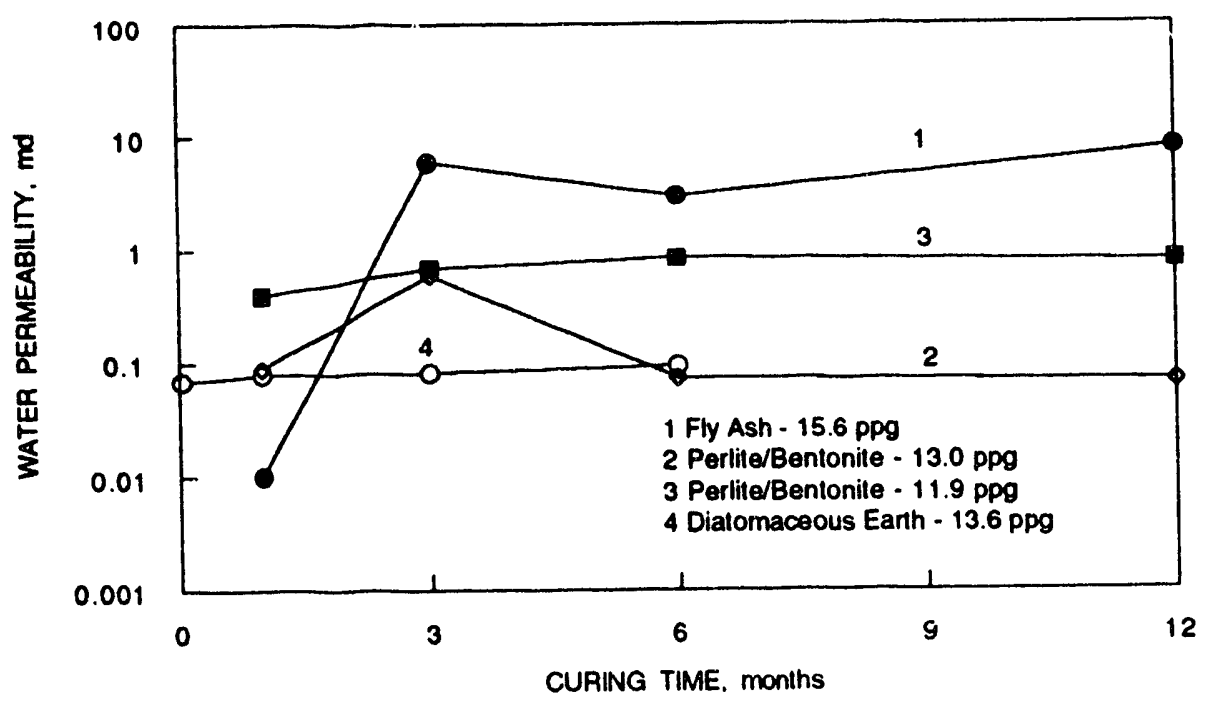

FIGURE. 10.8. - Permeability performance of conventionally extended Portland cement at $600^{\circ} \mathrm{F} .{ }^{7}$ 
characteristics at steam injection temperatures. Although foamed cement with densities as low as 9 ppg show excellent performance characteristics in terms of compressive strength, their water permeabilities are somewhat higher than microsphere cement. ${ }^{3}$

A typical cement formulation recommended for most steam injection wells could consist of 50\% Class G cement, 35\% -200 mesh silica flour and 15\% microspheres.

\section{Cementing Practices}

Given a good composition of thermally stable, bondable cement, it is essential that the cement be applied properly to assure adequate zonal isolation and uniform bond quality. Good cementing practices is even more critical in thermal wells to ensure that the integrity of the bond is maintained under temperature induced stress conditions. Cement should be returned to the surface on every string of casing to assure complete fill-up of cement in the casing hole annulus and to anchor the casing firmly to the ground.

Prior to the cementing operation, the drilling mud must be removed to assure good stable bonding. Mud removal can be enhanced through the use of spacers and washes. ${ }^{9}$ Most operators use chemical preflushes ahead of the cement job to help remove the mud in the casing and formation wall. The chemical preflush, which is normally water-based, should contain a good mud thinner and a surfactant to leave the pipe and formation surface in a water-wet condition. ${ }^{11}$ Care should be exercised in selecting the mud thinners, since some of them (such as quebracto, lignosulfonates) added to water may retard cement setting. 1 Dilute mix of Portland cement put in turbulant flow is an excellent preflush and aid in erosion of gelled mud and filter cake. Because of great variation in mud system, the chemical wash should be selected for the particular mud system in use.

Effective centralization is a critical factor in obtaining a good primary cement job. Enough centralizers must be used to produce a uniform sheath of cement. In straight hole, one centralizer per joint is recommended. Centralizers should be placed in gauge sections of the hole as determined by caliper or other logs. In crooked hole, centralizer placement depends on hole deviation.

Floating and guiding equipment should be used to assure good cement job. Float collars should be located one or two joints above the float shoe to prevent mud contaminated cement from being placed outside the bottom casing joining.' Use of scratchers should be given serious consideration, since they aid in the removal of mud cake and break the mud gel. They also help to mix up the mud with cement, thus reducing channeling. Hole washout must be taken into consideration in estimating the cement volume required to achieve the desired fill-up. The actual cement volume to be used should be at least $15 \%$ more than the estimated value. 
The success of the cement job depends on the quality of cement mixing. Weight of cement slurry should be monitored to ensure that the correct amount of water is used to prepare the slurry. Wiper plugs should be used to wipe mud off casing ahead of cement as well as to separate mud and cement. Consideration should be given as to whether or not to reciprocate and/or rotate the casing while cementing to assure successful mud displacement and enhance the formation of good uniform cement sheath. Cement should be circulated near turbulence condition to aid in the removal of mud and to reduce the possibility of mud channels remaining in the productive zone. Use of friction reducers with the slurries promote turbulence flow and should be considered.

Good operator and service company supervision during cementing operations is critical to minimize cement job failures. The slurry should be placed at the highest practical rate without exceeding the fracturing pressure of the formation. Use of sonic or ultrasonic logs are recommended to monitor the presence of cement and the quality of casing-cement bond. Proper interpretation of the log is critical and the service of experienced engineers should be enlisted to interpret the logs.

\section{SUMMARY}

This chapter presents a brief overview of thermal well cementing practices. Neat Portland cements (API Class A, G or $\mathrm{H}$ ) are not appropriate for completing steam injection wells. These cements lose their compressive strength and show permeability increases at temperatures above $230^{\circ} \mathrm{F}$. However, Portland cements with appropriate additives can be used to cement steam injection wells, provided well temperatures do not exceed $600^{\circ} \mathrm{F}$. Above this temperature, high alumina cements are recommended. Fine mesh silica flour $30 \%$ to $60 \%$ by weight of dry cement should be mixed with Portland cement and used in thermal applications.

Since the formation associated with the steam injection wells are usually unconsolidated and weak, high density cements should not be used. Ceramic microspheres can be used to prepare ultra low density cements with acceptable performance for steam injection wells.

Good cementing practices are critical in steam injection well completion. Cement returns to the surface is a must. The hole should be well circulated prior to cementing. Pipe should be suitably equipped with floating and guiding equipment. Adequate number of centralizers must be used to assure good cement sheath. During cementing operations, mud removal can be greatly enhanced through the proper application of spacers and washers. Use of bottom plugs, chemical washes, excess cement, and good supervision will assure good cementing job.

\section{REFERENCES}

1. Allen, T. O. and A. P. Roberts. Production Operations, v. 1; Well Completions, Workover and Stimulation, chapter 4. Oil and Gas Consultants International, Inc., Tulsa, Oklahoma, 1978. 
2. Cementing For Ultra-High Temperature Wells. Halliburton Services. Technical Bulletin No. C-1297.

3. Nelson, E. B. Improved Cement Slurry Designed For Thermal EOR Wells. Oil \& Gas J., v. 84 , No. 48 , Dec. 1, 1986, pp. 39-44.

4. Eilers, L. H. and R. L. Root. Long-Term Effects of High Temperature on Strength Retrogression of C $t$ ments. Pres. at the 46th Annual California Regional Meeting of the Soc. of Pet. Eng., Long Beach, California, Apr. 8-9, 1976. SPE paper 5871.

5. Taylor, H. F. W. The Chemistry of Cements. Academic Press, London, v. 2, 1964.

6. Smith, D. K. Silica Flour-Mechanism For Improving Cementing Composition For High Temperature Well Conditions. Pet. Eng. International, v. 52, No. 15, December 1980, pp. 43-48.

7. Nelson, E. B. and L. H. Eilers. Cementing Steamflood and Fireflood Wells-Slurry Design. Pres. at the 34th Annual Technical Meeting of the Pet. Soc. of the Canadian Institute of Mining, Banff, Alberta, Canada, May 10-13, 1983. Paper No. 83-34-23.

8. Chmilowski, W., A. Frankiw and R. J. Ford. Evaluation and Improving Thermal Cementing Practices. Pres. at the 35th Annual Tech. Meeting of the Pet. Soc. of the Canadian Institute of Mining, Calgary, Alberta, Canada, June 10-13, 1984, Paper No. 84-35-115.

9. Griffin, T. J. and W. Chimilowski. Cement Spacers and Washes Can Improve Stimulation and Production Characteristics of Oil and Gas. Pres. at the 29th Annual Tech. Meeting of the Pet. Soc. of the Canadian Institute of Mining, Calgary, Alberta, Canada, June 13-16, 1978. Paper No. 78-29-12.

10. Olanson, M. T. Application of Foam Cements in Alberta. Pres. at the 35th Annual Tech. Meeting of the Pet. Soc. of the Canadian Institute of Mining, Calgary, Alberta, Canada, June 10-13, 1984. Paper No. 84-35-72.

11. Cain, J. E. and S. H. Shryock. Cementing Steam Injection Wells in California. J. Pet. Tech., v. 18, No. 4, April 1966, pp. 431-436. 


\section{APPENDIX 10-A \\ THERMAL WELL CEMENTING SERVICE VENDORS}

A. Thermal Well Cementing Services

1. Dowell-Schlumberger Inc.

12012 Wickchester, Suite 300

Houston, TX 77079

Telephone: (713) 870-8959

2. Halliburton Services

1015 Bois d' Arc, Drawer 1431

Duncan, OK 73536

Telephone: (405) 251-3760

3. BJ-Titan Services Company

5500 Northwest Central Drive, Suite 100

P.O. Box 4442

Houston, TX 77210

Telephone: (713) 462-4239 


\section{CHAPTER 11 \\ THERMAL WELL LIFTING EQUIPMENT}

\section{INTRODUCTION}

The production of oil from thermal wells by artificial lifts is mor', difficult and expensive than producing from conventional wells for several reasons. Lifting conditions can vary widely during steam stimulation cycles. Temperatures may range from $75^{\circ}$ to $\left.6(1)\right)^{\circ} \mathrm{F}$, viscosities from $10,000 \mathrm{cP}$ to $1 \mathrm{cP}$, water-oil ratios from 0.1 to 20 , liquid production rates from 10 to $: .000 \mathrm{bbl} / \mathrm{day}$, gas-oil ratios from 50 to $1,000 \mathrm{SCF} / \mathrm{STB}$ and sand cuts from 0 to $18 \%$. These conditions impose severe strain on the lifting systems. Produced vapor, though mostly steam, may also contain acid gases. The presence of high temperature, high water cut and acid gases can result in downhole corrosion. Although different types of artificial lift equipment has been utilized to lift oil from steamed well, the most prevalent form of lift for fluids in thermal operations is the conventional rod pump. Corrosion and abrasion (due to sand production) in combination with the mechanical stresses of a reciprocating pump jack takes a heavy toll on the downhole pump. Problems associated with the lifting of heavy oil in thermal well by pump jacks has resulted in the emergence of newer breeds of pump jacks offering the contiol and flexibility required for optimizing production in these wells.

This chapter presents an overview of the pumping problems associated with the lifting of heavy oil from thermal wells. The problems are discussed primarily as they affect rod pumps.

\section{THERMAL WELL PUMPING PROBLEMS}

Thermal wells are generally associated with low gravity. high viscosity crudes, produced from uncansolidated formation. Some of the pumping problems associated with such walls include rod floating, sand production, steam flashing, varying produced gravity, varying inflow rates, and system operational problems.

\section{Rod Fall and Rod Drag}

In heavy oil wells, the rate of movement of the sucker rod on the downstroke is greatly influenced by oil viscosity. In steam operations, prior to steam breakthrough, the downhole temperatures are low enough that the oil tends to stay viscous. The viscous oil can cause considerable viscous drag in the production equipment. This viscous drag or frictional force on the rod can be easily overcome during the upstroke of the pump jack. However, during the downstroke only gravitational furces aid the rod movement and the frictional forces can considerably slow down the rod movement.

The rate at which the rods move on the downstroke is called the rod fall or rod float rate. It is typically in the range of 10 to $60 \mathrm{ft}$ per minute ( 0.5 to 3 strokes per minute). 1 Thus, the rod float rate constrains the beam pumping unit operation. Attempting to run the pump jack at a speed faster 
than the rate at which the rod can sink creates a condition known as rod float. Rod float will result in the polished rod clamp and carrier bar to separate on pump downstroke.

Since pump jacks are normally a single speed device, the carrier bar travels at the same speed on the upstroke as on the downstroke. The resulting collision between the downward moving clamp and rod string and upward moving carrier bar can cause major damage to both surface and downhole equipment.

To accommodate extra rod stresses resulting from viscous forces, oversized rod strings are usually used. Since the oversized rod reduces the annular clearance between the rod coupling and the tubing inside diameter, it aggravates the rod float problems. Most operators attempt to soften the rod float effect by providing maximum annular clearance with the use of larger diameter tubes.

To date, many operators avoid rod float conditions by lowering the pump speed downstroke through the use of motor sheaves. ${ }^{2}$ Since the fluid production rate is limited not by pump size, but rather by pumping speed, rod float restricts well productivity. Production restrictions can result in high fluid levels in the well, which increases the backpressure on the well. Increased backpressure reduces inflow rates and will result in the loss of average production.

Many operators use a longer stroke surface unit and downhole pump to increase production. However, this is a costly and only partially effective solution. A larger subsurface pump diameter could be installed to increase production, but pump diameters are limited by sand settling problems, nump compression ratios and protection from high temperatures because of steam. Thus, productivity of a well is severely impaired by rod float. On some wells, increased backpressures cause sand to settle.

Further, the high viscosity of heavy oil causes conventional subsurface pumps to operate less efficiently because of slow closure of traveling and standing valves. ${ }^{3}$ The viscous friction of fluid flowing through the traveling valve on the downstroke further reduces the rod fall rate. To avoid rod float, the upstroke travel rate must match the downstroke rate. This imposed slow upstroke results in sluggish closure of the traveling valve. Thus, a percentage of production is lost on every stroke. ${ }^{3}$ In many wells, restricted flow because of rod tloat will keep a well from being purnped off.

\section{Sanding}

Much of the world's heavy oil is found in unconsolidated formation with high sand content. Sand production from unconsolidated heavy oil reservoirs is one of the major problems affecting heavy oil production from thermal wells. Production of sand particles with the fluid causes severe operating problems because of abrasive effects of sand on downhole equipment and accumulation of sand across the perforations. Experience with thermal recovery projects in unconsolidated reservoirs indicates that despite the use of sand exclusion measures, some sand production is 
unavoidable. Furthermore, fluctuating wellbore conditions due to well stimulation and varying production rates may also cause an increase in sand production. The presence of sand in the production fluids damage the sucker rod pump. Damages to the pump include erosion of the ball and seat, and seizure of the plunger. ${ }^{4}$

Unlike conventional operations where a well is routinely pumped off and the pump jack shut down to reduce the effects of fluid pound, pumps in thermal wells are kept running to avoid complications imposed by a well sand flow. When fluid stops moving, the sand held in suspension in the fluid settles out on the pump. This condition often necessitates costly workover and frequent servicing of the pumping equipment. In extreme cases, sand problems dictate a complete recompletion of the well. In wells where sanding is severe, operators have reported pulling sucker rod pumps only after three weeks of service because of wear and plunger seizure. 4

\section{Steam Breakthrough}

When thermal wells are pumped too fast, hot fluid and in some cases steam itself is brought back to the surface. This can result in damage to the surfice equipment and cause production rates to drop. Steam interference can significantly influence pump performance and adversely affect pump efficiencies. Field investigations in Canada revealed that many cyclic wells where steam is produced along with oil, steam significantly affected the pump performance. The barrel fillage ranged from $60 \%$ to $80 \%$ and the corresponding pump efficiencies were $30 \%$ to $68 \% .^{5}$

\section{Production Conditions Variations}

In steam operations, the composition, gravity and viscosity of the produced oil can and does change daily. This is because of the steam distillation and solvent drive mechanism associated with such processes. Further, oil and stimulation fluids (steam, hot water, and noncondensible gas) do not flow into the wellbore at a constant ratio. This is because of the gravity override and fingering of the stimulation fluids as well as uneven heating of the reservoir sand.

Varying inflow rates and the fluid properties causes rod fall rate to change. As discussed previously, fluctuation in the rod fall rate seriously impairs the pump performance. The traditional approach to this problem is to monitor the operation of the beam unit closely and implement appropriate corrective action as needed. If the operator foresees a change in rod float rate or a pump off condition becomes imminent, he alters the pump speed rate to correct the problem. This is usually done by changing the pump drive belt sheaves. This approach is not only labor intensive and inefficient but also very expensive. Further, the daily changes in fluid gravity causes the beam pump to remain out of balance most of the time. 


\section{System Operational Problems}

Beam pumping units are uswally designed and manufactured according to the API RP IIL specifications. ${ }^{6}$ Since this specification does not consider problems peculiar to thermally stimulated wells, any pump designed according to this specification is inappropriate for heavy oil lifting. Most of the production system failures such as parted rods, overstressed or busted gear boxes and low pump efficiencies (high fluid level) can be traced to the faulty design. For example, for a $12^{\circ}$ API oil, the API specification underestimates the gear box loadings by as much as $300 \%$. This is because the specification does not account for the head effects caused by the extremely high viscosities of heavy oil. ${ }^{3}$

In the conventional beam unit, the upstroke and downstroke speeds are matched by adjusting the counterweights on the walking beam. In the heavy oil wells, extra counterweights are needed to overcome the viscous forces during the upstroke. Since the downstroke speeds are limited by the rod fall rate, the gear box does not receive any torque from the rods. Thus, the gear box must lift the entire counterbalance unassisted. On the other hand, if attempts are made to balance the unit to match for the downstroke, the unit may become overly - $^{-}$terbalanced for the upstroke. In this situation, the gear box must not only lift the rod and fluid loads, but must also overcome the viscous force without additional counterweights. In either situation, the gear box is overstressed.

\section{SOLUTIONS TO HEAVY OIL THERMAL WELL PUMPING PROBLEMS}

Though the conventional beam pumping unit is versatile, reliable, inexpensive, and widely used in the oilfield, they may be inefficient in meeting the production demands of steamflood production wells. Their operating range is limited and does not provide the flexibility needed to optimize the production from these wells. The rigid mechanical coupling of the system units (i.e., crank, pitman and the beam) do not permit stroke lengths to vary dynamically. Stroke length adjustment is essential to accommodate the varying inflow rates and to reduce gear box stress.

Traditional approaches used in the United States thermal operations to improve the pump performance include: (1) setting the pump speed to achieve an estimated average production; (2) alter pump speeds mechanically by changing sheave size; (3) use of variable speed motors to change pump speed; and (4) use of pump off controllers. Each of these approaches have limitations. By setting the pump speed to achieve an average production, the man-hours needed to change pumping speeds is eliminated. However, with this approach, pump efficiency is reduced because of the increased time needed to produce the water back after steam breakthrough. Further, as pointed out earlier, if the well inflow is higher than the average production rate, this can result in high fluid levels in the well and this has the effect of causing sand settling. If the average production rate is greater than well inflow rate, higher pump speed will result in severe fluid pound and unnecessary maintenance. The limitation of changing motor sheaves to alter pump speed were 
already discussed. The use of a variable speed motor to change pump speed, though attractive from the operational prospective, has its limitations. Use of variable speed motors require someone to watch production rates or fluid pound indications to determine when to change the pump speed. Over and under counterbalancing can be severe when variable speed motors are used. ${ }^{3}$ The required gear box torque will be increased considerably if tie unit is slowed on the downstroke, because the counterbalance inertia cannot be used to assist the motor.

The inadequacies of the conventional beam pumps to meet the service demands of heavy oil production have led to the development of alternate pumping techniques. These include modification of conventional pump jacks to improve its flexibility and novel pumps such as the diluent pumps, cavity pumps and chamber lift pumps. None of these pumps are widely accepted and they are used principally in the heavy oilfields of Canada and Venezuela, where the oil is more viscous than those found in the United States.

\section{Novel Pump Jacks}

The downhole pump, the sucker rod, the produced fluid, and surface unit all contribute to the efficiency and economics of heavy oil production. Of these, the surface unit plays a major role and any improvement in its performance can result in significant improvement in the pump efficiency. An ideal surface unit should embody all of the following characteristics: ${ }^{3}$

- minimal capital outlay

- $\quad$ long, slow pump strokes

- low surface profile

- infrequent and uncomplicated maintenance

- $\quad$ self optimized production rate

- $\quad$ high mechanical efficiency

- robust construction

- minimal wear to downhole equipment

- $\quad$ variable upstroke and downstroke speeds

- use of field proven technology.

Several arrangements that are coupled with existing conventional pump jacks to achieve one or more of the aforem ntioned characteristics have been marketed in the past decade. Since these systems were developed to meet certain production application requirements, they have sacrificed some of the desirable characteristics of a conventional beam unit. The use of these novel pump jack units in the field are growing, especially in Canada. There are differences between the various systems in their approach and capabilities. A brief overview of few selected units are presented here to appraise the operator of the options available to him. Many of these units are prototypes 
and are field tested in Canada. The authors are not aware of any of these units being used in the United States.

\section{HEP Pump ${ }^{7}$}

This is a hydraulic, variable speed, surface pumping unit that utilizes a hydraulic system to transmit energy from the prime mover to the sucker rod string. The pump was developed to eliminate the gear box in the conventional beam unit in favor of a high torque, low speed motor.

The system uses Hydraulics to transmit the power from the prime mover to the sucker rod strings, Electronics to control the rod motion, and a Pneumatic system to provide counterbalance effects. Hence, the name HEP.

The system utilized a double-acting piston and cylinder hydraulic motor, mounted on the wellhead to actuate the rod string. The piston rod is connected to the polished rod by means of flexible wireline, carrier bar and rod clamp. A variable displacement pump, which is capable of a wide range of discharge rates, is used to hydraulically transmit input power from the prime mover to the hydraulic piston. The displacement pump discharge rate and direction of motion are controlled electronically. In this way, the motion of the polished rod is controlled automatically. Stroke speed and the velocity profile are varied by changing the control panel settings. This feature allows upstroke and downstroke rod speeds to vary independent of each other. Counterbalance for the pumping system is provided by a nitrogen filled hydraulic system. The unit offers 3 different stroke lengths and the desired stroke length can be selected by a switch inside the electronic control panel.

The HEP has exhibited its superiority over conventional beam pumps in the field tests. However, the system has two major drawbacks that prevent its widespread application. First, the reliability of hydraulic cylinders (the system that transmits power from the prime mover to the rod strings) in relation to long-term continuous operation is suspect. Secondly, difficulties have been encountered in effectively counterbalancing the system. There are two concerns with the nitrogen filled hydraulic counterbalance system: leakage and actual counterbalance effect. ${ }^{8}$ As a gas, the nitrogen pressure is dependent on ambient temperature and wide variations in temperatures affect the counterbalance capability. Also, since the pressure varies inversely as volume, large volumes are needed to minimize pressure fluctuations.

\section{PC 3000 System $^{3}$}

The PC 3000 system operates like an air-balanced beam pump unit and utilizes a low speed, high torque hydraulic motor and a nitrogen system to provide the needed counterbalance. A hydraulic system is utilized to lift the beam, rod string, and fluid load on the upstroke. A hydraulically driven winch is used to pull the beam in the downstroke. This system also allows the 
operator to vary the upstroke and downstroke speed independently to accommodate any pumping condition. The unit is still in the developmental stage and waiting field trial.

\section{Variable Speed Beam Pump 2}

This system is a conventional beam pump unit equipped with a variable speed controller to vary the upstroke and downstroke speed independently. The unit also gives the operator control over the acceleration and deceleration of their units at each end of the stroke. This feature permits the operator to fine tune the stroking profile. Since the stroke length are restricted by the walking beam geometry, this unit has no provision to adjust the stoke length. Counterbalance is achieved as in the conventional pump.

This unit is a prototype system and has been field tested to a limited extent. Field trials are promising, but several problems are yet to be solved sutisfactorily. Rapid variations in well pumping conditions cause the unit to operate erratically and necessitate the operator to make frequent adjustments to maintain proper operation.

\section{Diluent Pumpy}

Diluent pumps are used to lift highly viscous sand laden crude oils. The system depends on the use of a diluent to lower the viscosity of in situ crude and make it pumpable. Downhole blending also improves rod fall and pump performance. Figure 11.1 shows the schematic of a diluent pump used in the Cat Canyon field of California to produce the $6^{\circ} \mathrm{APl}$ oil. This pump is activated by sucker rods and requires dual tubing strings. The sucker rods and pump plunger operate in one string called the power string and the other string acts as a conduit for produced fluids. The diluents are injected through the hallow sucker rods or side strings to improve rod fall and pump performance. The dual tubing strings arrangement permits the isolation of sucker rods and pump plunger from the viscous sand laden crudes. These pumps are more expensive to install and operate. Their use is usually restricted to tar sand cyclic wells.

Other types of pumps used in producing heavy oil include chamber lift (gas lift) pump ${ }^{10}$ and cavity pump. ${ }^{11}$ These are prototype pumps developed and used in Venezuela to produce heavy crudes. The chamber lift pump is a modified version of the conventional intermittent flow gas lift pump with an accumulating chamber and is employed to lift heavy oil from wells with very low bottomhole pressure and in cyclic wells.

The cavity pump is basically a subsurface rotary positive displacement pump actuated by sucker rods, which in turn are driven by a motor installed at the wellhead. The advantage of such a pump lies in its ability to move the fluid continuously, contrary to beam pump which produces only on upstroke. Some of the operational conditions used that have to be considered with this pump include:11 


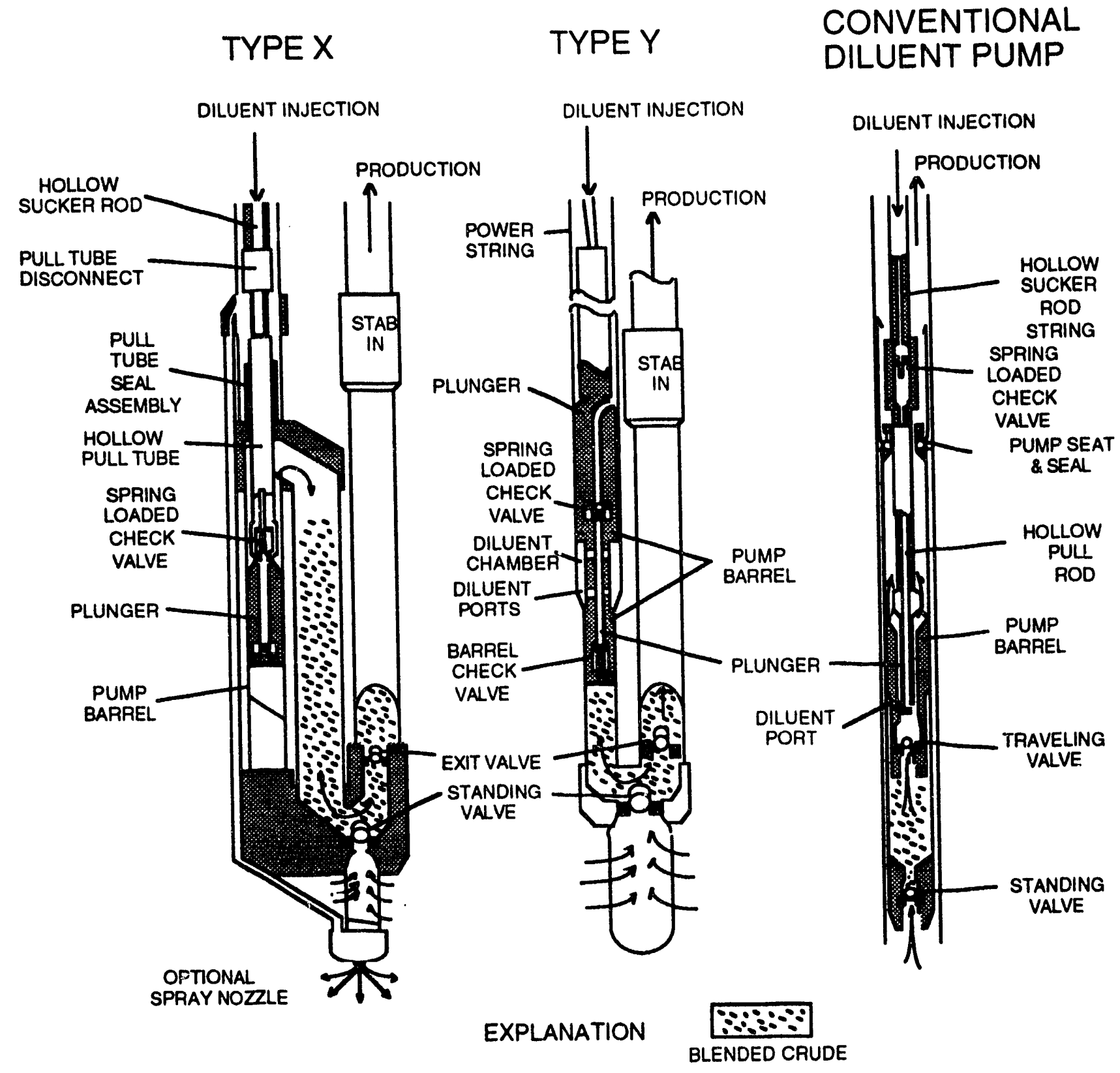

FIGURE 11.1. - Schematic of a diluent pump used in the Cat Canyon field of California to produce the $6^{\circ} \mathrm{API}$ oil. ${ }^{9}$

1. Fluid level has to always be a minimum of $300 \mathrm{ft}$ above the pump to avoid starter damage due to friction heat.

2. In wells with high sand production, a prepack filter must be used below the pump to avoid starter damage.

3. Wells with high GOR will require gas anchors and pumps with sufficiently large capacities to handle gas and liquid. 


\section{U.S. Thermal Well Pump Systems}

Despite its disadvantages, rod pumps are used almost exclusively in U.S. thermal oil production. This is because the alternative lifting methods such as the gas lift are more problem prone and economically unattractive to operate. Both insert pumps and tubing pumps are used in the U.S. steamflood operation. Insert pumps are preferred over tubing pumps due to the undesirability of performing a tubing job to replace a worn pump barrel in a potentially hot well. Most operators use the heavy-wall, full-barrel, top hold down pumps with stainless steel friction ring assemblies. Many operators employ slow speed, longer stroke pumps to handle large volumes of fluid produced after steam breakthrough. Operator's' experience indicate that it is not possible to obtain accurate liquid levels in wells producing large volumes of steam. Field experience in such wells, indicate basing pumps off condition on fluid pounding alone is not sound and can often lead to steam lock in the pump. ${ }^{14}$

\section{Use of Pump-Off Controls in Thermal Well}

When the productive capacity of a well is less than the pump lifting capacity, the pump barrels are only partially filled during the upstroke. This is known as a 'pump-off' condition 11 and can lead to severe fluid pound problems. ${ }^{12}$ The fluid pound associated with pump-off is responsible for damage to the rod string, pump, and in some cases, surface equipment. The pump-off problem can be eliminated if the pumping system capacity can be matched exactly to the productivity rate of the reservoir. This is very difficult to achieve in practice and impossible in thermal wells.

As stated previously, the inflow rate in thermal wells are constant but varies over a wide range. For example, in cyclic wells the inflow rate may vary from about $20 \mathrm{bbl} /$ day gross before stimulation to in excess of $300 \mathrm{bbl} /$ day after stimulation. This creates a unique pumping problem. Since the fluid production rate depends on the pump speed, it is impossible to accommodate both extremes at a constant speed. If the pumping speed is set to satisfy higher production rates, then as the cycle progresses the inflow rate decreases leading to a pump-off problem and unnecessary maintenance. If the pumping speed is set to satisfy the lower production rate, it is obvious that there will be production loss during the early stages of the production cycle. Similar situations can arise in steamfloods where the inflow rates are low before steam breakthrough and high after breakthrough.

As a compromise, it is a common practice in steam injection operations to set the pump speed to achieve an average production rate for the flood or cycle. However, this severely reduces the pumping efficiency because of the increased time needed to produce the water back and to achieve a pumped-off condition.

Through the application of pump-off controllers, it is now possible to operate pumping units at faster pumping rates without sacrificing equipment, production or man-hours. Pump-off 
controllers are increasingly being used in California thermal operations to improve pumping efficiency. ${ }^{13-14}$ One large California cyclic steam operator set the initial pumping unit speed to satisfy the peak production rate for the well. As the production rates declined and a pumped-off condition was approached he was able to detect the condition with the help of a pump-off controller and shut down the unit for a preset time to allow entry of fluid to the well. This solved the problems of pumping unit and downhole damages associated with fluid pound. ${ }^{13}$ This approach also has the advantages of power savings and reduced maintenance cost while providing an efficient way to produce steam stimulated wells. The savings realized by this particular operator included: 14 31\% reduction in power consumption; $23 \%$ reduction in well work expenditure and a substantial increase in per well oil production. In spite of its demonstrated advantages, pump-off controllers are not yet used widely because of its high initial cost (about $\$ 4,500 /$ well installed) and availability of cheaper alternatives such as variable speed motors.

\section{SUMMARY}

The production of oil from thermal wells by artificial lifts is more difficult and expensive than producing conventional wells. Pumping problems encountered in the production of heavy oil from thermally stimulated wells include: high sand production. varying produced gravity, varying inflow rates, varying viscosity, vapor interference and system problems. Because of its versatility, reliability and low cost, rod pumps are the pump of choice in thermal operations. However, severe problems are encountered in the use of rod pumps as the lifting device in thermally stimulated heavy oil ivells. These include rod floating and overloading due to high fluid viscosity, pump sticking and erosion with high sand production, heavy crude plugging, and gas locking under steamflood conditions. The inadequacies of the conventional beam pumps to meet the service demands of heavy oil production led to the development of alternate pumping techniques. These include modification of conventional pump jacks to alleviate some of the aforementioned problems, and novel pumps such as the diluent pumps, cavity pumps and chamber lift pumps.

These new breeds of pumps are still in the prototype stage and used principally in the heavy oil fields of Canada and Venezuela. In the United States, despite its drawbacks, rod pumps are used almost exclusively in the thermal operation. Insert type rod pumps are used in the United States thernal operation. Use of pump-off controllers and variable speed drives are used to extend the operating range of a given rod pump.

A list of thermal well lifting equipment vendors is included in Appendix 11-A. It is recommended that the operators follow the pump vendor's recommendation in selecting the appropriate lifting equipment for the production well. 


\section{REFERENCES}

1. The University of Texas-Lessons In Well Servicing and Workover-Artificial Lift Methods, Lesson 5-A home study course. Petroleum Extension Service, The University of Texas, Austin, Texas, 1971.

2. Beyea, D. F. and M. J. McKinnon. Optimizing Pump Speed Throughout Production Cycles. Pres. at the Fourth Annual Canadian Heavy Oil and Tar Sands Technical Symposium, Calgary, Alberta, Canada, Feb. 18, 1987.

3. Cockshutt, D. and W. Thomas. New Developments in Beam Pumping Technology: PC 3000. Pres. at the Canadian Heavy oil Association Thermal Well Completion Seminar, Edmonton, Alberta, Canada. Aug. 11, 1988. Proceedings of Thermal Well Completions Seminar, D. J. Theriault, Editor.

4. Sudol, T., R. Ridley and D. Nguyen. New Sucker Rod Pump Design for Sand Producing Wells. Pres. at the 5th UNITAR International Conference on Heavy Crudes and Tar Sands, Aug. 4-9, 1991, Caracas, Venezuela-R. F. Meyer, Editor. Heavy Crude and Tar Sands-Hydrocarbons for the 21 st Century, v. 2, published by Petroleos de Venezuela, S.A., Caracas Venezuela, October 1991.

5. Wong, A. and K. E. Frankiw. Analysis of Thermal Well Pumping Performance at the Norcen-Bodo Steam Pilot. Pres. at the Canadian Heavy Oil Association Thermal Well Completion Seminar, Edmonton, Alberta, Canada, Aug. 11, 1988.

6. American Petroleum Institute-Recommended Practices for Design Calculation for Sucker Rod Pumping System, API-RP IIL, 4th Edition. American Petroleum Institute, Division of Production, Dallas, Texas, June 1988.

7. Tomlinson, C. E. T. and R. J. Scot. The Application of a Hydraulic, Variable Speed Pumping Unit for Heavy Oil Production. Pres. at the 1st Annual Canadian Heavy Oil and Oil Sands Technical Symposium, Calgary, Alberta, Canada, Feb. 16, 1984.

8. Hogervorst, G. J. and T. B. Kimmel. Pump Jacks: A Changing Technology. Pres. at the 35th Annual Technical Meeting of the Petroleum Society of CIM, Calgary, Alberta, Canada, June 10-13, 1984. Paper No. 84-35-04.

9. Vonde, T. R. Specialized Pumping Techniques Applied to a Very Low Gravity, Sand Laden Crude - Cat Canyon Field, California - In The Future of Heavy Crude Oils and Tar Sands. First UNITAR International Heavy Oil Conference Proceedings edited by R. F. Meyer and C. T. Steele. McGraw-Hill Book Co., New York, 1981. Chapter 64. pp. 574-585. Also pres. at the 50th Annual California Regional Meeting of SPE, Los Angeles, California, Apr. 9-11, 1980. SPE paper 8900.

10. Caceres, C. A. and O. L. Cordero. Chamber Lift: Updating Technology and Putting It To Work. Pres. at the 5th UNITAR International Conference on Heavy Crudes and Tar Sands, Aug. 4-9, 1991, Caracas, Venezuela. Conference Proceedings, v. 2, R. F. Meyer, ed. Published by Petroleos de Venezuela, S.A., Caracas, Venezuela, October 1991.

11. Uzcategui, E. Application of Progressive Cavity Pump in Maraven's Heavy Oil Fields. Pres. at the 5th UNITAR International Conference on Heavy Crudes and Tar Sands, Aug. 4-9, 1991, Caracas, Venezuela. Conference Proceedings, v. 2, R. F. Meyer, ed. Published by Petroleos de Venezuela, S.A., Caracas, Venezuela, Octnber 1991. 
12. Westermann, G. W. Successful Application of Pump-Off Controllers. Pres. at the 52nd Annual Fall Tech. Conf. \& Exhib. of the Soc. of Pet. Eng., Denver, Colorado, Oct. 9-12, 1977. SPE paper 6853.

13. Acton, J. F. Pump-Off Controller Application for Midway-Sunset Cyclic Steam Operations. Pres. at the 1981 California Regional Meeting, Bakersfield, California, Mar. 25-26, 1981. SPE paper 9915.

14. Yoch, R. J., R. L. Williams and J. A. Jones. Pump-Off Control Application in Thermal Recovery Operations. Pres. at the California Regional Meeting, Ventura, California, Apr. 8-10, 1987. SPE paper 16366. 


\section{THERMAL WELL LIFTING EQUIPMENT SUPPLIERS}

\section{A. Rod Pump Vendors}

1. Trico Industries Inc.

15707 S. Main Street

Gardena, CA 90247

Telephone: (213) 516-5000

2. Lufkin Industries Inc.

P.O. Box 849

Lufkin, TX 75902-0849

Telephone: (409) 634-2211

3. Sunward Industries

6800 Hampden Avenue

Denver, CO 80224

Telephone: (303) 758-4141

4. Subsurface Pumping System Inc.

14711 Bentley Circle South

Tustin, CA 92680

Telephone: (714) 665-6867

5. Peterson Industries Inc.

2800 S. Peterson Road

Claremore, OK 74017

Telephone: (918) 342-1977

$$
\text { 1-800-388-7867 }
$$

B. Rod Pump Controls and Analysis

System: Pump Off Controllers

1. Delta-X Corporation

1000 S. Loop West, Suite 150

Houston, TX 77054

Telephone: (713) 748-1184

$$
\text { 1-800-231-9813 }
$$

2. Dura Controls Ltd.

5535-97 Street

Edmonton, Alberta,

Canada T6E-3H8

Telephone: (403) 437-5961 


\section{CHAPTER 12 \\ USE OF INSULATED TUBULARS IN THERMAL PROJECTS}

\section{INTRODUCTION}

Heat losses in the steam injection well can be very detrimental to a steamflood project. Unless efforts are made to minimize losses, the economics of the project can be severely impacted by increased energy costs and, in the case of deep reservoirs, the steam quality can be reduced to an unsatisfactory level. High heat losses can also raise casing temperatures to a level :hat risks failure under the stress of thermal expansion.

Insulated tubing is frequently used to minimize heat loss in the injection well, and maximize the downhole steam quality. This will also lower the longitudinal expansion and thermal stress in the casing.

The object of this chapter is to discuss briefly the wellbore heat losses and how they can be minimized using insulated tubing. The topics discussed include (1) wellbore heat losses; (2) advantages of using insulated tubing; (3) insulated tubing design requirements; (4) insulated tubing construction and selection criteria; (5) insulated tubing installation procedure; $(6)$ insulated tubing performance; and (7) insulated tubing cost effectiveness.

\section{Wellbore Heat Losses}

Generally, in thermal recovery of petroleum, low quality steam is used for injection so that low quality feedwater, free of hardness, may be used to generate steam. Because the saturated steam carries less heat than superheated steam, it is important that the steam reach the formation with as little heat loss as possible. As deeper formations are considered, the heat losses in the wellbore become even more important.

Crawford ${ }^{1}$ has shown that for 2.5 in. tubing in a 7-3/8-in. casing, the heat losses in Btu's/d may be approximated from a chart. Fis example was developed for a well depth of $1,000 \mathrm{ft}$ in which $250 \mathrm{bbl} / \mathrm{d}$ of $400^{\circ} \mathrm{F}$ steam was injected. The total heat loss could range from 1 million Btu's/d up to more than 16,000,000 Btu's/d. This depends on the overall heat transfer coefficient between the tubing and the formation. This coefficient ranges from 5 for the lower figure to 240 for the higher loss. For uninsulated tubing, a reasonable value for the coefficient is between $\mathbf{8 0}$ and 160, giving a total heat loss between 10,000,000 and 15,000,000 Btu's/d, or approximately 15,000 pounds of steam condensed per day. This is equivalent to 45 burrels of water. For deeper wells, the loss becomes even greater; at $2.000 \mathrm{ft}, 100$ barrels of con ensation, and at 5,000 to $6,000 \mathrm{ft}, 200$ barrels.

The important variables in calculating the heat loss are the diameters of the tubing and the casing, the temperature and pressure of the injected steam, and the depth of the well. Equations have been developed by Ramey ${ }^{2}$ and Satter $^{3}$ but they are complicated, and tedious calculations are 
necessary to apply them. However, charts have been prepared by Huygen and Huitt, ${ }^{4}$ and they are much easier to apply. One of these charts is shown in figure 12.1. This chart is for 2-1/2-in. tubing in 5-1/2-in. casing, and gives heat losses both for injection into the casing and injection through the tubing. For $400^{\circ} \mathrm{F}$ steam injected through tubing, the heat losses for the first day would be $600 \mathrm{Btu} / \mathrm{hr}$ - $\mathrm{ft}$. For the 1,000 ft well, the daily loss would be 14.4 million Btu. After a year, this would decrease to 9.6 million. Using a chart for 7 -in. casing, these numbers do not change appreciably. They check reasonably well with the previous calculation. It is of some interest that injection through the casing would increase these values for heat loss to 36 million Btu and 14.9 million Btu.

These losses have caused a number of studies to be made for methods of improving the efficiency of steam delivery. One showed that a packer at the bottom of the well would prevent steam from coming back up the annulus between the tubing and the casing. An attempt to use an insulating fluid in the annulus gave problems largely due to decomposition of the fluid. ${ }^{5}$ Painting the outside of the tubing with aluminum paint gave some success but is difficult to apply. Willhite ${ }^{9}$ has shown how these procedures affect the heat transfer coefficient in figure 12.2.

\section{Benefits of Using Insulated Tubing}

The most successful method of reducing wellbore heat losses is to use insulated tubing. A comparison of the heat losses by Davis et al. ${ }^{6}$ is shown in figure 12.3. Uninsulated 2-7/8-in. tubing in a 7-in. casing was compared to insulated tubing similar in size over the range of 1,000 to 3,000 ft well depth. The benefit of the insulation is increased as the depth of the well increases. Besides the obvious savings in the amount of steam used, there is an indirect savings in the ability to use a smaller generator capacity with consequent savings in capital investment.

Not only is insulation very effective in reducing heat losses, it also results in a lower casing temperature. This lower temperature reduces the stresses that are placed on the casing and cement by expansion. The prevention of casing failure due to heat stress is an important factor. Steam injection down wells with poor cement bonding, inadequate or unsupported casing leads to casing failure. The cause of the failure is excessive variation of casing temperature.

\section{Insulated Tubing Design Requirements}

Different criteria are necessary for cyclic injection and steamfloods. In the former, the well is used for both injection of steam and for production of oil. In early stimulations, the steam was injected down the annulus between the tubing and the casing. Later the steam was injected down the tubing with the rods and pump intact.

The tubulars used to conduct the steam downhole into the oil-bearing formation present different requirements from surface line applications and, therefore, require different design 


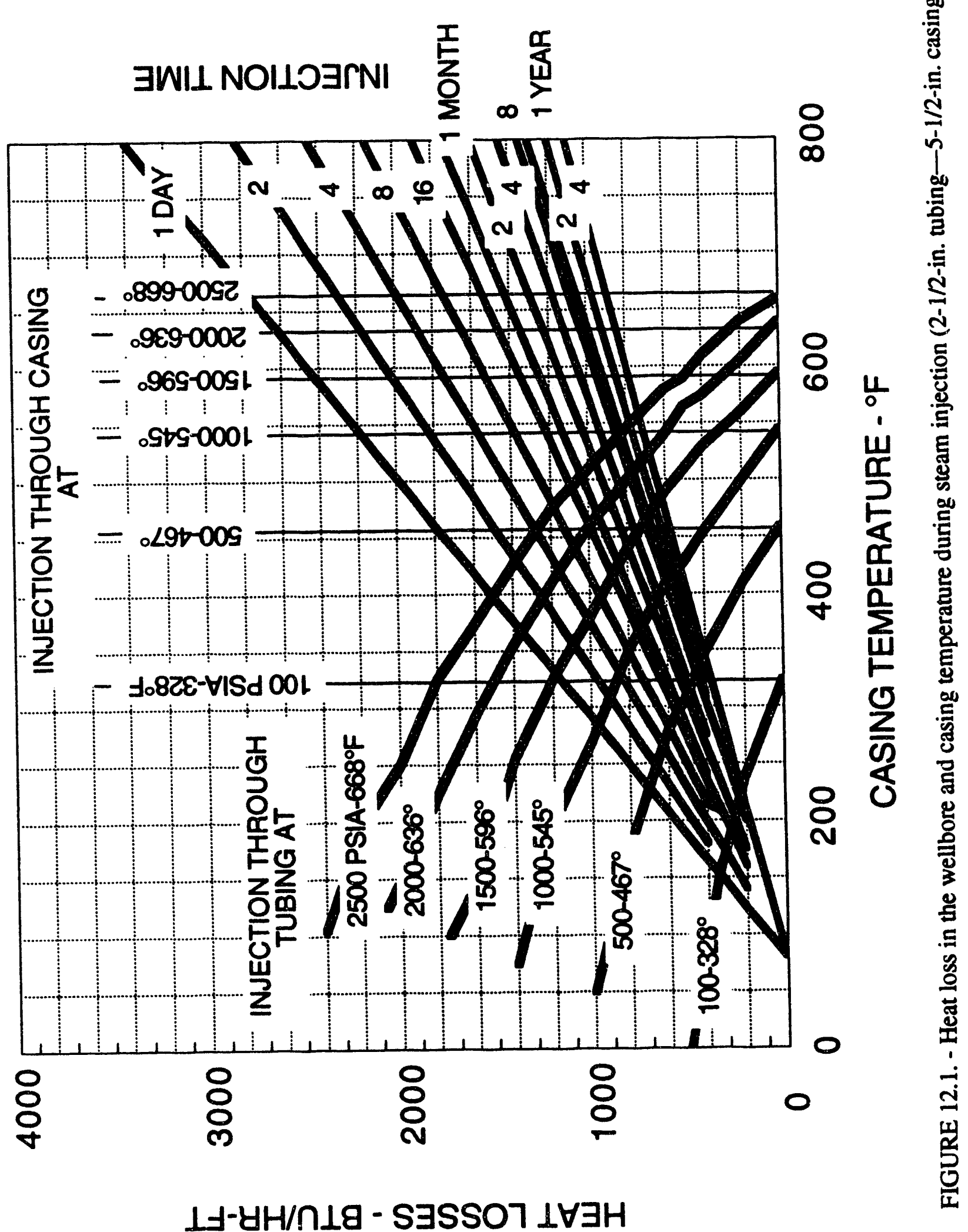




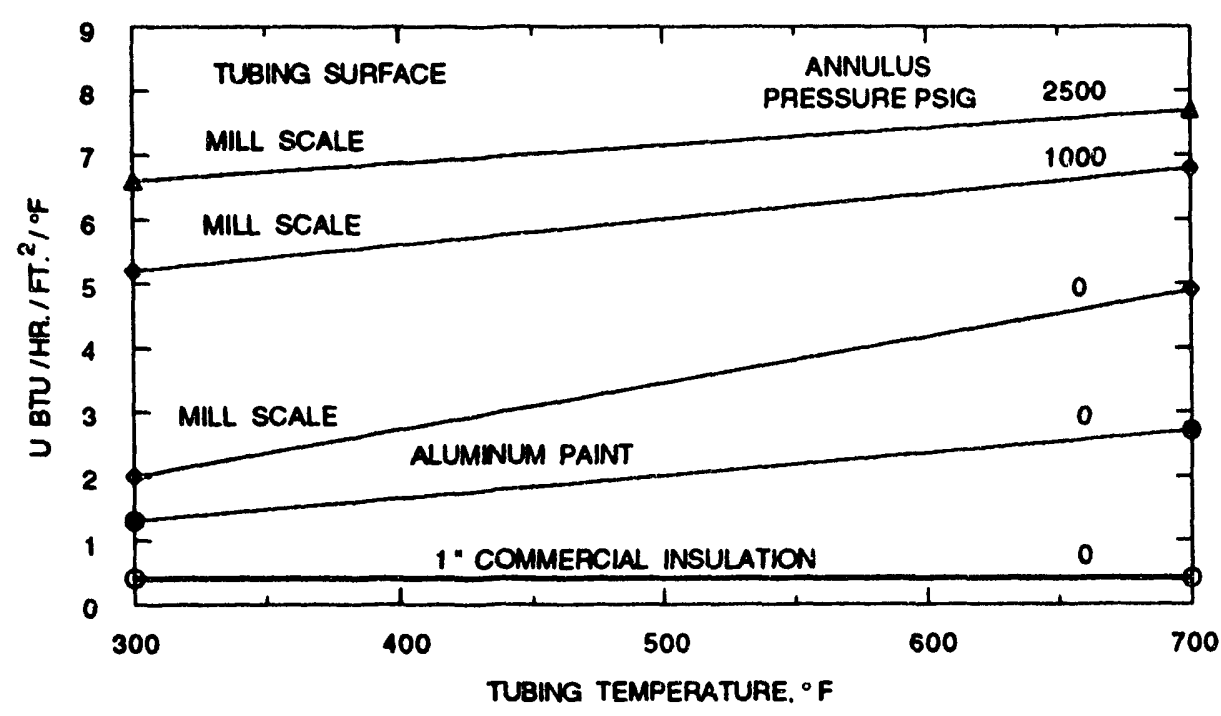

FIGURE 12.2. - Variation of overall heat transfer coefficient (U) with tubing temperature for different tubing surfaces and annulus pressure. ${ }^{9}$

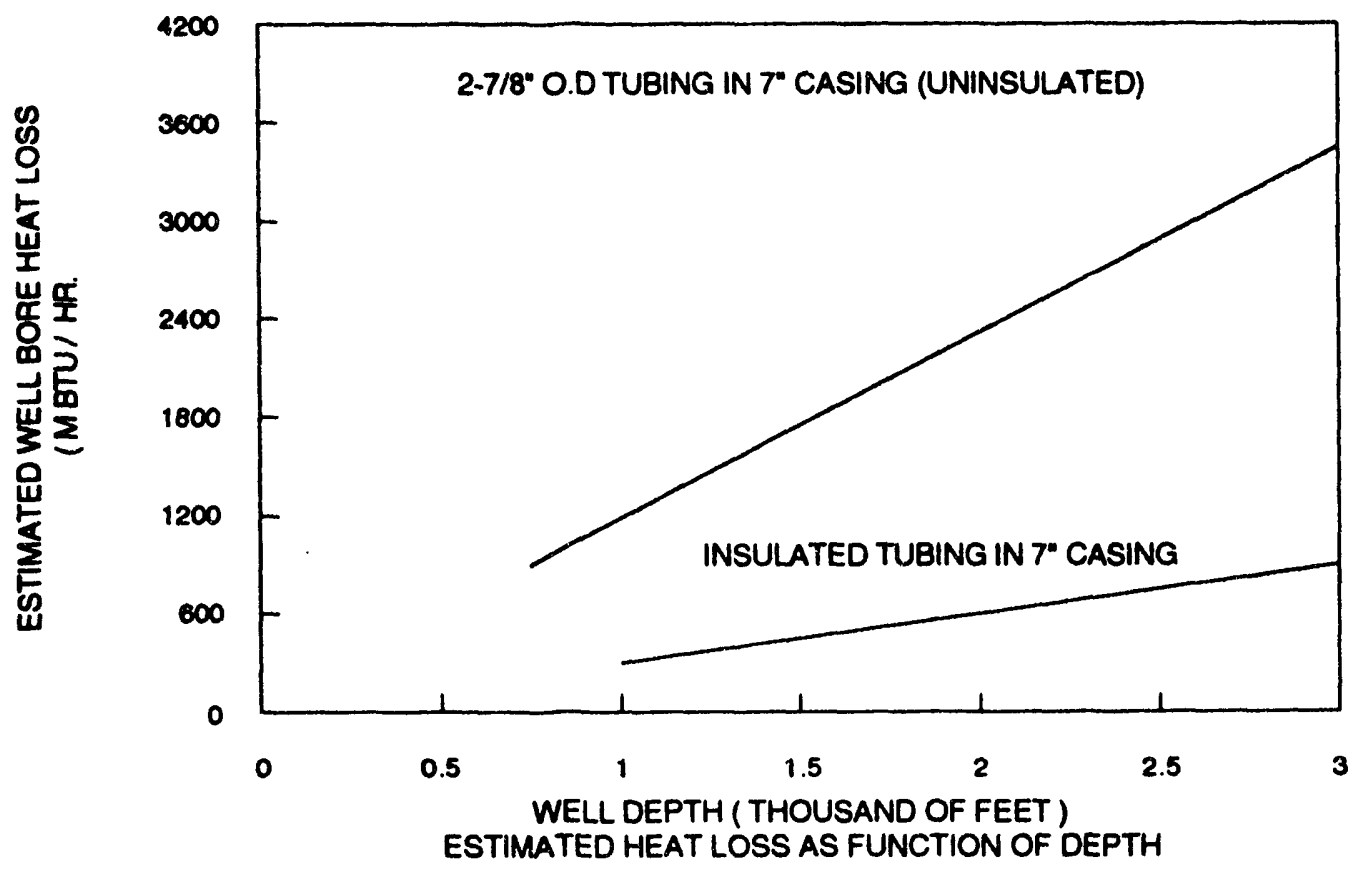

FIGURE 12.3. - Estimated heat loss as function of depth. ${ }^{6}$ 
approaches than insulated surface lines. The in-well tubulars must be of restricted diameters to conform to well-casing size. Sufficient casing clearance and size tolerance must be provided to accommodate couplings and the effects of well deviation from vertical. The insulated tubular must be able to sustain the various loads associated with vertical running and pulling as well as the need to support its own weight when suspended from the wellhead.

The environment of the well is such that corrosion resistance to well fluids and sour gas is also a problem not faced by the surface-line insulation. To satisfy these special needs, the design trend for insulated tubulars has been to use an inner API tube to convey the steam and an outer API tube to carry the loads and protect the insulation in the sealed annulus between the tubes. In these dual tube applications, with an inner tube diameter of 2 in. or greater and an outer tube of 4.5 to 6 in. diameter, the limit of net insulation thickness is approximately 1 in. This requires highly effective insulation material and a relatively large differential expansion across a small gap due to thermal differences from the inner to the outer steel tubes.

\section{Insulated Tubing Types and Selection Criteria}

Two basic designs of insulated tubulars can be classified as: (1) prestressed concentric insulated tubing, and (2) double wall tubulars with expansion bellows. 6 They are shown in figure 12.4 .

Welding the inner tube to the outer tube provides mechanical and sealing integrity of the insulating media. Weld placement and follow-up heat treating affect the thread profile.

Prestressing the inner tube compensates for thermal stress differences between it and the outer tube. During steam injection the high temperature inner tube tends to expand more than the lower temperature outer tube. Resultant compressive loads on the inner tube without adequate inner tube prestressing could cause the tubing to tail. Required prestress depends on the relative tubing sizes as well as the expected temperature variations. Insulated tubing, used for both injection and production, requires design flexibility allowing for the outer string being both hotter and cooler than the inner string.

The threads must provide a satisfactory mechanical connection to prevent leakage. Use of a strong connection with a sealing element accomplishes this purpose.

An example of the double-wall tubular is the Kawasaki Thermal Systems (formerly General Electric Co.) Therm Case ${ }^{\mathrm{TM}}$ insulated tubular. The most often requested size is the combination of a 2-3/8-in. tube as the steam conductor and 4-1/2-in. API tubing as the outer covering of the insulation. The patented insulated tubular, figure 12.5, uses a multilayer fiber and foil insulation in a reduced pressure inert gas environment to achieve thermal isolation. The inner and outer tubing are hermetically sealed at each end of the 40-ft joints through a metallic bellow welded to each tube. 


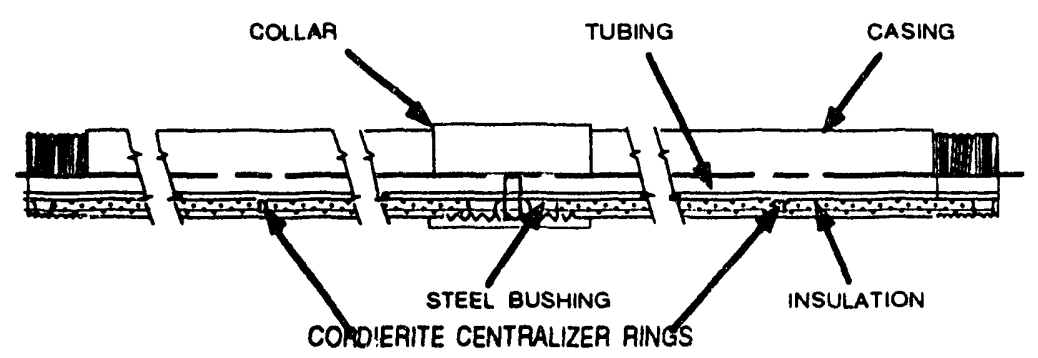

B. DOUBLE WALL WIH BELLOWS

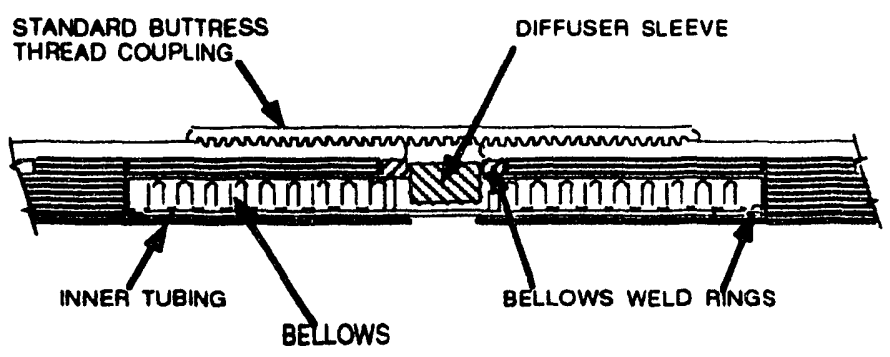

FIGURE 12.4. - Schematic of basic insulated tubular designs. 6

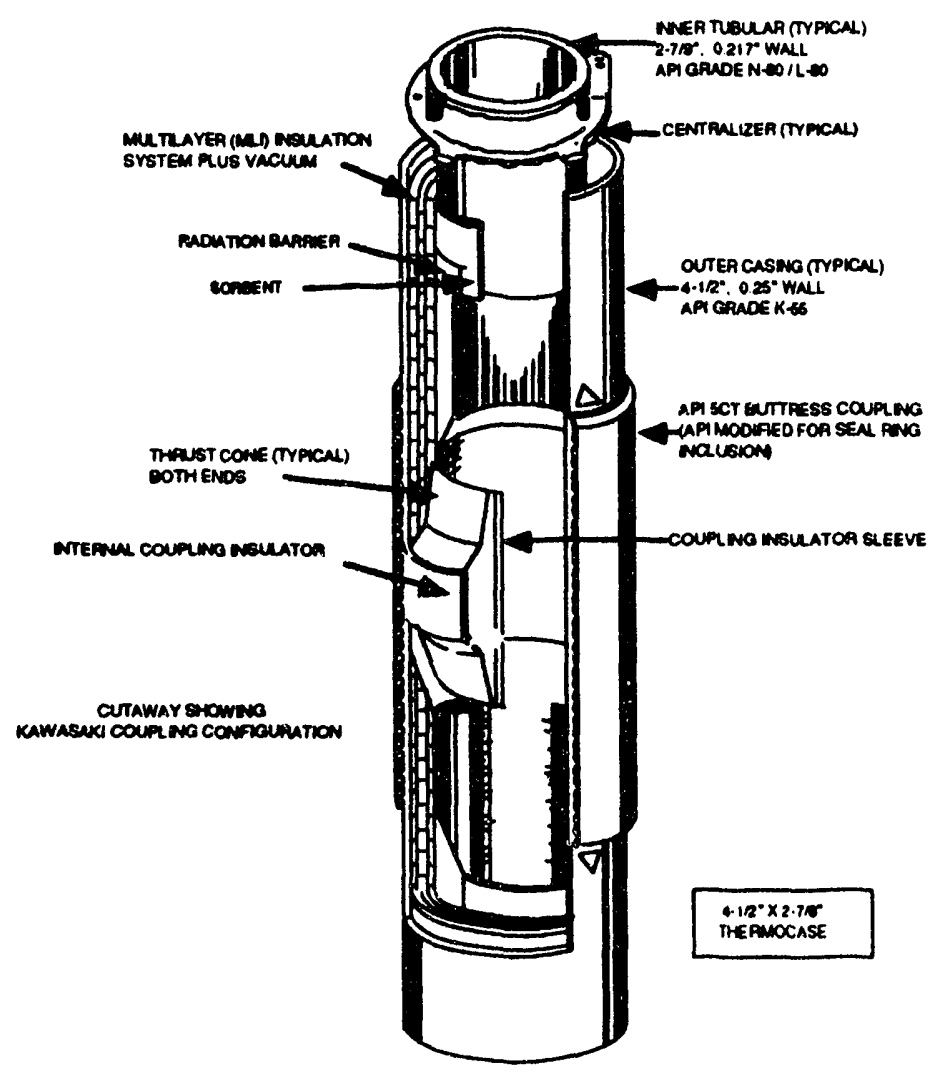

FIGURE 12.5. - Typical insulated tubing construction. ${ }^{10}$ 
The individual assemblies are joined by conventional threaded couplings secured at the time of deployment into the well. The newest and most effective of the Thermocase ${ }^{r \mathrm{M}}$ series is the 750 model which has the insulation annulus at a high vacuum supported by gathering agents to maintain the vacuum. An exploded view of this insulated tubular is depicted in figure 12.6.

\section{Insulated Tubing Installation Procedures}

Completion designs are dependent on casing strength and location of other zones relative to the zone being steam stimulated. Three variations of the insulated tubing string completion design and reasons for their use can be cited. 7

1. Expansion joint immediately above the packer and water in the tubing/casing annulus. This design produced heat losses on noninsulated expansion joints capable of degrading cement above the steam zone.

2. Expansion joint at the surface with the annulus blown dry, packer immediately above perforations. The use of this design in old wells with $\mathrm{H}-40$ casing resulted in negligible boil off and no casing damage. Concern over compressional loads causing packer failure or cork screwing of the tubing limited the design to shallow wells.

3. No packer or expansion joint, tubing bottom at perforations. This was the least expensive insulated tubing completion and was used where cement integrity immediately above the steam stimulated zone was unimportant. Adequate strength casing was necessary to prevent casing failure. This design resulted in highest overall heat losses.

Use of shorter (Range 2) length tubing permits easier handling on slant and small service rigs. The tubing will not bow as much as on longer tubing resulting in less likelihood of thread galling due to misalignment, especially with slant rigs. Rig operating times are less with the Range 2 tubing strings.

The use of thermal packers with thermoplastic elements and external expansion joints have been useful in avoiding operational problems including steam leakage at high pressures. Some packers have inadequate springs in the packer setting mechanism and the springs take on a permanent set and do not function properly on packer release, but this is corrected by using highertemperature rated springs. Operational problems with packers are more common on deviated wells.

The critical time when handling insulated tubing was with the tubing and the casing hot. Some precautions that can be taken to minimize the risk of failure include:

Flow wells back. This allows well cooling and takes advantage of high production rates.

Pump hot kill fluid down the tubing after the well dies. The tubing can be picked up and hung free, the well remains dead.

Unset and leave packers to allow contraction before attempting to pull them out of the hole. 


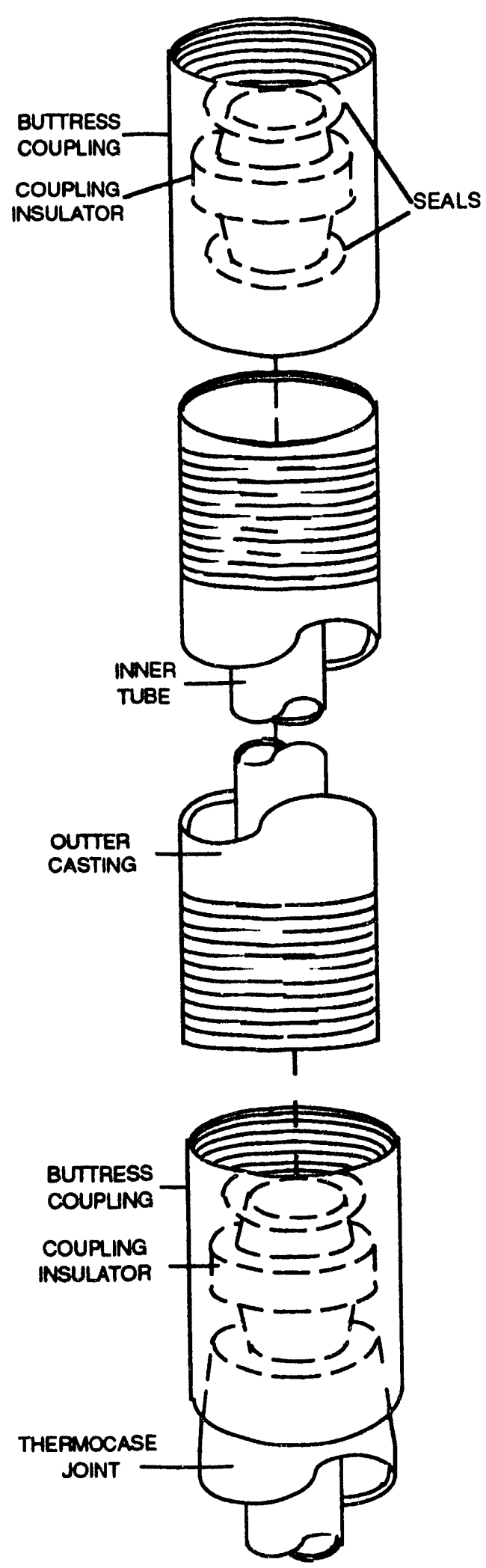

FIGURE 12.6. - Exploded view of a field installed insulated tubular. ${ }^{10}$ 


\section{Insulated Tubing Performance}

As an example of the benefits of insulated downhole steam injection tubing, overall heat losses were evaluated for uninsulated 2-7/8-in. tubing and insulated tubing in a 7-in. casing. Actual wellbore losses are strongly influenced by the quality of well installation, specific reservoir characteristics, and several other factors. In this evaluation overall heat losses were conservatively analyzed by a method proposed by Ramey ${ }^{2}$ on an equivalent basis for insulated and uninsulated tubing. As illustrated in figure 12.3, heat losses in the injection well are a primary function of wellbore configuration and well depth and are independent of steam flow over a range of practical applications. Thus, the impact of wellbore heat losses, particularly for uninsulated tubing, becomes more significant at greater well depths and lower per-well steam-injection rates. The use of insulated tubing can reduce the wellbore heat loss by over $70 \%$ compared to uninsulated tubing.

\section{Insulated Tubing Cost Effectiveness}

An example of the cost effectiveness of insulated tubing is given in table 12.1. The insulated tubing chosen is Kawasaki Thermal Systems Thermocase ${ }^{T M}$ tubing. Although this tubing is expensive ( $\$ 40 / \mathrm{ft})$, it is widely used and durable. In the table it is compared with bare injection tubing. The case chosen is for a well 3,000 ft deep and the use of steam at $596^{\circ} \mathrm{F}$ and 1,500 psia.

As shown in the table, the heat loss for the bare tubing is $45.9 \%$ while that for the insulated tubing is only $14.6 \%$. The payout is shown for $\$ 14$ oil to be 11.8 months. Thus, the insulated tubing should pay out in a relatively short time for well depths greater than $3,000 \mathrm{ft}$ and at steam rates of less than $15,000,000 \mathrm{Btu} / \mathrm{hr}$.

\section{SUMMARY}

Heat losses in the wellbore are quite appreciable and become greater as the depth of the well increases. Consequently, much consideration has been given to methods for minimizing these losses. Isolation of the tubing from the cusing by a packer gives some improvements as does painting the tubing with aluminum paint. However, the most effective method is to insulate the tubing. This has been shown to be cost effective with a payout of less than 2 years. Vendors such as the one listed in Appendix 12-A can help in the design and selection of insulated tubulars for steam injection wells. 
TABLE 12.1. - Cost Effectiveness of Insulated Pipe

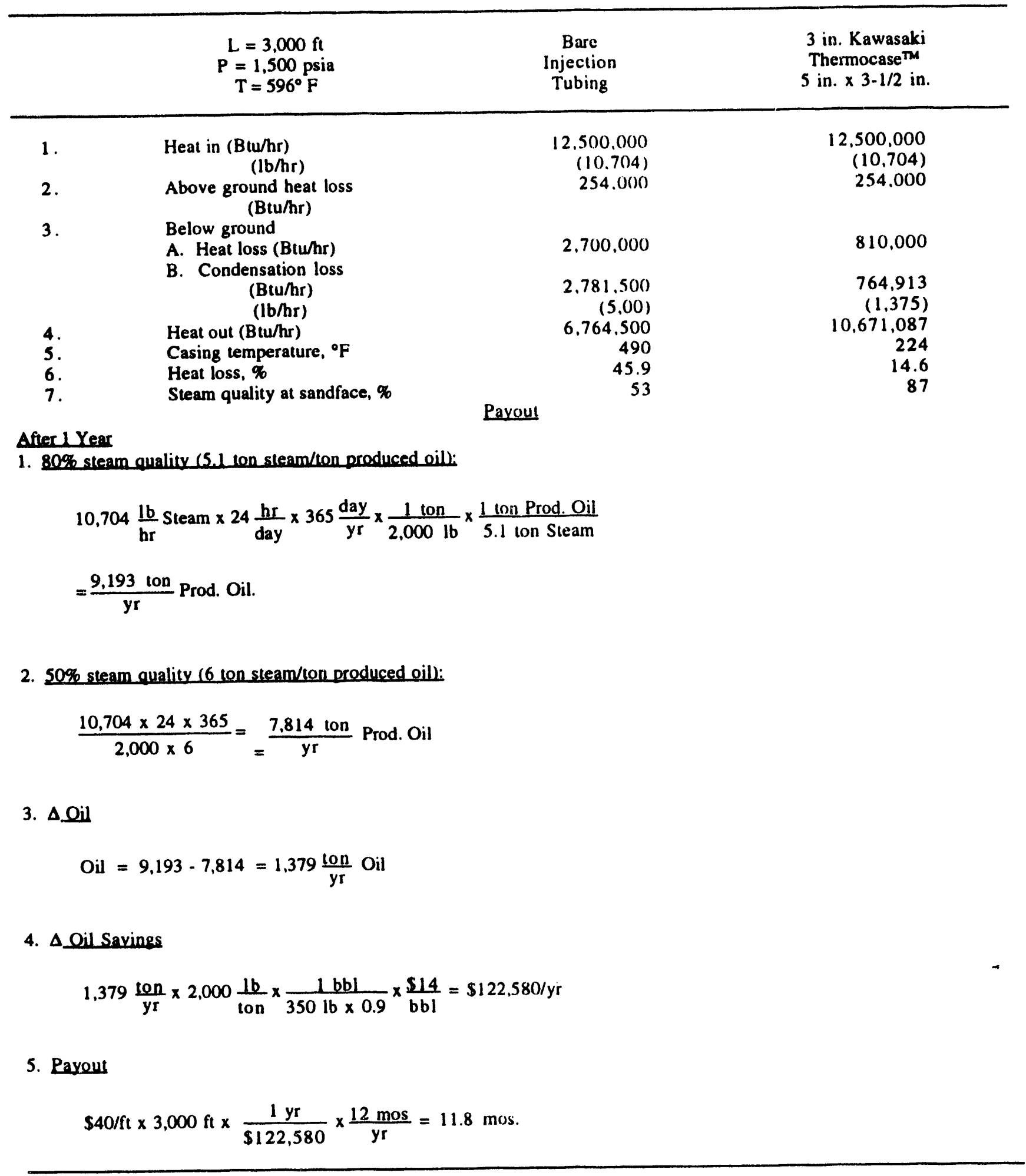




\section{REFERENCES}

1. Crawford, Paul B. Heat Loss When Injecting Steam Down Tubing in Thermal Recovery Programs. Producers Monthly, v. 30, No. 11, November 1966, pp. 16-17.

2. Ramey, H. J., Jr. Wellbore Heat Transmission. J. Pet. Tech., v. 14, No. 4, April 1962, p. 427.

3. Satter, Abdus. Heat Losses During Flow of Steam Down a Wellbore. J. Pet. Tech., v. 17 , No. 7 , July 1965 , pp. $845-851$.

4. Huygen, Hans H. A. and J. L. Huitt. Wellbore Heat Losses and Casing Temperatures During Steam Injection. Producers Monthly, v. 30, No. 8, August 1966, pp. 2-8.

5. Willhite, G. P., J. H. Wilson and W. L. Martin. Use of an Insulating Fluid for Casing Protection During Steam Injection. J. Pet. Tech., v. 19. No. 11, November 1967. pp. 1,453-1,456.

6. Davis, J. S. and J. P. Fanaritis. The Application and Economics of the Use of Insulated Injection Tubing With Oil Field Steam Generators. Chapter 70) in The Future of Heavy Oil and Tar Sands, edited by R. F. Meyer, J. C. Wynn, J. C. Olson. Second International UNITAR Conf., Caracas, Venezuela, February 1982, McGraw-Hill, New York, pp. 675-684.

7. Kutzak, A. R. and D. W. Gunn. The Use of Insulated Tubulars in Thermal Projects. Pres. at the Soc. Pet. Eng. California Regional Meeting, Bakersfield, CA, Apr. 5-7, 1989. SPE paper 18810.

8. Wrobel, J. R. and J. Raydan. Applications Summary on the Use of General Electric Co. Thermocase $^{\text {TM }}$ Insulated Steam Tubulars for Thermal Recovery of Low API Gravity Crude. Chapter 67 in The Future of Heavy Oil and Tar Sands, edited by R. F. Meyer, J. C. Wynn and J. C. Olson. Second International UNITAR Conf., Caracas, Venezuela, February 1982, McGrawHill, New York, pp. 653-659.

9. Willhite, G. P.. Over-all Heat Transfer Coefficients in Steam and Hot Water Injection Wells. J. Pet Tech., v. 19, No. 5, May 1967, pp. 6(1)7-615.

10. Kawasaki Thermal System: Therm Case ${ }^{T M}$ Insulated Tubular Technical Bulletin. Kawasaki Thermal Systems Inc., Tacoma, WA, 1989. 


\section{APPENDIX 12-A \\ DOWNHOLE INSULATED TUBING SUPPLIERS}

1. Kawasaki Thermal Systems Inc.

5401 Business Park South.

Suite 223

Bakersfield, CA 93309

Telephone: (805) 328-9404 


\section{CHAPTER 13 \\ SAND CONTROL PROBLEMS}

\section{INTRODUCTION}

Some oil-bearing formations are so weakly held together that sand grains are produced with the oil. This presents several difficulties. If the sand is lifted to the surface, separation and disposal are required. It poses abrasion problems both to the tubing and to the pumps. It may clog flow patterns and reduce the production of oil. Clogging may occur in the formation itself or in the slots, perforations, or screens of the producing equipment.

While sanding may be a problem with primary production wells, the problem becomes much greater when steam is injected into the formation. Some of these extra difficulties may be mentioned. Steam dissolves the gravel packing at the bottom of the well as well as the formation sand. It pushes the gravel away from the screen and into the formation sand. The dissolved silica precipitates as the steam cools. The condensed steam swells clays and precipitates scales.

Because of the non-uniformity of the occurrence of the unconsolidated sands, it is difficult to give a general treatment of the problems. Each well must be evaluated on its own to give the most advantageous solution to the problem. However, there is a great deal of experience which can be brought to bear on the design.

This chapter will discuss some of the parameters used in deciding how to design the well completion. The subjects to be discussed are: (1) Occurrence and identification of problem causing sands, (2) Prevention of problems in producing wells, (3) Use of open-hole or gravelpack completion, (4) Screens, (5) Gravel packing (6) Design of gravel packs for steam injection processes, and (7) Chemical methods of sand control.

\section{Occurrence and Identification of Problem-Causing Sands}

Sand control must be considered if the well produces or is expected to produce sand grains with the oil. This is the result of producing from an unconsolidated sand formation. Unconsolidated sands range from the so-called "quicksand," in which the binding forces of the formation are very minor through the partially consolidated sand which releases some sand during oil production. Cores are difficult to obtain from"quicksand." Cores from the partially consolidated sand cores appear to be solid but crumble when handled.

Unconsolidated sands most frequently occur in the shallow tertiary formations which are the primary target oî steam stimulation operations. Sanding is a problem in California, in Alberta, Canada, in Venezuela, and other locations, but does not occur with sufficient regularity to be predicted from location alone. However, the occurrence of sand in nearby wells should alert the operator to be prepared for sand. 
Many times a steam stimulation project follows a period of production without stimulation, and the history of the primary production should indicate whether sanding is likely to be a problem. However, in wildcat or frontier situations, it may be worthwhile to conduct a test on the well before deciding on the completion method.

Testing usually involves producing the well at gradually increasing rates until either sand is produced, or the anticipated rate of production is reached. The test may be made either on the well or on a particular interval of the formation. If sand is produced, then sand control methods should be considered.

There are several ways in which logs can be used to predict the tendency of a well to produce sand. One such method is the combined modules technique, developed by Stein and Hiltie ${ }^{1}$ and is based on data from acoustic and density logs. The combined modules is compared with results from a weli test; and, assuming that all wells in the field are completed similarly, their values for the combined modules would show their tendency to produce sand. The lower the value, the less likely is the well to produce sand. A later report indicated a method for applying the combined modules to wells of different completion geometries. 'This uses a comparison of well parameters (production rate, formation volume factor, permeability, viscosity of reservoir fluid, number of perforations) to make the comparison with the test well. Another method is the mechanical properties log developed by Schlumberger which is based on resistivity, density, acoustic, and neutron logs.

Some wells produce sand free until water cuts increase significantly or until production problems occur. Consequently, it is necessary to be alert for signs of sanding after production starts. Some of the production problems that may be observed are: sucker rod pump failure by sand cutting or seizing; sand fill up in settling tanks or oil-water separators; and erosion of surface chokes and elbow and tee fittings by flowing sand. A common problem that starts sand flow in a producing well results when of slots in a slotted liner erode to the extent they no longer prevent sand entry.

\section{Prevention of Problems in Producing Wells}

Although it may seem obvious, it is much easier to take preventive measures rather than wait for problems to arise that require remedial treatment. The most important preventive measure one can take is to assure that the well is completed properly.

In an effort to minimize completion costs, many steam injection operators have adopted poor completion techniques. Wells should be completed in accordance with the best accepted practice for a given area. Although the use of underreamed open holes and conventional gravel packing systems are adequate in many California fields, they may not be satisfactory in other fields. Gravel packs in open hole wells sometimes tends to slump soon after the start of steam injection. In other 
cases, adaptation of open hole gravel packing techniques has resulted in the deposition of dirt and fluid loss additives on the formation and plugging of screens with solids. Some of this plugging is removed by the first steam that is injected, but this produces thief zones. This is due to both the solubility of silica in steam and the physical force of steam injection.

Surveys ${ }^{2,5}$ of steam stimulation projects have revealed a number of problems relating to sanding. These are shown in Table 13.1. To make an intelligent choice for a production program it is necessary to obtain as much information about the character of the formation as possible. For example, in some wells the production of sand leads to cavities which may cause the casing to deform; in other wells the sand body may be fluid enough to reconform and fill the space.

\section{Use of Open-Hole or Gravel Pack Completion}

Canadian reservoirs have encouraged more experimentation in sand control because of the pervasive occurrence of unconsolidated sand. The early wells were completed with open hole completion and underreaming. This was based on the assumption that open hole completion would result in higher production and that the sand could be handled above ground. Special pumping methods, downhole equipment, and surface facilities were developed to handle uncontroiled sand production economically. Indeed, in areas where sanding is a minor problem, this approach is still used. Today, open hole completion is more prevalent in California heavy oil fields than in Canada.

Sand flow from unconsolidated formations can be controlled through chemical or mechanical means to prevent or correct a variety of potentially serious and costly problems, such as production loss caused by sand bridging in casing, tubing, and/or flowlines; failure of casing or liners from removal of surrounding formation by compaction and erosion; abrasion of downhole and surfare equipment; and disposal of produced formation materials.

Some of the first efforts to prevent the sand from being produced involved screens-a technique long used in water wells. Amoco Canada ${ }^{(3)}$ experimented with four configurations in the Lindbergh field:

1. Wire-wrapped screen gravel-packed inside casing,

2. Wire-wrapped screen gravel-packed inside open hole,

3. Wire-wrapped screen inside open hole without gravel pack (i.e., "barefoot" screen)

4. Wire-wrapped screen inside perforated casing without gravel pack.

All systems were found to be effective in controlling sand, but all showed lower production rates than offset producers. The "barefoot" open-hole completion had the highest production but is not suited to formations with interbedded water and gas or with poor hole stability. It was decided that the wire-wrapped screen inside perforated casing was most suitable for the Lindbergh field. 
TABLE 13.1. - Sanding Problems Encountered in U.S. Steam Stimulation Projects

\begin{tabular}{|c|c|c|c|}
\hline Location & Problem & Sohution & Reference \\
\hline $\begin{array}{l}\text { Kern River Field } \\
\text { California }\end{array}$ & $\begin{array}{l}\text { Sanding: } \\
\text { Pump Life 3-4 mos. } \\
\text { Liner scralched each } \\
\text { time it was pulled }\end{array}$ & $\begin{array}{l}\text { Wire wrapped screen } \\
\text { inside open hole }\end{array}$ & (2) \\
\hline $\begin{array}{l}\text { Midway Sunset Field } \\
\text { California }\end{array}$ & $\begin{array}{l}\text { Severe sanding with } \\
\text { jet perforations }\end{array}$ & $\begin{array}{l}\text { Use of } 65 / 8 \text { inch } \\
50 \text {-mesh foamed-in-tight- } \\
\text { hole stotted liners }\end{array}$ & (2) \\
\hline $\begin{array}{l}\text { Mount Poso Field } \\
\text { California }\end{array}$ & $\begin{array}{l}\text { Failure of lead seal } \\
\text { adapter at the liner lop } \\
\text { Inadequate gravel packing }\end{array}$ & $\begin{array}{l}\text { Replaced adapter } \\
\text { Sodium aluminate } \\
\text { consolidation treatment }\end{array}$ & (2) \\
\hline $\begin{array}{l}\text { Tatums Field } \\
\text { Oklahoma }\end{array}$ & Sanding & $\begin{array}{l}\text { Gravel-packing inside } \\
\text { open hole (no screens) }\end{array}$ & (2) \\
\hline California Fields & Sanding & Gravel-Packing & (5) \\
\hline
\end{tabular}

Dome Petroleum, on the other hand, investigated 4 sand control methods including open hole, gravel pack, and cased completions with screens. Dome decided that cased hole would work the best in Lloydminster fields. Conclusions on the use of screens are shown in table 13.2. Dome concluded that each project had different constraints on the producing wells, which were not compatible with screen usage (e.g., high gas rates or tough emulsions), but that wire-wrapped screens inside casing resulted in an effective completion and improved a specific well's cash flow. They recommended research be performed to find a better method of pumping fluid containing high sand cuts.

\section{Screens}

The simplest, most consistently reliable approach to sand control is the application of mechanical sand retention devices. Screens, slotted liners, and gravel are used. In this aspect of sand control technology, the most important single design consideration is the proper sizing of linear openings or gravel pore space relative to producing formation particles.

Formation grain size is required to properly size mechanical devices for bridging or absolute stoppage, without undue limitation of flow capacity. This information is obtained through sieve analyses of representative samples of formation material. Formation samples may be obtained from sidewall samples or cores prior to completion. Cores provide the best source because sidewall, bailed, or flowed samples are subject to contamination.

When slotted liners or wire-wrapped screens are used for sand control without a gravel pack, slot width must be properly sized relative to the formation sand to be excluded. Coberly showed 6 that where sands have a broad size distribution, as in California, a slot width of twice the 
TABLE 13.2. - Use of Screens on Canadian Oil Sands. ${ }^{4}$

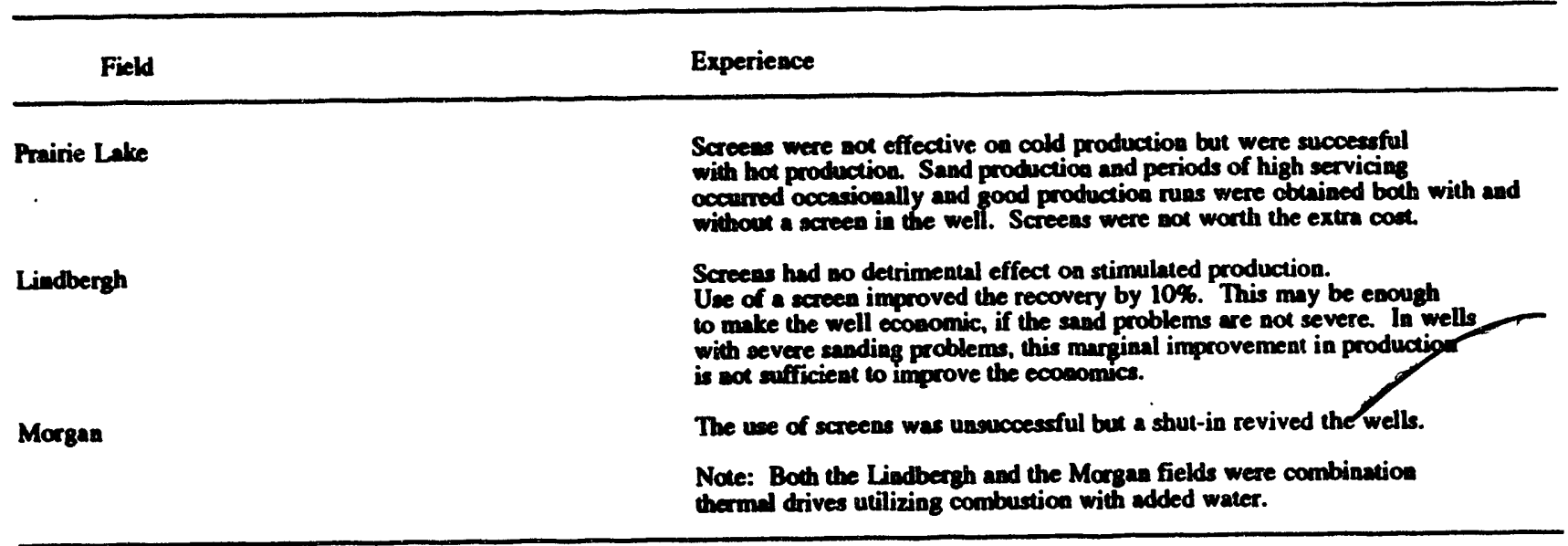

10 percentile diameter of the formation would facilitate bridging and retain most of the sand. The 10 percentile diameter is the theoretical sieve size that will pass $90 \%$ of the total formation sample. Where sands are more uniform and rounded, the recommendation may be to make the slot width equal to the 10 percentile diameter so that more of the sand will be retained. Slots may be tapered, with the small dimension on the outside of the liner or screen, so that it will be self cleaning.

Slotted liners 7 may be obtained with slots ranging from $0.012-0.50$ inches. While they have a relative low initial cost, there are disadvantages to their use. The smallest slot widths may be too large for some producing formations. Compared to wire-wrapped screens they have a relatively small inlet area and, because they are made from low carbon steel, are somewhat subject to corrosion or erosion.

Available wire-wrapped screen types include: wrapped-on-pipe, grooved type, ribbed type, and all-welded (Fig. 13.1). The wire is normally stainless steel wrapped on $\mathrm{J}$ or $\mathbf{K}$ grade pipe. Slot openings as narrow as 0.003 inch can be obtained. Wire-wrapped screens are less subject to corrosion/erosion than slotted pipe, and they have greater flow capacity. The wrapped-on-pipe screen has the least flow capacity, and the all-welded screen has the highest flow capacity.

\section{Gravel Packing}

The use of a gravel pack is the most common procedure in the control of sand. The term "gravel" is a misnomer, as a fine sand is the usual medium. The size of the gravel is selected similarly to the selection of slot size for screens. The sieve analyses of the formation sand are used to determine the size of the gravel which will satisfactorily retain the formation sand when the well is producing oil. 


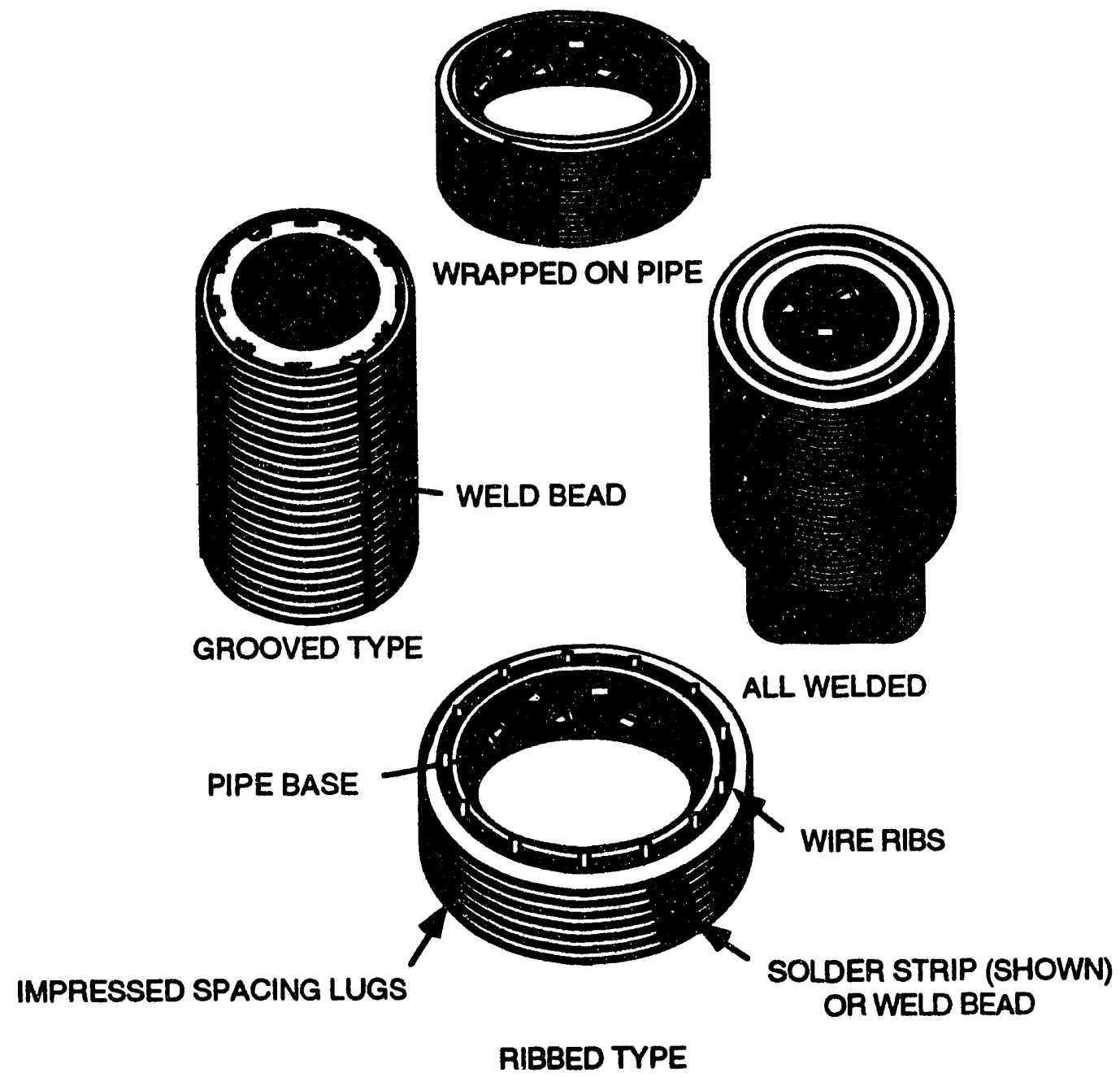

FIGURE 13.1. - Types of Screens. 7

The median size of the formation sand grains is obtained from the sieve size, which will pass $50 \%$ by weight of the sand. The diameter of the sand grain corresponding to that sieve size is obtained $^{8}$ from table 13.3. According to work by Saucier, ${ }^{9}$ gravel six times that size will be most satisfactory (Fig. 13.2) with larger gravel allowing too much formation sand to pass and smaller gravel reducing the production rate. For example if the formation sand median is 140 mesh, the sand grain size is 0.0049 in. and six times that would be 0.0294 inch. The latter corresponds to 25 mesh, and referring to Table $13.4,10$ the commercial size sand would be 20-40 U.S. mesh.

There are three variations on gravel packing. The first involves packing the open hole, and this provides the highest production rate if the formation sand is retained sufficiently. The second 
TABLE 13.3. - Sand Sieve Sizes

\begin{tabular}{|c|c|c|c|c|c|c|c|}
\hline \multicolumn{4}{|c|}{ STANDARD SIEVE OPENINGS ${ }^{1}$} & \multicolumn{4}{|c|}{ STANDARD SIEVE OPENINGS ${ }^{l}$} \\
\hline \multicolumn{2}{|l|}{ MESH } & \multicolumn{2}{|c|}{ SIEVE OPENING } & \multicolumn{2}{|l|}{ MESH } & \multicolumn{2}{|c|}{ SIEVE OPENING } \\
\hline $\begin{array}{l}\text { U.S. } \\
\text { Series }\end{array}$ & $\begin{array}{l}\text { Tyler } \\
\text { Series }\end{array}$ & Inches & Millimeters & Series $^{\text {U.S }^{2}}$ & $\begin{array}{l}\text { Tyler } \\
\text { Series }\end{array}$ & Inches & Millimeters \\
\hline $\begin{array}{l}2 \overline{1 / 2} \\
3\end{array}$ & & $\begin{array}{l}0.315 \\
0.312 \\
0.265\end{array}$ & $\begin{array}{l}8.00 \\
7.925 \\
6.73\end{array}$ & $\begin{array}{l}25 \\
30\end{array}$ & $\begin{array}{l}24 \\
28\end{array}$ & $\begin{array}{l}0.0280 \\
0.0276 \\
0.0232\end{array}$ & $\begin{array}{l}0.71 \\
0.701 \\
0.589\end{array}$ \\
\hline $31 / 2$ & 3 & $\begin{array}{l}0.263 \\
0.223\end{array}$ & $\begin{array}{l}6.68 \\
6.73\end{array}$ & 35 & & $\begin{array}{l}0.0197 \\
0.0195\end{array}$ & $\begin{array}{l}0.50 \\
0.495\end{array}$ \\
\hline 4 & $31 / 2$ & 0.221 & 5.613 & 40 & & 0.0165 & 0.42 \\
\hline 4 & 4 & 0.185 & 4.699 & 45 & $\begin{array}{l}35 \\
42\end{array}$ & $\begin{array}{l}0.0164 \\
0.0138\end{array}$ & $\begin{array}{l}0.417 \\
0.351\end{array}$ \\
\hline 5 & s & $\begin{array}{l}0.157 \\
0.156\end{array}$ & 4.00 & so & 48 & $\begin{array}{l}0.0117 \\
0.0116\end{array}$ & 0.297 \\
\hline 6 & & 0.132 & 3.36 & 60 & 70 & 0.0098 & $\begin{array}{l}0.295 \\
0.250\end{array}$ \\
\hline 7 & 6 & $\begin{array}{l}0.131 \\
0.111\end{array}$ & $\begin{array}{l}3.327 \\
2.83\end{array}$ & 7 & 60 & 0.0097 & $\begin{array}{l}0.246 \\
0.210\end{array}$ \\
\hline 8 & 7 & 0.110 & $\begin{array}{l}2.83 \\
2.794\end{array}$ & 70 & 65 & 0.0082 & $\begin{array}{l}0.210 \\
0.208\end{array}$ \\
\hline 8 & 8 & $\begin{array}{l}0.0937 \\
0.093\end{array}$ & $\begin{array}{l}2.38 \\
2.363\end{array}$ & 80 & 80 & $\begin{array}{l}0.0070 \\
0.0069\end{array}$ & $\begin{array}{l}0.177 \\
0.175\end{array}$ \\
\hline 10 & & 0.0787 & 2.00 & 100 & & 0.0059 & 0.149 \\
\hline 12 & 9 & 0.078 & 1.981 & & 100 & 0.0058 & 0.147 \\
\hline 12 & 10 & $\begin{array}{l}0.0061 \\
0.065\end{array}$ & $\begin{array}{l}1.68 \\
1.651\end{array}$ & $\begin{array}{l}120 \\
140\end{array}$ & $\begin{array}{l}115 \\
150\end{array}$ & $\begin{array}{l}0.0049 \\
0.0041\end{array}$ & $\begin{array}{l}0.124 \\
0.1104\end{array}$ \\
\hline 14 & 12 & 0.0555 & 1.41 & 170 & 170 & 0.0035 & 0.088 \\
\hline 16 & 12 & $\begin{array}{l}0.055 \\
0.0469\end{array}$ & $\begin{array}{l}1.397 \\
1.19\end{array}$ & $\begin{array}{l}200 \\
230\end{array}$ & $\begin{array}{l}200 \\
250\end{array}$ & $\begin{array}{l}0.0029 \\
0.0024\end{array}$ & $\begin{array}{l}0.074 \\
0.062\end{array}$ \\
\hline & 14 & 0.046 & 1.168 & 270 & 270 & 0.0021 & 0.053 \\
\hline 18 & 16 & $\begin{array}{l}0.0394 \\
0.0390\end{array}$ & $\begin{array}{l}1.00 \\
0.991\end{array}$ & $\begin{array}{l}325 \\
400\end{array}$ & $\begin{array}{l}325 \\
400\end{array}$ & $\begin{array}{l}0.0017 \\
0.0015\end{array}$ & $\begin{array}{l}0.044 \\
0.037\end{array}$ \\
\hline 20 & & 0.0331 & 0.84 & & & & \\
\hline & 20 & 0.0328 & 0.833 & & & & \\
\hline
\end{tabular}

1 Chemical Engineers' Handbook, 3rd. Edition, MoGraw Hill.

2 Hydraulic Fracturing Proppane Screens used in U.S.

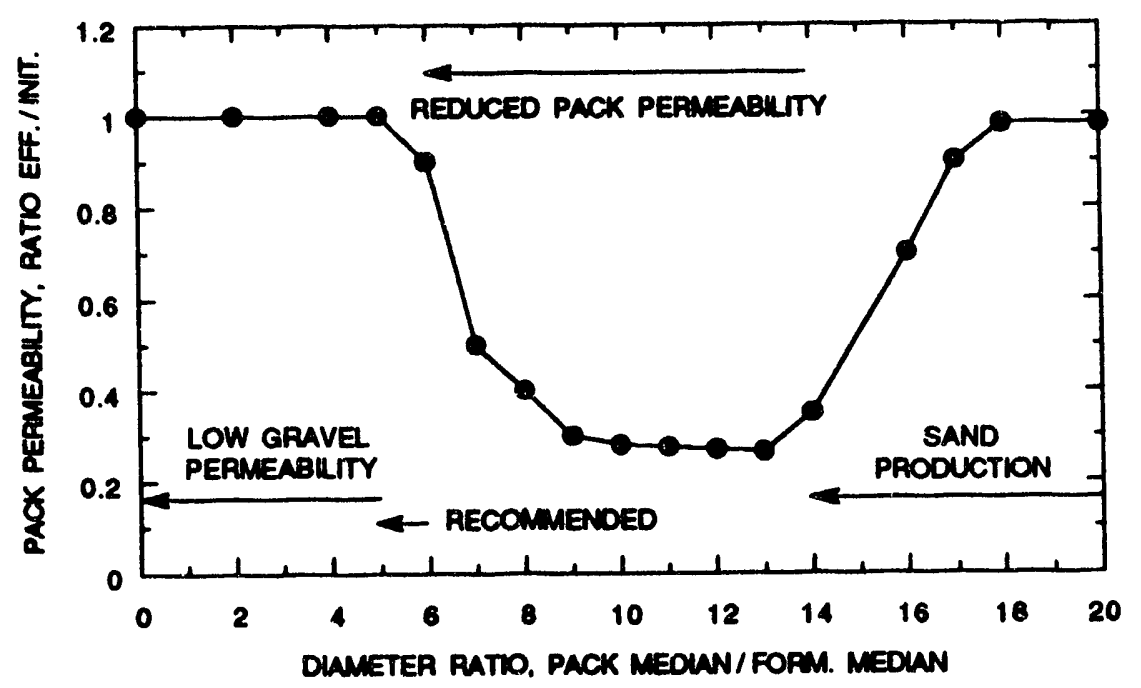

FIGURE 13.2. - Gravel size selection (After Saucier). ${ }^{9}$ 
TABLE 13.4. - Most Commonly Utilized Gravel Sizes for Sand Control

\begin{tabular}{lcc}
$\begin{array}{l}\text { Gravel size, } \\
\text { U.S. Mesh }\end{array}$ & $\begin{array}{c}\text { Gravel size, } \\
\text { in. }\end{array}$ & $\begin{array}{c}\text { Screen Gauge, } \\
\text { in. }\end{array}$ \\
\hline $8-16$ & $0.094-0.047$ & 0.028 \\
$12-20$ & $0.066-0.033$ & 0.02 \\
$16-30$ & $0.047-0.023$ & 0.016 \\
$20-40$ & $0.033-0.0165$ & 0.012 \\
$40-60$ & $0.0165-0.0098$ & 0.008 \\
\hline
\end{tabular}

involves packing the annulus between the liner and the casing. The third squeezes the gravel through the casing and the formation.

The procedure for gravel packing as outlined by Suman 11 for the third variation consists of six steps:

1. Run a wash tool with cup packers to clean the perforations and circulate out a cavity behind the cement. Backsurging may be used in low pressure wells that could be damaged by washing.

2. Prepack perforations by pumping properly sized gravel into the cavity outside the cement using a viscous fluid and high gravel concentration up to 15 pounds sand per gallon fluid $(1,800$ kilograms per cubic meter).

3. Apply squeeze pressure and drive fluid out of gravel to compact the perforation pack. Reverse out excess gravel.

4. Run screen and circulate gravel into place using viscous or non-viscous fluid.

5. Pull work string with screen wash pipe.

6. Run production tubing, latch into top of screen and set a production packer to keep screen pack in place.

Although laboratory tests 11,12 indicate that the severe conditions in the well might be expected to destroy the gravel pack, most installations seem to hold up fairly well. Vigilance is necessary to be sure that the pack is doing its work, and replacement may be called for if the sand production increases.

\section{Design of Gravel Packs for Thermal Wells}

To demonstrate the special requirements of a thermal gravel pack, the most basic hookup 14 will be discussed. The completion (Fig. 13.3) consists of a bull plug, high temperature screen, blank pipe, expansion joint, gravel pack extensions with sliding sleeve or a perforated extension, and a retrievable high temperature seal bore packer. The equipment deviations from a standard gravel pack are the high temperature screen, expansion joint, and high temperature packer. 


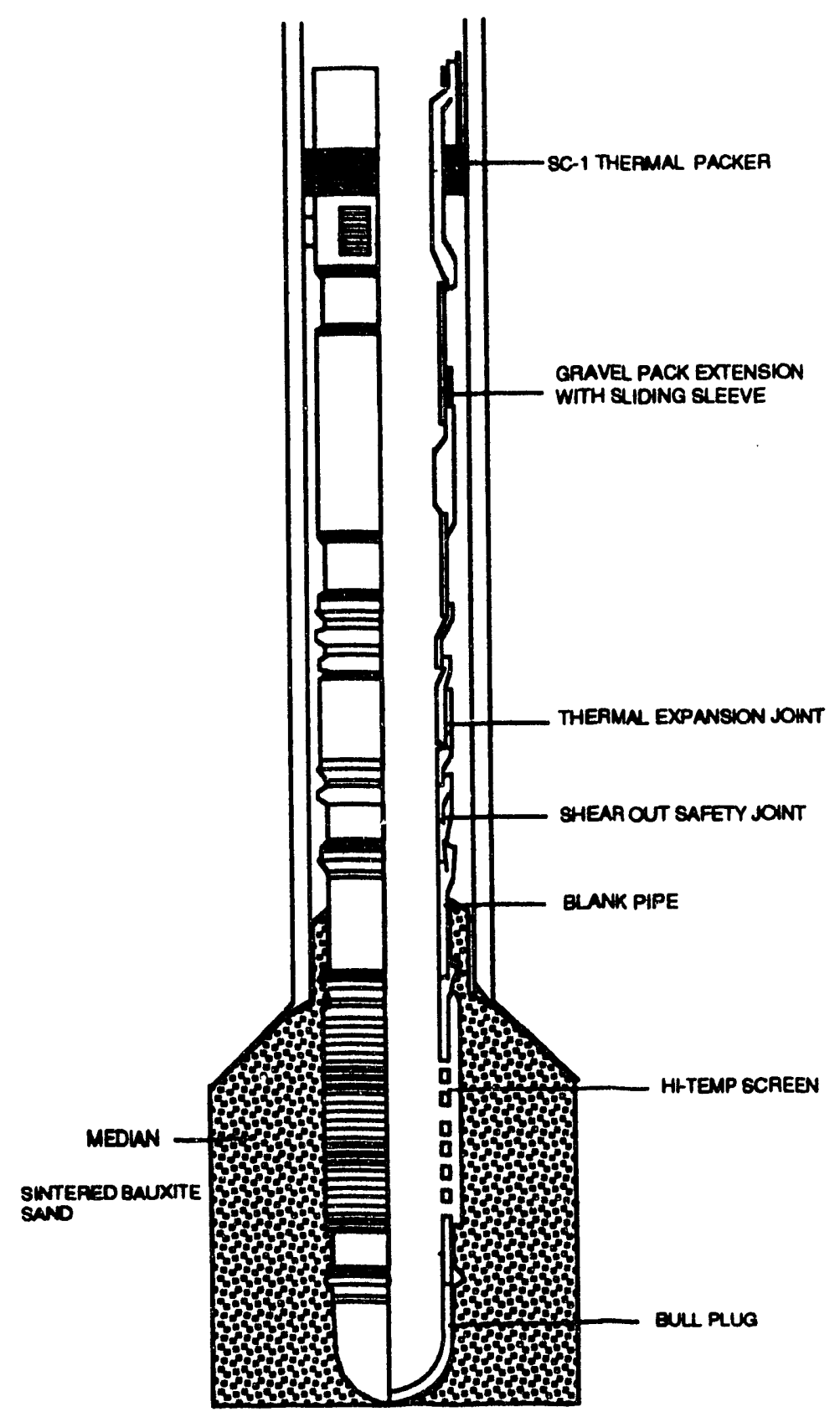

FIGURE 13.3. - Schematic of a thermal well gravel pack completion. 15

The most important element in a successful thermal gravel pack installation is the ability to retain sand both from the gravel pack or the formation without restricting production. The retention of sand is just as important as the inability to produce or inject because of plugging.

High Temperature Screens. Wire-wrapped screens and slotted liners are most commonly used to hold the gravel-pack material in place. A typical wire-wrapped screen for high temperature sand control application is shown in figure 13.4. Slot plugging has been shown to be a primary disadvantage of slotted liners and not a consequence of a wire-wrapped screen. This is 


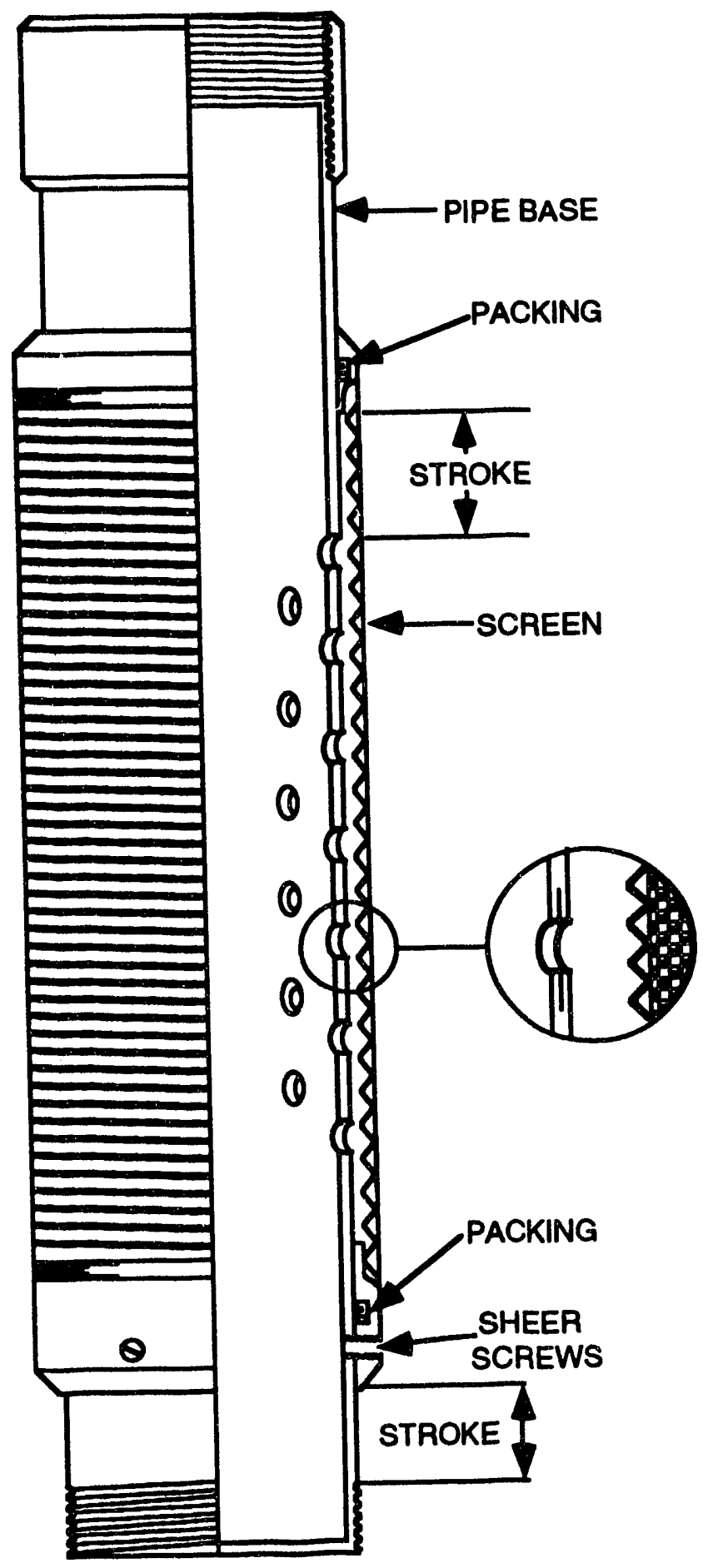

FIGURE 13.4. - High temperature screen. 15 
largely due to the slot opening being paralleled to the direction of expansion. As the slotted liner expands due to the temperature change, the gravel pack grains are "rolled" or forced into the slot opening, since the moving liner is in direct contact with the grains.

Slotted liners are generally designed to provide only $2.5 \%$ to $3 \%$ of their surface area open to flow. This is required to maintain the tensile strength. With such a small amount of area open to inflow, even a minor amount of plugging will restrict production. Slotted liners, with slots cut perpendicular to the axis pose significantly reduced tensile strength and are unsuitable for most applications.

Wire-wrapped screens offer a greater amount of open surface area, some 10 to 20 times that of an equal size slotted Liner. Successful screen designs must address one of the two consequences of thermal stimulation, i.e., resistance to thermally generated forces or allowance for expansion. Screen designs should permit a large ID screen which will not restrict production or injectivity, but the OD should be sized to provide a minimal radial clearance of 0.75 to $1.0 \mathrm{in}$. with the casing ID. This will facilitate gravel pack removal.

Expansion Joints. Expansion joints are run in the thermal gravel pack system to protect the screen assembly, gravel-pack extensions, and gravel-pack packer from forces caused by the screen base elongation and contraction. It is designed to prevent buckling of the blank pipe and screen assemblies by relieving the thermally generated forces. The system must be designed to allow for the expansion of the entire assembly. The expansion joint should be rotationally locked to facilitate removal of the gravel-pack assembly if necessary. 14

To eliminate space-out difficulty, and to ensure that the assembly is positioned on bottom, the expansion joint should be shear-pinned in the fully expanded position while running the assembly into the well. The packer is set and the gravel pack is performed with the expansion joint in position. When the forces caused by thermal expansion exceed the shear pin ratings, the expansion joint is activated and collapses to relieve the expansion forces.

The shear value of the pins should be adequate to prevent premature shear while landing the screen on the bottom, but must also be weak enough to shear before any damage occurs due to screen expansion. Normally a $14,000 \mathrm{lb}$ force shear rating is acceptable.

The high-temperature seal is the same as the high-temperature screen seal. Neither of these seals are exposed to large pressure differentials and primarily serve as barriers to movement of solids. Since the function is not that of a dynamic seal, premature wear and failure is not a concern.

High Temperature Packer: The primary objective of the gravel-pack packer is to create a seal that will perform satisfactorily for the life of the completion. The high-temperature packer is a retrievable, seal-bore packer which can be used both as a gravel-pack packer and an 
injection/production packer. The primary design consideration given to this piece of equipment is the selection of a packing element system.

Through the use of insulated tubing, heat losses can be minimized and a higher temperature steam can be injected into the formation. With the ability to reach a $550^{\circ} \mathrm{F}\left(290^{\circ} \mathrm{C}\right)$ downhole temperature and 2,000 psi (13,780 kPa) sandface pressures, conventional oilfield packing systems are not adequate. Packing elements that do not fail at high temperature must be used in the packing system to maintain sealing integrity. Carbon fibers, graphite; and, until recently, asbestos are used as packing elements in high temperature applications.

The bulk-material-packing-element systems typically utilize multiple packing elements and low-alloy-steel backup rings with wire mesh extrusion rings. These rings help support the bulk materials which are not resilient and therefore lack compression-set resistance. Compression-set resistance, a feature of elastomeric packing elements, is the elastic characteristic that maintains sealing integrity.

Some packers intended for thermal applications employ a metal-to-metal packing element consisting of soft alloys such as brass, lead, or aluminum. Such packing systems are very good gravel migration preventers but are generally capable of withstanding only a 1,500 psi $(10,300$ $\mathrm{kPa}$ ) pressure differential. Critical internal packer connections are typically sealed through the use of threaded metal-to-metal seals. With careful design and manufacture, these seals are effective in providing proper pressure containment at elevated temperatures.

\section{Chemical Methods of Sand Control}

Treatments to consolidate formation sand are available ${ }^{10}$ but are largely for low-temperature use. They consist of resins which are pumped into the formation and are allowed to set up either on a time schedule or by injecting a curing agent. Such resins are epoxy types, phenol formaldehyde, or furan resins. Generally, they are not used in steam stimulation wells because they are unstable at higher temperatures. The use of sodium aluminate to consolidate sanding wells has been reported. 7

\section{SUMMARY}

Sand control is an important consideration in steam stimulation of heavy oil because much of the heavy oil occurs in formations with unconsolidated sands. However, because its occurrence is not easily predictable, each well must be designed based on its specific characteristics.

In some instances, the preferable procedure is to produce the sand with the oil and perform the separation above ground. However, it is often more desirable to leave the sand in the formation. 
Although both mechanical and chemical methods are available for sand control, the mechanical techniques are usually the choice for thermal wells. These include slotted liners, screens, gravel packs, and various combinations of these. Special equipment for thermal wells include temperature screens, expansion joints, and high temperature packers. Vendors such as those listed in Appendix 13-A are well equipped to design a sand control program for thermal production wells and should be consulted.

\section{REFERENCES}

1. Stein, N. and D.W. Hiltie. Estimating the Maximum Production Rate Possible from Friable Sandstones Without Using Sand Control. J. Pet. Tech., v. 24, No. 9, September 1972, pp. 1157-1160.

2. Chu, C. State-of-the Art Review of Steamflood Field Projects. J. Pet. Tech., v. 37, No. 10, October 1985, pp. 1887-1902.

3. Lea, J.F., and D.W. Middleton. Development of Sand Control Techniques for Steam Stimulated Wells in the Lindbergh Field. Energy Processing/Canada (May-June 1986) 14-17.

4. Marjerrison, D.M., and J.A. Sayre. Dome Petroleum's Experience with Sand Control in Lloydminster Heavy Oil Fields. Pres. at the 38th Annual Technical Meeting of the Pet. Soc. of CIM, Calgary, Alberta, Canada, June 7-10, 1987. Paper No. 87-38-05.

5. Farouk, Ali, S.M., and R.F. Meldau. Current Steamflood Technology. J. Pet. Tech. v. 31 , No. 10, October 1979 , pp. 1332-1342.

6. Coberly, C.J. Selection of Screen Openings for Unconsolidated Sands. API Drilling and Production Practices, 1937, pp. 189-201.

7. Suman, G. O. Jr. World Oil's Sand Control Handbook. Gulf Publishing Co., Houston, TX, 1975.

8. Ayres, H. J., and J. Ramos. Guidelines to Sand Control-Part 2. Petroleum Engineer, v. 44 , No. 9, September 1972 , pp. 82-98.

9. Saucier, R.J. Considerations in Gravel Pack Design. J. Pet. Tech., v. 26, No. 2, February 1974, pp. 205-212.

10. Halliburton Services. Sand Control Brochure, 1974.

11. Suman, G. O. Jr, and R. E. Snyder. Sand Control Design Criteria and Gravel Packing Concepts. Pres. at the Soc. Pet. Eng. International Tech. Symposium, Beijing China, Mar. 1826, 1982. Paper SPE 10031.

12. Underdown, D.R. and Kamalendu Das. Stability of Gravel Packing Materials for Thermal Wells. Presented at the Soc. of Pet. Eng. International Symposium on Oilfield and Geothermal Chemistry at Denver Co., June 1-3, 1983. Paper SPE 11793. 
13. Sacuta, A., D.M. Nguyen, and G. A. Kissel. Stability of Nickel-coated Sands as a Gravel Pack Material for Thermal Wells. Presented at the Soc. Pet. Eng. California Regional Meeting, Oakland, CA, Apr. 2-4, 1986. Paper SPE 15058.

14. Weirich, J.B. and T.E. Zaleski. Thermal EOR requires special design for gravel packs. Oil Gas J., v. 84, No. 46, November 17, 1986, pp. 45-50.

15. Weirich, J. B. and E. T. Zaleski. Gravel Pack Equipment Requires Special Design for Thermal Recovery. Presented at the Canadian Heavy Oil Association Thermal Well Completion Seminar, Edmonton, Alberta, Canada, Aug. 11, 1988. Paper No. 3 


\section{APPENDIX 13-A \\ SAND CONTROL AND GRAVEL PACK SYSTEM VENDORS}

1. Baker Sand Control System 1010 Rankin Road

P.O. Box 61486

Houston, TX 77208-1486

Telephone: (713) 443-7590

2. Solum Oil Tool Corporation 2750 Rose Avenue

Signal Hill, CA 90806-1928

Telephone: (213) 427-5504

3. Halliburton Services

Drawer 1431

Duncan, OK 73536

Telephone: (405) 251-3760

4. Guiberson Division

Dresser Industries

P.O. Box 6504

Houston, TX 77265

Telephone: (713) 750-2301

5. Houston Well Screen Company

11939 Aldine Westfield

Houston, TX 77039

Telephone: (713) 449-7261

6. Otis Engineering Corporation

P.O. Box 819052

Dallas, TX 75381-9052

Telephone: (214) 418-3000 


\section{CHAPTER 14 \\ STEAM INJECTION PROFILE CONTROL \\ INTRODUCTION}

When steam is injected into a nonuniform formation, the steam enters the formation with a flow inversely proportional to the resistance encountered. Thus, the greater amount of steam will enter the more permeable (less resistant) sections of the formation while lesser amounts of steam enter the less permeable (more resistant) sections. If the formation consists of several sand layers separated by shale stringers, the steam will seek the most permeable layer and as that zone is depleted the resistance becomes less until a thief zone may develop where the steam is diverted from the oil and has little effect on its recovery.

In early completions where an open hole gravel pack was used with the tubing ending at the top of the formation, the amount of steam entering each layer of the sand was determined by the permeability of the layer. In addition, water would separate from the steam and migrate to the bottom because of higher density, and the bottom layer would only be exposed to water instead of steam. The first improvement was to extend the tubing to the bottom sand layer so that the mixed water/steam would contact the lowest layer but also would be forced up the annulus to contact the other layers.

It is, of course, desirable to know how effectively the steam is contacting the oil, and considerable effort has gone into measurement of the amounts of steam going into the various parts of the formation. Originally, the spinners that were used to measure water injection were applied to steam measurement. A temperature survey was also used. However, more sophisticated methods using radioactive tracers have become common.

Various methods have been used to improve the injection profile. These depend in part on the completion method that was chosen for the well. It is also desirable to know the profile at some distance from the injection, and monitoring wells. These methods also reveal the effects of steam override in which the steam has risen to the top of the formation because of gravity, leaving the bottom part of the formation untouched.

This chapter will discuss (1) distribution of steam liquid and vapor in the wellbore, (2) measurement of steam injection profile including spinners, steam surveys, and radioactivity methods, (3) methods of improving steam injection profiles, and (4) monitoring wells.

Vendors such as those listed in Appendix 14-A should be consulted to develop a steam injection profile control program.

\section{Distribution of Steam/Water in Tubing}

Steam of less than $100 \%$ quality has the possibility of separating into two phases. The extremes range form mist flow to annular flow. ${ }^{1}$ These two conditions are shown in figure 14.1. 


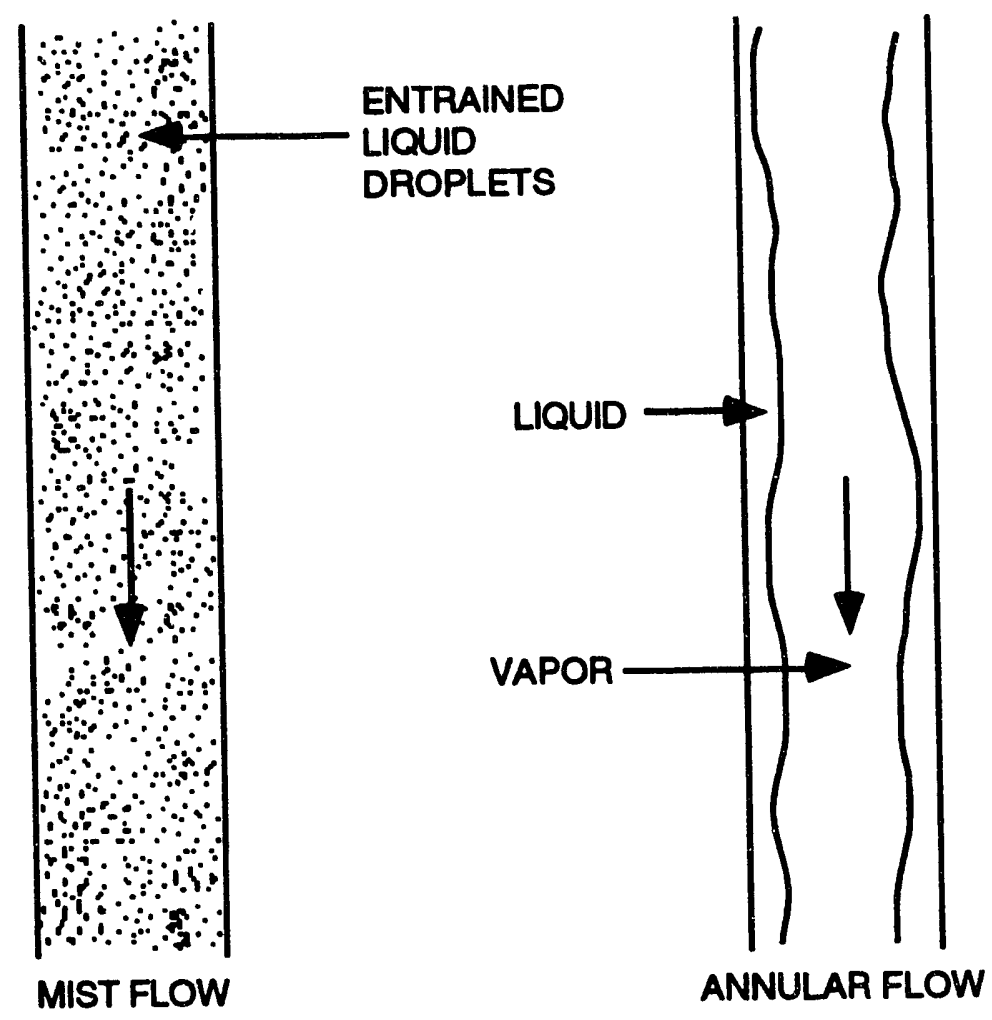

FIGURE 14. 1. - Mist and annular flow regimes for two-phase flow. ${ }^{1}$

For the mist flow, the velocity of the two phases are essentially equal, while for the annular flow the velocities may be quite different. By the use of radioactive tracers, a determination of the regime existing in the process may be determined.

The effect of the phase separation is important to the determination of the injection profile because the water brings much less heat to the formation than the steam. Thus, if a lower zone is receiving only water, it will be stimulated much less than the upper zones which receive steam. For this reason, completion practices have changed from the early open hole completion with the tubing terminating ahead of the formation to be stimulated to a completion where the tubing goes to the bottom of the well and introduces the steam there to rise up the annulus.

\section{Measurement of Steam Injection Profile}

Measurement of the steam injection profile is important so that adjustments may be made in the production methods to assure a complete sweep across the total oil-bearing formation. Various tools have been used, but the radioactive tracers seem to be gaining the preferred status. Earlier methods included spinners and temperature surveys. 


\section{Spinners}

The spinner is a direct approach to measuring the velocity of the steam at different positions in the well. ${ }^{2}$ The tool is basically a free rotating impeller positioned in the pipe by a centralizer. The steam passing the tool causes the impeller to rotate at a rate proportional to the velocity of the steam. The rate of rotation is translated into an electrical signal which is transmitted to the surface through the logging cable.

The configuration of the spinner is shown in figure 14.2. In many respects it is similar to the spinners used to measure the injection of water into a waterflood injection well, but because of the higher temperature of the steam environment some changes are necessary. Conventional electrical insulation and packing materials are not satisfactory and teflon has been used. The high velocity of the steam results in high rotation rates that require strengthening the impeller and its support.

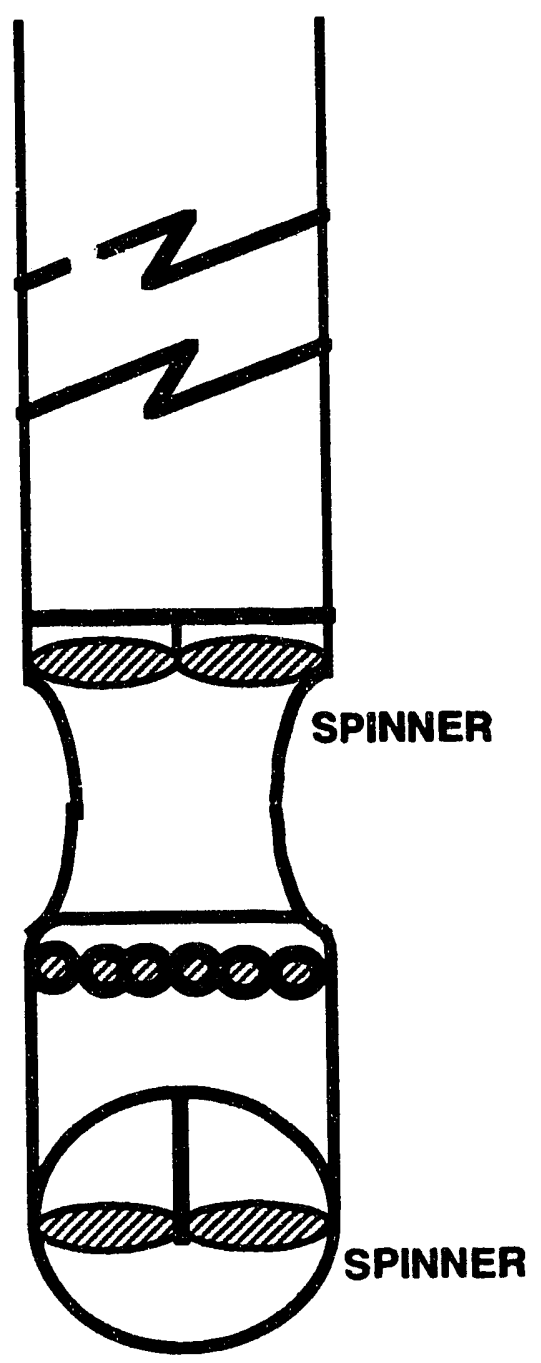

FIGURE 14.2. - Diagram of spinner tool. ${ }^{2}$ 
The survey procedure is likewise similar to that for the water injection. However, because of the higher velocity of the steam, it may be necessary to bypass the steam while the spinner is lowered through the tubing. A general procedure for a spinner survey is given in table 14.1.

TABLE 14.1. - Procedure for Determining Steam Injection Profile Using a Spinner ${ }^{2}$

1. Record impeller RPM at the following stations: 30 to $50 \mathrm{ft}$ below the bottom of the tubing, 5 to $10 \mathrm{ft}$ above the liner top, 5 to $10 \mathrm{ft}$ below the liner top, and just above the perforations. This procedure will detect losses between the stations except at the liner top.

2. Make a down survey at 40 to $60 \mathrm{fpm}$ and stop at tha depth where the impeller stops rotating.

3. Make an up survey at 40 to $60 \mathrm{fpm}$.

4. Make a down survey at 60 to $80 \mathrm{fpm}$ to pickup. This run will locate the liquid level, if any. If the surveys check, the tool is withdrawn.

5. The recordings at the surface are a plot of spinner RPM versus depth. The plot is equated to percent steam entering the formation by assuming the highest value of RPM is equal to $100 \%$ of the steam and the zero RPM represents $0 \%$ of the steam.

Examples of two runs are shown in figure 14.3. Figure 14.3a shows a well where the steam is being distributed over the face of the formation. Figure $14.3 \mathrm{~b}$ shows a well that illustrates the need for profile improvement. Although the perforation interval is about $500 \mathrm{ft}$, practically all of the steam is entering a $15 \mathrm{ft}$ section. This also shows the liquid level as some $150 \mathrm{ft}$ above the bottom of the perforations.

\section{Temperature Surveys}

A temperature survey ${ }^{2}$ during steam injection shows only the lowest point of steam injection which is indicated by a rapid cooling to the normal well temperature. This start of rapid cooling is also the top of the liquid level and should check with the value determined by the spinner survey. The temperature survey is primarily a supplement to the spinner survey in determining the injection profile.

The temperature measuring tool used in steam wells is the normal instrument adapted for work in the higher temperature. It has a thermistor with a much wider range of temperatures. An improved instrument using a platinum resistance thermometer was recently described. ${ }^{3}$

Used as a supplement to the spinner survey, the temperature survey is shown in figure 14.3. In figure 14.3a, the temperature is shown to slowly cool off but with no liquid level to cause the rapid cooling. In figure $14.3 \mathrm{~b}$, at the point of injection, the temperature drops but then becomes constant down to the liquid level where it starts to cool down to the formation temperature. 


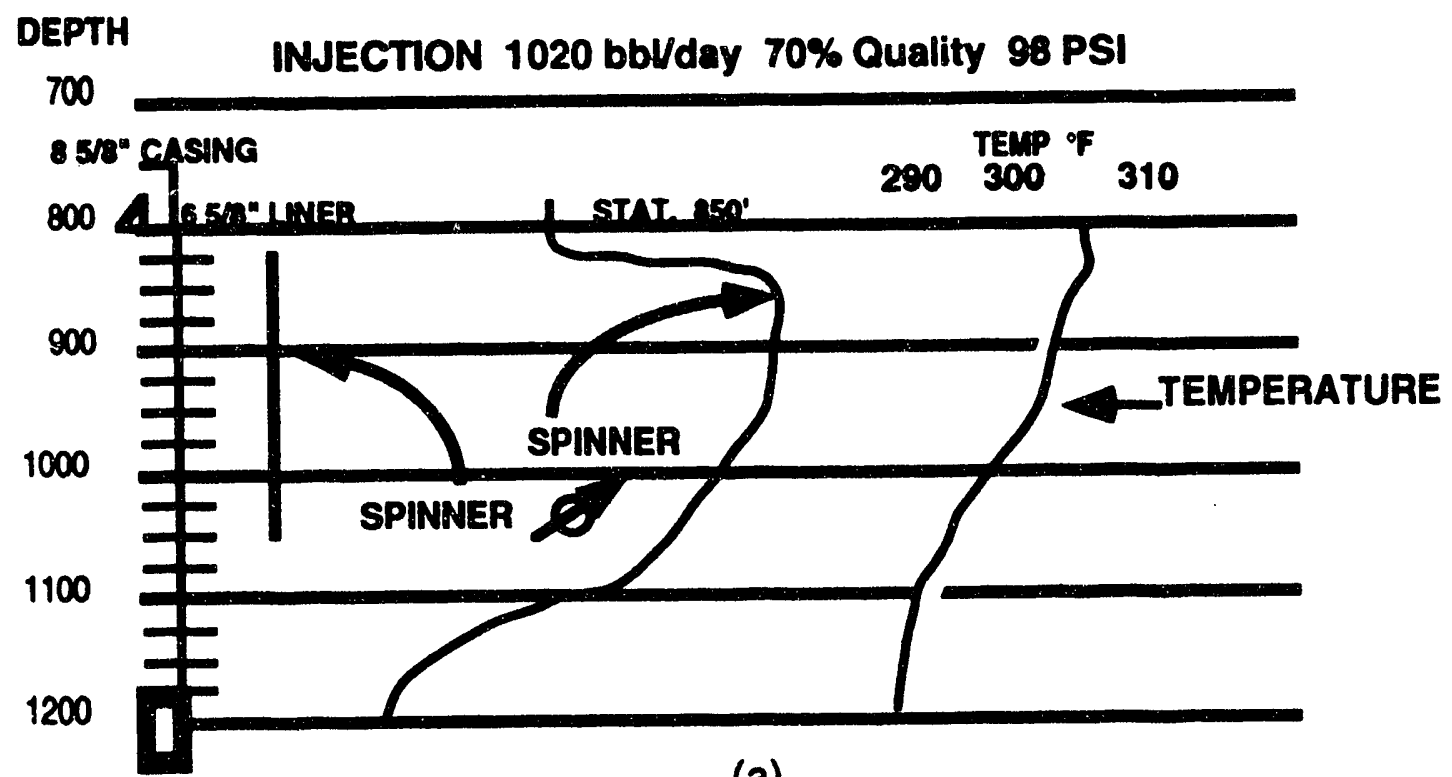

(a)

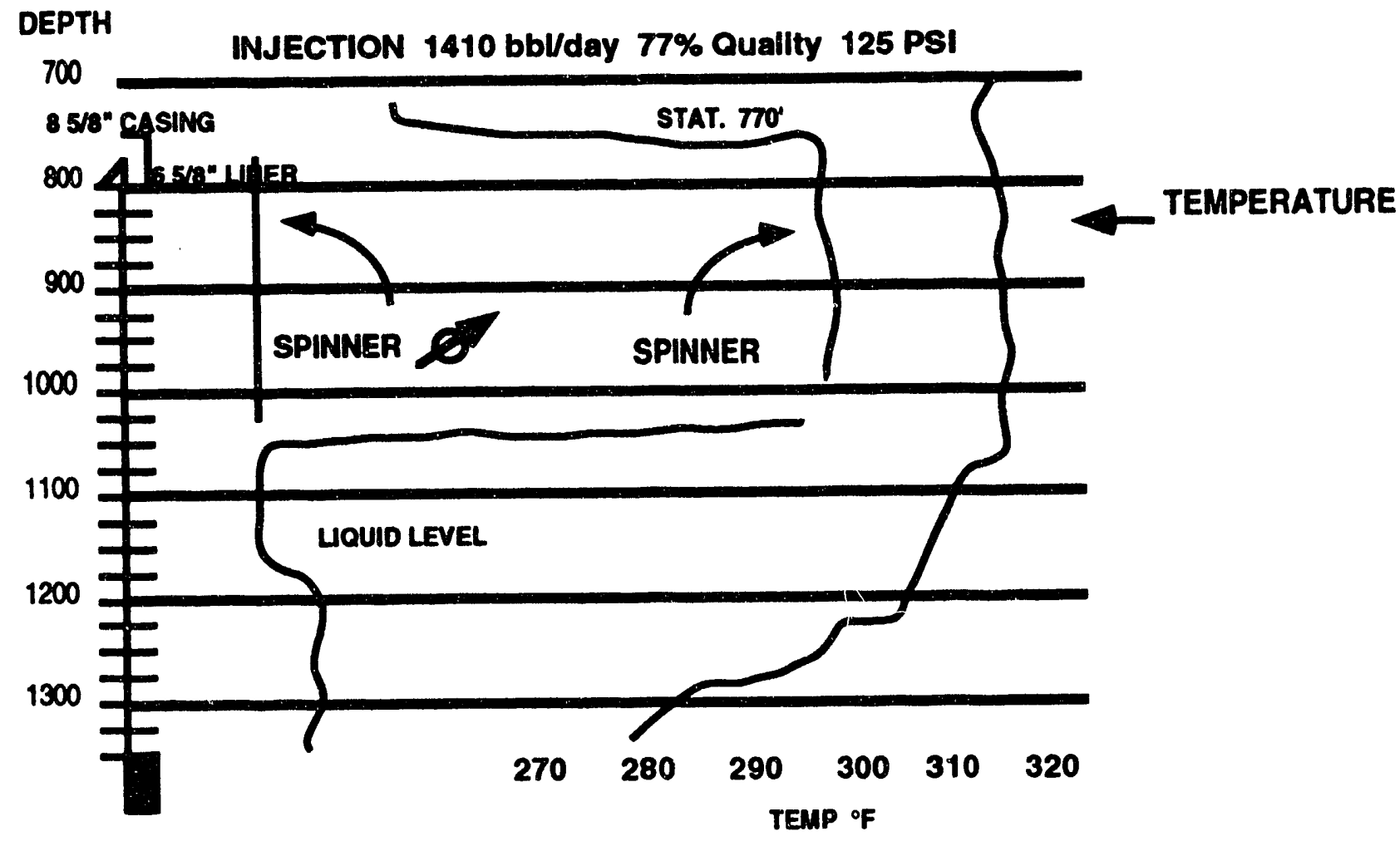

(b)

FIGURE 14.3. - Steam spinner surveys. ${ }^{2}$ The upper chart is an acceptable one, while the lower chart shows need for profile improvement. 
When the temperature survey is used by itself to determine the profile, it is usually used during the soak period. It is assumed that the hottest sections received the most steam. Thus qualitatively, a profile can be obtained by equating injection to sections of elevated temperatures.

\section{Radioactive Tracer Surveys}

The information that can be obtained from the spinner and temperature surveys is limited. The inertia of the spinner makes its results questionable at low inputs of steam, and the qualitative nature of the temperature survey leaves much to be desired. Beyond that, these surveys are not applicable when the tubing is run to the bottom of the well and many completions are made in that manner. Consequently, it is important to have a method which will not have these problems. The use of radioactive tracer surveys was developed to fill this need.

The first systems depended on the use of radioactive iodine, I-131. This material has a short half-life (8.1 days) and is not particularly hazardous if properly handled. It decays to stable xenon131 through the emission of five beta particles (electrons) and six gamma-ray photons. It was injected in the form of sodium iodide or methyl or ethyl iodide. ${ }^{4}$ The procedure was to run a gamma log as a base line; inject the radioactive tracer so that it would plate out where the steam entered the formation; and then run another gamma log to see where it had plated out. The amount of gamma radiation detected indicated the amount of steam passing that point.

Because of its solubility in water, sodium iodide tends to collect in the water phase of the steam and thus indicates higher injectivity for those parts of the formation contacted by water. Methyl or ethyl iodide was used to maintain the iodide in the steam phase, but Nguyen 5 has shown that these iodides decompose in the hot steam and are absorbed by the water.

An alternative which measures the steam rather than the water is the use of radioactive inert gases such as krypton-85 (Kr-85) and xenon-133 (Xn-133). Properties of these gases as well as those of iodine-131 are compared in table 14.2. The procedure using these gases differs somewhat from that used with sodium iodide. A slug of tracer is injected into the steam flow stream and tracer velocity is measured at specific depths in the well. This is done with a dual gamma detector where the time to pass from one sensor to the next is measured. Knowing the wellbore geometry, the amount of steam passing the point can be calculated. A combination of the methods ${ }^{6-7}$ using iodide to determine water and inert gas for steam gives the most complete information.

Radioactive steam tracer surveys are routinely run in steam injection wells to check for tubing holes, packer leaks, open perforations, and steam migration behind casing. These surveys are required by the California Division of Oil and Gas. Current California regulations require that krypton- 85 instead of sodium iodide-131 be used in steam tracer surveys. ${ }^{8}$ 
TABLE 14.2. - Properties of Tracers

\begin{tabular}{lccc}
\hline & \multicolumn{1}{c}{ Kr-85 } & Xn-133 & I-131 \\
\cline { 2 - 3 } \cline { 4 - 4 } Water solubility at steam & 0 & 0 & $100 \%$ \\
Charge & 0 & 0 & -1 \\
Half-life & $10.7 \mathrm{yrs}$. & 5.2 days & 8.0 days \\
Energy level & $517 \mathrm{kev}$ & $81 \mathrm{kev}$ & $364 \mathrm{kev}$ \\
\% Gamma Emissions & 0.5 & 99.0 & 100 \\
\hline
\end{tabular}

The procedure for the survey using iodide-131 is given in table 14.3. The most common survey is run with the sodium iodide dissolved in water. If the injected steam is in one phase or in the mist regime, this is satisfactory. The sodium iodide may also be dissolved in methyl alcohol. This has been shown ${ }^{8}$ to tag both the gas phase and the liquid phase. To use this system, it must be recognized that the velocity of the gas phase is faster than that of the water phase. This results in two spikes on the record, and they must be interpreted to show how much steam and water are entering a formation. Methyl or ethyl iodide has been used in an attempt to place the iodide in the steam phase, but it has been shown ${ }^{5}$ that each decomposes in the hot steam and forms hydrogen iodide which is soluble in water.

TABLE 14.3. - Procedure for Running Radioactive Tracer Survey With Sodium Iodide ${ }^{2}$

1. Run a background gamma $\log$ from the surface to pickup depth. As in the case of the temperature tool, it is usually not necessary to bypass the steam while running into the well.

2. Bring the gamma logging tool to a station above the liner top and record the radiation intensity continuously.

3. Inject the tracer slug. As the slug passes the gamma tool the increased intensity will be recorded.

4. As soon as the slug is past the logging tool, run a gamma log down to pickup depth.

5. Immediately make a $\log$ up to the surface to detect any possible casing leaks.

6. The steam injection profile is constructed using the gamma logs. The increase in intensity over background for any interval is attributable to the tracer being carried to that area by the injected stean. The area under the enhanced gamma curve less the area under the background $\log$ is equated to the total amount of steam being injected. By dividing the interval into the zones of particular interest and measuring each area, the percentage of the steam going into any zone can be calculated. A cumulative curve can then be drawn by adding up the percentage and plotting percent of steam left against depth. 
The procedure for using the inert gases is shown in table 14.4. Although this is a more expensive test, it adequately measures the steam going into the various zones. The vapor phase of the steam is the most important phase from a heat content and volume standpoint. Both krypton and xenon are thermally stable gases and have no charge so that they do not associate with the formation. The plating out technique is therefore not applicable. The use of this method on three types of completions is shown in figure 14.4 where the tubing ends (a) above the perforations, (b) below the perforations, and (c) within the perforations. For both (a) and (b), measurements are taken at four positions while for (c) only three positions are necessary.

The velocity can also be used to measure the quality of the steam at the injection area. 4 The wellhead steam flow rate, the downhole pressure, and the vapor velocity are used to develop this equation:

\section{Steam Quality (in percentage) $=$}

$247 \times$ Density of vapor $x$ Distance between detectors $x$ cross-sectional area

Steam flow rate (BPD water equivalent) $x$ Transit time in sec.

In the above equation:

Density is in lbm/cu ft;

Distance between Gamma ray detectors is in $\mathrm{ft}$; and

Cross-sectional area is in sq $\mathrm{ft}$.

TABLE 14.4. - Procedure for Running Radioactive Tracer Survey Using Inert Gas Tracers

1. The dual gamma ray detector is lowered into the well and held stationary at a specified depth.

2. A slug of radioactive inert gas tracer is injected into the surface steam line.

3. The gamma ray counts from the surface and downhole detectors are displayed on the chart recorder and stored in the computer.

4. The tool is then moved to another depth of interest and another slug of tracer is injected.

5. The vapor phase injection profile is calculated directly from the tracer transit times across the dual gamma tool. In some cases, vapor velocity may be too high for accurate determination of transit time across the tool. In these cases transit times from surface to tool measured at two different depths are substituted. These transit times are converted to an equivalent transit time based on the distance between detectors on the logging tool.

6. The vapor phase injection profile is determined by material balance between total flow and flow at different depths. At a given depth, the fraction of the total flow by the tool is given by:

Fraction of total flow $=$

Transit time for $100 \%$ flow in sec

Transit time at a given depth in sec. 


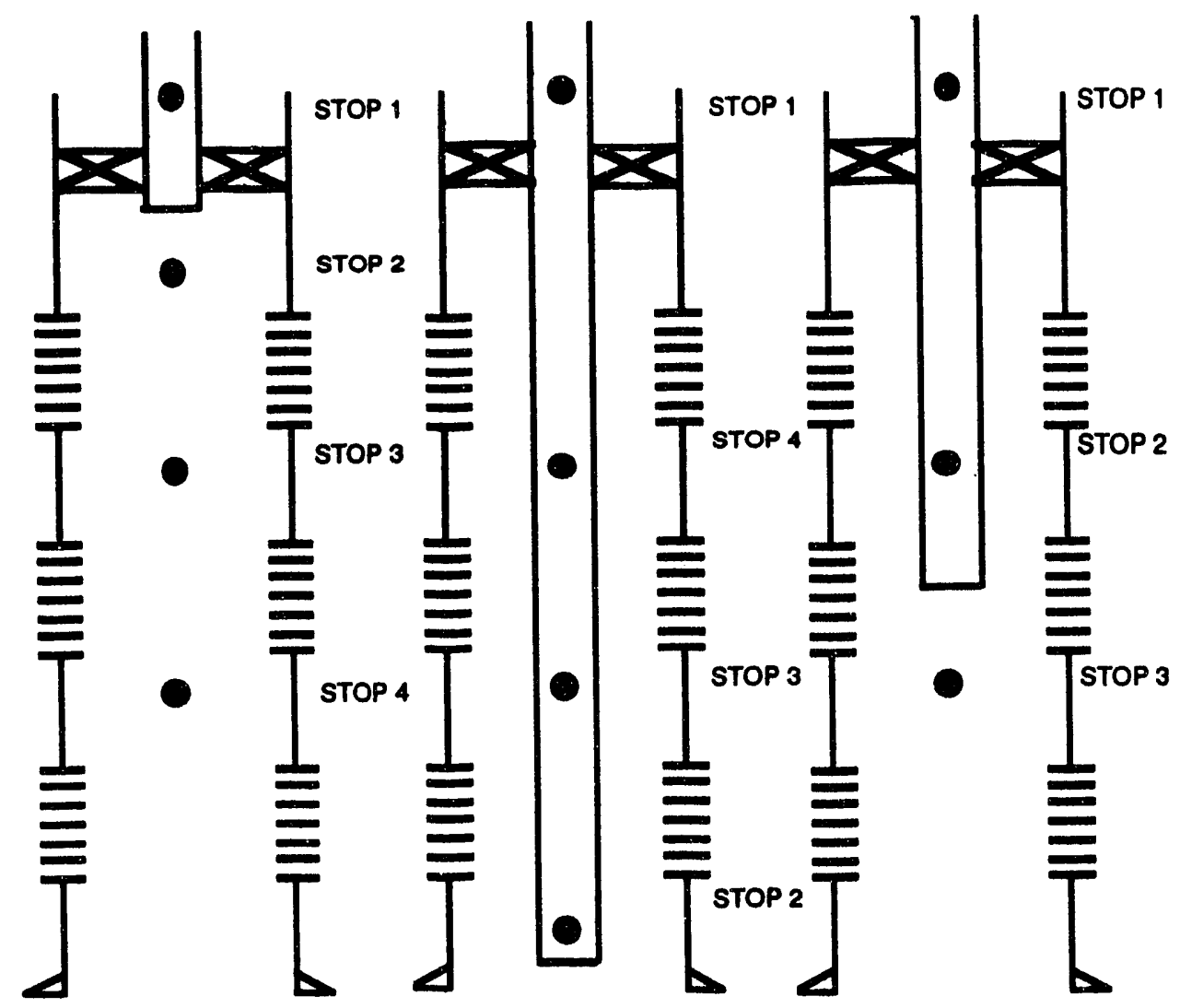

(a)

(b)

(c)

FIGURE 14.4. - Survey points for different tubing tail configurations. 5

(a) above perforations, (b) below perforations, (c) within perforations.

An example of the combination method ${ }^{4}$ is a steam injector completed with four 0.25 in. jet holes per $\mathrm{ft}$ over three perforated intervals (Fig. 14.4). The tubing ends within the bottom set of perforations. The steam packer is set $5 \mathrm{ft}$ above the top perforations. Both a vapor phase survey using krypton and a conventional liquid phase survey using sodium iodide were run. Surface to tool transit times were determined from stops 1 and 3 to determine the $100 \%$ flow transit time in the annulus. It was 0.83 seconds. Stops 2 and 3 showed annular transit times of 1.7 and 1.1 seconds, respectively. Using the equation in table 14.4, the percentage of total vapor flow going by stops 2 and 3 is $49 \%$ and $75 \%$. Thus, the flow is $49 \%$ out of the top perforations, $26 \%$ out of the middle set, and $25 \%$ out of the bottom set. These results and the results from the sodium iodide survey are shown in figure 14.5. The liquid phase survey shows almost all of the liquid exiting the bottom set of perforations. Calculating the steam quality by the above equation shows that between stops 1 and 3, it was 37\%. This can then be used to calculate the heat distribution for the well, and this is shown in figure 14.5 to be $33 \%, 20 \%$, and $47 \%$ for the top middle, and bottom perforations respectively, 


\section{Methods of Altering Profiles}

Early use of open hole gravel pack completions, ${ }^{8}$ revealed that the vertical steam distribution was poor. Initial attempts to achieve selective injection included the injection of plugging agents such as ground calcite, using the resistance of the gravel pack outside the liner combined with close fitting stingers inside the liner, and filling the liner with gravel to cover a thief zone. However, no satisfactory solution was found to divert steam in a fully slotted, gravel packed liner.

With blank sections (nonslotted) in the liner string, both mechanical and plugging methods were described. ${ }^{8}$ In the mechanical method, a steel friction ring was mounted on a mandrel that was forced by pipe weight into a slightly smaller polished nipple installed in the liner. These provided cutoffs between productive zones so that after steaming the lower formation, it was cut off and the steam pressure opened the sleeve to steam the upper formation. The plugging method also required special hardware: a port collar and an opening/squeeze tool. The port collar was placed in the middle of blank liner sections. The opening/squeeze tool opens and closes the collar and forced the plugging material into the pore space of the gravel pack to effectively block any steam flow behind the section of blank liner separating the zones of interest. Although cement was tried, better plugging agents were songht and a mixture of bentonite, silica flour, barites and water was extensively used. A mixture of polymer gel, bentonite, and cement was also used.

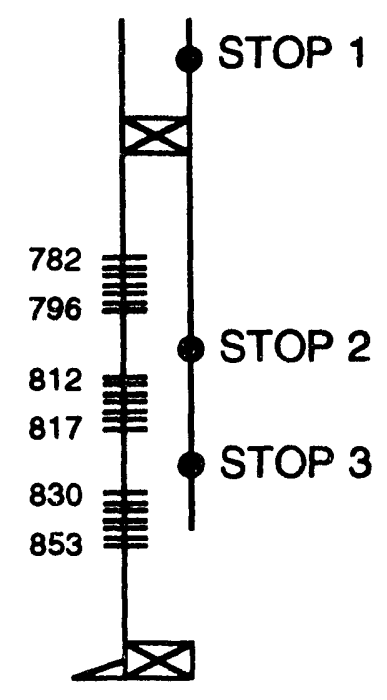

(a)

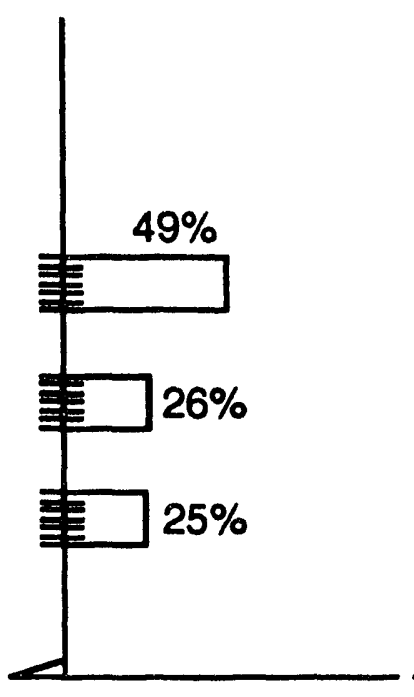

(b)

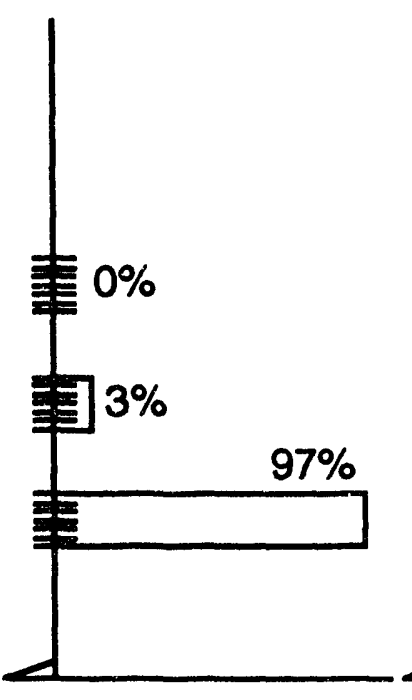

(c)

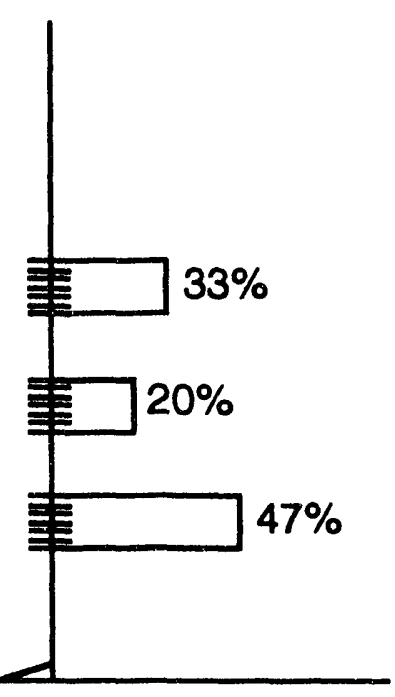

(d)

FIGURE 14.5. - Survey results. 5 (a) well configuration, (b) vapor phase profile by krypton, (c) liquid phase profile by sodium iodide, (d) heat profile. 
The unconsolidated nature of the California sands have caused several schemes of profile improvement to be developed. Notable among them are the limited access method based on perforation designs and the concentric tube and the parallel tube methods.

\section{Concentric Tube Method}

Concentric-pipe injection was one of the first methods used to control steam injection into two oil sands using a single wellbore.9-10 A schematic of the process is shown in figure 14.6. Steam is injected simultaneously into the inner and outer pipes which are used to separate the flow for injection into the two target sands.

Normally 1-1/4-in. tubing is run inside 2-7/8-in. pipe in wells completed with 5-1/2-in. casing or 2-3/8-in. pipe is run inside 4-in. pipe for wells completed with 7-in. casing. A downhole expansion device is used on the outer pipe and the wellhead is modified to handle expansion of the inner pipe. A single-string thermal packer is set above the upper oil zone to prevent the steam from flowing up the casing annulus. A second single-string thermal packer is set between the two target oil zones to keep the injected steam separated into the individual zones. The tail of the outer pipe is located opposite the upper oil zone and the tail of the lower pipe is located opposite the lower oil zone. A variation of this method uses the casing as the outer pipe.

A number of problems have caused this method to be less popular than some other methods. The pressure drop through the annulus between the two pipes is greater than that in the inner pipe causing heat flow from the inner to the outer pipe and increasing steam quality in the outer pipe and decreasing steam quality in the inner pipe. In practice this exchange of heat results in severe scale buildup.

\section{Parallel Tubing Injection}

The parallel tubing method ${ }^{10}$ places two tubing strings side-by-side in the wellbore. The completion scheme is shown in figure 14.7. The wellhead is modified to handle two pipes. A large casing (typically 7 -in. or 9-5/8-in.) is required to accommodate the two strings. A dual-string thermal packer is used above the upper oil zone and a single-string thermal packer is placed between the two target oil zones. Insulated tubing is used between the packers to reduce heat loss where one of the strings is in direct contact with low-pressure steam in the tubing-casing annulus.

The system is run in three stages:

1. Set the permanent thermal packer

2. Set the dual packer assembly with the long string.

3. Stab in the short string with a J-latch.

A travel joint on the long string and the J-slot seal assembly on the short string allows independent expansion of both strings.This system shows no differential in quality of delivered steam, and divides the steam as desired. 10 


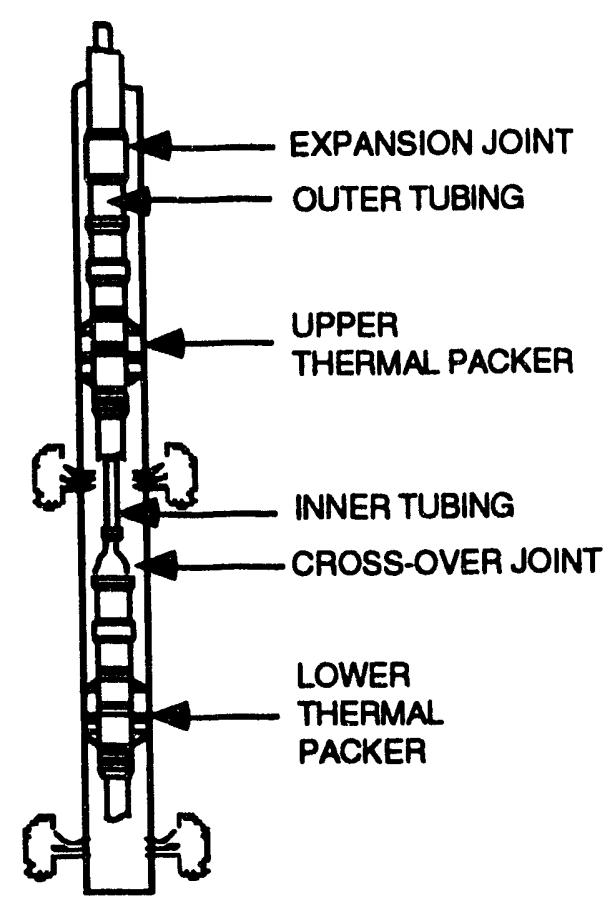

FIGURE 14.6. - Schematic of concentric tubing completion. ${ }^{11}$

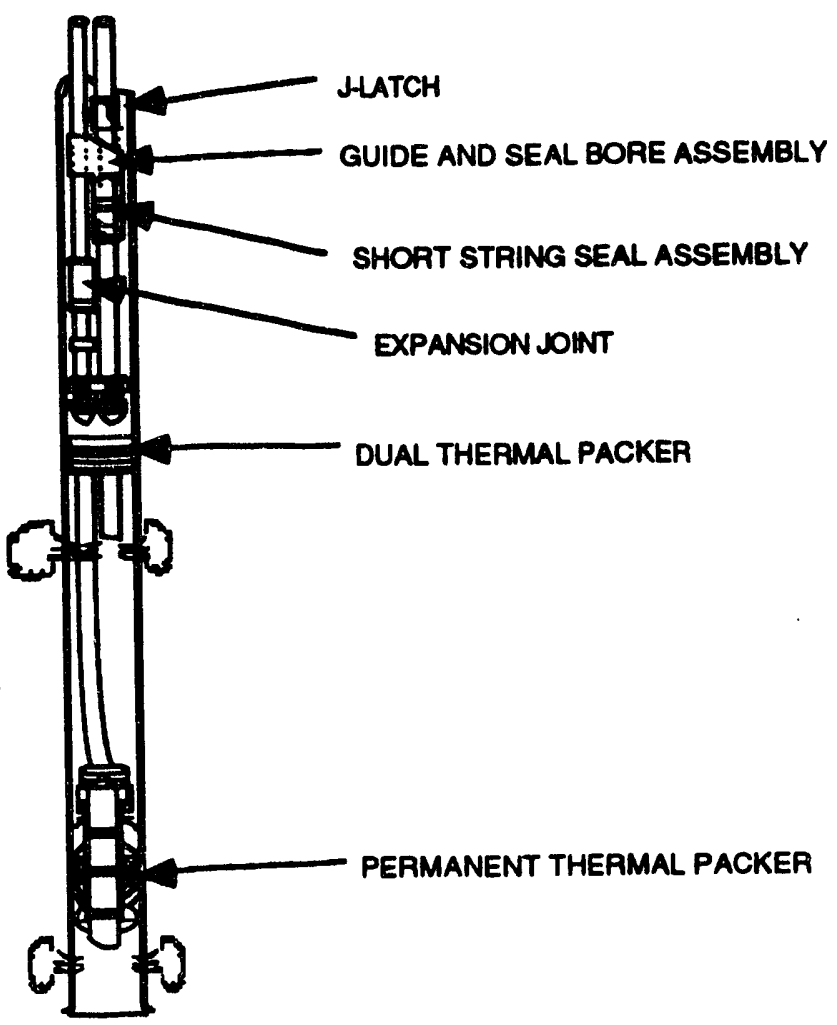

FIGURE 14.7. - Schematic of parallel tubing completion. ${ }^{11}$ 


\section{Limited Entry Injection}

A standard completion procedure for steam injection wells is the open hole, gravel-packed, slotted liner configuration shown as the first design in figure 14.8. The slotted liner is designed with slots as large as possible to permit steam delivery and still maintain the gravel pack integrity. The slots are uniform over the length of the producing zone and steam is delivered somewhat equally over the formation. This results in an injection profile which may not fit the requirements, especially if there are zones separated by shale stringers.

It was discovered that selected perforation of the casing would distribute the steam in a more desirable manner. First mentioned by Gates and Brewer ${ }^{11}$ and later described by Small, ${ }^{12}$ these completion practices are shown as the second and third examples of figure 14.8. The perforations are sized to attain critical flow conditions. They are distributed vertically in order to obtain the desired injection profile.

Under critical flow conditions, changes in the pressure downstream cannot be transmitted upstream because the steam velocity in the perforation equals the velocity of sound in steam. Critical flow conditions prevent the reservoir pressure from influencing the flow mechanics in the perforation. Therefore, at constant upstream pressure, the maximum steam flow rate cannot be exceeded regardless of even an extremely low reservoir pressure. However, the steam injection rate can be increased by simply increasing the bottom hole injection pressure.

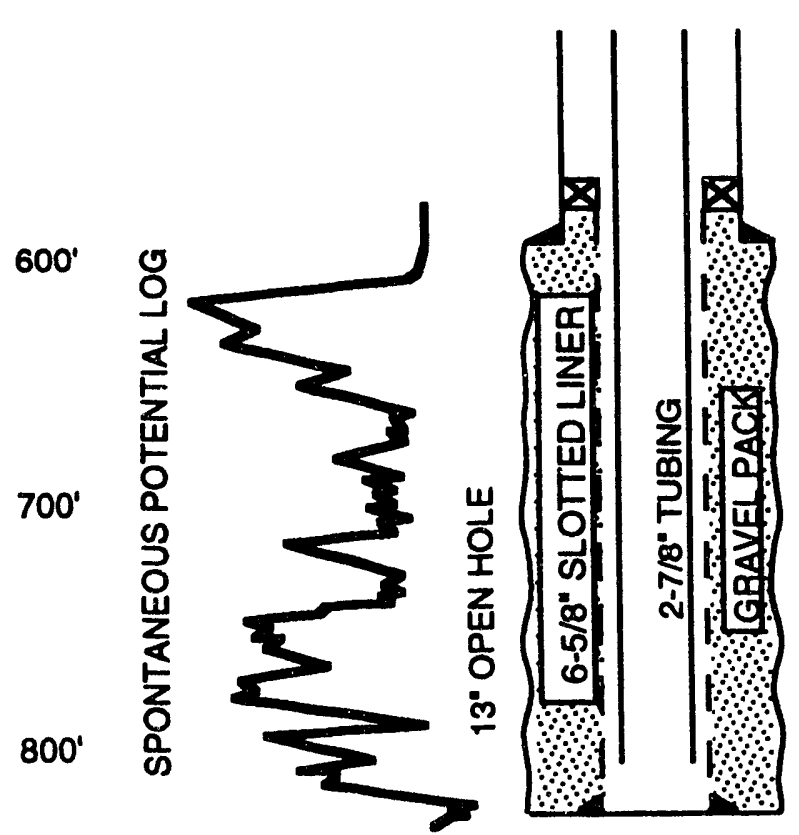

(a)

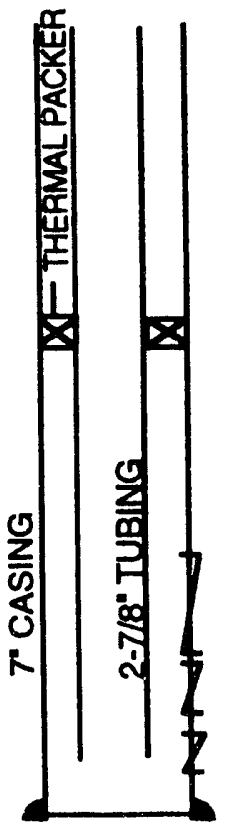

(b)

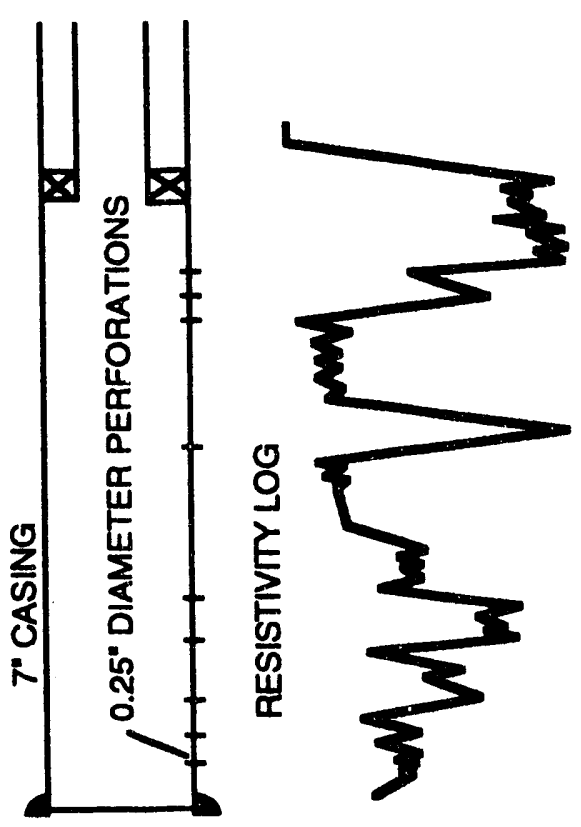

(c)

FIGURE 14.8. - Three steam injection well completion designs. ${ }^{13}$ 
For critical flow to be maintained (at a steam quality of 60\%), the ratio of reservoir pressure (or discharge pressure) to downhole injection pressure must be less than 0.578 (Table 14.5). For a bottomhole injection pressure of 450 psia, the reservoir pressure must be less than 260 psia. As formations considered for steam injection are generally low pressure reservoirs, this does not pose a severe restriction.

To help achieve uniform injection profiles, it is important that the diameter and shape of each perforation be as uniform as possible. Therefore, perforating guns and charge designs are carefully selected to provide the most accurate hole size possible.

To assure proper sizing of the perforations, some designs for limiied entry injection place the perforations in the tubing instead of the casing. As these can be prepared on the surface, they can be more accurately sized. 11-12 In addition, limited entry outlets may be designed and constructed in various ways as long as critical flow may be achieved and maintained. For example, critical flow nozzles, chokes, or steam deflectors can be used.

TABLE 14.5. - Calculation of the Critical Pressure Ratio ${ }^{13}$

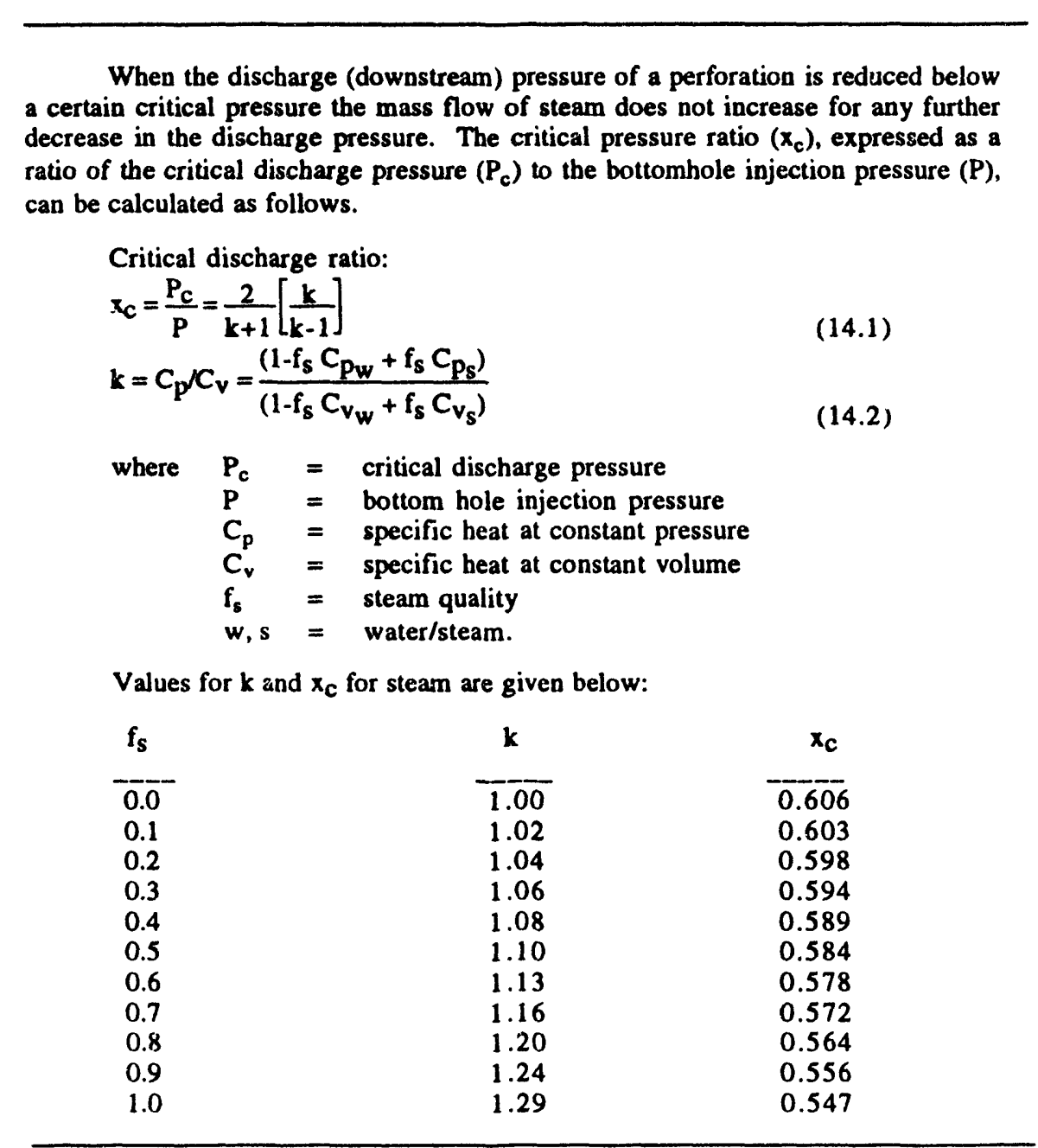


Critical flow nozzles consist essentially of a short cylinder with a flared approach section. In general, the lengti: of the straight section tube is about $1 / 2$ times the throat diameter but can be longer. In addition, a tapered divergent section can be added at the exit of the throat to provide some degree of pressure recovery of the exiting steam.

Steam chokes are quite similar to nozzles but have no convergent entry or divergent exit sections. Chokes are commonly used in surface lines to limit steam flow. However, they may be used downhole. 14

An example of a steam deflector is shown in figure 14.9. A portion of the steam flow exits the tubing string through single or multiple slots located concentrically around the tubing. The total area of the milled slots is equal to the cross-sectional area needed to achieve and maintain critical flow.

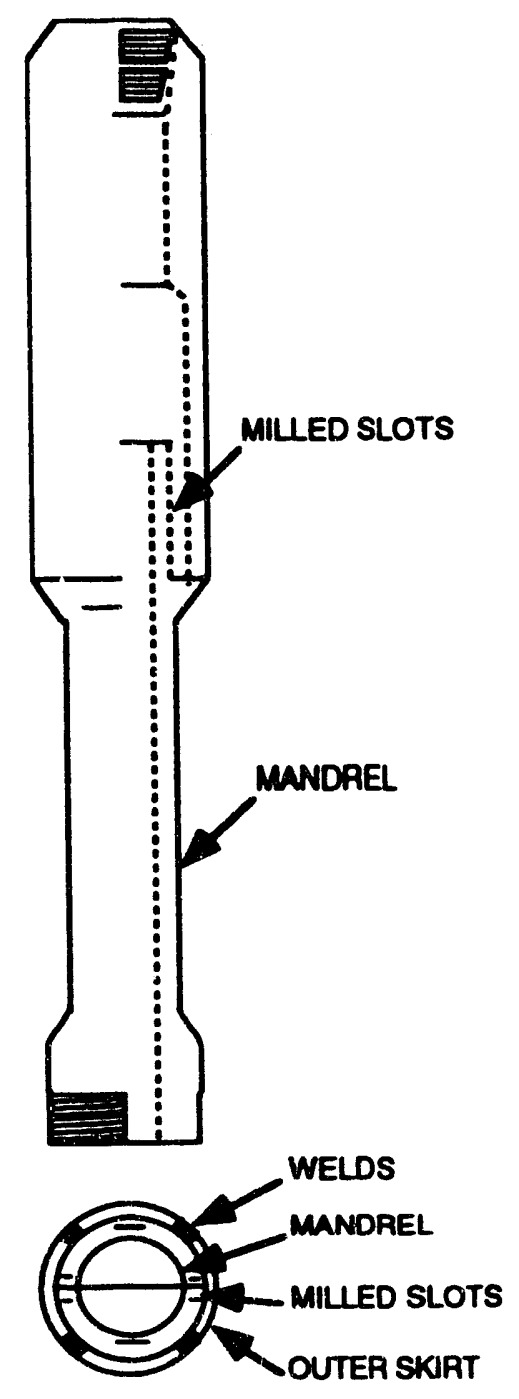

FIGURE 14.9. - Steam deflector design. ${ }^{11}$ 
An example of limited entry injection using critical flow chokes is shown in figure 14.10. A thermal packer is placed between the two target oil zones to keep the injected steam separated once it has passed through the limited entry outlets. The pipe above the top packer may be bare or insulated. However, the section of the pipe exposed to low pressure steam in the casing between the two packers should be insulated to prevent excessive heat loss from the steam inside the tubing.

\section{Use of Monitoring Wells}

Monitoring wells are most frequently used in connection with steam injection projects, 15 usually to obtain a temperature survey. Not only does this give the time of arrival of the steamflood front, but it also provides some measure of the profile of the front. This may offer an opportunity to make corrections in the plan for the steamflood. Some of the precautions to be used in the evaluation of temperature data have been stated. 16

In addition, the temperature survey indicates the amount of steam override which is occurring. Because steam is lighter than the oil, it tends to rise and may become segregated at the top of the formation. Thus, the oil at the bottom of the formation may remain untouched. Some effort has gone into the study of using steam foams to prevent steam override. 17

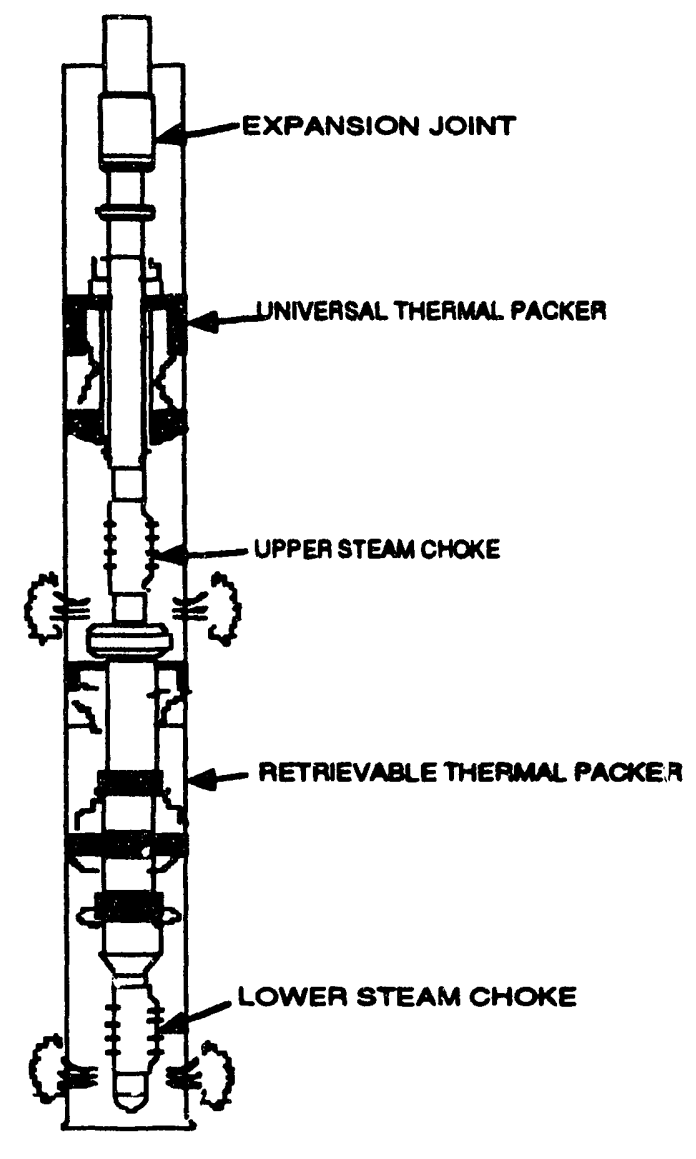

FIGURE 14.10. - Schematic of limitid entry completion. ${ }^{11}$ 


\section{SUMMARY}

Steam injection profiles are a measure of the effectiveness with which the steam contacts the oil-bearing formation. They can be measured by spinner surveys, by temperature surveys, and by radioactive tracer techniques. When the profile is found to be undesirable, it can be changed by diverting the steam. This can be done by plugging a thief zone or by directing the steam to a particular zone. In the parallel tube method, tubes lead the steam to particular sections of the formation. Limited entry techniques may also be used in which perforations are placed opposite to sections according to the amount of steam required by that section. Monitoring wells are used to check the temperature profile out in the formation.

\section{REFERENCES}

1. Elson, T. D. and K. C. Hong. Distribution of Steam Liquid and Vapor in an Injection Wellbore. R. F. Meyer, J. C. Wynn, J. C. Olson, eds. The Future of Heavy Oil and Tar Sands, Second International UNITAR Conf., Caracas Venezuela, February 1982, McGraw-Hill, New York, pp. 662-665.

2. Bookout, Donald E., J. J. Glenn, Jr., and Herman E. Schaller. Injection Profiles During Steam Injection. Producers Monthly, v. 31, No. 8, August 1967, pp. 2-8.

3. Dillier, J. M. and R. H. Clark. Downhole Temperature Measurements. U.S. Patent 4,811,598, Mar. 14, 1989.

4. Lichtenberger, G. P. A Primer on Radioactive Tracer Injection Profiling. Pres. at the 28th Annual Southwestern Petroleum Short Course, Lubbock, TX. Apr. 23-24, 1981, pp. 251265.

5. Nguyen, T. V. and C. E. Stevens. The Use of Inert Gas Radioactive Tracers for Steam Injection Profiling. Pres. at the SPE California Regional Meeting, Long Beach, CA, Mar. 23-25, 1988. Paper SPE 20035.

6. Nguyen, T. V., B. Davenport, C. E. Stevens, J. C. Reis, and R. S. Millhone. steam Injection Profiling. U.S. Patent 4,817,713, Apr. 7, 1989.

7. Nguyen, T. V. and B. Davenport. Steam Injection Profiling. U.S. Patent 4,793,414, Dec. $27,1988$.

8. Crowe, T. L. A Radioactive Steam Comparison Between Krypton-85, Xenon-133, NaI131 (Methyl Alcohol Base) and NaI-131 (Water Base). Pres. at the Soc. Pet. Eng. 60th California Regional Meeting, Ventura, CA, Apr. 4-6, 1990. Paper SPE 20035

9. Burkill, Guy C. C. How Steam is Selectively Injected in Open Hole Gravel Packs. World Oil, v. 194, No. 1, January 1982, pp. 127-136.

10. Anderson, G. W. and S. O. Hutchison. Concentric Steaming String Downhole Apparatus. U.S. Patent 4,399,865, Aug. 23, 1983. 
11. Hong, K. C. and S. Griston. New Methods for Controlled Injection of Steam Into Multiple Sands. Pres. at the 61 st Ann. Tech. Conf. and Exhib. of the Soc. Pet. Eng., New Orleans, LA, Oct. 5-8, 1986. Paper SPE 15472.

12. Gates, C. F. and S. W. Brewer. Steam Injection Into the D and E Zones, Tulare Formation, South Belridge Field, Kern County, CA. J. Pet. Tech., v. 14, No. 21, March 1975, pp. 343-348.

13. Small, G. P. Steam-Injection Profile Control Using Limited-Entry Perforations. Pres. at the 1985 California Regional Meeting of the Soc. Pet. Eng., Bakersfield, CA, Mar. 27-29, 1985. Paper SPE 13607.

14. Hong, K. C., S. Griston and J. W. Ault. Limited Entry Method for Multiple Zone, Compressible Fluid Injection. U.S. Patent 4,640,355, Feb. 3, 1987.

15. Webb, C. H. Downhole Fixed Choke For Steam Injection. U.S. Patent 4,770,244, Sept. 13, 1988.

16. Widmyer, R. H. Use of Monitor Observation Wells the Monitoring and Evaluation of Oil Recovery Projects. Pres. at SPE/DOE Fifth Symp. on E hanced Oil Recovery, Tulsa, OK, Apr. 20-23, 1986. Paper SPE/DOE 14956.

17. Griston, S. Fluid Effects in Temperature Observation Wells. Pres. at the 64th Annual Tech. Conf. and Exhib. of the Soc. of Pet. Eng., San Antonio, TX, Oct. 8-11, 1989. Paper SPE 19740.

18. Patzek, T. W. and M. T. Koinis. Kern River Steam Foam Pilots. Pres. at the SPE/DOE Enhanced Oil Recovery Symp., Tulsa, OK, Apr. 17-20, 1988. Paper SPE/DOE 17380. 


\section{APPENDIX 14-A \\ STEAM INIECTION PROFILE CONTROL SERVICE VENDORS}

A. Spinner Tool and Survey

1. International Tool Company

7339 Kingsly

P.O. Box 803

Houston, TX 77001

Telephone: (713) 641-0373

B. Radioactive Tracer and Temperature

Surveys

1. Halliburton Logging Services

550 Ming Avenue, Suite 190

Bakersfield, CA 93309-8401

Telephone: (805) 833-1952

2. Atlas Wireline Services

10205 Westheimer

Houston, TX 77042

Telephone: (713) 972-4000

3. Exploration Logging Inc.

7000 Hollister Road

Houston, TX 77040-5337

Telephone: (713) 744-3600

4. Schlumberger Well Services

5000 Gulf Freeway

Box 2175

Houston, TX 77252-2175

Telephone: (713) $928-4000$ 


\section{CHAPTER 15 \\ EMULSION PROBLEMS IN STEAM INJECTION PROJECTS}

\section{INTRODUCTION}

A large portion of the oil produced by steam injection process is accompanied by water in the form of an emulsion. The emulsion problem is much more severe in thermal operations than in waterflood. The stability of the emulsion varies widely with the crude oil properties and producing formation. These emulsions are difficult to break and the separation of the two phases consumes considerable time, money, and efforts and requires specialized equipment and techniques. To minimize the transportation and process costs, the crude oil purchasers limit the water content of the oil they purchase to less than $3 \%$. The cost of processing the produced fluids to meet the purchaser's specification is second only to the fuel cost, and any savings in the treatment cost significantly impacts the economics of the operation and improves the profits. The treatment costs can be lowered by studying the treatment problem and selection and use of appropriate treating methods, equipment, and procedures. This requires a basic understanding of the emulsions and treating methods. The purpose of this chapter is to appraise the reader about how the crude oil emulsions are formed and to discuss briefly the methods used in treating and breaking the emulsion. The equipment used to dehydrate the crude oil is discussed in detail in chapter 16.

\section{Definition of an Emulsion}

An emulsion is a stable mixture of two immiscible liquids with one liquid intimately dispersed in the second liquid in the form of fine droplets. The dispersed fluid is called the internal or discontinuous phase while the continuous fluid is called the external phase. For an emulsion to remain stable, the presence of a third component called the emulsifier is necessary. The emulsifier inhibits the coalescence of the droplets. A common example of an emulsion is mayonnaise which is a suspension of olive oil in vinegar with egg as the emulsifyin ${ }_{b}$ agent.

An oilfield emulsion is an intimate mixture of oil and water. When water is dispersed in oil, it is called a water-in-oil (w/o) or a "normal" or "regular" emulsion. It is the most common form of oilfield emulsion. When oil is dispersed in water, it is called an oil-in-water (o/w) or a"reverse" emulsion. Reverse emulsions are more common in steam injection operations due to large production of water. A w/o emulsion is usually very thick and viscous. A drop of this emulsion does not disperse when added to water. This is the kind of emulsion that is treated in wash tanks and heater treaters. The o/w emulsion is usually less viscous than the oil itself and is usually brownish in color. A drop of this kind of emulsion will readily disperse when added to water. The following discussion is concerned with w/o emulsions because most oilfield emulsions are of this type. 


\section{Emulsion Formation and Stability}

Two conditions must be satisfied before oil and water can form a stable emulsion.

a. There must be sufficient agitation to disperse water in oil or oil in water as minute droplets. The agitation necessary to mechanically break a liquid into fine droplets can result from the passing of fluids through pumps, chokes, tubing, manifold, valves or other surface or subsurface equipment. The greater the amount of agitation, the smaller is the size of discontinuous phase droplets. Emulsions that have smaller droplets of discontinuous phase are usually more stable and more difficult to treat than those that have larger droplets.

b. Presence of an emulsifying agent is also necessary to form an emulsion. Emulsifying agents are surface-active compounds that attach themselves to the dispersed water droplets in the oil and form a protective film around it. This film prevents the droplets from joining the adjacent particles of water. The emulsifying agents commonly found in crude oil include asphaltenes, resins, oil soluble organic acids, and napthanic compounds. Oil wet solids such as sands, clays, silt, scale, and corrosion products that collect at the oil-water interface also act as emulsifiers.

The formation of emulsions result in the creation of an electric charge on the dispersed particles. With isolated exceptions, the emulsified oil droplets carry a negative charge. Generally, low gravity high viscosity crude oils form a more stable emulsion than oils of high API gravity. Asphaltic based oils also emulsify more readily than paraffin based oils. The factors which affect the stability of emulsions are as follows:

(a) The differences in densities of the crude oil and water;

(b) oil viscosity;

(c) the cut or volume percentage of dispersed water in the crude oil;

(d) age of the emulsions;

(e) solids.

I. Viscosity: The rate of movement of a water droplet through the oil phase is directly proportional to the viscosity of the crude. The water droplets move more slowly through a high viscous crude and require more time to separate and settle down than in a less viscous crude.

II. Density Difference: A greater density differential between water and oil will cause the water droplets to settle faster. If an oil is heavy, that is, has high specific gravity, it will tend to keep water drops in suspension longer. Similarly, fresh water droplets which weigh less will not tend to settle as rapidly as heavier salt water droplets.

III. Water Percentage: In addition to droplet size of the dispersed liquid, the ratio of these droplets to the total fluid volume will also affect the emulsion stability. An emulsion 
with $50 \%$ oil and $50 \%$ water will separate more readily than an emulsion wherein the percentage of the dispersed phase is considerably less than the external phase. This phenomena has to do with the distance between water particles which directly influences the force of attraction between droplets. The greater the distance between particles, the weaker the force of attraction, and the less the probability of coalescence.

IV. Age of Emulsion: A fresh emulsion is usually less difficult to treat than an aged emulsion which has had a chance to set and settle out most of its free water. What remains, after the free water has settled out, is an emulsion with fewer droplets of dispersed water; therefore, there is less chance of colliding and coalescing, and consequently the emulsion is more stable than when it is first produced.

V. Solids: Solids such as sand, silt, clays which are often produced with oil and water tend to concentrate at the oil-water interface and contribute to emulsion stability.

\section{Methods Used to Break Emulsions}

In order to break a crude oil emulsion, it is necessary to rupture the interfacial film which surrounds the droplets and coalesce the dispersed droplets. This can be accomplished by the following ways:

(1) Thermal

(2) Chemical

(3) Mechanical

(4) Electrical

Thermal: In the thermal method, the heat is applied to break the emulsion. The use of heat to break emulsion has the following benefits:

(a) Heat reduces the viscosity of the oil, and causes thermal currents to set in within the treating vessel. As a result of these thermal movements, small droplets of fluids will collide, rupture the film, and coalesce. Also, the reduced viscosity allows the water droplets to settle more rapidly through the less viscous oil.

(b) Heat increases the density difference between the oil and water, thus accelerating the settling of the water droplets.

(c) Heat also melts and solubilizes solids such as paraffins which may be acting to stabilize the emulsion, thereby removing them from the interface.

(d) Heat may also cause the fluid droplets to expand to a point that they will rupture their captive films, especially in the presence of chemical deemulsifiers.

Chemical: Dehydration in most steam injection operations is accomplished by the use of chemical emulsion breakers. This method is popular because the chemicals are easily applied to the emulsion at reasonable cost, and usually minimizes the amount of heat and settling time required. 
The chemical deemulsifiers are surface active agents that migrate to the oil-water interface, lower the tension between oil and water and thus rupture or weaken the captive film sufficiently to disperse the emulsifier back into the oil. For the chemical to be effective it must have (a) a strong attraction to the oil/water interface; (b) an attraction for water droplets with similar charge and bring them together; (c) the ability to neutralize the emulsifier and promote the rupture of the interfacial film; and (d) the ability to make solid particles such as clays to water wet and cause them to leave the interface and be diffused into the water droplets.

It must be remembered that a given chemical emulsion breaker may be excellent and efficient for one emulsion and entirely unsatisfactory for another. It is important for effective and economical treatment that the operator enlist the service of the chemical supplier such as those listed in Appendix 15-A to analyze his specific problems and recommend a suitable chemical deemulsifier.

Mechanical: If the intensity of the collision between the dispersed droplets is sufficiently high, the interfacial film can be ruptured faster than the droplets can be reformed, and the emulsions breaks. This is the principle behind mechanical methods of treatment of emulsion. Mechanical agitation, ultrasonic vibrations, and centrifuging are some of the ways emulsions are resolved. Agitation techniques are not widely employed in the oilfield because agitating most oilfield emulsions has the tendency to make the emulsion worse.

Electrical: The small water droplets dispersed in the crude oil can be coalesced by subjecting the water in oil emulsion to a high voltage electric field. Under the influence of the electric field, water droplets become mutually attractive due to induced electric charges on the drops. The effect of these charges and the resultant forcible collision of drops overcome the stabilizing films, and a rapid separation of oil and water follows.

\section{Emulsion Breaking}

\section{A. Oil-in-Water Emulsions}

These will be discussed first because they are more prevalent in steam injection operations. A stable oil-in-water emulsion is a colloidal system of electrically charged oil droplets surrounded by an ionic atmosphere. Steamflooding encourages the formation of these emulsions because of the high water to oil ratio, shearing in the formation, and the presence of emulsifying agents such as silt and clays in the formation. There is nothing that can be done to prevent the formation of oilin-water emulsions.

Some emulsification is also caused in surface equipment by pumping wells off, gases coming out of solution, and centrifugal pumps in the gathering system. In the steam injection operation, the pumps are often pounded in order to keep the wells pumped off anci to produce the maximum amount of oil. The emulsions, however, are made worse as a result. The principal gas that comes 
out of solution in a steam injection operation is carbon dioxide. Since the release of carbon dioxide causes water to become acidic, it encourages the formation of oil-in-water emulsions. Therefore, the only thing that can be done to reduce the formation of oil in water emulsions in the wells and production gathering system is to design the system such that the fluids are in laminar flow and avoid centrifugal pumps wherever possible.

Oil-in-water emulsions can be broken by chemical and/or physical methods. Chemicals are commonly used to treat these emulsions and to enhance mechanical treatment. In breaking emulsions, the stabilizing factors must be neutralized to allow the emulsified droplets to coalesce. The accumulated electrical charges on the emulsified droplet are neutralized by introducing charges opposite to that of the droplet. Chemical emulsion breakers provide this opposite charge. The dielectric constants of water and oil cause emulsified oil droplets to carry negative charges. Therefore, to destabilize an oil-in-water emulsion, a cationic (posit:ve charge) emulsion breaker should be used.

The treatment of oil in water emulsions is normally divided into two steps:

1. Coagulation. This is destruction of the emulsifying properties of the surface-active agent or neutralization of the chirged oil droplet.

2. Flocculation. This is agglomeration of the neutralized droplets into large separable globules.

Both inorganic and organic oil in water emulsion breakers are available from chemical service companies. Organic emulsion breakers are the preferred emulsion breakers in Kern River Field because part of the produced water is usually discharged into an agricultural canal, and there are limitations on the amount of inorganic materials in that water. "Inorganic" emulsion breakers contain inorganic salts such as zinc or chromium or iron which increase the specific gravity of the water and encourage separation of water and oil.

The selection of a chemical for breaking oil-in-water emulsions must be done with care to make sure that this chemical is compatible with the oil treating chemical and does not have any undesirable side effects. One good rule-of-thumb is to use products from the same chemical company for both treatments. The chemical companies are very aware of incompatibility problems and can supply products that work together effectively.

The preliminary testing for oil-in-water emulsion breakers is the bottle test in which the service representative places samples of the emulsion in glass bottles, adds various doses of his chemical, shakes the bottles and observes the effect of the chemical on water clarity. The following pitfalls are present in this kind of bottle testing:

1. The sample should be fresh and tested immediately at the site. Do not believe any results on a sample that has been shipped. Several days of agitation on a truck or train serve to break most emulsions. 
2. The chemical should be used neat ( $100 \%$ straight out of the bottle) even though only very small amounts are being used, and measurement is difficult. Dilution of oil-in-water emulsion breaker chemicals affects their $\mathrm{pH}$ and decreases their effectiveness.

3. The amount of agitation used in the testing should simulate the amount of agitation actually found in the system. Emulsion breakers which work only after prolonged hard shaking will not usually work in a system that only has $s$ short run of pipe that is in laminar flow.

One final precaution: The effectiveness of the chemical program is generally composed of 30 to $40 \%$ the effectiveness of the chemical and 60 to $70 \%$ the effectiveness of the chemical company service representative. Chemical companies all have effective chemicals, however, there will be large variations in the abilities of the representative who provides the service.

\section{B. Water-in-Oil Emulsions}

Water-in-oil emulsions are viscous, concentrated emulsions which are formed when oil comes into contact with water and solids. It has been observed in many steam injection operations that breaking the obvious oil-in-water emulsion that is produced as a byproduct of steamflooding reveals a "hidden" water-in-oil emulsion which then must be treated in order to be able to sell the oil. Water-in-oil emulsions are stabilized by formation fines and asphaltenes.

Water-in-oil emulsions are also broken by a combination of time, temperature, and chemical. The chemical treatment of this kind of emulsion is directed toward destabilizing the dispersed water droplets and solids or destroying the emulsifying agents. The mechanical facilities which are usually wash tanks or heater treaters are critical here. The facilities and the chemical must work together for cost-effective separation. There is frequently a close balance between heat and chemical. The field engineer needs to study carefully the cost of heat vs. the cost of the chemical in his own system.

It should be emphasized that no two oilfield emulsions are alike. The chemicals and procedures used to treat the emulsion produced from one field may not work on an emulsion from a different field. Within the same field, emulsions can vary from well to well and from year to year during the life of the field.

The selection of a chemical to break water-in-oil emulsions must be done with the same care as with oil-in-water emulsions. Bottle testing is again used as a guide to selecting the chemical. Here the oil phase emulsion is poured into bottles, allowed to come to the temperature of the system, chemical added and the water drop recorded over a period of a few hours. At the end of the test a sample of oil from near the oil-water interface should be tested to determine how much water is remaining, that is, whether the sample is "dry" and the oil can be shipped.

The following precautions apply to this kind of testing:

1. Fresh samples should be used within a few hours of sampling to get reliable results. 
2. Neat chemical, not dilutions, should be used.

3. Oil-in-water emulsion breaker as well as water-in-oil emulsion breaker should be present in the final stages of testing to check for poiential chemical incompatibility.

4. The temperature and time used in the testing should closely simulate those actually present in the treating situation.

The chemical service companies also provide water-in-oil emulsion breakers.

\section{SUMMARY}

There are two kinds of oilfield emulsions: oil-in-water emulsions, in which water is the continuous phase and water-in-oil emulsions, in which oil is the continuous phase. Both kinds of emulsions are broken by a combination of time, temperature, agitation, and chemical.

The selection of emulsion breaking chemicals should be accompanied by bottle testing which carefully simulates system conditions. The emulsion breaker chemical is only as good as the chemical service company representative who administers the chemical program. If the oilfield is remote, and no service will be provided, the company should make provision for training of its own personnel in chemistry and emulsion breaking.

\section{GENERAL REFERENCES}

1. Bansbach, P. L. and D. V. Bessler. Cold Treating of Oilfield Emulsions. Pres. at the 22nd Annual Southwestern Petroleum Short Course, Lubbock, TX, April 1975,.pp. 241-249.

2. Smith, H. V. and K. E. Arnold. Crude Oil Emulsions in Petroleum Engineering Handbook, edited by H. B. Bradley. Chapter 19, Soc. of Pet. Eng., Richardson, TX, 1987, pp. 19-1 to 9-15.

3. R. A. Brewer. Chemelectric-The Electrical Coalescing Treater. Pres. at the 13th Annual Southwestern Petroleum Short Course, Iubbock, TX, April 1966, pp. 145-153.

4. Bertness, T. A. Thermal Recovery: Principles and Practices of Oil Treatment. Pres. at the Soc. of Pet. Eng. 40th Annual Fall meeting, Denver, CO, Oct. 3-6, 1965. SPE paper 1266. 


\section{EMULSION TREATMENT CHEMICAL SUPPLIERS}

1. Nalco Chemical Company, VISCO Division 4851 Stine Road

Bakersfield, CA 93313

Telephone: (805) 834-6590

2. Tretolite Chemicals

Petrolite Oil Field Group

333 Paliner Drive

Bakersfield, CA 93309

Telephone: (805) 397-5105

3. Baker Performance Chemicals Inc.

3920 Essex Lane

Houston, TX 77027

Telephone: (713) 599-7400

4. Eisenman Chemical 3900 Essex Lane

Houston, TX 77027

Telephone: (713) 439-8764

5. Champion Chemical Inc.

Oil Field Chemicals Division

105 Wilco Building

Midland, TX 79701

Telephone: (915) 563-0863 


\section{CHAPTER 16 \\ SURFACE PRODUCTION FACILITIES}

\section{INTRODUCTION}

Aside from water treatment and steam generation systems, a steam injection project contains several types of hardware for the collection, treatment, and disposal of the produced fluids. Collectively, this hardware is called the surface production facility (see Fig. 16.1) and includes a production gathering system and the oil dehydration and storage system. A casing gas vapor recovery system is used to recover and process the produced vapor from the well casing and is also found in many large steam injection projects. The pipings, vessels, and other items associated with the vapor recovery system are not part of the production facilities.

In steam injection operations, more than a third of the nonfuel operation costs result from the operation of the production facilities. History of steam injection operations reveal many projects have failed as a direct result of an improperly designed and operated surface facility. The proper design and operation of the surface equipment is of critical importance to the success of any steam injection operation. The objectives of this chapter are to present an overview of the design and operation features of various production equipment and their operational problems. A list of production equipment vendors is presented in Appendix 16-A. The service of these or others should be enlisted in the selection of equipment.

\section{PRODUCTION GATHERING SYSTEM}

The production gathering system is nothing more than a multitude of pipelines and associated pumps used to transport the produced fluids to the treatment plant. The automatic well test system (AWT) is an integral part of the gathering system. The system may contain one or more lines that branch off to each well or it may consist of a separate line to each well as distribution dictates. The complexity of the production gathering system network depends on the size of the project.

A schematic of a typical production gathering system network is shown in figure 16.2. It consists of (1) a production manifold that receives the fluids from the production well and transports them to the oil dehydrations facility directly or through a main gathering manifold; (2) a series of lines from individual wells, which route the production either to the production manifold or to a common test line or to a purge line through an automatic three-way diverter valve; (3) a common test line that gathers the flow from individual wells and transports it to a test tank for the purpose of gauging and testing the oil and water production; and (4) a purge line that also serves as an observation line. In a cyclic operation, the production manifold also serves as the steam injection manifold for a certain period of time when the wells are being steamed. Similarly, the line to each well from the manifold is a dual purpose line used for steaming the well for a certain period 


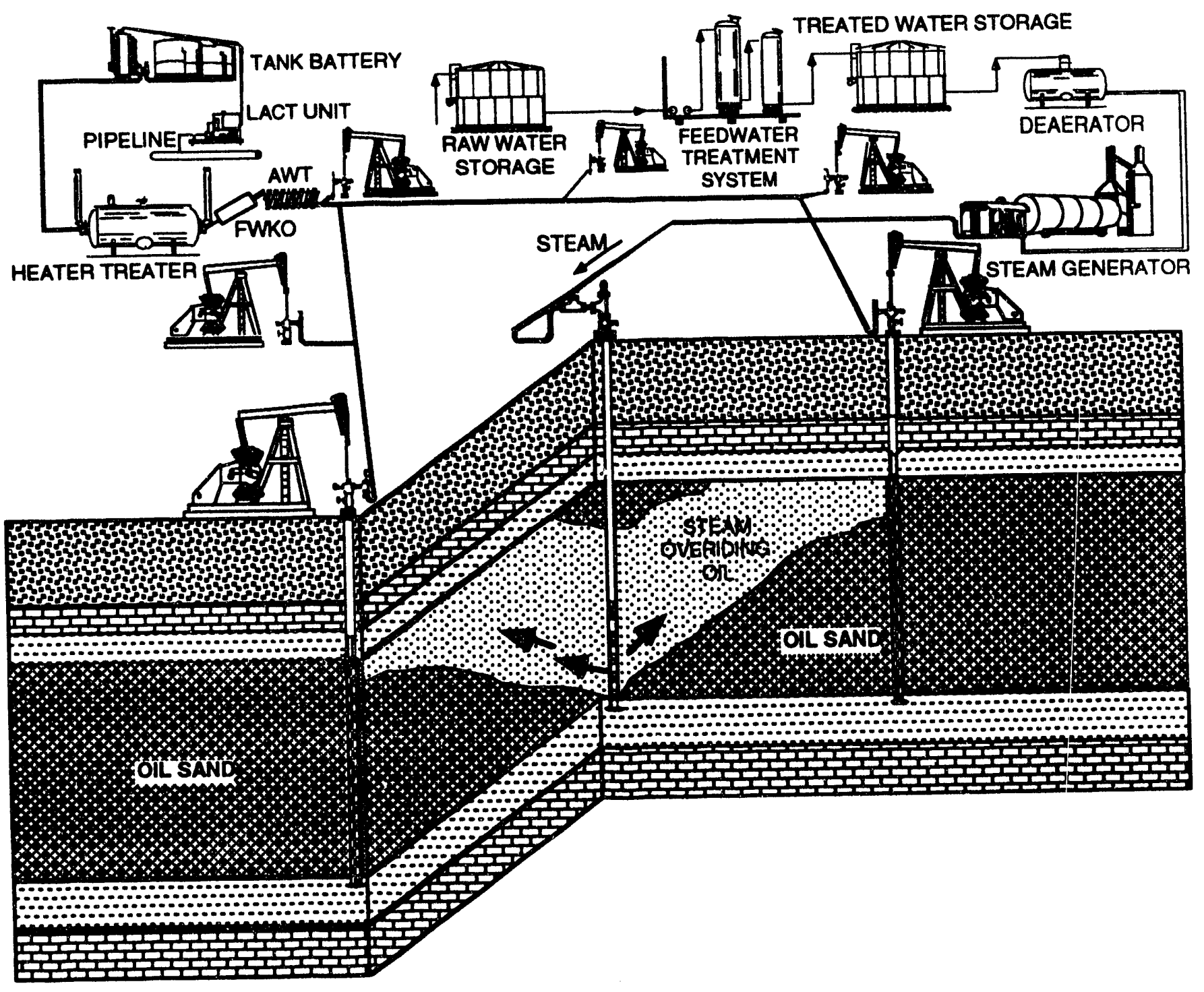

FIGURE 16.1. - Schematic of a steamflood surface production facility. 


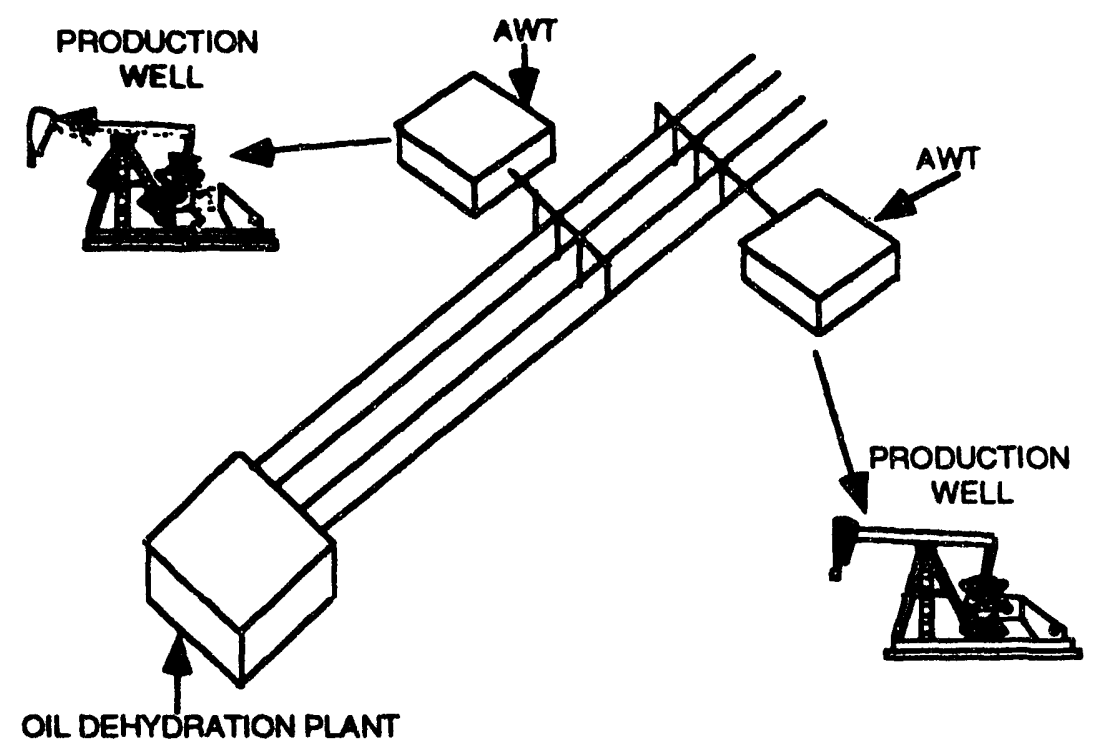

FIGURE 16.2. - Schematic of a typical steamflood production gathering network.

of time. Usually a single production/injection manifold serves about 20 wells. The size of the lines used in the gathering system depends on the volume of fluids produced and may range from about 4 in. for individual lines to about 24 in. for the main manifold. Depending on the size of the project, the total length of the gathering network ranges from several thousand feet to several miles.

The entire production gathering system is energized by the pumping units. The pump must have sufficient capacity to lift the projected amount of fluid and transport it to the treatment plant. The line pressures must be kept down to avoid backpressures on the pumping units. Hence, the lines must be sized properly to keep the pressure down. In designing the production gathering system, flexibility and the need for the maintenance and repair of lines must be kept in mind. In large projects, two or three parallel gathering lines are used in different parts of the field to permit shutdown of the parts of the system for repair and maintenance.

Since steaming processes often times produce gases such as $\mathrm{CO}_{2}$ and noncondensible hydrocarbons along with steam, it is important that air eliminators be installed throughout the production gathering system to remove the gases. If these gases are not removed, they will build up on the top of the pipe and restrict the flow of the production fluids. When this happens, the solids are concentrated in the liquid stream. This, together with the increased velocity, will dramatically increase erosion of the lines.

In many large California steam injection projects, of ten times the production comes from the leased properties. Under the terms of the lease agreement, it may require separating oil and water 
at the lease line and metering of the oil. If such is the case, then separate facilities must be constructed at the lease line to separate oil and water. The lease facilities usually consist of a primary and secondary wash tank and one or more shipping tanks. The oil is skimmed from the primary to secondary and then to the shipping tank. When the shipping tank is full, it is manually gauged, prior to shipping to the oil dehydration plant. A positive displacement pump is utilized to pump the oil back into the production gathering system. The water is waterlegged into the drain tank. Any oil collected at the top of the drain tank is skimmed and pumped back into the production gathering system using positive displacement pumps. Depending on the size of the project, several drain tanks (each with a capacity of 500 to $1,000 \mathrm{bbl}$ ) are utilized to hold the water from the lease tanks. The water is also discharged into the production gathering lines using centrifugal pumps.

Since the produced fluids are in emulsified form, an emulsion breaker (a chemical that aids the breakup of the emulsion) is injected into the gathering line to resolve the emulsion. High temperature, longer residence time, and agitation all aid in the breakup of the emulsions. Since all of the parameters favorable to the breakup of the emulsion are present in the gathering system, usually only a small amount of chemical is added to the system to initiate the breakup of emulsion. The emulsion breakers feed points are usually located downstream of the AWTs. Only a minimum amount of chemical needed to initiate the breakup of the oil-in-water emulsion must be added and full advantage of the residence time in the line should be taken. Careful attention must be paid to the amount of treatment chemicals used because overtreating would inhibit the resolution of waterin-oil emulsion formed in the oil dehydration plant.

Use of single reverse emulsion breaker throughout the gathering system is recommended to permit the ease of administration and to avoid potential incompatibility problems which could exist if two or more chemicals were used. Emulsions and emulsion breaking are discussed more fully in chapter 15.

\section{Automatic Well Test (AWT) Units}

The AWT unit is utilized to measure the oil and water production rates from individual wells and is an essential component of the oilfield production gathering system. Accurate measurement of crude oil production from individual wells is needed for a variety of reasons.

Individual fluid production from wells is necessary for optimizing production operations and for reservoir management. It is also needed for calculating royalty and working interest payments and for guiding daily production operation. In large operations, each individual well is expected to contribute its share to total oil production and the AWT unit provides a means of determining the well productivity and indicates when to shut down uneconomic wells. Production data are also needed to meet any contractual requirements and government regulations. 
In steam injection operations, data obtained from AWT units are utilized as the number one diagnostic tool to determine the changes in reservoir characteristics and to establish well workover needs. These data are also utilized in many instances to gauge the success (both technically and economically) of the steam injection process. ${ }^{1}$ Hence, it is important that data gathered from AWT units be accurate and reliable. To illustrate how vital these data are, consider a typical waterflooded reservoir in the United States.

Many U.S. waterflooded reservoirs are currently producing at high watercuts, and most of them contain wells that are capable of producing in excess of 500 barrels of fluid per day (bfpd). For such wells, a small error in the watercut will result in a large percentage error in the oil production rate. For example, a well producing 600 bfpd at a $95 \%$ watercut is producing 30 barrels oil per day (bopd). If the watercut is measured at $94 \%$ or $1 \%$ less than actual value, the calculated oil rate would be 36 bopd. The 6 bopd difference represents a $20 \%$ error in oil production rate. Not only is the oil production rate of this well incorrect, other wells in the system will have to make up the difference if an allocation method is used. Since this is usually the case, this may result in the continued production of uneconomic wells. Unfortunately, it is sometimes very difficult or uneconomical to obtain accurate production data because of the time consuming nature of the tests and difficulties in the caibration and operation of metering devices and sampling equipment. The problem is even more acute in steam injection operations. The hawking of a variety of well test hardware designs, as well as a wealth of recent AWT related papers, is a testimony to the difficulties in obtaining accurate and reliable production data.

\section{The AWT System}

There are several popular production well testing methods used in the oil patch. All techniques employ a test vessel to separate oil, water and gas, and meters to measure the flow rate of individual phases. A typical automatic well testing system used in an oilfield is shown in figure 16.3. This system consists of a group of test/production manifolds, a test vessel and metering elements. The well to be tested is diverted to the test vessel, by activating a three-way control valve on the test/production manifold. Many installations use a three-phase separator (a direct-fired heater treater) to separate and measure the oil, water, and gas individually. Other installations use a two-phase vessel and measure the watercut with a continuous sampler such as a capacitance probe on the emulsion stream. The two-phase vessels are less expensive to purchase and to operate than the three-phase heater treater type arrangement and require no emulsion breakers. Due to severe emulsion problems, three-phase separators are universally used in steam injection operations.

The volume of the produced fluid is usually measured with the aid of positive displacement or turbine meters. These meters have moving parts which are subject to erosion and corrosion and 


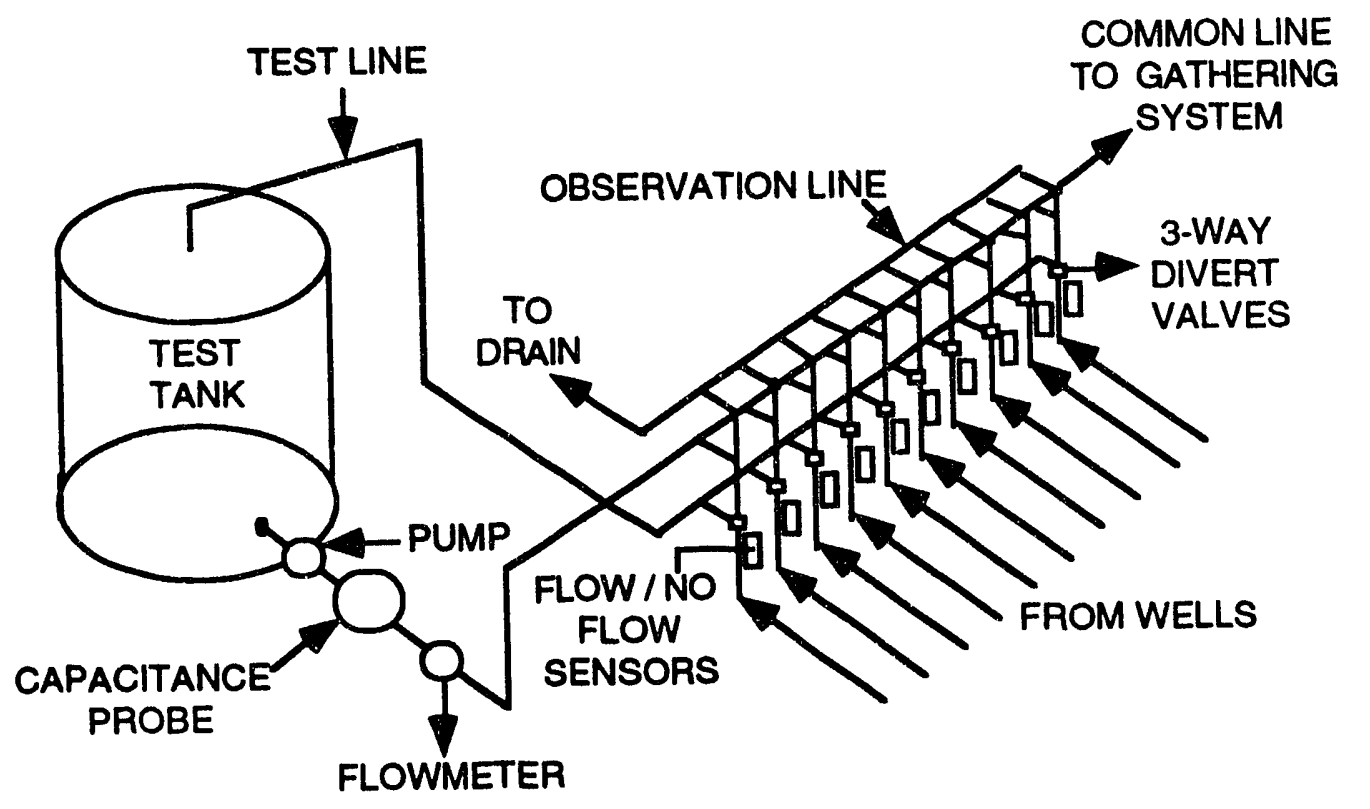

FIGURE 16.3. - Schematic of steamflood automatic well testing system.

eventual failure. Further, since these moving parts do not fail in an obvious manner, they require constant and costly calibration and testing. Without such tests and calibration, the problem of faulty meter readings will go undetected and introduce error in measurements. For these reasons, mass flow meters are increasingly being used in larger steam injection operations to improve the accuracy of well test data. ${ }^{3}$ Further, since the mass flow meters do not have any moving parts, they are practically maintenance free, and the meter calibration is relatively simple. Also, mass flow meters are not affected by the variation in fluid volume caused by thermal expansion and contraction. Mass flow meters, however, are more expensive than common oilfield flow meters and require more training for operators.

\section{TREATMENT OF PRODUCED FLUIDS}

The oil produced by steam injection is accompanied by water and much of this is produced in the form of emulsion. The shearing action of steam through the formation causes a rather severe oil-in-water emulsion. Further, the thermal wells are usually pumped-off to maximize the oil recovery and also increases the severity of emulsion. Since much of the steam injection operation is conducted in unconsolidated formations, sand is produced along with the fluids. The water and sand must be removed from the oil before it can be sold to refineries. In addition, the produced water must be treated to remove oil and solids before it can be recycled. Water is separated from oil in a dehydration plant. Most of the sand also drops out of the fluid in the treatment plant. Further, solids separation can be achieved by centrifuge or flotation techniques. A variety of treatment systems are marketed to treat and dehydrate the emulsified oil. In selecting a treating 
system, a number of factors should be considered in determining the most desirable method of treating the crude oil to meet sales requirements. Some of these factors are (1) tightness of the emulsion, (2) specific gravity of the oil and produced water, (3) corrosiveness of the crude, produced water and casing head gas, (4) scaling tendencies of the produced water, (5) quantity of fluid to be treated and percent of water in the fluid, and (6) equipment operating pressures.

In steam injection operations, chemicals and heat are used to destabilize the emulsion. The addition of heat has a dual effect, i.e., the specific gravity and viscosity of the oil both decrease as the temperature is increased. This combination of decreased specific gravity and viscosity of the oil amplify the differences in densities between oil and water. This difference in densities aids in the separation of water from oil.

A variecy of equipment is used in steam injection operations to dehydrate the oil and to remove sand. These include: freewater knockout vessels, wash tanks, heater treaters, and storage tanks. The sediments from the tank bottoms are cleaned using desanders. In addition, accessory equipment that is not basically necessary to the operation of the dehydration plant is also included as part of the dehydration plant. These include the lease automatic custody transfer (LACT) units and cooling towers to cool the produced waters for treatment in the depurators.

Not all of these units are found in all operations. The amount and type of equipment needed depend on the volume of the fluids to be handled, severity of emulsion and sanding problems, waste water specification, etc. Several different types of equipment or systems may satisfactorily resolve an emulsion, but particular types of equipment or systems may be superior to others because of basic considerations in design, operation, initial cost, maintenance, and operating costs, and performance. 5 Effort should be made to select the minimum number of pieces of equipment for each treating system to lower initial and operating costs.

Basic descriptions of various pieces of equipment used in a steamflood dehydration plant are as follows.

\section{Freewater Knockout (FWKO) Vessels}

In steam injection operations, where large volumes of water are produced along with oil, it is both desirable and economical to separate as much water from oil as possible before attempting to treat the emulsion. The freewater knockout vessels or oil-water separators are used for this purpose. The FWKO vessels are the first of a series of equipment utilized to dehydrate the oil. The hot produced fluids from the gathering systems enter the FWKO vessels where the produced oil and emulsion are allowed to separate from water. FWKO units are normally large cylindrical vessels which operate under pressure for the free gravity separation of oil and water. The oil-water interface in the vessel is controlled by an interface level control which operates a water discharge valve. 
Depending on the volume of the produced fluids, one or more FWKO vessels are used in the process. The vessel must be large enough to permit the separation of water from oil in reasonable time. Both vertical and horizontal configurations are utilized. Schematics of horizontal and vertical FWKOs are shown in figures 16.4 and 16.5, respectively. In tables 16.1 and 16.2 , the size and capacities of the horizontal and vertical vessels are given. 4

The residence time in the FWKO ranges from 3 to 6 hours. The free water is removed from the vessel through a water dump valve (usually controlled by a capacitance type interface controller). This prevents the dumping of oil out of the water dump valve by keeping the emulsion-freewater interface level at a predetermined set point. Normally, there is no oil discharge valve and the oil, emulsion, and gas is flowed through a connection in the top of the vessel on to the treating system.

Variations of freewater knockouts are often used to accomplish specific treating purposes. Flow splitters are one variation of the freewater knockout designed for specific applications. The flow splitter vessels have two or more separate compartments to collect the oil before it is discharged from the freewater knockout. The oil is discharged in multiple streams, depending on the number of separate oil compartments in the vessel. The free water is discharged from the vessel as it would be in a standard horizontal freewater knockout using an interface level control and water discharge valve. The oil flows over adjustable weirs into separate compartments and each is equipped with an oil level control and separate oil discharge valve. Any gas separated is discharged out the top of the vessel through a separate gas line. The purpose of these vessels is to ratio the oil out of the freewater knockout to different pieces of treating equipment. This type of vessel would have application where the oil volume, produced and passed through the freewater knockout, was so large that it could not be handled by a single piece of treating equipment. Therefore, the flow splitter is used to ratio the oil flow to several treaters. Or, the operator may already have several items of treating equipment on hand and wants to use them in a large central treating installation where the flow has been increased due to a steamflood.

Many steamflood operators use a cone-bottom FWKO. This design is used if sand production is anticipated to be a major problem. Normally, $45^{\circ}$ and $60^{\circ}$ cones are used as the bottom head of the vessel. Water jets are usually used to dislodge and flush the sand from the vessel.

Emulsion breakers and antifoaming agents are usually added upstream of the FWKO to partially break the emulsions. The gross emulsions leaving the FWKO usually consist of $40 \%$ water and $60 \%$ oil and, depending on the operation, the water content of emulsion may range from $10 \%$ to $50 \%$. The water leaving the FWKO vessel usually contains about 100 to $400 \mathrm{ppm}$ of oil and this oil is usually recovered in a depurator. 


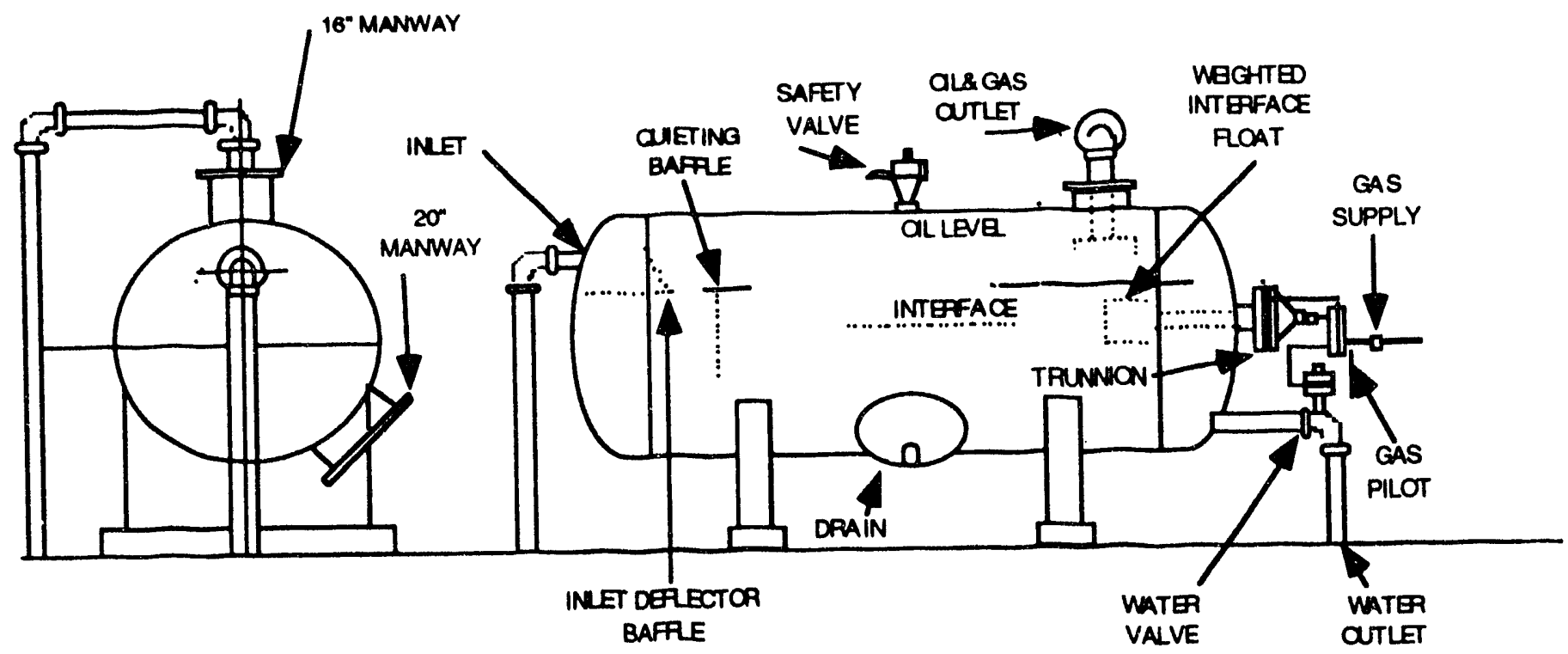

FIGURE 16.4. - Typical horizontal freewater knockout. ${ }^{4}$

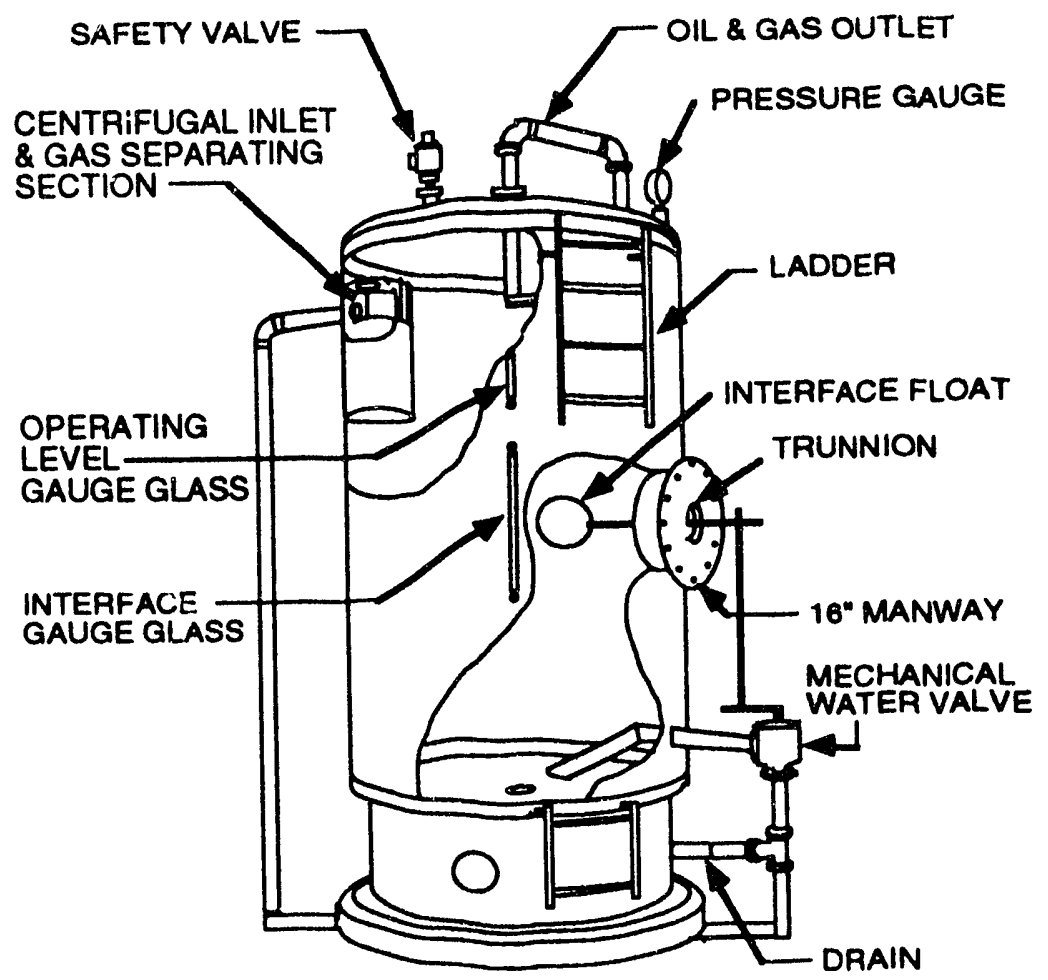

FIGURE 16.5. - Typical vertical freewater knockout. 4 
TABLE 16.1. - Specifications for Horizontal Freewater Knockouts 4

\begin{tabular}{|c|c|c|c|c|c|c|c|}
\hline \multicolumn{5}{|c|}{ Specifications } & \multicolumn{3}{|c|}{$\begin{array}{c}\text { Volume of } \\
\text { fluid in vessels }\end{array}$} \\
\hline $\begin{array}{c}\text { Size } \\
\text { Dia. } x \\
\text { length, } f t\end{array}$ & $\begin{array}{l}\text { W.P. } \\
\text { psi }\end{array}$ & $\begin{array}{c}\text { Inlet \& } \\
\text { Outlet } \\
\text { Conn., in. }\end{array}$ & $\begin{array}{l}\text { Drain } \\
\text { Conn., } \\
\text { in. }\end{array}$ & $\begin{array}{c}\text { Standard } \\
\text { water } \\
\text { valve, } \\
\text { in. }\end{array}$ & $\begin{array}{c}\text { Vol. } \\
\text { Water, } \\
\text { bbl }\end{array}$ & $\begin{array}{l}\text { Vol. } \\
\text { Oil, } \\
\text { bbl }\end{array}$ & $\begin{array}{l}\text { Total } \\
\text { Vol., } \\
\text { bbl }\end{array}$ \\
\hline $\begin{array}{r}3 \times 10 \\
4 \times 10 \\
6 \times 10 \\
6 \times 15 \\
8 \times 15 \\
10 \times 15 \\
10 \times 20 \\
10 \times 30 \\
10 \times 40 \\
10 \times 50 \\
12 \times 40 \\
12 \times 50\end{array}$ & $\begin{array}{l}50 \\
50 \\
50 \\
50 \\
50 \\
50 \\
50 \\
50 \\
50 \\
50 \\
50 \\
50\end{array}$ & $\begin{array}{c}3 \\
4 \\
4 \\
4 \\
4 \\
6 \\
6 \\
6 \\
6 \\
8 \text { In - } 6 \text { Out } \\
8 \\
8\end{array}$ & $\begin{array}{l}2 \\
3 \\
3 \\
3 \\
3 \\
4 \\
4 \\
4 \\
4 \\
4 \\
4 \\
4\end{array}$ & $\begin{array}{l}3 \\
4 \\
4 \\
4 \\
4 \\
6 \\
6 \\
6 \\
6 \\
6 \\
6 \\
6\end{array}$ & $\begin{array}{r}6.9 \\
12.5 \\
29.1 \\
41.7 \\
76.7 \\
124.0 \\
159.0 \\
228.8 \\
296.8 \\
366.7 \\
431.8 \\
532.5\end{array}$ & $\begin{array}{r}5.4 \\
9.3 \\
23.0 \\
32.8 \\
60.5 \\
102.9 \\
131.2 \\
188.1 \\
243.7 \\
300.5 \\
371.0 \\
471.7\end{array}$ & $\begin{array}{r}12.3 \\
21.8 \\
52.1 \\
74.5 \\
137.2 \\
226.9 \\
290.2 \\
416.9 \\
540.5 \\
667.2 \\
802.8 \\
989.7\end{array}$ \\
\hline
\end{tabular}

TABLE 16.2. - Specifications for Vertical Freewater Knockouts ${ }^{4}$

\begin{tabular}{|c|c|c|c|c|c|c|c|c|}
\hline \multirow[b]{2}{*}{$\begin{array}{c}\text { Size } \\
\text { Dia. } x \\
\text { length, } f t\end{array}$} & \multirow[b]{2}{*}{$\begin{array}{l}\text { W.P. } \\
\text { psi }\end{array}$} & \multicolumn{2}{|c|}{ Specifications } & \multirow[b]{2}{*}{$\begin{array}{l}\text { Standard } \\
\text { water } \\
\text { valve, } \\
\text { in. }\end{array}$} & \multirow[b]{2}{*}{$\begin{array}{l}\text { Approx. } \\
\text { wt. lb. }\end{array}$} & \multicolumn{2}{|c|}{$\begin{array}{c}\text { Volume of } \\
\text { fluid in vessels }\end{array}$} & \multirow[b]{2}{*}{$\begin{array}{l}\text { Total } \\
\text { Vol.., } \\
\text { bbl }\end{array}$} \\
\hline & & $\begin{array}{c}\text { Inlet \& } \\
\text { Outlet } \\
\text { Conn., in. }\end{array}$ & $\begin{array}{l}\text { Drain } \\
\text { Conn.. } \\
\text { in. }\end{array}$ & & & $\begin{array}{c}\text { Vol. } \\
\text { Water, } \\
\text { bbl }\end{array}$ & $\begin{array}{l}\text { Vol. } \\
\text { Oil, } \\
\text { bbl }\end{array}$ & \\
\hline $\begin{array}{r}4 \times 10 \\
6 \times 10 \\
8 \times 10 \\
10 \times 10\end{array}$ & $\begin{array}{l}50 \\
50 \\
50 \\
50\end{array}$ & $\begin{array}{l}4 \\
4 \\
4 \\
4\end{array}$ & $\begin{array}{l}3 \\
4 \\
4 \\
4\end{array}$ & $\begin{array}{l}3 \\
4 \\
4 \\
4\end{array}$ & $\begin{array}{l}2,000 \\
3,500 \\
6,300 \\
8,700\end{array}$ & $\begin{array}{l}10.2 \\
24.1 \\
45.4 \\
75.0\end{array}$ & $\begin{array}{l}11.2 \\
25.2 \\
44.8 \\
69.9\end{array}$ & $\begin{array}{r}21.4 \\
49.3 \\
90.2 \\
144.9\end{array}$ \\
\hline
\end{tabular}

The FWKO is relatively maintenance free. The main problem which occurs is the buildup of solids on the bottom of the tanks. The tanks must be cleaned periodically, depending on the severity of solid buildup.

\section{Settling Tanks}

Some steam injection operators use settling tanks instead of heater treaters to dehydrate oil. Various names are given to these settling tanks and some of the most common are gun barrels, wash tanks and dehydration tanks. Designs for these tanks differ in detail from vendor to vendor and field to field. The essential components of a settling tank include: a gas separation chamber or gas boot, a downcomer, water wash section, spreader or deflector plates, and oil collectors. The 
internal design of the wash tanks vay from operator to operator and depends on the overall process selected for the facility, emulsion properties, flow rates, and desired effluent qualities. Many settling or wash tanks employ heat to aid in the treatment process. Heat can be added to the liquid by an indirect heater, a direct heater, or any type of heat exchanger.

A direct fired heater, also called a "jug heater," is one in which the fluid to be heated comes in direct contact with the immersion type heating element or heating tube. The units are normally constructed so that the heating element can be removed for cleaning, repair, or replacement. Direct heaters are usually used to heat low pressure noncorrosive liquids.

An indirect fired heater is one in which the fluid passes through tubes immersed in a bath of water or other heat transfer medium. The heat transfer medium, in turn, is heated by an immersion type heating element similar to the one used in a direct fired heater. Indirect fired heaters are more expensive than direct fired heaters and cost more to maintain. Indirect fired heaters are generally used to heat corrosive or high pressure fluids.

Schematics of a wash tank, used by one large California steam injection operator to dehydrate the oil, is shown in figure 16.6. These are 10,000 barrel welded mild steel tanks and have internals consisting of two stacks of heating coils and a spreader bar. The tanks are maintained at $190^{\circ} \mathrm{F}$ by circulating steam through the heating coils.

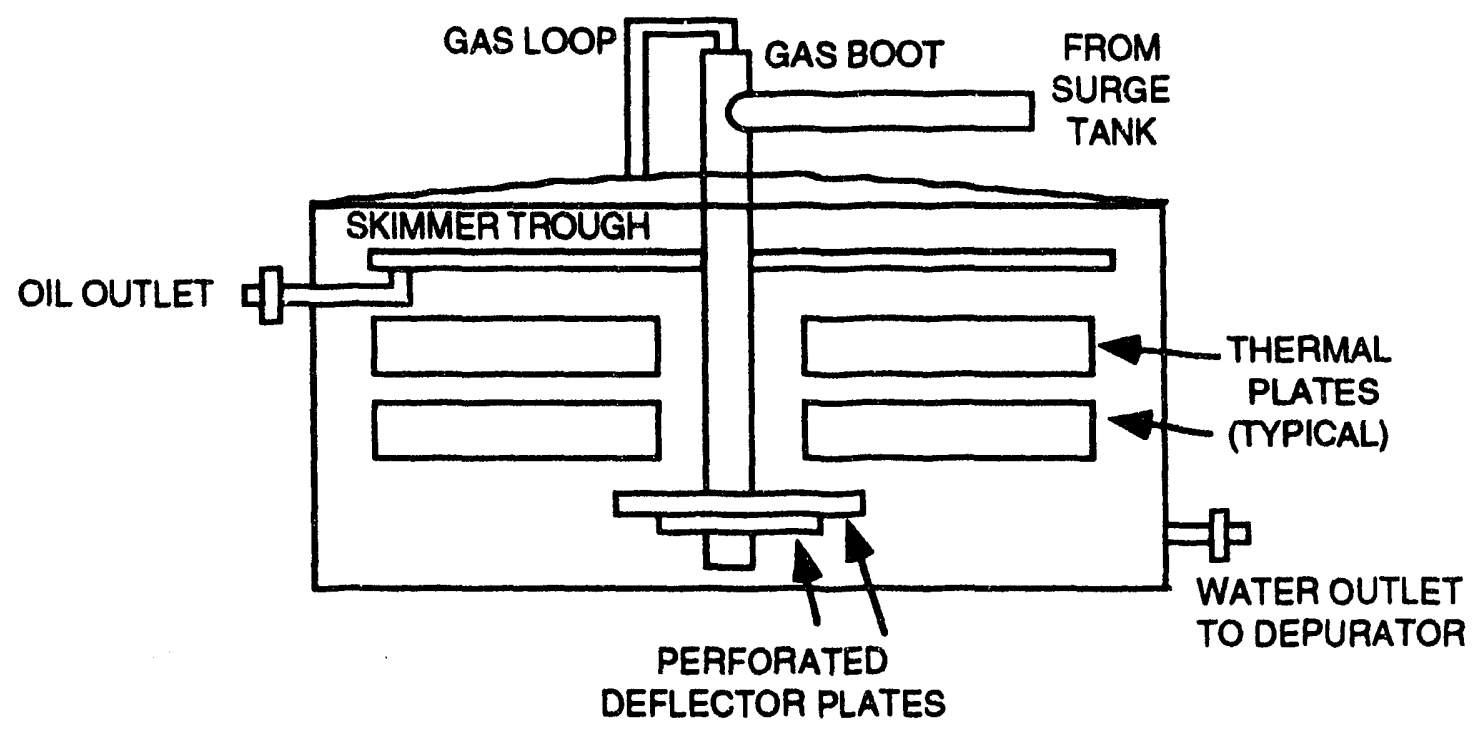

FIGURE 16.6. - Schematic of an oilfield wash tank. 
The function of the gas boot is to separate gas from the incoming fluid stream. The emulsion enters the gas boot, where a momentum change causes gas to separate. The gas boot is usually a simple piece of pipe as shown in figure 16.6. In some units, they are more elaborate and contain nozzles or baffles to help separate gas. The oil and water then passes through the gas boot to enter the bottom of the tank through a spreader device. An oil-water interface is maintained in the tank by means of an outside water leg on the tank or through the use of an electronic probe. Electronic probes are most often used in heavy oils to sense the interface and automatically trigger a water dump valve.

A downcomer directs the emulsion below the oil-water interface to the water wash section. In large tanks, such as the one shown in figure 16.6, a spreader is used to distribute the flow over the entire cross-section of the tank. The function of the spreader or the deflector plate, which contains small holes or slots, is to disperse the emulsion into very small droplets which are subjected to washing action as the droplets float to the top of the tank. This permits the water released from the emulsion to drop out. If the droplet size is too big, there will not be sufficient "washing" action and the oil will take longer to dehydrate.

The whole key to efficient wash tank operation is maintaining a stable oil-water interface which is well above the accumulated sediment. The plant operator should check the location and appearance of oil pad every hour and adjust the pad as needed to maintain a good interface. However, all changes should be made slowly.

Maintenance of wash tanks consists of keeping the heating coils in good condition and cleaning the accumulated tank bottoms every 3 months. Since heat aids in the breakup of the emulsion, it is important that heating coil surfaces be film free to promote better heat transfer. Oil cuts in the wash tanks must be monitored every 2 hours or so with the objective being to have a water and sediment free oil (less than $3 \%$ basic sediment and water [BS\&W]) under normal operating conditions. In large operations, the oil from the first wash tank is skimmed to a second wash tank and then to the shipping tank. This is is accommodate any upsets and to ensure that the dehydrated oil meets the pipeline specification.

\section{Heater Treater}

Most steam injection operators use heater treaters to break emulsions. A heater treater is a pressure vessel that operates on the same principle as the wash tank. A heater treater can heat the emulsion to temperatures above the boiling point of water, without boiling the water.

The heater treater (also called an emulsion treater) combines all of the various pieces of equipment used to treat an emulsion in one vessel. The heater treater is designed to include in one unit any or all of the following elements: oil and gas separator, freewater knockout, heater, water washing section, filter section, stabilizing section, heat exchanger and electrostatic field. 
Although the heater treaters can be operated a atmospheric pressure, they are often operated under low working pressure (typically from 10 to $50 \mathrm{psig}$ ), depending on the construction of the vessel and the type of controls used. Heater treaters are available in both vertical and horizontal configurations. The emulsion, along with the treating chemicals, enters the vessel near the top and flows downward.

\section{Vertical Treaters}

One of the most commonly used crude oil emulsion weating system is the vertical heater treater. A variety of designs are available. Three such designs are shown in figures 16.7, 16.8 and 16.9.

In the design shown in figures 16.7 and 16.8 , the emulsion enters near the top of the treater into a gas separation section. In figure 16.9, the emulsion enters near the bottom and flows upward into a gas separation. This section must have adequate space to separate gas from the liquid. The gas separation section usually has an inlet diverter and a mist extractor.

The emulsion flows through a downcomer to the bottom portion of the treater, which serves as a FWKO and water wash section. This section should be sized for sufficient retention time to allow the free water to settle out. This will minimize the amount of fuel needed to heat the liquid rising through the heating section.

The oil and emulsion flows upward through the water which serves as a washing medium. The water is heated by a fire tube projecting into this compartment. After leaving the heated water wash, the emulsion rises into a settling space where water is broken out of the emulsion, settles out, and falls back into the water wash. The clean oil rises and passes through the oii outlet. The water in the bottom of the unit passes out a water outlet to the disposal system. The oil-water interface level is control' 2 by an interface controller or an adjustable external water leg. The operating pressure is kept well above the saturated steam pressure at the operating temperature to prevent the water from boiling.

\section{Horizontal Heater Treuter}

The external and internals of a typical horizontal heater treaters are shown in figures 16.10 and 16.11. The horizontal treaters operate much like vertical treaters. The incoming emulsion, with chemical added, enters the front section of the treater where gas is flashed. The liquid flows downward to near the oil-water interface where the emulsion is water washed and the free water is separated. The oil and emulsion rises past the fire tubes and flows into a second section of the vessel where water is broken out of the emulsion and falls back into the bottom. The clean oil is removed through the outlet. The oil-water interface in the inlet section of the vessel is controlled by an interface controller. which operates a dump valve for the free water. 


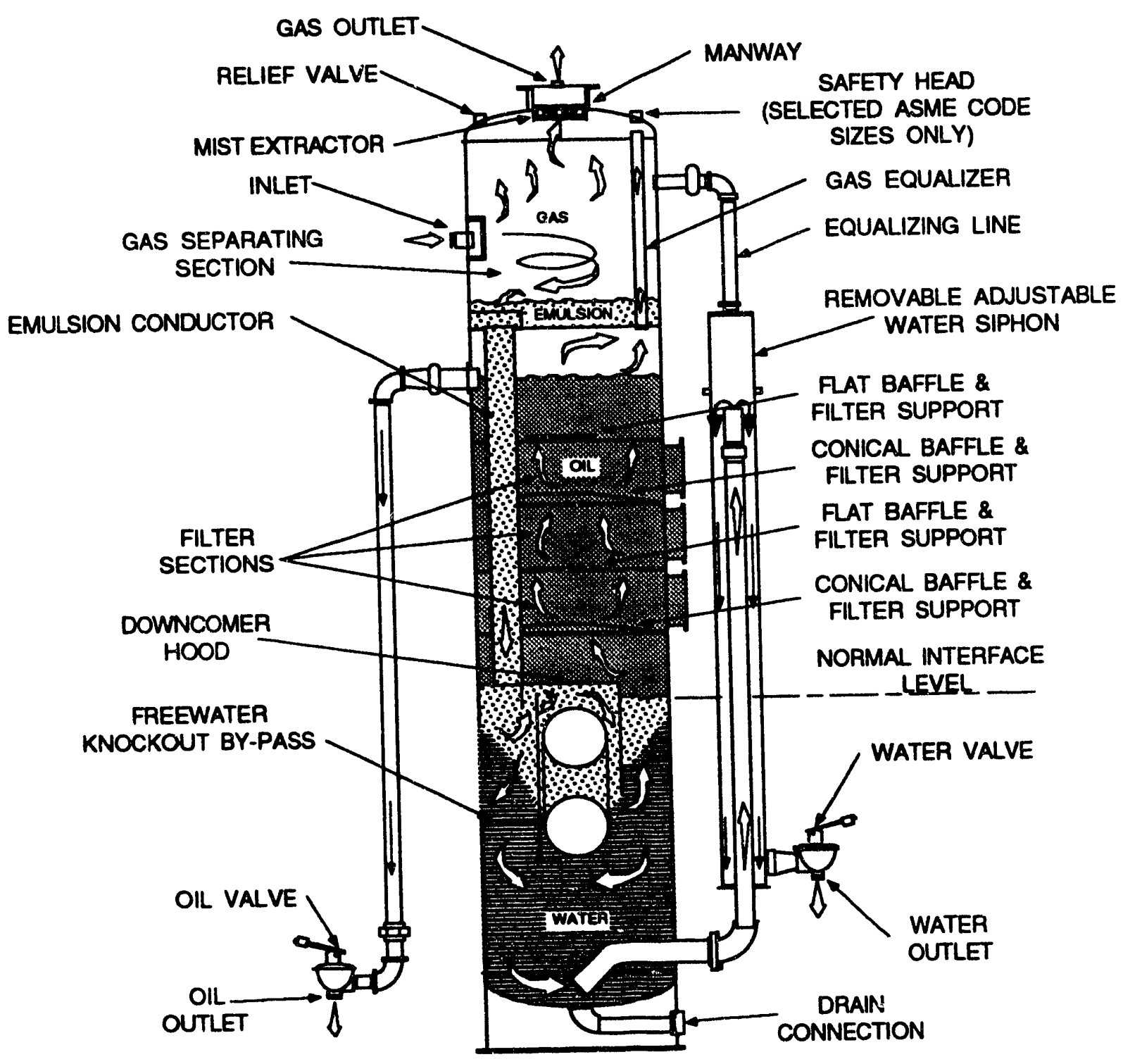

FIGURE 16.7. - Schematic of a vertical heater treater. 4 


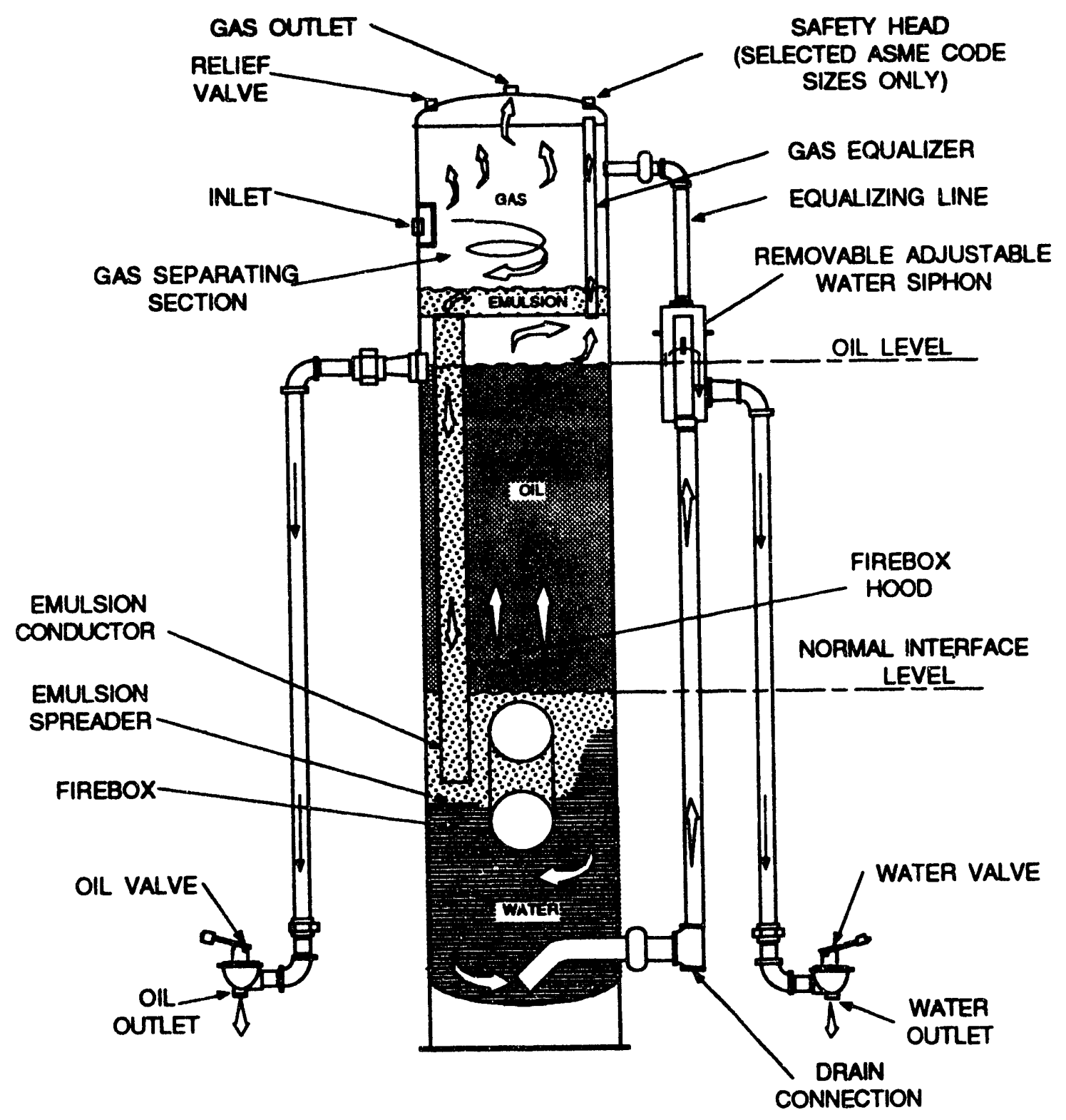

FIGURE 16.8. - Schematic of a second type of vertical heater treater. 4 


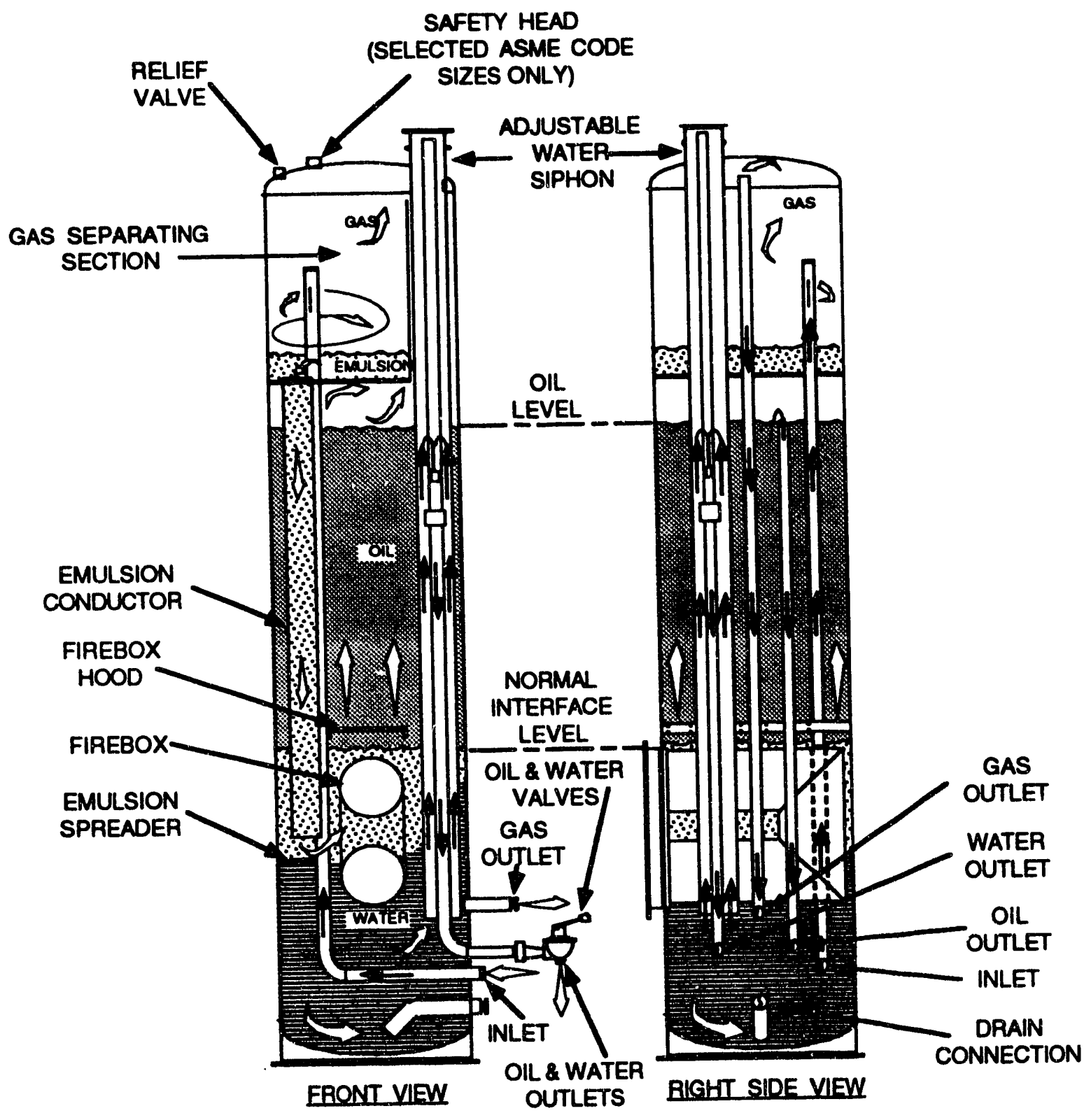

FIGURE 16.9. - Schematic of a third type of vertical heater treater. ${ }^{4}$ 


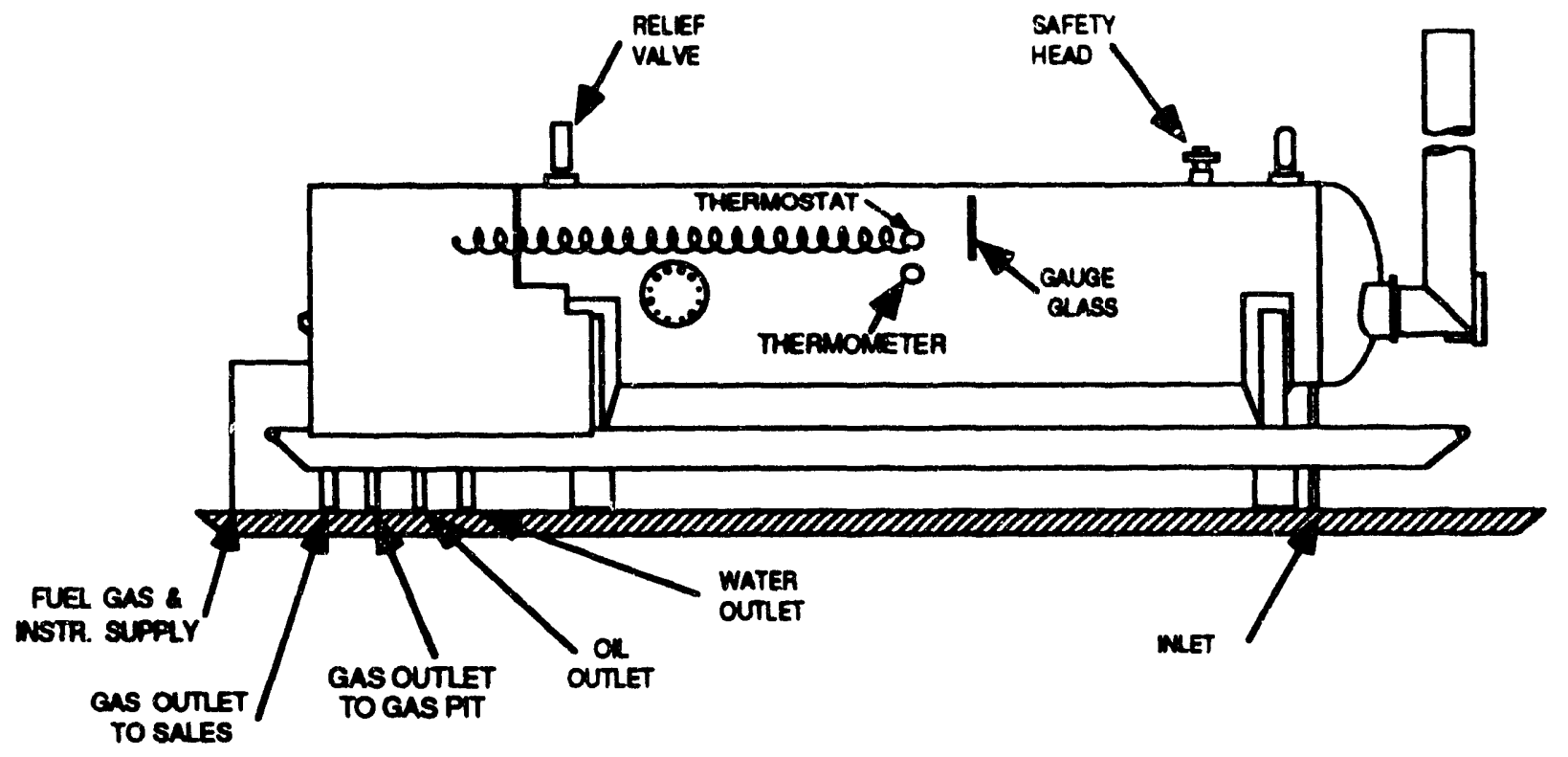

FIGURE 16.10. - Schematic of one type of horizontal heater treater. ${ }^{4}$

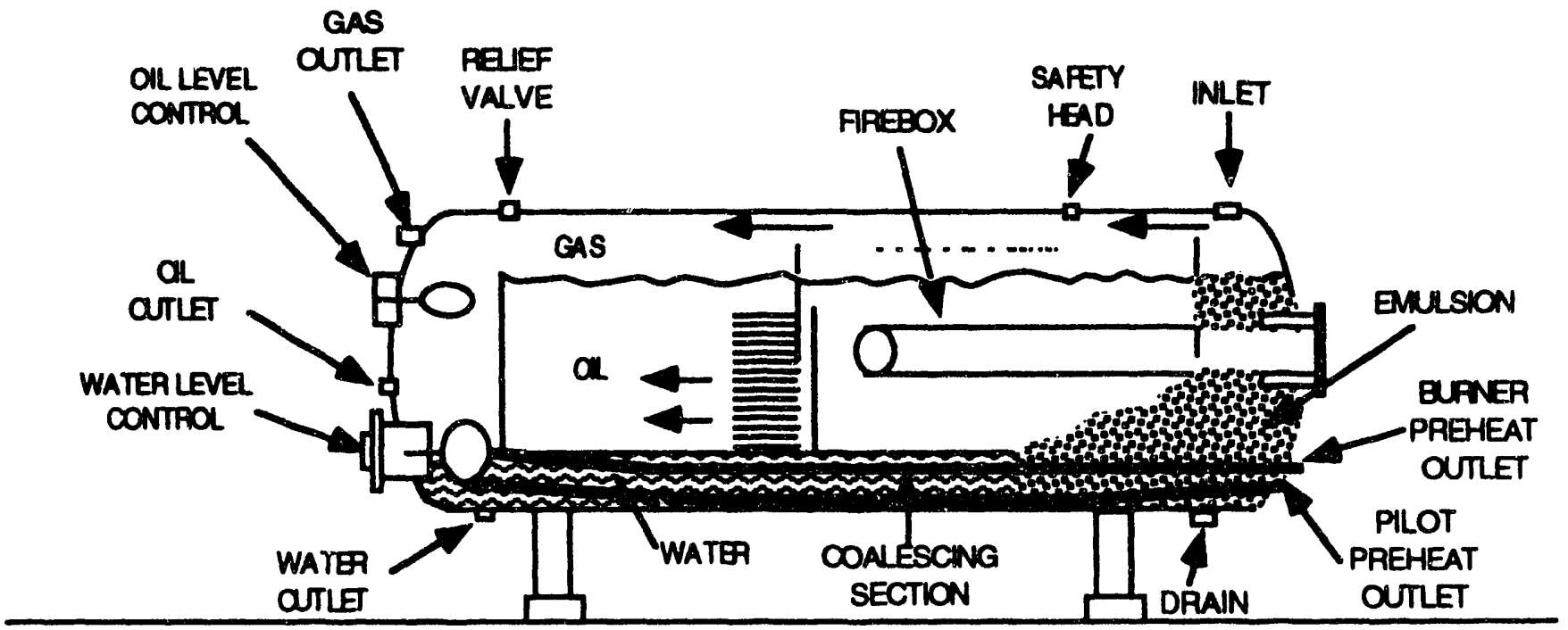

FIGURE 16.11. - Schematic of a second type of horizontal heater treater. 4 
Generally, horizontal treaters have a larger settling or coalescing section than vertical treaters and, therefore, are often used to treat heavier oils. The larger sizes of the horizontal treaters allow for larger fire boxes and therefore the capability to handle larger volumes of fluids. Also, the oilwater interface area in a horizontal treater is larger, and this permits more rapid settling of oil and water particles within the vessel. One possible disadvantage of horizontal treaters is that they require more floor space than vertical designs.

The dimensions of a typical horizontal heater treater used in a steamflood operation are $12 \mathrm{ft}$ in diameter by $30 \mathrm{ft}$ in length and can process 540 barrels of fluid. These units are usually operated at $60 \mathrm{psig}$ and $260^{\circ} \mathrm{F}$.

\section{Electrostatic Treaters}

Electrostatic treaters (see figure 16.12), often called chemelectric or electrochemical treaters, are similar to horizontal heater treaters except that high voltage, alternating current electric grids are added. Electricity is often an effective means of breaking emulsions. As the heated emulsion rises through the electric field, the water droplets are given a charge. When charged, the droplets move about rapidly, colliding with each other with enough force to coalesce into larger and larger drops until they settle out. The clean oil continues to rise to the top of the vessel where it is collected and removed.

The electrical system consists of a transformer and electrodes which are suspended, one above the other, in one section of the unit. The electrodes are usually arranged so their crosssectional area is perpendicular to flow of the fluids.

With electrostatic treating units, it is possible to use lower heating temperatures than are used with the other units. It is also sometimes possible to treat the emulsion at the temperature at which it is produced with no additional heat. Not only do lower temperatures require less fuel to fire the heater, they also lessen problems with scale and corrosion formation and, most importantly, reduce the chance of gravity and volume losses that occur at higher temperatures. One disadvantage of an electrostatic treater is that the grid is prone to plugging by solids. This would lead to a particularly difficult situation with oil from unconsolidated formations such as those found in California.

Practically all oil requiring treatment contains a certain amount of entrained sludge and solids, and a bottom drain is provided on most heater treaters to permit removal of these materials. The presence of a large quantities of solids can be a problem in any heater treater, but particularly for those electrostatic units where plugging is frequently observed.

\section{Emulsion Breaker Treatment}

A good emulsion breaker treatment is vital to the success of most heater treater operations, because the emulsions are generally severe enough that heat alone will not resolve the emulsion in a 


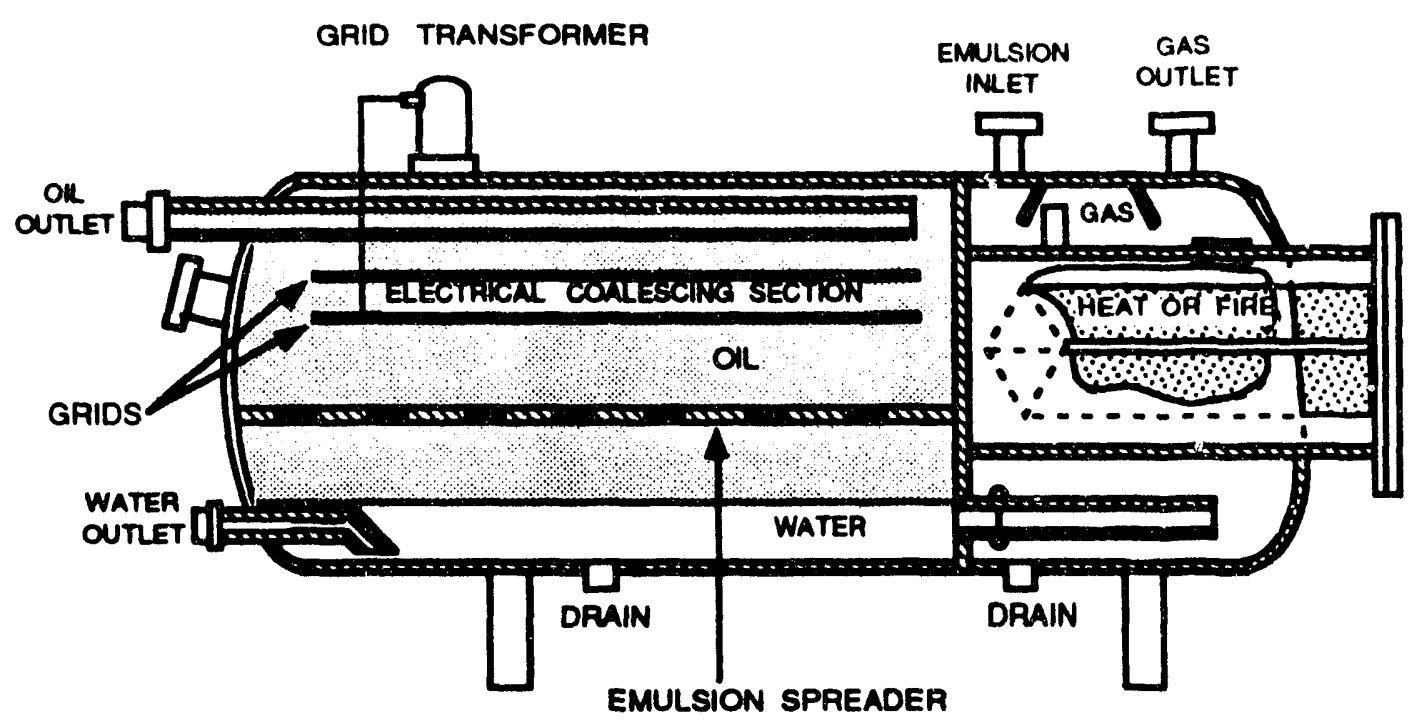

FIGURE 16.12. - Schematic of an electrostatic treater.

reasonable amount of time. Careful bottle testing (see chapter 15), will identify chemicals which will provide fast water drop and dry oil at the interface. It must be remembered, however, that the results of bottle testing cannot always be taken too literally. In the cases of unconsolidated formations, such as Kern River, CA, control of solids and a good interface are vital to the success of the separation process, be it wash tanks or heater treaters. A small amount of emulsion remaining at the interface after the first day of operation will build up on the subsequent days and eventually upset the treater entirely.

As with all oil and water separation processes, careful monitoring is the key to success. Oil cuts (BS\&W) and oil counts should be monitored every 2 to 4 hours. In addition, pressures, temperatures, chemical usage, and fuel consumption should be monitored daily for cost-effective operation.

\section{Lease Automatic Custody Transfer (LACT) Unit}

A lease automatic custody transfer (LACT) system is an arrangement of equipment designed for the unattended transfer of liquid hydrocarbons from producing leases to the transporting carrier. Proper means must be provided for quality determination ( $\%$ BS\&W), net-volume determination and fail-safe operation. The basic systems are divided into two categories: (1) measuring tank systems and (2) positive displacement (PD) metering systems. A schematic for a positive displacement metering system is used in steamflood is shown in figure 16.13 . 


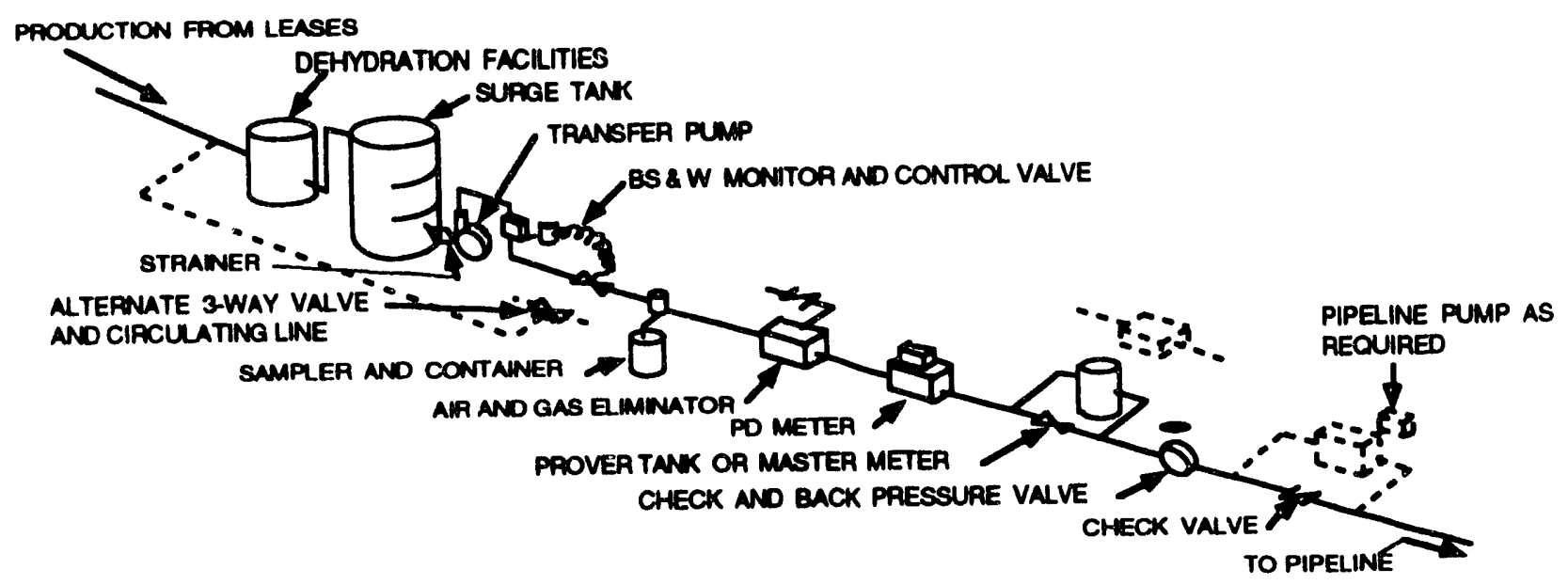

FIGURE 16.13. - Schematic of a LACT system.

A PD meter is a device installed in a piping system in which flowing liquid is constantly and mechanically isolated into segments of known volume. These segments of liquid are counted as they are displaced, and their accumulated total continuously and instantaneously indicated by the meter register in units of liquid quantity. These fixed quantity liquid segments are united as they emerge from the measuring element.

\section{Tank Bottoms Cleaning}

In the U.S. and other parts of the world, the reservoirs associated with steam injection operations are unconsolidated. Sand is, therefore, produced along with the formation fluids and drops out in the tanks in the dehydration facility. In many large steam injection operations in California, the sand collects at the rate of almost $1 \mathrm{f} / \mathrm{wk}$ at the bottom of FWKO (to include wash tanks or heater treaters), and must be removed periodically to maintain effective treating action. In large operations, the tank bottoms are usually cleaned once every 3 months. The tank bottoms usually contain considerable amounts of oil and can be recovered by cleaning the sediments. The profits realized from the sale of this oil usually pays for the cleaning and disposal costs of the tankbottom materials.

The oily bottom sediment is first hosed into a concrete pit. A slurry pump, located at the bottom of the pit, is utilized to transfer the sediment to a process tank. The contents of the process tanks are thoroughly mixed and transferred to a sediment tank through a set of hydrocyclones. The solids, which drop out in the hydrocyclone, are further treated. The liquid portion is returned to the process tank. The liquid portion is recycled several times through the hydrocyclone until the fluid returning to the process tank is nothing but water and oil. The most common type of hydrocyclone used to separate the fluid from sand is the cyclone desander. 


\section{Cyclone Desanders}

Cyclone desanders (hydrocyclones) are commonly used in steam injection operations to separate sand particles from the liquid. Cyclone desanders are conical-shaped devices that make use of centrifugal force to separate the solid from the liquid.

The fluid enters through a tangential opening in the large end of the cone-shaped housing. This results in a whirling motion or "cyclone" action of the fluid. The fluid and solid particles move downward in a spiral pattern forcing the heavy particles to move toward the outer perimeter of the cone. Gravity forces these particles to slide downward and force out the apex. The remainder of the fluids move toward the vacuum created at the center of the cone, and are drawn off at the top as overflow. The overflow contains particles less than $\mathbf{3 0}$ microns in size and sends them to a sediment tank.

The sediment accumulated in the sediment tank is pumped to a decanting centrifuge using a cavity pump. A light solvent is usually injected into the pump suction to aid in the recovery of oil. The decanting centrifuge is a rotating cone-shaped drum, which turns at high speed and thus effectively separates the solids. An augur within the rotating drum scrapes the particles off the side of the drum and forces them out of the discharge port. The fluid in the center of the drum is discharged through the liquid discharge port. The cleaned solids are hauled to a disposal site.

\section{Operation, Maintenance and Monitoring Considerations}

Neither the equipment nor the operation of a steam injection oil dehydration plant are particularly complicated. However, careful monitoring of fluid and equipment is critical for proper plant operation. In large steam injection operations, where the dehydration plant spreads over a large area, the operation is manpower intensive. Some of the operating and maintenance problems associated with dehydration plant include: malfunction of burners in the heater treater; deposition of soot on the walls of the fire tube; deposition of scales and solids on the heating tubes and nearby surfaces; sand buildup; erosion of pumps and valves, due to the abrasive actions of sand; malfunction of water dump valve; malfunction of instruments and controls; and corrosion. Smith 5 has discussed, in considerable detail, these and other operational problems associated with emulsion treating equipment. He also discussed the economics of crude oil emulsion treatment. Interested readers are directed to reference 5 for more details.

\section{Automation of Dehydration Plant}

Because of the large physical size of a dehydration plant, and the equipment used, operations tend to become highly labor intensive in large steam injection operations. For example, the oil dehydration plant in one large California steamflood operation covers 11 acres and consists of 7 freewater knockouts; 17 heater treaters; 21 storage tanks; and 5 LACT units; and numerous pumps, valves, and other miscellaneous equipment. ${ }^{6}$ The operation and maintenance of such a 
plant is highly labor intensive. If an upset occurs, it may take from 20 minutes to one hour to locate the trouble spot. Operations such as these would highly benefit from automation. The current trend in large steam injection operations is to automate production operations to reduce operational costs. The oilfield automation goes by various names such as "Supervisory Control and Data Acquisition (SCADA)" and "Sample Control and Alarm Networks (SCAN)." These are discussed more thoroughly in references 6 and 7. Depending on the complexity of operation, the installation costs will range from 1 to 3 million dollars. Maintenance costs include those associated with the daily upkeep of the system, monthly computer software maintenance, monthly hardware maintenance, and skilled labor. In Table 16.3, the cost and benefits of oilfield-production automation is depicted. 8 Automation is expensive, and an economic analysis must be performed to justify the investment and maintenance costs of the system.

\section{SUMMARY}

As a result of severity of emulsion problems and sand production in steam injection operations, the cost of processing the produced fluids to meet the pipeline specification is significant and second only to the fuel cost. By judicious selection of equipment, and adopting prudent operation practices, treatment costs can be lowered. A variety of equipment, along with chemical deemulsifiers, are utilized to treat the thermally produced oil. These include gun barrels, heated wash tanks, heater treaters, electric dehydrators, and hydrocyclones. Not all the equipment is used in all the steam injection operation. The nature and severity of produced emulsions dictate the type of equipment most appropriate for a particular job. The type, configuration, size and usage varies from field to field.

This chapter has briefly described the facilities and equipment commonly used in steam injection operations to process the produced fluid. The overall treatment costs can be lowered by selecting the equipment and facilities based on ease of operation, initial cost, maintenance cost, and performance. Efforts should be made to select the minimum number of pieces of equipment and simplest design to optimize initial and operating costs. The system should be designed to accommodate the maximum anticipated throughput. The amount of excess capacity to be built into the treating system should be based on an assessment of the cost of the extra capacity balanced against the risk of not being able to treat the peak throughput. Only the equipment needed to accomplish the task should be purchased and installed at the start of the project. Additional features or equipment can be added later in the life of the project, if necessary. 


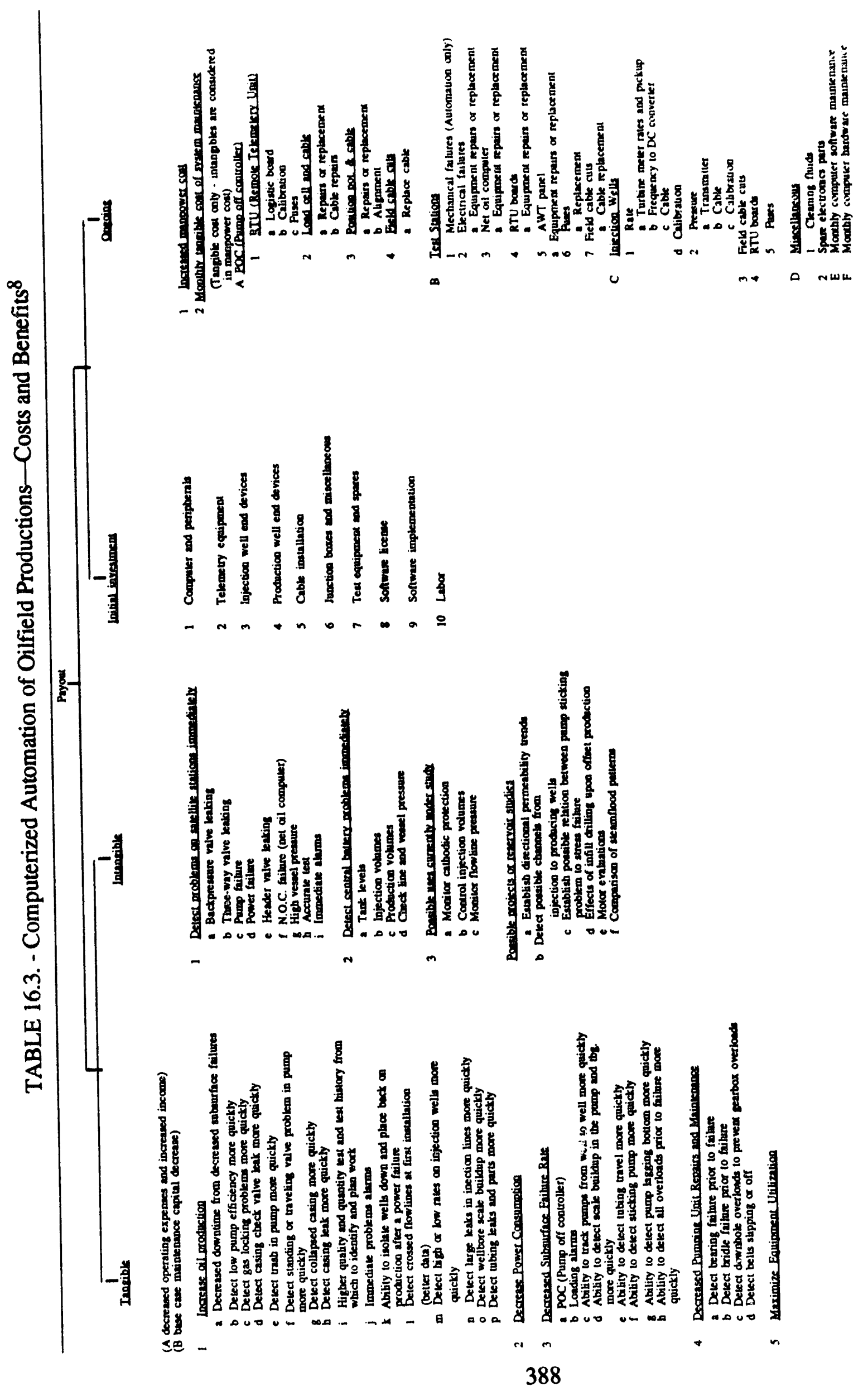




\section{REFERENCES}

1. Flahive, R. M. and P. J. Hickey. Production Well Testing Utilizing a Mass Flow Meter. Paper pres. at the 62nd Annual Fall Meeting of the Soc. of Pet. Eng., Dallas, TX, Sept. 27-30, 1987. SPE paper 16882.

2. Hohn, P. P. and F. R. Morton. Capacitance Water-Cut Probe Utilization in the Kern River Field. Paper pres. at the Soc. of Pet. Eng., California Regional Meeting, Bakersfield, CA, Apr. 5-7, 1989. SPE paper 18780.

3. Christianson, B. A. and E. L. Berger. San Ardo Field Production Testing System upgrade. Paper pres. at the Soc. Pet Eng. International Thermal Operations Symp., Bakersfield, CA, Feb. 7-8, 1991. SPE paper 21533.

4. Sivalls, C. R. Crude Oil Treating Systems Design Manual, Technical Bulletin No. 166, Rev. 2. Sivalls Inc., Odessa, TX, September 1986.

5. Smith, H. V. and K. E. Arnold. Crude Oil Emulsions, Chapter 19 in Petroleum Engineering Handbook. Edited by H. B. Bradley, Soc. of Pet. Eng., Richardson, TX, 1987, pp. 19-1 to 19-34.

6. Strome, R. K. and K. P. Beal. Heavy Oil Dehydration Facility Retrofitted With Computer. Paper pres. at the Soc. of Pet. Eng. International Thermal Operations Symp., Bakersfield, CA, Feb. 7-8, 1991. SPE paper 21535.

7. Shore, R. A. The Kern River SCAN Automation System-Sample Control and Alarm Network. Paper pres. at the Soc. of Pet. Eng., California Regional Meeting, Bakersfield, CA, Nov. 8-10, 1972. SPE paper 4173.

8. Jentsch, W. A. and R. D. Marrs. Computerized Automation of Oilfield Production Operations: An Extensive. Five Year Study Into the Costs and Benefits. Paper pres. at the Soc. of Pet. Eng., 61st Annual Fall Meeting, New Orleans, LA, Oct. 5-8, 1986. SPE paper 15392. 


\section{STEAM INIECTION PRODUCTION FACILITIES VENDORS}

A. Surface Production Equipment Vendors

1. NATCO, A Division of

National Tank Company

Brookhollow Central III, Suite 750

2950 N. Loop West

Houston, TX 77092

Telephone: (713) 683-9292

2. Sivalls Inc.

2200 E. 2nd Street

P.O. Box 2792

Odessa, TX 79760

Telephone: (915) 337-2624

3. Modular Production Equipment Inc.

P.O. Box 690965

Houston, TX 77269-0965

Telephone: (713) 320-8796

4. Daniel En-Fab Systems Inc.

3905 Jensen Drive

P.O. Box 21361

Houston, TX 77226-1361

Telephone: (713) 224-7937

\section{B. Automatic Well Test (AWT) System}

1. Petroleum Automation Systems Inc.

$325 \mathrm{~S}$. Hale Avenue

Fullerton, CA 92631

Telephone: (714) 773-4040 


\section{CHAPTER 17}

\section{STEAM INJECTION PROJECT PERFORMANCE MONITORING TOOLS}

\section{INTRODUCTION}

The cost-effective operation of a steam injection project will requive filigent monitoring. The perfornance of an individual well and surface equipment, especially the sieam generator, must be constantly monitored and appropriate action taken when problems arise in order to reduce operation and maintenance costs.

Fuel, labor, and supplies make up more than $50 \%$ of the steam injection project's operating expenses. Hence, constant monitoring and control of these costs are crucial to the economics of the operationi. In a typical steam injection project, approximately $30 \%$ of the produced oil is consumed to generate steam. Any improvement in the steam generator thermal efficiency would reduce total fuel use and increase the operating revenues. For example, the fuel requirements of an oil-fired $50 \mathrm{MM}$ Btu/hr steam generator can be reduced by roughly $5,300 \mathrm{bbl} / \mathrm{yr}$ by a $5 \%$ increaui: in thermal efficiency. This would result in an increase of over $\$ 63,000 / y r$ in operating revenues at an oil price of $\$ 12.00 / \mathrm{bbl}$. Thermal efficiency of the steam generator can be irmproved by monitoring and controlling the excess oxygen used in the combustion process and the flue gas exit temperature. In addition, fuel requirements can te reduced by optimizing the steam injection rate to an individual well pattem. When carefully monitoring the steam injection profile and the casing gas production, the operator can optimize the injection rate.

Apart from the water treatment and steam generation costs, a steam injection project will iricur numerous ciher expenses such as those associated with the operation and maintenance of surface production facilities, servicing of the wells, disposal of produced waters, and steamflood monitoring. These expenses are by no means minor and must be carefully monitored and controlled to improve the project's operating margins. The operational costs can be lowered by fine tuning the performance of all field facilities.

Monitoring tools and procedures provide the data necessary for optimizing project performance. These inclucie the acquisition of physical data such as pressure, temperature, flow rate, and fluid volumes as well as economic data such as fuel usage rate and itemized costs of operating the surface facilities. The performance data must be made available to the field personnel on a predetermined time schedule so that corrective actions can be taken to improve equipment performance. The economic data must also be made available to the engineering staff and management so that informed decisions can be made.

Several steam injection operation monitoring tools have evolved over the years and can be broadly grouped into two categories: (1) physical data monitoring tools and (2) economic data monitoring tools. Examples of physical data monitoring tools include an automatic well testing 
system, steam generator fuel usage report, water treatment plant throughput, and electrical power consumption. Examples of economic data monitoring tools include surface facility operational cost reports and capital equipment replacement cost reports. Following is a brief discussion of various steam injection operation monitoring tools.

\section{Physical Data Monitoring Tools}

\section{Automated Well Testing}

The automatic well test units (AWT) are an important steamflood performance monitoring tool. Data obtained from these units are utilized as the number one diagnostic tool to determine the changes in reservoir characteristics and to establish well workover needs. These data are also utilized in many instances to gauge the technical and economic success of a steam injection project. Though simple in concept, the operation and maintenance of an AWT unit is expensive and requires the service of an impressive number of technicians and field personnel.

\section{Steam Generator Fuel Usage Report}

Steam injection operations are energy intensive, and fuel costs account for more than $50 \%$ of operation and maintenance expenses. In many areas, lease crude is burned to generate steam. This reduces the volume of fuel available for sale. Hence, close control of fuel usage is critical to the economics of an operation. For these reasons, a daily report of fuel use should be a part of every steam injection operation. This report should contain not only the amount of fuel (in equivalent barrels of fuel oil) burned the previous day, but also the volume of fuel consumed at each generator site and the fuel objective for that day. This report must be distributed to the operating personnel on time so that appropriate actions can be taken to correct or improve their operations.

\section{Steam Distribution-Steam Injection Rates}

Since steam usage and hence fuel consumption can be lowered by optimizing the steam injection rate to an individual pattern, an accurate $\log$ showing the volume of steam injected into each well should be maintained. This log should include weekly steam intake by each injection well and should list any injectivity problems. The rate of steam injection into each well should be calculated periodically from pressure readings taken on a similar time schedule. This steam usage report should then be distributed to the appropriate operating and engineering personnel so that any identified problems can be corrected.

\section{Water Treatment System}

The successful operation of a steam injection project depends primarily upon a trouble-free water treating system. Field experience indicates that most steamer downtime is caused by water treating problems. Hence, the water treatment facility must be closely monitored and any 
operational problems reported on a daily basis. A daily report of plant throughput volumes should be prepared with appropriate comments regarding the operation of the plant during the preceding 24-hr period. Also, as in the case of fuel usage report, it should be prepared and distributed to the operating personnel on time.

\section{Electric Power Consumption Report}

Next to the cost of the fuel used for steam generation, the single largest operating expense in steam injection operation is the purchase or onsite generation of electric power. The electric requirements of individual equipment must be carefully monitored and actions taken to optimize electrical power consumption. Metering equipment must be installed at various points of use and periodic reports on electric power consumption be prepared. This report must then be distributed to the appropriate personnel so the operator can recognize the affects of his activities on electrical costs.

\section{Comments on Physical Data Monitoring Tools}

Steam injection operations are field specific and each field will require a different set of operating reports. The examples cited in the previous paragraphs are intended to provide a guide as to the type of report that has been found most useful in steam injection operations. Other examples of reports of value to the operating personnel may include: (1) flue gas analysis and flue gas temperature monitoring reports, (2) oil dehydration facility upset report, etc. However, before embarking upon the preparation of a new report, the purpose of the report and its value to the operating personnel should be given careful consideration.

\section{Economic Data Monitoring Tools}

Once the physical parameters affecting the performance of a steam injection operation have been identified and optimized, action must be taken to reduce operation and maintenance expenses. The economic optimization begins with a break down of field activities into their primary functions and the cost of performing each activity. The operating expenses associated with each task is usually presented as fuel and non-fuel expenses. The non-fuel expenses include: (1) employee wages and benefits, (2) cost of contractor supplied services, (3) materials and supplies expense, (4) utilities, and (5) overhead expenses. Fuel expenses include both, cost of purchase and storage.

The operating expenses must be presented to the operating personnel as unit costs. For example, the water treatment plant operation expense should be reported as $\$ / b b l$ of softened water and the production gathering expense as $\$ / \mathrm{bbl}$ of gross fluid produced. Presenting operating expenses to field personnel in such a fashion enables them to make informed decisions. Examples of this might include the decision to use an additional amount of chemical emulsion breaker and thereby reduce the heater-treater fuel requirements. This not only allows the operating personnel to 
forecast the effect of such a change, but also enables them to pinpoint the success or failure of this change in operations. The operating expense report also allows the performance of 'what-if' calculations and forecasts the effect of physical and operating parameter changes on operating expenses under various scenarios.

\section{Monitoring Capital Expenses}

The equipment associated with the steam injection operation is mechanical in nature and as such, will wear out with use and require replacement. Also, advances in technology render certain equipment obsolete and therefore it must be replaced. Capital money must be used to replace the worn out or obsolete equipment. Periodical reports on the physical condition and the cost of maintenance for each piece of equipment must be prepared and presented to personnel responsible for capital expenditures. Such a tool not only allows management personnel to make informed decisions, but also monitors the success of their activities.

Since the expenditure of capital funds for either maintenance or expansion, usually involves the coordination of the installation or construction of several pieces of equipment, it frequently becomes difficult to determine which activities are proceeding on schedule, which are behind, and which are ahead of schedule. Since current expenditures are often a good indicator of activity, monitoring of capital expenditures on a monthly basis can be an effective tool for project planners and designers. By reviewing this report, the activities showing higher than projected expenses can be given a closer look and corrective action taken.

\section{Monitoring Tools Improvement}

A well designed monitcring tool allows the operational personnel to better understand the effects of their decisions and actions on their own operation, as well as the interactions of their operations with other activities. However, no tool is perfect, and there is always room for improvement. Monitoring tools can be improved and made more useful by incorporating the user recommended changes. Since the recommendations for improvement in monitoring tools must come from those individuals directly involved in day-to-day field operations, management should ensure that effective communications exist at all levels of operation.

\section{GENERAL REFERENCE}

Dever, R. E. and F. A. Womack: Production Data Reporting and How It Aids Surveillance in Thermal Recovery Fields. Pres. at the 1983 California Regional Meeting of the Soc. Pet. Eng., Ventura, California, Mar. 23-25, 1983. Paper SPE 11683. 


\section{CHAPTER 18 \\ ENVIRONMENTAL ISSUES}

\section{INTRODUCTION}

In recent years, steam injection operators have been faced with increasingly stringent environmental regulations which are oriented towards preventing or ameliorating significant degradation of air and water quality and land use. These environmental laws and regulations significantly impact the design and operation of steam injection processes. Federal, state, and local agencies are all involved in the enactment and implementation of various environmental laws and regulations. Although the laws and government agencies that administer the environmental programs differ from state to state, the overall pattern of administering these laws is uniform throughout the country.

Prospective steam injection operators are required to obtain necessary environmental permits before an operation can begin. These permits require operators to monitor the environmental conditions of their operations, keep certain records, and report periodically to the enforcing agency. Violation of environmental regulations will result in severe penalties or criminal convictions. Hence, it is essential that the operators be aware of the essence of these regulations, so that inadvertent noncompliance with applicable environmental rules and regulations can be avoided.

The purpose of this chapter is to outline the steps involved in obtaining an environmental permit and to briefly summarize the environmental laws of relevance to steam injection operations. Only federal laws are summarized. Since the environmental regulatory and compliance requirements of the states vary from state to state, they are not discussed. Recently, the U.S. Department of Energy published an EOR environmental regulation handbook ${ }^{1}$ detailing state environmental laws. It is recommended that the prospective operator consult this or other publications ${ }^{2-5}$ for the requirements of the state where they plan to conduct an operation.

\section{ObTaINING AN ENVIRONMENTAL PERMIT}

Before a steam injection operation can begin, an operator must obtain necessary environmental permits from the federal, state and local agencies to conduct the operation. This section, adapted from reference 1 , describes the general procedures for obtaining environmental permits and offers some general pointers about post-construction compliance and enforcement.

\subsection{Obtaining an Environmental Permit}

Step 1. Define Operation 
The specific type of operation planned will determine which permits will be needed, and how much time should be allowed from project conception to actual operation. For example, a chemical recovery process may involve handling, use, and disposal of chemicals that are very strictly regulated. A thermal recovery project, on the other hand, will have little or no solid waste to dispose of, but will generate significant amounts of air pollution. The more precisely one can define the project at the start (e.g., which chemicals will be used; what size compressor will be needed) the better one can focus on the relevant laws and permits.

\section{Step 2. Identify the Eacility Site}

Because environmental laws are designed to protect the quality of the environment and because environmental conditions vary from place to place, the permits needed and the conditions for obtaining them will depend on the site chosen. If several alternative sites, or a general area has been defined, environmental conditions and permit requirements should be used as criteria for selecting a specific site. An operation that is unacceptable at one site may be acceptable at another site only a short distance away. Air quality, for example, can be extremely variable.

\section{Step 3. Survey Environmental Conditions at the Candidate Site(s)}

A quick survey of environmental conditions should identify critical problem areas before any substantial investments are made. The types of information to look for at this time include general descriptions of air and water quality, hydrological factors affecting injection for reservoir pressure maintenance and/or waste disposal, special topographic features (e.g., wetlands, floodplains), special land areas in the vicinity (e.g., natural preserves, federally-owned lands), and similar characteristics that might entail extraordinary environmental standards or permit procedures.

\section{Step 4. Identify the Required Permits}

Steps 1-3 may not actually occur in sequence. Rather, they are three of the elements in the environmental evaluation of site and operational feasibility. Once a site or small number of sites have been chosen and the operating mode determined, the required permits can be identified. This chapter will be useful as a starting point for this step, but it will be important to verify current requirements with the regulatory agencies before proceeding further. The following considerations should be kept in mind when identifying the required permits.

a. Review potential requirements for every aspect of the operation that "pollutes" or modifies the natural environment: air pollution (including on-site storage of oil or volatile chemicals), wastewater streams, anything injected into a well for either production or waste disposal, surface and subsurface construction, and surface transport (trucks and roads, pipelines). Some details (e.g., roads) may not be covered by state or federal law but will probably be subject to municipal or county permits.

b. Review both federal and state requirements. An operator may even need permits from both the federal and state governments for the same discharge. If the facility site is on 
federal lands, the permit requirements established for that area by the agency in charge should be identified, in addition to the general environmental laws described in this handbook.

Step 5. Establish Direct Contact with the Permitting Agencies

Early contact with the agencies responsible for granting permits has several benefits:

1. The latest requirements and any pending regulatory changes are immediately available.

2. Clarification of confusing requirements and direct verification as to whether or not a permit is needed.

3. Immediate help is available for determining requirements of specific application forms.

4. "Good faith" can be established in complying with agency rules.

5. Personal contacts can help smooth out any administrative problems.

6. Avoids surprises of requirements not clearly spelled out in a specific law.

7. A facility can be described in favorable terms before opposing entities contact the agency.

8. Plans can be changed early on if modifications are necessary to avoid unattainable requirements or if newly promulgated regulations have to be met.

Step. 6. Identify the Environmental, Engineering, or Other Needed Studies

Very close attention should be given to the information required to obtain each permit. A common frustration experienced by many permit applicants is to be told by an agency, at the last minute, that they need to undertake an environmental study to answer a particular question. Careful reading of permit applications and discussions with agency staff should enable environmental requirements to be identified early in the process so the project will not be delayed.

\section{Step 7. Initiate the Necessary Studies}

For some facilities, the environmental studies will take one or two years to complete. A case in point for steam injection facilities is ambient air quality monitoring. The U.S. EPA requires a full year of monitoring data for a pre-construction permit application, which means that planning for monitoring must begin about two years before the expected date for starting construction.

\section{Step 8. Complete the Permit Applications}

Once all required information has been collected, the application forms can be completed. Usually, there is no advantage in filing applications far in advance of the deadline; in fact, some permits become invalid if they are not "used" within a certain time. On the other hand, if the expected review time is, for example, 6 months, submitting the application 9 to 12 months before construction will provide a cushion for bureaucratic delay and negotiation of disputed terms or appeals from adverse agency decisions. 


\section{Step 9. Stay in Touch With the Agency}

By staying in touch periodically with the person assigned to review your application, the operator keeps attention on the application and shows the agency genuine interest in compliance and desire to avoid time delays. Periodic contact is also the best way to uncover any disputed issues, while there is still time to resolve them by supplying more information or by negotiation. It is important to maintain records of telephone calls, meetings, and correspondence-it may be advantageous if there is opposition to the proposed facility, either inside or outside the agency.

\section{Step 10. Take Advantage of Procedural Rights}

The typical agency procedure for reviewing and deciding on a permit application is as follows:

1. Application submitted.

2. Application reviewed for completeness; applicant notified if application is complete or if more information is required.

3. Agency makes a tentative (or proposed) decision to grant or deny permit, or to grant it under certain conditions.

4. Agency gives public notice of its tentative decision (including notice to the applicant). Some types of permits require specific notice to adjacent property owners.

5. On request, agency holds a public hearing to hear the comments and criticisms of the applicant and any project supporters or opponents.

6. Agency reviews written comments and remarks made at hearing and reaches a final decision.

7. Agency notified applicant and other interested parties of final decision.

8. Within a certain time after the final decision, any interested party (including the applicant) can appeal the agency decision through an established administrative appeal process.

9. Appeals board (commission, examiner, etc.) conducts hearing (usually like a trial) and upholds or overturns any agency decision.

10. Finally, parties may take their case to state or federal court to seek "judicial review" of the final decision after appeal.

The permit applicant has the same rights as any other person to request hearings, appeal agency decisions, or seek judicial review by the courts. If one believes the agency misunderstands the project, misinterprets the law, or is providing unfair treatment, then procedural rights should be used as a counter measure. In many systems the right to appeal, or the right to judicial review, depends on utilizing early opportunities to to resolve a specific point. 


\subsection{Compliance and Enforcement}

Theoretically, compliance with environmental regulations is a simple matter. The permit received will specify the operating standards to be achieved and any other conditions, limitations, or requirements. As long as one abides by the permit, compliance is achieved. In the real world, however, a number of common problems and questions arise th?t can be answered generally for all states and the federal agencies.

\subsubsection{Compliance}

\section{Upsets. Equipment Failure. Etc.}

Most environmental laws impose "strict liability" on the facility, which means that the government is legally justified in penalizing every violation, regardless of size or fault.

Permits may or may not expressly provide for minor violations due to occasional situations. If a permit does not make any provision, the general administrative practice is to excuse occasional violations due to circumstances beyond the operator's reasonable control. However, if negligence contributed to the violation or if a facility has a record of problems, enforcement will probably be stricter.

\section{Changes in the Facility or Its Operation}

Generally, a permit to construct, discharge, or operate is specific to the location, facility design, and method of operation identified in the permit application. Any significant changes from the operation so described will probably require a modification of the permit or a completely new permit, unless the level of discharge is being reduced. The permit or the specific procedural rules of the agency may also specify when notice is to be given to the agency of any changes in the facility or its operation. Relocation of the facility also usually requires a new permit.

\section{Changes in Laws and Regulations}

Permits will generally insulate operators from changes in the "rules of the game." There are several important exceptions to this general statement, however. Foremost is the fact that most permits are issued for fixed periods ( 5 years is common). At the end of that period, the operator must apply for a permit renewal, and the agencies may use that opportunity to introduce any new legal requirements. Most permit programs also allow the permit to be revoked or modified at any time for various specified reasons. For example, a wastewater discharge containing toxic compounds is subject at any time to new controls on the toxics. Frequent violation of the permit is normally grounds for revoking it. 


\subsubsection{Enforcement}

\section{Monitoring, Recordkeeping, and Reporting}

More often than not, a permit will require monitoring of environmental conditions, the keeping of certain records, and periodic reporting to the agency. The U.S. EPA and most state agencies take these requirements seriously, because they rely on self-monitoring and self-reporting to identify trouble spots. The few criminal convictions that EPA has obtained for violation of environmental laws have involved failures to report activities, falsification of monitoring data, and similar infractions. Close adherence to these requirements will stand an operator in good stead if involved in more substantial problems with the agency.

\section{Reporting Spills}

A special reporting requirement in the Clean Water Act applies to spills of oil or hazardous substances. Most states have a similar law. Under federal law, any spill of oil (or any spill above specified amounts of over 300 listed substances) that reaches or may reach surface water must be reported immediately after it is discovered to the EPA or to the Coast Guard. The source of the spill will be liable for a moderate penalty $(\$ 500-\$ 5,000)$ in addition to all costs of clean-up or containment.

\section{Inspections}

Virtually every environmental law authorizes state or federal officials to inspect a facility and owner's operation records during business hours. (They are also authorized to enter a facility at any time to take emergency measures to protect the environment or the public health.) Although the Supreme Court has ruled that OSHA inspections cannot be conducted against the owner's will without a warrant, the decision may not apply to environmental laws. In any case, such warrants will be routinely issued because of the broad authority granted to these agencies.

\section{Enforcement Against Violations: Penalties}

The environmental laws usually allow an agency to choose between suing a violator immediately in court and issuing some type of administrative order to the violator to correct a violation. In practice, agencies almost always use the administrative order approach, if only because litigation is time-consuming and expensive. In fact, many agencies prefer to use informal negotiations rather than formal orders to obtain compliance. This is especially true at the state level; as a rule, EPA prefers the formal approach.

For minor violations, the agencies usually seek simply to have the problem corrected. More significant violations, or repeated violations, will probably also result in a civil penalty. A civil penalty, which the agency can collect just by proving the violation, is designed to compensate for 
the environmental damage that occurred. It carries no implication that the source acted criminally; criminal penalties are separately authorized and can be imposed only after a court conviction.

The statutes often authorize enormous civil penalties, such as $\$ 25,000$ per day. However, penalties of that size are reserved for the largest corporations and the worst violations. More routinely, penalties for small facilities will vary from about $\$ 500$ to almost $\$ 10,000$ for the entire violation, depending on how long it lasted, how serious the environmental harm was, and how much money the violator saved by allowing the violation to occur. The compliance record of the violator, his efforts to correct the violation, and his general attitude toward the agency will also influence the amount of the penalty. If one feels strongly that the amount of the penalty that the agency is asking for is too high, the whole case can be brought to court where the judge sets the penalty.

Final authority for all enforcement matters lies with the courts. If in disagreement with an agency about whether a violation occurred, about the corrective measures to prevent further violations, or about the penalties or other sanctions they seek, the matter may be brought to court to be decided by a judge or a jury, as the case may be. The agency usually has the choice of going directly to the court without providing advanced notification to the violator.

In order to answer correctly the questions in the permit application, a prospective thermal EOR operator should be aware of the essence of the environmental rules and regulations of relevance to his project. The following sections briefly summarize the major federal environmental laws and regulations of relevance to thermal operations.

\section{Major Laws}

The environmental laws that have the greatest impact on steam injection processes pertain to air quality, water quality, hazardous wastes and environmental quality. Following is a list of major federal laws that have relevance to steam injection processes.

Air Quality - Clean Air Act and Amendments

Water Quality - Clean Water Act and Safe Drinking Water Act

Hazardous Wastes - Resource Conservation and Recovery Act (RCRA)

Environmental Quality - National Environmental Policy Act (NEPA)

\section{Federal Regulatory Framework}

The federal environmental policy is formulated by codifying a variety of public laws and acts. Any new program enacted by congress is called an act. Acts are amended through the enactment of public laws. A public law may include amendments to several acts.

The environmental statutes, whether an act or a public law, are periodically published as United States Codes (USC). The USC is organized into different titles. For example, statutes pertaining to clean air act can be found in Title 42, Sections 7401 and the following (42 USC 7401 
et seq.). Regulations promulgated by federal agencies are initially published in the Federal Register (FR). The final versions of the regulations are then incorporated into the Code of Federal Regulations (CFR). The CFR is updated quarterly and published in its entirety annually. Since regulations take effect as soon as the final version appears in the FR, a person cannot be sure of full regulatory compliance by reviewing the current edition of the CFR. Regulations pertaining to the environmental area can be found in the Title 40 of CFR.

\section{Enforcement Agencies}

The environmental regulations are enforced by a number of agencies. At the federal level, the U.S. Environmental Protection Agency (EPA) is entrusted with enforcing laws dealing with air quality, water quality, hazardous wastes, and hazardous materials. At the state level, many different agencies are involved with implementing and enforcing laws pertaining to different environmental areas. The State EOR environmental regulatory agencies are shown in Table 18.1. The agency jurisdiction may sometimes overlap. As an illustration, a summary of different agencies and their principal area of authority in California are outlined.

\section{Air Resources Board (ARB)}

The ARB is a state agency whose primary responsibility is to coordinate the state-wide air quality programs. It is also responsible for implementing programs designed to attain the state and national ambient air quality standards. In addition, this agency supervises the overall scheme to control toxic air pollutants and conducts research on various air quality matters.

\section{Air Pollution Control and Air Quality Management Districts (APCD/AOMD)}

These are county or multi-county agencies responsible for implementing the state air quality laws pertaining to stationary sources of air pollution. There are 34 single county APCDs, five multi-county APCDs, and three AQMDs.

\section{State Water Resources Control Board (SWRCB)}

Like ARB, SWRCB is a state agency whose primary function is to coordinate the state's water quality program. The SWRCB has the authority to regulate the discharge of wastes to land and injection of toxic waste to wells.

\section{Regional Water Quality Control Boards (RWOCB)}

RWQCB is a regional agency responsible for administering the state's water quality program within the region. It also has the authority to develop water quality control plans, issue of waste discharge permits, and regulate waste disposal sites. The state is divided into nine RWQCBs.

\section{Department of Health Services (DHS)}

DHS is a state agency entrusted with implementing the state's hazardous waste laws and regulations including hazardous waste facility permitting. 


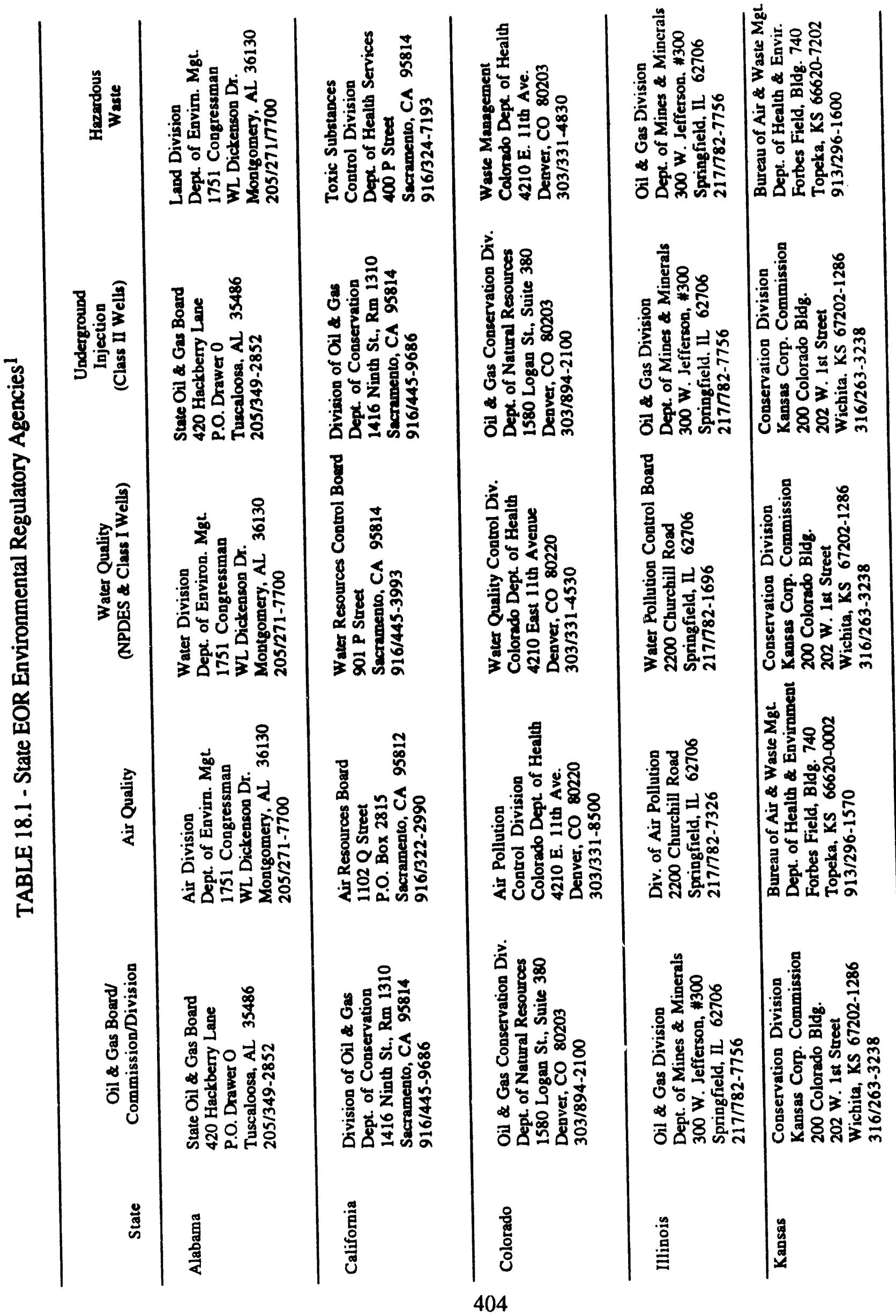




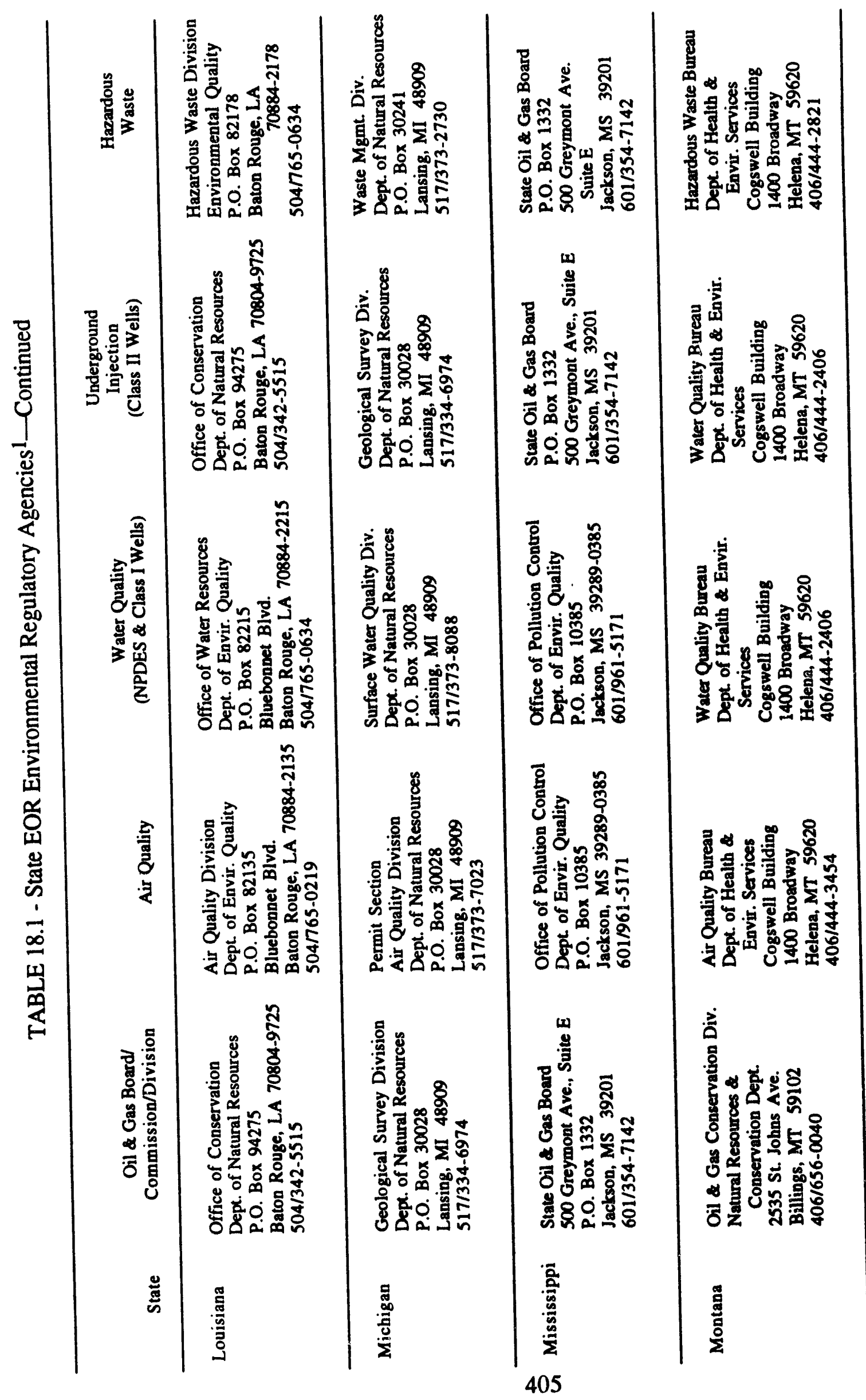




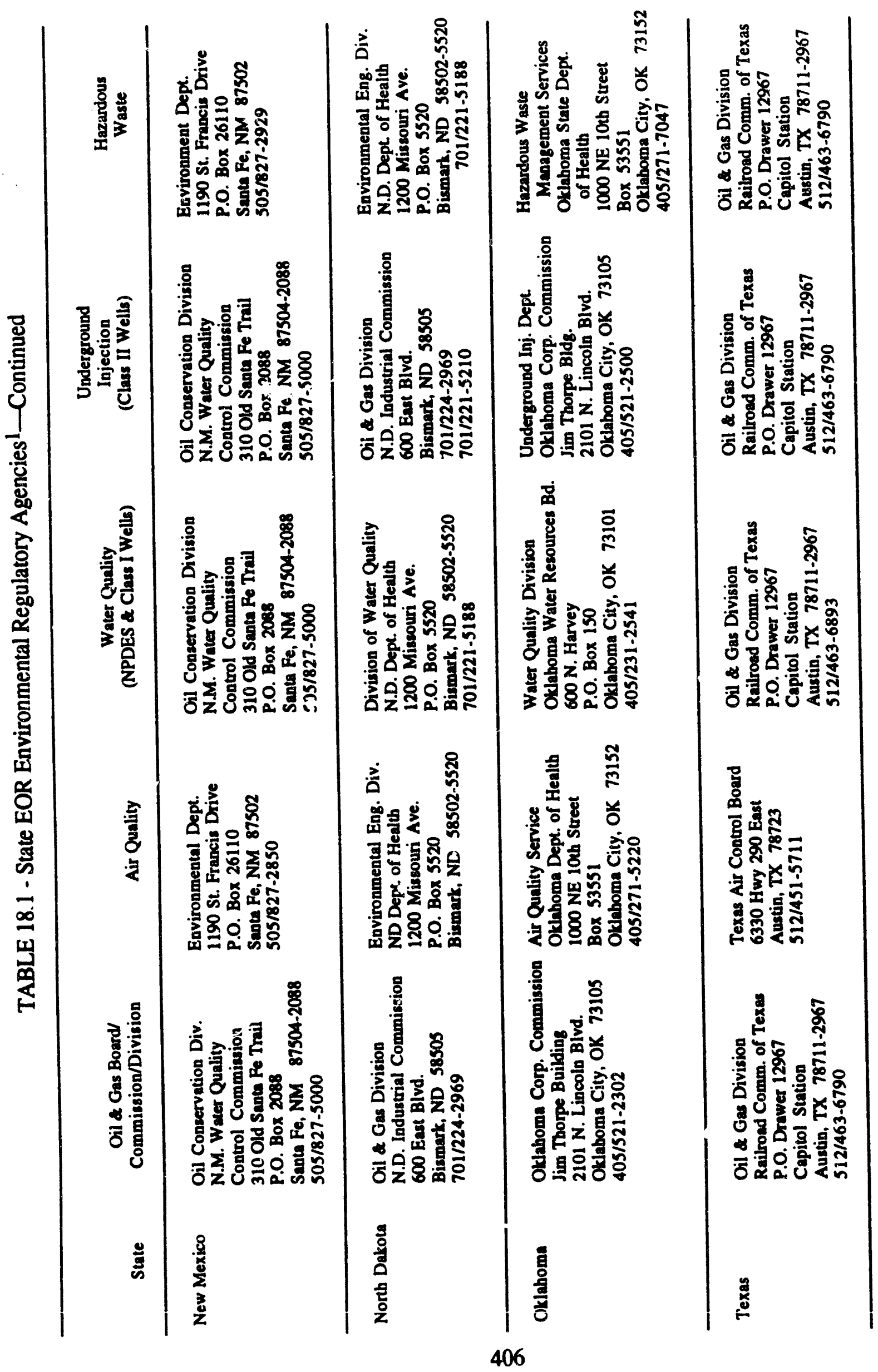




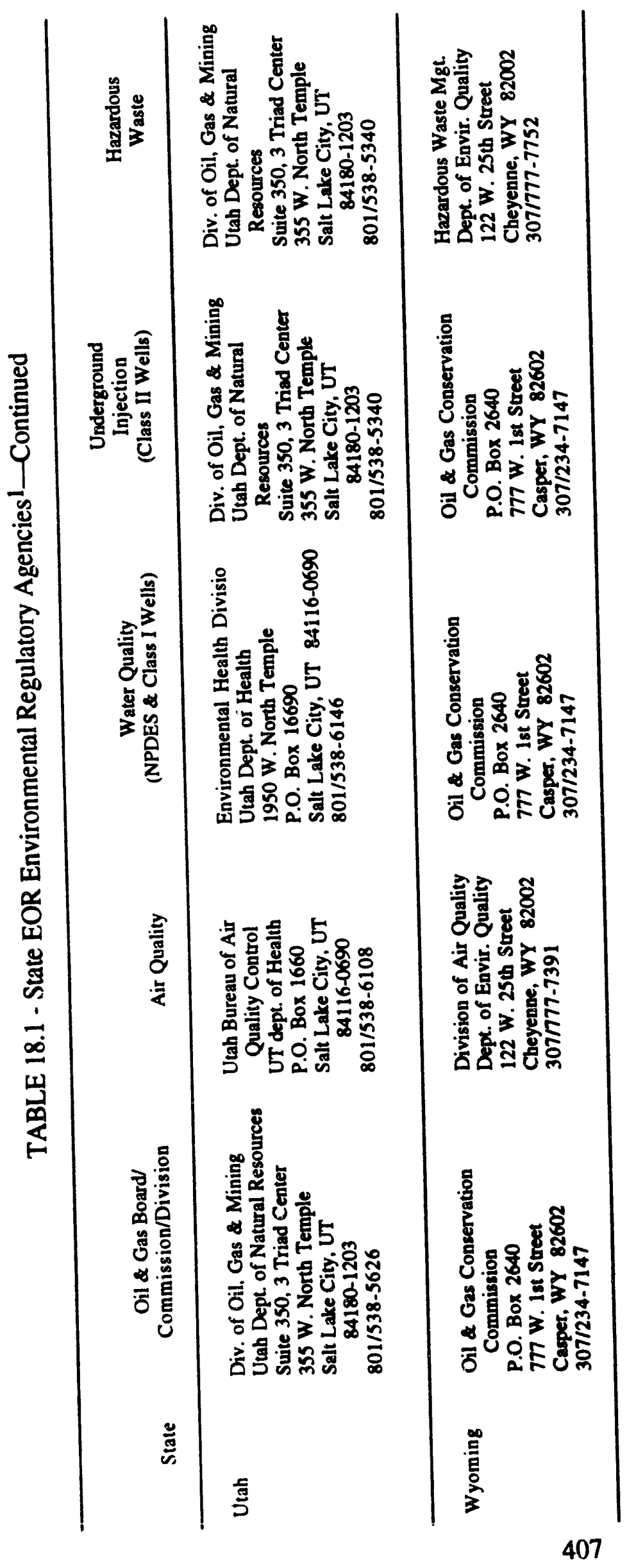


Normally, the lowest level of government agency is given the authority to implement the various laws and regulations. For example, the APCD is responsible for enforcing air quality laws and regulations including issuance of permits for new air pollution source within the district. However, some districts are permitted to regulate only portions of laws. In such cases, the agency which retains portions of authority may also be involved, and agency overlaps can occur.

The major federal environmental regulations that impact steam injection operations are briefly described in the following pages. Other applicable federal regulations of relevance to steam injection operations are summarized elsewhere. ${ }^{1-2}$ The abbreviations used in this chapter are listed in Table 18.2.

\section{Air Quality Regulations Impacting Steam Injection Operations}

The federal government plays a leading role in developing a regulatory framework within which all thermal enhanced oil recovery operators must operate. Federal environmental regulations and standards supersede all less stringent state and local regulations. State and local governments, however, do have the authority to promulgate and enforce environmental standards more stringent than their federal counterparts. For example, State of California's air quality requirements are more stringent than those stipulated under federal statute. Kern County, CA, has adopted even more stringent measures to attain and maintain state and national ambient air quality standards. This section briefly describes, in general terms, the federal air quality regulations to which the steam injection operators must comply.

The U.S. Environmental Protection Agency (EPA) is the primary agency entrusted with the responsibility of implementing the Federal Clean Air Act (CAA). The purpose of CAA is to protect and enhance the air quality and to attain the National Ambient Air Quality Standards (NAAQS). Under the CAA, each state has the primary responsibility to prepare and submit to the EPA, a State Implementation Plan (SIP) which details the method by which NAAQS are attained and maintained. EPA regulations pertaining to air quality can be found at 40 CFR Subchapter C - Air Programs.

The provisions of CAA that impact steam injection operators are as follows:

National Ambient Air Quality Standards.

National Ambient Air Quality Standards (NAAQS) are the primary guidelines used to measure the air quality of a region. NAAQS sets the ceilings for which each pollutant may not exceed. EPA set the NAAQS according to established criteria. These criteria are reviewed at least once in every 5 years by an independent scientific committee. The air quality standards are set on the basis of scientific data and analysis only. EPA is not required to consider economic or technical feasibility in setting air quality standards. 
TABLE 18. 2. - Abbreviations Used in Text

\begin{tabular}{ll}
\hline APCD & Air Pollution Control Dist. (California) \\
ARB & Air Resources Board (California) \\
AQCR & Air Quality Control Region \\
AQMD & Air Quality Management Dist. (California) \\
BACT & Best Available Control Technology \\
CAA & Clean Air Act (federal) \\
CCR & California Code of Regulations \\
CFR & Code of Federal Regulations \\
CWA & Cleen Water Act (federal) \\
DHS & Dept. of Health Services (California) \\
DOG & Div. of Oil Ges (California) \\
EPA & Environmental Protection Agency (federal) \\
LAER & Lowest Achievable Emission Rate \\
NAAQS & Natl. Ambient Air Quality Standards \\
NPDES & Natl. Pollutant Discharge Elimination \\
NSPS & System \\
PL & New-Source Performance Standards \\
PSD & Public Law \\
RCRA & Prevention of Significant Deterioration \\
RWQCB & Resource Concervation and Recovery Act \\
SDWA & Regional Water Quality Control Board \\
SIP & (California) \\
SWRCB & Safe Drinking Water Act \\
USC & State Implementation Plan \\
UIC & State Water Resources Control Board \\
\hline & (California) \\
\hline & U.S. Code \\
Underground Injection Control
\end{tabular}

There are two types of air quality standards: primary and secondary. The object of the primary standards is to protect the public health, while allowing for ample margin of safety. The aim of the secondary standard is to specify a level of air quality considered necessary to protect the public welfare from known or anticipated adverse effects, including the effects on economic values and personal comfort.

CAA has designated six pollutants as harmful, and standards have been established. These pollutants include: sulfur dioxide $\left(\mathrm{SO}_{2}\right)$, nitrogen oxides $\left(\mathrm{NO}_{\mathbf{x}}\right)$, particulates, carbon monoxide (CO), ozone, and lead. At one time, EPA had adopted NAAQS for hydrocarbons, but these standards were later rescinded. These standards are implemented through SIPs (CAA, Section 110). Most steam injection operations employ lease crude fired steam generators. These crude oil fired steam generators emit $\mathrm{SO}_{2}, \mathrm{NO}_{\mathbf{x}}$, and particulates. In addition, oilfield wellheads can emit hydrocarbons, depending on the degree of control employed.

EPA has designated 247 Air Quality Control Regions (AQCR). Although NAAQS should not be exceeded in any of the regions, they are not directly enforceable. EPA has set emission limitations for each pollutant to attain NAAQS. If the actual air pollutant concentration in an air district exceeds NAAQS, more stringent pollution control devices on the emission source are imposed to lower the concentration to an appropriate level. EPA has rated the AQCR as either 
'clean' or 'nonattainment' for each criteria of pollutant. Nonattainment areas are those areas in which state and federal ambient air quality standards have not been met for the specified criteria pollutant. Procedures to bring the nonattainment areas to attainment are implemented by SIPs. The current national primary and secondary ambient air quality standards are shown in Table 18.3.

TABLE 18.3. - Current National Primary and Secondary Ambient Air Quality Standards

\begin{tabular}{|c|c|c|c|}
\hline Air contam yant & Averaging time & $\begin{array}{l}\text { Federal primary } \\
\text { standard }\end{array}$ & $\begin{array}{l}\text { Federal secondary } \\
\text { standard }\end{array}$ \\
\hline Nitrogen dioxide 1 & Annual average & $\begin{array}{l}100 \mu \mathrm{g} / \mathrm{m}^{3} \\
(0.05 \mathrm{ppm})\end{array}$ & $\begin{array}{l}100 \mu g / \mathrm{m}^{3} \\
(0.05 \mathrm{ppm})\end{array}$ \\
\hline \multirow[t]{4}{*}{ Sulfur dioxide } & Annual average & $\begin{array}{c}80 \mu_{g} / \mathrm{m}^{3} \\
(0.03 \mathrm{ppm})\end{array}$ & -- \\
\hline & 24 Hour & $\begin{array}{l}365 \mu_{\mathrm{g}} / \mathrm{m}^{3} \\
(0.14 \mathrm{ppm})\end{array}$ & $\cdots$ \\
\hline & 3 Hour &.- & $1300 \mu g / m^{3}$ \\
\hline & 1 Hour & $\begin{array}{c}520 \mu \mathrm{g} / \mathrm{m}^{3} \\
(0.2 \mathrm{ppm})\end{array}$ & $\begin{array}{c}\text { (0.5 ppm) } \\
-\end{array}$ \\
\hline \multirow[t]{2}{*}{$\begin{array}{l}\text { Suspended } \\
\text { particulates }\end{array}$} & $\begin{array}{c}\text { Annual geometric } \\
\text { Mean }\end{array}$ & $50 \mu g / m^{3}$ & $50 \mu g / m^{3}$ \\
\hline & 24 Hour & $150 \mu_{g} / m^{3}$ & $150 \mu_{g} / m^{3}$ \\
\hline $\begin{array}{l}\text { Hydrocarbons } \\
\text { (corrected for } \\
\text { methane) }\end{array}$ & $\begin{array}{l}3 \text { Hour } \\
6-9 \text { AM }\end{array}$ & $\begin{array}{c}160 \mu_{g} / \mathrm{m}^{3} \\
2(0.24 \mathrm{ppm})\end{array}$ & $\begin{array}{l}160 \mu_{8} / \mathrm{m}^{3} \\
(0.24 \mathrm{ppm})\end{array}$ \\
\hline \multirow[t]{2}{*}{ Ozone } & 1 Hour & $\begin{array}{l}235 \mu \mathrm{g} / \mathrm{m}^{3} \\
(0.12 \mathrm{ppm})\end{array}$ & $\begin{array}{l}235 \mu_{g} / \mathrm{m}^{3} \\
0.12 \mathrm{ppm})\end{array}$ \\
\hline & 8 hour & $\begin{array}{l}157 \mu \mathrm{g} / \mathrm{m}^{3} \\
(0.08 \mathrm{ppm})\end{array}$ & - \\
\hline \multirow[t]{2}{*}{ Carbon monoxide } & 8 Hour & $\begin{array}{c}10 \mu \mathrm{g} / \mathrm{m}^{3} \\
(9 \mathrm{ppm})\end{array}$ & $\begin{array}{c}10 \mu \mathrm{g} / \mathrm{m}^{3} \\
(9 \mathrm{ppm})\end{array}$ \\
\hline & 1 Hour & $\begin{array}{l}40 \mu g / \mathrm{m}^{3} \\
(35 \mathrm{ppm})\end{array}$ & $\begin{array}{l}40 \mu g / \mathrm{m}^{3} \\
(35 \mathrm{ppm})\end{array}$ \\
\hline \multirow[t]{2}{*}{ Lead } & 90 Day & $1.5 \mu_{g} / \mathrm{m}^{3}$ & $1.5 \mu \mathrm{g} / \mathrm{m}^{3}$ \\
\hline & 30 Day & $0.25 \mu \mathrm{g} / \mathrm{m}^{3}$ & - \\
\hline
\end{tabular}

Source:

Note: $\quad$ ppm $=$ parts per million

$\mu_{g / m^{3}}=$ micrograms per cubic meter

$\mathrm{mg} / \mathrm{m}^{3}=$ milligrams per cubic meter

${ }^{1}$ Nitrogen dioxide is the only one of the nitrogen oxides considered in the ambient standards.

2 Maximum 3-hour concentration between 6 and 9 A. M. 


\section{State Implementation Plans (SIP) (42 USC 7410, Sec. 110)}

To implement the CAA, states are required to adopt and submit to EPA, a State Implementation Plan (SIP) detailing with the basic strategies for implementation, maintenance, and enforcement of NAAQS within the state. SIP forms the blueprint for achieving air quality goals within a state. The SIP provides the emission limitations, schedules, and time tables for compliance by stationary sources of air pollution such as oilfield steam generators. EPA must approve the SIP for each state. SIP should contain measures necessary for achieving the primary and secondary standards. In setting these measures, the state does not need to consider their technical or economical feasibility.

SIP must assure attainment of NAAQS by prescribed dates. SIP must meet federal requirements, but each state may choose its own mix of emissions for stationary and mobile sources to meet NAAQS. CAA prohibits the adaptation of any SIP without a public hearing, and the sources affected by SIP are expected to participate. Requirements of SIP are contained in $\mathbf{4 2}$ USC, Sections 7407(a) and 7410(a)(1).

\section{Emission Limitations}

CAA has developed minimum technological standards for various sources of air pollution. These sources are divided into two groups: stationary and mobile sources. Since stationary sources are the originator of pollutant in steam injection operations, only stationary source standards are outlined here.

In establishing the framework for controlling emissions from stationary sources, CAA makes a distinction between new and existing sources. Since it is typically less expensive for new sources to incorporate state-of-the-art control technologies, the regulatory burdens fall more heavily on the new sources. Existing sources are regulated through SIP. Each state must develop a standard of performance for existing sources using EPA guidelines. If a state fails to establish standards or if the state standards are not acceptable to EPA, EPA may promulgate its own standards.

To control the pollutants from new stationary sources, CAA directs EPA to establish 'New Source Performance Standards' (NSPS). NSPS reflect the degree of pollution control achievable through the best available and adequately demonstrated pollution control technique. In selecting the best available control technology for each pollutant, the EPA must take into account the cost of achieving such emission reduction and energy requirements.

EPA has delegated the authority to implement and enforce NSPS to various state and local agencies; although it always retains independent enforcement authority. 


\section{Prevention of Significant Deterioration (PSD) (42 USC 7470 et. seq.)}

In 1977, Congress amended the CAA to prevent significant future degradation of the Nation's clean-air areas. A clean-air area is one where the air quality is better than the ambient primary or secondary standard. Thus, the purpose of PSD is to "keep clean air ciean." To achieve the stated purpose, states were required to identify, in their SIP, emission limitations and other measures necessary to prevent significant deterioration of air quality with respect to criteria pollutants (42 USC, 7473).

To implement this program, CAA divided clean-air areas into three groups. This classification determines the increment by which $\mathrm{SO}_{2}$ and, suspended particulates may be increased in a given area. In Class I areas, which includes national parks and national wilderness areas, only a minor air quality degradation is permitted. Class II areas, which include regions designated by states as within national primary and secondary ambient air quality standards, moderate degradation is permitted. In Class III areas, which include all other regions, substantial air quality degradation is permitted. In no case does PSD permit air quality to deteriorate below secondary air quality standards. The permitted air quality increments for PSD are shown in table 18.4.

"Increments" are the maximum amount of deterioration that can occur in a clean-air area over the baseline. "Baseline" is the existing air quality for the area at the time the first PSD is applied. Increments in Class I areas are smaller than those for Class II, and Class II increments are smaller than those for Class III areas. For the purpose of PSD, a major emitting source is one which falls in one of 26 designated categories, and whose potential emission rate is greater than 100 tons/yr. Fossil fuel fired steam generators, which are greater than $250 \mathrm{MM}$ BTU/hr heat input are in the PSD designated categories. In addition to the 26 PSD designated categories, there is an additional "catchall" category designated as a major pollutant source-if it emits more than 250 tons/yr of designated pollutant. PSD defines the potential emission rate as the rate to be expected without air pollution control equipment.

Steam injection operations are a significant potential source of sulfur dioxide, nitrogen oxides, and particulates (assuming clustering of boilers). Most pollutants are emitted from crude oil fired steam generators. Most oil field steam generators used in steam injection operation are smaller than $250 \mathrm{MM}$ BTU/hr size and hence fall within the catchall category. These generators will be subject to PSD review if their potential emission rate exceeds 250 tons/yr. The typical emissions from oil fired steam generators of different sizes burning $1.09 \%$ sulfur fuel, are given in Table 18.5. It can be seen that a steam injection operator with two generators would be subject to PSD for $\mathrm{SO}_{2}$. 
TABLE 18.4. - Permitted Air-Quality Increments for Prevention of Significant Deterioration

\begin{tabular}{|c|c|c|c|c|}
\hline \multirow[b]{2}{*}{ Pollutant } & \multirow{2}{*}{$\begin{array}{l}\text { Averaging } \\
\text { Time }\end{array}$} & \multicolumn{3}{|c|}{ Air Quality Increments $\left(\mu_{g} / \mathrm{m}^{3}\right)$} \\
\hline & & Class I & Class II & Class III \\
\hline $\begin{array}{l}\text { Total suspended particulate } \\
\text { Lead } \\
\mathrm{SO}_{2}\end{array}$ & $\begin{array}{c}1 \text { year } \\
24 \text { hours } \\
3 \text { months } \\
1 \text { year } \\
24 \text { hours } \\
3 \text { hours } \\
1 \text { year } \\
8 \text { hours } \\
1 \text { hour } \\
1 \text { hour }\end{array}$ & $\begin{array}{c}5 \\
10 \\
\text { None } \\
2 \\
5 \\
25 \\
\text { None } \\
\text { None } \\
\text { None } \\
\text { None }\end{array}$ & $\begin{array}{c}19 \\
37 \\
\text { None } \\
20 \\
91 \\
512 \\
\text { None } \\
\text { None } \\
\text { None } \\
\text { None }\end{array}$ & $\begin{array}{c}37 \\
75 \\
\text { None } \\
40 \\
182 \\
700 \\
\text { None } \\
\text { None } \\
\text { None } \\
\text { None }\end{array}$ \\
\hline
\end{tabular}

TABLE 18.5 - Typical Emissions From an Oil-Fired Steam Generator

\begin{tabular}{|c|c|c|c|c|c|c|c|c|c|c|}
\hline \multirow{2}{*}{$\begin{array}{l}\text { Approximate } \\
\text { rated output } \\
\left(10^{6} \mathrm{Btu} / \mathrm{hr}\right)\end{array}$} & \multirow{2}{*}{$\begin{array}{c}\text { Typical } \\
\text { daily fuel } \\
\text { consumption } \\
\text { (bbl/day) }\end{array}$} & \multirow{2}{*}{$\begin{array}{l}\text { Typical } \\
\text { yearly operating } \\
\text { schedule } \\
\text { (days) }\end{array}$} & \multicolumn{4}{|c|}{$\begin{array}{l}\text { Emissions } \\
\text { (lb/bblfuel) }\end{array}$} & \multicolumn{4}{|c|}{$\begin{array}{l}\text { Emissions } \\
\text { (tons/year) }\end{array}$} \\
\hline & & & $\mathrm{SO}_{2}{ }^{1}$ & $\mathrm{NO}_{2}$ & Particulate & $\overline{H C}$ & $\mathrm{SO}_{2}{ }^{1}$ & $\mathrm{NO}_{2}$ & Particulate & $\overline{H C}$ \\
\hline 5 & 16 & 365 & 7.2 & 2.5 & 0.7 & 0.1 & 21 & 10.3 & 2.9 & 0.43 \\
\hline 10 & 50 & 292 & 7.2 & 2.5 & 0.7 & 0.1 & 52.6 & 18.3 & 5.1 & 0.73 \\
\hline 20 & 115 & 292 & 7.2 & 2.5 & 0.7 & 0.1 & 120.9 & 42 & 11.8 & 1.60 \\
\hline 50 & 220 & 292 & 7.2 & 2.5 & 0.7 & 0.1 & 220 & 76.7 & 21.5 & 3.07 \\
\hline
\end{tabular}

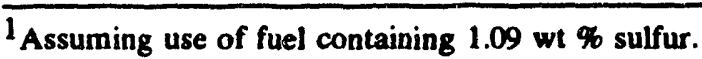

\section{Nonattainment Areas (NAA) (42 USC 7501 et. seq.)}

Nonattainment areas are those areas in which the state and federal ambient air quality standards have not been met for the specified criteria pollutant. For these areas, the SIPs must include plans to cleanup existing sources of emissions in order to achieve attainment. New construction in a NAA is prohibited unless SIP has been amended and approved by EPA. Sources wishing to locate in nonattainment areas must meet the following conditions:

a. Must show that the project will result in net air quality benefits.

b. Must comply with the "lowest achievable emission rate" (LAER). LAER is a type of emission rate which reflects the control technology available and the emission limits required by law.

c. Demonstrate that all other sources owned by the applicant within the state are in compliance with all applicable emission limitations and standards. 
d. Obtain emission offsets to achieve a net reduction in emissions. An offset refers to the amount by which other sources must reduce their emissions to allow for the amount to be produced by the new source; thus, making room for development.

To permit future new source construction in NAA, EPA allows existing source to bank offsets. A banked offset can be sold or traded to other sources.

\section{Best Available Control Technology (BACT) for Steam Injection Operation Pollutants}

Steam injection operations subjected to PSD regulations must employ the best available control technology to achieve maximum degree of reduction with respect to a particular source of pollutants. BACT is a pollution control technique defined for categories of equipment and takes into account energy and environmental and economic impacts along with other costs.

From a practical point of view, BACT can be a costly issue when permitting a new project. Since BACT is defined for categories of equipment, a district imposed BACT for a particular equipment may not have been previously tried. Even if proven in practice, BACT technology is often costly. In California BACT requirements vary with districts.

The BACT for the major steam injection operation related pollutants are as follows:

(a) $\mathrm{BACT}$ for $\mathrm{SO}_{2}$

The EPA approved BACT for the control of $\mathrm{SO}_{2}$ from oil fired steam generator is fuel oil containing less than $0.05 \%$ by weight sulfur, or the equivalent rate achieved by scrubbing.

(b) BACT for NOx

For $\mathrm{NO}_{\mathrm{x}}$, the EPA is requiring a case-by-case analysis. It maintains that BACT, at a minimum, shall be a modification of burner that will result in the least amount of oxygen to be consumed for combustion. California steam injection operators frequently utilize low $\mathrm{NO}_{\mathbf{x}}$ burners to control $\mathrm{NO}_{\mathrm{X}}$ emissions.

(c) BACT for Particulate Matter

BACT for particulate matter has not been defined. EPA maintains that $\mathrm{SO}_{2}$ scrubbers should satisfy the BACT requirements for particulates. This is because the $\mathrm{SO}_{2}$ scrubbers, although primarily designed for $\mathrm{SO}_{2}$ removal, also remove a small percentage of particulate matter.

Particulate matter emissions from oilfield steam generators are small, and it would take an average of nine or more $50 \mathrm{MM}$ BTU/hr units to produce more than 250 tons/yr.

\section{Lowest Achievable Emission Rate (LAER)}

Steam injection operators wishing to locate in nonattainment areas must comply with "lowest achievable emission rate" (LAER). LAER for a particular pollutant is the most stringent emission limit for the pollutant contained in the SIP's of the U.S. In no instance can the LAER be permitted to be less stringent than the amount allowed under an applicable new source performance standard. 
Unlike BACT, the LAER does not permit cost effectiveness to be taken into consideration. Thus, LAER is more stringent than BACT.

The LAER for an oil fired steam generator is considered to be $0.05 \mathrm{wt} \%$ sulfur in fuel or the equivalent rate achieved by scrubbing. This is based on technology achievable in practice for these types of sources. LAER, however, is a changing thing and must reflect the advances in technology and SIP's requirement. As SIP requirements change and become more stringent, LAER must reflect such changes. Similarly, as scrubber technology advances, LAER must also reflect such changes.

\section{The Clean Air Act (CAA) Amendments of 1990}

The CAA amendments of 1990 , signed into law on November 15, 1990, is the first major revision of the CAA since 1977. The act addresses several problems encountered in the 35-year history of the CAA. The 1990 amendments had made several significant changes to the NAAQS and revised the nonattainment programs. The revision contains new requirements that an area must meet before it can qualify as an attainment on unclassifiable area with respect to ozone, carbon monoxide, and particulate matters. The area classification provisions of the 1990 amendments is expected to result in redesignation of many currently attainment areas as nonattainment areas. The impact of 1990 CAA amendments on steam injection project sittings and operations will not become clear until well into the $90 \mathrm{~s}$, but is expected to be minimal. The salient features of the 1990 CAA amendments are summarized in reference 3.

\section{Water Quality Regulations Impacting Steam Injection Operations}

This section summarizes the major water quality laws impacting steam injection operations. These include Clean Water Act (CWA), Safe Drinking Water Act (SDWA) and Underground Injection Control (UIC) Program, Toxic Substances Control Act (TSCA), Spill Prevention Regulations and regulations governing the handling, storage, and disposal practices of oilfield waste waters.

\section{Federal Clean Water Act (CWA)}

The objective of CWA is to restore and maintain the chemical, physical, and biological integrity of the Nation's water. EPA has nationwide authority to implement CWA, including the promulgation of regulations.

To achieve its stated objectives, CWA has set effluent standards to limit discharges from point and nonpoint sources and established ambient standards to maintain the quality of surface waters. The Clean Water Act can be found at 33 USC starting at section 1251 . The EPA regulations are found at 40 CFR Subchapter D - Water Programs. 
Steam injection operation effluent guidelines are enforced through the National Pollution Discharge Elimination System (NPDES). To receive a discharge permit, a steam injection operator must comply with all applicable effluent limitations for the particular discharge under steam injection operations. NPDES are effective for terms not exceeding 5 years. NPDES permit are issued by EPA or by a state having a certified CWA program.

\section{Safe Drinking Water Act (SDWA)}

The SDWA has two primary objectives:

(a) Protection of public water supply system, and

(b) Protection of underground drinking water sources.

To accomplish these objectives, EPA has established:

(a) National Primary Drinking Water Regulations to protect public health (40 CFR, Part 141), and

(b) State Underground Injection Control (UIC) program regulations (40 CFR, Parts 144-149).

The National Primary Drinking Water Regulations establish maximum contaminant levels for possible physical, chemical, microbiological, and radiological pollutants in public water systems.

\section{UIC Wells}

The Underground Injection Control Regulations of SDWA require states to establish UIC waste disposal programs to prevent underground injection activities which endanger drinking water resources. Depending on the toxicity of the injected fluids, underground injection wells are classified as Class I, Class II, Class III, Class IV, or Class V wells. The definition of these wells is as follows:

Class I Wells used by generators of hazardous waste or owners or operators of hazardous waste management facilities to inject hazardous waste beneath the lowermost formation containing, within 1/4 mile of the wellbore, an underground source of drinking water.

Class II Wells which inject fluids:

(1) Which are brought to the surface in connection with natural gas storage operations, or conventional oil or natural gas production and may be commingled with waste waters from gas plants which are an integral part of production operations unless those waters are classified as hazardous waste;

(2) For enhanced recovery of oil or natural gas;

(3) For storage of hydrocarbons which are liquid at standard temperature and pressure. 
Class III Wells which inject for extraction of minerals.

Class IV Wells used by generators of hazardous waste or of radioactive waste for injection into a formation which, within 1/4 mile of the well, contains an underground source of drinking water.

Class V Injection wells not included in Classes I, II, III or IV.

Enhanced oil recovery operators are particularly interested in Class II injection wells. On rare occasions, an EOR operator may use a Class I injection well.

\section{Miscellaneous Regulations Governing Oil and Gas Wastewaters}

These regulations enforced by the U.S. Department of Interior (DOI) govern the handling, storage, and disposal practices of waste waters from thermal EOR fields located on federal and Indian lease lands. These regulations required that by October 1, 1977, the waste waters produced in oil and gas recovery operations be disposed only by:

(a) Subsurface injection

(b) Impoundment in lined pits, or

(c) Other acceptable methods.

Stringent limitations are placed upon the disposal of produced water in unlined pits. Monitoring requirements are established for disposal to both lined and unlined pits. Monitoring activities for water impounded in lined pits are to include daily measurements of chloride, sulfate, and other constituents which are potentially toxic to animal, plant, and aquatic life.

\section{Spill Prevention Regulations}

EPA has established regulations to prevent the discharge of oil and oil products into or upon the navigable water of the U.S. These regulations require the development of spill prevention control. As far as the steam injection operations are concerned, the practices of on-site mixing or storage of oil related substances will be affected by these regulations. In order to ensure compliance with these regulations, surface water monitoring during rainstorms as well as during and immediately following any discharge of retained waters into surface water bodies, is required.

\section{Classification of Injection Wells in California}

In California, wells injecting only filter backwash or filter backwash commingled with produced water are classified as Class II wells. Wells injecting water softener regeneration brine or air scrubber wastes into an oil producing formation are also classified as Class II wells. On the other hand, wells injecting water softener regeneration brine or scrubber liquor into a non-oil producing formation are classified as Class I or Class $\mathrm{V}$ wells. This classification depends on the toxicity of the injected fluid. 


\section{Waste Management Regulations Impacting Steam Injection Operations}

This section summarizes the federal and state waste management regulations impacting steam injection operations. The principal federal law that provides framework for managing waste is the "Resource Conservation and Recovery Aci" (RCRA).

\section{Resource Conservation and Recovery Act (RCRA) (42 USC, Sections 6901-6099K).}

Among the objectives of RCRA are the provisions for the safe disposal of discarded materials and the regulations for the management of hazardous wastes. The U.S. EPA is the primary agency which administers the provisions of RCRA. The act required EPA to prepare guidelines for the effective management of solid waste. The term "solid waste" is defined broadly to include garbage, refuse, and other discarded materials and includes liquids and gaseous materials together with solids.

The disposal practices for such wastes are to be such as to protect public health and welfare and prevent deterioration as required by other federal laws. This includes protection of the surface and groundwater quality from leaches and runoff, protection of ambient air quality, disease and vector control, safety, and esthetics. Many states implement their own solid waste programs. Most oilfield wastes were exempted from classification as hazardous waste by the EPA in 1988. Table 18.6 lists EPA classification of oilfield wastes under RCRA.

\section{Noise Quality Regulations Impacting Steam Injection Operations}

The U.S. Noise Control Act (42 USC, Section 4901, et. seq.) authorizes EPA to set ambient noise quality criteria. EPA requires the noise levels, because of the operation of one or more pieces of equipment, not to exceed a given value. This value depends upon demographic characteristics of the land surrounding the EOR site.

The noise associated with TEOR activities arise from two areas: site preparation activities and field test activities. The site preparation activities include activities associated with the drilling of observation wells, workover of existing wells, and movement of heavy-duty vehicles used in the operation of several major pieces of equipment. The typical pieces of equipment include crawler tractors, air compressors, diesel generators, pumps, and heavy trucks. The noise associated with field test activities arise primarily from the operation of steam generators.

Since most thermal EOR fields are in rural areas, compliance with noise requirements is not considered to be a major environmental issue. 


\section{TABLE 18.6. - EPA List of Exempt and Nonexempt Oilfield Wastes from RCRA Hazardous Management Requirements ${ }^{4}$}

Produced water

Drilling fluids

Drilling cuttings

Rigwash

Drilling fluids and cuttings from offshore operations disposed of onshore

Well completion, treatment, and stimulation fluids

Basic sediment and water and other tank bottoms from storage facilities that hold product and exempt waste

Accumulated materials such as hydrocarbons, solids, sand, and emulsion from production impoundments

Pit sludges and contaminated bottoms from storage or disposal of exempt wastes

Workover wastes

Gas plant dehydration wastes, including glycol-based compounds, glycol filters, filter media, backwash and moiscular sieves

Gas plant sweetening wastes for sulfur removal, including amine, amine filters, amine filter media, backwash, precipitated amine sludge, iron sponge, and hydrogen sulfide scrubber liquid and sludge

Packing fluids

Produced sand

Pipe scale, hydrocarbon solids, hydrates, and other deposits removed from piping and equipment prior to transportation

Hydrocarbon-bearing soil

Pigging wastes from gathering lines

Wastes from subsurface gas storage and retrieval, except for the listed nonexempt wastes

Constituents removed from produced water before it is injected or otherwise disposed of

Liquid hydrocarbons removed from the production stream but not from oil refining

Gases removed from the production stream, such as hydrogen sulfide and carbon dioxide, and volatilized hydrocarbons

Materials injected from a producing well during the process known as blowdown

Waste crude oil from primary field operations and production

Light organics volatilized from exempt wastes in reserve pits or impoundments or production equipment
Unused fracturing fluids or acids

Gas plant cooling tower cleaning wastes

Painting wastes

Oil and gas service company wastes, such as empty drums, drum rinsate, vacuum truck rinsate, sandblast media, painting wastes, spent solvents, spilled chemicals, and waste acids

Vacuum truck and drum rinsate from trucks and drums transporting or containing nonexempt waste

Refinery Wastes

Liquid and solid wastes generated by crude oil and tank bottom reclaimers

Used equipment lubrication oils

Waste compressor oil, filters, and blowdown

Used hydraulic fluids

Waste solvents

Waste in transportation pipeline-related pits

Caustic or acid cleaners

Boiler cleaning wastes

Boiler refractory bricks

Incinerator ash

Laboratory wastes

Sanitary wastes

Pesticide wastes

Radioactive tracer wastes

Drums, insulation, and miscellaneous solids 


\section{Sources of Pollution in Steam Injection Field Activities}

In this section, the source and type of pollutant likely to be generated in a typical thermal EOR production field are identified. The potential emission/effluents are described for the environmental parameters of air quality, water quality, and waste management.

\section{Air Quality}

In a typical steam injection project, air emissions occur during site preparation and field operations. Air emissions evidenced during site preparation facilities consist primarily of carbon monoxide, hydrocarbons, nitrogen dioxide, sulfur dioxide, and suspended particulates. In addition, uncontrolled fugitive dust emissions occur in areas of land disturbances caused by drilling, bulldozing, etc. The magnitude of the fugitive emissions depends upon the time of year, the methods of construction employed, the actual size of the area disturbed, and the type of control measure ttilized. Estimates of uncontrolled emissions from all equipment employed in the field during the site preparation phase are shown in Table 18.7.

Air pollutant emissions generated during a typical steam injection field activity include thrse emanating from steam generators and wellheads. The only significant emissions to the atmosphere in normal operation are those resulting from the burning of fossil fuels for steam generation. Most steam generators used in oilfields are in the $50 \mathrm{MM}$ BTU/hr heat input size range. Steam generators produce $\mathrm{SO}_{2}, \mathrm{NO}_{\mathbf{x}}$, and particulates. Additionally, small amounts of unburned hydrocarbons and traces of carbon monoxide are also emitted. Onsite storage tanks and wells to be steamed also emit hydrocarbons. Among these, sulfur dioxide is of critical concern because of the stringent federal, state, and local regulations limiting its legal emission level. Table 18.5 lists the typical emission rates for all pollutants expected for different sizes of generators. For this computation, it is assumed that the steam generator will use a fuel containing $1.09 \%$ sulfur by weight.

\section{Water Quality}

Steam injection operations produce large quantities of waste effluents. These waste effluents include those generated by site preparation activities, such as drilling and well workovers, effluent from production wells, flue gas scrubber waste, and water softener regeneration brine. Storm water runoff from construction areas has the potential to affect the quality of local surface water: Runoff from construction sites may include clay and silt particles, inorganic and organic matter from decayed vegetation and soil, oil from paved areas, and oil and grease from construction equipment. 


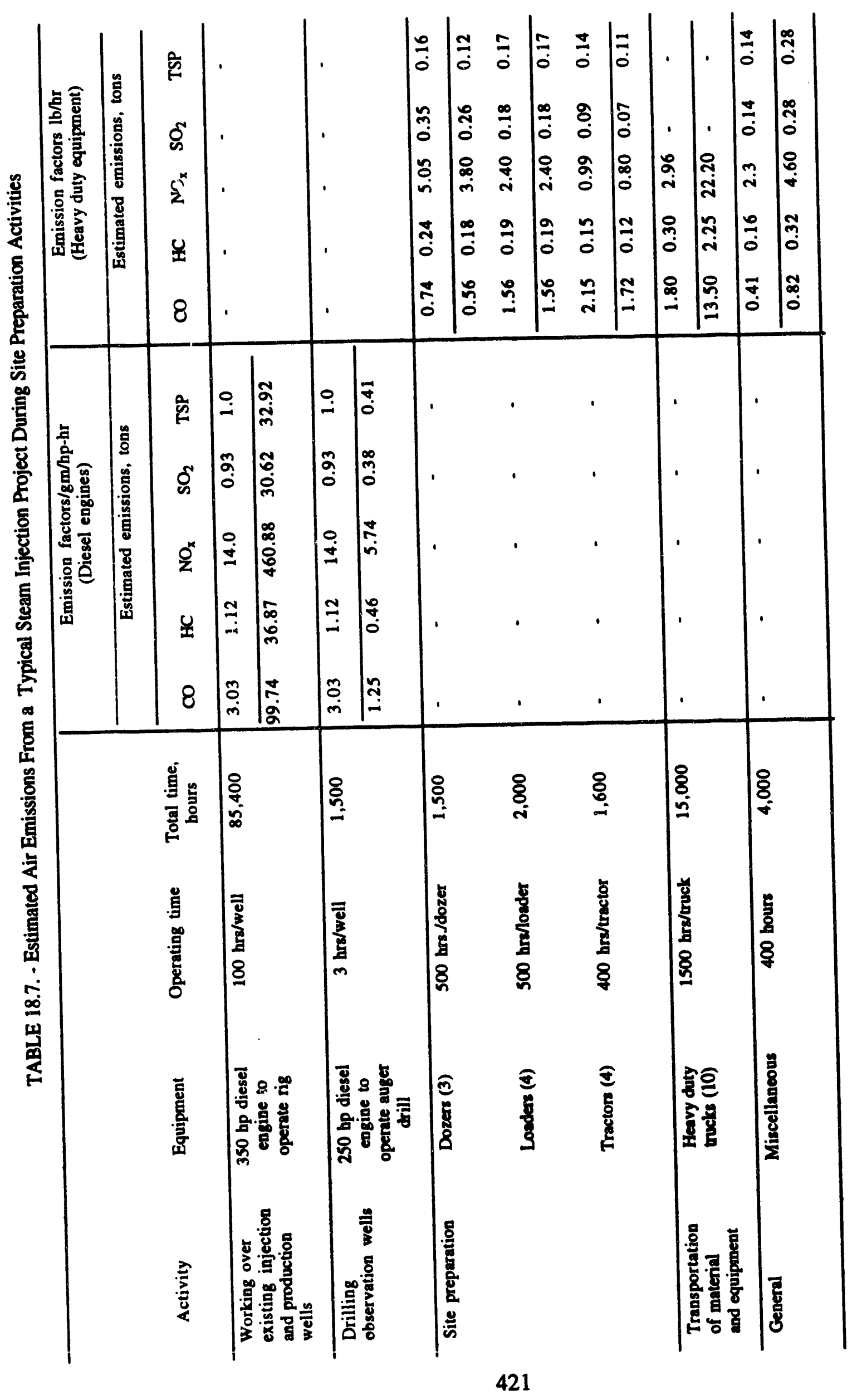


Local groundwater quality has the potential to be affected by steam injection waste water effluent disposal activities. Some of these include:

- Potential of seepage of injected or reinjected materials through the formation into underground aquifers;

- Potential of leaching from unlined waste disposal pits;

- Potential of accidental surface spills during storage and transport of waste effluents; and

- Potential of secondary fractures, which may connect the formation with aquifers.

Total protection of groundwater from waste is impossible because the control of all flow paths from waste to groundwater aquifers, except casing leaks, is beyond reliable engineering control.

\section{Waste Management}

A typical steam injection process generates wastes both during site preparation phase and field testing phase. The wastes produced from site preparation activities include:

- Clay, silt, and dust particles;

- Organic and inorganic matter from decayed vegetation;

- Drilling wastes such as mud, brines, etc; and

- Oil and grease from construction machinery.

The first two types of wastes are disposed of by landfill and are of no environmental concern. Drilling wastes and oilfield brines, because of their potential damage to local water and eco system, require careful handling and must be disposed of in state-approved sites.

The wastes generated from field operations activities include:

- Sludge produced from scrubbers;

- Spent liquids such as scrubber fluids;

- Oily wastes;

- Hazardous (toxic) wastes

The handling and disposal of these wastes call for special measures and are outlined as follows:

- The scrubber liquids must be treated onsite prior to their disposal into local surface waters;

- Scrubber sludges are difficult and costly to dispose of and are a potential source of contamination of local surface and subsurface water at the disposal site;

- The oily wastes are collected separately and are disposed of according to local regulatory requirements; and

- The hazardous wastes are handled in accordance with the state regulatory requirements. 


\section{SUMMARY}

The environmental requirements for candidate domestic steam injection oil recovery projects were identified and evaluated from federal, state, and local regulatory view points. From these, the following conclusions have been derived.

- Environmental regulations pertaining to ambient air quality and groundwater quality greatly impact the growth of the steam injection processes;

- Current regulations are sufficient for controlling noise pollution; and

- Environmental issues such as solid- and liquid-waste handling procedures require sitespecific details that must be evaluated against the applicable governmental regulatory requirements.

\section{REFERENCES}

1. Madden, M. P., R. P. Blatchford and R. B. Spears. Environmental Regulations Handbook for Enhanced Oil Recovery. U.S. Dept. of Energy Report No. NIPER-546, December 1991.

2. Sarathi, P. Environmental Aspects of Heavy Oil Recovery by Thermal EOR Processes. Pres. at the Soc. of Pet. Eng. Western Regional Meeting, Long Beach, CA, Mar. 20-22, 1991. SPE paper 21768.

3. Sarathi, P. Environmental Aspects of Heavy Oil Recovery by Thermal EOR Processes. J. Pet. Tech., v. 43, No. 6, June 1991, pp. 662-721.

4. IOCC. EPA/IOCC Study of State Regulations of Oil and Gas Exploration and Production Wastes, Interstate Oil Compact Commission, Oklahoma City, OK, December 1990.

5. American Petroleum Institute. API Environmental Guidance Document-Onshore Solid Waste Management in Exploration and Production Operations. American Petroleum Institute, Production Division, Dallas, TX, January 1989. 


\section{4}


APPENDIX 18-A

\section{THERMAL EOR ENVIRONMENTAL CONSULTANTS}

A. Thermal EOR Environmental Consultants

1. WZI Inc. 4800 Easton Drive, Suite 114 Bakersfield, CA 93309 Telephone: (805) 326-1112 

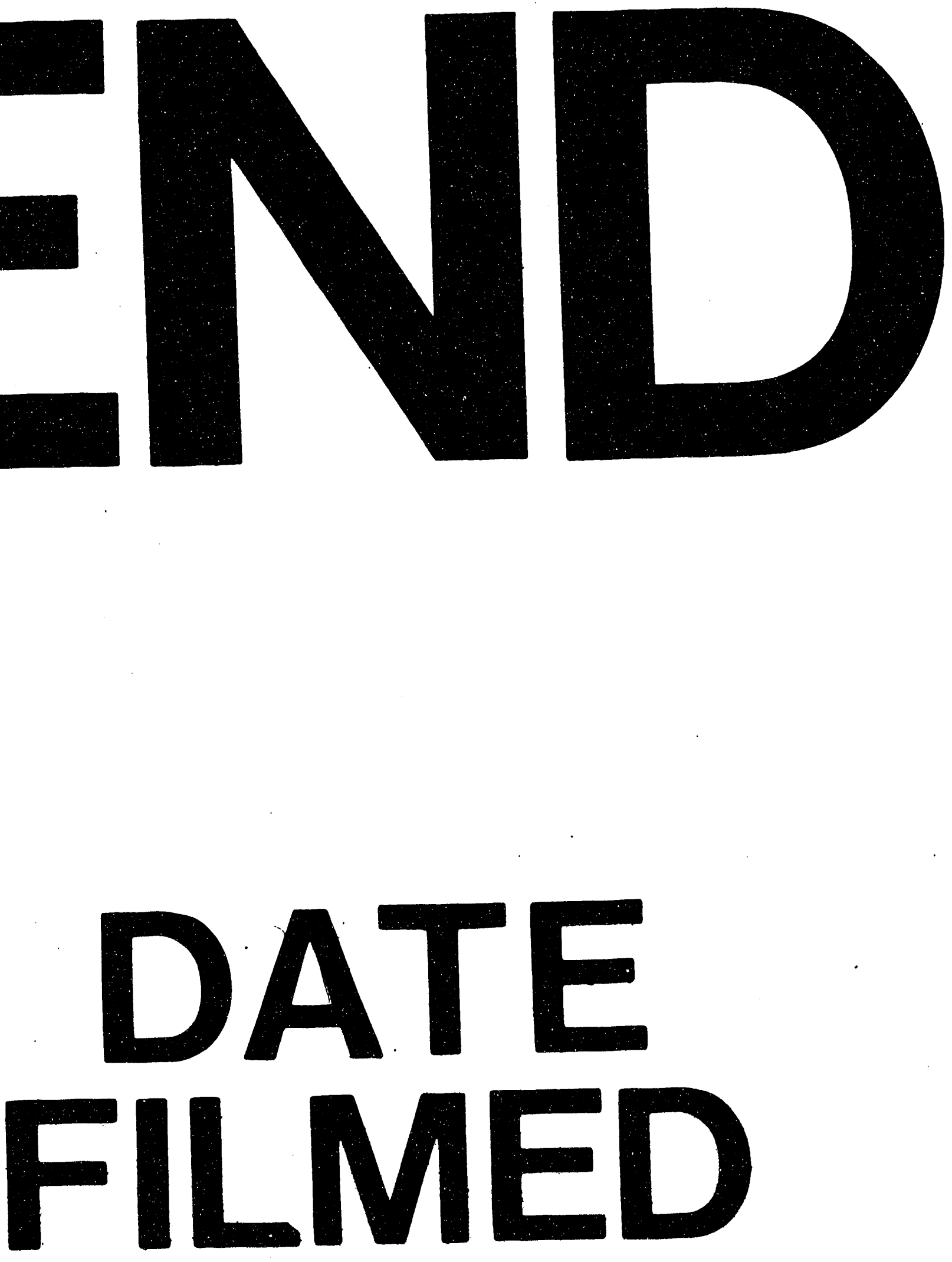

1

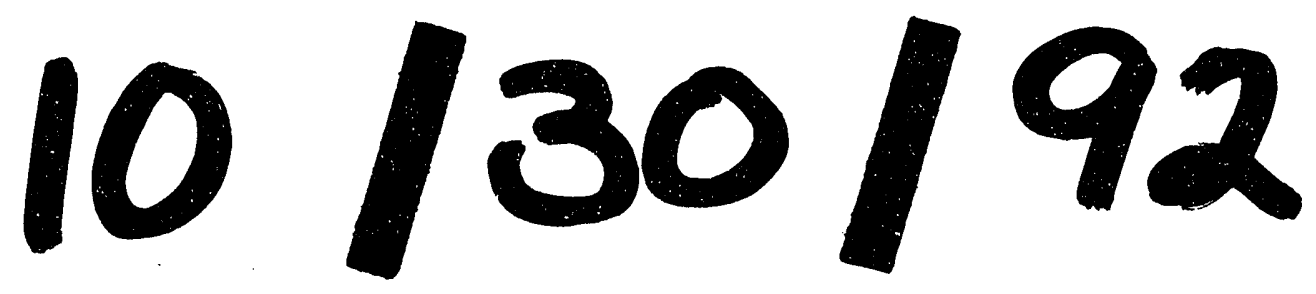


